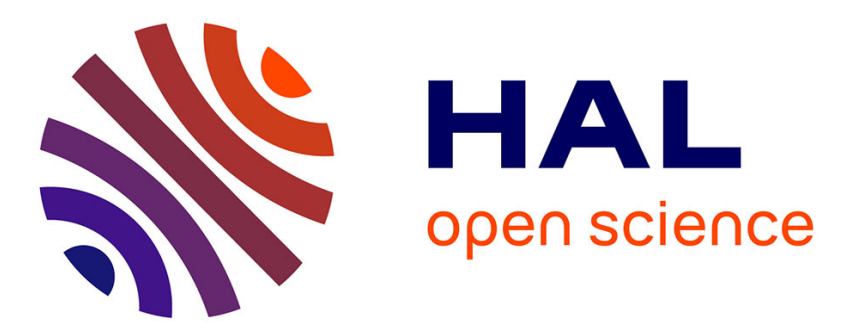

\title{
Divertissements et loisirs dans les sociétés urbaines à l'époque moderne et contemporaine
}

\author{
Robert Beck, Anna Madoeuf
}

\section{To cite this version:}

Robert Beck, Anna Madoeuf (Dir.). Divertissements et loisirs dans les sociétés urbaines à l'époque moderne et contemporaine. Robert Beck et Anna Madoeuf. Presses de l'Université F.-Rabelais de Tours, pp.410, 2005, Perspectives Historiques, 2-86906-203-6. halshs-00005324

\section{HAL Id: halshs-00005324 \\ https://shs.hal.science/halshs-00005324}

Submitted on 29 Jun 2016

HAL is a multi-disciplinary open access archive for the deposit and dissemination of scientific research documents, whether they are published or not. The documents may come from teaching and research institutions in France or abroad, or from public or private research centers.
L'archive ouverte pluridisciplinaire HAL, est destinée au dépôt et à la diffusion de documents scientifiques de niveau recherche, publiés ou non, émanant des établissements d'enseignement et de recherche français ou étrangers, des laboratoires publics ou privés. 


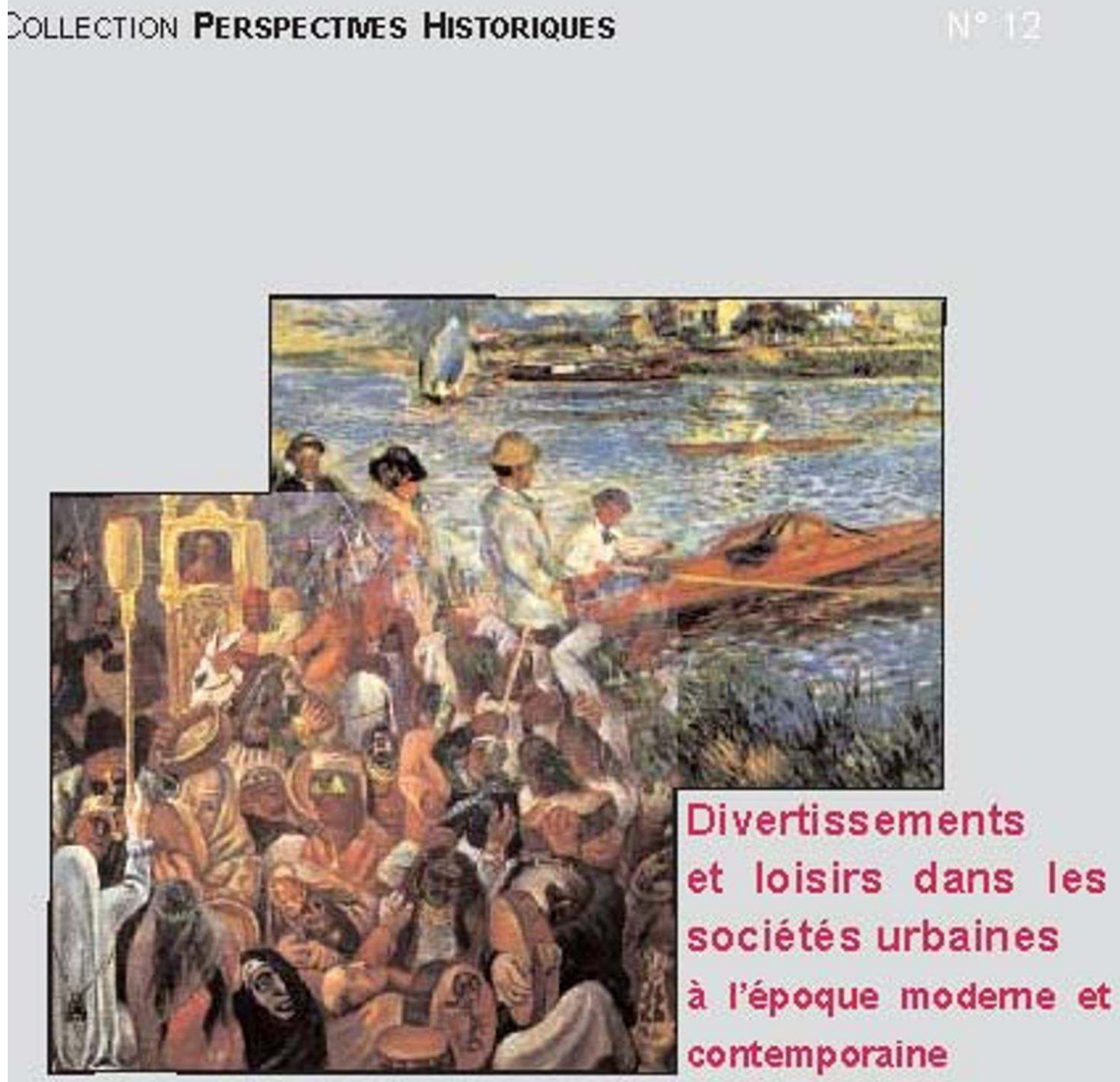

Coorabrax por Robert BECK et Arria Madguf

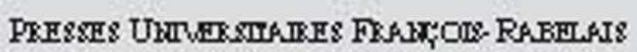

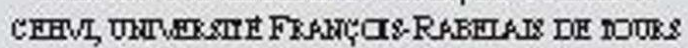

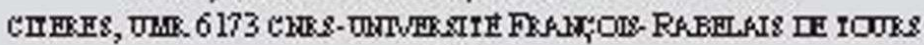
2005 


\title{
Divertissements et loisirs dans les sociétés urbaines à l'époque moderne et contemporaine
}

\author{
Robert Beck et Anna Madœuf (dir.)
}

Éditeur : Presses universitaires François-

Rabelais

Année d'édition : 2005

Date de mise en ligne : 2 mai 2013

Collection: Perspectives Historiques

ISBN électronique : 9782869063280

\author{
Édition imprimée \\ ISBN : 9782869062030 \\ Nombre de pages : 410
}

Ce document vous est offert par Université François-Rabelais de Tours

\section{Sbooks}

http://books.openedition.org

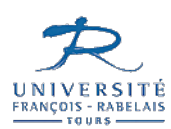

Référence électronique

BECK, Robert (dir.) ; MADEUF, Anna (dir.). Divertissements et loisirs dans les sociétés urbaines à l'époque moderne et contemporaine. Nouvelle édition [en ligne]. Tours : Presses universitaires François-Rabelais, 2005 (généré le 22 juin 2016). Disponible sur Internet : <http://books.openedition.org/pufr/593>.

ISBN : 9782869063280.

Ce document est un fac-similé de l'édition imprimée.

(c) Presses universitaires François-Rabelais, 2005

Conditions d'utilisation :

http://www.openedition.org/6540 


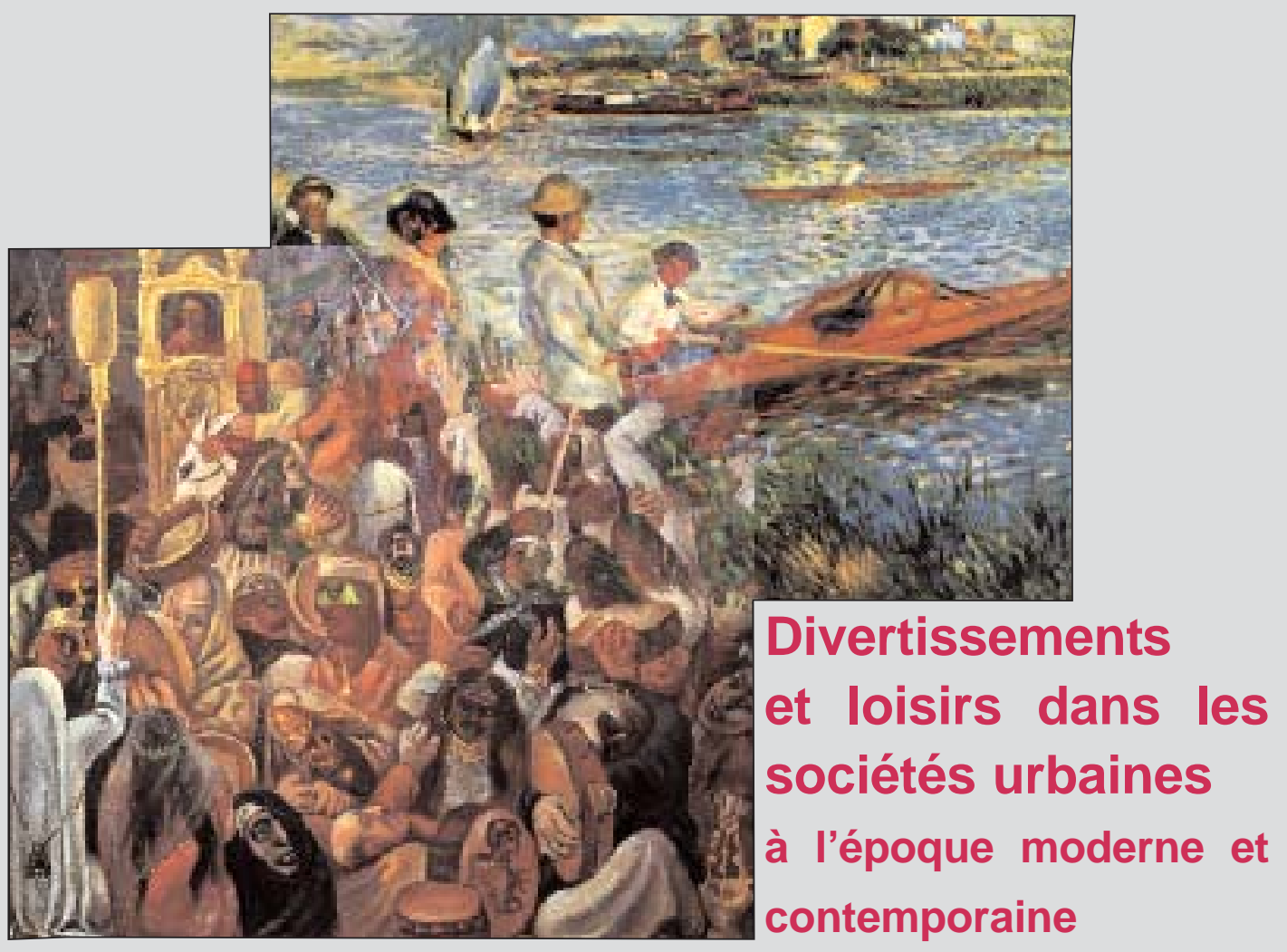

Coordonné par Robert BECK et Anna Madeuf

Presses Universitaires François-Rabelais CEHVI, UNIVERSITÉ FRANÇOIS-RABELAIS DE TOURS 


\section{DIVERTISSEMENTS ET LOISIRS \\ DANS LES SOCIÉTÉS URBAINES}

À L'ÉPOQUE MODERNE ET CONTEMPORAINE 

Collection Perspectives Historiques

\title{
Divertissements et loisirs dans les sociétés urbaines à l'époque moderne et contemporaine
}

\author{
Coordonné par Robert BECK \\ et Anna MAdeuf
}

ACTES Du COLLOQUe DIVERTISSEMENTS ET LOISIRS DANS LES SOCIÉTÉS URBAINES, UNE APPROCHE COMPARATIVE MONDE OCCIDENTAL-MONDE MUSULMAN

organisé par URBAMA et le CEHVI

Presses Universitaires François-Rabelais - 2005

3, rue des Tanneurs - BP 4103 - 37041 TOURS CEDEX 1 
Dans la même collection

Mis en page par Muriel HouRLIER

CITERES, UMR 6173 CNRS-Université François-Rabelais de Tours

Tous droits réservés, 2005

Publication du CEHVI, Université François-Rabelais de Tours

et de CITERES, UMR 6173 CNRS-Université François-Rabelais de Tours

Dépôt légal : 2005 


\section{TABLE DES MATIÈRES}

\section{INTRODUCTION}

Robert BECK et Anna MADEUF . . . . . . . . . . . . . . . . . . . . . 9

\section{I - DIMENSIONS IDENTITAIRES}

Loisirs urbains, loisirs ruraux dans les élites du XVIII siècle Olivier ZELLER . ............................. 29

Loisirs et sociabilités maçonniques au XVIII siècle Pierre-Yves BEAUREPAIRE

Vers une urbanisation des loisirs aristocratiques : la promenade urbaine comme lieu d'interprétation des loisirs de la cour dans la France des $\mathrm{XVII}^{\mathrm{e}}$ et $\mathrm{XVIII} \mathrm{e}^{\mathrm{e}}$ siècles

Sandra PASCALIS .............................. 45

Les loisirs dans le compagnonnage au XIX ${ }^{\mathrm{e}}$ siècle Jean-Marie MoINe ........................ 61

Espaces de loisirs de la société cosmopolite parisienne. L’influence de l'élite voyageuse, 1855-1937

Joanne VAJDA ................................ 83

L'image d'une ville. Le regard sur Brême d'un photographe amateur : Hermann Kippenberg (1863-1940)

Christian JOSCHKE

Espaces urbains du temps libre des femmes aux XIXe et $\mathrm{Xx}^{\mathrm{e}}$ siècles

Fiorenza TAROZZI .................................. 119

Du divertissement au loisir à Tunis : le cas de la danse

Maud NiCOLAS . . . . . . . . . . . . . . . . . . . . . . . . . . 133 


\section{II - FORMES ET USAGES DU TEMPS ET DE L'ESPACE}

Les loisirs du prince dans l'Italie de la Renaissance : entre diletto et studio

Florence ALAZARD

Diversion and Pleasure in Damascus During the Ottoman Period

Abdul-Karim RAFEQ ................................. 159

Hors la cour, au-delà de la foire : les spectacles du Palais-Royal

à Paris à la fin du XVIII e siècle

Olivier Dautresme . . . . . . . . . . . . . . . . . . . . . . . . 177

Les divertissements quotidiens d'un citoyen bavarois au XIXe siècle

Robert ВЕСK .................................. 195

Architecture des loisirs en France dans les stations thermales

et balnéaires (1840-1939)

Bernard ToulIER ............................... 211

Un loisir urbain, les cafés-concerts en Lorraine allemande et française 1870-1914

Jean-Christophe DIEDRICH ........................ 225

Les créations d'entreprises de loisirs. L’exemple de Tours (1870-1936)

Cédric PerRIN ................................. 243

Jour de fête aux magasins Decré. Univers ludiques et logiques

commerciales dans un grand magasin nantais (1950-1970)

Éric Monin . . . . . . . . . . . . . . . . . . . . . . . . 255

Les cinémas dans l'espace urbain : un siècle de mutations

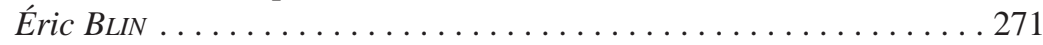

Disneyland, entre parc de loisir et modèle de ville pour la suburbia nord-américaine

Sophie DIDIER ............................. 285

Les jardins publics dans le monde arabe : territoire d'un loisir populaire

Gaëlle GILLOT ................................. 295

Bribes de vie, bribes de ville. Fêtes des saints (mouled-s) au Caire

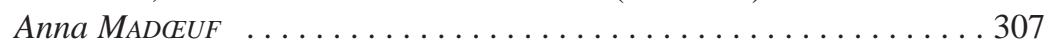




\section{III - CONTRÔLES ET ENCADREMENTS}

Urban Space, Public Pleasure and Cultural Conflict: the Seaside Resort in England c. 1840-1939

John K. WALTON

De l' ' homme laborieux » à la sociabilité bourgeoise : loisirs contrastés au Pirée pendant le XIX ${ }^{\mathrm{e}}$ siècle

Yannis YANNITSIOTIS ............................. 331

Espace de loisirs, espace politique : le café dans le monde arabe au XIXe siècle, l'exemple de Tripoli

Nora LAFI . . . . . . . . . . . . . . . . . . . . . . . . . . . . . . . 345

La querelle des « débuts » à Lyon au milieu du XIxe siècle : simple loisir théâtral ou expression de la toute puissance du public ?

Malincha GERSIN . . . . . . . . . . . . . . . . . . . . . . 355

Les bains de mer à Istanbul, $\mathrm{XIX}^{\mathrm{e}}$-Xx $\mathrm{XX}^{\mathrm{e}}$ siècles

Méropi Anastassiadou-Dumont . . . . . . . . . . . . . . . 367

Définir les loisirs publics en milieu urbain ; un enjeu moral et identitaire (Montréal et Toronto 1900-1940)

Michèle DaGENAIS . . . . . . . . . . . . . . . . . . . . . . . . 385

Loisirs dangereux : modernité, moralité et criminalité juvénile en Grèce dans les années 1950-1960

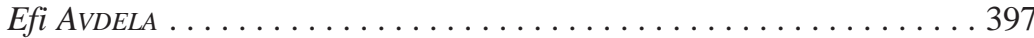

CONCLUSIONS

Philippe Chassaigne ........................... 407 



\title{
INTRODUCTION
}

\author{
Robert Beck et Anna Madeuf
}

Cet ouvrage présente, sous un intitulé légèrement modifié, les actes du colloque international " Divertissements et loisirs dans les sociétés urbaines, une approche comparative monde occidental - monde musulman ", qui a eu lieu à l'Université François-Rabelais de Tours du 15 au 17 mai 2003, et qui a été co-organisé par deux de ses centres de recherche, le Centre d'Histoire de la Ville moderne et contemporaine (CEHVI) et le Centre d'études et de recherches sur l'urbanisation du monde arabe (URBAMA).

Le lecteur pourrait être surpris par cette thématique des divertissements et loisirs par rapport à la seule société urbaine, mais la ville connaît effectivement des usages des loisirs qui lui sont spécifiques et s'inscrivent dans l'urbanité citons comme exemple la promenade qui ne se pratique pas dans les sociétés rurales (ou seulement par des gens de culture citadine). La ville est aussi créatrice de nouvelles pratiques ludiques définissant sa propre culture urbaine de divertissements et de loisirs : le théâtre, modèle de l'Antiquité repris à l'époque moderne, le jeu de paume sous l'Ancien Régime, le billard pratiqué depuis la même époque, les salons de jeux de nos jours... Cette culture des divertissements et des loisirs trouve aussi son expression dans le paysage urbain: ceci va de la construction et l'embellissement de bâtiments et d'espaces particuliers, comme les théâtres, les salles de jeux de paume, les promenades, en passant par les salles de café-concert et de cinéma, jusqu'à celui, tout à fait récent, des pistes pour la pratique du skate-board. L'importance de ces expressions spatiales des divertissements dans le paysage urbain se révèle pleinement dans les récits des voyageurs quand les théâtres et les promenades ${ }^{1}$ servent de critères décisifs pour juger de la beauté et de la

1 Voir, à ce sujet, la contribution de Sandra Pascalis. 
qualité de vie d'une ville. La ville, à la fois à travers l'invention, la pratique et la spatialisation des divertissements et des loisirs, possède donc des liens tout à fait spécifiques avec ceux-ci².

Il s'agissait d'un colloque historique, incluant les époques modernes et contemporaines. Pour enrichir la thématique de ce colloque et pour trouver des réponses à certaines questions, nous avons également choisi une approche comparatiste $^{3}$. Approche comparatiste d'abord au sein du monde occidental, avec des contributions concernant, à côté de la France, l’Angleterre, le Canada, l'Allemagne, l'Italie et la Grèce. Approche comparatiste ensuite entre le monde occidental, et le monde maghrébin et proche oriental. Qu'il nous soit permis, d'ores et déjà, de constater des différences finalement assez modestes, et de parler plutôt d'un certain décalage culturel - la fête dans le monde arabe (voir les contributions d'Anna Madœuf et de Gaëlle Gillot) ne rappelle-t-elle pas la fête disparue de nos villes, définie par l'exubérance et par la transgression périodique des normes ? La fonction des cafés pour la société des villes arabes, analysée par Nora Lafi, ne rappelle-t-elle pas celle des grands cafés de Vienne, mais aussi celle des tavernes à bière dans la société bavaroise... ?

\section{« DiVerTissementS » ET « LOISIRS »}

Mais comment justifier l'utilisation de ces deux termes, « divertissements » et « loisirs » dans l'intitulé du colloque et de cet ouvrage ? Selon une définition de 1740, reproduite par le dictionnaire Le Petit Robert, le terme « loisir » caractérise les occupations et les distractions pendant le «temps de liberté ». Or il ne peut y avoir de temps libre ressenti comme tel qu'à partir du moment où il y a un temps de travail bien délimité, qui se généralise dans les sociétés industrielles depuis la seconde moitié du XIXe siècle. Avant cette stricte délimitation en temps de travail et temps libre (qu'il faut répartir en outre entre temps biologique - sommeil, repas, hygiène corporelle -, et un temps pour soi), l'homme du peuple disposait assez librement de son temps de travail. Les exemples du compagnon vitrier Ménétra à la veille de la Révolution ${ }^{4}$, du tourneur en chaises Bédé vers $1820^{5}$ soulignent bien ce fait : ils quittent librement leur atelier pour aller boire un verre, et ils chôment le lundi, voire d'autres jours de la semaine, gardant ainsi une certaine autodétermination de leur temps de travail. Les divertissements des compagnons dont Jean-Marie Moine dresse le tableau, s’inscrivent en grande partie dans ce

\footnotetext{
2 Est-il un hasard que la revue Histoire Urbaine ait consacré son premier numéro aux loisirs (2000), soulignant ainsi une fois de plus les rapports spécifiques entre ceux-ci et les sociétés urbaines?

3 Pour une justification d'une telle approche, voir H. G. Haupt, «La lente émergence d'une histoire comparée ", in Passés recomposés. Champs et chantiers de l'histoire, Autrement, série «Mutations », nos 150-151, janv. 1995, p. 196-207.

4 D. Roche (prés.), Journal de la vie. Jacques-Louis Ménétra, compagnon vitrier parisien au XVIII siècle, Paris, Montalba, 1982.

${ }^{5}$ R. Gossez (prés.), Un ouvrier en 1820. Manuscrit inédit de Jacques-Étienne Bédé, Paris, PUF, 1984.
} 
contexte préindustriel d'une limite poreuse entre temps de travail et temps libre. Mais vers la fin du XIXe siècle, une discipline de travail stricte impose progressivement un temps de travail bien défini et calculé, se caractérisant par l'efficacité et par la productivité, dans les usines, ateliers et bureaux. Dorénavant, la nouvelle figure du « salarié » a du temps libre à sa disposition non seulement pour ses divertissements, terme qui va se dissoudre dans celui des loisirs, mais aussi pour le développement de sa propre personnalité, et finalement pour sa détente, conséquence de la découverte de la fatigue comme un des facteurs de la dégénérescence de la race6.

Ce temps de travail bien organisé et délimité provoque à son tour la revendication d'un temps pour soi par le mouvement ouvrier : il s'agit de l'exigence d'une journée de travail de huit heures, une des revendications majeures du mouvement ouvrier international avant 1914, à laquelle il faut ajouter celle du repos dominical ou hebdomadaire. Certes, en lisant les discussions menées lors des divers congrès des syndicats et bourses du travail avant 1914, c'est plutôt le souci du chômage et de l'alcoolisme ouvrier, ce dernier considéré comme la conséquence néfaste du surmenage imposé aux travailleurs, qui justifient cette revendication - mais il suffit de regarder l’imagerie conçue par la CGT en 1912 lors de sa lutte pour le congé du samedi après-midi ( « semaine anglaise ») pour comprendre toute l'importance que ce syndicat attribue dorénavant aux divertissements : il s'agit d'un ouvrier en train de pêcher dans le cadre d'une nature splendide, pendant que sa femme et sa fille cueillent des fleurs. Ce «temps pour soi », apparaît dès 1883 dans le pamphlet de Paul Lafargue, Droit à la paresse : après une journée de travail de trois heures, dont la courte durée se justifie par l'augmentation de la productivité grâce à la force croissante des machines, et par le souci d'éviter toute surproduction, créatrice de chômage, il resterait à la libre disposition des travailleurs un assez grand nombre d'heures7. Ils pourraient les consacrer au repos, aux activités civiques, au développement intellectuel, et finalement aux plaisirs. Il s'agit d'un pamphlet dont les thèses ont gardé une actualité frappante à une époque de productivité démultipliée...

\section{LES LOISIRS DANS L'HISTORIOGRAPHIE}

L’historiographie, à part quelques exemples, a longtemps négligé les loisirs ${ }^{8}$, soit en les ignorant, soit en les traitant comme une simple annexe aux études portant sur les différentes classes sociales. Il fallut attendre les années 1970 pour connaître les premiers ouvrages consacrant une étude entière à cette

\footnotetext{
${ }_{6}$ Quant au sujet de la fatigue, voir A. Rabinbach, Le moteur humain : l'énergie, la fatigue et les origines de la modernité, Paris, Éditions La Fabrique, 2004 ; pour l'ensemble d'une définition du loisir, nous suivons Joffre Dumazedier, Vers une civilisation du loisir ?, Paris, Seuil, 1972, p. 26-28 [1ère édition 1962].

7 P. Lafargue, Le Droit à la paresse, réfutation du droit au travail, de 1848, Paris, Oriol, 1883.

8 Pour des raisons de simplification, nous allons utiliser désormais le seul terme « loisirs ».
} 
thématique ${ }^{9}$ dans le sillage de Mai 68 , et surtout d'une sociologie beaucoup plus ouverte au sujet des loisirs. Celle-ci, sous l'impulsion de Joffre Dumazedier, s'est penchée sur la question d'une civilisation du loisir depuis les années $1950^{10}$, avant de se tourner vers l'étude des temps sociaux ${ }^{11}$, et elle trouve aujourd'hui sa prolongation, entre autres, avec les travaux de Christian Bromberger ${ }^{12}$. L'arrivée de la gauche socialiste au pouvoir en 1981 enfin, a comme conséquence la création d'un ministère du temps libre qui, même s’il s'avéra bien éphémère, souligne néanmoins toute l'importance que les sociétés occidentales attribuent dorénavant à cette question.

L'historiographie française découvre alors les loisirs comme objet d'études: l'édition d'une revue, Temps libre (dont l'existence s'avère également bien éphémère) en apporte aussi bien la preuve que l'organisation du colloque d'Amiens en novembre 1982 sur l'oisiveté et les loisirs dans les sociétés occidentales au XIXe siècle ${ }^{13}$. La publication de l'ouvrage L'avènement des loisirs, 1850-1960, sous la direction d'Alain Corbin ${ }^{14}$, constitue une nouvelle étape dans cette historiographie. Il y propose une synthèse ainsi que de nouvelles pistes de recherche, montrant ainsi tout l'intérêt qu'une telle histoire des loisirs peut présenter - constat que d'autres ouvrages parus depuis ne font que corroborer - pensons à Georges Vigarello, Passion sport ${ }^{15}$ ou encore à l'ouvrage collectif sous la direction de J.-P. Rioux et de J.-F. Sirinelli, La culture de masse en France de la Belle Époque à aujourd'hui ${ }^{16}$. Le support temporel des loisirs, le « temps libre ", est devenu à son tour objet de recherches historiques. André Rauch a ainsi étudié le temps des vacances et de ses usages ${ }^{17}$, alors que nous-même avons entrepris une étude de l'évolution historique du temps dominical ${ }^{18}$. La question du temps libre se retrouve aussi dans l'ouvrage récent consacré à l'histoire du temps de travail en France à l'époque contemporaine ${ }^{19}$.

Il s'agit donc d'une historiographie assez foisonnante qui concerne aussi bien les institutions des loisirs (bals publics, orphéons, cafés-concerts, cafés,

\footnotetext{
9 B. Cacérès, Loisirs et travail du Moyen Age à nos jours, Paris, Seuil, 1973.

10 J. Dumazedier, op. cit.

11 À titre d'exemple : N. Samuel, M. Romer, Le temps libre : un temps social, Paris, Librairie des Méridiens, 1984 ; R. Sue, Temps et ordre social, Paris, PUF, 1994.

12 Chr. Bromberger (dir.), Passions ordinaires. Du match de football au concours de dictée, Paris, Bayard, « Société », 1998.

13 Ad. Daumard (prés.), Oisiveté et loisirs dans les sociétés occidentales au XIXe siècle, colloque pluridisciplinaire, Amiens (novembre 1982), Abbeville, Paillart, 1983.

14 Paris, Aubier, 1995.

15 Paris, Éditions Textuel, 2000

16 Paris, Fayard, 2002.

17 Vacances et pratiques corporelles : la naissance des morales du dépaysement, Paris, PUF, 1988.

18 R. Beck, Histoire du dimanche, de 1700 à nos jours, Paris, Éditions de l’Atelier, 1997.

19 P. Fridenson, B. Reynaud, La France et le temps de travail (1814-2004), Paris, Odile Jacob, 2004.
} 
associations sportives...) $)^{20}$ que les loisirs par rapport à d'autres champs de recherche - il n’y a qu’à regarder la parution récente de l'Histoire du corps, pour se rendre compte des liens qui peuvent exister entre une telle thématique et les loisirs 21 .

\section{QUELQUES PISTES POSSIBLES D’UNE HISTOIRE DES LOISIRS}

Commençons par introduire deux distinctions : d'abord celle qui existe entre les loisirs dans l'espace public urbain (jeux publics, sports, promenade...) et les loisirs faisant partie de la vie privée et intime (pratique de la musique, du dessin dans un cadre privé, jeux de société, collections, voire la télévision...). Précisons dès maintenant que cette seconde catégorie trouve beaucoup moins son entrée dans l'historiographie, suite surtout aux difficultés que rencontre l'historien avide de pénétrer l'intimité des foyers - deux contributions seulement évoquent cet aspect des loisirs (Olivier Zeller, Robert Beck). Or il serait bien intéressant de connaître le rôle que ces activités privées peuvent jouer dans la vie quotidienne, à quel point ces loisirs intimes peuvent contribuer, par exemple à la cohésion familiale, associative etc., ou encore à une identité sexuelle et/ou sociale.

Une seconde distinction capitale à introduire concerne les sexes : les loisirs féminins au sein des sociétés urbaines, à conditions d'exister, sont de nature bien différente, avec des fonctions et des représentations bien divergentes de celles des hommes, faisant plutôt partie de la sphère privée, tout au contraire des loisirs masculins (voir la contribution de Fiorenza Tarozzi). Les rapports entre les femmes et les loisirs constituent encore un champ de recherche peu étudié, ce que démontre aussi ce colloque, qui met en scène surtout les loisirs masculins, ne faisant apparaître ceux des femmes que dans un cadre familial.

Deux grands axes définissent en général les questions concernant la thématique des loisirs dans les sociétés urbaines :

- les loisirs en tant que pratique sociale au sein de la société urbaine ;

- les rapports des loisirs à l'espace et aux rythmes de la ville.

- La pratique sociale des loisirs peut servir d'affirmation de l'identité sociale, mais aussi paroissiale - qu'on pense au fameux «palio » de Sienne, religieuse (voir Michèle Dagenais) et urbaine: l'identité de villes aussi différentes que Lens ou Marseille se définit en grande partie à travers leurs équipes de football, alors que celle de Limoges, pendant longtemps, se définissait à travers les succès de son équipe de basket. L’identité d'une ville peut s’affirmer aussi sous forme de fêtes historiques, souvent reconstituées par

$\overline{20}$ Nous n'avons absolument pas l'intention de dresser ici un tableau complet de cette historiographie.

21 A. Corbin, J.-J. Courtine, G. Vigarello, Histoire du corps, 3 t., Paris, Seuil, 2005. 
la bourgeoisie urbaine vers la fin du XIX ${ }^{\mathrm{e}}$ siècle pour commémorer des grands événements de l'histoire de cette ville. Mais l'existence de la fête efface peu à peu le souvenir historique et c'est elle qui contribue finalement à renforcer l’image de la ville - processus peu étudié jusqu'ici.

Les loisirs peuvent véhiculer la contestation ${ }^{22}$ - dès l'Ancien Régime, fêtes et révoltes se trouvent liées, de même que certaines institutions, comme les « abbayes de la jeunesse » véhiculent la contestation de l'ordre moral et social (mais aussi sa défense). Le public populaire des théâtres à l'époque de la monarchie censitaire utilise ces espaces pour exprimer son opposition contre les autorités religieuses et civiles (voir Malincha Gersin). Et que dire du carnaval, vecteur majeur de la contestation 23 ? De même, la culture ludique de la jeunesse du monde occidental des années 1960 porte en elle la révolte contre une guerre jugée sale, injuste et impérialiste, ainsi que contre une société de plus en plus consommatrice et figée dans ses convictions conservatrices.

L'utilisation des loisirs comme facteur de distinction sociale mériterait des études approfondies dans la suite des travaux du sociologue américain Thorstein Veblen sur la classe de loisir24. Alain Montadon25, quant à lui, montre ainsi l'exhibition du « beau monde » parisien sur les boulevards lors de ses « jours » et « heures » de promenade, moyen d'assurer et de confirmer une supériorité sociale mise en question. Pratiquer certains sports, comme l'équitation, le tennis, le golf, représentera ensuite un nouveau marqueur social, mais ces pratiques sont exposées aux « dangers » du mimétisme par les milieux plus modestes 26 , demandant ainsi de perpétuelles réinventions de pratiques ludiques propres aux classes supérieures.

C'est dans ce contexte qu'on peut inscrire la question de l'oisiveté, modèle antique de l'otium, c'est-à-dire la disposition libre du temps pour des activités intellectuelles, artistiques, politiques et ludiques. Le prince de la Renaissance, qu'évoque Florence Alazard, n’utilise-t-il pas ce loisir pour renforcer son pouvoir ? Disposer de temps libre pour soi ne fait-il pas aussi partie de la construction d'un charisme personnel ? Disposer librement de son temps suivant ce modèle aristocratique devient ainsi un marqueur social, toujours en vigueur à l'époque industrielle. Or la rencontre de ce modèle avec la nouvelle valeur, bourgeoise et morale, du travail, mériterait à son tour des études

\footnotetext{
22 Y.-M. Bercé, Fête et révolte. Des mentalités populaires du XVIe au XVIIIe siècle, Paris, Hachette/Pluriel, 1994 [1 ère édition 1976].

23 Voir à ce sujet A. Faure, Paris Carême-prenant. Du Carnaval à Paris au XIXe siècle, Paris, Hachette, « littérature \& sciences humaines », 1978.

24 T. Veblen, Théorie de la classe de loisir, Paris, Gallimard, « Sciences humaines », 1970.

25 A. Montandon, « Une pratique sociale/lieu de mémoire : la promenade », Francia, 25/2, 1998, p. 49-67.

26 Nous croyons cependant à l'existence d'une culture populaire authentique, avec ses divertissements, qui n'est pas le produit d'un tel mimétisme. Ce mimétisme populaire des pratiques culturelles venant des classes supérieures nous semble plus spécifique à l'époque de la culture de masses et à la disparition d'une culture populaire au cours de la seconde moitié du XIXe siècle.
} 
approfondies. Évoquons simplement une des conséquences de ce «rendezvous ", le nouveau rôle des femmes au sein des élites économiques et politiques du XIXe siècle, à qui les maris (ou pères) transfèrent la tâche d'exhiber leur otium, reflet de leur richesse et pouvoir.

À l'époque contemporaine, les loisirs peuvent aussi servir de moyen pour apaiser les conflits d'ordre social ou intergénérationnel. La création d'associations musicales et sportives dans le cadre des patronages au XIXe siècle poursuit comme but principal la domestication et la moralisation d'une classe ouvrière jugée dangereuse, et encore de nos jours, les élites considèrent le sport comme moyen de pacification de quartiers jugés difficiles. On peut s'interroger, dans ce contexte, sur la promotion et l'essor de certains loisirs que Joffre Dumazedier a qualifiés d' « apolitisants », comme la pêche, le bricolage ou encore le jardinage, ce dernier trouvant son expression dans le mouvement des jardins-ouvriers. Et que dire en général du loisir comme «illusion de libération ", concept cher à Henri Lefebvre et à Jean Baudrillard27 ? C'est peut-être aussi dans ce contexte qu'une interrogation critique sur la commercialisation des loisirs, rappelée par plusieurs auteurs, et notamment de ses fins devrait s'imposer : cette commercialisation ne contribue-t-elle pas à enlever aux loisirs tout caractère contestataire, à rendre l'individu passif et simple consommateur, susceptible à la propagande publicitaire - ce que les yippies américains en 1970 avaient déjà bien compris en occupant un des parcs de l'empire Disney... (voir la contribution de Sophie Didier). De façon plus générale : si les loisirs peuvent posséder une dimension contestatrice, il faut aussi s'interroger sur le rôle qu'on peut leur attribuer comme moyen de conservation de la société.

- Le second axe d'une histoire des loisirs dans les sociétés urbaines concerne leurs rapports à l'espace et aux rythmes de la ville. Il s'agit d'une thématique bien large dont nous allons développer un seul aspect, à savoir les divertissements et loisirs des classes populaires urbaines, et leurs relations conflictuelles avec la perception de ces pratiques par les élites. Ce développement doit montrer que la pratique des loisirs ne constitue absolument pas une activité anodine, mais qu'elle représente un enjeu important pour les forces religieuses, politiques et sociales à toutes les époques.

Sous l'Ancien Régime, les divertissements se trouvent souvent en rapport direct avec le sacré :

- d'abord sur un plan spatial : les espaces religieux, l'église, le cimetière qui la jouxte, la place devant l'église servent très souvent aussi de lieux de divertissements ;

- ensuite sur un plan temporel : ce sont les cycles imposés par la religion

27 R. Sue, «Contribution à une sociologie historique du loisir », Cahiers internationaux de sociologie, 38e année, juillet-décembre 1991, p. 291. 
qui rythment aussi les divertissements des fidèles, ou limitent des cycles profanes, comme celui du carnaval.

Or ces temps sacrés - fêtes religieuses, dimanches - avec leurs manifestations publiques comme les processions ou les pèlerinages, et ces lieux sacrés, constituent souvent l'occasion de débordements festifs (qu'on peut encore rencontrer dans le monde musulman, voir Anna Madœuf et Gaëlle Gillot), constamment dénoncés par les autorités religieuses - ce qui amène à se demander si ces cérémonies religieuses elles-mêmes ne constituent pas une sorte de divertissement, et à s'interroger sur la nature de la perception des célébrations religieuses par les fidèles, mélange de sacré et de profane...

La volonté de l'Église post-tridentine de resacraliser ces espaces et ces temps religieux (suppression d'un grand nombre de fêtes, nouvelle discipline dominicale, interdiction d'utiliser des espaces sacrés pour des activités jugées profanes...), mais aussi la volonté épuratrice des Églises réformées (à Zurich, le réformateur Zwingli aurait même interdit la promenade dominicale !) provoquent par conséquent de nombreux conflits entre autorités religieuses et fidèles. Les premières profitent progressivement du soutien des autorités laïques dans cette lutte contre la culture populaire dont la condamnation devient depuis le XVIII siècle un des leitmotive du discours des élites. Voltaire dénonce ainsi le pouvoir des cabaretiers, les seuls à profiter des fêtes religieuses. Une nouvelle sensibilité se développe au sein de la bourgeoisie qui n’arrive plus à tolérer les excès, supposés et vrais, d'une culture populaire bruyante et envahissante. À partir de la fin de l'Ancien Régime, les élites, dans un souci apparemment social et moral, commencent à confondre progressivement « temps libre » populaire et désordre - dorénavant, ce ne sont plus les fidèles en général mais les classes populaires, notamment celles des villes, qui se trouvent dans le collimateur.

La Révolution, en introduisant le calendrier républicain et en réduisant radicalement le nombre de jours "chômés ", s'inscrit entièrement dans ce discours qui donne la priorité au temps comme facteur économique - de même, Napoléon Ier qui, tout en rétablissant le calendrier traditionnel, le prive de la plupart des anciennes fêtes religieuses. Il s'exprime aussi pour le travail du dimanche afin d'éviter tous les abus du temps libre par les classes populaires.

Ce discours dénonçant systématiquement les dangers du temps libre populaire, d'une « oisiveté » populaire, se poursuivra jusqu'au milieu du $\mathrm{XX}^{\mathrm{e}}$ siècle, avant que la jeunesse "ne prenne le relais", comme le montre Efi Avdela à travers l'exemple de la jeunesse grecque. Il développe ses propres modèles d'un temps libre passé selon les normes de la bourgeoisie, qui prévoient même à l'intention des ouvriers l'aménagement de "parcs de loisirs » avant l'heure. Il s'agit d'institutions bien surveillées, situées sur des emplacements faciles à contrôler, par exemple sur des îles, ce qui n'est pas sans rappeler la construction des premiers parcs du groupe Disney, étudiée par Sophie Didier. 
Cette volonté de moralisation et d'encadrement montrée par les élites par rapport à la culture populaire d'abord, à celle des jeunes dans la seconde moitié du $\mathrm{XX}^{\mathrm{e}}$ siècle ensuite, permet à nos yeux de nombreuses interrogations sur ses vrais motifs. Elles pourraient ainsi susciter d'autres interrogations, par exemple sur les liens qui peuvent exister entre culture populaire et subversion....

Bref, ce modeste développement d'une seule dimension du rapport des loisirs à l'espace et aux rythmes de la ville pour montrer toute la richesse que l'histoire des divertissements et loisirs peut offrir. Quant à ce colloque, nous regrettons l'absence de certains thèmes, et notamment celui des loisirs « illicites ». Nous pensons, à titre d'exemple, à la danse et ses fonctions sous l’Ancien Régime, sujet déjà à une véritable régulation, et dont de nouvelles formes, valse, polka, etc., seront encore désapprouvées par les autorités au XIX ${ }^{\mathrm{e}}$ siècle, pour ne pas parler du rock'n roll du milieu du XXe. Les fonctions de ce plaisir dont seuls certains aspects ont été étudiés, mais aussi les causes profondes de sa désapprobation par les élites religieuses et civiles constituent d'excellents sujets d'étude - dont Maud Nicolas montre certains aspects dans sa contribution sur la danse dans la société urbaine de Tunis. On ne peut que regretter aussi, en évoquant les plaisirs « illicites », l'absence d'études portant sur la consommation de drogues 28 - l'importance d'une drogue comme le LSD pour le mouvement hippie est indiscutable, mais ne pourrait-on pas élargir cette étude à l'ensemble du mouvement contestataire des années 1960, ou à l'avènement de nouveaux modes de vie ? De même, quelle signification peuton attribuer à la consommation de boissons alcoolisées dans le pays de culture islamique? Et finalement, en évoquant le plaisir, dimension capitale des loisirs, on est obligé de constater la quasi-absence de toute évocation de la sexualité... (à la notable exception de la contribution de Jean-Marie Moine).

On peut aussi regretter l'absence d'une autre thématique, étroitement liée aux loisirs, celle de l'ennui. L’incapacité de l'individu à « organiser » utilement ce temps à soi, ainsi que ses causes, représentent un champ de recherche encore peu défriché en France, alors qu'on peut suivre l'évolution de ce phénomène depuis la fin du XIXe siècle dans le cadre d'un temps strictement organisé, de l'arrivée de la culture de masses, le recul de la fête et d'une culture populaire authentique, ainsi que de l'influence de la religion.... Le docteur Tardieu, n’écrit-il pas en 1903 que l'ennui du dimanche serait la simple conséquence de l'absence de Dieu ce jour-là29 ?

\footnotetext{
$\overline{28}$ Voir à ce sujet : E. Retaillaud-Bajac, Usages et usagers de drogues dans la France de l'entredeux-guerres, thèse de doctorat, Université d’Orléans, 2000.

29 É. Tardieu, L'ennui, étude psychologique, Paris, Alcan, «Bibliothèque de philosophie contemporaine », 1903.
} 


\section{QuELQUeS SUGgESTIONS DE LECTURE}

Une société qui se fonde, s'organise et se développe selon les logiques du travail et de la production, et où, parallèlement, le temps libre prend de l'ampleur, court le risque de la vacuité du temps non travaillé, et est menacée par l'absurdité. Aussi, nos sociétés contemporaines, pour réussir leur projet, se doivent d'organiser simultanément le temps et le sens de cette dualité. De ce fait, le temps et le sens du loisir ne sont pas « autres », ni supplémentaires, ni décalés, ni à interpréter par défaut ou par excès. À titre d'exemple, on peut évoquer le cas du curriculum vitce, soit une fiche signalétique présentant les compétences et aptitudes d'un individu à occuper un type d'emploi donné. Dans ce cadre, il n'est pas incongru - il est même recommandé - d'évoquer un ou plusieurs hobby(s), de divulguer d'autres facettes de soi que celles explicitement requises. Ce document se veut le reflet d'une identité individuelle globale, qui, même sommaire, exprime néanmoins comment le temps « mort », ou l'ennui, sont en quelque sorte des tabous dans des sociétés qui s’identifient par la densité et la complétude.

La pratique d'un loisir participe légitimement, voire de manière presque obligée, de la façon dont l'individu contemporain crée et met en scène sa « personnalité ». Le loisir ne commence pas mécaniquement après les heures de bureau, non plus qu'il ne s'inscrit seulement dans le créneau du rythme social induit par la réduction du temps de travail... Le loisir est devenu élément de définition et de constitution des sociétés contemporaines, il façonne et juxtapose les différentes sphères d'existence des individus, depuis le cadre urbain - ici mis en exergue - jusqu'à la sphère domestique - moins illustrée - et si l'on prend en considération cet objet étrange et d'interprétation polysémique qu'est la télévision, il niche donc au cœur du logis, au plus près de l'être humain.

Saisis à l'échelle de la ville, les loisirs engendrent même des cités d'un genre particulier, comme le montre Sophie Didier, en présentant le modèle intégral proposé et théorisé par Disney. Disneyland, du parc de loisir à la ville idéale, est une utopie urbaine en ce sens que ce modèle se donne à interpréter comme une réussite, non une parodie de cité mais une possibilité de ville, inspirée du rêve américain, donc mieux que la "vraie ville ». Ces formules urbaines, élaborées depuis la transposition en trois dimensions d'un monde imaginaire, se sont diffusées dans l'espace urbain américain et le groupe Disney participe de ce fait légitimement à la création et à l'aménagement d'espaces publics.

De la même manière, il existe un modèle de ville thermale ou balnéaire, comme en témoigne Bernard Toulier, en traitant d'exemples français. La composition de ces villes particulières, leur architecture et leur structure, traduisent un projet urbain orienté ; les formes construites et produites révèlent, en détail et globalement, la nature de leur conception, ce sont des villes modelées et modulées, comme ajustées aux loisirs qui les ont fondées. 
Par ailleurs, la lecture même d'une ville, de ses lieux, de ses topographies, peut être conditionnée par l'orientation d'un regard associé à un mode de vie, c’est le cas du Paris (1855-1937) révélé par Joanne Vajda, capitale sous l'influence d'une élite cosmopolite, adepte notamment des «skating-rinks » (patinoires) et autres jeux à la mode. Cette élite voyageuse, par sa fréquentation et son impulsion, a façonné une nouvelle géographie de Paris et a contribué à forger sa représentation de " capitale des plaisirs ». Également à Paris, et toujours dans l'exploration d'une géographie ludique, Olivier Dautresme, à partir cette fois-ci, d'une approche ponctuelle, montre comment le Palais-Royal à la fin du XVIII e siècle, a été un enjeu des spectacles et des genres théâtraux, un lieu atypique et expérimental, un entre-deux « hors la cour et au-delà de la foire ».

Comme le suggère Maud Nicolas, danser lors d'un mariage aujourd'hui en Tunisie n'est pas nécessairement très amusant, au contraire. Pour nombre de participants, cela peut être un moment d'exposition obligé, très préparé ; il faut alors se contrôler, danser selon son genre, danser selon son lien de parenté avec les mariés, danser de manière codifiée selon qui l'on est. Il faut donc « savoir ». Il s’agit en fait d'un exercice de bienséance appliquée, où la retenue est de mise et où mouvements et gestes sont avant tout signifiants, notamment dans la composition d'une ronde rituelle, où la distribution et les postures des protagonistes font partie du cérémonial et scellent les alliances. Par contre, autre moment et autre dimension de la danse, ce qui semble plus spontané et plus joyeux, ce sont les quelques pas ou mouvements esquissés en surimposition d'autres activités fort peu excitantes, telles les corvées ménagères. Travailler en dansant, danser en travaillant, ou travailler et danser ?

De fait, l'amusement ne craint pas le paradoxe et l'on peut aussi, semblet-il, parfois s'amuser fort bien tout seul et même lorsque l'on est impliqué en premier lieu dans une activité contraignante. Au-delà de la capacité humaine à suivre ou à tenir simultanément plusieurs postures, au-delà du caractère versatile des individus, se font jour également, entre retenue et abandon, les déclinaisons de tous ces registres subtils de mise en scène de soi et des niveaux d'implication, spontanée ou affectée, aux actions en cours, et au-delà au monde. Ainsi, l'être humain génère ce que l'on pourrait qualifier, faute de terme adéquat, son « propre univers », et finalement c'est par l'activation d'un état d'esprit que chacun décide d'être, ou de ne pas être, dans le registre de l'amusement, ou encore fait le choix d'opter pour la simulation.

De manière générale, comme le précise également Fiorenza Tarozzi, le temps libre des femmes semble plus compté que celui des hommes, le corps des femmes plus exposé, contraint et contrôlé que celui des hommes, d'où ces postures hybrides et ces instants mitigés, divertissements fugitifs ou simples diversions en surimposition, comme dérobés à un autre temps ou à une logique autre.

Autre façon de faire la ronde, de composer cet exercice en boucle, de mettre en scène une figure où la rotondité est à la fois formelle et symbolique : celle évoquée par Sandra Pascalis décrivant la promenade du Cours-la-Reine 
à Paris au XVIIe siècle. En ce lieu précis et identifié de la capitale, dévolu à cet usage nouveau, le ballet orchestré des promeneurs et des carrosses semble être la transposition de l'étiquette et du protocole de palais à l'espace urbain. Ici, la ville n'est pas à parcourir, mais elle est investie en un lieu précis, lequel permet l'expression d’une véritable scénographie urbaine.

Illustrations complémentaires d'un usage de la ville comme lieu d'acclimatation expérimentale, les mouled-s du Caire (Anna Madœuf) sont des célébrations festives en l'honneur d'un personnage saint. Ces événements sont à la fois des pèlerinages et des fêtes, c'est un même terme qui, en Égypte, rend compte de cette complétude, laquelle ne se transcrit pas dans la langue française. Un même mot pour traduire des situations qui, bien que contrastées, s'élaborent dans un même geste. Ni loisirs, ni divertissements, les mouled-s sont cependant des occasions, des moments autres, des opportunités de rencontres qui illustrent comment l'espace de la ville est plastique, comment la fête permet de prendre en compte la réversibilité du décor social, d'interpréter et de transformer un cadre d'existence et, enfin, de manifester tout à la fois la joie d'être ensemble et celle d'être entre soi.

La somme ici présentée se veut aussi inscrite dans des perspectives comparatives, comparaisons de temps, de situations, de contextes sociogéographiques, d'expériences et d'expérimentations, et l'on peut noter, au préalable de cette exploration, que seuls les plaisirs dits « des sens » semblent consensuels ou du moins partagés, même si eux aussi, se déclinent et s'élaborent selon sa société d'appartenance, son époque, sa caste, son sexe, son âge. Bien sûr, certains plaisirs sont abondants ou rares, licites ou illicites, grossiers ou raffinés, inédits ou galvaudés, mais au-delà de tous ces paramètres à la complexité infinie, on remarquera que si les formes, les contextualisations et les recettes changent et que si l'on aime pour certains les chansons paillardes, les «beuveries » et les " gueuletons » (comme en témoigne JeanMarie Moine présentant les loisirs des compagnons au XIXe siècle) ou si l'on apprécie pour d'autres les repas fins, la musique et les dégustations (comme le suggère Pierre-Yves Beaurepaire évoquant les loisirs maçonniques au XVIIIe siècle), ce sont bien les mêmes ingrédients, les mêmes ressorts et les mêmes types de satisfaction qui sont à l'œuvre.

De ce point de vue, il faut souligner à nouveau que l'on ne saura rien, audelà de quelques allusions, des plaisirs dits de la chair ; les contributions à cet ouvrage sont, de ce point de vue, pudiques. Ici, encore une fois, l'intime restera chaste. C'est donc par défaut que ne seront pas explorées ici certaines formes de plaisir. Cependant, le corps reste là ; sa place et sa présence dans l'espace des loisirs, quasi obsédantes, font qu'il se donne généreusement, du moins à l'interprétation.

Dans la pratique des divertissements et l'avènement des loisirs, c'est tant le corps social que le corps individuel qui est sollicité, mais ce dernier est impliqué physiquement, formé, transformé, vêtu ou dévêtu, c'est un corps qui ne s'appartient plus, qui se donne et s'adonne. L'individu moderne est fait d'un 
corps pluriel, un corps plastique, souple, qui se définit selon des lieux, des moments et des types d'activités. Lorsque ce corps est citadin, il est conditionné par la mobilité, influencé par la vitesse, ou par l’idée de vitesse associée à celle de liberté. On remarque qu'évoluent aujourd'hui dans presque toutes - sinon toutes - les villes du monde, des joggers, ou de façon plus générale, des citadins vêtus - en totalité ou en partie - de joggings. Si un costume citadin universel existe, c’est peut-être celui-ci, cette tenue symbole de la déferlante du sport, de la transposition du geste sportif au mouvement urbain, mais aussi d'une nouvelle manière de s'intégrer à l'univers de la ville, soit une façon moderne et mondialisée d'être en ville, d'être de la ville et d’être à la ville.

Cette métamorphose ne se fait pas sans heurt, et l'exemple traité par Efi Avdela démontre comment le loisir juvénile, avec ses modes et modèles exogènes, apparaît brutalement dans la société grecque des années 1950. Le « teddyboyisme » trouble alors une société peu préparée à l'émergence de revendications identitaires de ce type qui semblent ainsi menacer l'ordre social.

Cependant, le corps n'est pas pour autant parfaitement anonyme, il demeure sexuellement référencé, et pour les femmes, cette mue et cette adaptabilité s’énoncent en des termes différents, comme en témoignent l'analyse de Fiorenza Tarozzi, en prenant comme exemples l'invention du maillot de bain et les débuts de la pratique féminine de la bicyclette, et l'analyse de Méropi Anastassiadou-Dumont pointant le rôle de la «nudité balnéaire » dans l'évolution des rapports homme-femme en Turquie au XXe siècle.

En complément de cette lecture, on peut ajouter que si un statut particulier semble caractériser de façon générale ceux qui se produisent publiquement sur une scène, ceux qui ont pour métier d’être exposés, artistes et gens du spectacle, pour la gent féminine, la stigmatisation peut prendre une tournure particulière. La frontière est parfois mince, dans les représentations souvent plus que dans la réalité, entre chanteuses, actrices et prostituées, comme l'évoque Jean-Christophe Diedrich traitant des cafés-concerts en Lorraine allemande et française (1870-1914). De même, la « querelle des débuts » à Lyon au milieu du XIX ${ }^{\mathrm{e}}$ siècle, voit les artistes livrés en pâture à un public souvent versatile, et l'on ne se prive pas de critiquer la robe ou l'aspect physique d'une chanteuse (Malincha Gersin).

Enfin, le loisir est, bien évidemment, une affaire commerciale ; le loisir se vend et le loisir s’achète, il s’intègre à la logique marchande. Le loisir nécessite des lieux, des équipements et des accessoires ; il participe de la créativité sociale et de la dynamique économique comme en atteste Cédric Perrin pour le cas de Tours, saisi entre 1870-1936. Cependant, le loisir est aussi par lui-même un vecteur ou, selon la terminologie actuelle, un concept de vente, un objet de marketing aux effets publicitaires certains. Le succès des magasins Decré à Nantes, étudiés par Éric Monin, repose en partie sur l'aménagement, à partir des années 1950, d’un espace ludico-commercial mettant l'accent sur la promotion d'accessoires inédits (un escalator) ou d’espaces décalés (toitterrasse avec piste d'atterrissage). Les effets de surprise et les éléments de 
modernité des lieux concourent au projet commercial du grand magasin. À une autre échelle, celle de la ville même, les loisirs, tant par leur localisation, leur diffusion que par leurs pratiques façonnent les catégories d'espaces urbains. Ainsi, en suivant au cours d'un siècle comment une même activité, éminemment urbaine, celle du cinéma, s'implante, se déploie et migre dans la cité en changeant de forme et de logiques spatiales, Éric Blin montre, à partir de l'exemple de Tours, comment les cinémas se sont localisés en centre-ville puis s’y sont raréfiés, tandis que naissait le multiplexe de périphérie. Celui-ci côtoie souvent d'autres surfaces dévolues aux loisirs ou plus exactement aux commerces liés aux loisirs, formant aux franges urbaines des pôles thématiques, des zones dont la trame similaire et répétitive se fonde sur une esthétique et une signalétique banalisées au fort pouvoir d'identification.

En choisissant deux espaces de références, Olivier Zeller a, quant à lui, tenté d'identifier, quels étaient, au sein de mêmes familles, appartenant aux élites du XVIIIe siècle et dotées de plusieurs résidences, les loisirs délibérément inscrits à la campagne ou en ville. Il existait évidemment des occupations spécifiques à ces deux univers, mais plus curieux est le fait que le contenu des bibliothèques était, dans les deux cas, différent ; la lecture de romans semblant associée à la campagne, et celle d'ouvrages érudits à la ville...

Si le loisir s'inscrit dans un contexte, il se place également dans un cadre et l'on peut ici noter le rôle dévolu à ce qu'il convient d'appeler la nature, même - ou surtout - si cette nature est en réalité une des composantes de l'univers urbain, lequel fait de la ville un monde composite et lui associe également des lisières et des extensions. Cette nature est typée : nature-verdure, naturemaritime, ou autre cas de figure, mais elle est une nature pensée et produite ; façonnée et aménagée, elle est mise en conformité avec un projet, auquel elle participe ; c’est une nature qui, plus qu’humanisée, est socialisée.

C'est à une promenade dans une nature proposée aux citadins (parcs, jardins, zoos), et interprétée par des citadins, au Caire, à Rabat et à Damas, que nous convie Gaëlle Gillot. Lors des jours de fête, ces lieux distingués sont investis massivement et permettent de s'approprier familialement et collectivement la ville, par le biais notamment du pique-nique et de la communion signifiée par l'installation et la prise d'aliments. Peu importe alors si le jardin fantasmé devient un lieu sur-fréquenté, il est surtout un lieu urbain, de rencontre et de côtoiement. Autre fonction de ces lieux banals, mais atypiques, de la ville que sont les jardins publics : ils peuvent constituer des sortes d'isolats où il est possible de se mettre à distance, tant de chez-soi que de la globalité de la ville. Émergent ainsi des espaces urbains d'un « troisième type », entre lieu public et endroit privé, où se love en particulier la mixité - encore problématique - des amoureux.

C'est bien depuis la ville et en fonction des besoins citadins que l'on invente les composantes de cette nature complémentaire qui va parfaire l'univers urbain. Nous soulignerons ici la diversité tant des références à l'élément aquatique que des usages de l'eau: vertus prophylactiques, 
utilisation esthétique, représentations sociales lient l'utilisation et la perception de l'eau sous toutes ses déclinaisons à la question des loisirs (bain de mer, eaux thermales, vapeur du hammam, fontaines, etc.). Les expériences sociales de cette relation, traitées par Méropi Anastassiadou-Dumont et John K. Walton sur, respectivement, les bains de mer autour d'Istanbul et la pratique des bords de mer en Angleterre, aux XIXe et XXe siècles, sont, en ce sens, des exemples comparables, et montrent également comment les villes se sont prolongées jusqu'aux rivages.

Traitée sur le mode panoramique par Abdul-Karim Rafeq, c'est une existence riche en plaisirs et en raffinements que celle des bourgeois damascènes, durant la période ottomane. Il semble malaisé de départager ce qui relève de la vie ordinaire de ce qui tend à être des moments d'exceptions, le « fondu-enchaîné » semble parfait tant sont divers et multiples les lieux, formes et temps d'une vie urbaine qui paraît, pour certains, rythmée par des sollicitations plurielles et des transitions subtiles. C'est peut-être justement dans la construction de ces rythmes, dans cette fluidité apparente, dans cette trame qualitative que se définit alors l'appartenance à l'élite citadine de Damas.

En changeant d'optique, en passant de la fresque à une approche plus focalisée, cette réversibilité est lisible de la même manière, mais depuis un lieu unique, celui du café, qui s’avère de ce point de vue duel. Ainsi, Nora Lafi montre comment convivialité et urbanité y sont mises en scène par les notables ayant en charge la gestion et la gouverne de la cité, dans le Tripoli du XIX ${ }^{\mathrm{e}}$ siècle. Là, c'est le sens même du café, perçu et vécu comme lieu de convivialité, qui est utilisé à d'autres fins, en faisant un espace politique. Le café, élément structurant et constituant de la ville, point de repère spatial, joue aussi un rôle de fabrique, de négociation et de repère de l'ordre social. Le café des notables tripolitains est aussi le lieu qui spatialise (ou qui confisque ?) et tempère les débats...

Autres formes de débats, ceux relatifs à la question de la défense et de la diffusion des loisirs, on note que ces discours s'alimentent d'emprunts à une logique de cercle vertueux. Ainsi, les loisirs contribueraient à un équilibre social, on leur affecte des vertus complémentaires et indispensables. Les loisirs permettent tout simplement de travailler mieux, tel est l'argumentaire en faveur du développement des fonctions et des lieux de loisirs dans la ville du Pirée au XIX ${ }^{\mathrm{e}}$ siècle (Yannis Yannitsiotis). Dans un contexte tout autre, et selon un énoncé formulé autrement, le principe demeure le même pour un personnage dont le rôle et la fonction sont prééminents ; si l'on se distrait, ce peut être pour pouvoir ensuite se livrer à un labeur et à une concentration plus intenses : c'est notamment le cas du prince dans l'Italie de la Renaissance (Florence Alazard). Autre illustration de cette lecture d'une distribution au pouvoir équilibrant, de cet enjeu symbolique de la mise en place des structures et acteurs polyformes des loisirs, cette fois-ci à l'échelle de la ville : le partage et la recherche de l'équité entre franco-catholiques et anglo-protestants dans l’appropriation de Montréal et de Toronto au XXe siècle (Michèle Dagenais). 
Rares ici sont les contributions ciblées et construites depuis la (les) perspective(s) d'un individu unique, et les questions inhérentes à ce type d'approche sont, de ce fait, de nature différente. Ainsi, au-delà de ce que nous apprenons sur la vie sociale de Franz-Caspar Krieger, citoyen de Landshut au $\mathrm{XIX}^{\mathrm{e}}$ siècle, grâce au décryptage de son journal intime effectué par Robert Beck, on peut se demander si la pratique même de l'écriture d'un tel document participe du loisir et comment interpréter cette lecture ? En rendre compte, les écrire, même sans fantaisie ni fioriture aucune, n'est-ce pas savourer encore une fois, par leur mise en mots, ces soirées animées et ces dégustations de bière ? Quel est le sens de cette consignation écrite, de l'élaboration de ce qui deviendra une collection linéaire de loisirs détaillés de façon méthodique et méticuleuse ? Des énoncés peut-être sans surprise mais non sans mystère, car l'exposition d'une intimité révèle surtout des zones d'ombre ; bien qu'il relate une partie de sa vie, Krieger semble pourtant ne rien dire de lui-même. À cette collecte de mots, semble ici répondre la collecte de clichés d'Hermann Kippenberg (1863-1940), photographe amateur, qui, avec la même application, doublée de la compétence technique indispensable à cet effet, parcourt et photographie sa ville, Brême, et les environs de celle-ci (Christian Joschke).

On ne peut alors que regretter l'absence, dans cet ouvrage, d'une interprétation de la dimension psychanalytique des loisirs, tant la manière compulsive et maniaque dont ces deux personnages ont collecté et saisi, tout au long de leurs vies, l'un des scènes et l'autre des paysages, puis les ont transcrits, l'un en mots, l'autre en images, semble relever d'un sens partagé du détail et d'une commune obsession du souvenir...

Ces absences ne peuvent cependant pas cacher toute la richesse de ce colloque si stimulant, qui montre très bien, et le lecteur pourra s'en convaincre, tout l'intérêt et toute la richesse d'une histoire des loisirs et toute l'abondance de ses approches et problématiques. 
Arrivés à ce stade, il ne nous reste plus qu'à exprimer de sincères remerciements à tous ceux sans qui ce colloque et cette publication n'auraient jamais vu le jour. Nous pensons d'abord aux directeurs de nos centres de recherches, à MM. Pierre Robert Baduel (URBAMA), Philippe Chassaigne (CEHVI) et Bernard Heyberger (EMAM). Un grand merci va aussi à la MSH « Villes et Territoires » de l'Université François-Rabelais de Tours, et à sa directrice Mme Sylvette Denèfle ainsi qu'à $M$. Serge Thibault directeur de CITERES, pour leur soutien. De même, le ministère de la Recherche, le ministère des Affaires Étrangères, le Conseil régional de la Région Centre, le Conseil général du département d'Indre-et-Loire, ainsi que l'Université François-Rabelais de Tours elle-même : toutes ces institutions nous ont aidés financièrement et matériellement.

Nos remerciements vont aussi aux universitaires et chercheurs qui ont accepté de faire partie de notre comité scientifique - Mme Michelle Perrot, MM. Pierre Robert Baduel, Alain Corbin, Dominique Poulot et Olivier Zeller. Nous remercions aussi tous ceux qui ont accepté la tâche de diriger une séance de ce colloque - Mme Brigitte Maillard, MM. Alain Corbin, Jean-François Troin, Bernard Heyberger, Olivier Zeller et Dominique Poulot.

Mais qu'aurait été ce colloque sans l'aide si efficace de nos collègues Pascal Liévaux et Manuel Charpy ? De même, nous ne pouvons pas oublier ici l'aide, les conseils et la gentillesse d’Évelyne Dequéant, ni le patient et rigoureux travail de Muriel Hourlier, non plus que la participation de Katharine Scott et de Florence Troin.

Nous remercions aussi nos étudiants qui ont accepté de nous aider pour rendre la vie des participants plus agréable.

Et finalement, de grands remerciements aussi aux Presses universitaires François-Rabelais de l'Université de Tours qui ont accepté de publier les actes de ce colloque, ainsi qu’à Christian Calenge, responsable de la collection. 



\section{I - DIMENSIONS IDENTITAIRES}





\section{LOISIRS URBAINS, LOISIRS RURAUX DANS LES ÉLITES DU XVIIIe SIÈCLE}

Olivier ZELLER

Université Lumière Lyon 2

On connaît les multiples fonctions assurées par les « maisons des champs » à l'époque moderne. En cas d'épidémie, celles-ci offraient un asile éloigné des foyers de contagion et des chemins de propagation tout en garantissant la satisfaction des nécessités alimentaires. Elles accentuaient donc très largement l'inégalité sociale devant la mort. Ces maisons constituaient en même temps un élément patrimonial essentiel, qui permettait aux possédants urbains de vivre " du leur », " de leur cru », réalisant l'idéal d'une économie domestique fermée en faisant venir vins, grains, salaisons et fruits de leurs domaines. Symboliquement, la possession offrait de riches possibilités onomastiques. Se parer de noms de terre fut longtemps l'une des étapes vers l'agrégation à la noblesse; puis l'usage se répandit de distinguer les cadets en substituant le nom de différents biens au patronyme de la lignée. Dans le même ordre d’idées se plaçaient les conduites de nature à signifier et à renforcer la notabilité locale, du recrutement de jeunes ruraux comme serviteurs urbains aux donations faites à la paroisse de campagne.

\section{TEMPS URBAIN ET TEMPS RURAL}

L'aspect qui retient ici l'attention correspond à une troisième fonction essentielle : celle d'espace de loisir. Très généralement, les élites gagnaient la campagne à l'époque des grandes récoltes : moissons et vendanges. Cet usage imprimait un rythme caractéristique à la vie des villes. Les cours de justice, 
dont l'activité était si importante sous l'Ancien Régime, entraient dans le sommeil des « vacances » judiciaires, ne laissant fonctionner qu'une chambre des vacations. Dans le même temps, un ralentissement de l'économie était probablement lié à l'absence des principaux clients de tous ceux qui pratiquaient un métier rare tourné vers la production de luxe ou vers les services. Au XVIIIe siècle, les théâtres se vidaient au point que le montant des abonnements mensuels fît l'objet de réductions. Mais les directeurs ne mettaient guère à l'affiche que des reprises, réservant les créations aux jours d'affluence ouvrant l'année théâtrale après Quasimodo ou l'achevant durant les mois d'hiver. Cette léthargie estivale frappait également les principaux cercles de sociabilité : cercles, clubs, académies, sociétés savantes, loges maçonniques.

Pour les riches urbains, le séjour à la campagne n'était pourtant pas synonyme de rupture des relations sociales. Bien au contraire fonctionnaient des réseaux temporaires de sociabilité élitaire, au besoin tissés à l'échelle de plusieurs paroisses : il suffisait d'envoyer un valet porter les invitations. Le fait que celles-ci soient volontiers griffonnées sur un simple billet, voire au dos d'une vieille carte à jouer incite à penser que, transportés hors du cadre de représentation sociale permanente que constituait la ville, les membres des élites prenaient des libertés avec le formalisme ordinairement imposé par le code des convenances. Toujours est-il que les loisirs ruraux permettaient de nombreuses rencontres : les amis et voisins étaient priés à dîner, des parties de chasse étaient organisées, des pièces de théâtre amateur étaient représentées. Parfois, les feux d’une loge maçonnique étaient même allumés.

\section{L'APPORT DES PAPIERS DE FAMILLE}

Il est possible de dépasser cette vision globalisante, donc réductrice, en recourant au filon heuristique particulièrement riche que constituent les papiers de famille. Des fonds entiers, souvent inexplorés, restent conservés de nos jours par les descendants des notables d'Ancien Régime, au moins lorsque la transmission du patrimoine immobilier a été assurée, la continuité démographique établie et le statut social relativement préservé. De tels fonds recèlent des correspondances, des pièces littéraires, des travaux scolaires, des notes personnelles, des recettes, des livres de raison, des comptabilités, outre les inévitables sacs à procédure. Même si leur exploitation ne peut déboucher que sur des monographies posant nécessairement le problème de leur représentativité, elle permet une finesse d'analyse et une observation du détail impossibles à obtenir par les études de masse. En particulier, les notes personnelles, les correspondances et les livres de raison livrent des éléments précieux sur les stratégies et les motivations. Une autre richesse tient également à la connaissance des consommations, de l'environnement matériel et des pratiques quotidiennes. À ce titre, l'étude de trois fonds d'archives privées laissées par des nobles du XVIII siècle montre les rapports entre résidence et loisir. 
PREMIER CAS : LES CONSUlS LyONNAIS BRAC ET LEUR MAISON BEAUJOLAISE

Le nom de La Perrière désigne une maison de maître située en Beaujolais, au pied du mont Brouilly, dans la paroisse de Saint-Lager. Constituée originairement d'une simple maison de vigneron, elle appartint dès le début du XVIIe siècle à une famille résidant dans la toute proche ville de Beaujeu, les Brac. À la fin du siècle, elle fut promue résidence unique du médecin Antoine Brac et, considérablement agrandie, devint le centre du domaine agro-viticole constitué par trois générations. Mais le départ du fils aîné François Brac, son installation définitive à Lyon comme avocat et sa désignation comme consul de cette ville fixèrent à Lyon le domicile principal et fit de La Perrière une résidence champêtre éloignée de quelque quatorze lieues. Rien ne changea à la génération suivante, l’aîné François-Pierre-Suzanne Brac étant avocat et consul comme son père.

Évidemment, l'éloignement rendait difficiles des déplacements fréquents : il fallait prendre le coche d'eau jusqu'à Belleville, puis effectuer le reste du chemin en voiture. Aussi l'organisation familiale permettait-elle seule de maintenir l'œil du maître sur place. La surveillance des vignerons et des domestiques, ou encore la conduite des nombreux travaux entrepris incombaient à des Brac chanoines de Beaujeu - l'oncle puis le neveu - ainsi à un cadet chevalier de Saint Louis jouissant d'une mince retraite. Au besoin, les sœurs restées célibataires partageaient leurs activités entre Lyon et SaintLager. Les avocats Brac père et fils ne regagnaient donc le domaine de leurs ancêtres qu'au temps des vacances judiciaires, prolongeant leur séjour jusqu’à la Saint-Martin qui voyait traditionnellement les comptes annuels être arrêtés avec les vignerons.

De nombreux indices montrent l'importance de ce séjour en termes de pratiques de loisir. Tout d'abord, l'existence d'une sociabilité spécifique de voisinage : on invitait des propriétaires voisins, des bourgeois de Lyon, des curés des paroisses voisines à des dîners suivis de parties de cartes où l'on jouait petit jeu. On participait également à des parties de chasse. En 1757, on fit l'acquisition d'un billard, que monta l'ébéniste lyonnais Hennequin moyennant 300 livres. Surtout, la consistance de la bibliothèque rurale s'oppose totalement à celle de la ville. À Lyon, François-Pierre-Suzanne Brac, bibliophile averti, régnait sur un ensemble de plus de 4000 volumes constitué par l'accumulation lignagère, mais surtout par ses propres achats. Il s'agissait essentiellement de droit, de médecine, de morale et de religion; romans, théâtre et œuvres frivoles étaient significativement rares. La bibliothèque des champs était très différente : 58 titres seulement, dont l'Académie des Jeux, le Jardinier François, la Maison Rustique, la Maison académique. Cette spécificité était liée à l'un des loisirs favoris de l'avocat, la culture potagère qui l'amenait à faire planter de nouveaux légumes par ses valets, en particulier des pommes de terre. 
En 1770, un plan manuscrit du jardin attribua des dénominations humoristiques aux différents lieux. Pour François-Pierre-Suzanne Brac, la carrière de pierres éponyme devint carrière de marbre de Paros, une tonnelle, le cabinet des amoureux, un sentier, l'allée des beaux esprits, une terrasse, la salle de bal, les alentours étant baptisés Vigne de Falerne et le Bois de cyprès. Tout converge: les séjours d'automne étaient largement voués à une sociabilité ludique.

Deuxième cas : Le Receveur des tailles Pierre Valesque, entre Lyon et LA NORENCHAL

La deuxième étude permise par les archives privées porte sur Pierre III Valesque, receveur des tailles alternatif de la Généralité de Lyon. L’implantation de sa lignée à Lyon était toute récente. Son père et son oncle étaient venus de leur Languedoc natal pour apprendre la finance et trouver un emploi dans les bureaux. Par une remarquable double réussite, l’oncle était devenu receveur des tailles et le père, de commis épicier, était devenu l'un des plus gros négociants de cette spécialité, assez riche pour être nommé trésorier de l'Hôtel-Dieu, en être remercié par une nomination anoblissante au consulat de Lyon et pouvoir acheter à l'un de ses fils la deuxième charge alternative de receveur des tailles.

Ainsi, la maisonnée Valesque réunit-elle pour un temps, place SaintPierre, les trois ménages constituant une véritable famille souche répartie sur trois niveaux d'habitation : celui du père François II (1706-1791), celui du fils aîné Pierre III Valesque (1737-1794) et celui du fils cadet, Francois II Valesque (1734-1816). Mais les membres de cette impressionnante concentration s’égaillèrent rapidement. En 1770, François II acheta à Saint Didier au Mont d’Or la propriété de La Guerrière où il passa désormais le plus clair de l'année. Surtout, Pierre III épousa en 1770 Marguerite Monlong, fille d'un riche fabricant de soieries, également consul de la ville de Lyon. Valesque put dès lors jouir des charmes de la Norenchal, petit manoir situé à Fontaines-surSaône, à quelque trois lieues au nord de Lyon. L’iconographie conservée par les descendants souligne la fonction ludique de cette résidence champêtre. Le bâtiment est dessiné à gros traits, en arrière plan. Le moyen plan développe la perspective offerte par les jardins d'agrément, mais aussi par le potager. Surtout, le premier plan met en scène les membres de la famille se promenant dans une allée: les couples se promènent sous des ombrelles, les enfants courent ou jouent au cerceau, le petit chien gambade. Manifestement, le rôle assigné à la résidence champêtre était de servir de cadre à cette exaltation du bonheur familial. Mais Valesque alla plus loin, et finit par installer l'ensemble de sa famille à La Norenchal. Lui-même ne se rendait à Lyon que pour suivre ses affaires, ce qui lui imposait d'accomplir deux chevauchées hebdomadaires. Il n’est donc pas exagéré de constater que la résidence champêtre, lieu de loisir, l’avait emporté sur la résidence urbaine, lieu de travail. 
Troisième CAS : LE FERMIER GÉNÉRAL JACQUes JosePh BRAC DE LA PERRIÈRe, ENTRE PARIS ET SURESNES

Le dernier dossier d'archives utilisé fournit un exemple très explicite de choix comparables. Après avoir été promis à l'état de jésuite et vécu de nombreuses années au sein de la Compagnie, Jacques-Joseph Brac de La Perrière (1726-1794) suivit un cursus atypique qui, d’employé surnuméraire famélique, fit de lui l’un des fermiers généraux du crépuscule de l’Ancien Régime. Comme tel, il se trouvait professionnellement astreint à une résidence parisienne proche de l'Hôtel des fermes, et il louait un appartement sur la butte Saint Roch, rue Thérèse. Mais il acheta en 1781 un domaine à Suresnes, au pied du mont Valérien et, très vite, il en fit la résidence familiale, préférant s’imposer de véritables migrations pendulaires pour exercer dans la capitale des fonctions extrêmement prenantes. La richesse de sa correspondance, très fournie, est d'expliciter les motifs de ce choix résidentiel.

La vie urbaine était clairement décrite en termes répulsifs. La Perrière souffrait de l'exiguïté, certes relative, de son logement parisien : " il nous est impossible d'avoir un chat dans la maison, nous sommes dix maîtres et dixsept domestiques, pas un pouce de libre », écrivait-il. En même temps, il trouvait l'air de la capitale irrespirable : « dès que je rentre dans Paris, son air épais me rend mes vapeurs ». Et beaucoup de lettres évoquent le désir de fuir les importuns et de mettre un terme au surmenage. Les loisirs de la capitale pesaient peu dans la balance : "les spectacles et autres folies de Paris ne vous touchent plus guère, je vous invite à venir nous voir à Suresnes ou nous vivons paisiblement et ou nous en dirons de bonnes », écrivait en 1789 le fermier général à son frère resté à Lyon. À cette époque, les séjours parisiens étaient limités au strict minimum professionnel, le théâtre de la vie familiale et des sociabilités amicales étant fixé à Suresnes.

La résidence champêtre présentait en effet de nombreux aspects attractifs. Le calme et le bon air, certes. Mais, surtout, Suresnes était riche de possibilités de loisir. Les correspondances fourmillent de notations à cet égard, et quatre d'entre eux sont parfaitement identifiables.

Avant tout, le jardinage. Jacques-Joseph se passionnait pour son potager, au point d'en chanter les vertus dans ses exercices de versification. Ainsi, le poème intitulé Mon jardin chanta «l'artichaut vigoureux » et le «fertile concombre » poussant dans un lieu dépeint comme espace de félicité familiale où les enfants s’amusent à jardiner.

Par ailleurs, la campagne permettait les invitations sélectives. Elles permettaient de se soustraire aux relations protocolaires en réservant Suresnes aux parents, aux amis et aux très proches collègues. Les indices relevés dans les lettres permettent de supposer avec beaucoup de vraisemblance la pratique de relations empreintes de simplicité et de familiarité.

Le rejet de la société des financiers parisiens apparaît dans l'une des pièces écrites par le fermier général, Les voisins corrigés, ou l'envie punie, où 
la micro-société de la butte Saint Roch ${ }^{1}$ se trouvait brocardée. Un perron pour scène, quelques orangers en caisse pour décor, les membres de la famille pour acteurs: il n'en fallait pas plus pour monter un spectacle de ce théâtre de société que les élites du temps appréciaient tant. Cette forme de loisir était très volontiers associée aux grandes réjouissances. Ainsi, Brac de La Perrière écrivit-il une pièce de circonstance quand il se rendit avec les siens chez son gendre Parseval de Frileuse non à Paris, mais à Mantes, autre résidence champêtre.

Une activité de loisir assez proche était constituée par le chant en société. La culture lyrique fondée sur la connaissance des grands airs d'opéra était très répandue. Sur leur musique, l'on improvisait de nouvelles paroles. Par exemple, sur le célèbre Brillant Soleil des «Indes Galantes », la Perrière écrivit un éloge humoristique de son ami le fermier général Victor de SaintAmand, manifestement destiné à être interprété lors d'une fête entre intimes.

L'association entre loisirs familiaux et résidence champêtre est enfin signifiée, une nouvelle fois, par l'iconographie. Le tableau représentant la maison de Suresnes en méprise totalement l'architecture. Le bâtiment est rejeté en arrière plan, le jardin apparaissant en position moyenne. Le premier plan est occupé par une scène montrant les adultes se promenant et les enfants tirant leur cadet dans un petit chariot. C'est exactement le système iconographique utilisé pour représenter la Norenchal. Sans doute les collections de famille contiennent-elles de nombreux autres exemples de représentation de maisons de loisir des années $1780 \ldots$ La valorisation de tels lieux est d'ailleurs confirmée par le portrait collectif que le fermier général fit réaliser vers 1782 par Garneray : la famille fut placée dans le cadre champêtre de Suresnes, l'un des enfants étant juché sur un superbe mouton.

\section{CONCLUSION : ESPACE PROFESSIONNEL ET ESPACE LUDIQUE}

Méthodologiquement, l'apport des études de cas consiste pour une large part dans la reformulation ou l'affinement des hypothèses. La présente étude n'échappe pas à la règle, et permet principalement d'avancer quatre propositions.

Avant tout, la résidence rurale s'inscrivait dans trois rythmes de vie différents. Que l'anachronisme me soit pardonné : chez Valesque et le fermier général, le déplacement hebdomadaire vers la campagne prenait la figure d'un véritable week-end, dont le début était avancé dans toute la mesure du possible. Ce n'était que chez l'avocat François-Pierre-Suzanne Brac que l'éloignement rendait cette pratique impossible, et la résidence rurale correspondait au modèle général des vacances judiciaires, donc à un rythme annuel. La troisième temporalité s'inscrivait dans le cours de la vie : l'acquisition d'une maison des champs ou d'un château pouvait être explicitement destinée à jouir

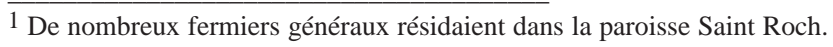


de cette période de loisir continu qu'était la retraite. Sitôt ses affaires abandonnées, François Valesque père quitta Lyon pour résider dans son domaine de La Guerrière, à Couzon au Mont d'Or. De même, le fermier général Jacques-Joseph Brac de La Perrière fit d’importantes acquisitions en Beaujolais dans les années 1780 dans l'espoir de quitter Paris sans retour et de revenir couler une retraite qu'il espérait douce auprès de ses parents et de ses amis.

Dans un autre domaine, le choix de la résidence rurale traduisait une nette répulsion pour la vie urbaine. Jacques-Joseph Brac de la Perrière et Pierre Valesque fuyaient le bruit, les puanteurs, les promiscuités et les importunités de la ville. Aux discours dominants sur la ville immorale et malsaine répondait un ressenti brossant l'image de la ville incommode: des attitudes assez banales dans ce second XVIIIe siècle.

Le rôle de cadre ludique joué par les résidences champêtres était également assez prévisible. La pratique du jardinage, la promenade, la possession d'animaux familiers, les jeux d'extérieur, le théâtre de société nécessitaient tous de l'espace. Le logement urbain ne permettait guère que le chant, la musique, la broderie et le trictrac, formes de loisirs amplement attestées par les inventaires après décès.

Le véritable intérêt des trois études de cas présentées ici réside ailleurs. Il tient dans une stratégie de répartition du temps entre ville et campagne articulée en termes d’organisation familiale. La résidence champêtre pouvait devenir le domicile normal de l'épouse et des enfants, l'usage de la ville étant réduit à l'exercice d'un état manifestement ressenti comme une corvée. Ainsi, le goût des loisirs et le dégoût du milieu urbain avaient produit une nette séparation entre l'usage de l'espace urbain réduit à l'exercice professionnel et celui de l'espace rural élu cadre de la vie familiale et ludique. Une remarque à vérifier par de nouvelles études de cas.

\section{Sources}

Archives de La Perrière, série E1, passim. Archives de la Norenchal, AP2, fonds Valesque, passim.

Fonds Brac de La Perrière, passim. 



\title{
LOISIRS ET SOCIABILITÉS MAÇONNIQUES AU XVIII SIÈCLE
}

\author{
Pierre-Yves BEAUREPAIRE \\ Université de Nice Sophia Antipolis, \\ Centre de la Méditerranée moderne et contemporaine et \\ Sociologie, histoire, anthropologie des dynamiques culturelles, \\ UMR CNRS-EHESS Marseille
}

Les recherches en cours sur la sociabilité maçonnique mettent en évidence l'existence d'une « Maçonnerie de société » qui déborde le cadre du temple pour investir le théâtre mondain, et proposer aux élites urbaines une offre de loisirs et de divertissements particulièrement relevée. Issue du monde des confréries, elle s'impose dans ce qui est un authentique commerce de société en se montrant compétitive, inventive, en laïcisant progressivement ses pratiques, et en assurant une veille sociable qui lui permet de répondre sans délais aux attentes nouvelles. Elle participe de la prégnance du modèle aristocratique au XVIIIe siècle, que de récentes études sur les sociétés que l'on nommera salons au XIXe siècle, et le théâtre de société, ont revisité et apprécié1. Notons d'ailleurs que l'aristocratie qui anime cette Maçonnerie de société tient la direction de l'Ordre maçonnique en France depuis la fondation du Grand Orient - avec les ducs de MontmorencyLuxembourg et d'Orléans - mais aussi en Prusse, dans l'aire baltique ou en Russie. Significativement, les critiques à l'encontre des loges qui « au lieu de s'occuper des travaux de l'Art Royal, tiennent des loges de femmes, donnent des

\footnotetext{
${ }_{1}^{1}$ Antoine Lilti, Le Monde des salons. La sociabilité mondaine à Paris dans la seconde moitié $d u$ $X V I I{ }^{e}$ siècle, thèse pour le doctorat en histoire sous la direction de Daniel Roche, Université de Paris I Panthéon-Sorbonne, 2003, 806 p.
} 
bals et jouent la comédie dans leur loge »² émanent d'ateliers socialement disqualifiés et exclus du théâtre mondain.

La Maçonnerie de société vit au rythme de l'ouverture de nouveaux ateliers, des bals qui saluent leur entrée sur le théâtre mondain. Elle pratique un tir à l'arc chevaleresque au sein des Nobles Jeux et crée les premiers clubs de golf, tout en manifestant son adhésion aux Lumières et la conscience de son rôle social en soutenant les créations de Musées ou de leurs déclinaisons: sociétés des Philathènes de Metz, collège des Philalèthes de Lille. Dans les orients plus modestes, elle favorise l'ouverture de salles de lecture et de bibliothèques publiques. À chaque fois, il s'agit de maintenir l'entre-soi d'une société d'élus consciente de son excellence, tout en ménageant des passerelles vers le public et en manifestant l'utilité de la Franc-maçonnerie.

C'est particulièrement net dans le domaine du théâtre et des concerts. Les loges huppées sont à la fois à l’origine de sociétés de concerts par souscription, mais privilégient la culture légitime, celle des amateurs, en organisant des concerts amateurs et jouant en société des pièces de théâtre. On connaît également la vogue au XVIIIe siècle du théâtre de société, où l'on est entre-soi, à la fois acteur et spectateur. Les ego-documents de maçons du XVIIIe siècle témoignent de l'importance de ces divertissements. Les membres de la prestigieuse loge parisienne des Amis Réunis qui revendique de former un club à l'anglaise dans son livre d'or, se réunissent ainsi au Palais-Royal, où ils signent le bail de la Société Olympique, et au château de La Chevrette. Chaque été, alors que s’effectue la migration mondaine vers la campagne, et que les Amis Réunis interrompent leurs travaux parisiens, La Chevrette accueille les membres de la loge et ses visiteurs de marque. L'hôte de La Chevrette est Savalette de Magnanville, garde du Trésor royal. Son fils, Charles Pierre Paul Savalette de Langes est connu comme fondateur du régime des Philalèthes, académie de recherches en hautes sciences qui réunit les plus grands noms de la Maçonnerie européenne, mais il distribue également les rôles au théâtre de société de La Chevrette, auquel participent notamment ses parents Pierre François Denis Dupleix du Perles et Guillaume Joseph Dupleix de Bacquencourt, et leurs alliés: Marie-Daniel Bourrée de Corberon, son frère aîné, Pierre Philibert marquis de Corberon ${ }^{3}$, musicien talentueux, et son épouse Anne-Marie, nièce du banquier de la Cour et fermier général Jean-Joseph de Laborde. On donne des pièces d'auteurs à succès comme Charles Collé 4 et Carmontelle. Euvre du premier, La Vérité dans le vin 5 met ainsi « en scène une petite historiette mondaine et libertine » 6 .

\footnotetext{
2 Bibliothèque nationale de France, Cabinet des manuscrits, FM, FMㄹ 423, dossier Amitié de Strasbourg, folio 19.

${ }^{3}$ Aide-major aux Gardes françaises.

${ }^{4}$ Attaché au théâtre du duc d’Orléans, il publie en 1777 son Théâtre de société en trois volumes.

5 Voir http://www.chass.utoronto.ca/ trott/societe/soc_C.htm

6 Antoine Lilti, « Public ou sociabilité ? Les théâtres de société au XVIIIe siècle », dans Christian Jouhaud et Alain Viala dir., De la publication entre Renaissance et Lumières, Paris, Fayard, Groupe de recherches interdisciplinaires sur l'histoire du littéraire, 2003, p. 284.
} 
Une lettre de Savalette de Langes à son cousin Dupleix du Perles datée du 12 septembre 1772 témoigne de cette pratique du théâtre de société par les membres des Amis Réunis - qui sont en l'espèce parents, confidents et frères en Maçonnerie :

« Eh bien paresseux [...]

J'ai cinq à six rôles à te proposer -, et des projets de plus vaste étendue à te communiquer, mais, ma foi, pour ce soir je n'ai pas le temps. Mais voici les rôles que je suis chargé de te proposer. Mande-moi promptement si naturellement tu acceptes :

Le jour de la fête: Le médecin malgré lui. Lucas paysan mari de la nourrice.

Dans la parodie de La reine de Golconde, Usbekh, confident Premier ministre de la reine.

Pour les autres jours : dans le légataire universel, le rôle de Géronte, le légataire; dans Nadine, Blaise ou à choisir marin ; dans Le Joueur, Doranthe, l'oncle du joueur (rôle de complaisance); dans Les fausses infidélités, Mondor ou à ton refus je le jouerai, tu en es le maître.

Tu vois que tu n'es pas mal partagé. J'attends ta réponse pour arrêter définitivement la liste des rôles. Nous jouerons vraisemblablement pendant une semaine et sûrement tu t'y amuseras, car tous ceux qui composent la troupe t'aiment et te désirent beaucoup. Dumaisniel est très libre à présent et nous pratique toujours dans le cantori. Aussi nous musiquerons. Crois-moi, mon ami, laisse ta maîtresse et tes amis de Paris et reviens dans le pays, où tu trouveras des gens qui t'aiment et te désirent et surtout un bon et sincère ami qui t'aime de tout son cœur et t'embrasse de même [...].

$\mathrm{Tu}$ trouveras rue Saint-Jacques au Temple du Goût, chez la Veuve Duchesne, les exemplaires en fascicule. Je t'enverrai bientôt le rôle d'Usbekh ${ }^{7}$.

L’espace social ${ }^{8}$ plus que public - malgré Habermas - est indissociable de cette offre de loisirs et de divertissements mondains. Si elle brille au sein de la sphère maçonnique - où la concurrence est rude - en mettant sur pied des loges prestigieuses par la qualité de leur recrutement, la magnificence de leurs temples et des fêtes qu'elles organisent, la Maçonnerie de société a clairement d'autres objectifs, briller à la cour comme à la ville sans renoncer à l'entre-soi cultivé dans le retrait du temple. Pour ce faire, elle investit l'espace domestique : un rideau tendu, un tapis de loge portatif, des grades conférés par communication et non lors de cérémonies de réception, la loge est partout où le cercle des amis choisis qui se reconnaissent comme pairs se forme et se

\footnotetext{
7 Archives départementales des Yvelines, E 905, lettre du 12 septembre 1772 publiée par Robert Chabot, "Une correspondance inédite (1771-1792) entre Savalette de Langes et son cousin Dupleix du Perles », dans Chroniques d'histoire maçonnique n49, 1998, p. 18-19. Voir également Yves Durand, Les fermiers généraux au XVIIIe siècle, Paris, PUF, 1971, p. 545-546.

8 Pierre-Yves Beaurepaire, L'espace des francs-maçons. Une sociabilité européenne au XVIII siècle, Rennes, Presses universitaires de Rennes, « Histoire », 2003, 231 p.
} 
rejoint: villes d'eau, fêtes princières ou champêtres, cour, congrès diplomatiques. La Maçonnerie de société investit aussi bien les châteaux et les manoirs que les hôtels particuliers et les résidences urbaines. En témoigne le physicien et antiquary William Stukeley :

«Nous avons créé une petite loge de maçons, bien réglée [...]. Nous avons pris l'habitude d'organiser tous les mois une réunion de société pour danser avec le beau sexe, et une réunion hebdomadaire, pour discuter entre hommes de condition ${ }^{9}$.

Stukeley réunit ses frères dans son jardin où il a élevé un temple d'inspiration druidique.

La Franc-maçonnerie s'approprie et lit l'espace du jardin, comme un espace serein de conversation, de "société », où l’on peut parler entre pairs, entre frères et sœurs, de sujets maçonniques et profanes, sans devoir se plier aux interdits rigoureux qui règlent les échanges dans le sanctuaire. Le jardin est un espace fraternel, mais ouvert sur la société. Les francs-maçons s'intéressent aux jardins des Nobles-Jeux de l'arc, qu'ils redessinent et enrichissent symboliquement. Au château de Troissereux près de Beauvais, le diplomate franc-maçon Marie Daniel baron Bourrée de Corberon fait aménager un « jardin maçonnique » inspiré de Bernard Palissy où il accueille ses visiteurs ${ }^{10}$. C'est en Saxe et à Pétersbourg, où il aime à s'y promener en compagnie du baron Heyking et du comte Brühl, que le diplomate français les a découverts et appréciés11. Le Substitut général du Grand Maître comte de Clermont, Augustin Chaillon de Jonville12, l’a précédé, en faisant aménager un jardin symbolique dans le parc du château de Jonville où il accueille le roi de Danemark Christian VII en octobre 1768 pendant son séjour en France13. Le Sommier de la vente des Biens nationaux de la ville de Paris indique la vente d'un «jardin de l'Amitié », rue des Petites-Écuries, section Poissonnière, appartenant aux francs-maçons ${ }^{14}$, tandis qu'à Montpellier, Jean-Jacques Régis de Cambacérès cotise pour l'entretien du «jardin des

\footnotetext{
9 Steven C. Bullock, Revolutionary Brotherhood. Freemasonry and the transformation of the American Social Order, 1730-1840, The University of North Carolina Press, Chapel Hill, 1996, p. 9. 10 Je remercie M. et Mme Tranié, actuels propriétaires, de m’avoir ouvert les portes du château de Troissereux, ainsi que Franck Rolland.

11 Journal de Corberon, 24 juillet 1775.

12 Situé à Saint-Fargeau-Ponthierry dans l'actuel département de Seine-et-Marne.

13 Bibliothèque de l’École nationale des mines, manuscrit 15, notes du chimiste et minéralogiste Antoine Monnet. Informations communiquées par Michel Jonville, auteur de Généalogie Chaillon de Jonville (Guyenne-Ile de France), Paris, chez l'auteur, 1995, 126 p. Par la suite, un monument funéraire sera élevé à proximité en la mémoire de François Joseph Guichard, membre de l'Heureuse Réunion de Paris.

14 Sans plus de précision. Voir Hippolyte Monin, Lucien Lazard, Sommier des biens nationaux de la ville de Paris conservé aux Archives de la Seine, Publications relatives à la Révolution française, Paris, 1920, p. 443-444.
} 
francs-maçons » à hauteur de 5 livres par an ${ }^{15}$. Le jardin appartient à la Vraie Humanité :

«Les motifs de cette association étant de réunir des amis d'une convenance réciproque, de leur procurer l'amusement des jeux permis, et l'agrément de la lecture des nouveautés intéressantes [...]. Le nombre total des associés est fixé irrévocablement à cinquante $» 16$.

Avec le jardin privé, l'espace maçonnique ne se limite pas à l'espace sacré, au sanctuaire replié sur lui-même. Multipolaire et modulable, il est ouvert sur la vie sociale, ce que confirme l'enjeu majeur des agapes. En effet, les agapes célèbrent l'affection, l'amour fraternel, c'est le sens précis du mot grec agapê. Elles ne se réduisent pas au banquet copieusement arrosé que prennent pour cible les écrits de divulgation. D’ailleurs, les travaux maçonniques se poursuivent en tenue de table, en «salle humide », avec un rituel spécifique. Mais les francs-maçons aspirent à sortir les agapes de l'espace contraignant et réglé des travaux de l'Art Royal, pour pouvoir cultiver plus librement et joyeusement le plaisir d'être ensemble sans pour autant renoncer à leur caractère fraternel.

La loge comme société d'amis choisis unis par le lien de l'initiation partagée est un espace de commensalité. C'est pourquoi à côté des banquets d'obligation et de réception - souvent pris en charge par les nouveaux membres -, les ateliers organisent des ambigus - c'est-à-dire des buffets froids - comme à Saint-Jean d'Écosse de Marseille, des pique-niques à l'Union écossaise de Berlin ou des croustillades à Amitié et Fraternité de Dunkerque17. Un ami de Corberon, Karl-Heinrich von Heyking se souvient avec émotion d'un souper de cent couverts organisé par les Trois Globes, orient de Berlin18. Quant à Bertin du Rocheret, il fournit en vin de Champagne les loges parisiennes en vue, à l'époque des Ducs sous l'acacia, en même temps qu'il

\footnotetext{
15 Information communiquée par Laurence Chatel de Brancion qui a inventorié les papiers maçonniques Cambacérès acquis par l'Université Kokugakuin de Tokyo. Contrairement néanmoins à ce que cette biographie de l'archichancelier a indiqué lors du colloque Francmaçonnerie et histoire de Rouen (14-16 novembre 2001), ces documents sont bien accessibles aux chercheurs. Ils sont même en ligne sur le site de l’Université :

http://kotodama.kokugakuin.ac.jp/digital/diglib/kanba/mag1/pages/page001.html

16 Cité par Pierre-François Pinaud, Cambacérès, le Premier Surveillant de la Franc-maçonnerie impériale, Paris, EDIMAF, 1998, p. 31-32.

17 Il faut également penser aux luxueux services de faïence maçonnique - vaisselles, flacons et soupières - que les loges ou les frères fortunés comme le marquis de Villeneuve, baron des États du Languedoc, font fabriquer: voir notamment Franc-maçonnerie et faïences, catalogue de l'exposition de Nevers, Palais ducal, 2000, 213 p.

18 Bibliothèque universitaire, Varsovie, Rps BUW 360, Mes réminiscences ou mémoires de C[harles-Henri] B[aron] d'H[eyking] écrits par lui-même avec les portraits de plusieurs hommes du nord, tracés d'après nature, tome II, 1 ère partie, chapitre VIII, n. p.
} 
commande une escadre de l'Ordre de la Félicité à Ay près d’Épernay en $1746^{19}$, où il possède un pressoir.

En outre, faire des agapes et de la salle des banquets un temps et espace de transition entre la fin des travaux de loge et le retour à la vie profane, permet de convier les femmes à se joindre aux frères en contournant les réticences des maçons hostiles à toute intrusion féminine dans le temple. À Salins, en Franche-Comté, lors de l'installation de la loge d'adoption l'Union parfaite le 15 mai 1777 - à laquelle participe Choderlos de Laclos qui écrira bientôt Les liaisons dangereuses -, Hennezel orateur de la loge Henri IV du régiment de Toul-Artillerie ne cache pas sa satisfaction :

"Ainsi mes frères jouissons sans trouble d'une société vive et enjouée, qu'une gaîté douce une plaisanterie fine viennent embellir nos banquets que les fleurs les plus belles réjouissent nos sens, craignons seulement que leurs parfums trop savourés ne produisent l'ivresse $»^{20}$.

Si les agapes montrent la capacité de la Maçonnerie de société à s’affranchir des limites du temple, les fêtes au succès desquelles elles contribuent, font l'objet d'une publicité volontaire. La Maçonnerie de société construit et gère son image publique. Expert en gastronomie - il fait venir à Saint-Pétersbourg du vin de Lunel pour accompagner les huîtres du golfe de Finlande dont il régale ses invités -, acteur et observateur méticuleux d'une vie de société particulièrement riche qu'il décrit avec gourmandise à son oncle Samuel Formey, secrétaire de l'Académie des sciences de Berlin, Johann Albrecht Euler en est le témoin. Profane, Euler n’est pas invité à la fête ; en revanche, il assiste au spectacle que Melissino offre à sa loge et au public :

«Saint-Pétersbourg, 24 juillet/5 août 1775

Nous eûmes [le 19 juillet] à souper les Professeurs Krafft, Guldenstadt, Georgi'21 et ma sœur. Après ce souper, c'est-à-dire à 10 heures, nous fûmes encore en deux carrosses, M. Guldenstadt, ma femme et moi dans l'un, Mrs. Kraft et Georgi dans l'autre. Tout droit à Caminoi Ostrovo, où les francs-maçons donnèrent la plus belle fête du monde. Le général Melissino de l'artillerie comme Grand Maître de la loge étant à la tête. Il y avait grand souper et bal en masque dont nous ne fûmes pas n'ayant pas été invités. Mais nous nous fîmes donner une bonne place pour voir un feu d'artifice des plus goûteux et très magnifique, qui dura depuis 11

19 De même, en Basse-Normandie, les Séran de Saint-Loup qui associent dès les années 1740 l'Art Royal à une vie de société et mondaine active, appartiennent à l'ordre de la Félicité : Caen, archives privées du Bâtonnier Jean-Claude-Delauney, papiers Séran de Saint-Loup, lettre de Mlle du Clariel, 6 août 1747.

20 Bibliothèque nationale de France, Cabinet des manuscrits, FM, FM ${ }^{2}$ 412, Extrait du Livre d'architecture de la loge Saint-Jean sous le titre distinctif de L'Union Parfaite à l'orient de Salins, discours du frère Hennezel, cité par Gilles Gudin de Vallerin, «Installation par Choderlos de Laclos d'une loge d'adoption à Salins (Jura) en 1777 », dans Mémoires de la Société pour l'histoire du droit et des institutions des anciens pays bourguignons, comtois et romands, 1991, p. 132.

21 Ses collègues au corps des cadets dont Euler est directeur des études. 
heures et demi jusqu'à minuit et demi ; de sorte que cette fois-ci nous ne revînmes au logis qu'encore vers deux heures » 22 .

À Londres, le Freemason's magazine recherche clairement une audience qui déborde la sphère maçonnique. La rédaction se veut notamment attentive au public féminin auquel elle destine tout particulièrement de copieux articles consacrés à la mode et aux artistes en vue ${ }^{23}$. La vie du monde et des spectacles fait l'objet de comptes-rendus réguliers, auxquels sont associés ceux des fêtes de l'Ordre que des correspondants ont fait parvenir à la rédaction. Le souhait d'intégrer les festivités maçonniques à la vie de société est manifeste. Il s'inscrit dans l'aspiration de la Grande Loge à être reconnue d'utilité publique et partie intégrante de l'Establishment.

En Suède, le duc Charles de Sudermanie, frère du roi Gustave III et futur Charles XIII, Grand Maître des francs-maçons depuis 1780 et Vicarius Salomonis du Grand chapitre illuminé de Stockholm depuis 1777, préside de magnifiques fêtes sur l'île de Riddarholmen, siège de l'Ordre maçonnique, à Ekolsund, au château de Rosersberg, ou encore à Drottningholm. Des tournois sont organisés où s'affrontent des chevaliers en armure, en présence du roi et de la cour. En 1785, la fête a pour thème la " Conquête de la forêt enchantée », avec en arrière-plan la libération de Jérusalem, très présente dans la mythologie des hauts grades templiers. Le duc lui-même y participe en armure $^{24}$. Des gravures et des comptes-rendus immortalisent ces rencontres qui précèdent les assemblées du chapitre templier réservées aux membres de l'Ordre. Un banquet de plusieurs centaines de couverts et un feu d'artifice concluent la fête. Le duc Charles associe clairement ses ambitions maçonniques - prendre le contrôle de la Stricte Observance Templière en Europe - aux intérêts stratégiques suédois dans l'aire baltique25. Les offensives du rite suédois en Prusse et en Russie inquiètent d'ailleurs Frédéric II et Catherine II. Les fêtes que le Grand Maître organise, témoignent non

22 Berlin, Staatsbibliothek zu Berlin, Preußischer Kulturbesitz, Handschriftenabteilung, Nachlaß Formey, lettre à Samuel Formey du 24 juillet/5 août 1775.

23 « Nor will the Ladies in this particular be forgotten - a portion of every succeeding number will be offered to their peculiar attention; and care will be taken that no subject of an improper tendency shall ever disgrace those volumes which it will be the unremitted endeavours of the proprietors to render worthy of a place in the well-chosen library of genuine taste, in all it's elegant varieties : where, without a fear, the owner may admit a wife, a sister, or a daughter, assured that female delicacy will in it's amusement find instruction ". Freemasons' Magazine, a general and complete library, printed and published by J. W. Bunney, $\mathrm{n}^{\circ} 7$ Newcastle-street, Strand, « and sold by all the Booksellers in Town and the country », August 1793, p. 3.

24 Elle est depuis 1988 exposée au musée de l'ordre maçonnique suédois à Stockholm. Voir Tom C. Bergroth, "Le rêve chevaleresque secret de la Franc-maçonnerie ", dans Renaissance traditionnelle, $\mathrm{n}^{\circ} 120$, octobre 1999, p. 278-282.

25 Voir « Expansion maçonnique et relations internationales : le modèle suédois », dans PierreYves Beaurepaire, L'Europe des francs-maçons XVIII ${ }^{-X X I} I^{e}$ siècles, Paris, Belin, Europe \& Histoire, 2002, p. 48-60. 
seulement de sa passion pour la chevalerie et les templiers, qu'il partage avec son frère Gustave, mais célèbrent aussi publiquement la puissance d'une Maçonnerie royale, résolument chrétienne et chevaleresque.

Avec la Révolution, la sociabilité maçonnique organisée entre en léthargie, à quelques exceptions près. Avec l'émigration et les bouleversements politiques, la Maçonnerie de société qui s'épanouissait dans l'Europe d'Ancien Régime a vécu, ses membres ne reviendront pas dans les ateliers désormais suspects d'avoir dissout le lien social. Loisirs et divertissements n'ont pourtant pas disparu de l'offre de sociabilité des loges nouvelles, mais ils s'agit à présent de salles de billard ou de cercles où par le biais de la philanthropie, la bourgeoisie maçonnique d'aspiration libérale discute des affaires de la cité et s'émancipe progressivement du dogme de la non-intrusion des francs-maçons dans le champ politique. Une page de l’histoire de l’Art Royal a été refermée. 


\section{VERS UNE URBANISATION}

DES LOISIRS ARISTOCRATIQUES : LA PROMENADE URBAINE COMME LIEU D'INTERPRÉTATION DES LOISIRS DE LA COUR DANS LA FRANCE DES XVII ${ }^{e}$ ET XVIII SIÈCLES

La promenade est un des éléments clefs pour qui veut comprendre les implications sociales des embellissements urbains des Temps modernes. Témoignant d'une sensibilité nouvelle portée à la nature et de l'ouverture progressive des villes sur la campagne environnante, le cours planté est conçu, au début du XVIIe siècle, comme lieu de pratiques sociales avant de devenir une solution formelle à l'agrandissement de la cité ou aux questions circulatoires, puis une réponse aux problèmes hygiénistes et à la régénération urbaine. Envisagée comme un lieu d'expression et d'interprétation des loisirs de la cour aux XVIIe et XVIIIe siècles, l'analyse de la promenade implique celle des principes d'urbanisation des activités aristocratiques et de la constitution de l'identité citadine d'un public élitiste1. De fait, l'intitulé même

\footnotetext{
${ }^{1}$ L'histoire des conditions de création matérielles, juridiques et financières des promenades comme leurs fonctions d'embellissement urbain ou d'hygiène publique font l'objet d'une thèse de doctorat, actuellement en cours : La nature citadine : promenoirs plantés et lieux de promenade urbains et publics en France du Grand Siècle à l'aube de la Révolution, D. Rabreau (dir.) Université Paris-I Panthéon-Sorbonne, Centre Ledoux.
} 
de cette contribution exclut l'étude de la promenade du peuple, qui pourrait être le sujet d'une autre publication.

Une partie des sources consultées - traités de savoir-vivre, répertoires de jurisprudence, chroniques, guides de voyageurs ou représentations picturales forme une documentation normative qui dépeint des conduites prescrites et non des comportements réels². Généralement composées pour et par une élite, ces informations reflètent l'imaginaire d'un groupe dominant, pensée qui dévoile des codes identitaires tout en contribuant à la composition idéalisée de la société3. Souvent reprises d'un guide à l'autre, ces descriptions stéréotypées normalisent l'activité de la promenade mais les pratiques sont corrigées par la réalité des faits dévoilée dans les archives municipales et de l'intendance ou les affiches de police. Ainsi, la distinction des classes reste courante dans la littérature ou les figurations, alors que dans la vie quotidienne, les populations se mélangent plus que ne le suggère la théorie. De même, l'ordre et les convenances ne sont pas toujours respectés par l'élite, comme voudraient le faire croire les sources, mais ces dérives sont rarement évoquées en dehors des registres de police. Il s'agit donc de comprendre le contexte urbain, politique et social qui entraîne la naissance des promenades durant la seconde modernité, de cerner les origines de ces espaces, les activités qui s’y déroulent, la mise en place de comportements liés à cette activité de loisir et la constitution d'une étiquette sociale urbaine.

\section{DE L'INVENTION DE LA PROMENADE URBAINE À LA CRÉATION DU COURS PLANTÉ}

«Ce n'est pas qu'on ne puisse faire remonter à une antiquité reculée l'usage des promenades publiques [...]. En France, il n'existait point, à proprement parler, de promenades publiques avant Louis XIV, sauf quelques plantations irrégulièrement alignées dans l'intérieur ou aux abords des grandes villes [...] »4.

Par ce résumé historique partisan, A. Alphand et le baron Ernouf présentent le XVIIe siècle comme un tournant dans l'aménagement des espaces plantés : si durant l'Antiquité ou le Moyen Age, des étendues de verdure servaient à l'utilisation collective des citadins, leur rôle semble différent selon l'époque, la

2 Jean-Louis Harouel, « Caliban hors du jardin. Le droit d'accès au jardin public parisien à la fin de l'Ancien-Régime », Histoire du droit social. Mélanges en hommage à Jean Imbert, Paris, PUF, 1989 ; Christine Lamarre, "Ouvrir ou fermer son jardin ? Bienséance et convivialité au XVIII siècle ", dans Alain Montandon (dir.), Les espaces de la civilité, Mont-de-Marsan, Edition Interuniversitaires, 1995 ; Louis-Michel Nourry, Les jardins publics en province, Rennes, Presses Universitaires de Rennes, 1997.

3 Voir d'ailleurs Jacques Revel, « Les usages de la civilité », dans Philippe Ariès et Georges Duby (dir.), Histoire de la vie privée, t. III, De la Renaissance aux Lumières, Paris, Seuil, 1986, p. 170.

${ }^{4}$ Adolphe Alphand et Alfred-Auguste Ernouf, L'art des jardins : parcs, jardins, promenades, Paris, 3 édition, 1886, p. 298. 
culture, l’idée de la nature, la religion ou la situation politique des sociétés qui les créent. Ces jardins peuvent alors être difficilement considérés comme les ancêtres des promenoirs français. Pourtant, dès le XVIe siècle, différents exemples isolés révèlent la lente intégration du vert dans la ville. Ainsi, dans son traité d'architecture de 1554, le Siennois Cataneo suggère de border d'arbres l'intérieur des murs d'enceinte pour des raisons de stratégie militaire5, conseil à rapprocher de la plantation des remparts des villes d'Anvers et de Lucques ${ }^{6}$. Il ne faudra qu'un pas pour que ces espaces soient ensuite utilisés par les citadins comme lieux de promenade, de récréation et de rencontre. Ce changement de goût se reflète dans la permanence de l'utilisation des prés, l'ouverture de certains jardins de particuliers ou d'ordres religieux à un public choisi, l'accès aux aires de jeu, comme le mail dont le spectacle attire les promeneurs, ainsi que la création de jardins conçus pour le public ${ }^{7}$.

La France innovera à partir du milieu du XVIIe siècle en systématisant l'aménagement d'un nouveau type de promenoir conçu pour le divertissement des citadins : il s’agit du cours, ou corso en Italien. Selon Furetière, ce terme désigne un :

"Espace qu'on traverse par un mouvement progressif, quand un corps est transporté d'un lieu à un autre. [... C'] lest aussi un lieu agréable où est le rendezvous du beau monde, pour se promener à certaines heures, et se dit tant du lieu que de l'assemblée qui s'y trouve »8.

Ce mot exprime donc à la fois l’idée de déplacement, le cadre de la promenade et la pratique sociale engendrée par le site ${ }^{9}$.

Le corso (Ill. 1) apparaît au XVIe siècle en Italie où il se déroule dans la plus belle et la plus grande rue de la ville ${ }^{10}$ ou dans tout endroit suffisamment vaste pour accueillir la parade des carrosses, comme les places devant les palais privés ou administratifs, les parvis d'églises ou les quais ${ }^{11}$. On se rend également hors les murs : les bords de mer, les environs des remparts ou les routes deviennent les lieux de rendez-vous de l'aristocratie pourvu qu'ils soient plats, suffisamment

\footnotetext{
5 Pietro Cataneo, L'architettura, Venise, 1554, cité dans F. Panzini, ibid., p. 7.

6 Franco Panzini, Per i piaceri del popolo. L'evoluzione del giardino pubblico in Europa dalle origini al XX secolo, Bologna, Zanichelli, 1993, p. 80.

7 Ibid., p. 46 : Le jardin de l'Arsenal est l'un des premiers parcs parisiens réalisé pour le public, son aménagement devenant un archétype de la nature citadine.

8 Antoine Furetière, Dictionnaire Universel, La Haye, A. et R. Leers, 1690.

9 A. Montandon, Sociopoétique de la promenade, Clermont-Ferrand, Presses universitaires Blaise Pascal, 2000, p. 42.

10 Antoine-Chrysostome Quatremère de Quincy, Encyclopédie méthodique. Architecture, Paris, chez Mme Agasse, 1801-1820, vol. II, p. 138 : « Cours. [...] Dans plusieurs villes d'Italie on donne le nom de cours, corso, à la plus belle et la plus grande rue où l'on a l'usage, aux jours de fête, de donner encore des courses de chevaux [...]».

11 Ferdinand Boyer, «Les promenades publiques en Italie du nord au XVIII siècle », La vie urbaine, $n^{\circ} 3$, juillet-septembre 1959, et « Les promenades publiques en Italie du centre et du sud au XVIII ${ }^{\mathrm{e}}$ siècle ", La vie urbaine, n4, octobre-décembre 1960.
} 
larges pour permettre aux voitures de se croiser et qu'éventuellement, ils offrent une belle vue ${ }^{12}$. En 1580, Montaigne en décrit le principe :

«Le plus commun des exercices des Romains, c'est se promener par les rues; et ordinairement l'entreprise de sortir du logis se fait pour aller seulement de rue en rue sans avoir où s'arrêter; et il y a des rues particulièrement destinées à ce service. À dire vrai, le plus grand fruit qui s'en retire, c'est de voir les dames aux fenêtres, et notamment les courtisanes [...] ${ }^{13}$.

\section{Illustration 1 : Le Corso de Rome}

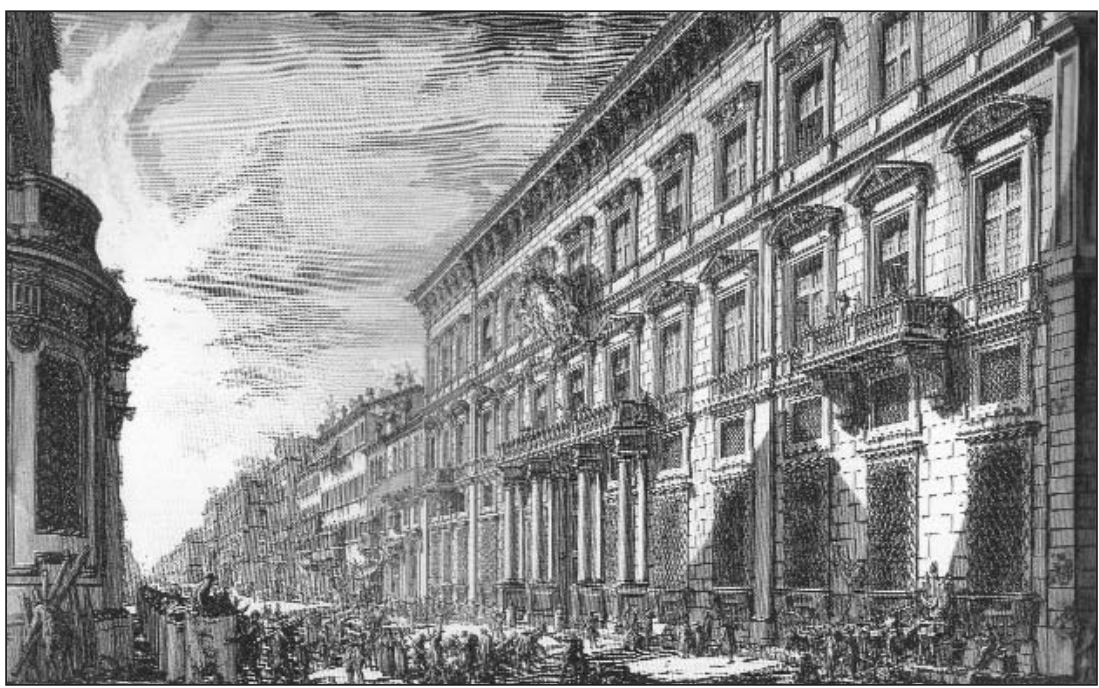

L'emplacement du corso varie en fonction des saisons et l'heure diffère selon le climat. On fait le cours le jour du Carnaval et, pour la promenade ordinaire, après le dîner, puis deux heures avant la nuit ${ }^{14}$. On peut y retourner après le spectacle. Ceux qui ne possèdent pas de voiture vont et viennent sur les trottoirs, sous les portiques, sur les bas-côtés de la voie utilisée pour le corso ou dans les jardins privés ouverts à l'intention du public ${ }^{15}$. Ces espaces sont donc investis par les citadins, sans qu'aucun aménagement n’y ait été réalisé. Les ardeurs du soleil, la poussière, le manque de place ou d'air ne semblent pas importuner les promeneurs.

Cette activité est importée en France par une reine d'origine italienne, au début du XVIIe siècle. Sauval nous apprend que le cours est :

\footnotetext{
12 Ibid.

13 Michel de Montaigne, Voyage en Italie par la Suisse et l'Allemagne (1580-81), Paris, Les œuvres représentatives, 1932, p. 187.

${ }^{14}$ F. Boyer, op. cit.

15 Ibid.
} 
"[...] un mot nouveau et une nouvelle chose, de l'invention de Marie de Médicis. Jusqu'à sa régence, on ne savait point en France d'autres moyens d'user de la promenade qu'à pied et dans les jardins, mais alors elle fit passer de Florence à Paris la mode de se promener en carrosse, aux heures les plus fraîches de l'après-dîné : ce qui se pratique maintenant en tant de lieux »16.

À Paris, on se rend sur le cours Saint-Antoine, aux abords de la Bastille, où la rue du faubourg Saint-Antoine et la rue Saint-Antoine sont envahies par les voitures ${ }^{17}$. En 1616, Marie de Médicis transforme les conditions de ce loisir en créant une scène spécifique à cette activité : il s’agit du Cours-la-Reine (Ill. 2 et 3). Cet ensemble d'avenues s'étend sur 1300 mètres le long de la Seine, entre le jardin des Tuileries et le pré de la Savonnerie au pied des collines de Chaillot (actuelle place de l'Alma). L'allée centrale mesure une vingtaine de mètres de large, ce qui permet à cinq ou six carrosses de rouler de front sans s'incommoder18; la largeur des contre-allées fait la moitié de l'avenue centrale. Le Cours est ponctué en son centre par un rond-point planté (à la hauteur de l'actuel pont des Invalides), d'une centaine de mètres de diamètre19, et «plus de cent voitures peuvent y tourner commodément » 20 .

La structure innovante du Cours devient bientôt un modèle typiquement français caractérisé par une organisation tripartite, les espaces de promenade étant différenciés en avenues carrossables ou piétonnes. Le terme de cours sera appliqué aux promenoirs qui suivent cette typologie formelle. Les allées plantées d’arbres sont à l'origine du succès rencontré ; de nouvelles recherches permettraient d'en comprendre la source, probablement influencée par la symbolique de l'avenue de château ${ }^{21}$. La promenade française devient indissociable de cette caractéristique, comme en témoigne la définition de Richelet: "Cours : Lieu où l'on va se

\footnotetext{
16 Henri Sauval, Histoire et recherches des antiquités de la ville de Paris, Paris, Charles Moette et Jacques Chardon, 1724, Genève, Minkoff reprint, 1973, t. II, livre VII, p. 287.

17 Marcel Poëte, La promenade à Paris au XVIIe siècle. L'art de se promener. Les lieux de promenade dans la ville et aux environs, Paris, Librairie Armand Colin, 1913, p. 99, 100, 105.

18 H. Sauval, op. cit., livre VI, p. 671 ; John Evelyn, The state of France as it stood in the IXth year of this present monarch Lewis XIIII, Londres, 1652, cité dans M. Poëte, op. cit., p. 111.

19 Paul d'Ariste et Maurice Arrivetz, Les Champs-Élysées. Place de la Concorde, Cours-la-Reine, Jardin des Champs-Élysées... Étude topographique, historique et anecdotique jusqu'à nos jours, Paris, Émile-Paul, 1913, p. 30. A.-G. de Manet, « Les promenades parisiennes. Le Cours la reine à travers les âges ", Le mois littéraire et pittoresque, t. XXXI, janvier-juin 1914, p. 525.M. Poëte, op. cit., p. 111. 20 Ibid.

21 Selon Pierre Richelet, Dictionnaire français, 1680, t. I, fac-similé Genève, 1994, l'avenue est un «Chemin par où on aborde. [...]. Grande allée qui conduit dans quelque maison de plaisance et qui de part et d'autre est ordinairement bordée d'arbres». Denis Diderot et Jean le Rond d'Alembert (dir.), Encyclopédie ou dictionnaire raisonné des sciences, des arts et des métiers, 1765, réédition Stuttgart, 1967, t. I : l'avenue "est une grande allée d'arbres [...]. Ces sortes d'avenues sont ordinairement plantées à l'entrée d'une ville ou d'un château, comme l'avenue de Vincennes près de Paris ». Les liens entre avenue de château et avenue de ville sont développés dans M. Poëte, op. cit., p. 342 et Daniel Rabreau, « La promenade urbaine en France aux XVII et XVIII siècles : entre imaginaire et planification », dans Monique Mosser et Georges Teyssot (dir.), Histoire des jardins de la Renaissance à nos jours, Paris, Flammarion, 1991, p. 301.
} 
promener; grandes et belles allées bordées de tilleuls»22. L'intégration de la nature dans la promenade est à l'origine du succès du Cours-la-Reine, au détriment du cours Saint-Antoine. Ce dernier est démodé dès la fin du règne de Louis XIII à cause de son manque d'aménagement, sa situation dans la ville, l'absence de perspective et de panorama, qualités attribuées au Cours-la-Reine.

\section{Illustration 2 : Boulevard Saint Antoine, Paris}

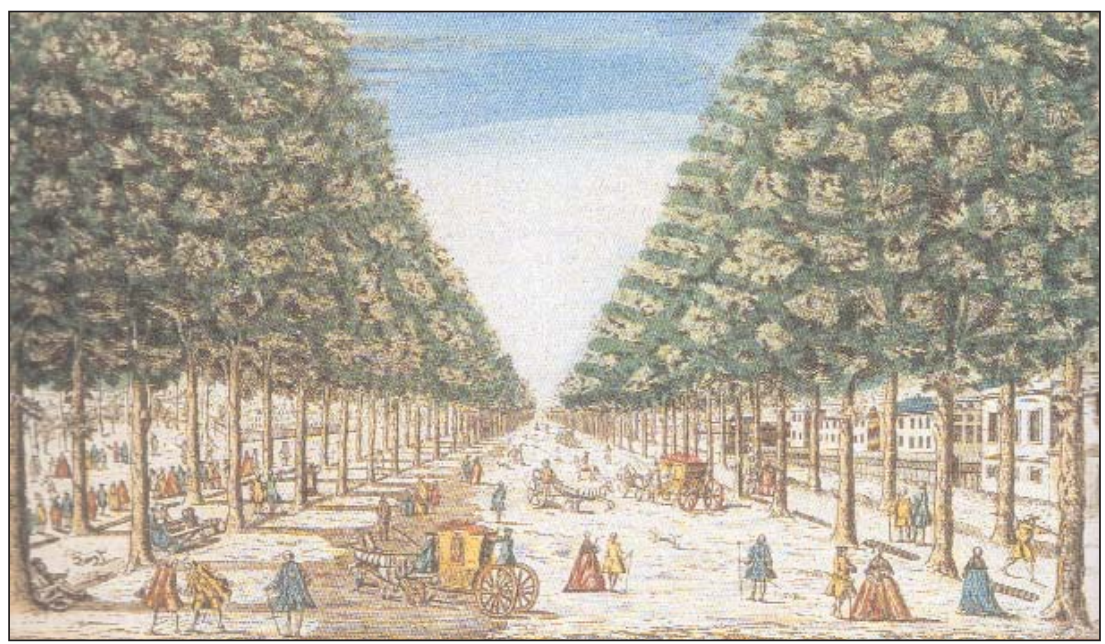

Illustration 3 : Cours-la-Reine, Paris

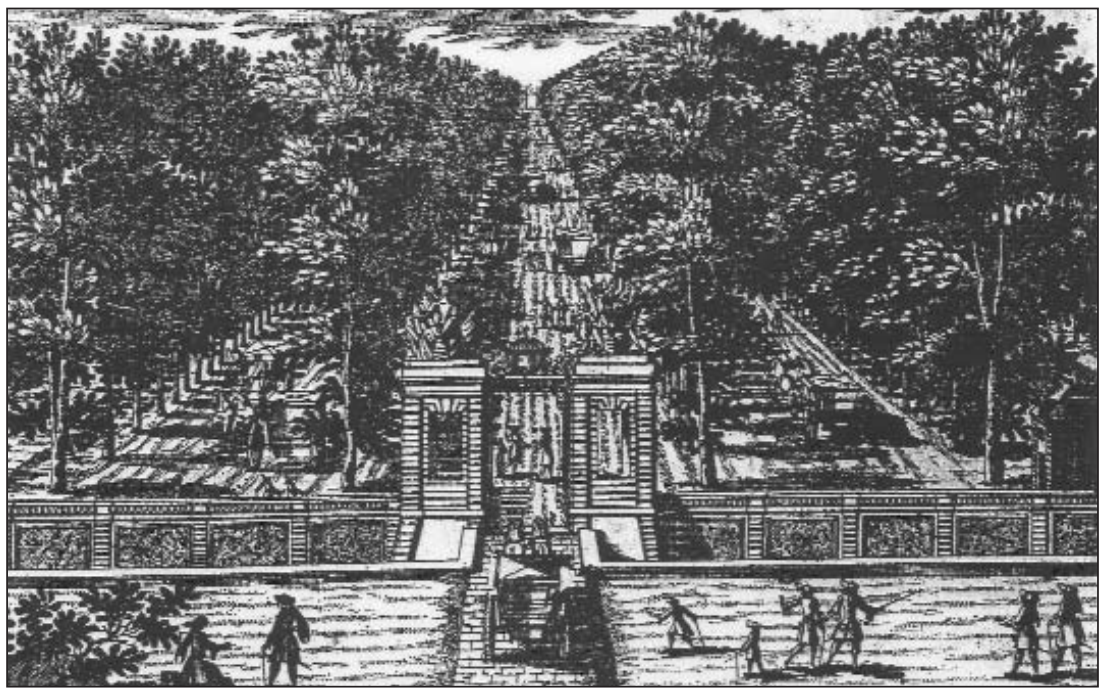

22 P. Richelet, op. cit. 
Ainsi, Marie de Médicis importe en France une manière de se promener pour laquelle elle fait réaliser des travaux d'embellissement novateurs, créant une typologie qui se diffuse rapidement dans le royaume. Cet aménagement correspond à une activité particulière ayant sa propre finalité : on ne s’y rend que pour la promenade à carrosse ou à pied, il ne s'agit pas d'un lieu de passage ou d'un parcours entre deux emplacements ${ }^{23}$. Différents promenoirs prendront l'appellation emblématique de "Cours-de-la-Reine », en hommage à celle qui fut l'initiatrice de ce modèle en France, comme à Rouen (1649)24, à Caen (1676)25 ou à Dijon (1762)26.

\section{LA PROMENADE, UN LIEU D'EXPRESSION PARISIEN DE L'ÉTIQUETTE SOCIALE URBAINE}

La promenade au Cours-la-Reine est initialement réservée à la famille royale et à la haute société27. Cette activité est proposée par une reine aux membres de sa cour qui quittent l'espace du parc de château pour un lieu semiurbain à la périphérie de la ville. Comme le souligne $\mathrm{D}$. Rabreau, la promenade est le pendant pacifique et citadin de la chasse aristocratique ${ }^{28}$. Des usages précis s'établissent au Cours-la-Reine qui devient ainsi le théâtre de l'expression de l'esprit courtisan. L'étiquette et le cérémonial de la société de cour reflètent une organisation hiérarchisée dans laquelle les gestes révèlent la place de chacun, symbolisant la distribution du pouvoir et des charges ${ }^{29}$. Le cours s'inscrit dans une répartition réglementée et reconnaissable des espaces $^{30}$ : les allées sont fermées à leurs extrémités par un portique architecturé, décoré de bossages rustiques et gardé par un portier ; les côtés sont protégés par des fossés ${ }^{31}$ de manière à en surveiller l'accès. Se promener au Cours-la-Reine devient donc un moyen d'affirmer dans l'espace sa réussite sociale et les privilèges liés aux grâces du roi ou à son rang32. Ce contexte n'échappe pas à Louis XIV qui se plaît à en jouer dès 1650 en honorant régulièrement le Cours de sa présence 33 . Tous ses courtisans veulent alors s’y montrer et avoir l'honneur d'y être vus : la règle est d'arrêter sa voiture devant

\footnotetext{
23 F. Panzini, op. cit., p. 50.

24 A. M. Rouen, Registre A26, A28, A40, Chartrier tiroirs n57, nº77, etc.

25 D. Rabreau, op. cit., p. 304.

26 Jean-Baptiste Noellat, Guide du voyageur et de l'amateur à Dijon, ou statistique monumentale de la capitale de l'ancienne Bourgogne, Dijon, Bonnefond-Dumoulin, 1829, p. 305.

27 D. Rabreau, op. cit., p. 304.

28 Ibid., p. 301.

29 Norbert Elias, La société de cour, Paris, Calmann Lévy, 1974 ; J. Revel, op. cit., p. 169 ; C.-

L. Haroche et A. Montoia, «Le duc de Saint-Simon et la dimension politique de l'espace dans la société d'Ancien Régime », in A. Montandon (dir.), Les espaces de la civilité, op. cit., p. 11-26.

30 Rabreau, op. cit., p. 301.

31 M. Poëte, op. cit., p. 112.

32 J. Revel, op. cit., p. 198.

33 M. Poëte, op. cit., p. 130.
} 
celle du roi ou des membres de la famille royale ${ }^{34}$ et les femmes doivent ôter leur masque ${ }^{35}$. Il faut ensuite attendre plusieurs heures pour que les carrosses attirés par la présence du roi ou des princes de sang quittent la promenade 36 .

La manière de se promener est codifiée et consiste à se déplacer en voiture sous les allées ombragées. Ce type de loisir à l'italienne s'adapte d'autant plus facilement en France que le luxe ${ }^{37}$ et le goût des carrosses se sont développés depuis le règne de Louis XIII ${ }^{38}$. Leur quantité permet d'ailleurs de juger du succès du Cours, d'où la fréquente exagération de leur nombre dans les descriptions39. La vacuité du terrain entraîne un jeu de va-et-vient qui permet de se croiser et de se rencontrer plus que de se déplacer. On fait défiler les voitures en ovale afin d'apercevoir les autres promeneurs dans leur voiture, les chevaux marchant au petit pas. Le Cours est donc un rendez-vous social et mondain que décrit La Bruyère :

"L'on s'attend au passage réciproquement dans une promenade publique ; l'on y passe en revue l'un devant l'autre; carrosses, chevaux, livrées, armoiries, rien n'échappe aux yeux, tout est curieusement ou malignement observé; et selon le plus ou moins de l'équipage, ou l'on respecte les personnes ou on les dédaigne $»^{40}$.

On vient profiter du spectacle qu'offrent les autres promeneurs : "se promener consiste à aller voir, à se faire voir et à être vu»41, la perruque, la parure ou le fard participant à cette mise en scène. Le Cours est une sorte de salon en plein air: on devise, chante, lit et se rend agréable aux compagnies ${ }^{42}$. Les hommes à cheval suivent les dames et vont d'un carrosse à un autre, rendant cette sortie "tout ensemble promenade et conversation $4^{4} \ldots$ La politesse y règne: "On s'entre-salue sans se connaître ; et les hommes qui sont presque toujours découverts, n'oseraient manquer à saluer les dames, à moins de passer pour incivils »44. Le Coursla-Reine devient donc un lieu d'expression de l'urbanité telle que la définit

\footnotetext{
34 Ibid.

35 Le gazetier Jean Loret, à propos du dimanche 9 mai 1655, cité dans M. Poëte, op. cit., p. 126 et 182.

36 Frères de Villiers, cité dans M. Poëte, ibid., p. 130.

37 M. Poëte, ibid., p. 93 et suiv.

38 H. Sauval, op. cit., livre XII, p. 650. Daniel Roche (dir.), Voitures, chevaux et attelages du XVIe au XIXe siècle, Paris, Association pour l'académie d'art équestre de Versailles, Établissement public du musée et du domaine national de Versailles, 2000.

39 M. Poëte, op. cit., p. 105 : dans leur Journal, les frères de Villiers comptabilisent plus de trois mille carrosses au cours de la porte S. Antoine, les 6 février 1657 et 5 mars 1658, alors que Nemeitz n'en décrit que six cent à la fin du règne de Louis XIV...

40 Jean de La Bruyère, Les Caractères de Théophraste avec les caractères ou les mœurs de ce siècle, 7 éd., 1692, réédition Paris, H. Chamion, 1999, p. 301.

41 D. Rabreau, op. cit., p. 301.

42 La chasse au vieil grognard de l'antiquité, s. l.,1622, p. 24.

43 Madeleine de Scudéry, Artamène ou le Grand Cyrus, 1650-1653, cité dans P. d'Ariste, op. cit., p. 30.

44 H. Sauval, op. cit., Livre VIII, p. 287.
} 
Furetière $^{45}$. Il entraîne un ensemble de codes et de comportements soumis aux normes de la courtoisie et de la civilité, donc de la vie publique ${ }^{46}$. Il est créé par une élite qui transpose une étiquette de palais à un espace urbain, la promenade matérialisant les prérogatives des pairs.

La création du Cours-la-Reine est concomitante de l'ouverture de jardins royaux et aristocratiques parisiens. L'exemple des Tuileries (Ill.4) est caractéristique car il s'agit d'un des premiers parcs rendus accessibles au public et il est, sans conteste, le plus fréquemment étudié et cité en exemple au risque de simplifications historiques. Ce jardin est initialement réservé à la famille royale et à la Cour mais les citadins peuvent y pénétrer dès le début du XVIIe siècle lorsque cette dernière est hors de Paris ${ }^{47}$. Les longues allées ombragées sont propices à la marche, à la conversation et au jeu48. Selon un compte de 1624, le portier reçoit 150 livres de gages «pour lui donner moyen de vivre sans prendre aucun salaire ni gratification de ceux qui entrent »49: les sujets du roi peuvent donc venir s'y délasser. Le jardin subit régulièrement des aménagements pour les visiteurs à tel point qu'il devient une référence en matière de promenade dans toute l'Europe, dès le milieu du XVIIe siècle et jusqu’à la fin du siècle suivant 50 .

L’ouverture de parcs privés au public semble s’inscrire dans la tradition romaine du XVIe siècle, selon laquelle les familles italiennes exposent leurs collections d'antiques dans les jardins qu'elles rendent accessibles. L’invitation à la découverte est manifestée par une inscription sur un mur ou sur la porte d'entrée, la Lex Hortorum ${ }^{51}$. Cette dernière indique généralement que le jardin est réalisé pour l'agrément des amis, pour le délice des citoyens et des étrangers ou pour la jouissance des artistes et des poètes ${ }^{52}$. Elle décrit également le bon usage du jardin où les visiteurs sont assez libres, pouvant déambuler et se reposer tant qu'ils n'endommagent rien 53 , comme à la villa Borghèse sur le Pincio : "Va où tu le désire, cueille ce que tu veux, pars quand

\footnotetext{
$\overline{45}$ A. Furetière, op. cit. : « Urbanité. Civilité, politesse, courtoisie qu'on trouve parmi les gens du beau monde. L'urbanité consiste aussi aux jeux et passe-temps, et à entretenir une compagnie sans offenser personne ». Ce simple jeu d'esprit, ce trait d'humour propre à une catégorie de personnes distinguées devient peu à peu une politesse propre à culture de la ville comme en témoigne le Dictionnaire universel Français et latin, vulgairement appelé Dictionnaire de Trévoux, nouvelle édition, Paris, compagnie des libraires associés, 1771.

46 J. Revel, op. cit., p. 169.

${ }^{47}$ M. Poëte, Paris, la vie et son cadre. Au jardin des Tuileries. L'art du jardin. La promenade publique, Paris, 1924, p. 143.

48 Raoul Boutrays, Lutetia, 1611, cité dans M. Poëte, ibid., p. 145.

49 Cité dans M. Poëte, ibid., p. 143

50 F. Panzini, «Le plus intéressant jardin public au monde », Monuments Historiques n 177 , novembre 1991.

51 David-R. Coffin, « The lex hortorum and access to gardens of Latium during the Renaissance », Journal of garden History, vol. 2, n³, juillet-septembre 1982.

52 Ibid., p. 205.

53 Ibid., p. 206.
} 
tu en as envie »54. Il ne faut pourtant pas interpréter le droit à l'accès de ces jardins selon un sens moderne, puisque l'entrée est régie suivant certains codes - en témoigne le fait que l'inscription soit en latin, langue élitiste55. Le jardin est probablement interdit aux proscrits de la société romaine du XVIe siècle tels les mendiants ou les Juifs 56 .

\section{Illustration 4 : Le jardin des Tuileries, Paris}

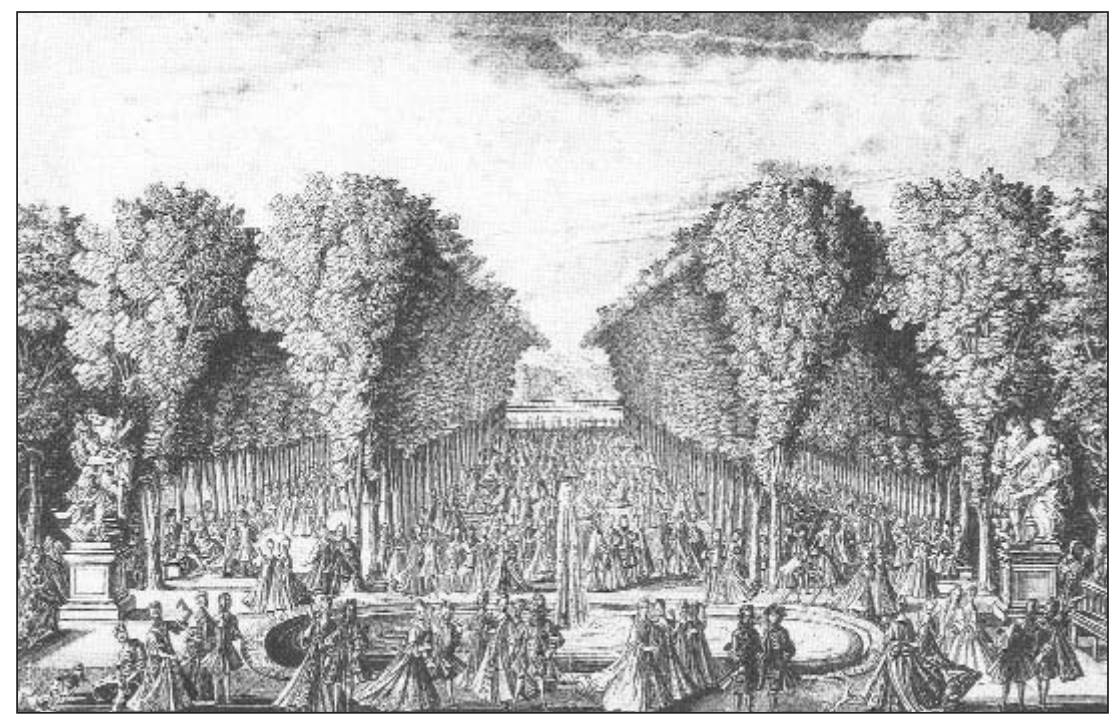

En France, le caractère public du jardin ne signifie pas non plus qu'il soit accessible à tous. Aux Tuileries, la présence de portes ou de grilles d'entrée, de fossés protecteurs, de portiers et de gardes assure une sélection des "citoyens qui se présentent sous des dehors honnêtes »57. Sont exclus les soldats, les domestiques, le menu peuple et les mendiants 58 . Un siècle après l'ouverture de cette propriété royale, l'avocat au Parlement, de La Croix, justifie ce rejet par la volonté de conservation de cet enclos ${ }^{59}$. Le peuple peut jouir de toutes les promenades le jour de la Saint-Louis, car «il est juste que la maison du père commun des Citoyens soit le jour de sa fête ouverte à tout son peuple »60 : à Paris, l'entrée des parcs des Tuileries et du Luxembourg, du Jardin du Roi et de la place Royale est permise indistinctement à tous ${ }^{61}$. Mais

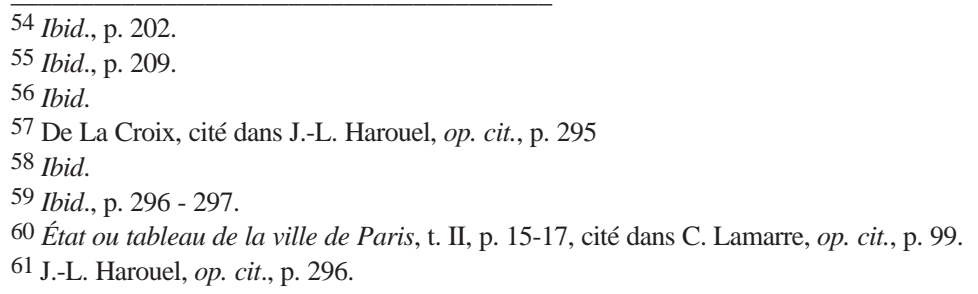


alors que l'ouverture des jardins italiens est une preuve de la vertu de splendeur des propriétaires ${ }^{62}$, celle des parcs royaux révèle la disposition de magnificence du monarque, car ils « ne sont ni si grands et si spacieux qu'afin que tous leurs enfants puissent s'y promener »63. On se promène sous l'œil bienveillant et généreux du propriétaire, en l'occurrence le détenteur du droit divin, un membre de sa famille ou de sa cour. L'étiquette au jardin y est essentielle car :

" tous ceux qui entrent dans un Jardin public pour s'y promener ou pour le traverser, doivent respecter l'image du maître qui est dans tous les lieux qu'ils parcourent, et s'y conduire comme si le maître lui-même les y suivait »64.

Le jardin révèle et met en scène l'affection des Français pour leur souverain65; il s’inscrit dans la politique de propagande qui cultive le « sentiment national » selon lequel la Monarchie forme une grande famille autour de son roi.

La création du Cours-la-Reine et l'ouverture des jardins royaux ou aristocratiques participent à la mise en place d'un nouveau cadre urbain. Elles présentent des caractéristiques communes telles que leur origine royale, la sélection des promeneurs, l'importance de l'étiquette sociale et du jeu des apparences, l'utilisation des allées devenant le théâtre de la mise en scène de la bonne société. La différence notable entre cours et jardin réside en ce que le second est ouvert à un public plus large que le premier, permettant un certain brassage social. De plus, la forme du jardin permet une diversité de plaisirs que le cours n’offre pas. Le moyen de la promenade (à pied ou en voiture) s'explique simplement par la nature du lieu. La création d'espaces plantés en France s’inspirera de l'ouverture du jardin et de la forme efficace du Cours-laReine, divulguant l'étiquette de la cour hors de l'aire du château.

\section{LA PROMENADE COMME NOUVEAU SYMBOLE DE LA MAGNIFICENCE DU ROI : VERS LA DIFFUSION ET L'URBANISATION D'UN LOISIR AULIQUE ?}

La création de promenoirs suivant le modèle du Cours-la-Reine se développe rapidement dans les Généralités. Rouen ou Aix-en-Provence semblent parmi les premières villes à se doter de telles structures dès 1649, offrant pour la première fois au public des lieux plantés pour la promenade. Ce

\footnotetext{
62 David-R. Coffin, op. cit., p. 213 : l'humaniste et homme d'état napolitain Giovanni Pontano, dans ses Traités sur les vertus sociales, 1498, accorde à l'architecture le rôle de refléter l'image du propriétaire. La vertu de magnificence s'exprime par des démonstrations visant au bien-être public et la vertu de splendeur, par des commandes, comme le jardin, relevant de la sphère privée.

63 Charles Perrault, Mémoires de ma vie, Paris, Renouard et H. Laurens, 1909, p. 126.

64 De La Croix, cité dans J.-L. Harouel, op. cit., p. 296.

65 C. Lamarre, op. cit., p. 98.
} 
mouvement se généralise à partir de 1670, lorsqu'un arrêt du Conseil du roi impose le pavement et la plantation d'une partie des fortifications parisiennes, signe tangible de la politique de pacification menée dans le royaume66. Suivant cet exemple, la typologie du cours est appliquée presque systématiquement à toutes les places créées pour la promenade. Louis XIV poursuit ainsi le mouvement amorcé par Marie de Médicis, en diffusant à l'ensemble de son royaume un modèle formel lié à une activité de loisir aulique. Comme l'ouverture des jardins au public, les promenoirs sont l'œuvre de la magnificence royale car ils sont généralement conçus sur ordre du souverain ou par ses représentants dans les Généralités (gouverneurs militaires au XVIIe siècle, intendants de Généralité sous Louis XV67, ingénieurs des Ponts et Chaussées ou municipalités). Ils incarnent donc une vision royale et parisienne en rendant l'allée linéaire omniprésente dans le royaume, ces perspectives évoquant à la fois l'avenue de château - réminiscence seigneuriale - le Coursla-Reine - symbole du courtisan et le jardin régulier de Versailles - apogée du pouvoir absolu68.

La diffusion de cette structure dans la ville au XVIIIe siècle devient un signe d'allégeance à l'autorité monarchique qui impose une vision officielle de l'embellissement par sa maîtrise du territoire national. Les promenades semblent reprendre la fonction allégorique de la place royale, espace conçu autour de l'effigie du souverain pour actualiser la reconnaissance publique. La statue matérialise la "présence symbolique du roi »69 : l’image de Louis XIV, conquérant, sévère et distant, fait place à celle de Louis XV, père du peuple, «roi pacificateur, bon et juste »70. "Au couple sujet/peuple du XVIIe siècle s'oppose le couple de citoyen/public du XVIIIe siècle »71. Cette évolution se traduit d'un point de vue formel : si au XVIIe siècle, le programme de la place royale consiste en un local architecturé et urbain servant d'écrin à la statue et conçu pour le rituel du rassemblement des sujets, la métamorphose du pouvoir absolu ${ }^{72}$ entraîne au siècle suivant de nouvelles conceptions sociales et donc urbaines. Associée à la promenade73, la place royale incarne l'aspiration de la monarchie à la paix et au bonheur des sujets ${ }^{74}$ en participant à la «nouvelle

\footnotetext{
66 AN H2* 1822, 7 juin 1670, cité dans Yoann Brault, «Le plan de Pierre Bullet (1673-1675) », Les grands Boulevards, Paris, Action artistique de la ville de Paris, 2000, p. 29.

67 D. Rabreau, op. cit., p. 304.

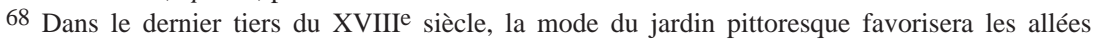
sinueuses qui invitent à la découverte du paysage et à la rêverie. Mais l'allée droite reste omniprésente dans les jardins des palais urbains et des parcs publics : cf. entre autres Jean-Marie Morel, Théorie des Jardins, Paris, 1776, Genève, Minkoff Reprints, 1973, p. 18-19.

69 D. Rabreau, Paris, capitale des arts sous Louis XV. Peinture, sculpture, architecture, fêtes, iconographie, Bordeaux, W. Blake \& co., 1997, p. 39.

70 Ibid., p. 22. Daniel Roche, La France des Lumières, Paris, Fayard, 1993, p. 243-248, 595-597.

71 D. Rabreau, Paris, capitale des arts..., op. cit., p. 22.

72 Ibid., p. 25.

73 D. Rabreau, « La promenade urbaine... », op. cit., p. 304.

74 D. Rabreau, Paris, capitale des arts..., op. cit., p. 22.
} 
physionomie urbaine, fidèle image d'un [gouvernement] synonyme de changement et de bien-être ${ }^{75}$. Ce parti urbain, rappel du forum à l'antique ${ }^{76}$, est celui de la place Louis XV à Paris (actuelle place de la Concorde)77, véritable transition entre le jardin des Tuileries, les avenues des ChampsÉlysées et le Cours-la-Reine, de la place royale du Peyrou à Montpellier conçue entre 1688 et 169378 et aménagée en promenoir au milieu du XVIIIe siècle par la plantation de la terrasse inférieure ${ }^{79}$, ou de l'un des projets présenté à Nîmes lors de la création du jardin de la Fontaine ${ }^{80}$. Par l'implantation de la statue du roi "aux champs", la cité s'ouvre sur le paysage, offrant des perspectives sur le reste du royaume. La nature prend ainsi une place importante dans l'histoire politique des villes, acquérant la même valeur d'action civique que Diderot accorde à l'art, avec ses vertus éducatives et moralisantes. Solution à des motivations idéologiques, la promenade transpose la question du style parlant et des objectifs symboliques du grand genre à l'embellissement urbain. La promenade a été conçue pour la cour, que l'Encyclopédie définit de manière obsolète, mais révélatrice, comme :

«Le centre de la politesse d'une nation [... dont la perfection] passe dans le langage, dans les jugements, dans les sentiments, dans le maintien, dans les manières, dans le ton, dans la plaisanterie, dans les ouvrages d'esprit, dans la galanterie, dans les ajustements, dans les mœurs mêmes [...] ${ }^{81}$.

Dès 1630, la monarchie absolue a su soumettre la noblesse en lui consentant «le privilège visible de l'éminence sociale » 82 et en l'offrant à l'admiration du reste de la société83. Le modèle proposé s'étend bientôt au sein du «nouveau public urbain formé par l'aristocratie citadine, la bourgeoisie marchande et l'élite culturelle »84, qui se développe dès la première moitié du XVIIe siècle85. Ce mouvement s'accentue sous la Régence, lorsque la cour

\footnotetext{
75 Ibid., p. 17.

76 Nombreuses sont les places royales du XVIIIe siècle qui associent différents bâtiments administratifs, juridiques et financiers, symboles des pouvoirs étatiques et locaux assemblés autour de l'image du souverain.

77 Charlotte Chastel-Rousseau, «Promenades d'Anglais sur la place Louis XV ou les aperçus critiques d'un mode d'embellissement à la française », Dix-huitième siècle n³2, Paris, PUF, 2000.

78 The Oxford Companion to gardens, Oxford-New York, Oxford University Press,1987.

79 Jeanne Hugueney, « Le caractère social de l'art au XVIIIe siècle : les jardins publics », Actes du XVIIe congrès international d'histoire de l'art, La Haye, 1955, p. 473-474.

80 D. Rabreau, « La promenade urbaine... », op. cit., p. 309.

81 Encyclopédie..., op. cit.

82 J. Revel, op. cit., p. 197.

83 Ibid.

84 F. Panzini, « Le plus intéressant jardin public au monde », op. cit., p. 58. D. Roche, La France des Lumières, Paris, Fayard, 1993, p. 235 - 237.

85 Hugues Neveux, "Prélèvements et contrôles urbains », dans G. Duby (dir.), Histoire de la France urbaine, t. III, La ville classique, Paris, Seuil, 1981, p. 92.
} 
s'émancipe de Versailles en découvrant les charmes de Paris où elle étale ses modes de vie86. L'étiquette et les coutumes auliques s'urbanisant, la ville prend sa revanche87. Ainsi que le souligne L.-S. Mercier et malgré l'Encyclopédie, la cour n'a plus le monopole de l'apparition sur la scène de la ville :

«Le mot de cour n'en impose plus parmi nous, comme au temps de Louis XIV. [...]. Du temps de Louis XIV, la cour était plus formée que la ville ; aujourd'hui la ville est plus formée que la Cour [...]. La ville parle avec assurance sur tout et sans relâche [...]. La ville, où sont tous les arts et toutes les lumières, [...] décide hardiment, parce qu'elle sent sa force $[\ldots] \gg 88$.

La création des promenades et la diffusion des rites de socialisation vont de pair avec le développement des valeurs de civilité qui s'imposent en France dans le dernier tiers du XVIIe siècle89. Les traités d'éducation permettent l'imitation des comportements sociables des élites, en diffusant certains codes comme les principes du contrôle des expressions du visage et du dressage des corps ${ }^{90}$. L’imaginaire de cette nouvelle société en marge de la cour se crée et s'exprime par la quête d'une identité urbaine ${ }^{91}$ nationale à laquelle participent les salons et les librairies, les clubs et les cafés, le développement des représentations de théâtre et d'opéra, autant de cadres induisant des pratiques sociales et des comportements appropriés ${ }^{92}$.

Contrairement au Cours-la-Reine ${ }^{93}$ ou aux jardins princiers, les promenoirs du royaume sont généralement ouverts à tous les états. Cependant, on ne peut pas parler de vulgarisation du rituel de la promenade quand la référence imitée demeure la cour ${ }^{94}$. En s'urbanisant, ce loisir reste élitiste car il est codifié par « la tenue vestimentaire, l'allure, le rythme de la marche »95

86 D. Rabreau, «La promenade urbaine... », op. cit., p. 302 ; Nicole Castan, « Le public et le particulier », dans P. Ariès et G. Duby (dir.), op. cit., p. 431.

87 J. Revel, op. cit., p. 431.

88 Louis-Sébastien Mercier, Tableau de Paris, 1783, réédition Paris, Mercure de France, 1994, t. I, chapitre 347 « De la Cour », p. 953-954.

89 J. Revel, op. cit., p. 201.

90 Ibid., Jean-Baptiste de la Salle, Les règles de la bienséance et de la civilité chrétienne, 1703, réédité dans Jean-Pierre Seguin (dir.), La bienséance, la civilité et la politesse enseignées aux enfants, Bruxelles, Le Cri et Paris, J.-M. Place, 1992. Le chapitre 5 « Des divertissements », article II « De la promenade », p. 172-175, décrit les règles sociales à suivre lors de la promenade à pied.

91 D. Rabreau, Paris, capitale des arts..., op. cit., p. 16.

92 D. Roche, Les Républicains des Lettres : gens de culture et Lumières au XVIIIe siècle, Paris, Fayard, 1988.

93 F. Panzini, op. cit., p. 45, P. d'Ariste et M. Arrivetz, op. cit., p. 30 : les barrières sont supprimées avant d'être rétablies le 23 juin 1766 par M. de Marigny qui impose l'usage de laissez-passer, en ordonnant aux portiers « de ne les ouvrir qu'aux princes de sang et aux personnes autorisées, sous peine de perdre leur place». Quelques années plus tard, le passage est libre pour « tout carrosse, soit de personnes qualifiées, soit de bourgeois, les fiacres et voitures de charge devant passer uniquement par le quai ».

94 C. Pieau, La promenade dans les jardins publics parisiens au XVIII e siècle, mémoire de DEA d'histoire de l'art et d'archéologie, D. Rabreau (dir.), Centre Ledoux, Université Paris-I, 2003, p. 36. 95 L.-M. Nourry, op. cit., p. 20. 
ou la compagnie avec laquelle on déambule. Les citadins fréquentent les promenoirs à certaines heures et occupent les allées en fonction de leur catégorie sociale96. La qualité de l'équipage et les démonstrations de richesse restent des marques de différenciation qui s'exhibent dans l'avenue carrossable. On se reconnaît selon l'espace fréquenté et l'on protège son territoire, comme à Marseille (Ill. 5) où la partie du Cours (actuel cours Belsunce) proche de la Canebière est réservée à l'élite, tandis que l'autre tronçon est fréquenté par le peuple ${ }^{97}$. La sélection des promeneurs 98 s’opère généralement de manière tacite, comme le décrivait déjà La Bruyère : " L’on se donne à Paris sans se parler comme un rendez-vous général mais fort exact, tous les soirs au Cours ou aux Tuileries [...] »99. De fait, la mode impose l'usage de ces lieux et en exclut l'ignorant : les jours et les horaires deviennent des convenances qu'il faut connaître100, ce à quoi suppléent les guides dont les informations permettent au nouvel arrivant de s’intégrer à la société brillante. Le titre de l'ouvrage de J.-C. Nemeitz est éloquent : Séjour de Paris, c'est-àdire Instructions fidèles pour les voyageurs de condition ${ }^{101}$.

\section{Illustration 5 : Cours Marseille}

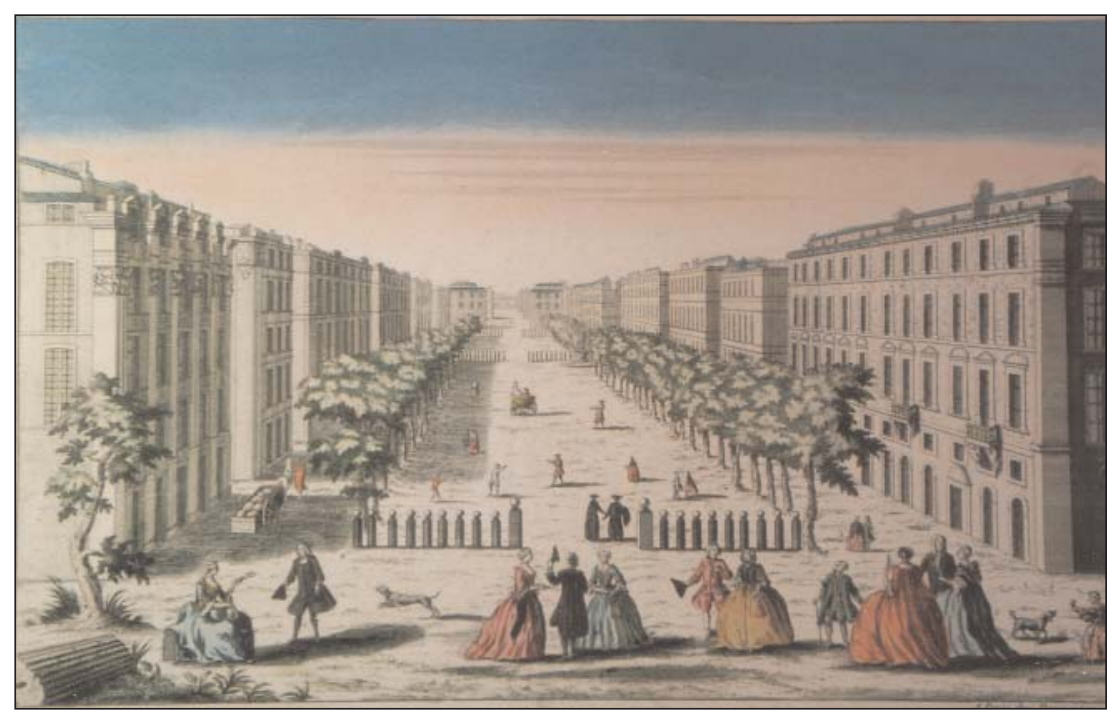

96 Ibid., p. 32.

97 Henri Villard, « L'ancien Cours et ses abords à la fin du Second Empire », Bulletin Officiel du Musée du Vieux Marseille, n³6-37, juillet-août 1935, p. 132 et André Bouyala d'Arnaud, Évocation du Vieux Marseille, Paris, 1961, p. 338.

98 F. Panzini, op. cit., p. 45 et suiv.

99 J. de La Bruyère, op. cit., Paris, E. Michallet, 1688, p. 111.

100 C. Lamarre, op. cit., p. 99.

101 Joachim-Christoph Nemeitz, Séjour de Paris, c'est-à-dire Instructions fidèles pour les voyageurs de condition, comme ils doivent se conduire s'ils veulent faire un bon usage de leur temps et argent durant leur séjour à Paris [...], Leide, J. Van Abcoude, 1727. 
Ces distinctions sociales sont parfois imposées par des arrêtés municipaux, héritiers codifiés de la Lex hortorum. Des réglementations se transmettent du jardin au promenoir urbain dont l'accès reste sélectif et contrôlé, comme l'interdiction d'y porter des armes, d'y jouer à des jeux importunant les promeneurs ou risquant d'abîmer les plantations. D’autres mesures révèlent que tous ne s'y conforment pas, moins par malice ou par esprit de revendication que par incompréhension de l'usage de ces espaces : les femmes utilisent la fontaine du cours pour laver leur linge, d'autres y font paître leurs animaux ou considèrent la promenade comme un simple chemin, en faisant passer leur charrette dans les allées ${ }^{102}$. Les mélanges de populations semblent être tolérés lorsqu'il s'agit de la présence de petits métiers qui animent la promenade et la rendent plus confortable: bouquetières, enfants que l'on charge de billets, vendeurs de gâteaux... 103. L'épanouissement de la prostitution, favorisé par les jeux de rencontre amoureuse sous la frondaison des arbres, entraîne quant à lui une confusion de classes, condamnée par les moralistes 104.

Ainsi, la coutume libérale italienne d'ouverture des jardins prend en France une dimension politique toute autre. La condition sociale du propriétaire ou du créateur de ces espaces et la notion de magnificence d'un Grand vis-à-vis des sujets déterminent les modalités d'accès. Peu à peu, ce loisir de cour et l'étiquette qui en découle se transmet par glissement, par mimétisme et par désir de promotion sociale à l'ensemble des promenoirs du royaume. En s'urbanisant, ce rituel de la promenade entraîne une codification des usages, la création de règlements de police remplaçant les habitudes aimables de la cour ${ }^{105}$. Mais tandis qu'à Paris les cours sont devenus des lieux d'étalage de richesses et de rendez-vous galants, ils sont généralement fréquentés en province par une société bourgeoise aux mœurs "saines » et à la fortune peu démonstrative. Et contrairement à la vision idéale de l'Encyclopédie, la promenade citadine ne consiste pas en une recherche d'exercice physique, mais elle manifeste plutôt l'urbanité d'une société. La multiplicité des fonctions des promenoirs de province permet un développement original dont la forme s'éloigne du cours en associant les caractéristiques de la place royale, du belvédère, du square ou du jardin. Les villes des Généralités ne se contentent donc pas d'imiter les modèles parisiens même s'ils restent des sources d'inspiration évidente, mais elles proposent une riche variété de solutions plastiques en réponse aux contraintes des sites. Les promenoirs de France deviennent d'ailleurs aux yeux des voyageurs une caractéristique française remarquée. Dans son journal, Arthur Young ne s'exclame-t-il pas : "par leurs promenades publiques, les villes de France sont bien supérieures à celles d'Angleterre »?

\footnotetext{
102 A. M. Rouen, Chartrier n57 ; A. M. Marseille, série 1BB ; A. M. Nantes, série FF, etc. 103 Caroline-Stéphanie de Genlis, Dictionnaire critique et raisonné des étiquettes de la Cour ou l'Esprit des étiquettes et des usages anciens comparés aux modernes, Paris, 1818, t. II, p. 167.

104 C. Pieau, op. cit., p. 35.

105 F. Panzini, op. cit., p. 47.
} 


\title{
LES LOISIRS DANS LE COMPAGNONNAGE
}

\section{AU XIX ${ }^{\mathrm{e}}$ SIÈCLE*}

\author{
Jean-Marie MoINE \\ Université François-Rabelais de Tours, CEHVI
}

Évoquer le compagnonnage ne conduit pas à envisager d'emblée le loisir et la distraction. Le compagnonnage est un type d'association dont les modes de fonctionnement sont étroitement liés au travail: formation professionnelle en suivant les étapes d'un cursus (accession à des grades pendant le Tour de France), sélection d'une élite ouvrière sur les critères du bel ouvrage. Le tout s'incarnant dans des formes et pratiques sociales fortement marquées par les traditions. Dans l'historiographie du compagnonnage les loisirs occupent la portion congrue1. Étienne Martin Saint-Léon, en 1901, a consacré trois lignes aux distractions : «Le soir on se retrouve, on devise gaiement, on fume, on joue aux cartes ou aux

\footnotetext{
* Mes plus vifs remerciements vont au Musée du compagnonnage de Tours pour son appui documentaire et logistique.

${ }^{1}$ C'est un thème du reste marginal dans l'historiographie de la classe ouvrière. Voir par exemple les grandes thèses de Rolande Trempé, Les mineurs de Carmaux 1843-1914, Paris, Éditions Ouvrières, 1971 et Yves Lequin, Les ouvriers de la région lyonnaise (1848-1914), Lyon, Presses Universitaires de Lyon 1977 : quelques paragraphes chacun à propos des budgets ouvriers. Georges Duveau semble faire exception dans La vie ouvrière sous le Second Empire, Paris, Gallimard, 1946, avec une soixantaine de pages sur les loisirs dans son chapitre IV sur les mœurs. Le mouvement ouvrier s'est peu interrogé sur la question des loisirs, même après Le droit à la paresse de Paul Lafargue (1883). Voir les communications d'Angèle Kremer-Marietti, «Les avatars du concept de loisir au XIXe siècle dans la société industrielle et dans la philosophie sociale » et Alain Garrigou, « Socialisme et loisir au XIXe siècle » dans Adeline Daumard (dir. ), Oisiveté et loisirs dans les sociétés occidentales au XIXe siècle, Abbeville, Paillard, 1983, p. 31-50, et Robert Beck, Histoire du dimanche de 1700 à nos jours, Paris, Éditions de l'Atelier, 1997, p. 290-304.
} 
dominos. Parfois quelque ténor ou baryton improvisé se fait entendre et l'heure du repos arrive... ». Complétées par une note opposant la «conduite beaucoup plus régulière » et les "mours plus honnêtes" des compagnons aux «tentations dégradantes» auxquelles cédaient "la grande majorité des autres ouvriers», surtout les célibataires ; et une page sur la chanson pour en souligner l'importance². Dans la même ligne Émile Coornaert, qui a cité les trois lignes de son prédécesseur, s'est limité au côté bien ordonné de la sociabilité compagnonnique : on buvait « en règle » tant dans les circonstances solennelles qu'à l'improviste. S'il s'est étendu un peu plus c'est aussi sur la chanson3. Semblable orientation : brièveté du propos, accent sur les loisirs codifiés, chez Jean-Pierre Bayard ${ }^{4}$ et Abel Poitrineau' ${ }^{5}$. Il n’y a guère que Pierre Barret et Jean-Noël Gurgand qui ont accordé une place importante aux loisirs avec un chapitre spécial : " Les habits du dimanche », tout en demeurant dans la tradition par la caractérisation globale de la distraction chez les compagnons : «modeste et éprouvée »6.

L'originalité de cet ouvrage, à la perspective quasi ethnologique, c'est qu'il est fondé sur une utilisation beaucoup plus copieuse des mémoires et autobiographies. Qui ont été aussi ma source essentielle. Les informations relatives aux loisirs y sont nettement plus abondantes qu'on ne pourrait s'y attendre a priori et elles permettent de brosser un tableau, impressionniste certes, mais plus par une multiplicité de petites touches que par de grands coups de pinceau. Qui restitue les aspects négligés par une historiographie généralement focalisée sur les loisirs organisés et ritualisés : les distractions et amusements plus spontanés, plus libres, plus laissés à la fantaisie de l'individu et du groupe.

\section{LE TEMPS ET L'ARGENT : DES CONTRAINTES ?}

Les compagnons mémorialistes ont souligné la pénurie de l'un et de l'autre. «Le matin, à l'établi à cinq heures précises, le soir n'en sortant qu'à huit heures sonnées", soit treize heures de travail, "[...] l'hiver, l'été et toujours! et toujours », "[...] par conséquent font peu de loisir. Cette existence est bien rude ", soupirait le menuisier Agricol Perdiguier

\footnotetext{
2 Le compagnonnage, son histoire, ses coutumes, ses règlements et ses rites, Paris, Librairie du Compagnonnage, réédition 1977, p. 249 et 277. Les compagnons étaient censés être préservés par un encadrement de type familial et "un sentiment remarquable de [la] dignité d'homme». Étienne Martine Saint-Léon indique avoir assisté à trois bals, digne illustration de cette supériorité morale : «On s'amuse franchement, mais décemment et honnêtement » (p. 267).

${ }^{3}$ Les compagnons en France du Moyen Age à nos jours, Paris, Éditions Ouvrières, 1966 ; dans le chapitre V : «La vie des compagnons », p. 228, 231, 236-237, 240.

${ }^{4}$ Le compagnonnage en France, Paris, Payot, 1978, p. 191-192, 243, 257-258. Cinq occurrences sur la chanson dans l'index.

5 Histoire du compagnonnage, Lyon, Horvath, 1992, p. 55-57, 74.

6 Ils voyageaient la France, Vie et traditions des compagnons du tour de France au XIXe siècle, Paris, Hachette, 1980, p. 289-317.

7 Agricol Perdiguier (Avignonnais la Vertu), Mémoires d'un compagnon, 1854-1855, Paris, Librairie du Compagnonnage, réédition 1977, p. 192 et 112.
} 
À Marseille en 1871 la journée du charron Ferdinand Flouret n'était que de dix heures, de sept à dix-huit heures, avec une coupure d'une heure à midi ; mais quelques années plus tard à Paris il travaillait douze heures8. À Tours en 1842 le boulanger Jean Baptiste Arnaud se félicitait du peu de travail qu'il avait à l'Hôpital général ce qui lui laissait plus de temps libre que partout ailleurs9. C'était une exception. À l'inverse le bourrelier Alexandre Victorien dans une lettre du 1er août 1894 se plaignait qu'il n'avait guère l'occasion de jouer du piston tant il avait de travail ${ }^{10}$. Souvent il fallait faire des heures supplémentaires, parfois de nuit (témoignage de Perdiguier). À Mèze dans les années 1900 le maréchal-ferrand Abel Boyer ferrait encore après le souper, au terme d'une journée de douze heures, les chevaux de halage du canal du midi11. La durée du travail ne s'est réduite que lentement. Vers 1925 Pierre Morin, apprenti menuisier, travaillait encore onze à douze heures ; il n’a connu la journée de huit heures qu'en novembre 1931 quand il est arrivé en Algérie12.

Les compagnons jouissaient-ils du dimanche, "notre jour de repos, de récréation » sous la plume de Perdiguier ${ }^{13}$ ? Pas toujours ! Le serrurier Pierre Moreau, de Château-Renault, citait un de ses camarades de Vendôme qui lui avait dit : "Nous voyons beaucoup de maîtres qui exigent que leurs ouvriers travaillent pendant les sept jours de la semaine ${ }^{14}$. Le dimanche matin, à Nantes au milieu des années 1880, le bourrelier Auguste Batard allait réparer les harnachements dans les administrations ; à Marseille il était pris pendant presque tout son dimanche ${ }^{15}$. À Nantes et Agde vers 1900 les maréchaux jouissaient de leur dimanche mais à Bordeaux et Toulouse c'était seulement de l'après-midi et à Saint-Nazaire ils travaillaient jusqu'à seize heures à cause du service des forges de Treignac ${ }^{16}$. C'est quand le travail pressait que les compagnons devaient y occuper une partie du dimanche. En revanche les

\footnotetext{
8 Francis Laget et Jean-Michel Mathonière (documents réunis et présentés par), Ferdinand Flouret et le compagnonnage, 1991, p. 16 et 22.

9 Jean-Baptiste Arnaud (Libourne le Décidé), Mémoires d’un compagnon du Tour de France, Rochefort, A. Giraud, 1859, p. 307.

10 Alexandre Victorien, Lettres du Tour de France, dactylographié, Archives du Musée du compagnonnage, Tours.

11 Abel Boyer, Le Tour de France d'un compagnon du devoir, Paris, Imprimerie du Compagnonnage, 1957, p. 95.

12 Pierre Morin, Compagnon du devoir au XXe siècle, Paris, Librairie du Compagnonnage, 1994, p. 16 et 69 .

13 «[...] un seul ! C'était peu ! eh bien! il suffisait à nous rendre heureux » Agricol Perdiguier, op. cit., p. 96. Temps libre ou temps du travail prolongé, le dimanche n'est quasiment jamais évoqué sous l'angle des devoirs religieux par les compagnons mémorialistes, non hostiles à la religion mais souvent critiques du clergé. Il semble que l'assistance à la messe ait été bien souvent limitée aux grandes occasions, telles les fêtes patronales.

14 Pierre Moreau, De la réforme et des abus du compagnonnage et de l'amélioration du sort des travailleurs, 1843, p. 54, cité par Pierre Barret et Jean-Noël Gurgand, op. cit., p. 103.

15 Auguste R. Batard, Souvenirs d'un apprenti bourrelier-harnacheur compagnon du Tour de France 1887-1891 par Nantais la belle conduite, Nantes, Union compagnonnique, 1956, p. 16 et 35. 16 Abel Boyer, op. cit.
} 
apprentis semblent avoir été couramment assujettis ce jour-là au nettoyage des ateliers et boutiques, en particulier les menuisiers ${ }^{17}$.

Les compagnons ne se soumettaient pas à d'aussi longues journées et semaines de labeur sans résistance et sans s'octroyer certaines libertés. C'était une vieille tradition. Au XVIIIe siècle les typographes présentés par Philippe Minard n'hésitaient pas à s'absenter pour aller boire un pichet ; ils fêtaient la saint-lundi18. "L'ouvrier choisit évidemment le jour qui lui convient le mieux » notait le « pays » de Pierre Moreau, sans consentement du patron bien sûr. En 1840 Arnaud a passé deux mois à Paris presque sans travailler et pas seulement en raison du chômage qui frappait alors les boulangers, nombreux à traîner " au tournant de la halle au blé », leur lieu de rencontre. À Lyon la même année il a profité encore de deux mois d'oisiveté, en partie consacrés à taquiner les muses, grâce aux bontés d'un compagnon. À Carcassonne, à la fin des années 1830, le chaudronnier Pierre Ameline s'est offert quatre jours de liberté pour participer au carnaval19. À Nîmes dans les années 1900 Boyer arrivait souvent en retard à l'atelier parce qu'il faisait la fête tous les soirs ${ }^{20}$. À Fouras (près de La Rochelle) pendant l'été 1925 Morin embauchait à cinq heures mais à dix heures il allait «jouer au baigneur ou manger des huîtres sur les rochers "; le patron fermait les yeux et rejoignait parfois ses ouvriers avec un litre de vin blanc... Son employeur lyonnais en 1931 a été moins libéral : il l'a mis à la porte parce qu'il s'était octroyé une semaine de congé pour visiter l'Exposition coloniale à Paris21.

Cet appel du temps libre et du loisir contre l'imperium du travail entrait aussi en compétition avec les obligations du perfectionnement professionnel. Les jeunes compagnons étaient tenus à un effort de formation continue, en tout cas dans certains métiers: ils suivaient des cours, dispensés par des compagnons chevronnés, en général de dessin. Barret et Gurgand indiquent que les plus studieux, qui passaient soirées et dimanche à « travailler le trait », étaient rares22. À un Perdiguier, fort assidu aux cours quand il était apprenti à Avignon puis pendant son Tour de France, en particulier à Marseille ou Bordeaux où la journée s'achevait à sept heures du soir23, ou à un Morin qui a suivi des cours du soir à Grenoble, Lyon ${ }^{24}$ et Tours, où il occupait ses dimanches à dessiner des escaliers - mais à quinze ans il séchait les leçons de l'instituteur pour jouer aux cartes chez la buraliste -, on peut opposer un

\footnotetext{
17 Témoignages de François-Joseph Fourquemin, Souvenirs d'un menuisier nivernais au XIXe siècle, Autun, Éditions du Pas de l’Ane, 1998 ; Agricol Perdiguier, op. cit. ; Pierre Morin, op.cit. $18 \mathrm{Ph}$. Minard (prés.), Typographes des Lumières, suivi des anecdotes typographiques de Nicolas Contat, Seyssel, Champ Vallon, 1989, p.135.

19 Gabriel Désert, «Les mémoires d'un travailleur bas normand. Première moitié du XIXe siècle », Annales de Normandie, juin 1969, p. 162.

20 Abel Boyer, op. cit., p. 121.

21 Pierre Morin, op. cit., p. 18 et 58.

22 Pierre Barret, Jean-Noël Gurgand, op. cit., p. 142 et 297.

23 Agricol Perdiguier, op. cit, p. 61, 76, 131.

24 Leur suspension pendant l'été lui a permis de participer aux répétitions d’une harmonie.
} 
Fourquemin qui préférait à l'école de trait les promenades dans Paris, un carnet de croquis à la main il est vrai.

La prolongation du savoir-faire professionnel dans le loisir, à la manière de « l'ouvrier vrai » décrit par Denis Poulot ${ }^{25}$, qui, les soirs, « [bibelottait] une invention qui souvent [réussissait]», semble avoir concerné certains compagnons sans avoir été généralisée. Le charron Flouret créait des modèles réduits de véhicules hippomobiles. À La Rochelle, selon le témoignage de Morin, les compagnons passaient leurs soirées à tailler des maquettes. On n’hésitait pas à sacrifier les loisirs au chef-d'œuvre. Ainsi le charpentier Joseph Voisin, devenu entrepreneur à Tours dans les années 1880, a occupé pendant trois ans tous ses dimanches et toutes ses soirées à une telle réalisation avec ses fils²6.

Les loisirs supposaient des moyens financiers. Or nous ne sommes «pas riches » constatait Perdiguier. Apprenti à Avignon à partir de 1822 il ne recevait " pas la moindre pièce de monnaie pour passer son dimanche », ce que son père compensait un peu en lui donnant dix sous. L'année suivante il touchait son premier salaire en changeant de maître : dix sous par jour ce qui représentait, puisqu'il était nourri et logé, trois francs par dimanche, une «somme énorme »27, qui semblait promise à s’offrir bien des agréments. Le premier mouvement des compagnons, qui étaient des hommes jeunes, voire encore des adolescents, n'était pas d'épargner mais de dépenser sans trop compter. Fourquemin, dès qu'il a gagné quelque argent, en 1817, s’est empressé de rendre des visites à son grand-père " pour le faire boire un coup »28. Ameline, apprenti chaudronnier à Rennes, noçait régulièrement avec quelques camarades, « de sorte [qu'il ne travaillait] que pour [ses] fins plaisirs »29. Même son de cloche chez Flouret : aspirant il gagnait 4,25 F à 4,50 F par jour, sa pension lui en coûtait trois, «le reste on le dépensait joyeusement ». En faisant étape à Angers pendant son tour de France, il a gaspillé en deux jours avec les compagnons de la ville toutes ses économies et la "mère » a dû lui payer son omnibus pour Tours $^{30}$. À Marseille en 1834 ou 1835 le cordonnier-bottier Toussaint Guillaumou et ses amis sont partis en excursion au château d’If en dépit du faible viatique trouvé au fond des poches : quatorze francs ; le tenancier de la guinguette où on déjeuna accepta de faire crédit jusqu'au dimanche suivant ${ }^{31}$.

\footnotetext{
25 Denis Poulot, Question sociale. Le sublime ou le travailleur comme il est en 1870 et ce qu'il peut être, Paris, Marpon/Flammarion, réédition de 1887, p. 38.

26 Joseph Voisin, Histoire de ma vie et cinquante ans de compagnonnage, Tours, Imprimerie du Progrès, 1931, p.19.

27 Agricol Perdiguier, op. cit., p. 55 et 58.

28 François-Joseph Fourquemin, op. cit., p. 108.

29 Gabriel Désert, art. cité, p. 157-158. Il a passé ensuite six à sept mois à Nantes sans se faire d'amis et en a conclu que sa bourse ne s'en portait que mieux.

30 Francis Laget, op. cit, p. 18 et 21. Il prenait soin d'ajouter qu’un tel incident était demeuré exceptionnel : «je n'ai jamais refusé mais toujours dans les limites permises par l'état de mon porte-monnaie $[\ldots] »$.

31 Toussaint Guillaumou (Carcassonne le bien aimé du tour de France), Les confessions d'un compagnon, [1863], 1996, Paris, J. Grancher, p. 87-88.
} 
La tendance à la prodigalité poursuivait une tradition largement répandue. En commentant le journal du vitrier Ménétra, Daniel Roche a souligné que la sociabilité des compagnons, au XVIIIe siècle, accumulait toutes sortes de pratiques qui étaient « autant d'aubaines pour manifester une symbolique de l'appartenance et du don, pour afficher spectaculairement les valeurs de la consommation libératrice et condamner la lésine »32. Au début du XXe siècle les maréchaux qui ferraient la « cavalerie aristocratique » dans le quartier des Champs-Élysées et se laissaient dévorer par la passion des courses demeuraient bien dans cette lignée33. Le cas limite semble avoir été représenté par ces «Enfants de la jubilation », cinq compagnons boulangers fréquentés par Arnaud lors de son séjour parisien. Ils ne travaillaient presque jamais, préférant vivre de «bonnes fortunes ». Arnaud a passé avec eux trois jours à Versailles, à " dépenser agréablement », les cinquante francs envoyés par ses parents. Il y est retourné peu après : cette fois c’est un compagnon qui venait de toucher l'indemnité prévue pour un remplacement dans l'armée, qui l'a flambée dans un « copieux déjeuner » avec la bande ${ }^{34}$. Souvent le désir et le goût de la dépense étaient bridés par la dure réalité de l'impécuniosité. Venait le temps de la frustration. "Un seul jour de fête me gêne » soupirait Victorien dans une lettre du 20 mai 1895, écrite à Bordeaux. Dans cette même ville en 1899 Boyer fréquentait des brasseries "sans rien consommer »: "Notre pécule ne nous permettait pas de nous offrir même un bock, mais on s'asseyait tout de même, on crânait et finalement on déguerpissait [...] pour recommencer le même manège ailleurs ». À Toulouse ses 25 francs de salaire mensuel ne faisaient pas long feu ; la blanchisseuse payée il ne restait pas grand chose pour «aller dans le monde ». Aussi évitait-il les cabarets et refusait-il les invitations pour n’avoir pas à les rendre car «la moindre tournée vidait [son] escarcelle ». En chemin pour Béziers, la ville où il a été reçu compagnon fini, il a renoncé à visiter Carcassonne car «l'écu de cinq francs qui [lui] restait en poche limitait [ses] moyens de tourisme [...] »35. En 1930 à Grenoble, Morin a dessiné pendant les trois jours de repos dont il disposait pour le Nouvel an parce qu'il n'avait presque plus d'argent ; après une excursion à Albi, le 15 août, deux ans, plus tard, il a renoncé à toute nouvelle sortie par nécessité d’économiser avant son départ pour Montpellier ${ }^{36}$.

\footnotetext{
32 Daniel Roche (prés.), Journal de ma vie. Jacques Louis Ménétra compagnon vitrier au XVIIIe siècle, Paris, Montalba, 1982, p. 346.

33 Abel Boyer, op.cit, p. 215.

34 Jean-Baptiste Arnaud, op. cit., p. 186-187 et 195.

35 Abel Boyer, op. cit, p. 41, 84-86.

36 Pierre Morin, op. cit., p. 39 et 97.
} 


\section{LES COMPAGNONS TOURISTES ${ }^{37}$, EXCURSIONNISTES ET PROMENEURS}

Les compagnons étaient des ouvriers géographiquement très mobiles, en tout cas pendant les quelques années de leur Tour de France. Il ne s’agissait pas d'une errance à la recherche d'emplois successifs, fréquente dans la classe ouvrière du XIXe siècle, ou de la migration saisonnière caractérisant certains métiers, tels les maçons de la Creuse, mais d'une mobilité organisée, fondatrice de l'identité du compagnonnage. À la faveur des étapes du Tour de France se manifestait un véritable désir de découverte des «curiosités remarquables », des «beautés admirables ${ }^{38}$, des lieux et monuments pittoresques des villes et régions traversées ou habitées temporairement. Cette «attraction touristique »39, qui semble avoir échappé aux historiens du tourisme 40 , était déjà présente chez Ménétra à fin des années 1750: en Provence il a visité Avignon, le tombeau de Nostradamus à Salon-deProvence, a excursionné au mont Ventoux, à la fontaine de Vaucluse, au pont du Gard, est allé voir les ponts de bateaux à Arles. Elle est présente chez tous les compagnons mémorialistes 41 . Elle est très marquée chez Perdiguier. En 1825 entre Béziers et Bordeaux on le voit consacrer une demi-journée à la visite de Toulouse, l'année suivante entre Bordeaux et Nantes il a visité Rochefort, puis Angers lors de son voyage jusqu'à Chartres. À Paris en 1827 il s'est abandonné à une sorte de boulimie touristique : Père Lachaise, Louvre et Tuileries, Panthéon, Invalides, Hôtel de ville, Palais de justice, Palais royal et Palais du Luxembourg, Bourse, École militaire, arcs de triomphe, ponts, fontaines, places, statues équestres, Champs-Élysées et autres avenues, musées, bibliothèques, théâtres, jardins publics... Parti de Rochefort en juin 1837 dans l'intention de gagner la capitale, Arnaud a fait la découverte successive de La Rochelle, Marans, Luçon, Bourbon-Vendée, Nantes, où il s'est attardé plusieurs jours... Les Souvenirs... de Batard ont des allures de guide de tourisme. À Carcassonne il a acheté une carte portant l'inscription "Voir Carcassonne et mourir ». Mais il a survécu et à Nîmes il a été impressionné par les courses de taureaux 42 et les costumes chamarrés des toréadors. À Tarascon il a été spectateur du défilé de la Tarasque comme Perdiguier du carnaval de Béziers avec ses «paillades », saynètes mettant en scène des maris bernés. À Pâques 1890 (trois jours de congé !) il a arpenté Paris et vu la tour Eiffel, toute neuve.

\footnotetext{
37 Le terme ne se trouve que sous la plume de Boyer et de Morin, les deux plus récents (début $\mathrm{XX}^{\mathrm{e}}$ siècle) parmi les mémorialistes étudiés.

38 Expression de Jean-Baptiste Arnaud.

39 Expression de Daniel Roche, op. cit, p. 315.

40 Par exemple Catherine Bertho-Lavenir, La roue et le stylo. Comment nous sommes devenus touristes, Paris, O. Jacob, 1999.

41 En revanche ils n'ont pas tous fait le pèlerinage à la Sainte-Baume, emplacement légendaire du tombeau de Maître Jacques, un des fondateurs mythiques du compagnonnage.

42 Ameline y a aussi assisté.
} 
Le jour de l'arrivée d'un compagnon dans une ville était fréquemment occupé en partie par un premier tour. La découverte se poursuivait les dimanches suivants et si on n'en avait pas eu la possibilité on essayait de se rattraper avant le départ pour une autre cité. Ainsi Fourquemin en 1820 a tenu à voir le tombeau en marbre blanc du duc de Montmorency avant de quitter Moulins. Un aléa du Tour de France : le chômage, assez fréquent ${ }^{43}$, constituait une circonstance favorable pour la découverte touristique par le temps qu'il libérait. Les compagnons chômeurs étaient d'ailleurs désignés par le terme de "flâneurs ». Fourquemin a visité Paris avec son frère, avant de repartir pour Nevers, leur ville natale, parce qu'ils avaient perdu leur emploi. Dans les débuts de son périple c'est le refus de plusieurs embauches, qui ne lui avaient pas convenu, qui lui a fourni les « loisirs » pour la visite de Lyon, réitérée lors d'un passage ultérieur faute d'avoir trouvé du travail. Pour la même raison Ameline s'est attardé une journée à Toulouse avant de reprendre la route. À Bordeaux, Batard a patienté plus longtemps, sans davantage de succès, alternant sa recherche d'embauche avec des retours sur la place des Quinconces ou sur le grand pont de pierre aux 17 arches; il a visité Lyon quand son patron s'est séparé de lui. À Toulouse Morin a mélangé lui aussi la quête d'un emploi et la promenade « en touriste ». À Marseille, où sévissait un chômage complet, Boyer s'est retrouvé parmi une " ribambelle de flâneurs » à Notre-Dame de la Garde...

Cette célèbre église, comme Notre-Dame de Fourvière à Lyon, faisait partie de ces monuments qui étaient pour les compagnons des points de passage presque obligés par leur situation dominante et leur célébrité. D’autres, tels le pont de Gard, qui a laissé Arnaud «muet d'admiration », les vestiges romains à Arles et à Nîmes, le grand théâtre de Bordeaux, le pontcanal d'Agen... étaient appréciés parce qu'ils témoignaient du savoir-faire de ceux qui les avaient bâtis. On y gravait parfois un graffiti. Les " pays » étaient attentifs aux chefs-d'œuvre laissés par les compagnons des générations précédentes. Au musée de Lyon, Fourquemin a observé, sur les indications d'un compagnon se trouvant là, les châssis des vitrines fabriqués par des menuisiers du Devoir44. Morin s'est précipité au musée Borely pour admirer la Serrure de Marseille, sortie elle aussi des mains d'un devoirant. La curiosité technique conduisait le bourrelier Batard à se faire expliquer le fonctionnement des écluses alors qu'il longeait à pied le canal du Midi ; il a aussi visité les chantiers de La Ciotat et le port de Toulon. Les navires à Bordeaux ont fasciné Victorien en 1895, Boyer en 1900 : «Mon plus grand plaisir pendant les quelques heures de loisir dont nous disposions était d'aller

43 Le monopole de l'embauche exercé par les sociétés compagnonniques ne mettait pas leurs membres à l'abri. Dans les villes étapes du tour de France et pour chaque métier le rouleur centralisait les offres d'emploi et présentait les compagnons qui arrivaient aux employeurs. Parfois les compagnons se débrouillaient par eux-mêmes.

44 François-Joseph Fourquemin, op. cit, p. 122. 
voir entrer et sortir les bateaux du port, voir les bricks chargés de toiles, les terre-neuvas tourner sur leurs ancres en marée montante et descendante ${ }^{45}$. On était aussi attiré par des lieux plus étranges tel le musée d'anatomie de l'école de médecine à Montpellier. Ou par le spectacle offert par la richesse commerciale des grandes cités : "Les ai-je léchées les vitrines, ces devantures où tout m'éblouissait » s'exclamait Abel Boyer à propos de Nantes46.

Les compagnons mémorialistes ont multiplié les commentaires élogieux sur les villes visitées. Perdiguier s’adressait directement à Paris : «Le voyageur dès qu'il arrive dans tes murs, court à tout ce que tu renfermes d'intéressant, de beau, de sublime, et te connaît mieux, en dix jours, que le Parisien dans toute sa vie »47. Il trouvait Châlon sur Saône « fort jolie »; pour Arnaud, Nantes était " superbe » et Tours, sa " ville de prédilection », " une riante cité ». Aux yeux de Morin, Toulouse était "très agréable », Nîmes «admirable » et il s'extasiait aussi devant Alger. "Nîmes fournit à ma capacité d'admiration un trésor inépuisable " notait Batard dans ses Souvenirs. Boyer a résumé l’opinion générale : «Vraiment le Tour de France était une belle chose... »48. Un thème qu'on ne s'étonnera pas de trouver dans les chansons compagnonniques 49 .

L'excursion ou plus modestement la promenade étaient parmi les loisirs favoris des compagnons, le dimanche ou en soirée. Au XVIIIe siècle Ménétra s’était acheté un petit bateau, amarré sous le Pont-Neuf et, pendant un temps, le canotage jusqu'aux îles du côté de Charenton, vers Saint-Cloud ou Sèvres en compagnie de quelques amis et de leurs maîtresses, a égayé bien des dimanches. Plus tard, marié et installé, il a fait plus volontiers des promenades,

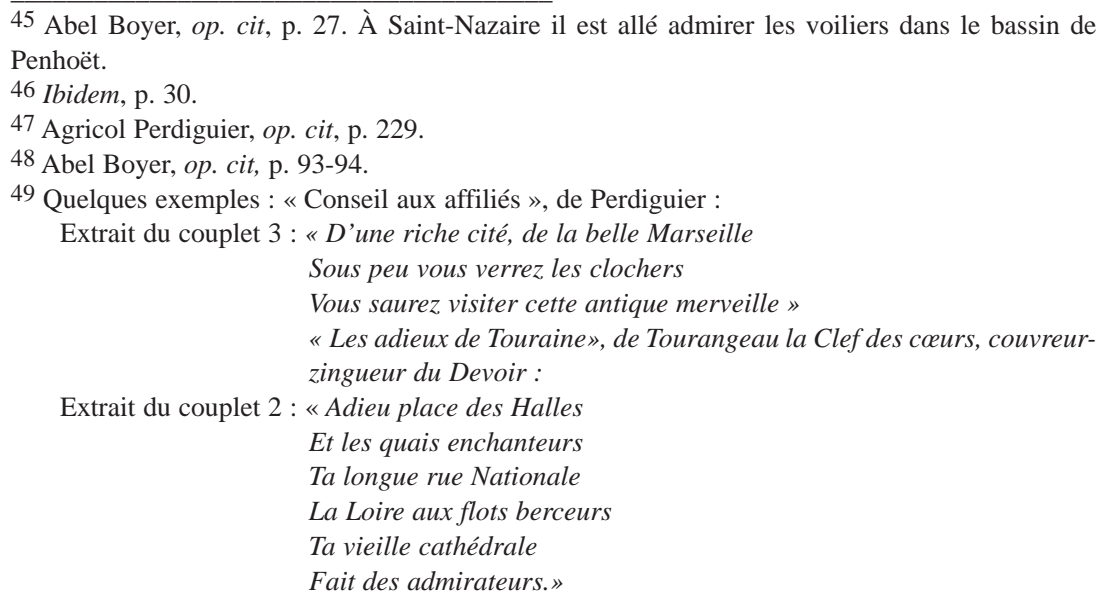

Dans « Les Adieux de Nancy », où il a passé un an bien qu'elle ne figurât pas parmi les villes du Tour de France, Jean François Piron, compagnon blancher-chamoiseur, a vanté les «beaux monuments » de «l'orgueil de la Lorraine », sa « superbe place royale », son « hôtel de ville imposant ».

L'arc de triomphe, la carrière

Près d'elle la pépinière,

Le Palais du gouvernement », etc. , ainsi que les « beaux environs ». 
certaines en compagnie de Jean-Jacques Rousseau ${ }^{50}$, ou avec ses enfants, aux Tuileries, aux Champs-Élysées, au Pré Saint-Gervais, au Mont Valérien, à Saint-Denis ou à Meudon. Perdiguier affectionnait tout particulièrement les promenades champêtres avec d'autres compagnons, ou parfois seul quand il sentait le besoin d' " un peu de rêveries ». Il a décrit ses impressions avec des accents rousseauistes : "Ces beaux lieux ont toujours remué mon être, les beautés de la nature ont eu plus de puissance sur mon âme que les beautés de l'art auxquelles je ne suis cependant insensible; je leur dois mes plus vives, mes plus profondes jouissances $» 51$. À Marseille ses promenades ont été souvent en mer, à Nîmes le jardin public non loin des arènes l'accueillait tous les soirs, à Montpellier il montait au Peyrou d'où on dominait « le plus vaste, le plus bel horizon »52. Lyon lui offrait les bords de la Saône et du Rhône et une ceinture de "lieux pittoresques »: ermitage du Mont-Cindre, bois de Roche-Cordon, grotte de la Roche-qui-pleure... A Nîmes Guillaumou et ses amis allaient souvent se délasser de leur journée par une promenade, parfois agrémentée d'une baignade dans la «belle fontaine » proche du temple de Diane. À Marseille Flonnet allait déguster des glaces sur la Canebière le dimanche.

La mer était pleine d'attraits. On allait observer le travail des pêcheurs. Dans sa correspondance Victorien a évoqué fréquemment ses sorties en bateau et ses baignades à Pornic, Arcachon, Gujan-Mestras. Quand il travaillait à Mèze, Boyer s'est promené en barque sur l'étang de Thau ; un dimanche il l'a traversé sur un petit vapeur jusqu'à Sète où il a pu voir des poulpes. À SaintNazaire il pêchait crabes et crevettes, à Agde des oursins. "Je ne me lassais jamais d'admirer cette mer bleue qui parfois prenait des tons verts et mordorés »53. Il était aussi attiré par la montagne. De Toulouse il est allé deux fois jusqu'à la frontière espagnole au col du Portillon. Morin a lui aussi largement profité des plaisirs de la mer et de la montagne. À Fouras il accompagnait des pêcheurs, à Royan il fréquentait la plage. Le second dimanche suivant son installation à la Rochelle il est allé à l'île de Ré avec un groupe : on a pris le petit train, après le déjeuner dans un restaurant on est parti à pied vers Saint-Martin-de-Ré en admirant au passage les fortifications de Vauban. Lors de son séjour à Grenoble la majorité de ses dimanches a été occupée par les randonnées et le ski. Il a assisté à un concours international de saut à ski et à une course de bobsleigh. À Toulouse, au moment du 14 juillet 1932 il a pris quatre jours de congé et s'est offert un circuit organisé dans les Pyrénées. Son séjour algérien a été fertile en promenades dans Alger et aux environs, parfois en louant des vélos. Rendre visite à de vieux compagnons

50 Rencontré à l'occasion de son travail à l'Hôtel du Saint-Esprit où demeurait le philosophe.

51 Agricol Perdiguier, op. cit, p. 96. Il les recommandait aux compagnons qui selon lui les négligeaient trop souvent.

52 Une excursion que fera aussi Morin presque un siècle plus tard.

53 Abel Boyer, op. cit, p. 93. 
était assez souvent un but de promenade, ou tout au moins l'occasion d'une pause. Certains mémorialistes (Perdiguier, Arnaud) ont souligné qu’ils préféraient les promenades aux bals ou aux attractions. Il n’en demeure pas moins que ces lieux étaient fréquentés assidûment par les compagnons.

\section{UNE SOCIABILITÉ RÉCRÉATIVE DE BANDE. CoMMENSALITÉ ET LIBATIONS}

Entre certaines formes de la sociabilité organisée et coutumière du compagnonnage et les loisirs spontanés et libres, il n’y avait pas de solution de continuité, en raison d'un caractère festif commun. La fête patronale, qui pouvait s'étaler sur plusieurs jours, son défilé jusqu’à l'église en habits du dimanche, avec les cannes et les rubans, précédé par une musique militaire, le banquet et le bal avec ses danses très codifiées (guilbrette, chaîne d'alliance) 54 , étaient d'abord un rituel symbolisant la cohésion de groupe. Elle était aussi un temps de réjouissance et de détente, évoqué par tous les compagnons mémorialistes. Chansons et libations étaient au programme. Le commentaire contemporain de François Icher :

«Dans la suite monotone des travaux et des jours, la fête patronale s'inscrit comme une rupture de l'ordre banal, une transgression [...] Pour le Compagnon, homme de métier par excellence, prendre tout son temps pour manger signifie qu'on s'affranchit provisoirement des contraintes du labeur ; c'est se situer dans le monde non du labeur et du chantier, mais du plaisir et du bonheur de se retrouver entre frères autour d'une bonne table » 55 , fait écho aux propos de Perdiguier : "[...] les imaginations s'exaltent, chacun est vraiment heureux et se voit transporté dans un paradis » 56 .

Le tour de France par lui-même suscitait bien d'autres instants de commensalité et de convivialité avec les repas d’accueil des arrivants, les banquets lors des départs avant la «conduite » de ceux qui s’en allaient « battre aux champs ».

D’une manière générale à cette sociabilité de groupe fermé se superposait une sociabilité de bande. Les compagnons étaient de jeunes hommes, ils en avaient l'instinct grégaire. Ils aimaient se retrouver ensemble dans une « atmosphère communautaire ", de "chaude et virile amitié »57, et multiplier les occasions de rire et de faire la fête. Voici en quels termes Guillaumou se souvenait de son séjour à Marseille en 1834-1835 : « [...] notre société était si nombreuse et si tapageuse et je n'avais pas vingt ans ! Je fus bientôt entraîné dans toutes les parties »58. Dans le Paris de la fin du XVIIIe siècle les

\footnotetext{
54 Les bals de compagnons ne se limitaient pas à ceux des fêtes patronales, plus solennels.

55 François Icher, Les compagnonnages en France au XXe siècle : histoire, mémoire, représentations, Paris, J. Grancher, 1999, p. 433.

56 Agricol Perdiguier, Le livre du compagnonnage, Paris, Pagnerre, 1841, p. 64-65.

57 Jean-Pierre Bayard, op. cit, p. 191-192.

58 Toussaint Guillaumou, op. cit, p. 62.
} 
typographes ou les vitriers comme Ménétra, leur journée terminée, applaudissaient ensemble aux spectacles de la rue : comédiens, marionnettistes,

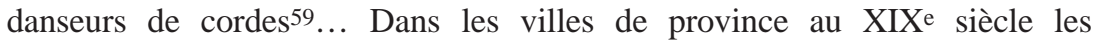
compagnons se rassemblaient le soir à la « cayenne », l'auberge qui était le siège de leur Devoir et où certains étaient logés, pour manger, bavarder, « casquetter » (Flouret), jouer aux cartes, aux dominos ou au billard, fumer60, chanter. Jules Vallés a évoqué dans L'enfant l'atmosphère joyeuse qui régnait chez la « mère » des menuisiers du Puy où l'emmenait parfois son oncle Joseph entre 1837 et 1839. À Nîmes chez celle des maréchaux-ferrants « [...] tous les soirs c'était la petite bombe », aux dires de Boyer61. Marguerite Duguet, "mère » de compagnons du devoir à Lyon, a témoigné de la « saine gaieté » qui régnait dans l'établissement tenu par sa tante dans les années 192062.

On pratiquait, au XVIIIe et au XIXe siècle, toutes sortes de jeux collectifs : paume-une, longue-paume, battoir, barres, boules, roulettes... À Montpellier Perdiguier et les compagnons menuisiers se poursuivaient avec un chiffon roulé en boule et trempé dans l'eau :

«Nous folâtrions [...]. Celui qui tenait la balle mettait tout en fuite; il ne trouvait personne d'assez gentil pour la recevoir de bonne volonté soit dans ses mains, soit sur une partie quelconque de son individu. La balle m'arrive, je m'en saisis et Vivarais le Cour content (Morel) est atteint à son tour. L'arme terrible est dans ses mains [...] Il se met à me poursuivre. Je tourne à droite, m'empare d'une pelle, saute sur l'abreuvoir [...] Voilà mon homme qui débouche par la porte, sans prévoir l'accueil qui lui est réservé [...] Un déluge tombe sur sa tête [...] Étourdi, désorienté, il recule, il se sauve ; et tous de rire et de me déclarer vainqueur... " ${ }^{63}$.

On s’amusait comme des grands gosses. Ménétra a fait des « niches » aux « malheureux » habitants de la juiverie de Carpentras. Voici le genre de farces qui «faisaient toujours pouffer de rire » les cordonniers à Marseille dans les années 1830 : "Tantôt c'est un globe plein d'eau qui tombait sur la tête de celui-ci, tantôt c'était le lit de celui-là qui se détraquait lorsqu'il croyait se coucher tranquillement ». Les bottines qu'un compagnon devait livrer étaient remplacées par un bonnet de laine. Au retour de la virée au château d’If, Guillaumou a subtilisé les vêtements de ses camarades en baignade après que ceux-ci l'aient laissé s'épuiser à rattraper la barque à la nage: «Nous rentrâmes en ville les meilleurs amis du monde »64. En 1900 à Nantes, Boyer

\footnotetext{
59 Ménétra a lui-même improvisé de petits spectacles. À Versailles il a installé, avec des tonneaux et des établis, un théâtre devant la boutique de son employeur : le vitrier du roi, et y a joué avec quelques complices la Parade du savetier et celle du tailleur, pour le public des valets de pied et des Cent Suisses. Il avait fait la «folie » de s'acheter une « défroque » d'Arlequin.

60 Une pratique semble-t-il déjà bien trop répandue. Avant son départ pour Bordeaux le père de Batard lui a donné ce conseil, qu'il a suivi : «ne fume pas ». Francis Laget, op. cit, p.17.

61 Abel Boyer, op. cit, p.121.

62 Marguerite Duguet, Mémoires d'une mère en Devoir, Paris, Librairie du Compagnonnage, 1979, p.14.

63 Agricol Perdiguier, Mémoires..., op. cit, p. 97.

64 Toussaint Guillaumou, op. cit, p. 84-88.
} 
a été emmené à la chasse au «daren », un animal imaginaire ; il ne s’est pas laissé prendre. Il a raconté, qu’à Lyon, les compagnons au chômage tuaient le temps en s'amusant des passants avec un porte-monnaie relié par une ficelle. À Saint-Laurent-du-Chamousset la distraction favorite, avant de se coucher, consistait à décrocher à coups de pieds les gros saucissons suspendus au plafond de la chambre.

Les compagnons étaient des habitués des restaurants, guinguettes, auberges, aux barrières à Paris, ou dans les environs des grandes villes, tels Les Volets verts près de Marseille ou La Mère l'Équipé sur les bords du Cher non loin de Tours. Ces établissements étaient des buts pour les promenades vespérales et dominicales. Ménétra était «très connu et toujours en bonne compagnie » dans les cabarets de la Courtille, sur les pentes de Belleville, de Champigny, de la Nouvelle France, de la Petite Pologne ; « [...] l'on voyait tous les riboteurs et riboteuses de Paris dans tous ces cafés et chaque table était une parade et il était de mon goût pour voir et entendre les farces »65. À Montpellier Perdiguier allait au faubourg de Boutonot manger la gibelotte de lapin «qui nous laissait, pour toute la semaine, un si bon souvenir». À Bordeaux une journée dans un parc des environs, avec volières, fleurs et statues, en compagnie d'une vingtaine de compagnons, s'est terminée au cabaret. À Lyon, avant d'être élu premier en ville, Perdiguier fréquentait régulièrement un estaminet de la Guillotière : "Là nous chantions, nous dansions sans musique, nous sautions par dessus les tables, nous franchissions des rangées de tabourets $» 66$.

La sociabilité compagnonnique était une sociabilité bachique. Le vin en était un élément de base tant dans ses aspects officiels que dans les activités récréatives plus libres. Les beuveries étaient incorporées dans le rituel. «Le Tour de France [était] un tour des vins »67. Arrivées et départs étaient inévitablement accompagnés d' "arrosages ». On débouchait des " bouteilles d'arrivants » lorsque des compagnons se présentaient dans une « cayenne » avec leurs lettres de recommandation. On emportait verres et bouteilles lors des conduites. Le topage, quand il était amical, s’accompagnait d'un échange des gourdes mais s’il y avait un débit de boisson à proximité on ne s'en tenait pas là. La chanson de Pierre Dupont : Les deux compagnons du devoir mettait en scène deux devoirants qui :

«[...] s'étaient rencontrés

À l'embranchement d'une route.

Et comme ils étaient altérés

Sous la tonnelle on but la goutte $\$ 68$.

65 Daniel Roche, op. cit, p.171 et 181.

66 Agricol Perdiguier, Mémoires..., op. cit, p. 96 et 285.

67 Daniel Roche, op. cit, p. 372.

68 Poursuivant ensemble leur chemin ils « [...] laissaient dans chaque hameau Rires francs et bouteilles vides ».

Pierre Dupont, Chants et chansons, Paris, A. Houssiaux, 1851. 
Un samedi soir à Montpellier, le premier en ville, qui avait mal porté une santé, fut taxé de deux bouteilles par Perdiguier et un groupe de compagnons réunis pour boire "en règle, dans les formes, avec de certains mots que chacun doit prononcer sans balbutier, sans se tromper d'une syllabe »69. On peut voir une transposition de cette manière de payer les amendes, tout ce qu'il y a de plus habituelle, dans ce "divertissement » pratiqué tous les dimanches à Saintes selon Ameline : «tirer le roi ». Celui qui trouvait la fève en était pour ses dix ou douze francs afin de "rafraîchir les dames " ${ }^{70}$. Le vin était omniprésent. Pour se désaltérer dans les "parties de plaisir » le petit blanc avait la préférence mais dans l'Hérault on buvait aussi du muscat, « à si bas prix dans ce département ${ }^{71}$. À Tours ou Montbazon en 1874 Flouret et ses camarades allaient tous les soirs vider une "fillette » de blanc avant d'aller souper. Dans ses Adieux de Nancy, Piron célébrait le « joli vin clairet » sablé "plus d'une fois, au bosquet. Avec [ses] amis en goguette; et dans le Lyon des années 1930 les parties de cartes des dimanches après-midi permettaient 'de vider un pot' » (Morin).

Les compagnons avaient, de longue date, la réputation d'être de francs buveurs et des piliers de cabaret. Pourtant selon Abel Poitrineau, malgré la fréquence des libations, «l'ivrognerie d'habitude » n'apparaissait pas comme « un problème aigu ${ }^{72}$. On peut s'interroger quant à l'optimisme de cette appréciation. Perdiguier remarquait que certains compagnons s'enivraient volontiers, notamment ceux qui étaient originaires des contrées où le vin était cher lorsqu'ils séjournaient dans le Midi. Parmi les raisons qui ont poussé Fourquemin à s'installer à son compte, avec son frère, en 1826, figurait l'obligation de vivre comme les camarades: "aller boire, ne rien faire certains jours. C'était pour nous une vie accablante ». Guillaumou a quitté Lyon pour Châlon parce que la mauvaise influence qu'il retrouvait le soir dans les gargottes avait fini par lui faire délaisser son travail : « on chopine et la journée se perd »73. Boyer notait, pour Lyon également, que les visites dans les ateliers des maréchaux en chômage se terminaient toujours au troquet : "Le métier donne soif ». La situation était pire à Paris : "Que de discours il m'a fallu prononcer sur la tombe des ces buveurs emportés par leur intempérance $»^{74}$.

69 Agricol Perdiguier, Mémoires..., op. cit, p. 101. Ce qui était aussi une façon de prouver qu’on résistait à l'ivresse. Le premier compagnon payait double quand il pêchait contre le règlement.

70 Gabriel Désert, art. cité, p. 162.

71 Aagricol Perdiguier, Mémoires..., p. 96. Le bon marché du vin expliquait la fréquentation des cabarets des barrières.

72 Abel Poitrineau, op. cit, p. 74.

73 Et même sa responsabilité de premier en ville. T.oussaint Guillaumou, op. cit, p. 114.

74 Abel Boyer, op. cit, p. 148 et 215. 
La sociabilité récréative de bande, juvénile et bachique semble s’être conciliée assez mal avec les loisirs intellectualisés : la lecture ${ }^{75}$ et le théâtre. Si l'évocation du vin et du cabaret est omniprésente chez les mémorialistes, celle des plaisirs de l'esprit est moins fréquente. Perdiguier a raconté ses soirées à Bordeaux en 1825-1826 avec un petit groupe de compagnons, passées à écouter l'un deux déclamer Othello, Hamlet ou Phèdre ou à lire "en famille » des "pièces sombres, terribles ». Il est lui-même devenu un habitué des théâtres, à Bordeaux, Nantes, Paris (où il s'entretenait avec des spectateurs aux entractes), Lyon, aux places du paradis, du colombier ou du poulailler. Sa préférence allait aux tragédies, par goût de l'histoire, ensuite aux ballets, enfin à l'opéra. Ce n'est guère qu’à Chartres, où le théâtre, sans troupe, recevait des acteurs en tournée, qu’il a assisté à des comédies. Ses lectures le ramenaient au théâtre puisque ses œuvres favorites, lues et relues, c’étaient les tragédies de Voltaire ${ }^{76}$ et Racine. Arnaud, en 1840 à Paris, allait au théâtre tous les deux jours. Flouret y a profité de billets de faveur procurés par un machiniste de la salle de la Porte SaintMartin. Batard, apprenti à Nantes, a fréquenté les matinées du Théâtre de la Renaissance, aux troisièmes galeries pour dix sous, Morin l'opéra d'Alger (répertoire classique et musique arabe) au pigeonnier à deux francs la place. C'étaient les mêmes qui lisaient. À Lyon Arnaud puisait dans la bibliothèque de son employeur des Brotteaux: Dauphiné la Vertu. Flouret trouvait le temps d'absorber «quelques bons bouquins ». On leur ajoutera Jean-Baptiste Godin, qui avant de devenir le grand industriel philanthrope que l'on connaît , a fait son Tour de France (1835-1837) et lisait les philosophes des Lumières depuis l'âge de quinze ans 77 ; et Pierre Huguenin, le menuisier imaginé par George Sand dans son roman Le compagnon du Tour de France (1843) qui empruntait clandestinement des livres dans le cabinet de lecture du château solognot où il effectuait des travaux de restauration et connaissait par cœur L'Émile, qu'il lisait à la veillée avec quelques amis compagnons. Ce dossier un peu mince suffit-il à contrebalancer les remarques de Perdiguier selon qui le travailleur amateur de livres était un "objet de railleries », ou d'Arnaud décrivant ses compagnons comme de "crédules ouvriers, aveugles et idolâtres de leurs préjugés »78.

Le recrutement élitiste et la forme initiatique du compagnonnage débouchaient-ils sur une société récréative refermée sur les seuls compagnons? Voire même sur des fractions de ce monde ? Le compagnonnage du XIXe siècle était divisé en devoirs rivaux dont les oppositions étaient telles qu’ils ne se

\footnotetext{
75 L'écriture aussi. En 1826 à Nogent-le-Roi, où les possibilités de distractions, hormis la promenade, n’étaient sans doute pas très variées, Perdiguier lisait et écrivait, « et tous [ses] instants de loisirs étaient ainsi occupés » (Agricol Perdiguier, Mémoires..., op. cit., p. 187). À Tours en 1842 Arnaud a entrepris la rédaction de ses Mémoires ce qui était « un plaisir, en même temps qu'un délassement » (Jean-Baptiste Arnaud, op. cit, p. 324).

76 Quatre petits volumes achetés à Bordeaux. S’y ajoutait La Henriade, emportée souvent en promenade.

77 Jean-Baptiste Godin, Solutions sociales, Quimperlé, La Digitale, 1979, p. 427.

78 Citées par Martyns Lyons, « La culture littéraire des travailleurs, Autobiographies ouvrières dans l'Europe du XIX ${ }^{\mathrm{e}}$ siècle », Annales Histoire sciences sociales, juillet-octobre 2001, p. 945.
} 
mêlaient pas dans les pratiques ludiques. La hiérarchisation des grades et des corps de métier suscitaient aussi des ségrégations. Ainsi les «goûters en société » des typographes parisiens, au XVIIIe siècle, tous les lundis et même d'autres jours, excluaient-ils les apprentis. À Blois vers 1837, selon le témoignage de Guillaumou, cordonniers et boulangers, c'est-à-dire des «soidisant » compagnons non reconnus ou mal reconnus par les autres, avaient choisi de passer ensemble les soirées du dimanche en abandonnant la rue aux charpentiers. Avec les employeurs, la plupart du temps des chefs de petites entreprises, souvent issus du compagnonnage, la séparation liée au statut social et à la génération n’était pas totale. En dehors même des manifestations officielles et ritualisées tels des "pâtés de veille », repas offerts par les maîtres 79 , et les bals de fête patronale où les compagnons faisaient danser patrons et patronnes ${ }^{80}$, les relations avec les maîtres s'élargissaient au-delà de l'espace-temps du travail et pas seulement dans des occasions aussi exceptionnelles que cette exécution d'un parricide à laquelle Boyer, son patron et ses collègues ont assisté à Toulouse ${ }^{81}$. À Lyon un dimanche Ménétra a été convié par son «bourgeois » à une promenade en famille jusqu’à une île de la Saône ; lorsqu'il a quitté la ville, le dit «bourgeois » a été invité au souper qui lui a été offert par les vitriers. Un 15 août le patron de Batard l'a emmené à Palavas-les-Flots. Celui de Victorien, un jour où la besogne manquait, lui a fait visiter le grand magasin de la Maison Hennessy à Cognac ; quelques jours plus tard il lui offrait une soirée au théâtre. Ce bourrelier semble avoir été particulièrement proche de ses ouvriers : il lui arrivait de les accompagner au café ; un soir il a accueilli chez lui une soirée crêpes : chacun avait cotisé pour la farine, les œufs, la graisse... et le vin. Les maîtres recevaient volontiers leurs ouvriers dans leurs « campagnes ». Si l'apprenti Jérôme mis en scène dans les Anecdotes typographiques de N. Contat semble avoir été invité surtout à cause de sa "fidélité à se rendre utile » (il ne rechignait pas à aider à la cuisine ou à passer le râteau dans les allées), Perdiguier allait parfois le dimanche « faire la partie aux boules » avec le menuisier qui le logeait dans le jardin qu'il possédait « hors ville ». À Tours en 1839, Arnaud a passé des « moments fort agréables » dans la maison de campagne de son employeur : le boulanger Gasté, de la place du Grand Marché82. Même chose pour Ameline à Saintes : il allait chasser ou cueillir des champignons avec le fils du «bourgeois »; au retour on buvait du vin chaud en mangeant des châtaignes ou on se rendait chez le grand-père déguster des eaux de vie.

Mais c'est surtout avec la jeunesse locale que se retrouvaient les compagnons. La remarque de Perdiguier à propos de Marseille où elle n’admettait guère "l'étranger au sol » à ses amusements, semble relever de

\footnotetext{
${ }^{79}$ La coutume s'en est perdue vers le milieu du XIXe siècle. Emile Coornaert, op. cit, p. 231.

80 Lesquels offraient parfois un bal à leur tour le lendemain.

81 Ils lui avaient fait pour la circonstance retarder son départ pour Bagnères-de-Luchon.

82 Qui le traitait comme son fils et en aurait bien fait son gendre. La maison était prêtée aux compagnons pour des assemblées initiatiques.
} 
l'exception. Un peu partout les compagnons participaient aux fêtes champêtres et aux bals. Les exemples abondent, chez Ménétra, chez Perdiguier, chez Arnaud dont les trois premiers mois à Château-Renault se sont écoulés « comme un songe de joyeux délire [...] les jeunes gens de la localité n'[ayant eu] aucune peine à [lui] faire descendre la pente de la folie [...] »83. Chez Ameline qui s'est amusé " au mieux" pendant le carnaval à Carcassonne: "Nous avions le bal paré et masqué, où l'on dansait, et où on pouvait danser le bon et le mauvais "84. Chez Batard qui s'est mêlé assidûment aux réjouissances des habitants de Charlieu, en majorité des soyeux, vers 1889, chez Victorien, chez Boyer qui a joué de l'accordéon dans une fête des conscrits et courait les corridas, à la belle saison dans les villages du Languedoc. À Montpelllier vers 1880, les charpentiers étaient souvent conviés aux bals des étudiants « où leur robustesse élégante, leurs goûts aventureux étaient appréciés »85. Dans l'entre-deux-guerres Morin était un habitué des bals, comme à Fouras, cette station balnéaire proche de La Rochelle où chaque soir la fête était « permanente [...] jusqu'à deux heures du matin » au point qu'il a failli y laisser sa santé, ou à Airvault (Deux-Sèvres) où il prenait pension dans un hôtel où se donnait un bal chaque dimanche. Violoniste il était régulièrement sollicité pour faire des remplacements dans les orchestres.

La sociabilité compagnonnique étant exclusivement masculine, hormis le rôle tenu par les « mères », les fêtes et les bals réintroduisaient l'élément féminin. Aux « assemblées » de Chartres et de ses environs « nous sautions comme des fous avec les jeunes filles » au son du violon et d'une grosse caisse, se souvenait Perdiguier avec émotion ${ }^{86}$. Flouret faisait « danser les petites Tourangelles qui n'avaient pas l'air de s'en montrer attristées »87. Celles d'Airvault non plus que Morin trouvait « sans préjugé et même assez aguichantes », ni celles de Fouras avec lesquelles on allait « en équipe sur la plage [...] prendre le bain de minuit [...]»88.

\footnotetext{
83 Jean-Baptiste Arnaud, op. cit, p. 152.

84 Pierre Ameline, op. cit, p. 71.

85 Pierre Barret et Jean-Noël Gurgand, op. cit, p. 305. D’après J. Loubet, « Souvenirs sur mon père, compagnon charpentier DD de L », Le Voile d'Isis, décembre 1925.

86 Agricol Perdiguier, Mémoires..., op. cit, p. 191.

87 Francis Laget..., op. cit, p.21.

88 Pierre Morin, op. cit, p. 104 et 18. Les loisirs ne sont évidemment pas sans liens avec l'exercice de la sexualité. À l'exception de ceux de Ménétra, qui s'avouait sans complexe "porté à la bagatelle » et pour qui la chasse au « gibier féminin » (de « toutes espèces » et en partie trouvé parmi les épouses, veuves et filles de maîtres et parmi la clientèle, religieuse y compris) était un souci de tous les instants, tant pendant ses deux tours de France qu'à Paris où il conduisait « ses sultanes » à la «chambre des conquêtes » (tapissée «tout en petites glaces par compartiments »), et qui après son mariage ne s'est pas privé de "donner des coups de canif dans le contrat » quand il trouvait «quelques poulettes à croquer», les mémoires de compagnons sont assez discrets. Le sage Perdiguier qui évoquait pudiquement les désirs éveillés lors des fêtes champêtres : «[...] bonheur extrême !... et pourtant incomplet », mais ne voulait pas se " livrer aux femmes perdues » (Agricol Perdiguier, Mémoires..., p. 206), était sans doute moins représentatif que le charpentier couvreur Tourangeau le Sérieux qui, dans l'entre-deux-guerres était client des «bordels de Tours » « où l'on baisait pour cinq sous » (La Nouvelle République du Centre-Ouest, 28-29 novembre 1978, cité par Pierre Barret et Jean-Noël Gurgand, op. cit, p. 105) ou que les deux compagnons qui enrubannaient les filles dans une «maison prostituée », au témoignage de Toussaint Guillaumou (op. cit, p. 211).
} 


\section{LA CHANSON}

La vie compagnonnique tout entière, depuis les manifestations officielles et ritualisées jusqu’aux loisirs les plus libres, était bercée par des chansons. La chanson était avec le vin, auquel elle était étroitement associée ${ }^{89}$, un autre élément de base de la sociabilité compagnonnique. Le vin l'irriguait et la chanson la rythmait. Les compagnons écrivains et les historiens sont unanimes à le souligner, et avec force. À Perdiguier : «Les chants [...] inspirent l'enthousiasme et ont une action incroyable dans la vie du compagnonnage » ${ }^{90}$, fait écho Pierre Moreau : "C'est pour ainsi dire l'âme du compagnonnage ». Même si chacun ne pouvait mettre en valeur ces belles voix de ténor (Arnaud par exemple) ou de baryton qui rappelaient à Marguerite Duguet les chants dans la forge de son père, même si le « bel canto du Midi et des Pyrénées » (Morin) n’avait pas des équivalents partout, chanter était à la portée de tous comme le soulignait Perdiguier :

«[...] nous ne sommes points savants; nous ne pouvons nous livrer faute d'une instruction suffisante [...] à des entretiens religieux, politiques, philosophiques, littéraires, scientifiques, artistiques, nobles, élevés, variés, intéressants, capables de nous captiver une journée entière... Eh bien! Que faire ? Chantons, c'est le plus facile. Nous chantions donc »91.

On chantait dans toutes les circonstances : aux réunions les plus officielles, pour la réception aux grades notamment, aux plus informelles, aux fêtes et bals, aux repas et banquets (au dessert), pour accueillir les arrivants, pendant les conduites, en promenade, à la veillée chez la mère, au cabaret, après les enterrements même. A tour de rôle et à l'unisson, et de préférence «à perdre haleine » (Perdiguier). De manière très codifiée, sous la direction du rouleur, avec bans frappés en cadence, ou dans la plus libre spontanéité. En tout cas dans la durée, une chanson en appelant une autre. Ceux qui ne savaient pas de chansons étaient mis à l'amende, d'un litre de vin'92 bien évidemment. « Chanter c'[était] notre passe-temps » (Boyer), chanter c'était « une habitude » et une « obligation » (Morin). La chanson était la forme idéale de l'expression de la joie, de la gaieté, du partage, du plaisir d'être ensemble, de la « chaleureuse fraternité » (Coornaert), une « manière de communier » (Poitrineau).

Le répertoire interprété était double. Les chansons profanes et populaires étaient des plus variées : chansons bachiques, sentimentales, grivoises (dans certaines limites) ${ }^{93}$, humoristiques, humanitaires, patriotiques, politiques

\footnotetext{
89 Un exemple parmi tant d'autres, ce point final des mémoires de Pierre Morin : « Alors, à votre santé, Pays et Coteries : chantons, trinquons, buvons, et bonne route », op. cit, p. 271.

90 Cités par Emile Coornaert, op. cit, p. 237.

91 Agricol Perdiguier, Mémoires..., op. cit, p. 193.

92 Témoignage de Ferdinand Flouret.

93 Selon Abel Boyer «pas de chansons canailles » à l'Hôtel de la Croix blanche, à Tours en 1903, où l'on chantait trois fois par semaine. Pas non plus de vulgarité et de gaudrioles chez la mère Duguet dans le Lyon des années 1930.
} 
parfois $^{94}$. S’y ajoutait un répertoire spécifiquement compagnonnique, très abondant, réutilisant la plupart du temps des airs connus. Nombreux sont les compagnons qui se sont essayés à écrire des chansons. Certains ont été des chansonniers très féconds et très appréciés, tels Vendôme la Clef des cœurs (Jean-François Piron), surnommé «le Béranger du compagnonnage », le tailleur de pierre Joli Cœur de Salernes (Frédéric Escolle), le cordier Languedocien l'Ami des filles (auteur du Blason et de La Canne, deux des chants les plus populaires du compagnonnage), le boulanger Rochelais l'Enfant chéri (Louis-Pierre Journolleau), le chapelier La Prudence le Bourguignon (Martin Bouchard), etc 95 . Parmi les compagnons mémorialistes plusieurs ont composé des chansons : Ménétra96, Perdiguier, Guillaumou, Boyer, Arnaud, le plus prolixe, dont le journal L'Indre-et-Loire, alors qu'il se trouvait à Tours en 1839, a publié Le Tour de France en le présentant comme " [sacrifiant] aux muses tous ses instants de loisirs ».

La chanson n'avait pas qu'une fonction récréative. Dans la première moitié du XIXe siècle, et encore au-delà, le compagnonnage était affecté par des oppositions farouches entre devoirs qui dégénéraient régulièrement en «bourrades ", bagarres, violences physiques qui laissaient parfois des morts sur le terrain. Les doleurs, c'est-à-dire les tonneliers, qui n’hésitaient pas à se servir de leurs outils tranchants, avaient la réputation d'être particulièrement dangereux. Dans son Livre du compagnonnage Perdiguier citait un article du Constitutionnel (28 février 1841) opposant l'image jugée trop idéale donnée par George Sand dans son Compagnon du Tour de France à l'affligeante réalité des brutalités innombrables : topages qui n’étaient qu' « assauts de bâtonnistes le long des chemins ", "promenades des barrières ou le bâton joue un si grand rôle "97. Il l'a confirmé dans ses Mémoires : "Le Tour de France était tout belligérant. Les compagnons étaient des guerriers, les compagnonnages des armées ennemies [...] »98. Les seules pratiques sportives évoquées dans les autobiographies, hormis la marche à pied et, mais c'est au XXe siècle : le cyclisme, la culture physique, le ski et la natation (Morin), étaient d'ailleurs les arts martiaux. À Tarare, racontait Fourquemin, aspirants et compagnons allaient tous les dimanches matin prendre les leçons de savate, de chausson, de bâton et de canne ${ }^{99}$. Perdiguier et Guillaumou l’ont observé eux aussi100.

\footnotetext{
$\overline{94}$ Par exemple des chansons bonapartistes dans les premières décennies du XIXe siècle selon le témoignage de Perdiguier. Le bonapartisme populaire s'enracinait dans les années d'enfance, pendant le Premier Empire, d'une génération de compagnons. Voir notamment sur les jeux militaires et les influences paternelles les mémoires de François-Joseph Fourquemin et A.gricol Perdiguier.

95 Le Musée du compagnonnage, à Tours, conserve une soixantaine de chansons inédites d'Alphonse Meniot (Alphonse le Berry), serrurier à Châteauroux, signées : Le forgeron de la paix. 96 Qui pendant son Tour de France a écrit une chanson sur la vie à Carpentras et une autre pour remercier les compagnons d'Auxerre de leur bon accueil.

97 P. 95-96.

98 Agricol Perdiguier, op. cit, p. 87.

99 François-Joseph Fourmequin, op. cit, p. 132. Il prenait soin d'ajouter : «[...] je ne donnais nullement dans ces sciences-là » qui lui faisaient tenir le compagnonnage « en horreur » au point de ne plus vouloir en gravir les grades.

100 Dans le meilleur des cas l'entraînement à la violence débouchait sur des combats entre champions.
} 
Les chansons " guerroyantes », « insultantes » (Perdiguier) participaient à la violence. Si parfois l'affrontement s'arrêtait à un échange de couplets haineux complétés par des grossièretés, elles avaient le plus souvent un effet de provocation et d'excitation à la bataille.

"Les compagnons ont des chants dignes des cannibales, les uns hurlent qu'ils veulent trancher la tête et manger le foie des dévorants ; les autres qu'ils veulent arracher la peau du ventre et boire le sang des gavots », se désolait Perdiguier ${ }^{101}$. Et Guillaumou renchérissait: "[...] le Tour de France chantait la gloire en alimentant les prisons et les hôpitaux »102.

C'est Perdiguier qui le premier, conscient du rôle de la chanson dans la sociabilité compagnonnique, a eu l'idée de l'utiliser comme moyen de pacification en substituant aux "chansons de secte» des "chansons de régénération» porteuses de valeurs d'amour, d'union, de fraternité, de concorde, de réconciliation. Il a fait école. Parmi ses émules on se contentera de citer Arnaud qui, après avoir été séduit « d'une façon extraordinaire » par les chansons "belliqueuses et entraînantes " s'est mis à "[chanter] la réforme " au fil des étapes de son tour de France, en rencontrant un « enthousiasme » qui l'amena à multiplier ses compositions ${ }^{103}$. Et Guillaumou, beaucoup moins fécond, dont chaque couplet du Rêve, une chanson qui lui avait été inspirée par un orgue de Barbarie jouant sous sa fenêtre, se terminait par : «Embrassez-vous fils de Soubise, de maître Jacques et Salomon »104.

Au XIXe siècle le compagnonnage s'enracinait dans le monde de la petite entreprise traditionnelle et artisanale, dont le poids demeurait très fort dans la France en voie d'industrialisation. Néanmoins il était représentatif de la classe ouvrière préindustrielle donc affectée par un certain déclin. Il était en crise, ses effectifs reculaient tandis que se développaient d'autres formes d'associations ouvrières avec le syndicalisme qui recrutait de plus en plus dans le prolétariat de la grande industrie. Y avait-il, dans ce contexte, une originalité de la sociabilité récréative, ludique, festive du compagnonnage, comme semblent le penser ses historiens, ou bien s'immergeait-elle dans la nébuleuse du loisirs populaire et ouvrier en général ?

Bien des traits décrits dans les mémoires analysés ici se retrouvent dans les autobiographies d'ouvriers qui n'appartenaient pas au compagnonnage, pour ne

\footnotetext{
101 Agricol Perdiguier, Mémoires..., op. cit, p. 145.

102 Toussaint Guillaumou, op. cit, p. 119.

103 Jean-Baptiste Arnaud, op. cit, p. 120.

104 Toussaint Guillaumou, op. cit, p. 257. Outre maître Jacques, le père Soubise et le roi Salomon sont les fondateurs mythiques du compagnonnage. En rédigeant ses Confessions en 1863, Toussaint Guillaumou exprimait un certain scepticisme sur les effets bénéfiques du nouveau répertoire compagnonnique : "On parle de progrès dans le compagnonnage ; je ne les vois que dans les chansons, et encore...» (p. 357).
} 
citer que ce type de source. Les contraintes du temps et de l'argent et les biais pour s'en affranchir, les divertissements offerts par les spectacles de la rue après la journée de labeur à Paris, la fréquentation des cabarets, et des caboulots, des bals-musette, des salles de chanson, la convivialité bien arrosée et s'épanchant dans les chansons, les noces à tout casser et en bande, la promenade ou l'excursion du dimanche, la préférence pour le mélodrame chez ceux qui allaient au théâtre... tout cela n’était bien sûr pas propre aux compagnons ${ }^{105}$. Écoutons Jean-Baptiste Dumay décrire son séjour à La Ciotat en 1861-1862 :

"[...] j'étais le boute en train de toutes les parties dans les réunions des jeunes gens de mon âge et chaque dimanche, quand ce n'était pas une grande partie de bateau à l'Ile verte (huit fois), où l'on déjeunait et dînait, c'étaient des voyages d'agrément à Marseille ou à Toulon surtout, où je retrouvais là de nombreux Creusotins avec lesquels je faisais de bruyantes parties de plaisirs »106.

Le goût des maréchaux parisiens (pas tous compagnons du reste) pour les courses de chevaux fait écho à celui des mineurs de Carmaux pour les jeux de hasard : gibier, baccarat, chemin de fer, poule au billard107. La médiocrité de la culture au témoignage de Martin Nadaud sur son garni parisien des années 1830 où n'entraient ni livres, ni journaux : « on peut dire qu'on mangeait et qu'on dormait sans jamais songer à la culture de l'esprit »108. Le compagnon charpentier parisien étudié par Frédéric Le Play en 1856109, qui promenait sa petite famille en habits du dimanche, emmenait ses enfants voir un spectacle une fois par an, allait de temps en temps dîner chez un cousin, banquetait avec ses collègues à la fin de chaque chantier grâce au "pour-boire » alloué par le patron, et élevait un oiseau, fait irrésistiblement penser à «l'ouvrier vrai » décrit par Denis Poulot. Et les Enfants de la jubilation évoqués plus haut au «vrai sublime »110. Certains aspects pourraient sembler plus spécifiques aux compagnons. La fête patronale ? Songeons à la Sainte-Barbe chez les mineurs. L' « attraction touristique » ? Sans doute oui à cause du Tour de France mais on en trouve des traces chez Dumay ou Norbert Truquin111. La chanson ? En partie parce qu'au répertoire populaire s’ajoutait celui, à contenu identitaire, spécifique au compagnonnage.

105 Voir par exemple Fabrice Laroulandie, Les ouvriers de Paris au XIXe siècle, Paris, Christian, 1997, p. 162-168.

106 J.-B. Dumay, Mémoires d’un militant ouvrier du Creusot (1841-1905), Paris, Maspero, 1976, p. 94.

107 Rolande Trempé, op. cit, p. 311-312.

108 M. Nadaud, Léonard, maçon de la Creuse, Paris, La Découverte, 1998, p. 59.

109 F. Le Play, A. Focillon, « Charpentiers de Paris. De la corporation des compagnons du devoir d'après les renseignements recueillis sur les lieux en avril et mai 1856 ", Les ouvriers des deux mondes, tome 1, 1857, p. 20-21. Il s'agissait d'un charpentier né en 1815, marié, qui avait effectué son Tour de France en 1838-1840.

110 Agricol Perdiguier a anticipé Denis Poulot en opposant le «bambocheur » aux ouvriers «plus sages » dans son « Dialogue moral et religieux entre Lyonnais et Bordelais » intégré à son Livre du compagnonnage.

111 Norbert Truquin, Mémoires et aventures d’un prolétaire 1833-1887, Paris, G. Tautin, 1974. 
La crise du compagnonnage a suscité un besoin de réforme. Les préoccupations réformatrices ont d'ailleurs inspiré les récits autobiographiques souvent (et les chansons !), en particulier chez Perdiguier et chez Arnaud lequel a présenté ses mémoires comme le fruit de ses «méditations régénératrices »112. Un rôle a-t-il été assigné aux loisirs dans les projets de rénovation? C’est incontestable chez Perdiguier où s'exprimait à la fois la revendication du loisir comme activité légitime et un désir de le moraliser :

"Les plaisirs les plus simples, les plus enfantins, les moins coûteux, sont ceux qui ont le plus de charme, qui laissent le plus longtemps, les plus heureux souvenirs »; "[...] vivons avec sagesse, avec sobriété, honnêtement, c'est ma pensée; mais un peu gaiement si possible... Dieu nous a donné la vie, ne la rendons pas malheureuse, ne l'abrégeons pas par des ennuis volontaires [...] »113.

Mais là encore, on remarquera que le souci de respectabilité à travers la moralisation des loisirs n'était pas une originalité du compagnonnage. Au reste le divertissement demeurait subordonné au labeur. Pierre Morin qui, de tous les compagnons mémorialistes, est celui qui a accordé le plus de place aux loisirs et semble leur avoir consacré le plus de temps, tranchait : « Le travail bien fait est le seul valable, et ce travail passe avant tout. Les loisirs c'est du superflu »114.

\footnotetext{
112 Jean-Baptiste Arnaud, op. cit., p. 307.

113 Agricol Perdiguier, Mémoires..., op. cit, p. 98 et 192.

114 Pierre Morin, op. cit, p. VI.
} 


\section{ESPACES DE LOISIRS DE LA SOCIÉTÉ COSMOPOLITE PARISIENNE. L’INFLUENCE DE L’ÉLITE VOYAGEUSE, 1855-1937}

Joanne VAJDA

EHESS, Paris

À partir de la seconde moitié du XIXe siècle, Paris devient une destination privilégiée pour l'élite voyageuse. Le tourisme culturel incarné par le Grand Tour (qui représente l'apogée de l'éducation aristocratique) se transforme progressivement en un tourisme de plaisirs ${ }^{1}$. Cette métamorphose est due à l'arrivée d'une génération pour laquelle le voyage est une occasion de dépenser son argent en débauches de tous genres.

Mais que doit Paris à cette élite voyageuse ? Les nouvelles formes de sociabilité de la société cosmopolite influencent-elles les divertissements? Comment l'architecture installe cette société dans l'espace parisien ?

Les loisirs deviennent une pratique sociale qui participe à l'affirmation de l'identité de l'élite voyageuse, représente un élément d'intégration à la vie sociale parisienne et constitue un facteur de distinction sociale. La société cosmopolite devient une des causes d'évolution de l'espace parisien, qui marque la culture matérielle, les structures sociales et les lieux de sociabilité de l'époque.

\footnotetext{
1 Voir Daniel Roche (dir.), La ville promise. Mobilité et accueil à Paris (fin XVIIe-début XIXe siècles), Paris, Fayard, 2000, et Harvey Levenstein, Seductive Journey. American tourists in France from Jefferson to the jazz age, Chicago \& London, The University of Chicago Press, 1998.
} 
Les lieux de rencontre destinés aux divertissements et aux loisirs prennent des formes très diverses : cafés, restaurants, brasseries de femmes (lieux où l'on est servi par des dames costumées que l'on peut emmener avec soi à la fin de la soirée), bains, maisons de rendez-vous et maisons closes, lieux de rencontre pour homosexuels, mais aussi, cercles, skating-rinks (patinoires) et attractions. Ouverts pratiquement au tout venant, ces lieux sont créateurs de sociabilités particulières, qui se distinguent de celle de salon, car c'est ici que l'on fait des rencontres « intéressantes » et que l'on goûte à la vie de loisir de la capitale. C'est également là qu'un étranger peut étaler sa puissance financière et se forger une réputation en consommant de manière ostentatoire². Pour préciser l'image de «Paris, capitale des plaisirs » on évoquera certains aspects moins connus de ces lieux ${ }^{3}$ : la relation du milieu cosmopolite au milieu interlope à travers les cercles, l'implication des étrangers dans la multiplication des skating-rinks et le rôle joué par un seul homme, Joseph Oller, dans la création des attractions parisiennes.

C'est en croisant l'histoire de l'architecture, l'histoire sociale et l'histoire culturelle qu'il est possible de saisir l'impact des loisirs sur le développement urbain, leur poids économique, la manière dont ils sont commercialisés et la façon dont ils se professionnalisent.

\section{LES CERCLES}

Entre 1870 et 1890, les cercles se multiplient dans la capitale (on en dénombre 200 en 1885)4 . Une véritable industrie naît, liée à la pratique illicite des jeux, malgré les intentions (louables) affichées par les règlements et les statuts de ces établissements, organisés en vue de distractions de société. Les fondateurs s'appliquent à démontrer, que les relations tissées entre les membres profiteront au développement des rapports de commerce et d'amitié avec différents pays et que les cercles peuvent être une source importante de revenus grâce à l'apport des voyageurs étrangers 5 .

C'est à travers ces établissements que l'accointance de la société cosmopolite avec le milieu interlope se trouve facilitée. Les noms de certains cercles sont spécialement conçus pour attirer l'élite voyageuse masculine: Cercle Franco-Américain (ancien Washington-Club), Tourist-Club, Cosmopolitan Club (ancien City-Club), Cercle de France International

\footnotetext{
2 Thorstein Veblen, Théorie de la classe de loisir, Paris, Gallimard, 1978 [1 ère éd. américaine, 1899, 1 ère éd. française, 1970].

3 Je tiens à remercier Roxane Debuisson, Florence Quignard et Goulven Guilcher qui m'ont permis de puiser des informations dans leurs précieuses collections et m'ont signalé un certain nombre de documents, ainsi que le personnel des Archives de la Préfecture de police et de la Bibliothèque Historique de la Ville de Paris, et particulièrement Geneviève Morlet, que j'ai beaucoup sollicitée.

4 Édouard Brasey, La République des jeux. Enquête sur l'univers secret des jeux d'argent et de hasard, Paris, R. Laffont, 1992, p. 156.

5 Archives de la Préfecture de Police (APP). BA 349, Cercle de France International.
} 
(provenant de la fusion du Cercle de France avec le Grand Cercle International de Paris), Cercle des Deux Mondes (résultant de la fusion du Cercle Américain avec le Hunting Club), etc. Il existe des cercles créés par des étrangers pour des étrangers, tel le New York Club, situé 19, rue Scribe et approuvé le 16 novembre 1872, dont les fondateurs sont quatre Américains (un médecin, deux rentiers et un fabricant de canons) et qui ne comprend que des sujets américains6.

La préfecture de police s’évertue à démasquer les maisons de jeux, ce qui n’est pas chose aisée, car parmi les fondateurs figurent souvent des aristocrates ou des personnalités parisiennes jouissant d'une grande notoriété et membres de cercles fameux, comme le Jockey Club ou créateurs d'autres cercles. C'est le cas, par exemple, de Loubat, fondateur du Cercle Franco-Américain et du Cercle International de France, riche Américain, originaire de Bordeaux, ayant fait fortune à la Nouvelle Orléans, ami et parent du Ministre de l’Instruction Publique et des Beaux-Arts de l'époque. D’autres Américains, parmi lesquels le dentiste de Napoléon III, Thomas Evans, figurent aussi parmi les fondateurs du Cercle Franco-Américain, tandis qu’Arsène Houssaye et le prince Alphonse de Chimay font partie des fondateurs du Cercle International de France. Des aristocrates, parmi lesquels les princes Radziwill, Galitzin ou d'Orange acceptent de se faire payer par ces cercles pour prêter leurs noms ou pour contribuer activement au recrutement des membres7.

Les exploitants des cercles (en grande majorité Français) sont souvent connus des services de police comme des joueurs douteux. De nombreux tricheurs, appelés «philosophes » ou «grecs » (terme qui fait l'objet d'une plainte en juillet 1885, adressée par le Ministre grec au Ministre des Affaires étrangères $)^{8}$, connus aussi dans les villes d'eaux, sont là pour dépouiller les crédules, en particulier le riche étranger. On y rencontre aussi les « rastaquouères », terme par lequel on désigne à l’époque les étrangers aux allures voyantes affichant une richesse suspecte.

L'accès des « grecs » aux cercles est souvent facilité par leur appartenance à l'élite voyageuse et c’est ce qui les rend difficilement repérables. On n’ose pas porter plainte contre eux, d'une part pour ne pas s'avouer dupé, d'autre part à cause des hautes relations qu'ils entretiennent. Par exemple, le prince de Formosa y Aragona, italien de Naples est expulsé du territoire français le 13 février 1908 pour cause de tricherie au Traveller's Club. Son dossier ${ }^{9}$ révèle les multiples liaisons qui existent entre l'élite voyageuse et la société parisienne. Le prince loge au 224, rue de Rivoli chez son amante, la comtesse de Castries. Au Traveller's Club, où se côtoient aristocrates étrangers, membres de familles royales, gros banquiers, négociants et industriels, le prince de Formosa entre en combinaison avec les «grecs » du grand monde, le marquis de Rudini, le marquis del Monte et le comte Leontieff, ex-gouverneur de l’Abyssinie.

\footnotetext{
6 APP BA 356, New York Club.

7 APP BA 348 et BA 349, Cercles.

8 Archives du Ministère des Affaires étrangères, Grèce, Carton 6, 129.

9 APP BA 2204, Noblesse étrangère.
} 
Lors de l'Exposition Universelle de 1878, beaucoup de cercles s'ouvrent en prévision de l'arrivée des étrangers. Les propriétaires du Cercle FrancoAméricain, malgré des problèmes de fonctionnement, affirment leur volonté « de marcher jusqu'à l'exposition, car avec leur titre et les Anglais qu'ils ont dans le comité, ils espèrent gagner beaucoup » ${ }^{10}$. Pour attirer les étrangers de passage à Paris, de nombreux cercles font la chasse aux joueurs en envoyant des invitations nominatives aux nouveaux clients des grands hôtels. Au City-Club on donne de fréquents dîners pour coopter les nouveaux joueurs. Le métier de racoleur existe et se pratique dans les grands cafés, au Café Américain, au Café de la Paix, au Café Riche et sur les boulevards. Cette pratique du recrutement perdure encore cinquante ans plus tard, ainsi que témoigne un rapport de 1932 au sujet d'Israël Khiat, dit Hai-Khiat, d'origine tunisienne, considéré comme joueur professionnel et racoleur de cercles, qui fait des longs séjours à Paris depuis 1905 et descend au Grand Hôtel, se faisant passer pour un journaliste11.

La tolérance au sujet des jeux dans les cercles, tout comme dans les casinos, s'explique par les intérêts économiques de cette pratique qui contribue à la prospérité nationale par l'intermédiaire des énormes revenus perçus par le fisc ${ }^{12}$. Les jeux de hasard sont une distraction très recherchée par la société cosmopolite. Leur suppression risque d'éloigner cette clientèle oisive, qui alimente par ailleurs d'autres branches de l'économie française (le commerce, les industries du luxe et l'hôtellerie). La plupart des cercles dont nous avons pu suivre le parcours ont une durée de vie assez courte (environ cinq ans), leur fermeture étant généralement ordonnée par la préfecture de police pour cause de grosse tricherie ${ }^{13}$.

Les étrangers de passage dans la capitale sont facilement admis dans les cercles, à l'exception des grands cercles fermés, tels le Jockey Club. C'est ce qui rend fluctuant le nombre de membres. Le Cercle Franco-Américain compte en 1889, 351 membres permanents et 141 membres temporaires. Quelques années plus tard on dénombre 450 membres permanents et 900 membres temporaires. On vient au cercle en début d'après-midi pour faire son courrier et lire la presse, on y dîne et on reste jusque tard dans la nuit pour jouer aux cartes. Les cercles délaissés par la société cosmopolite périclitent.

La plupart des cercles se trouvent dans les quartiers les plus fréquentés de la capitale ${ }^{14}$ et sont aménagés de manière somptueuse. L'exploitant du Grand Cercle International de Paris envisage de l'installer rue du Faubourg SaintHonoré dans l'hôtel particulier des Pereire et de le doter d'un cabinet de

\footnotetext{
10 APP BA 348. Cercle Franco-Américain.

11 Archives du Ministère des finances. B 33241, Activités des étrangers dans les milieux financiers, 1920-1946.

12 Jules Maurille, «Les cercles et les casinos ", in Les Échos de Paris, n¹9, septembre 1885, p. 498-501, et Archives de la Chambre de Commerce et d'Industrie de Paris. V,1.00 (2), Maisons de jeux. 1805-1933.

13 Voir par exemple la faillite du City Club, Archives de Paris. D11U3-953, Faillite 7709.

${ }^{14}$ Le Cercle Franco-Américain se trouve 4, place de l'Opéra, le Tourist-Club est au 31, av. de l’Opéra, le City-Club au 11, bd des Italiens, le Cercle des Deux Mondes s'installe 30, rue de Grammont, etc.
} 
lecture pourvu d'une bibliothèque cosmopolite, de fumoir, restaurant, café, salle d'escrime, billards, jeux d'adresse, grande salle de fêtes, etc. Ne pouvant louer ce lieu, il établit le cercle au 1er étage du 6, boulevard des Capucines, où les travaux d'aménagement durent cinq mois, de mai à octobre 1878, ce qui laisse supposer que l'aménagement est tout aussi somptueux que celui projeté pour le Faubourg Saint-Honoré.

\section{LES SKATING-RINKS}

Déjà en 1813, la Glacière (derrière la gare du chemin de fer de Sceaux) est très recherchée par les amateurs de glisse. "Pas d'étranger qui traversât Paris sans aller la visiter [...]; on y revêtait des costumes originaux, exotiques pour la plupart; le polonais y était en faveur »15. Sous le Second Empire le patinage est à la mode. On patine sur les lacs gelés du Bois de Boulogne et du Bois de Vincennes, sur le bassin de la Villette ou dans les bassins gelés des jardins publics (aux Tuileries, au Palais-Royal ou au Luxembourg). Mais c’est pendant la IIIe République que ce sport prend toute son envergure16. On construit des espaces spécialement destinés à la pratique du patinage sur glace ou du patinage à roulettes, les skating-rinks ${ }^{17}$. Lieux de plaisirs très recherchés, aujourd’hui oubliés, ils se caractérisent par une architecture éphémère.

C'est vers 1870, à l'initiative de la colonie américaine de Paris, que l'on établit un rink, rue Jean Goujon, pouvant contenir de 600 à 800 patineurs. Lieu de rendez-vous de l'élite des Américains, Canadiens et Russes, c'est surtout un endroit où l'on se rend pour flirter.

Entre novembre 1875 et décembre 1876, une frénésie s’empare de Paris ; on aménage une quinzaine de skating-rinks dans toute la ville et pour toutes les classes, ce qui est peu comparé à Londres qui en possède une quarantaine, sans compter ceux des faubourgs (une vingtaine) ${ }^{18}$.

Parmi les établissements les plus connus s’adressant à une clientèle aisée, où les étrangers de distinction dominent, on compte le Skating du Cirque des Champs-Élysées, celui de la place d’Eylau (future place Victor Hugo), le Skating Palais (av. Bugeaud 30-34, 55, av. du Bois de Boulogne et rue Picot), le Skating Rink du Faubourg Saint-Honoré (au n¹30) et celui de la Chaussée d'Antin (15, rue Blanche, 16, rue de Clichy).

\footnotetext{
15 BHVP, Actualités, Série 106, Coupure de presse sans titre, 12 janvier 1914, Le costume de « lancier » polonais est décrit dans L'Autorité, $1^{\mathrm{er}}$ janvier 1888.

16 Paul Bonhomme, Les sports pour tous. Le patinage à glace et à roulettes, Paris, Nilsson, s.d. [1911], p. 17.

17 Le terme est directement repris de l'anglais où rink désigne plus précisément une patinoire, à la différence du ring qui est une enceinte où se déroule une activité sportive. Le mot " patinoire » apparaît en français en 1897, mais le terme skating-rink continue à être employé, ainsi que ses dérivés : skatiner, skatinage et skatineur.

18 Henry Mouhot, La rinkomanie, Paris, Amyot, s.d. [2e éd.,1876], p. 91.
} 
Les étrangers, notamment Anglais et Américains, sont pratiquement toujours impliqués dans la création de ces lieux. Des sociétés se constituent, parfois même en dehors du territoire français, pour les gérer, les directeurs, les employés et même le matériel étant souvent d'origine étrangère ${ }^{19}$. Les noms de quelques hommes d'affaires d'origine étrangère, déjà présents à Paris dans d'autres industries, reviennent régulièrement. Charles Goodwin, d'origine américaine, fabricant de machines à coudre mais aussi de patins, fait partie des sociétés qui exploitent le skating du Cirque et celui du Luxembourg20. Harding, concessionnaire de tramways 21 est aussi fondateur de la société qui gère le skating de la place d'Eylau, tout comme William Morris, propriétaire de plusieurs skating-rinks en Angleterre qui figure aussi parmi les commanditaires de la société qui exploite le Skating-rink du Cirque des Champs-Élysées.

Le voisinage immédiat n’accueille pas toujours favorablement la construction de ces lieux. Le Skating-Rink de la place d'Eylau, qu'une compagnie anglaise souhaite ouvrir sur le terrain de l'ancien hippodrome, fait l'objet de protestations de la part du curé de la paroisse Saint-Honoré. La préfecture de police, soutenue par deux conseillers municipaux (Deligny et Denis) et par le vice-président du Sénat (Duclerc) est favorable au projet, sous prétexte que :

«Le quartier désire la création de ce dernier établissement. Presque uniquement traversé par de larges avenues, et par suite, un peu désert, un peu mort, il compte que le Skating Rink lui apporterait un peu d'animation, un peu d'activité commerciale »22.

L’installation des patinoires nécessite généralement la location ou l’achat de surfaces importantes de terrain dans la capitale. Le skating-rink de la Chaussée d'Antin est ouvert le 30 décembre 187623 par une compagnie anglaise qui paie environ $850000 \mathrm{~F}$ à la Ville de Paris pour l'acquisition d'un terrain de $4200 \mathrm{~m}^{2}$ et une somme équivalente pour les travaux. Les sociétés gérantes se lancent généralement dans d'énormes dépenses d’installation, ce qui mène paradoxalement à la faillite, puis à la disparition de ces lieux.

Les espaces sont luxueux et confortables, généralement conçus par des architectes, qui participent à la création d'une architecture spécifique répondant à ce nouveau programme. Le Skating-rink du Faubourg SaintHonoré est l'œuvre d'architectes français (Chatenay et Roux). Les

\footnotetext{
19 L’Américain James Plimpton possède dès 1865 un brevet d'invention pour la fabrication des patins à roulettes employés au Skating Palais et au Skating du Faubourg Saint-Honoré. Conclusions pour la Compagnie Paris Skating-Rink (limited) demanderesse Delacourtie contre Frederick-Adolphus Spiller défendeur Caillet, Tribunal Civil de la Seine, $3^{e}$ Chambre, [Factum], Paris, A. Hennuyer, [1880].

20 Archives de Paris. D11U3 - 859. Faillite 3396.

21 Il est aussi l'inventeur des locomotives à vapeur qui portent son nom et fonctionnent à partir de 1876 sur les lignes de la compagnie Tramways Sud, dans la banlieue sud de Paris. Cf. D. Larroque, M. Margairaz, P. Zembri, Paris et ses transports XIXe-XXe siècles. Deux siècles de décisions pour la ville et sa région, Paris, Recherches/AHICF, 2002, p. 103 et 370.

22 A.P.P. DA 129. Skating Rink des Champs-Élysées, Rapport du 15 mai 1876.

23 L'emplacement correspond à celui de la Folie Richelieu (1730), du Deuxième Tivoli (18111826) et à celui du Casino de Paris (1890).
} 
constructions sont en pans de bois apparent et vernis et «les enduits extérieurs sont décorés de bandes peintes simulant des assises alternées de briques »24. La salle est en style russe et parmi les espaces annexes (qui font $800 \mathrm{~m}^{2}$ ) on compte des cabinets de lecture et des salons d'une grande élégance (Ill. 1 et 2).

C'est l'architecte Ydée, secondé par Sotty, qui conçoit le rink de la Chaussée d'Antin d'une surface de $1482 \mathrm{~m}^{2}$. La construction, d'une grande hardiesse, rappelle les projets d'Hector Horeau : entièrement métallique, d'une hauteur qui atteint 15,40 m, elle comprend 110 colonnes en fonte creuse et est exécutée en moins de quatre mois (Ill. 3 et 4). La ventilation se fait à l'aide de châssis mobiles situés dans les combles. Un promenoir large de 3,20 m sépare la piste d'une rangée de loges. Un bar à l'anglaise permet aux patineurs de se faire servir debout, sans quitter le rink. Sous une rotonde ornée de glaces se trouve un café. La décoration, sobre, à cause de la rapidité d'exécution, rappelle le décor de théâtre, étant peinte sur toile. L'orchestre est à mi-hauteur des colonnes, au-dessus de l'entrée de la rue Blanche.

Des entreprises très connues participent à la construction de ces lieux : la Compagnie Générale des asphaltes de France réalise le rink du Skating Palais, les Grands Magasins du Louvre et les Magasins de la Paix procurent l'ameublement du Skating du Luxembourg, tandis que Walcker, fabricant d'articles de voyage, 3, place de l'Opéra, fournit les nattes qui ornent les murs des salons du Skating Palais, les tables en bambou, les sièges en rotin et les billards chinois ${ }^{25}$. Voici comment on présente cet établissement, considéré comme l'un des plus beaux du monde, lors de sa réouverture le 9 mai 1877 :

«Le Rink entièrement refait, la création d'un salon fumoir, d'un salon de conversation et d'un salon spécialement affecté à MM. les abonnés, salon où la richesse de l'ameublement le disputera à la décoration artistique et à la profusion d'objets d'art qui seront exposés, nous donnent la certitude que le Skating Palais sera le seul établissement de Paris digne du public d'élite qui avait bien voulu le prendre sous son puissant patronage ${ }^{26}$.

On ne pratique guère le patinage pour des raisons médicales, malgré ce que l'on veut faire croire, mais pour la distraction qu'il procure, «pour les rapports sociaux qu'il engendre et l'occasion de parader »27. C'est le nouveau remède contre l'ennui, évitant à ceux qui le pratiquent la tyrannie de la flânerie monotone sur les boulevards. C'est pourquoi, les skating-rinks deviennent un complément des bals. Le bal Bullier (carrefour de l’Observatoire) (Ill. 5), mais aussi Mabille (av. Montaigne), le Casino (rue Cadet) ou encore les Folies Bergère en possèdent un. Cette association fonctionne toujours à l'ÉlyséeMontmartre (bd. Rochechouart) entre 1908-1916. L’orchestre est un ingrédient indispensable de ce type de distraction. Au Skating Palais, par exemple, se produit en 1878 un orchestre de 65 musiciens sous la baguette de Jules Javelot.

\footnotetext{
${ }^{24}$ La Semaine des Constructeurs, n³, 29 juillet 1876, p. 30-32, « Skating-rink du Faubourg SaintHonoré, MM. Chatenay et Roux, architectes » par Roux.

25 Archives de Paris. D11U3 - 877, Faillite 4027.

26 BHVP, Actualités. Série 106, Lettre aux abonnés, mai 1877.

27 Henry Mouhot, op. cit., p. 13.
} 
Illustration 1 : Skating-Rink rue du Faubourg Saint-Honoré. Façade

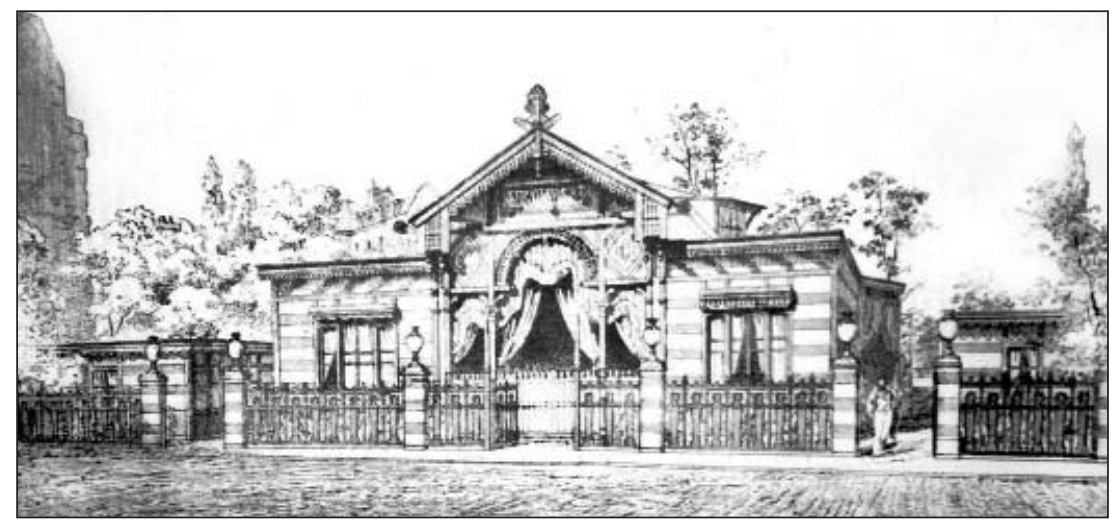

La Semaine des constructeurs, 1876

Illustration 2 : Skating-Rink du Faubourg Saint-Honoré. Plan

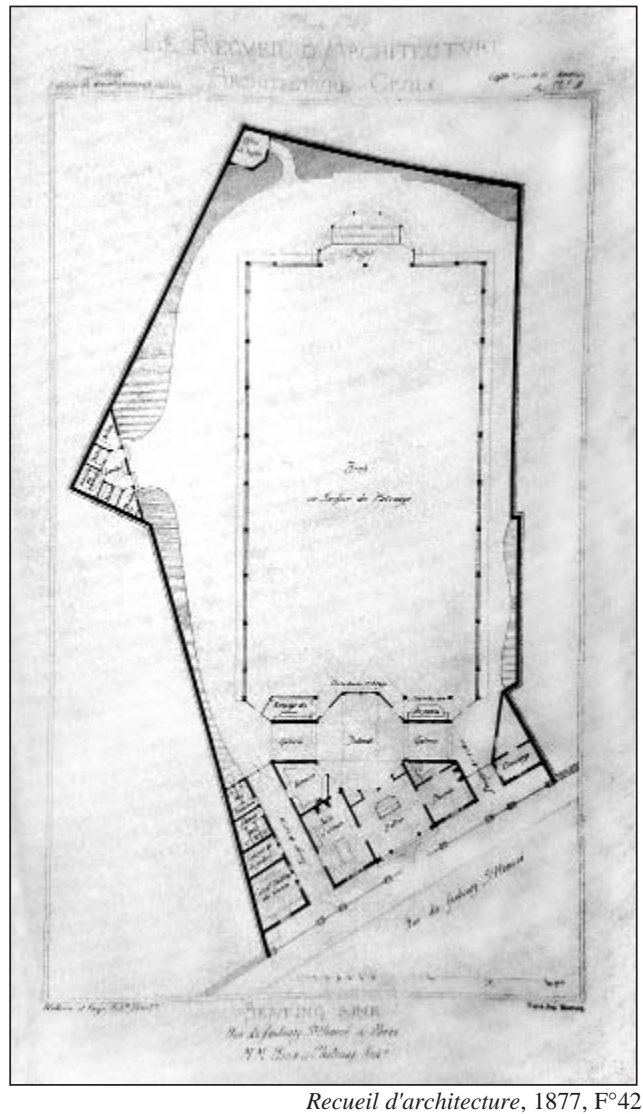


Illustration 3 : Skating-Rink de la Chaussée d'Antin

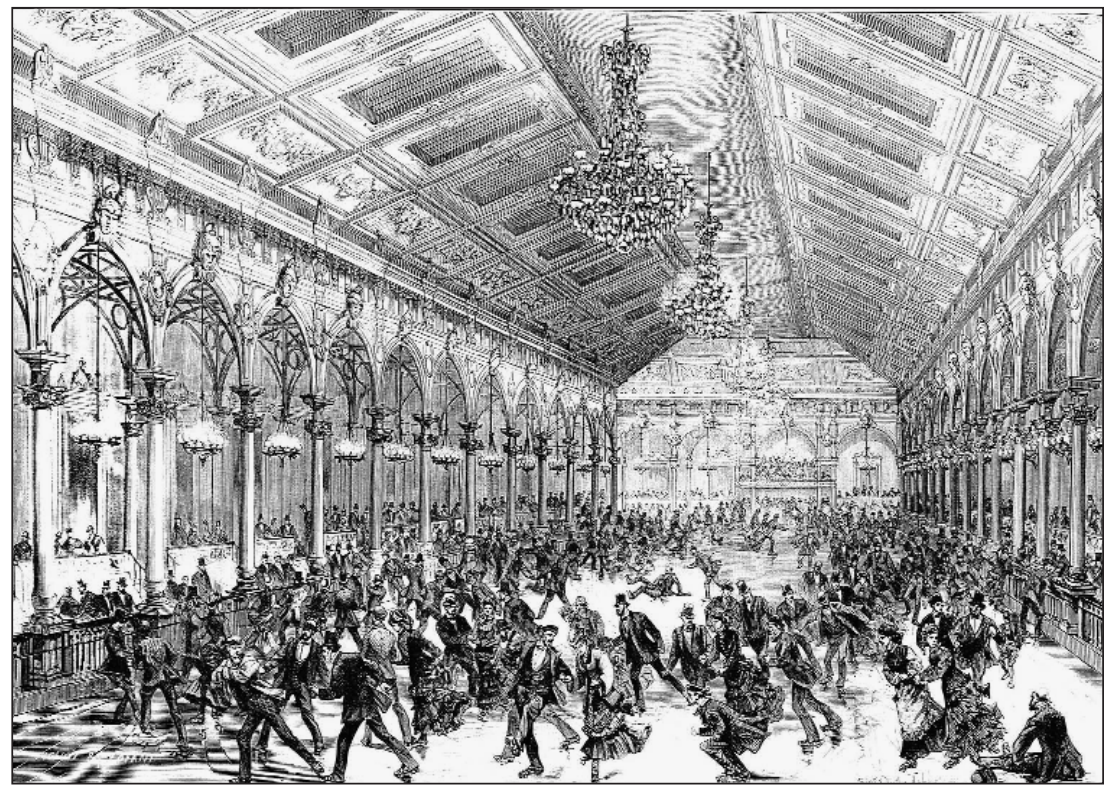

L'Illustration, 23 décembre 1876

Illustration 4 : Skating-Rink de la Chaussée d'Antin

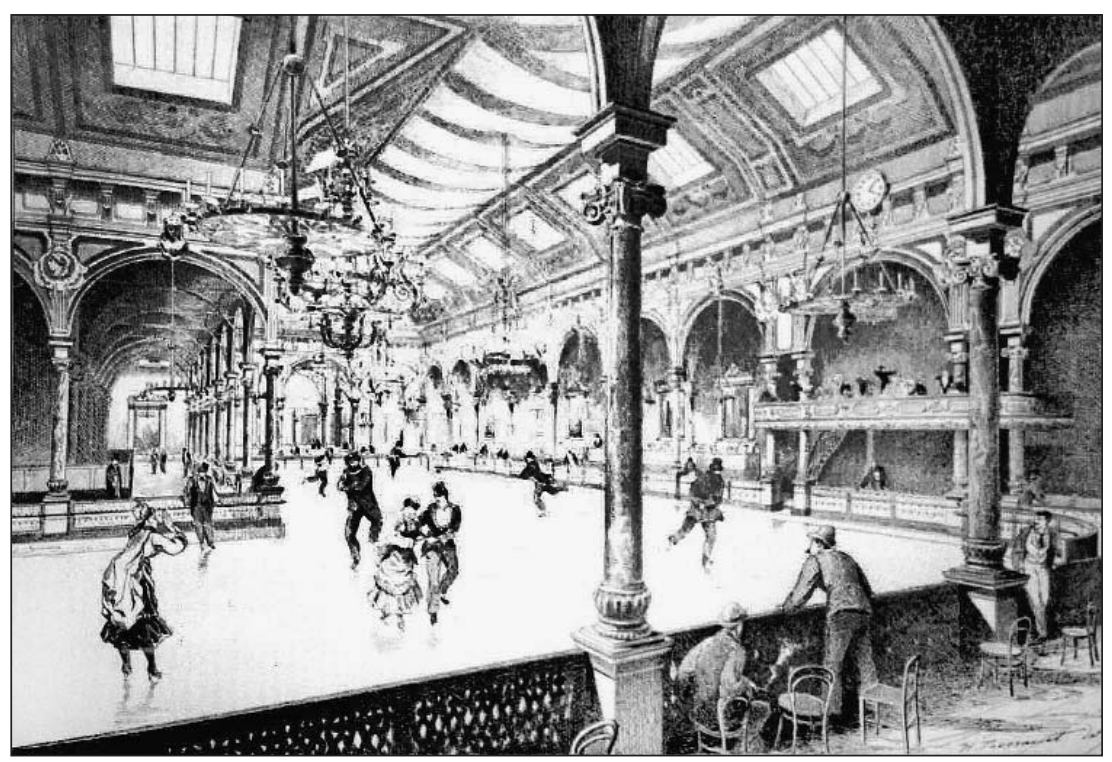




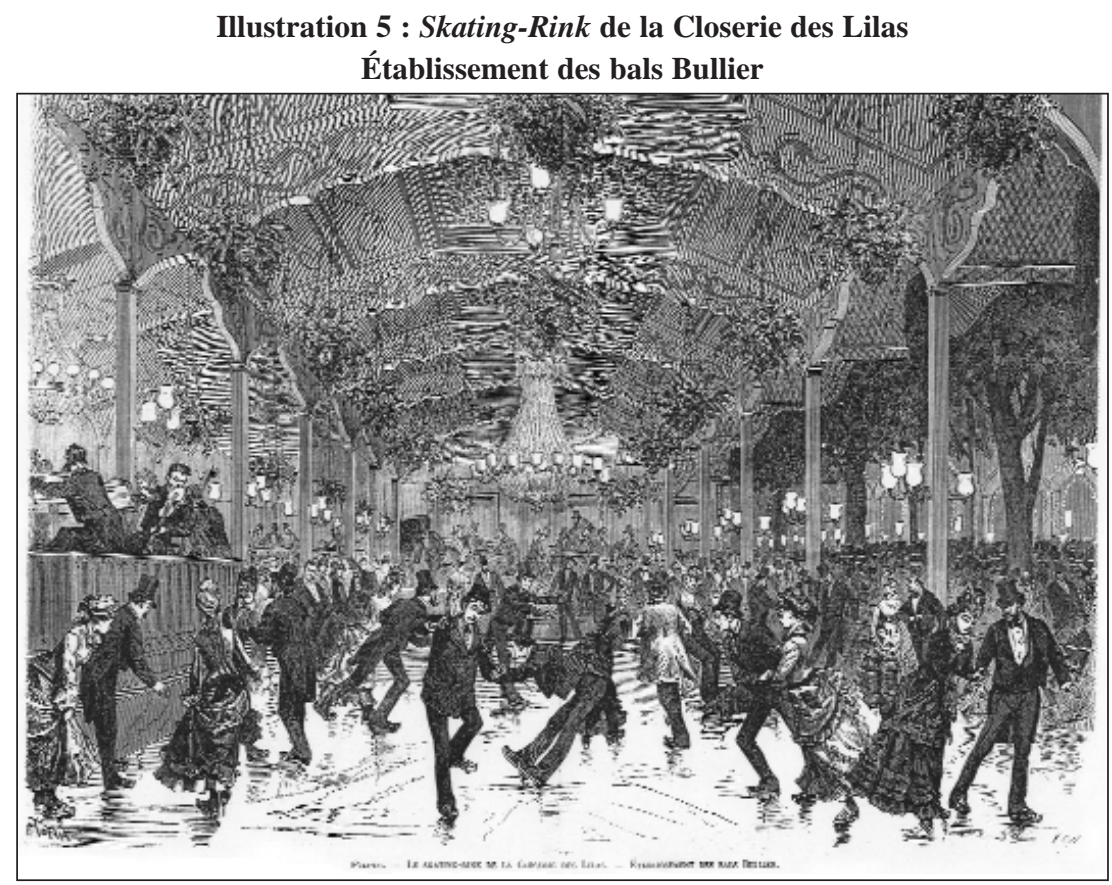

Illustration, 15 avril 1876

La police estime à 8000 et 10000 le nombre de personnes venues à l'inauguration du Skating Palais le 23 avril 1876. Entre 1000 et 2500 personnes sont présentes les jours habituels. Son public appartient à l'aristocratie, à la bourgeoisie et au grand demi-monde. Les rapports de police notent la présence du ministre des Finances, du ministre de l'Agriculture et du Commerce, ou encore d'Émile de Girardin et de Don Carlos. Les fêtes, une constante des skating-rinks, se succèdent, comme le bal de charité organisé par la princesse Rattazzi, le 15 juillet 1876, dont les billets sont en vente, entre autres, au Grand Hôtel. Lors d'une fête américaine on enregistre 950 entrées. De nombreux membres, Anglais et Américains, du Comité de l'Union FrancoAméricaine - fondé dans le but de réunir les fonds nécessaires à la construction de la Statue de la Liberté - sont présents 28.

Les grandes demi-mondaines, dont Cora Pearl, Blanche Hardy, Gabrielle Wiart et Hortense Dorsay, fréquentent assidûment le lieu. Lors d'une grande fête de nuit, c'est Adeline Mettais, femme galante qui gagne la première course de vitesse des dames 29 .

Par ailleurs, les rapports de police mentionnent la présence de nombreux étrangers de passage, que les publicités qui paraissent dans les guides (Ill. 6)

28 APP - DA 130, Skating Palais, Rapport 6 juillet 1876 et lettre du baron Baillot, 10 juillet 1876. ${ }^{29}$ APP - DA 130. Skating Palais, Rapport 13 juin 1876. 
incitent à s’y rendre seuls ou accompagnés de leurs familles, amenés par des équipages luxueux. Parmi eux, «deux hindous vêtus de leur costume national et appartenant à la suite du prince Yung, ont chaussé des patins et se sont lancés sur le rink, mais peu habitués à ce genre d'exercice, ils ont dû y renoncer aussitôt ${ }^{30}$.

\section{Illustration 6 : Publicité pour le Skating Palais}

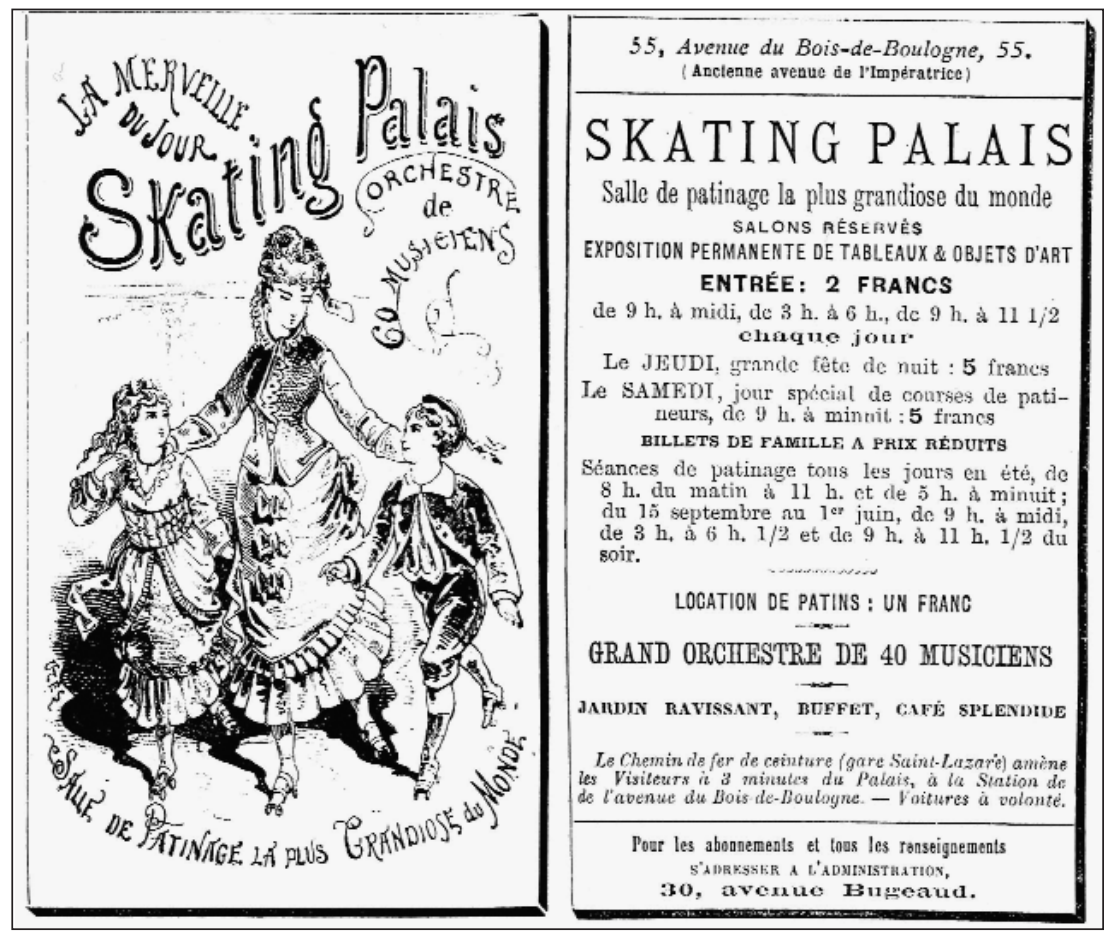

Guide Conti, Belgique en poche, 2e éd. 1877

Dans les années 1890, la Gran Plaza de Toros (60, rue Pergolèse), après les courses de taureaux, attire les patineurs par sa glace artificielle. Le sol a été creusé, une cuvette en béton cimenté a été coulée et $16 \mathrm{~km}$ de tuyaux de fer réfrigérants placés dessus. La couverture provisoire de l'espace est un chef d'œuvre de charpente, avec des fermes en bois de 56 m de portée31.

En 1893 est créé le Palais de Glace (Ill. 7), aux Champs-Élysées, une salle circulaire de $40 \mathrm{~m}$ de diamètre et $14 \mathrm{~m}$ de haut. Durant l'été la salle fonctionne comme salle de concerts et spectacles ou manège vélocipédique. En 1897, Paul Bernard est nommé directeur, après avoir assuré pendant près de 20 ans

30 APP-DA 130. Skating Palais, Rapport du $1^{\text {er }}$ août 1876.

31 L'Illustration, 28 décembre 1889. 
la direction d'autres lieux d'amusements : l'Eldorado, l'Éden Théâtre, les Montagnes Russes et le Moulin Rouge ${ }^{32}$.

Illustration 7 : Palais de Glace, saison 1922-1923

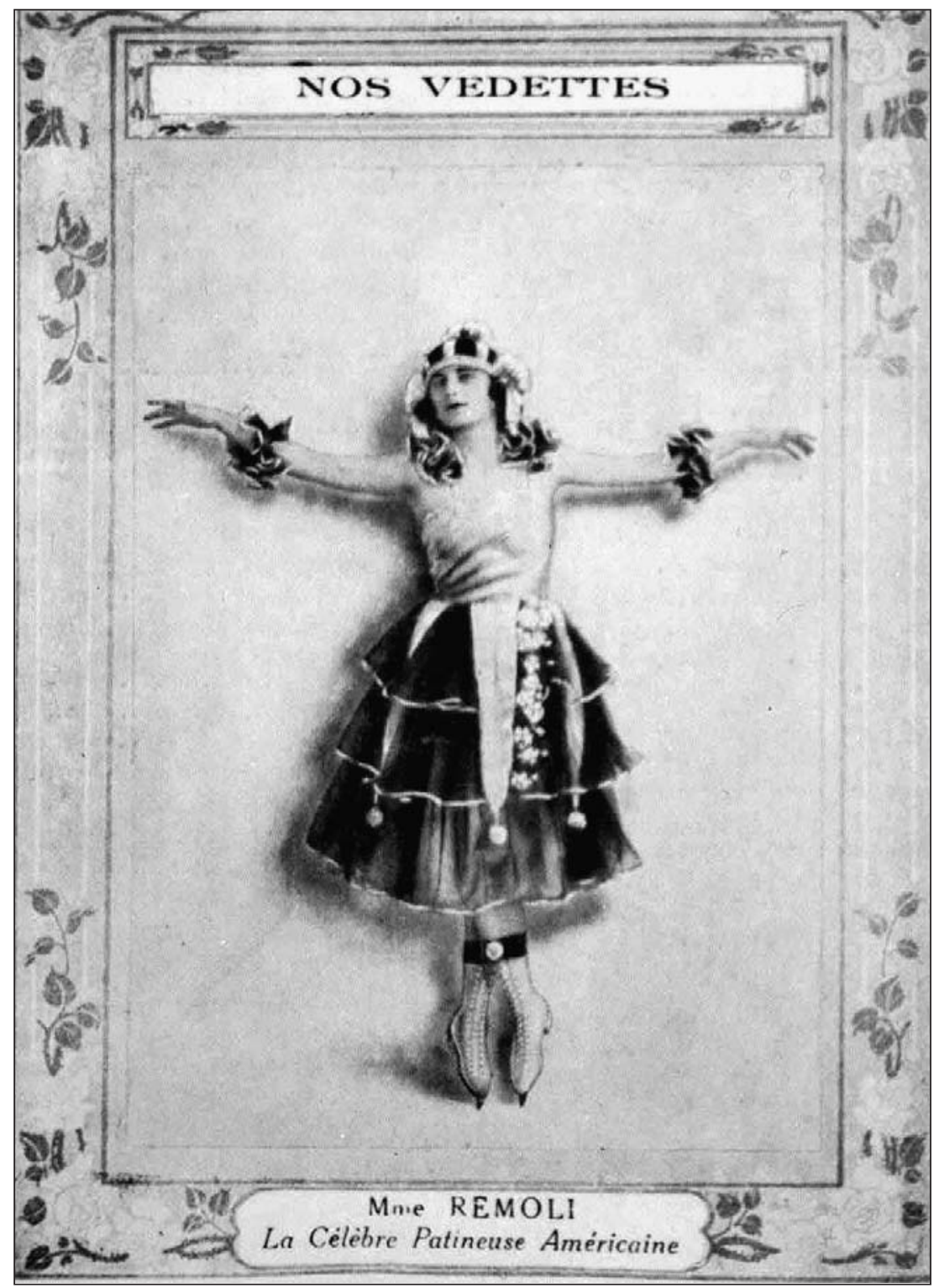

BHVP, Actualités, Série 106

32 BHVP - Actualités, Série 106, Notice sur Paul Bernard. 
Parallèlement, on patine sur de la glace naturelle au Bois de Boulogne, au Vésinet ou à Versailles. La Ville de Paris devient entrepreneuse de patinage à partir de 1893, accordant une concession sur le lac supérieur du Bois de Boulogne pour l'aménagement d'une enceinte de patinage, dont une partie des recettes lui revient. Des traîneaux de style russe sont mis à la disposition du public, constituant également une source de revenus pour la Ville. C'est visiblement une affaire profitable, puisque les concessions sont adjugées en 1900 pour cinq ans contre $37100 \mathrm{~F}$ par an ${ }^{33}$. Les Parisiennes et les étrangères y affluent et rivalisent d'élégance. Parmi les noms cités par Le Figaro du 19 janvier 1914 : le prince et la princesse Wolkonski, la baronne de Gunzbourg, la marquise de Pomereu, le duc de Morny, le prince de Kapurthala et Porfirio Diaz.

Les patins à roulettes ne sont pas pour autant oubliés, comme preuve, l'ouverture le 21 décembre 1892 du Columbia Elite Roller Skating-Rink, tenu par Ridgely et Simmons, dans le Palais des Beaux-Arts, au Champ de Mars, avec une entrée par la Galerie Rapp ${ }^{34}$. Le parquet s'étend sur $3500 \mathrm{~m}^{2}$ et l'aménagement coûte plus de $250000 \mathrm{~F}$.

Autour de 1910, de nouveaux établissements apparaissent, dont on retrouve souvent les publicités dans les guides touristiques. Ces lieux possèdent les ingrédients désormais indispensables des loisirs parisiens : le bar américain et le tea-room.

L'Hippodrome Skating Rink (boulevard de Clichy) est inauguré le 1er octobre 1909 par C. P. Crawford et F. A. Wilkins, selon lesquels c'est l'endroit « où les touristes et voyageurs de toutes les parties du monde civilisé affluent et jettent à pleines mains leur or »35. C'est probablement ce qui les décide à ouvrir en janvier 1910 un second établissement l'American Skating-Rink (39-41, rue Saint-Didier, place Victor Hugo). Le Luna Park possède aussi un skating-rink, dont on parle beaucoup dans la presse lors de sa réouverture en novembre 1910.

Il semble que la Première Guerre mondiale met fin à la construction des patinoires, mais un article paru dans le Figaro en 1876 prévoit la tournure que prendra cette distraction 36 :

«Pour peu que cette mode continue, j'entrevois même le jour où l'asphalte de nos rues et de nos boulevards sera sillonné par les skatineurs...Chaussés de patins à roulettes et se tenant à la main, nous verrons chaque soir des bandes de gommeux et de gommeuses se rendre au Bois... ".

\section{LES ATTRACTIONS}

Les attractions connaissent un grand succès auprès du public parisien et auprès des étrangers de passage. Un nom, aujourd'hui oublié, ne peut pourtant

\footnotetext{
33 Le Temps, 29 décembre 1892, L’Éclair, 5 janvier 1893, et Le Petit Journal, 30 décembre 1899.

34 BHVP - Actualités, Série 106, Invitation.

35 BHVP - Actualités, Série 106, Lettre, s.d. signée Crawford et Wilkins.

36 Cité par Henri Mouhot, op. cit., p. 121.
} 
être séparé de l'histoire des spectacles parisiens. C'est celui de Joseph Oller, espagnol d'origine catalane, arrivé en France en 1841 à l'âge de deux ans. La capitale française lui doit l'invention du PMU (Pari Mutuel Urbain) en 1867, mais aussi un certain nombre de créations, et non des moindres, qui représentent aujourd'hui encore l'image de Paris aux yeux des étrangers.

Le Pari Mutuel étant déclaré illicite en 1875, l'agence, située au 28 boulevard des Italiens, est aussitôt transformée par Oller en une salle d'attractions où le public se presse, les Fantaisies Oller. En 1878, l'endroit devient le Théâtre des Nouveautés où triomphe Feydeau.

En 1885 Oller ouvre la Grande Piscine Rochechouart, $600 \mathrm{~m}^{2}$ et 500 cabines. L'année suivante il inaugure une autre piscine rue Saint Honoré, près de la place Vendôme. À l'emplacement du Panorama de Reichshoffen ${ }^{37}$, dont la façade, le vestibule et l'escalier sont dus à Garnier, Oller, conservant tout ceci, installe les Arènes nautiques, qui devient le Nouveau Cirque, cirque en hiver, piscine en été. Un mécanisme compliqué fait descendre la plateforme du cirque pour donner passage à l'eau que toutes sortes de dispositifs ingénieux chauffent ainsi que la salle. Un décor de glaces et de lustres, des moulures dorées et des tapisseries pourpres font que l'endroit passe aux yeux de ses contemporains pour la $8 \mathrm{e}$ merveille du monde.

Il élève en 1888 au 28, boulevard des Capucines, dans le centre de Paris, à proximité du Grand Hôtel et de l'Opéra, une " vaste halle ayant entrée sur rue par une barrière mobile à claire-voie et couverte à hauteur d'un $3 e$ étage »38 qui abrite les Montagnes Russes, véritable parc d'attractions originales pour Parisiens et touristes. Les journaux le présentent comme un des endroits les plus trépidants de Paris. Outre les montagnes russes proprement dites, construites en Angleterre39, on y trouve : chevaux à ressort, tir au javelot, débit de bière, orchestre, tir oriental, théâtrophone, labyrinthe mauresque, silhouette suédoise, oracle parisien, nègre automatique, miroirs grotesques, etc. Oller remplace la construction démolie en 1892, par la première salle de music-hall parisienne, l'Olympia, installée au rez-de-chaussée et une grande salle au sous-sol où se trouve le musée Oller, un cabinet de figures de cire.

Entre temps, en 1889, Oller construit le Moulin Rouge, qui devient très vite pour beaucoup d'étrangers le symbole de Paris. La salle de bal est transformée en music-hall en 1903. Les personnalités étrangères qui le fréquentent sont trop nombreuses pour être énumérées.

En 1892, il ouvre le Jardin de Paris (Ill. 8), un parc d'attractions pour clientèle distinguée, relié par un service d'omnibus spécial avec le Moulin Rouge.

Si certains des lieux crées par Oller existent toujours, son étonnante capacité à multiplier les loisirs parisiens a un peu été oubliée aujourd’hui.

37 Installé à l'emplacement du cirque Franconi, puis du Bal Valentino.

38 Archives de Paris, D1P4-185, Calepins de cadastre, Bd. des Capucines.

39 Ferran Canyameres, L’homme de la Belle Époque, Paris, Éd. Universelles, 1946, p. 68. 
Illustration 8 : Les Anglais au Jardin de Paris, dessin de Couturier

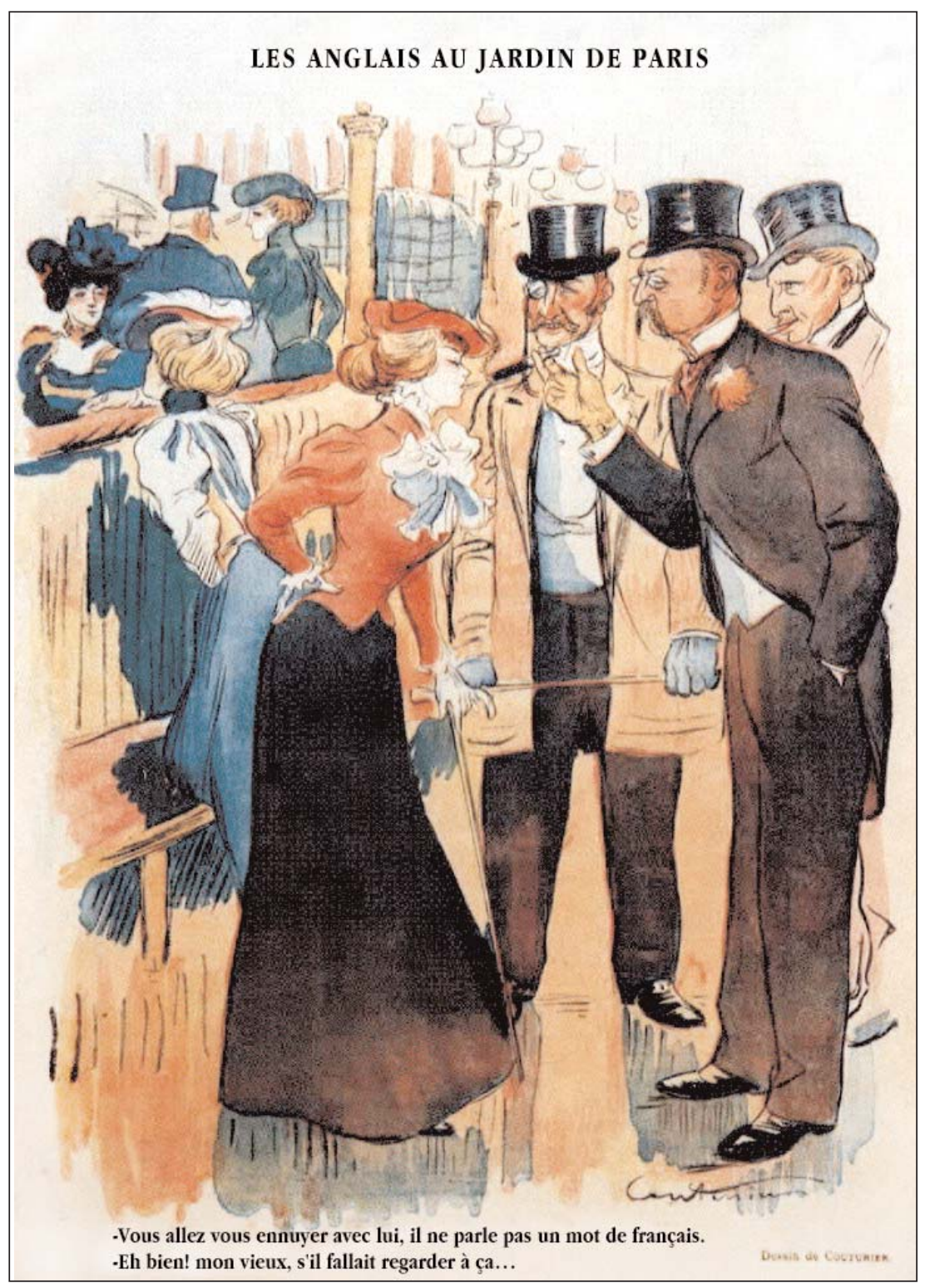

Le Rire, $\mathrm{n}^{\circ} 246,22$ juillet 1899 
On s’aperçoit à travers une telle analyse que les lieux de loisirs, souvent liés au cosmopolitisme relèvent non seulement de la frivolité et du voyage mais aussi de la spéculation foncière et de l'activité économique. Les entrepreneurs répondent à la demande de l'élite voyageuse qui exige une ville conforme à ses attentes nées des récits de ses prédécesseurs. C’est ce qui peut expliquer le fait que l'initiative de multiplier les loisirs appartient souvent aux étrangers. Ces espaces de rencontre, où les conventions sont beaucoup moins rigides, donnent aux touristes l'impression de goûter à la vie parisienne. Paradoxalement, ces lieux, dont la naissance et l'existence sont souvent dues aux étrangers, participent à la construction de l'identité parisienne, certains d'entre eux devenant l'emblème de Paris, capitale des plaisirs.

\section{BibliographiE :}

\section{Cercles :}

Yriarte Charles, 1864, Les cercles de Paris. 1828-1864, Paris, Librairie parisienne, $311 \mathrm{p}$.

Cavaillé Augustin, 1875, Les filouteries du jeu, révélations, Paris, Ghio, 353 p.

Agulhon Maurice, 1977, Le cercle dans la France bourgeoise. 1810-1848. Étude d'une mutation de sociabilité, Paris, A. Colin, 107 p.

\section{SKATING-RINKS :}

Chapus Eugène, 1854, Le sport à Paris, Paris, L. Hachette et Cie, 316 p.

Dolivet Charles, 1876, Le skating-rink. Ouvrage sur l'art du patinage et tous les exercices et agréments qui se rattachent aux plaisirs de cette récréation, Paris, Impr. du Skating-Rink, 48 p.

Mouhot Henry, La rinkomanie, Paris, Amyot, s.d. [2e éd. 1876], 175 p.

Bonhomme Paul, Les sports pour tous. Le patinage à glace et à roulettes, Paris, Nilsson, s.d.[1911], 125 p.

[Exposition. Paris, Mairie du XXe arrondissement. 1984]. Deux siècles d'architecture sportive à Paris, piscines, gymnases..., Paris, Délégation artistique à la Ville de Paris, 1984, 81p.

\section{Attractions :}

Canyameres Ferran, 1946, L’homme de la Belle Époque, Paris, Éd. Universelles, $161 \mathrm{p}$. 


\section{L’IMAGE D’UNE VILLE. LE REGARD SUR BRÊME D’UN PHOTOGRAPHE AMATEUR : HERMANN KIPPENBERG (1863-1940)}

Christian JoschKE

EHESS, Paris

Dans l'étude des modalités de l'occupation de l'espace ou de la circulation des hommes, l'historien s'est penché avec raison sur les formes de traduction de l'expérience du territoire ${ }^{1}$. Elles nous informent en effet sur l'imaginaire géographique d'une époque : elles représentent une distanciation des acteurs par rapport à leur expérience du parcours, elles déploient les symboles qui font réagir les sensibilités. Or, parmi ces formes de traduction de l'expérience, l'image possède un statut essentiel pour au moins trois raisons. Tout d'abord parce qu'avec l'instantané photographique, l'image ponctue de manière régulière le parcours et s'inscrit dans le moment même de l'appropriation de l'espace. Ensuite, parce qu'elle permet aux voyageurs d'alors d'afficher les preuves de leur présence passée sur le territoire ; parce qu'elle sert la reconstruction sensible de l'expérience vécue, en constitue la mémoire visuelle. Enfin, parce qu'elle fut considérée par les voyageurs comme un outil de documentation et de description qui, se passant du langage, établit une relation plus immédiate avec le référé2.

\footnotetext{
1 Daniel Roche, Humeurs vagabondes. De la circulation des hommes et de l'utilité du voyage, Paris, Fayard, 2003 : «Chapitre premier. La production des récits de voyage », p. 19-48, qui renvoie à une historiographie abondante sur le sujet.

2 Claire Bustarret, «Vulgariser la civilisation d'après la photographie », in Stéphane Michaud (dir.), Usages de l’image au XIXe siècle, Créaphis, 1992, p. 51-58.
} 
C'est pourquoi, il importe d'exploiter la singularité de cette source en mesurant la part de l'image, son rôle et sa légitimité dans la représentation du territoire. Il importe également de s'interroger sur les répertoires formels investis dans cette représentation, et de repérer leur influence sur cette légitimation des images.

La diffusion du loisir photographique à partir des années 1890, notamment en Allemagne apparaît comme une étape majeure dans l'évolution des modalités d'appropriation de l'espace. Facilité par le développement de la photographie instantanée et de la plaque sèche, par la légèreté du matériel et par la diffusion des manuels d'initiation, il s'est surtout imposé dans le voyage ou l'excursion pour documenter tantôt des régions nouvelles tantôt des sites plus familiers ; voué à représenter un territoire, ce loisir contribue donc bien souvent aussi à renforcer une identité locale. L'exemple d'un photographe amateur de Brême, Hermann Kippenberg (1863-1940), nous permet de constater cette double vocation de la photographie: le fonds aujourd'hui conservé aux Landeshauptarchiv de Brême recèle à la fois des images d'excursions touristiques et des vues de Brême ${ }^{3}$. Cette double vocation nous est rendue d'autant plus sensible que Brême occupe une place particulière sur le territoire allemand. Séparée de son port, Bremerhaven, par plus de cinquante kilomètres, elle a su pourtant garder les caractères d'une ville hanséatique, distincte du reste de l'espace allemand - elle ne s'agrège à la zone de libre échange qu'en 1888. De plus, son image a été relativement préservée de l'industrialisation, puisque les industriels brêmois, pour échapper aux tarifs de douane prohibitifs, ont installé leurs usines loin du centre historique, au-delà de la frontière avec la zone de libre échange ${ }^{4}$. Ce fonds photographique, certes peu documenté par des archives écrites, ne nous introduit pas seulement dans l'univers visuel d'un Brêmois, il met aussi en valeur les inspirations formelles dont il a su tirer parti et montre l'évolution du rôle de l'image dans la construction de l'identité d'une ville.

\section{PédAgogue et Photographe AMATEur}

«Idéalisme, conscience du devoir, sens pratique [...] mais aussi amour de l'expression poétique, humour et personnalité chaleureuse $»^{5}$ - voici les qualités qu'on reconnaissait à Hermann Kippenberg dans sa ville. "Son amour profond, il le vouait au paysage de notre patrie et de sa ville natale, dont il captura les beautés dans d'innombrables images ${ }^{6}$. C'est un homme vif, aimable, un esthète enfin que l'on découvre, lorsqu'on se penche sur ce personnage resté pourtant en marge de l'histoire de Brême. Fils d'August

\footnotetext{
${ }^{3}$ Landeshauptarchiv (LHA) Brême, 10, B. Kippenberg.

4 Sur l'histoire de Brême, voir: Herbert Schwarzwälder, Geschichte der Freien Hansestadt Bremen, t. 1-4, Brême, 1975-85.

${ }^{5}$ Lothar Diemer, notice biographique, in Wilhelm Lürs (dir.), Bremische Biographie : 1912-1962, Brême, Hauschild, 1969, p. 270.

6 « Hermann Kippenberg » [notice nécrologique], Bremer Nachrichten, 2. Okt. 1940, p. 2.
} 
Kippenberg, un pédagogue qui marqua durablement le paysage éducatif de cette ville en fondant une école normale de filles (Lehrerinnenseminar), frère d'Anton, le directeur de la maison d'édition Insel Verlag à Leipzig, célèbre pour avoir édité Rilke et Hofmannsthal, Hermann resta dans l'ombre de ses frères et sœur7 . Il fut d'abord instituteur puis professeur de lycée professionnel.

Des responsabilités, il en eut certes, mais elles ne dépassaient guère le cadre brêmois : à partir de 1910, il présida l'Association de commerce et d'industrie et en 1920 il devint enfin directeur du lycée professionnel où il enseignait. Il accordait en fait à ses loisirs plus d'attention qu'aux enjeux de carrière : étranger à l'université, aux lettres et à la philologie, il n'en était pas moins l'ami des arts et de l'image technique. Membre dès 1890 de la Société brêmoise des amis de la photographie, président fondateur en 1894 de l'Association des photographes amateurs, puis président de la Société photographique, née de la fusion en 1895 des deux sociétés, Kippenberg était aussi l'auteur d'une œuvre photographique considérable déposée aux Landeshauptarchiv. Cette œuvre résultait, lit-on dans le journal local, de son " amour pour le paysage de [sa] patrie et de sa ville natale " et alimentait les «nombreuses conférences sur la Haute Weser, sur la région des marais et landes, et surtout sur le Vieux Brême"; une œuvre faite des "clichés merveilleux, qu'il agrémentait d'un discours clair et plein d'humour »8.

Cette œuvre documente donc deux territoires: d'une part des régions voisines - la Haute Weser, l'île d'Helgoland, les Landes - qu'il parcourut en touriste ; d'autre part sa ville natale, qu'il habitait. S'il ne nous est pas parvenu d'archives écrites sur ses conférences et s'il est donc impossible de confronter sources écrites et iconographiques dans la reconstruction de son expérience du territoire, les plaques diapositives peuvent néanmoins nous renseigner sur les modalités de représentation du territoire et sur les sources d'inspiration formelles investies dans cette documentation. Elles permettront donc de répondre à deux questions bien précises :

1) Pour quelles raisons la société brêmoise accorde-t-elle aux images une telle légitimité dans la représentation du territoire ? La question se pose quand on voit que la pratique photographique fut pour Kippenberg l'enjeu principal de sa présence dans l'espace public brêmois et de son maintien dans le milieu des érudits locaux ;

2) Observe-t-on une continuité formelle entre la représentation touristique du territoire et l'identité locale?

\footnotetext{
7 Plus âgé qu’Hermann Ludwig August et que Anton Hermann Friedrich, tous deux nés du second mariage de son père, Hermann fit une carrière bien moins brillante qu'eux. L'un, August, né en 1869, titulaire dès 1892 d'un doctorat de philologie et successeur de son père à la tête de l'école normale, pouvait se targuer de titres ronflants et de postes à responsabilités - Doktor, Oberlehrer, puis Professor et en 1935 Directeur du bureau de la coopération de la Basse Saxe. Tandis que l'autre, Anton, benjamin né en 1874, docteur ès lettres en 1901, directeur du Insel Verlag, la fameuse maison d'édition de Leipzig, édita Goethe et côtoyait Rainer Maria Rilke et Hugo von Hofmannsthal.

8 « Hermann Kippenberg » [notice nécrologique], art. cit., p. 2.
} 
Pour y répondre, il convient tout d'abord de considérer les cadres sociaux de la pratique photographique, ensuite, de s'interroger sur la forme donnée à la représentation des territoires parcourus en touriste et sur ses sources d'inspiration ; enfin, il faudra comparer ce type de représentation avec celui qui domine la représentation de sa propre ville, Brême ${ }^{9}$.

\section{PhOtographes AMATEURS ET SOCIÉTÉS PHOTOGRAPHIQUeS}

Quand Hermann Kippenberg adhéra au club photographique de Brême fondé en 1890 par John Droste, la pratique photographique avait commencé de se diffuser à un public nouveau. Dès la fin des années 1880, la photographie dite d'amateurs apparut et élargit le milieu jusqu'alors restreint d'une sociabilité scientifique et technicienne. Entre 1885 et 1890, les clubs et les revues photographiques se multiplièrent et proposèrent des orientations différentes de celles des anciennes sociétés savantes. Il s'agissait surtout de fédérer les amateurs, d'encadrer les pratiques nouvelles de ceux qui ne se disaient pas chimistes, mais simples usagers de la technique photographique. Apparu vers 1884 dans la littérature photographique pour remplacer les termes «Dilettant» ou «Liebhaber», celui d' «Amateur » désignait surtout le photographe de paysages, celui qui utilisait la photographie pour produire de belles images, sans prétendre - et c'est le point important - faire progresser les procédés ni travailler pour l'industrie ${ }^{10}$.

Ce loisir se développait sur le terrain déjà balisé par des réseaux de sociétés savantes et profitait ainsi de l'expérience d'une élite scientifique. Les nouvelles revues fondées à la fin des années 1880 étaient le plus souvent dirigées par des membres de sociétés photographiques prestigieuses, et publiaient des textes d'auteurs non moins connus dans le milieu des chimistes

\footnotetext{
${ }^{9}$ Sur les modes de perception de la ville, voir Karlheinz Stierle, La capitale des signes : Paris et son discours, Paris, Éd. de la Maison des sciences de l'homme, 2001 ; Dominique Poulot, Patrimoine et musées : l'institution de la culture, Paris, Hachette, 2001, Chapitre 6 : «L'invention du monument historique », p. 115-139.

10 Voir notamment C. E. Abney, «Photographische Amateure », Photographische Mitteilungen, 1884, Berlin, Robert Oppenheim, p. 290. Plus généralement sur le développement de la photographie amateur en Allemagne, voir Rolf Sachsse, «Der moderne Fotograf hat Angst vor sich selbst. Anmerkungen zur Geschichte der amateurfotografischer Makroorganisation in Deutschland », Fotogeschichte, 3e année, 1983, n8, 41-52, Enno Kaufhold, «Amateure mit Ansprüche. Die Kultivierung der Anspruchslosigkeit », Fotogeschichte, 2e année, 1982, nº, p. 11-21.

En France : Michel Poivert, Le pictorialisme en France 1892-1914, Thèse de Doctorat, Paris I, 1992 : en particulier, "Le statut de l'image et de l'amateur », p. 92-102, Martel Xavier, La photographie excursionniste en France, 1887-1914, mémoire de maîtrise, université de Paris I, 1996, et Clément Chéroux, Fautographie : petite histoire de l'erreur photographique, Crisnée, Yellow now, 2003, où l'auteur parle des jeux photographiques de ces amateurs nouveaux. Sur le développement de la photographie comme loisir dans l'espace privé, voir Timm Starl, Knipser. Bildgeschichte der privaten Fotografie in Deutschland und Österreich von 1880 bis 1980, cat. exp. Munich Stadtmuseum, 14 juin-20 août 1995, Munich/Berlin, Koehler \& Amelang, 1995.
} 
et physiciens"11. Les nouveaux clubs qui œuvraient à «favoriser la photographie amateur » accordaient une égale importance à s'assurer la solidarité des milieux savants qu’à faire progresser le nombre de photographes. Lorsque l'Association photographique libre de Berlin (Freie photographische Vereinigung) - un club créé en 1887 - publia un livre pour marquer les vingt années de son existence, son directeur, Franz Goerke, insista sur ses liens avec de nombreux instituts et sociétés savantes: l'Institut hygiénique, dont l'un des deux directeurs, Gustav Fritsch, fut également le président fondateur de l'Association photographique libre; l'Institut physiologique; la Société de géographie; la Société anthropologique de Berlin dont les membres éminents appartenaient aussi à l'association photographique; la Société allemande des amis de la photographie, avec laquelle il fut longtemps question de fusionner ; enfin, les clubs étrangers de photographes - le Photoclub de Paris, le Kamera Klub de Vienne et le Club londonien 12 .

En outre, les nouveaux clubs s'inpiraient des pratiques anciennes quand ils organisaient des concours sur la base de portfolios itinérants (Wandermappen)13. Cette technique avait été développée par les scientifiques pour correspondre à l'échelon international et s'échanger les résultats des progrès de la photographie. Elle était reprise par les nouveaux clubs, afin de les faire concourir sur des critères tant techniques qu'esthétiques : elle consistait à envoyer des clichés par la poste d'un club à un autre, en recueillant les appréciations de chacun ; lorsque chaque portfolio avait fait le tour de tous les clubs, on attribuait un prix au cliché le plus apprécié.

Ainsi, en exploitant au mieux les réseaux et les méthodes des sociétés savantes, les clubs continuèrent de se multiplier dans les années 1890 et regroupèrent, à partir de 1900, des amateurs issus de milieux sociaux moins élevés qu'auparavant ; on trouvait désormais dans les clubs des commerçants, des instituteurs, des pharmaciens et des comptables ${ }^{14}$. En élargissant leur recrutement, ils cherchaient sciemment à toucher un public de plus en plus nombreux. Si Hermann Kippenberg quitta la Société brêmoise des amis de la photographie et fonda en 1895 l'Association brêmoise de photographes amateurs c'était, semble-t-il, pour attirer de nouvelles recrues dans le sérail des

\footnotetext{
11 Photographische Rundschau (1887), Der Amateur-Photograph (1887), Lechner's Mitteilungen aus dem Gebiete der Literatur und Kunst, der Photographie und Kartographie (1889), Apollo (1894), Photographische Chronik (1894), Wiener photographische Blätter (1894), Photographisches Centralblatt (1898), Die Sonne (1904), Der Deutsche Camera-Almanach (1905), Photographie für Alle (1911).

12 « Die Chronik der Freien photographischen Vereinigung », in Franz Goerke (dir.), Denkschrift anlässlich des zwanzigjährigen Bestehens der Freien photographischen Vereinigung zu Berlin, Halle, Wilhelm Knapp, 1910, p. 35.

13 «Wandermappe », Photographische Rundschau, avril 1894, procès verbaux d'assemblées générales, p. 1.

14 On le remarque en examinant l'évolution des listes d'associations dans les revues telles que la Photographische Rundschau entre 1890 et 1910.
} 
photographes $^{15}$; le cercle initial était jugé repoussant parce qu'élitaire, et Kippenberg devait se charger de susciter de nouvelles vocations en fondant un club destiné au commun des Brêmois. Après avoir ainsi attiré, en 1895, 49 nouveaux membres, les deux sociétés fusionnèrent pour créer la Société photographique de Brême. En 1902, elle réunissait 139 membres ${ }^{16}$.

Le club de Brême mena ses activités avec ambition et de grands moyens : il organisa plusieurs expositions, publia une revue, acquit même, grâce à un don de la veuve de John Droste, la maison de son fondateur décédé en 1900, où furent aménagés « une bibliothèque, un laboratoire, un atelier, une salle de conférences pour 160 personnes, un salon pour dames, une cuisine, une chambre du club, une véranda et un cabinet pour le comité de direction »17. Cette ambition fut nourrie par l'assurance de la grande publicité de ses activités : il s’appuyait sur cette même structure associative, qui établissait un réseau étroit sur tout le territoire germanophone. Il publiait dans plusieurs revues d'amateurs - Die photographische Rundschau et Der Amateur Photograph - des appels à contributions pour ses expositions, ainsi que les comptes rendus de ses assemblées générales. Il s’appuyait donc sur un réseau dont l'efficacité provenait, comme nous venons de le voir, de l'expérience accumulée dans ce domaine par les sociétés savantes des années 1850 et 1860, et il contribuait ainsi à assurer la continuité entre les sociabilités savantes et le loisir photographique.

Ce loisir étendait donc des réseaux d'amateurs sur un modèle déjà éprouvé. Mais nouveau dans son ampleur, il était aussi nouveau par les idées qu'il véhiculait : il permit d'actualiser un discours valorisant la pratique des images au nom de l'éducation esthétique. En fait, cet argument pédagogique, nourri de la lecture de l'Anglais John Ruskin et l'Américain Peter Henry Emerson, fut transféré de la sphère institutionnelle des musées des Beaux-arts et des musées d'Arts et industries à la sphère des loisirs artistiques, ce qui supposait une double évolution, pratique et idéologique.

D’une part, la photographie n’apparaissait plus comme un loisir purement technicien car, à l'heure où les artistes-photographes pictorialistes produisaient leurs chefs-d'œuvres, on reconnaissait le caractère esthétique de cette activité18 : à l'instar de ces derniers, les amateurs « anonymes » se devaient

\footnotetext{
15 Lothar Diemer, «Hermann Kippenberg » [notice biographique], art. cit., p. 270 et «Die Geschichte der Photographischen Gesellschaft zu Bremen », in Harald Goergens (dir.), Photographische Gesellschaft Bremen von 1890. Jahrbuch 1995, Brême, 1995, p. 66. Cette information n’a pas pu être vérifiée. Il est également probable que le second texte se fonde sur le premier sans en avoir vérifié les sources.

16 «Bericht über die Tätigkeit der Gesellschaft seit Oktober 1900 », Jahrbuch der Photographischen Gesellschaft zu Bremen, 3e année, 1903, p. 45.

17 «Die Geschichte der Photographischen Gesellschaft zu Bremen », art. cit. p. 68, et « Das Droste-Haus », Jahrbuch der Photographischen Gesellschaft zu Bremen, op. cit., p. 62-66.

18 Sur l'esthétique pictorialiste, voir Michel Poivert, Le pictorialisme en France, op. cit., et Enno Kaufhold, Bilder des Übergangs. Zur Mediengeschichte von Fotographie und Malerei in Deutschland um 1900, Marburg, Jonas, 1986.
} 
d'obéir à des règles de composition inspirées notamment du fameux photographe britannique Henry Peach Robinson (1830-1901) et vulgarisées grâce aux manuels d'initiation à la photographie - la règle du nombre d'or, l'organisation des fuyantes dans l'image, la réduction géométrique des lignes de force, la perspective atmosphérique ${ }^{19}$. Kippenberg était au fait de ces principes artistiques. Non seulement il utilisait les règles de composition dans ses propres images mais il entretenait ses collègues de la Société brêmoise de l'évolution de la photographie artistique en Allemagne et en Angleterre20.

D'autre part, une grande partie de l'élite impliquée dans les institutions culturelles reconnaissait à l'image une fonction sociale héritée du premier $\mathrm{XIX}^{\mathrm{e}}$ siècle et encourageait les pratiques artistiques : il fallait insuffler dans le «peuple » (entendons bien sûr la bourgeoisie) le goût des belles choses pour stimuler la qualité de la production industrielle21. Cette idée fut reprise notamment par Alfred Lichtwark, directeur du musée des Beaux-arts de Hambourg entre 1886 et 1914, qui louait ardemment les activités « dilettantistes »22, autrement dit les loisirs artistiques. La photographie, «plus jeune branche à l'arbre du dilettantisme », avait une place d'honneur dans le concert des pratiques artistiques23. Elle renforçait l'idée d'édification (Bildung) tout en plaçant l'image au centre de ce «noble » projet. Ainsi la pratique photographique assurait certes une continuité entre les sociabilités savantes et les nouveaux clubs de loisir photographique, mais elle se chargeait d'une valeur pédagogique nouvelle fondée sur son caractère esthétique. Elle quittait en quelque sorte le domaine purement technique pour prendre place parmi les «pratiques de représentation » et se charger de leurs vertus.

\section{LE TERRITOIRE PHOTOGRAPHIQUE DU TOURISTE}

Ce changement de statut de la pratique photographique la rapprochait en tous points de celle du dessin. Non seulement elle se chargeait du même

19 Henry Peach Robinson, Pictorial Effect in Photography being Hints on Composition and Chiaroscuro for Photographers, Londres, 1869, [rééd. Robert A. Sobieszek, New York, 1971] repris dans ses grands traits par les innombrables manuels d'initiation à la photographie, par exemple : Ludwig David, Rathgeber für Anfänger im Photographiren, Halle, Wilhelm Knapp, 1893.

20 « Bericht über die Tätigkeit der Gesellschaft seit Oktober 1900 », Jahrbuch der Photographischen Gesellschaft zu Bremen, 3 année, 1903, p. 43 : une des conférences tenues à la fin de l’année 1901 est donnée par Kippenberg et s'intitule « Deutsche und ausländische Kunstphotographie ».

21 Sur le goût comme enjeu économique, voir Ingeborg Cleve, Geschmack, Kunst und Konsum. Kulturpolitik als Wirtschaftspolitik in Frankreich und Württemberg (1805-1845), Göttingen, Vanderhoeck \& Ruprecht, 1996 et Nadine Besse, « Construire les arts, construire les mœurs. La fonction du musée d'art et d'industrie selon Marius Vachon », in Stéphane Michaud (dir.), L'édification : morales et cultures au XIXe siècle, Paris, Créaphis, 1993.

22 Alfred Lichtwark, Die Bedeutung der Amateur-Photographie, Halle, Wilhelm Knapp, 1894, p. 1. 23 Sur Alfred Lichtwark, voir Helmut Leppien (dir.), Kunst ins Leben : Alfred Lichtwarks Wirken für die Kunsthalle und Hamburg von 1886 bis 1914, catalogue de l'exposition, Kunsthalle, Hambourg, 9. déc. 1986, $1^{\text {er }}$ fév. 1987, Hannovre, Schäfer, 1986. 
argument pédagogique, mais elle accentuait le rôle que le dessin avait donné à l'image dans les pratiques des voyageurs et des touristes. Avec la diffusion de la photographie instantanée à la fin des années 1880, la commercialisation de la plaque sèche, qui permettait de développer les images longtemps après leur exposition à la lumière, grâce à la légèreté du matériel, le voyage trouvait dans la photographie une alliée toujours plus précieuse. Le photographe ponctuait son parcours de courts instants destinés à la prise de vue, et faisait ainsi de l'excursion une recherche permanente de points de vue. Les modèles pour cette pratique étaient diffusés par plusieurs biais. Tout d'abord, la littérature photographique faisait de l'esthétisation de l'espace un thème majeur de l'initiation artistique. En assimilant volontiers le regard et la prise de vue photographique - «L'amateur apprend à ajuster l'appareil à son regard »; «Ainsi, d'une simple vue on a fait une image »24, Alfred Lichtwark décrit «le sens pour l'espace et les proportions [qui] s'éveille chez [l'amateur]». Et Lichtwark d'insister sur le parcours comme une recherche permanente de formes et de motifs : "On cherche le motif simple et le point de vue, d'où il peut être perçu comme une unité »25. Dans ces pages emphatiques, la photographie sert avant tout la représentation du paysage et s'associe naturellement au parcours du territoire.

En second lieu, ces modèles étaient diffusés par le canal de la «protection de la petite patrie » (Heimatschutz), un mouvement culturel très répandu visant à sensibiliser le public au patrimoine architectural et paysager des régions d'Allemagne, à créer des institutions culturelles et des musées locaux, à favoriser l'excursion et l'alpinisme26. Les défenseurs de ce mouvement publiaient des manuels destiné à ce qu'Oscar Schwindrazheim, auteur de quelques-uns de ces petits livres, appelait «l'excursion artistique » (Kunstwanderung). Guides touristiques sans attribution locale, ils se contentaient de décrire une promenadetype dans « notre village », en proposant des choix de motifs ou d'objets dignes d'une attention particulière, esthétique et historique : l'entrée de la ville, son enceinte, les rues, les places, la mairie, les maisons anciennes, les maisons modernes, les intérieurs, les portes, les fenêtres, les échoppes, les enseignes, les monuments, les fontaines, les jardins, le cimetière, les véhicules et les costumes27. Enfin, les guides touristiques mutlipliaient eux aussi les références pittoresques et indiquaient des points de vues sur les cartes routières.

\footnotetext{
24 Lichtwark, op. cit., p. 8.

25 Ibidem, p. 7.

26 Sur le Heimatschutz, voir notamment Alon Confino, The Nations as a Local Metaphor. Württemberg, Imperial Germany, and national memory, 1871-1914, Chapel Hill et Londres, Univ. of North California Press, 1997 et Andreas Knaut, Zurück zur Natur! Die Wurzeln der Ökologiebewegung, suppl. 1 (1993) du Jahrbuch für Naturschutz und Landschaftspflege, Munich, Arbeitsgemeinschaft beruflicher und ehrenamtlicher Naturschutz, 1993.

27 Oscar Schwindrazheim, Kunst- und Wanderbücher, t. 1 : Unsere Vaterstadt, t. 2 : Stadt und Dorf, t. 3 : In der freien Natur, Hambourg, Gutenberg, 1907.
} 
Hermann Kippenberg correspondait à ce profil de photographe. Il découvrait les régions voisines en touriste: de son séjour sur l'île d'Helgoland28, destination particulièrement appréciée par les touristes allemands, il rapportait de beaux paysages marins, des vues de villages, des portraits de pêcheurs et des scènes de plages ; au cours d'un autre voyage, celuilà dans la Haute Weser, il avait collecté de nombreux documents sur le château et l'église de Corvey et sur la porcelaine de Fürstenberg, il avait profité des paysages vallonnés saisis dans des compositions d'inspiration romantique. Dans ses collectes, il associait la fonction documentaire et la fonction artistique de la photographie. L'expérience esthétique du paysage, la recherche du motif, les règles de compositions - composition parfois corrigée par un nouveau cadrage à l'aide de bandes de papier adhésif -, tout ce qui faisait du photographe un artiste méritait toute l'attention de Kippenberg. Mais ces images auraient été bien inutiles si elles n'avaient servi un discours érudit sur les régions parcourues : c'était-là le but de ses conférences illustrées - aussi, la première diapositive donne-t-elle le titre d'une série documentaire, «L'Oberweser, dans la couronne des hauteurs boisées » (Oberweser, im Kranze waldiger Höhen), conférences données vraisemblablement dans la « maison Droste », le local de l'association photographique, entre 1900 et 1919.

La projection photographique avait pris son essor à cette même époque, quand, sous l'effet de la popularisation des sciences, les sociétés photographiques destinèrent leurs conférences à un public plus large. Certaines d'entre elles avaient connu un grand succès en offrant aux savants ou aux historiens les moyens matériels et logistiques dont elles disposaient, pour organiser des conférences illustrées. Ainsi voyait-on à Berlin se multiplier les conférences de vulgarisation scientifique, sous l'égide de l'Association photographique libre et du musée d'ethnologie qui mettait son auditorium à sa disposition ${ }^{29}$. Certes il s'agissait-là de présenter en images les progrès de la science, mais les conférences les plus populaires étaient des récits de voyages. Entre 1889 et 1900, les projections à caractère géographique et ethnographique, données dans le cadre de l'Association photographique libre de Berlin étaient deux fois plus nombreuses que celles destinées à la vulgarisation scientifique 30 . La projection photographique avait pour ainsi dire trouvé son genre. Grâce à la mise en série des images, elle permettait de reproduire le parcours du photographe, de maintenir dans l'exposition la même structure que dans la découverte du territoire elle-même et de captiver ainsi un public de plus en plus nombreux.

\footnotetext{
28 Île rétrocédée par l'Angleterre à la faveur de l'accord dit « Helgoland-Sansibar » conclu en 1890.

29 « Die Chronik der Freien photographischen Vereinigung », in Franz Goerke (dir.), Denkschrift anlässlich des zwanzigjährigen Bestehens der Freien photographischen Vereinigung zu Berlin, Halle, Wilhelm Knapp, 1910, p. 17-46.

30 En témoigne l'évolution des sujets des conférences de la Freie photographische Vereinigung de Berlin. « Die Chronik der freien photographischen Vereinigung », art. cit., p. 17-46.
} 
Cette adéquation entre le genre - le récit de voyage - et la forme - la projection-, qui avait rendu ces événements si populaires, Hermann Kippenberg en jouait avec virtuosité. Il organisait son récit en plaçant, au début et à la fin, des images « d'entrée » et de « sortie »; en indiquant par une carte la référence topographique du récit ; en ponctuant la projection d’indices cinétiques, photographies montrant les moyens de transport - bateau à vapeur, voiture -, les routes, le fleuve ; en introduisant enfin le photographe lui-même dans le cliché, sorte de mise en abîme visant à intensifier le rapport du spectateur à l'espace, du photographe à son sujet. Tous ces procédés renforçaient l'adhésion du référent (le récit) au référé (l’espace), donnant au spectateur l'illusion d'un parcours physique du territoire.

Associée à celle du voyage ou de l'excursion, la pratique du loisir photographique générait donc une image cohérente du territoire. La projection diapositive s’accordait avec le récit de voyage, car la dimension temporelle, certes elliptique mais néanmoins structurante de la série, s’associait à la dimension spatiale des images (l’espace représenté) et aux raccords entre les images (tel lieu représenté s'inscrit en continuité avec tel autre lieu représenté). De plus, cette adéquation entre le genre et la forme était renforcée chez Kippenberg par des procédés visant à multiplier les références topographiques et cinétiques ; des procédés qui se nourrissaient donc d'une expérience faite à l'extérieur du territoire propre au photographe, à l'extérieur de sa ville, Brême. Le parcours du touriste érudit avait donné à l'image du territoire cette forme dynamique, qui mettait en scène l'image-document dans le récit illustré d'une traversée.

L'image, on l'a vu, tirait sa légitimité de deux facteurs. D’une part, la pratique photographique était valorisée par une sociabilité savante et une fonction pédagogique. D’autre part, son répertoire formel, inspiré des manuels photographiques et des brochures du Mouvement pour la protection de la petite patrie (Heimatschutzbewegung), s’adaptait au genre du récit de voyage. Grâce à cette légitimité, Kippenberg avait pris place dans l'espace public de Brême. Au tout début des années 1910, il put ainsi ajouter sa voix à celle des érudits locaux : tandis que se constituaient les collections du musée historique de Brême, Kippenberg lui aussi s’intéressa en érudit à sa ville. Il mit ses compétences de photographe à la disposition de la commission du musée. Mais pour maintenir ici aussi la légitimité de l’image dans la représentation du territoire, il fallut que Kippenberg cherchât des inspirations formelles ailleurs que dans les revues d'amateurs.

\section{LA VILLE À LA LUMIÈRE DE L'ARCHIVE}

Les photographies de Brême de Hermann Kippenberg conservées au Landeshauptarchiv de Brême appartiennent à deux groupes bien distincts. D’une part, les négatifs sur verre, reclassés dans le fichier général des vues de Brême classées par sujet. D’autre part, les plaques diapositives - gélatino-bromure sur 
verre, c’est-à-dire le même support que les photographies commentées plus haut - séparées des négatifs, classées avec les diapositives d’excursions et formant des suites relativement cohérentes d'images. Bien que dans les deux groupes, les photographies aient été prises sur une période également longue - entre 1890 et 1930 -, leurs caractéristiques formelles sont très différentes.

Dans le premier, il s’agit le plus souvent de vues de façades de bâtiments, tantôt frontales, tantôt en légère perspective, dénuées de présence humaine : il s’agit sans doute dans chacune de ces vues de documenter un bâtiment, de le montrer avec le plus de recul possible (Ill. 1). «Ses photographies de monuments brêmois réalisées suivant la technique photogrammétrique présentent une documentation singulière de nombreux bâtiments aujourd'hui [en 1940] détruits »31; "singulière » en effet, puisque l'équipement de Kippenberg rendait apparemment difficile la mise en œuvre de cette technique complexe, dont peu de clichés respectent ici les critères (en particulier : la prise de vue frontale et le redressement des fuyantes).

Le second groupe est plus varié : dans plusieurs séries, on trouve des vues de rues, d'architecture, de ponts, de monuments, de bas-reliefs et de sculptures, confrontées avec des reproductions de documents historiques, gravures, dessins ou tableaux de Brême et de ses grands hommes. Pour ces deux groupes d'images, il n'existe que peu d'archives écrites qui pourraient nous éclairer sur leur utilisation. Quelques conjectures sont néanmoins possibles pour mettre en lumière l'influence des répertoires formels et de l'expérience photographique, investis dans la construction d'une identité urbaine.

Les photographies d'architectures classées dans le répertoire général des vues de Brême ne semblent pas avoir fait l'objet de commandes de la part des autorités municipales. Lorsqu'il fut question de procéder à l'inventaire photographique des bâtiments de Brême - inventaire commandé au directeur des bâtiments Erhardt en 1903 par la commission d'histoire de l'art (Kunsthistorische Kommission) - la municipalité fit appel à des photographes professionnels mieux équipés, Stickelmann et Louis Koch32. De même, les vues du second groupe ne répondaient apparemment à aucune commande officielle. Cependant, on peut imaginer pour ce dernier groupe deux types d'utilisations. D'une part, elles constituaient un ensemble de diapositives apparemment destinées aux séances de projection déjà citées. Il est certain que Hermann Kippenberg a donné des conférences sur Brême, ses grands hommes, ses monuments, ses lieux historiques, son économie, où il montrait les portraits, photographies d'architecture et de monuments et les reproductions de documents anciens. D’autre part, il est également certain que Kippenberg a mis ses compétences de photographe à la disposition du nouveau musée historique de Brême.

\footnotetext{
31 Hermann Kippenberg [notice nécrologique], art. cit., p. 2.

32 Lettre de la direction des bâtiments au maire Hildebrandt, Brême LHA, B. 13 Nr. 1, 90-94 et rapport de Erhardt : « An die Kommission zur Erhaltung kunsthistorischer Denkmale zu Händen des Herrn Senators Rassov », 16 décembre 1924, Brême LHA, B. 13 Nr. 1, 125-136.
} 
Illustration 1 : Grosse Johannisstrasse 85, 1910, négatif sur verre, 13 x $18 \mathrm{~cm}$

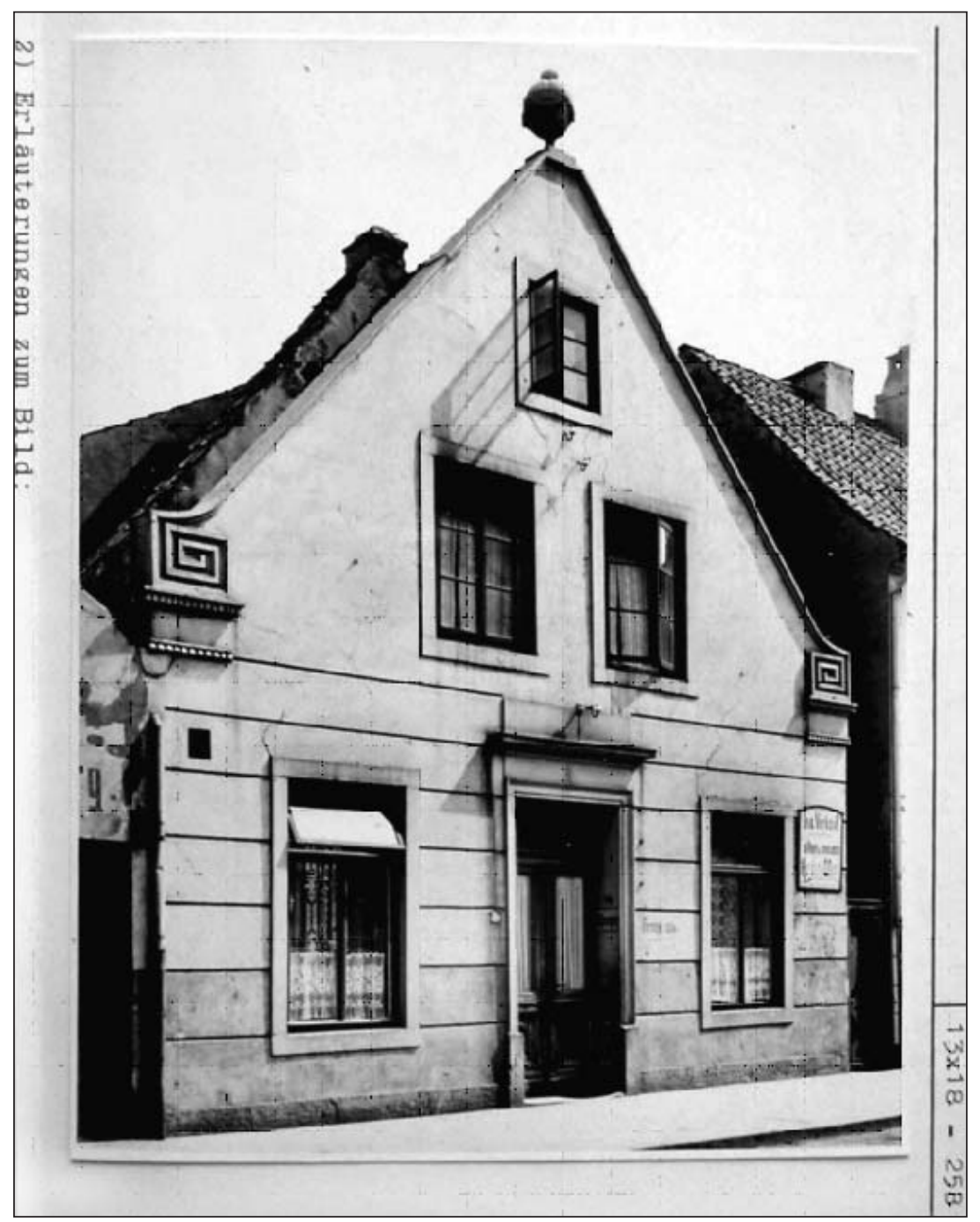

10 b, (1910) - 102

Les premières collections de ce musée (Historisches Museum) furent constituées par la Commission d'histoire de l'art de la ville en 1897 (date ante quem) et le musée ouvrit ses portes en 1906. À l'occasion du 70e anniversaire de Johannes Focke, son fondateur et directeur, le 14 mai 1918, le musée prit le nom de Focke Museum für Bremische Altertümer (il porte aujourd'hui encore le nom de Focke Museum). Kippenberg était membre du comité directeur : il fut nommé en 1909 pour cinq ans et son mandat fut renouvelé pour la période de 1914-1918 ; 
s’il ne figure pas comme photographe sur les inventaires du musée, il lui offrit pourtant ses services. Il participa à la composition de l'ouvrage Alt-Bremen (Le Vieux Brême)33, préfacé par Johannes Focke et reproduisant 100 gravures anciennes (Ill. 2) - cartes et vues de Brême -, un ouvrage d'un "prix élevé », censé " contribuer à renforcer l'amour du pays [...] et introduire à l'histoire locale de Brême »34. Non seulement Kippenberg avait vraisemblablement reproduit les documents présentés dans le livre, mais il réussit également à l'éditer aux presses du Insel Verlag de Leipzig, la maison dirigée par son frère Anton.

\section{Illustration 2 : Hans Weigel, Brême, 1564. \\ Reproduction de Kippenberg, s. d., positif sur verre 9 x $12 \mathrm{~cm}$ ]}

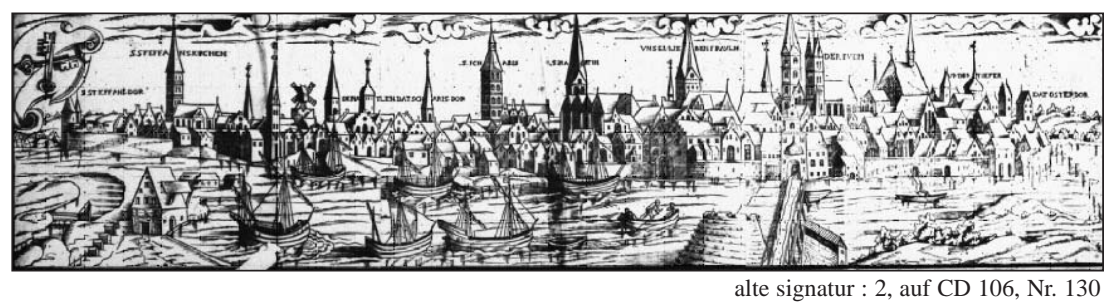

Hermann Kippenberg avait donc pris part activement à une des activités éditoriales du musée et avait ainsi un contact répété avec des documents historiques. C'est la manipulation de ces archives qui influença son activité photographique. En plus du travail sur ce livre, il est fort probable qu'il ait participé, au moins de manière informelle, à l'exposition permanente du musée, regroupant, dans sa version d'avril 1909, de nombreuses vues d'architectures décrites dans le journal Bremische Rundschau :

«Il y a en plus de ces images [gravures et documents historiques] les photographies d'anciennes maisons brêmoises, que le musée fit réaliser avant leur destruction. D'autres reproductions de bâtiments et de fragments d'architecture de la Renaissance et du Rococo occupent une autre partie de cette salle. Au-dessus de ces pièces se trouve suspendue une vue du Wall [le bord du canal] composée de plusieurs images, avec des reproductions des maisons, fidèles à ce qu'elles étaient au début du siècle dernier » 35 .

Donner une vue de la ville fidèle à son visage historique, mettre au jour les marques du temps, distinguer le nouveau de l'ancien en s'appuyant sur les documents du passé et les images modernes - voilà ce qu’était l’objectif de ce musée.

\footnotetext{
33 Focke-Museum für bremische Altertümer, Alt Bremen, préf. Johannes Focke, Leipzig, Insel Verlag, 1922.

34 Fockemuseum für bremische Altertümer, Jahresbericht für 1922, p. 5.

35 F. Hildebrandt, « Bremer Bilder im historischen Museum », Bremer Rundschau. Worüber man in der Bremer Gesellschaft spricht, 8 mai 1909, p. 8.
} 


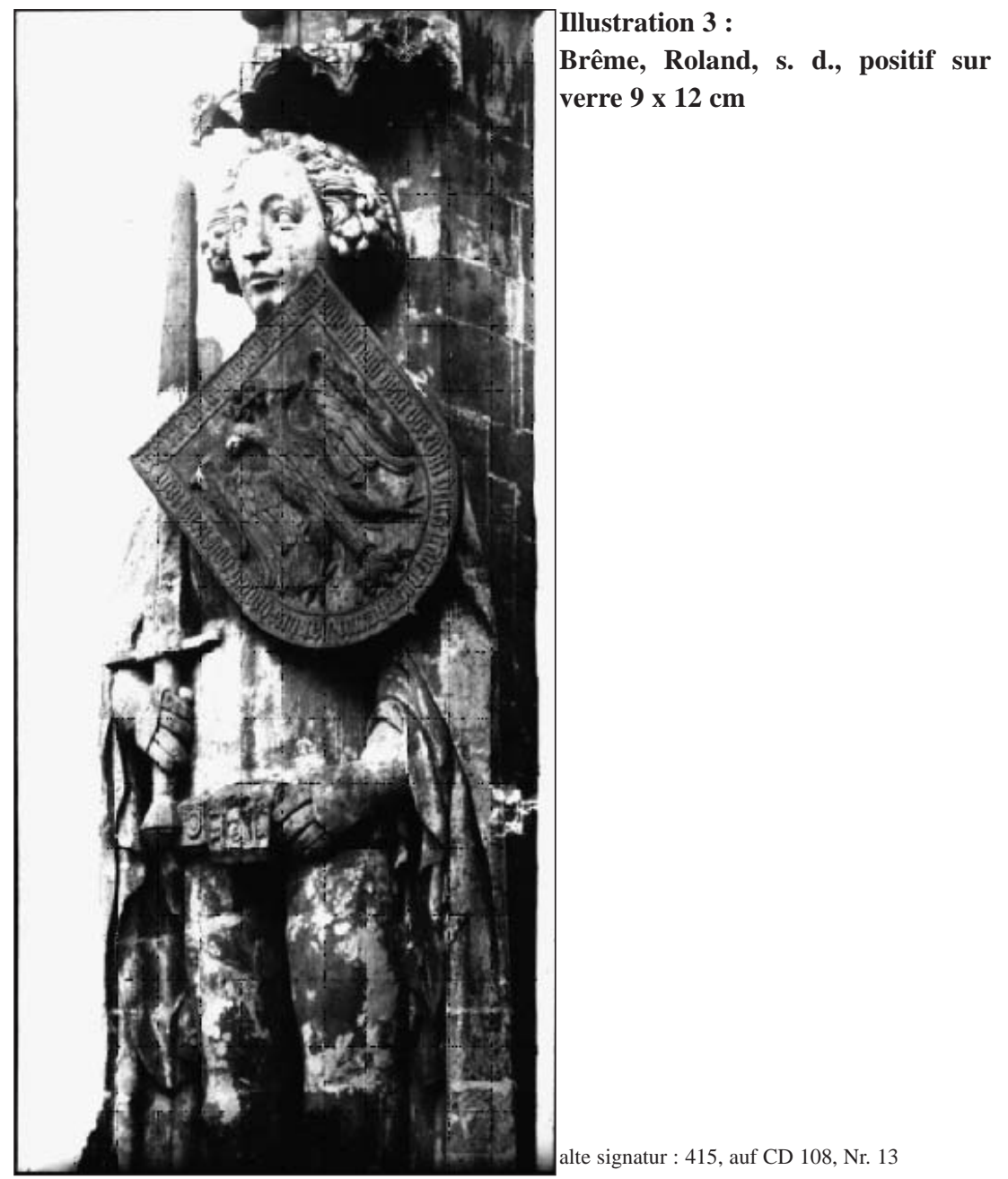

Impliqué dans cette entreprise, Kippenberg produisit dans son activité photographique une image de Brême conforme à cet idéal historiciste, et s'appuya abondamment sur les documents d'archives. Le contact avec l'archive, la nécessaire comparaison de l'ancien et du nouveau (Ill. 4 et 5), le goût des documents historiques furent le principal moteur de la production photographique brêmoise de Kippenberg. Si prompt à esthétiser son rapport à l'espace dans ses excursions touristiques, si attentif, dans la revue photographique publiée sous sa direction, aux usages artistiques et aux belles compositions en photographie, si assidu dans ses rapports avec les grandes revues d'amateurs qui fournissaient des modèles pictorialistes d'une grande perfection, Hermann Kippenberg n'en choisissait pas moins, pour ses vues de 
Brême, un répertoire de formes sans rien de commun avec les exemples artistiques fournis aux photographes amateurs. Il s’éloignait même du style qui caractérisait ses comptes-rendus d'excursions dans l'Oberweser ou sur l'île d'Helgoland. Aucune trace d'un parcours dans les photographies de Brême : elles se concentrent le plus souvent sur un thème ou un sujet, complétant d'autres documents présentés à titre de comparaison. Ainsi, les vues aériennes prises à la fin des années 1920 faisaient-elles clairement écho à une gravure de 1850 (Ill. 6, 7 et 8) ; ainsi, à l'instar des gravures du XVIIe siècle, les vues dégagées des ponts montraient-elles la circulation sur le pont et les bateaux sur le fleuve. Kippenberg actualisait dans son «tableau » de Brême un répertoire de formes tirées de ses fréquentations érudites des archives.

\section{Illustration 4 :}

Brême, Cathédrale, projet de la façade ouest,

s. d., positif sur verre $9 \times 12 \mathrm{~cm}$

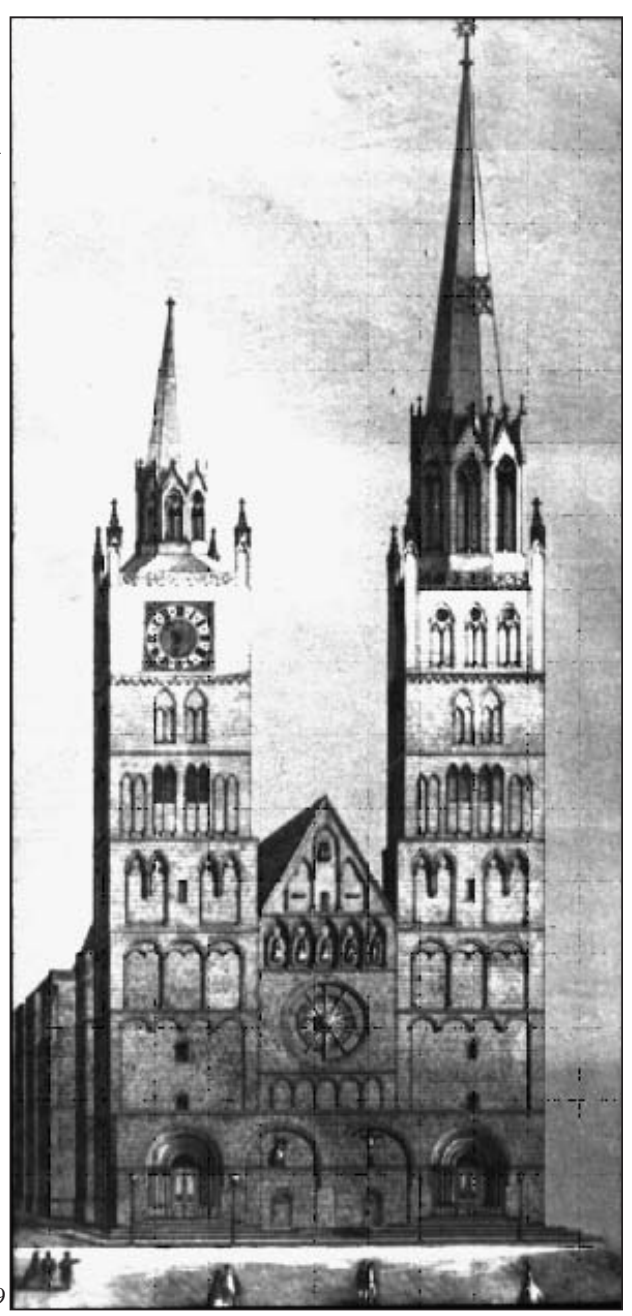


Illustration 5 : Brême, Cathédrale, s. d., positif sur verre 9 x 12 cm

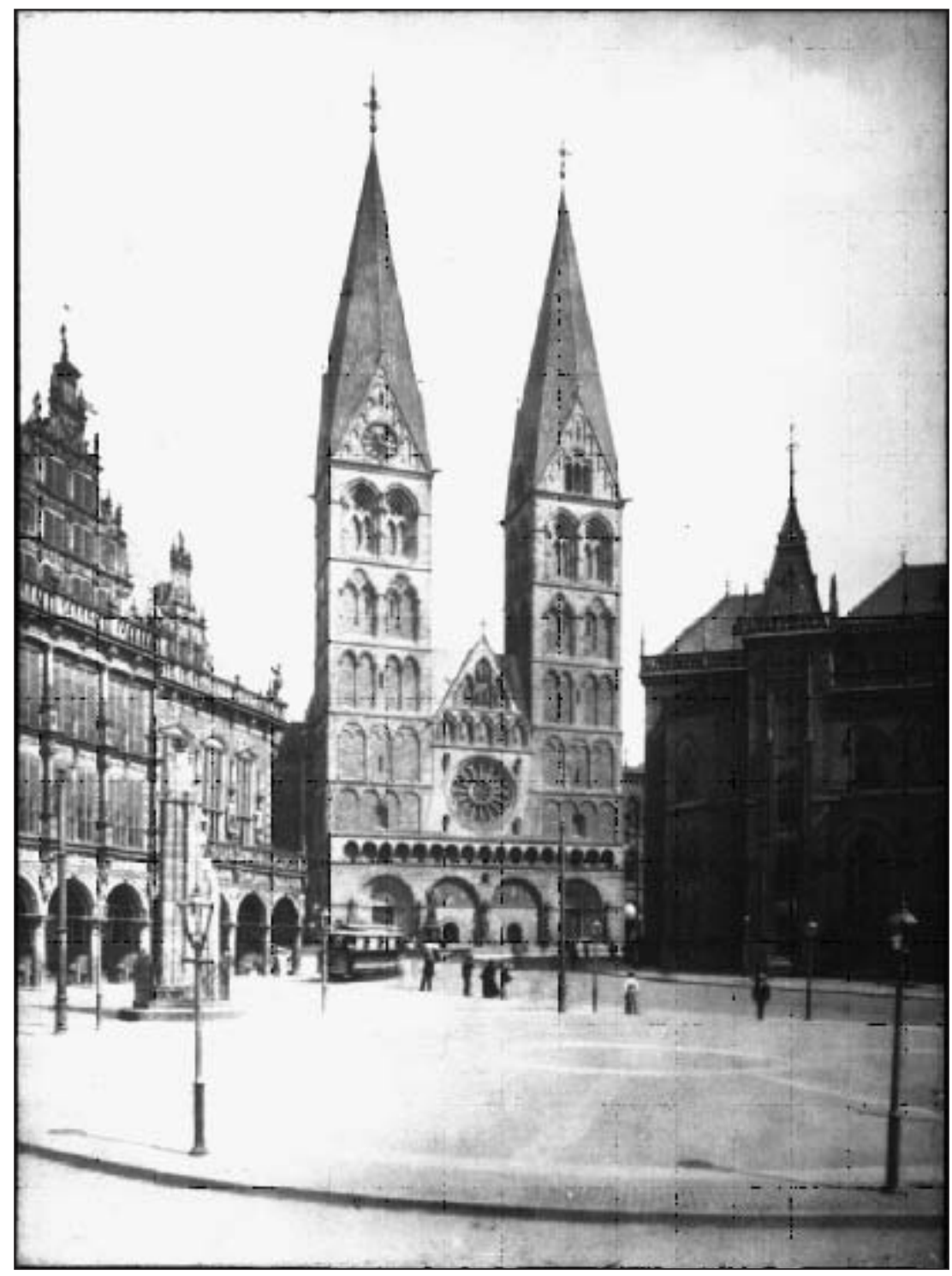

alte signatur : 190, auf CD 107, Nr. 70 
Illustration 6 : Adolph Eltzner, Brême, 1851, reproduction de Kippenberg, s. d., positif sur verre $9 \times 12 \mathrm{~cm}$

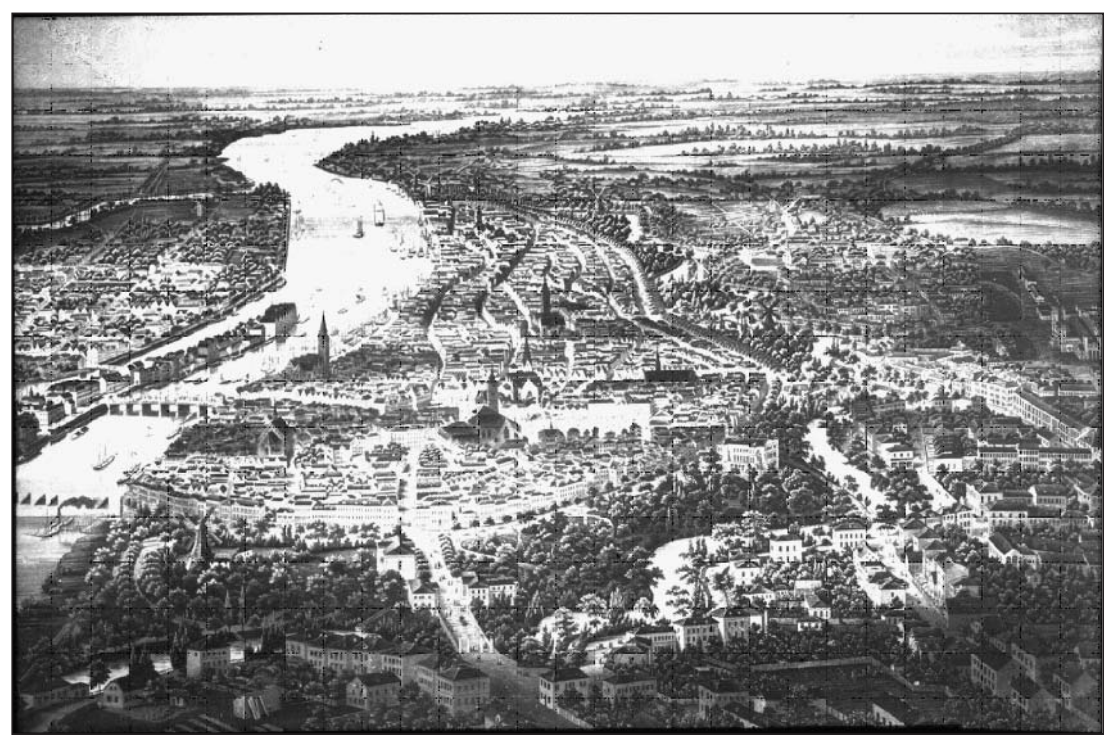

alte signatur : 23, auf CD 106, Nr. 152

Illustration 7 : Brême, place du marché vue de la tour de la cathédrale, s. d., positif sur verre $9 \times 12 \mathrm{~cm}$

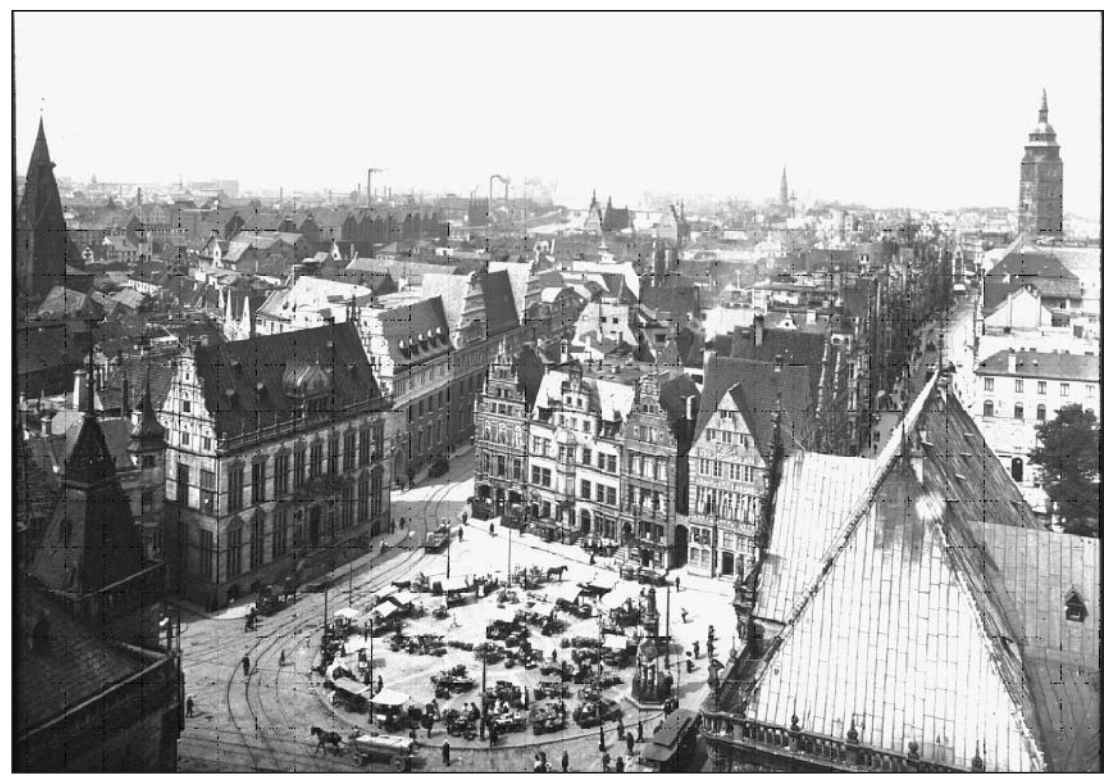


Illustration 8 : Brême, avion au-dessus de la Neustadt, s. d., positif sur verre $9 \times 12 \mathrm{~cm}$

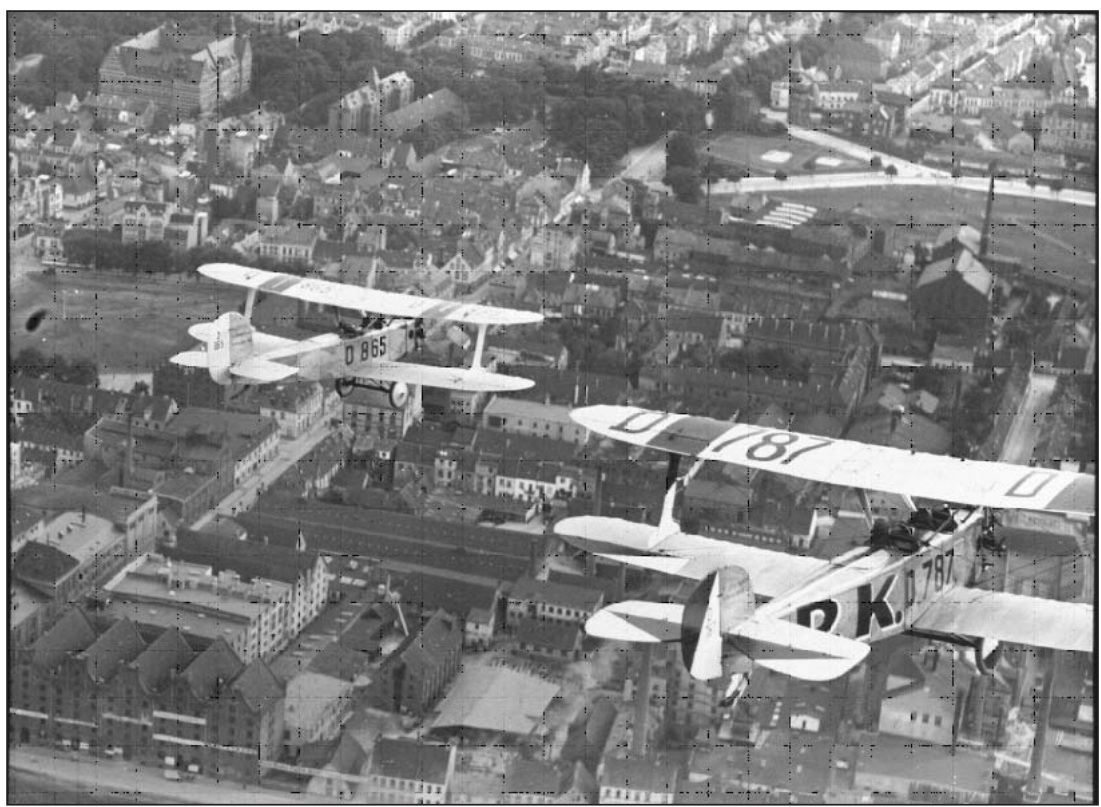

alte signatur : 690, auf CD 108, Nr. 297

"Le paysage est un émetteur d'images qui facilitent le passage du conscient à l'inconscient, la topo-analyse fournit des symboles sur lesquels réagit la sensibilité, mais ces opérations s'effectuent [...] en fonction de mécanismes datables »36. Datables en effet, si l'on s'accorde à dire que le « moment photographique » à la fin du XIXe siècle, a accéléré l'évolution des sensibilités et qu'avec lui l'image devient un document privilégié pour représenter le territoire. L'exemple de Kippenberg nous permet de constater la place qui fut accordée aux images dans le rapport des hommes à l'espace. Dans ses conférences, Kippenberg n'ajoutait à ses photographies que sa parole orale, aussi peu perceptible pour l'historien d'aujourd'hui qu'elle fut étrangère à son projet; il s'agissait pour lui de conserver la mémoire visuelle d'un territoire voué au changement.

Si, placé dans le contexte du développement du loisir photographique, cet exemple nous renseigne sur le statut de l'image et sur les raisons de sa légitimité dans la représentation du territoire, il nous communique aussi, grâce aux choix formels qui y sont exhibés, la nature des imaginaires différenciés de l'identité territoriale. D'une part, l'imaginaire du touriste marqué par l'irruption

36 Alain Corbin, Le territoire du vide. L'Occident et le désir du rivage. 1750-1840, Paris, Aubier, 1988, p. 321-322. 
de l'image dans le moment de la découverte du territoire, bref, par une expérience esthétique de l'espace, réinvestie brillamment dans l’organisation visuelle du récit de voyage. D’autre part, l'imaginaire de la ville, l'identité urbaine, fondée sur un travail comparatif de l'image et du document d'archive, au service de la stratification des représentations d'une ville-palimpseste.

Si différents soient-ils, ces deux imaginaires restent pourtant liés dans leur pratique et dans leur projet. Dans leur pratique, puisque c'est le voyage qui avait contribué à légitimer l'usage des images dans la production d'un discours sur le territoire : le tourisme instituait la projection diapositive pour organiser visuellement un discours. C’est donc le détour vers les régions étrangères à la circulation quotidienne qui motivait de facto l'investissement par l'image d'une identité urbaine. Ces deux imaginaires du tourisme et de la ville furent aussi liés dans leur projet proprement « présentiste » (avant l’heure), puisqu’à la sensibilité mémorielle vint s’ajouter, dans l'un comme dans l'autre, l'espoir de fixer l'image du territoire dans son instant présent ${ }^{37}$. Plus qu'aucune forme de traduction de l'expérience territoriale, la photographie a su cristalliser le désir de voir s'éterniser l'instant du parcours et de raccourcir la distance virtuelle entre le vécu et sa représentation.

37 François Hartog, Régimes d'historicité. Présentisme et expériences du temps, Paris, Seuil, 2003. 



\title{
ESPACES URBAINS DU TEMPS LIBRE DES FEMMES AUX XIXe ET XXe SIÈCLES
}

\author{
Fiorenza TAROZZI \\ Université de Bologne
}

\section{LE POURQUOI D'UNE DISTINCTION DE GENRE}

Dans la société contemporaine les différents emplois du temps quotidien dépendent en grande partie des horaires de travail et du temps consacré au travail domestique et aux tâches familiales qui, à certaines périodes de la vie, occupe une place essentielle dans l'organisation du temps libre, tout particulièrement pour les femmes. La perception du peu de temps qu'elles ont à se consacrer à elles- mêmes et au contraire de la consistance de celui qu'elles consacrent aux autres (et aux tâches domestiques et familiales) fait partie, du reste, de l'histoire des femmes et du rôle de fille, d'épouse et de mère qui, au cours du temps, leur a été attribué.

«La femme vit dans la maison» lit-on dans un manuel d'économie domestique en usage dans les écoles italiennes en 1950 :

"Elle sait bien que vivre à la maison ne veut pas dire seulement partager de tout cœur les soucis de ses proches, assister avec la délicatesse d'une petite sœur un malade, être attentive et diligente, conciliante et forte, tenace et prudente; cela ne veut pas dire seulement se taire dans la douleur, donner du courage dans le danger, inciter au bien, accompagner dans les difficultés, sourire aux retours ; mais employer toutes les ressources de son esprit pour créer un climat d'ordre et de beauté, une atmosphère de sérénité constante »1.

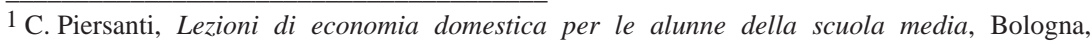
Zanichelli, 1950, p. 2-3. 
La femme, dans la société bourgeoise du XIXe siècle comme dans les classes populaires, ne semblait rien vivre de moderne : tout simplement les devoirs qui, le siècle précédent, étaient considérés comme ceux des dames de bonne famille étaient étendus à toutes les jeunes filles, ils s’étaient uniformisés dans tout l'univers féminin, comme s'ils ne pouvaient absolument pas être remis en question. Et ces devoirs étaient : offrir soi-même à la maison, à son mari, à ses enfants.

Il est donc vrai alors que le temps libre pour les femmes n’était (et n’est) qu'un rêve ? Ou bien, si l'on affronte la question dans une autre perspective, la mosaïque du temps féminin se révèle-t-elle, différente bien sûr de celle des hommes, mais avec plus de facettes ? Essayons cette autre lecture.

\section{ESPACES ET MODÈLES DE TEMPS LIBRE AU FÉMININ}

Dans le tableau Il Pergolato (1866) Silvestro Lega représentait l'image du temps libre des femmes par des dames occupées à converser, par une petite fille qui jouait et il ajoutait de façon significative la bonne au travail qui s’apprêtait à les servir. À côté de l'attitude noble et du maintien étudié de ces figures, nous avons les lieux occasionnels de réunion pendant les brèves pauses de travail qui caractérisent le temps libre dans la société paysanne de ces mêmes années et que les tableaux de Cristiano Banti Riunione di contadine et Confidenze illustrent bien.

Ces représentations mettent clairement en évidence l'opposition entre travail et repos, entre travail et loisir. Lewis Carrol, le « père d'Alice », perçoit, pour sa part, l'importance du temps et place brusquement face à son héroïne occupée à un jeu de petite fille, un lapin blanc rapide et extravagant, dont les courses frénétiques soulignent la lutte éternelle contre le temps, scandée par la montre qu'il porte au cou.

" Alice commençait vraiment à en avoir assez de rester assise sur le banc à côté de sa sœur, sans avoir rien à faire. Une fois ou deux elle avait jeté un coup d'œil sur le livre que sa sœur était en train de lire, mais il n'y avait ni images ni dialogues; et je me demande bien à quoi ça sert de lire un livre sans images ni dialogues ? " pensait Alice $^{2}$.

À quoi cela sert de lire ? Ou mieux à quoi cela sert aux femmes de lire ? La réponse est assez simple: pour les femmes la lecture a représenté, en particulier dans les siècles passés, un des rares moments de distraction et ce qui n'est pas secondaire, une distraction qui leur a permis l'acquisition d'une éducation et d'une forme d'alphabétisation, si minime soit-elle. La femme, à qui l'accès à l'école fut longtemps limité ou à qui on ne concéda qu'une modeste instruction, était cependant souvent en mesure de lire (cet enseignement lui étant donné dans le cercle familial) parce que cela lui permettait d'être à son tour éducatrice de ses enfants. Bien évidemment il

$\overline{2}$ L. Carroll, Alice nel paese delle meraviglie e nello specchi, Milano, Bompiani, 1970. 
s'agissait de lectures édifiantes : on apprenait à lire sur les pages de la Bible, on apprenait à vivre à partir du texte sacré.

Ce modèle de lecture fut dominant jusqu'à la fin du XVIIIe siècle ; une petite révolution eut lieu au cours du XIXe, quand l'adolescente commença à se plonger dans la lecture de romans et par leur intermédiaire se créa un paradis artificiel. Le danger de ce tournant fut aussitôt perçu: le livre représentait une fuite du quotidien et de la paix domestique. Et qui plus est, la société était en danger, parce que ce genre de lecture ne prédisposait pas la femme aux idéaux traditionnels de mère, d'épouse, d'éducatrice, de protectrice de la maison, mais au contraire la transportait dans un monde idéalisé, loin des règles habituelles. Dans ce cas la femme lisait pour rêver, pour s'évader et donc pour échapper aux normes et aux conventions, exactement le contraire de ce qui lui était consenti. Cependant la lecture devint aussi pour les femmes un élément de socialisation. La lectrice multiplie les textes, les fait circuler et a besoin d'une structure qui lui mette à disposition un nombre de livres de plus en plus important. C'est ainsi que naquirent des sociétés de lectures, des bibliothèques pour le prêt, des cabinets de lecture ouverts aux femmes. Il ne s'agissait pas de lieux exclusifs, au contraire, des personnes très différentes aux intérêts variés pouvaient y accéder. Déjà nombreux en Allemagne, ils se répandirent très vite dans d'autres pays, jusque dans les centres secondaires. Dans un deuxième temps ces lieux devinrent de véritables centres de cultures où les femmes trouvaient de nouveaux repères, si elles ne craignaient pas les moqueries et les regards méfiants auxquels elles s'exposaient quand elles s'efforçaient d'acquérir une culture de façon autonome et de participer plus vivement à la vie politique et sociale.

Quand les femmes du peuple abordèrent elles aussi la lecture, les conservateurs les plus invétérés ne manquèrent pas d'en souligner les dangers, en la désignant comme un moment d'oisiveté au sens péjoratif du terme. La publication de romans feuilletons ou de fascicules bon marché fut considérée comme une manifestation de mœurs dissolues, une forme de débauche néfaste autant que l'alcoolisme pour l'homme: le roman feuilleton (disait-on) produisait dans les cerveaux des femmes les mêmes ravages que la boisson dans les cerveaux masculins.

Dans les milieux bourgeois du XIXe, en revanche, on acceptait communément l'image de la jeune lectrice et des scènes où des petites filles jouent et des adolescentes lisent font partie d'une représentation que l'on retrouve souvent dans l'iconographie de l'époque, où l'on peut voir aussi des jeunes filles qui jouent du piano, peignent ou brodent, qui jouent au volant ou passent leur journée entre repas, bals, visites de politesse et soirées au théâtre.

À l'époque où le salon et la maison constituaient les lieux essentiels de la socialité, le théâtre était, à l'extérieur, un espace où les femmes jouaient un rôle de premier plan. C'étaient les dames et les demoiselles de la bonne bourgeoisie, pour lesquelles aller au théâtre faisait partie intégrante de la formation culturelle, qui étaient les animatrices des soirées théâtrales. Mais 
pour les femmes des classes plus élevées aussi, le théâtre représentait une distraction appréciée, très souvent proposée aussi dans les petits théâtres (qui ne manquaient presque jamais dans les maisons des nobles) où elles se produisaient avec le cercle de la famille et des amis et pour eux. Elles en ont laissé des souvenirs dans leur journal, elles l'ont raconté dans leurs échanges épistolaires.

Si la soirée au théâtre restait en grande partie une expérience des classes les plus élevées, aux spectacles diurnes, qui se déroulaient dans les théâtres plus populaires et souvent dans les arènes, le public changeait : ouvriers, artisans, commerçants, mais aussi travailleurs et jeunes filles romantiques s'y pressaient ; pour eux on montait des spectacles « spéciaux », aux teintes fortes, avec des héroïnes féminines car ces séances étaient destinées aux blanchisseuses qui se reposaient du travail pénible des lessives ou aux travailleuses.

Une autre distraction très féminine était le bal. À ce propos, il faut faire quelques observations. Alors que du cercle, lieu exclusivement masculin, les femmes étaient habituellement exclues, le cercle ouvrait ses portes aux dames, quand leur présence servait à créer une ambiance gaie et frivole, du moins comme l'entendaient les membres de sexe masculin ; pour les femmes, au contraire, en particulier pour les jeunes filles, le bal était une occasion de rencontre, un moment de socialisation auquel les mères préparaient leurs filles très scrupuleusement et avec une attention méticuleuse, suivant les principes inspirés par la bonne tenue, l'élégance, l'amabilité, la modestie. C'étaient là les qualités que les jeunes filles devaient faire apprécier au moment de leur entrée dans la société, débuts qui advenaient généralement à l'âge de dix-huit ans environ, à une soirée dansante.

Et pour cette occasion les manuels d'éducation étaient bourrés de conseils et de recommandations. Ainsi Mantea (Gina Sobrero) écrivait-elle dans son manuel du savoir-vivre Le buone usanze (Les bonnes manières) :

«Au bal, la jeune fille ne va pas trop décolletée, c'est de très mauvais goût [...]. Elle ne danse jamais deux fois avec le même cavalier, mais elle peut dans la soirée lui accorder plus d'un tour ; en dansant elle se tient droite mais pas raide morte, elle n'a pas l'air de s'abandonner dans les bras de son compagnon, elle ne boude pas mais il ne faut pas qu'elle bavarde trop ou qu'elle rie avec son danseur; elle ne doit pas le regarder dans les yeux, mais elle ne doit pas non plus tourner la tête d'un autre côté comme s'il lui répugnait ; enfin elle est polie et sérieuse d'abord parce qu'elle doit l'être, ensuite parce qu'elle ne peut qu'y gagner »3.

Le bal était aussi une distraction populaire. Sans aucun caractère officiel dans ce cas, les soirées de bal se déroulaient de façon plus spontanée, les comportements étaient plus naturels.

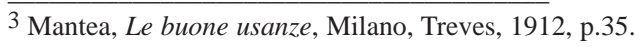




\section{SORTIR : LA FEMME NOUVELLE}

Le long XIXe siècle, qui s'ouvre, selon les historiens, par la grande révolution en France et se termine par la Première Guerre mondiale, voit les femmes entrer sur la scène politique avec Olimpie de Gousge qui rédige une Déclaration des droits de la femme et de la citoyenne en 1791, et avec leur présence individuelle dans les clubs jacobins ou leur participation collective sur les places. Ce siècle les repousse dans la famille, dans la condition de compagne de l'homme qu'on estime fondamentale pour elles, de reproductrice de l'espèce, d'éducatrice des enfants. Il les fait entrer dans le monde du travail au moment de la révolution industrielle et, dans ce nouvel espace, l'individu femme peut devenir semblable à l'individu homme, au travailleur et au citoyen jusqu'à rompre les liens symboliques qui le rattachent à son père et à son mari, et enfin il lui permet d'accéder, par le féminisme naissant, à des espaces publics pour une participation à la vie politique.

C'est dans la deuxième moitié du XIXe siècle qu'un nouveau modèle féminin commence à s'affirmer, que les contemporains appelaient « la femme moderne » et que l'historien E. J. Hobsbawm a défini comme "la femme nouvelle »4. Distinguer ce qui caractérise cette modernité et où les traits de la nouveauté apparaissent de façon plus évidente signifie faire une lecture au féminin d'une histoire lue jusque-là en grande partie comme une histoire d’hommes. Les espaces occupés ou occupés différemment constituent un élément important pour ces évaluations.

C'est certainement la rencontre avec le monde industriel qui a provoqué les transformations les plus évidentes. Dans la société préindustrielle la vie de la femme est caractérisée par l'indissolubilité des tâches domestiques et du travail : à la campagne la femme travaille comme l'homme, chez les artisans elle aide son mari dans la gestion de la boutique. Mais c'était une époque où les espaces ne se distinguaient pas : maison et lieu de travail coïncidaient et les rythmes irréguliers étaient imposés par des facteurs internes et externes à la famille, au groupe, au village. De même les activités de fabrication maison typiquement féminines s'exerçaient dans le cadre domestique.

Le processus de modernisation, dont la révolution industrielle constitue le moment fort, transforme en partie aussi les modèles féminins. Cela est bien sûr essentiellement un effet de la révolution économique mais aussi de la séparation de la maison et du lieu de travail. Certes, pour une grande partie des femmes cette nouveauté marqua un recul, et signifia les réduire au rôle de ménagères, sujets qui n'étaient plus en mesure de produire un revenu; pour d'autres au contraire ce fut l'occasion de sortir de la maison, de trouver un nouvel espace et un nouveau travail qui ne soient plus ceux de la bonne, de la servante mais aussi ceux de la vendeuse, de l'employée, de l'infirmière, de l'institutrice.

$\overline{4}$ E. J. Hobsbawm, L'età degli imperi, Roma-Bari, Laterza, 1987. 
"La femme moderne pour nous est celle qui, libérée des préjugés médiévaux, rassérénée et forte grâce à une juste conception de la vie, rompt le joug séculaire que l'homme lui imposa selon la vieille théorie du droit du plus fort, et tout en restant féminine par sa douceur et sa bonté, sait défendre sa propre dignité et attribuer un prix à son travail ».

C'est ainsi qu'en 1905 sur les pages de La donna socialista (un des hebdomadaires les plus intéressants destinés aux femmes du XXe siècle qui ne faisait que commencer) la directrice Ines Oddone Bitelli proposait à ses lectrices le nouveau modèle féminin, en tant que présence consciente auprès de l'homme à la maison et à l'extérieur, dans le monde de l'économie domestique et familiale, dans celui du travail comme dans celui de l'engagement social.

Donc sortir : des habitudes, de la maison, du monde familier, de la tutelle des pères, des frères et des maris. Sortir : pour acquérir une plus grande liberté de mouvement dans la vie sociale. Sortir, comme l'écrit Michelle Perrot ${ }^{5}$, physiquement : se promener dans les rues, entrer dans les cafés, participer à un meeting, voyager. Ce qui signifiait aussi renouveler les espaces et en occuper de nouveaux : ceux de l'engagement social, ceux de l'engagement politique et ceux, plus personnels, du temps libre.

La multiplication des offres, des occasions, la diffusion de nouvelles modes contribuèrent également à ce renouvellement des mentalités et des mœurs. L'une des premières est la mode des bains de mer. Si la mer dispensait largement ses bienfaits salutaires, les stations balnéaires dispensaient beaucoup d'espace et de temps pour le divertissement. Et les dames y avaient un rôle de premier plan et des places réservées. Le bain de mer ne constituait qu'un petit moment de la vie balnéaire, qui se déroulait en grande partie sur la terre ferme ; non sur la plage mais au cercle sportif, au café, dans les salles de bal. La plage était une ligne de frontière inhospitalière, mouvante, poussiéreuse, fastidieuse quand le vent se levait. L'absence d'une vie de plage dans la culture balnéaire du XIXe (il est opportun de le répéter d'autant plus qu'il s'agit de femmes) était due aussi au fait qu'on ne reconnaissait aucune fonction thérapeutique au soleil, et que découvrir son corps était considéré comme immoral : longues chemises, robes de plage, peignoirs jusqu'aux pieds constituaient l'équipement indispensable pour les baigneurs. L'exposition en maillot de bain, surtout pour les dames, devait être réduite au minimum nécessaire et les structures des équipements balnéaires étaient essentiellement conçus pour préserver les baigneuses des regards. Et si sur les plages du nord les baigneurs, entièrement habillés, étaient conduits jusqu'à l'eau dans des cabines en bois tirées par des chevaux. Sur les plages méditerranéennes, on préférait les cabines qui donnaient directement sur la mer, et seulement à cet endroit-là les baigneurs et les baigneuses, après avoir ôté leurs vêtements et

\footnotetext{
5 M. Perrot, «Uscire », in G. Fraisse-M. Perrot, Storia delle donne. L'Ottocento, Roma-Bari, Laterza, 1991.
} 
endossé des maillots extravagants, pouvaient se tremper et se baigner. Et on faisait très attention à éviter toute immoralité dangereuse : les cabines des hommes et celles des femmes étaient soigneusement séparées.

L'utilisation des bords de mer et une familiarité grandissante avec la plage, dès le début du nouveau siècle, furent les signes de l'évolution des comportements des vacanciers. L'accoutumance avec «les activités et les gestes de la plage » qu'hommes et femmes acquirent progressivement produisait des changements non négligeables dans leurs comportements. Les milieux, les structures, la façon de s'habiller, tout changeait. Les femmes furent elles aussi les artisans de ces changements, en commençant à porter des maillots qui "sont ce qu'on peut imaginer de plus gracieux » et qui sont décrits ainsi sur les pages du Secolo illustrato (1892) :

« bas, noirs de préférence. Un corset serrera la taille, mais un corset tout à fait spécial en toile ajourée, en tulle, en canevas ou fileté, sans ressorts, avec de simples baleines, fermé devant par de petites ailes qui se croisent derrière et se serrent à volonté ».

Le maillot de bain ne libérait pas le corps de la femme, au contraire il lui comprimait le buste encore plus que ne le faisaient les habits normaux, et ces mille oripeaux, ces fanfreluches et ces gracieux lacets empêchaient en fait les mouvements, l'exercice de la natation et symbolisaient l'immobilité, l'oisiveté absolue à laquelle les femmes étaient contraintes.

Mais il suffit d'attendre quelques décennies et tout, ou presque, changea également sur les plages, espaces de plus en plus accueillants, bien équipés pour recevoir non seulement les aventureux ou les téméraires, mais les premiers amateurs d'un corps parfaitement bronzé. Le bronzage, mode bénéfique mais aussi hédoniste, conquit le sexe féminin encore plus que les hommes, les femmes se sentant de plus en plus libres de montrer leur propre corps. Il s’agit certainement d'une émancipation des mœurs, mais la nécessité de répondre aux exigences d'une industrie naissante telle que l'industrie de la cosmétique n’y fut pas étrangère, avec en particulier les crèmes hydratantes capables de maintenir la peau douce en lui donnant en même temps cet aspect sombre et raffiné, ce hâle en somme. Pour la femme de l'après Première Guerre mondiale le modèle le plus audacieux fut celui de Coco Chanel qu'une photographie de 1918 montrait étendue au soleil, " librement » dévêtue mais portant des gants parce qu' « une femme du monde ne pouvait ni en public ni en privé montrer des mains de travailleuse ».

Sur les plages, la femme du $\mathrm{XX}^{\mathrm{e}}$ siècle put donner libre cours à ses aspirations, faire ce que jusque-là, elle ne pouvait réaliser que dans des espaces clos : pratiquer un sport et libérer son corps des lacets, corsets, dentelles et froufrous ; plus aucune femme ne se sentait exemptée de porter, au bord de la mer, dans les journées ensoleillées d’été un maillot bénéfique à sa santé, qui en même temps en augmentait le charme et les capacités de séduction. 


\section{TOUTES SPORTIVES}

Le sport a accompagné la formation de la femme nouvelle en lui donnant de nouveaux espaces, une grande liberté de mouvement, et aussi un habillement plus léger, débarrassé des crinolines encombrantes, des corsets rigides et des mille lacets et cordons qui l'enveloppaient. La bicyclette devint un des symboles de cette petite révolution. Quand, au début, les femmes à bicyclette se montraient seulement dans les cercles sportifs, on estimait qu'il s'agissait simplement d'un passe-temps mondain, mais les femmes à bicyclette en ville étaient observées d'un regard de reproche et critiquées (il était inévitable pour monter sur le vélocipède de remonter sa jupe et de montrer sa cheville). On en vint à dire que pédaler n'était pas naturel pour les femmes, et même nocif pour leur santé. On utilisa l'arme de l'ironie pour essayer de ralentir une mode qui se répandait rapidement, on dénonçait le danger des femmes à bicyclette, on se servait des récits de collisions avec des voitures ou des personnes qui se promenaient tranquillement sur les trottoirs pour mettre au pilori les cyclistes.

Mais le vélocipède «était trop beau, nouveau, élégant, pratique, salutaire. Ainsi, un jour, même la fille du bourgmestre a enfourché le deuxroues. Un an plus tard sa mère l'imitait »6.

C'était le début du nouveau siècle et désormais l'époque où les pédaleuses étaient des merles blancs n'était plus qu'un souvenir. Grâce au nouveau moyen de transport les femmes sortaient de chez elles, et on les dota aussitôt de manuels de comportement pleins de normes plus ou moins progressistes. Quelques-uns avec un certain sens de l'ironie se souciaient de l'aspect physiologique et conseillaient aux femmes-cyclistes de s'asseoir correctement et de "disposer la selle de manière qu'elles ne soient pas obligées de trop soulever les jambes et qu'elles puissent étendre commodément les bras pour saisir le guidon » (Vademecum delle velocipediste). D'autres rappelaient aux dames que, dans toutes les situations, elles ne devaient pas oublier de se tenir de façon impeccable et de tout faire « avec mesure ».

Dans les milieux petits bourgeois, conservateurs par tradition, les dames qui pédalaient continuèrent longtemps à être traitées de "virago », ou pire encore de «femmes émancipées ». En 1896 une journaliste anglaise dit qu’elle était convaincue qu'une femme sur sa selle de bicyclette ne pouvait en aucun cas inspirer le désir d'être protégée et en tirait la conclusion qu'elle ne pouvait "éveiller l'intérêt de l'autre sexe ». En 1897 dans un journal de Hanovre on pouvait lire un article dont l'auteur allait jusqu'à soutenir que «les hommes préfèrent rester célibataires, plutôt que passer la vie aux côtés d'une pédaleuse ».

Des inquiétudes encore plus fortes étaient suscitées par la question de la chasteté des filles en âge de se marier, quand elles pratiquaient ce sport, ou ce

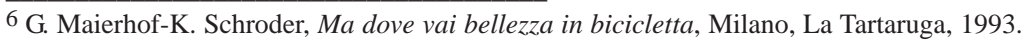


passe-temps si dangereux et si audacieux : le fait alarmant était que «les pédaleuses se casaient plus tôt que les autres » et pouvaient rencontrer leur futur mari sans le consentement de leur famille. C'est pourquoi les manuels de savoir-vivre pour les femmes insistaient sur la nécessité que les dames de compagnie ne laissent jamais seules les jeunes filles, ni même dans les écoles pour cyclistes. Et que dire alors du tandem?

« Grâce au tandem la dame instaure un rapport de plus grande familiarité avec son accompagnateur, c'est pourquoi le savoir-vivre impose, avec de bonnes raisons, qu'en compagnie de la dame il y ait toujours un proche ou un ami de la famille ».

Mais les femmes décidèrent de plus en plus nombreuses de pédaler et même de pédaler toutes seules : le rédacteur d'un autre vade-mecum pour les cyclistes, paru en 1897 était sûrement dans le vrai quand il indiquait la bicyclette comme un instrument appelé à briser l'étiquette, à rompre les conventions.

Par le sport, ou mieux encore par l'exercice de la gymnastique les femmes découvrirent d'autres espaces publics et privés, non seulement physiques mais aussi mentaux, et surtout l'espace de leur propre corps et la nécessité de lui consacrer une bonne partie de leurs loisirs.

Grâce à la propagande en faveur de la gymnastique et surtout en en faisant une matière scolaire, médecins, hygiénistes, pédagogues de la fin du siècle dernier entendaient former des jeunes filles douées d'une plus grande assurance, des caractères plus forts, des mères plus généreuses. La femme moderne devait se rénover non seulement dans le caractère mais aussi physiquement.

L'exaltation de ce double aspect de mère solide dans l'esprit et dans le corps connut son apogée durant les régimes totalitaires du $\mathrm{XX}^{\mathrm{e}}$ siècle. $\mathrm{Par}$ exemple, le fascisme soutenait des modèles consolidés, entre autres le modèle de la femme occupant rôles, espaces et temps séparés et spécifiques par rapport à ceux de l'homme. On essayait de cette façon de combattre ce mythe américain qui commençait à hanter l'imagination de beaucoup d'intellectuels en Italie comme d'ailleurs dans une grande partie de l'Europe. La culture américaine défiait les vieilles distinctions entre élite et peuple, mais aussi entre hommes et femmes. En Amérique, disait-on, toute jeune fille dès qu'elle peut subvenir à ses besoins se libère de la tutelle paternelle et maternelle, et se percevant comme une unité séparée de l’homme, elle veut avec un sans-gêne grandissant en occuper les espaces, en suivre les modèles même pour ses loisirs.

C'est aussi pour combattre ces nouvelles modes que le fascisme imposa aux jeunes femmes italiennes les vieux rôles d'épouse et de mère exemplaires, non sans les amplifier de façon non négligeable. L'ange du foyer ne devait pas limiter son action de service et d'aide à l’intimité du foyer, mais l'étendre à la société toute entière : assistance et propagande, éducation et hygiène des enfants, économie domestique, culture du jardin potager de la maison, assistance sociale dans les campagnes, dans les usines, dans les colonies à la mer et à la montagne, c’était là ses tâches supplémentaires, des travaux féminins jamais en rivalité avec ceux des hommes. Naturellement personne ne 
se demandait combien de temps la femme devait consacrer à ces activités, mais il est évident qu'elle les exerçait pendant ses loisirs, ou plutôt qu'elle prenait le temps sur ses loisirs. À cela s'ajoutait aussi le temps pour les assemblées, les parades, les défilés, les séances de gymnastique auxquels les femmes ne pouvaient pas se soustraire car ils étaient considérés comme des moments privilégiés de leur formation, comme un pivot de la politique du régime : de la politique démographique à la politique autarcique, avec une implication psychologique et idéologique aussi qui revêtit formes et mesures plus amples que prévu.

Parmi les initiatives les plus importantes on peut citer l'obligation de l'éducation physique liée à la nécessité de donner une nouvelle sève à une population débilitée par la malnutrition, par les maladies endémiques et les très mauvaises conditions d'hygiène des villes, des maisons et des coutumes. L'introduction de l'éducation physique comme matière obligatoire à l'école, à côté d'une série d'organisations au caractère purement sportif, fit connaître à la femme une dimension de la vie inhabituelle pour elle : la fréquentation de gymnases et de stades, la promiscuité avec l'autre sexe. La culture du sport féminin promue par le fascisme eut des effets considérables : beaucoup de jeunes filles pratiquèrent un sport et au cours des samedis fascistes des années trente, des groupes scolaires entièrement féminins participaient à des manifestations de gymnastique rythmique ou aux défilés. Pour la première fois des compétitions régionales et nationales d'athlétisme, de basket et de natation furent organisées.

La propagande à la fois prévisible et naïve pour inciter la femme à pratiquer une activité physique, convainquit progressivement les masses féminines de la nécessité de faire du sport, en considération de la valeur sociale et donc politique de cette activité. Il n'y eut pas, en revanche, une évaluation des changements profonds que cette propagande pouvait produire, car on ne comprit pas alors l'influence que le sport allait avoir comme facteur de changement au niveau de l'individu et de la société. En fait, avec le temps, des signes évidents révélèrent que la femme s'affranchissait peu à peu de la docile passivité avec laquelle jusque-là elle s'était conformée aux modèles de féminité que la tradition lui avait imposés.

Un signe révélateur de ce processus de transformation peut être vu dans le fait qu'elle commença à accepter l'éducation physique non comme une obligation ou un devoir mais comme un choix.

La femme «nouvelle » commença à prendre l'habitude de se ménager ou du moins à se chercher des espaces de temps destinés non seulement aux soins de sa personne, mais aussi à des activités ludiques telles que les activités sportives, et elle découvrit aussi qu'elle pouvait refuser de s'identifier avec le rôle de mère : pour accomplir son devoir de mère - qu'elle continuait à considérer comme le plus noble - il n'était pas nécessaire de s'annuler en lui et pour lui. 
Le sentiment de libération que cette découverte-conquête provoqua en elle l'incitait à prendre mieux soin de son corps et à ne pas renoncer à son charme même après l'accouchement (ce sentiment, toutefois, est resté longtemps élitaire, il ne s'est étendu à un grand nombre de femmes que durant ces dernières décennies, où l'on a vu se multiplier les salles de gymnastique fréquentées par des femmes de différents milieux sociaux et avec des horaires fonctionnels pour ménagères, employées, travailleuses, retraitées).

Si ce processus de détachement des rôles traditionnels, pendant les années du régime fasciste, concerna surtout les milieux urbains, les classes moyennes et celles de la haute bourgeoisie, effleurant à peine les zones rurales (où, entre autres, le taux des jeunes qui manquaient l'école était encore élevé, quand la scolarisation était le moyen privilégié de l'initiation à l'éducation physique), la diffusion de la culture du sport devint un phénomène de mœurs. La presse prit conscience du phénomène et dans les journaux féminins conseils, encouragements, recommandations se multiplièrent. Dans ce but de divulgation de la gymnastique, aux côtés de la presse, la radio se mobilisa : allumée à la bonne heure, sœur radio pouvait donner les ordres pour l'exécution d'exercices utiles. Et les journaux à la mode commencèrent à proposer des «modèles sportifs » créés par l'industrie de l'habillement qui, comme l'industrie cosmétique, était toujours prête à tirer profit des changements et des conditionnements des mœurs.

Comme il a été dit, cette culture du sport exclut beaucoup de catégories sociales et s'implanta en particulier dans les milieux de la haute bourgeoisie où elle prit souvent un caractère snob qui en dénatura le rôle et les fonctions les plus authentiques. Cela devint une mode, pour les femmes qui pouvaient se le permettre, de pratiquer des sports tels que le golf, la voile, l'équitation, et les meetings sportifs se transformèrent en rencontres mondaines telles qu'elles l'avaient été au début. Les loisirs comme le ski, la natation, le tennis, la régate de voiliers avaient pour les jeunes filles des années trente la même fonction que l'art de jouer d'un instrument ou de converser imposés aux jeunes filles de leur âge du siècle précédent : ils permettaient de vivre en société, ils offraient l'occasion de rencontres avec des jeunes gens de bonne famille et par conséquent augmentaient la possibilité d'un excellent mariage.

Quand on commença à percevoir les premiers effets que la promotion du sport avait produits sur les habitudes des femmes, on s'alarma et on tenta de dresser de nouvelles, ou plus exactement de vieilles barrières. L'activité physique des femmes fut accusée de provoquer des dommages à l'appareil génital et de porter atteinte à la pudeur. Sociologues, écrivains, médecins, et bien sûr l'Église commencèrent à diffuser des informations alarmantes concernant les effets nocifs du sport sur la procréation, mission féminine par excellence. Le seul élément positif de cette polémique rétrograde fut l'entrée en scène de médecins du sport, ce qui démarra la recherche scientifique dans le domaine des rapports entre physiologie féminine et activité physique. 
Une guerre vint à nouveau rompre ce système, une guerre qui appela les femmes à des tâches nouvelles et différentes ; elles n’eurent plus le temps de se consacrer à elles-mêmes justement quand elles commençaient à s’habituer à le faire.

Et ce ne fut certes pas facile de recommencer dans l'après-guerre, quand tout en leur attribuant des fonctions partiellement actives par rapport au passé, le monde qui les entourait continuait à nourrir des préjugés, des préventions à leur égard et à les laisser à mi-chemin entre une famille hiérarchisée et une société qui se modernisait, entre un corps de mère et un corps qui pouvait oser.

Les femmes devaient s’engager à nouveau sur un chemin montant pour atteindre des résultats à des moments différents dans les domaines politique, économique et social.

Le tableau semble changer seulement au cours de ces dernières décennies. En effet, c'est quand un changement dans la relation du couple, accompagné d'un nombre croissant d'appareils électroménagers, qui libèrent les femmes et leur permettent d'avoir du temps libre et c'est quand, dans le même temps, la science médicale a associé directement le corps sain et le corps athlétique que la passion pour le sport explose à nouveau. Partout des salles de sport, des centres de bien-être très fréquentés par les hommes et les femmes, où il est possible, comme il est d'usage de dire aujourd'hui de "se maintenir en forme ». Et quand la salle de gymnastique n'est pas près de chez soi (lieu d'ailleurs où on socialise beaucoup) et que l'on a quand même envie de se donner du mouvement on peut se consacrer au hobby de la course à pied, ou bien s'installer devant le téléviseur, insérer une des nombreuses cassettes vidéo qui présentent des cours de gymnastique, et exécuter les mouvements que des vedettes ou des cover-girls plus ou moins célèbres proposent.

\section{Bibliographie :}

On a peu écrit sur le temps libre des femmes, nous signalons sur ce sujet :

F. Tarozzi, «Il tempo libero delle donne tra Otto e Novecento », in D. Gagliani et M. Salvati (dir.) Donne e spazio nel processo di modernizzazione, Quaderni di Discipline storiche dell'Università di Bologna, Bologna, Clueb, 1995, et la section Donne e tempo libero des miscellanées Tempo libero e società di massa qui comprennent des essais de F. Tarozzi, M. De Giorgio, G. Turnaturi, M. Ridolfi. Des pages intéressantes sur le temps des femmes peuvent être lues dans la collection Storia delle donne, de M. Perrot et G. Duby, en particulier L'Ottocento (dir. de G. Fraisse et M. Perrot), Rome-Bari, Laterza, 1991 et Il novecento (dir. de F. Thebaud), Rome-Bari, Laterza, 1992 ; et encore dans : M. De Giorgio, Le Italiane dall' unità ad oggi, RomeBari, Laterza,1992 ; V. De Grazia, Le donne del regime fascista, Venise, Marsilio,1993. Une lecture agréable : le petit livre de G. Maierhof-K. Schröder, Ma dove vai bellezza in bicicletta, Milan, éd. La Tartaruga, 1993. Pour saisir la mentalité et le climat culturel des milieux bourgeois du XIX ${ }^{\mathrm{e}}$ les manuels de savoir-vivre sont particulièrement utiles, 
comme pour le $\mathrm{XX}^{\mathrm{e}}$ les livres d'économie domestique enseignée aux jeunes filles. Parmi les premiers nous rappelons : Marchesa Colombi, La gente per bene. Leggi di convenienza sociale, Turin, ed. "il giornale delle donne »,1877 ; M. Serao, Saper vivere, Florence Laudi, 1900 ; Mantea, Le buone usanze, Milan, Treves, 1912. Parmi les seconds : E. Randi, Economia domestica, Florence Marzocco,1949 ; C. Piersanti, Lezioni di economia domestica, Bologne, Zanichelli, 1950. 



\title{
DU DIVERTISSEMENT AU LOISIR À TUNIS : LE CAS DE LA DANSE
}

\author{
Maud NICOLAS \\ Université Blaise Pascal, Clermont-Ferrand II, LAPRACOR
}

Si on décrit le loisir comme un « temps dont on peut disposer en dehors de ses occupations ordinaires ", alors la danse à Tunis répond à cette définition d'une manière particulière. En effet, danser est une activité non seulement largement pratiquée par les Tunisiens dans le cadre de fêtes diverses telles que les mariages, les anniversaires ou les fêtes entre amis mais également dans le cadre plus intime de la maison, en particulier par les femmes.

Cette danse (dont la gestuelle se décrit principalement par des déhanchés qui suivent fidèlement le rythme de la musique) peut être qualifiée de " divertissement », puisqu'elle est revendiquée par les hommes et les femmes comme une manière de " se défouler » (c'est l'expression consacrée). Le lecteur voudra sans doute avoir une idée plus précise de la danse évoquée ici : on peut sans doute la rapprocher par sa forme de la célèbre "danse du ventre » (belly dance pour les anglophones) racontée par les orientalistes (écrivains, poètes et peintres) des siècles derniers et devenue objet de fantasmes en Europe. Comme celle-ci, l'essentiel des mouvements se situe au niveau du bassin. Toutefois, on ne rencontre que rarement à Tunis les ondulations et les vibrations caractéristiques de la "danse orientale » (cette fameuse danse du ventre originaire du Moyen-Orient). Des déhanchés, que permet l'alternance du poids du corps sur une jambe puis sur l'autre, caractérisent le "style » tunisois, encadrés par un port de bras systématique (de chaque côté du buste et légèrement fléchis) et quelques rotations de poignets (qui approchent souvent une main près du visage). Le costume des danseuses (et des danseurs !) à Tunis ne ressemble 
pas non plus au costume deux pièces porté habituellement par les danseuses orientales professionnelles (soutien-gorge et jupe fendue). On danse à Tunis habillé pour la circonstance, c'est-à-dire en robe de soirée ou ensemble fwta w blwza (pantalon bouffant et haut qui laisse voir une partie du ventre) quand il s'agit d'une fête habillée (la dernière soirée d'un mariage par exemple), et en costume pour les hommes. Mais on peut aussi danser à la maison, « entre soi », c'est-à-dire entre membres d'une même famille et amies proches, en tenue d'intérieur : ceci n'empêche pas les femmes, pour l'occasion, de se nouer un foulard ou une ceinture autour des hanches pour aider à mieux danser...

La forme de danse évoquée ici est celle que l'on rencontre au Maghreb de manière quasi systématique dans les fêtes évoquées ci-dessus. Pratiquée par un grand nombre de femmes et d'hommes, elle est l'expression d'une joie et constitue un des plus importants centres d'intérêt de la soirée pour les invités et leurs hôtes. Sans dénomination spécifique à Tunis, nous pouvons cependant qualifier cette activité de "danse sociale », dans la mesure où elle est un événement important partagé par un grand nombre de Tunisiens et Tunisiennes, qu'ils soient danseurs ou spectateurs de la fête.

Cette danse est bien plus encore, lorsqu'elle devient pour les femmes tunisiennes un moyen de s'évader des contraintes qu'impose leur vie quotidienne : ainsi la danse ponctue aussi parfois les tâches ménagères en s'y inscrivant comme une pause bienfaisante. Une Tunisienne me confiait ainsi, lors d'une enquête de terrain : "La dernière fois que j'ai dansé, c'était hier, en faisant à manger avec ma fille. Il y avait une chanson à la télé... ».

La danse se présente alors comme un moment privilégié qui entoure les activités répétitives et fatigantes d'un halo de gaieté. En témoignent les premières images du film franco-tunisien Satin Rouge, qui montrent l'héroïne effectuant le ménage en dansant. La danse en tant que "palliatif » ou " récompense » à la tâche est vécue de même par les hommes, en particulier les ouvriers et les dockers, dont le peintre tunisien Zoubaï Turki a immortalisé le rbwkh, la présentant comme la danse des « zoufris » (les ouvriers) qui, après avoir peiné, dansent pour oublier leurs lourdes tâches (Ill. 1).

\section{DANSES DIVERSES}

En fait, diverses formes de danse coexistent en Tunisie: des danses de discothèques (où la techno est en vogue) au folklore revisité (de nombreuses troupes professionnelles se produisent dans les hôtels pour touristes), en passant par la création contemporaine, les cours de danse classique, les performances des danseuses orientales professionnelles et les danses de transe qui se pratiquent lors des visites hebdomadaires aux saints, le paysage de la danse est multiple. Elles ne répondent cependant pas toutes avec la même constance à ce qu'on peut qualifier de pratique de loisirs ou de divertissement. Des préoccupations artistiques ou religieuses sous-tendent certaines d'entre elles, dont nous ne traiterons donc pas ici (même si ces préoccupations n'excluent pas une certaine forme de divertissement). 


\section{Illustration 1 : Dessin de Zoubaï Turki}

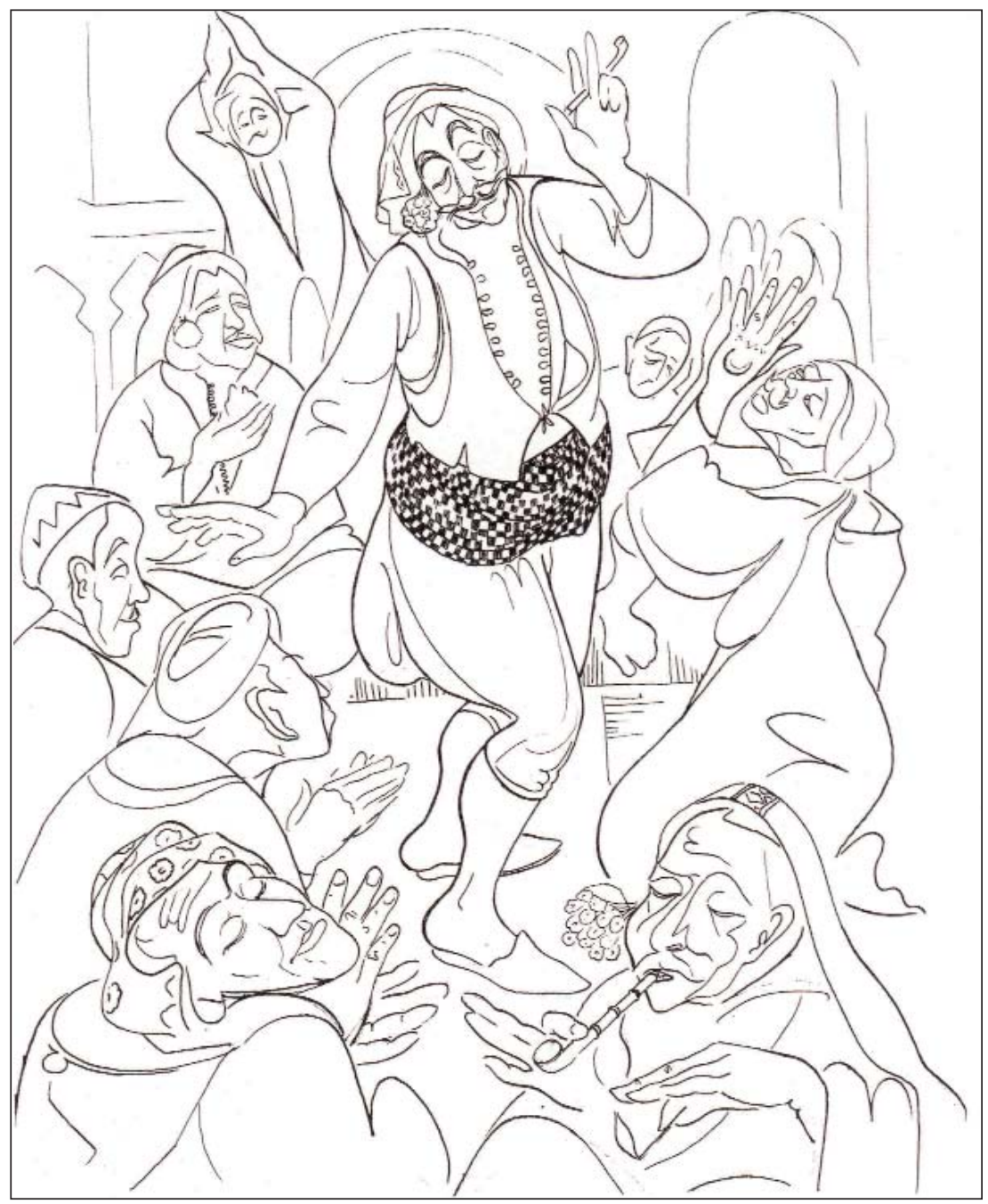

Le cas de la Troupe nationale des arts populaires est intéressant : plus qu'objet de divertissement, celle-ci est devenue un outil de promotion du patrimoine tunisien. L'histoire de cette troupe remonte à la fin des années 1950, au lendemain de l'indépendance de la Tunisie. Dans le souci de «sauvegarder le patrimoine chorégraphique » (ce sont les termes officiels), et surtout de renforcer un sentiment d'identité nationale, pour ce pays qui retrouvait sa liberté perdue depuis plus de 70 ans, le gouvernement décide en 1958 de confier cette sauvegarde à Salah El Mahdi, docteur en musique et personnage éminent dans ce domaine. Celui-ci a l'idée de faire des recherches dans le domaine de 
la danse folklorique en vue d'en créer un enseignement au Conservatoire national de musique et de danse, puis un groupe folklorique. Il confie alors aux danseurs folkloriques de l'époque (dont les célèbres sœurs Zina et Aziza) de collecter et de fixer les figures chorégraphiques des différentes régions du pays. Les chorégraphies dansées par la Troupe nationale des arts populaires de Tunisie sont des tableaux propres à chaque région du pays.

Même si les recommandations de l'époque insistaient sur l'importance de " garder le caractère du spectacle dans son concept d'origine ", et sur le minimum de l'arrangement des pas, la démarche s'inscrit dans un processus de folklorisation qu'ont connu bien des pratiques traditionnelles à travers le monde. Ainsi en Tunisie on n'hésita pas à faire appel à un chorégraphe d'Union Soviétique pour donner aux danses traditionnelles une forme chorégraphique "propre " ${ }^{1}$, c'est-à-dire établir des règles strictes quant au port de bras et à l'exécution des pas. Le souci des créateurs de ces danses folkloriques était également de leur donner un caractère scénique que leurs contextes d'origine ne proposaient pas forcément (Ill. 2). La danse y est mise en scène et décontextualisée, et constitue un divertissement pour les spectateurs, comme c'est le cas avec d'autres troupes régionales, plus petites, qui se produisent dans les nombreux hôtels du pays. Le phénomène est généralisable à l'ensemble des pays du monde arabe si l'on en croit C. Poché2.

\section{Illustration 2 : Troupe Laghbabi}

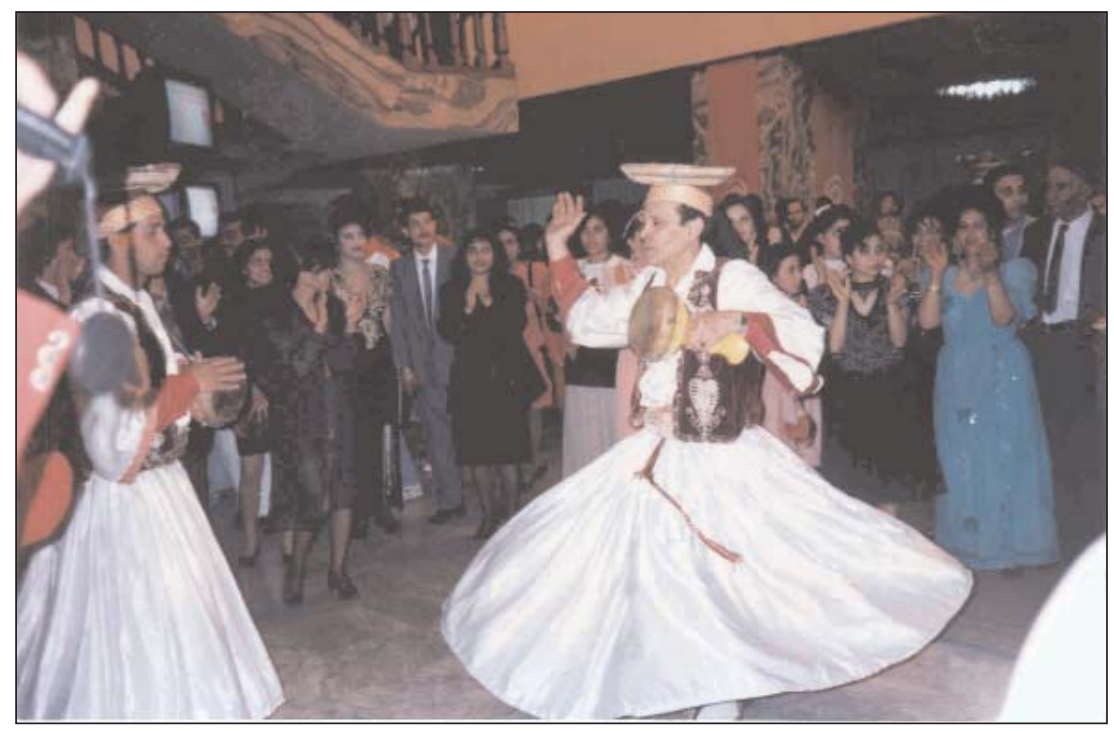

1 Selon les termes de Mohamed Laghbabi, danseur et ancien professeur de danse traditionnelle au Conservatoire national de musique et de danse de Tunis.

2 Djamila Henni-Chebra et Christian Poché (dir.), Les danses dans le monde arabe ou l'héritage des almées, Paris, L’Harmattan, 1996. 
Le parcours historique et géographique de la Troupe nationale des arts populaires de Tunisie en fait une excellente ambassadrice du pays dans le monde entier. Sa participation à de nombreux festivals véhicule une certaine image de la Tunisie et joue en quelque sorte le rôle de « vitrine » du pays.

Mais c'est encore la danse sociale ou « danse de tout le monde » (même si l'appellation n'est pas tout à fait juste, tout le monde ne rejoignant pas forcément la piste de danse) évoquée ci-dessus qui correspond le mieux à une forme de divertissement généralisé. Il est en effet difficile d'imaginer une fête à Tunis sans musique et donc sans danse, toutes deux participant souvent du même phénomène.

Contrairement à la danse folklorique qui présente des séries très distinctes de figures et d'enchaînements chorégraphiques, celle des fêtes paraît a priori assez uniforme. On va voir toutefois qu'il s’agit d'une pratique tout-à-fait structurée et que ce divertissement, loin d'être anodin, participe au contraire de manière active à la vie de la communauté réunie.

\section{DU DIVERTISSEMENT SYMBOLIQUE...}

Les mariages à Tunis se déroulent sur plusieurs jours, les fêtes se distribuant entre les familles du marié et de la mariée selon un ordre précis, pour ne faire qu'une le dernier soir. Si la danse est présente tout au long des fêtes - elle accompagne les préparations culinaires au sein du foyer, prend la forme de la transe lors de la soirée du hanna (pose du henné) de la mariée, se pratique aussi largement entre hommes, lors de la soirée du marié - c’est lors de cette ultime soirée qu'elle concentre le plus d'enjeux. Elle rassemble en effet un grand nombre de danseurs devant un public élargi, pour environ trois heures. Les mariés, assis dans des fauteuils le plus souvent loués pour l’occasion, sont installés sur une estrade décorée et font face aux invités tout en étant séparés d’eux par la piste de danse. L’orchestre est placé à côté du « trône » des mariés. De fait, il se distingue lui aussi des invités par la piste de danse. Cette disposition en vis-à-vis est toujours respectée, quel que soit le milieu social auquel appartiennent les familles qui organisent le mariage. Circulaire, elle organise l'espace de telle manière que les danseurs, qui sont des hommes et des femmes de l'assistance - précédés, quand les familles en ont les moyens financiers, d'une troupe professionnelle - se retrouvent, en décidant de se lever pour danser, au centre de la cérémonie. Cette position stratégique confère à l'acte de danser un pouvoir symbolique significatif. En effet, la « séance » de danse (qui se répète toujours selon le même schéma) semble constituer, au fond, l'ultime objectif de cette cérémonie. Les mariés ne sont pas au centre de l'espace. Certes, l'estrade sur laquelle ils sont juchés permet à tous les invités de les voir. La tenue même de la mariée, apprêtée, parée et « coincée » dans son fauteuil, les pieds souvent posés sur un coussin, renforce le caractère de « survisibilité » qu’on lui attribue. Pourtant, c'est la piste de danse qui, au centre de l'espace, va retenir l'attention des invités car c’est là précisément que « tout se joue » (Ill. 3). 


\section{Illustration 3 : Ronde lors d'un mariage}

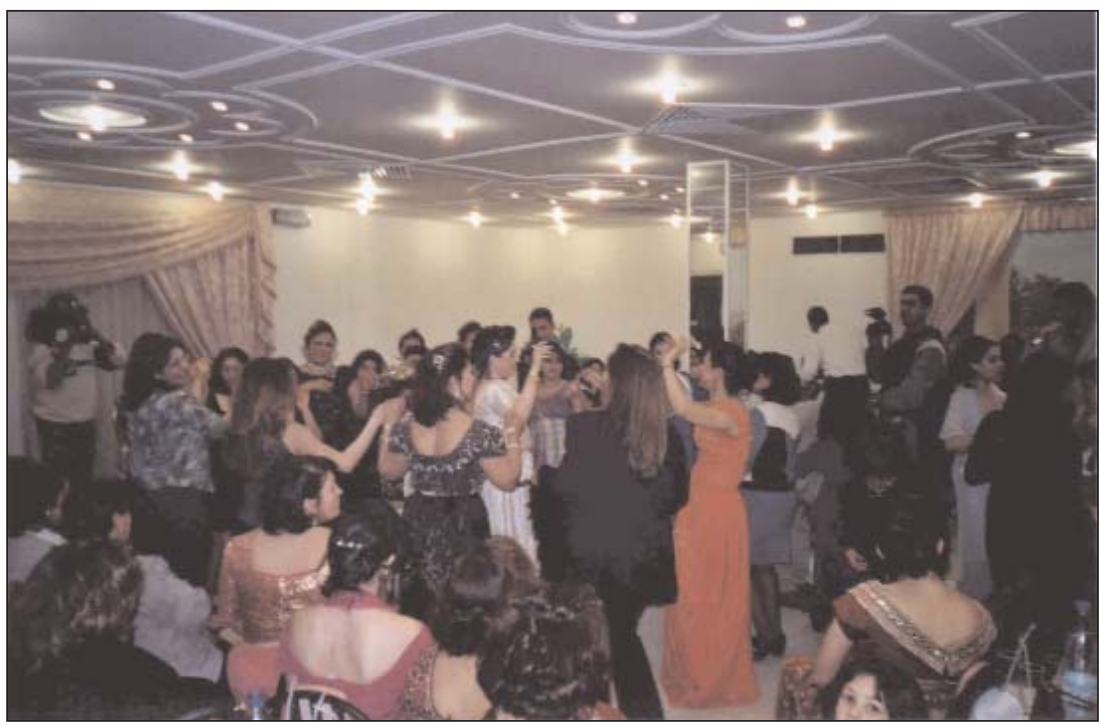

L'accès à la piste de danse est organisé selon un ordre précis et un droit conféré par le degré de connaissance (voire d’intimité) qui lie l'invité à son hôte. Il dépend aussi de ce que l'on peut appeler le « jeu de l'invitation », et qui concerne l'ensemble des règles qui décident, ou plutôt autorisent l'accès à la piste (M. Nicolas, 2000).

Lors d'une fête de mariage, les parents des mariés se doivent de danser, et nombreux sont ceux qui disent n’avoir jamais dansé excepté au mariage de leur fils ou de leur fille. D’ailleurs, toute l'assemblée attend cette danse symbolique, qui ne dure parfois que quelques secondes, et n’hésite pas, si elle se fait attendre, à leur agiter les bras par force. Pourquoi cette résolution à danser ? Les invités eux-mêmes, s’ils sont proches de la famille des mariés, sont très souvent tirés de leur chaise et dansent quelques secondes pour faire plaisir à leurs hôtes. Et bien c'est que danser est considéré comme une manifestation de sa joie. Danser, c'est approuver avec son corps l'objet de la fête, c'est apporter la preuve qu'on est heureux pour les familles, et que la fête est réussie. Cette pratique, par certains côtés, a quelque chose à voir avec la logique de don contre don au sens où l'entend $\mathrm{M}$. Mauss.

Ce divertissement a priori anodin et sans forme chorégraphique énoncée («on danse, c’est tout », entend-t-on le plus souvent), se caractérise tout de même par des formes récurrentes, notamment des figures de groupe. Très souvent, des rondes se forment sur la piste, les mains jointes et les bras levés au-dessus du plan horizontal. Les danseurs tournent autour des mariés en continuant d'exécuter la structure de pas. Puis, au bout de quelques instants, une des meneuses provoque un autre mouvement lui aussi récurrent : tout le 
monde s'accroupit, en se lâchant les mains pour mieux les frapper l'une contre l'autre. De cette façon, les mariés, qui, au centre du cercle autour duquel s'est rassemblé un certain nombre de proches, étaient jusque-là cachés du reste des invités, apparaissent alors clairement au reste de la salle. Cette "mise en valeur » semble être une manière, en se baissant, de les élever au-dessus de tous et dure quelques secondes. Puis la ronde reprend quelques instants avant de se dissoudre, action qui s’ensuit généralement du retour, accompagné, des mariés vers leur trône.

La taille de la ronde peut varier de trois à une quinzaine de personnes. Les petites rondes impliquant les mariés sont réalisées avec un parent, ou plus rarement une amie très proche, comme le frère de la mariée qu’on oblige souvent à rejoindre la piste malgré lui, mais qui se prête généralement au jeu en riant. Étonnante démonstration chorégraphique de la structure familiale élargie, cette danse vient légitimer l'arrivée du couple dans le groupe familial. À ce propos, J.-M. Guilcher a montré la signification symbolique de cet acte, démontrant que la ronde est, parmi toutes les formes de danse, celle qui possède «au plus haut degré ce pouvoir d'unification » ${ }^{3}$.

Composé exclusivement de membres des deux familles et d'amis les plus intimes, cet ultime cercle épure une fois de plus la sphère du privé en évacuant tout élément n’appartenant pas à celle-ci. Ne reste plus, dans ce cercle, que la structure « originelle » à partir de laquelle s'organise le tissu social de la cérémonie. C’est le moment aussi où les familles se mélangent. Les sœurs appellent les frères, et la ronde devient pour un bref instant le symbole de l’unité familiale. Les deux familles (respectivement du marié et de la mariée), qui jusqu’à présent avaient chacune leur tour organisé les festivités du mariage se retrouvent soudain réunies, ne formant plus qu'une seule et même famille. Elles en fournissent la preuve lorsque les frères dansent ensemble, les sœurs aussi. Enfin, les frères des uns dansent avec les sœurs des autres, signe d'une confiance entendue garantie par cette nouvelle fraternité.

Ce type de ronde, soudain et momentané, apparaît comme une constante dans les mariages tunisois. Quand on regarde de plus près qui sont les membres de la ronde, on s’aperçoit que ce sont, en très grande majorité, des membres de la famille et des amies proches. L’absence - souvent constatée d'hommes, hormis le marié, au centre du cercle, s'explique par le fait qu'ils sont moins nombreux sur la piste que les femmes. La ronde se constituant à partir des personnes qui dansent, ces derniers « échappent » à cette prestation soudaine, la meneuse n’allant pas chercher des personnes parmi le public. Mais on peut se demander si la prédominance des femmes n'est pas un élément proprement maghrébin de l'organisation sociale. On sait que la ronde rassemble, confirme les liens qui unissent ses membres, qu'elle est une représentation symbolique de la société. Les bras levés, les applaudissements tournés vers les mariés, la ronde célèbre l’union de deux êtres qui va perpétuer

3 J.-M. Guilcher, La tradition populaire en Basse Bretagne, Paris, Mouton, 1976, p. 57. 
la lignée. On « fait danser » ces derniers, (car ils ne décident pas, on les amène sur la piste) au centre, et leur couple est symboliquement accepté, et même célébré, par la ronde. En dansant ensemble au sein du cercle, ils sont intégrés à la communauté présente. Et cette communauté de femmes est connue par les ethnologues pour être au cœur du tissu social. Les femmes maghrébines sont à l'origine de l'organisation d'activités collectives (fêtes, cérémonies, pratiques religieuses) déterminantes pour la cohésion des groupes communautaires. Il est donc logique que l'intégration de cette union matrimoniale se déroule au sein d'un contexte féminin, qui plus est s'il est composé de membres des deux familles réunies. Car plus que l'union de deux individus, c’est celle de deux familles qui est célébrée ici.

\section{... AU LOISIR ORGANISÉ}

Cette pratique corporelle se caractérise par un savoir-faire qui se transmet par apprentissage diffus, résultat d'une immersion précoce et prolongée des enfants tunisiens dans un bain culturel musical et gestuel très présent en Tunisie, comme dans le reste du Maghreb. Dès leur plus jeune âge, les Tunisiens s'exercent et sont entraînés à la danse qui est alors associée à la joie et vécue comme un moment de détente joyeuse et d'amusement.

Cependant, l'apprentissage traditionnel ne suffit pas toujours à garantir la perpétuation de ce savoir-faire. Le cadre urbain est alors le lieu du passage d'une pratique de divertissement au loisir organisé : en effet, des cours de danse dite "danse orientale » sont apparus depuis quelques années dans la capitale qui prennent, en quelque sorte, le relais de la transmission générationnelle. Leur fréquentation est réservée à une certaine tranche de population, le niveau de vie de la plupart des Tunisiens ne permettant pas de se payer ce genre de distraction. Mais n'est-ce qu'une distraction ? Les motivations exprimées par les élèves (des femmes dont l'âge varie de l'adolescence à la cinquantaine environ) de ces écoles et conservatoires privés laissent penser qu'elles se situent au-delà du simple loisir. En effet, si le savoir technique dansé et la dépense physique sont des éléments recherchés, c’est un certain bien-être qui est revendiqué, bien-être proche de celui que procure le défoulement ressenti lors des fêtes où la danse est largement présente. Pour ces femmes souvent surmenées (entre activité professionnelle, tâches ménagères et éducation des enfants, il leur reste peu de temps pour s'occuper d'ellesmêmes), ces espaces-temps hebdomadaires de danse leur offrent la possibilité de "retrouver leur corps », selon l'une d'elles. On peut à ce propos avancer l'idée que la danse, dans le contexte des cours de danse orientale, s'inscrit dans la tradition maghrébine de l'entretien du corps féminin. Certains de ces cours de danse orientale sont d'ailleurs dispensés à Tunis dans un centre de beauté qui propose aussi épilation et manucure.

La démarche de s'inscrire aux cours de danse orientale s'explique aussi - de manière plus discrète - par la recherche de la performance artistique. Les 
motivations de certaines femmes se présentent ainsi : "Ma sœur se marie bientôt, il faut absolument que je sache danser ». Une explication s'impose : dans les mariages de la capitale, l'animation de la soirée est confiée habituellement aux femmes de la famille, généralement aux sœurs de la mariée ou, à défaut, à ses cousines ou à ses belles-sœurs. En « ouvrant le bal » et en invitant les gens à danser, ces «GO » sont investies d'une mission particulièrement importante dans la mesure où la réussite d'un mariage - et on sait à quel point c'est l'honneur de la famille qui est en jeu lors d'un mariage au Maghreb - se mesure au nombre d'invités qui occupent la piste de danse. Les cours de danse sont alors un des moyens de prendre confiance en soi et de se préparer à cette exposition sociale imminente. Il sera alors bien vu par tout le monde qu'elles fassent preuve d'une certaine aisance sur la piste de danse, aisance d'autant plus appréciée si elle est reconnue comme naturelle. On omet donc de préciser qu'on a pris des cours...

\section{DANSE ET IDENTITÉS}

Cette motivation à savoir danser est avant tout féminine. Les hommes dansent à Tunis mais en moins grand nombre que les femmes dans un contexte mixte, et plus volontiers entre eux. Leur virilité est en jeu. En effet, danser dans la capitale, contrairement à ce qui se passe en milieu rural où les hommes investissent en majorité l'espace de danse, est reconnu comme une activité féminine. Ceci s'explique sans doute en partie par l'importation en milieu urbain des musiques et d'une gestuelle venues d'Orient (la « danse du ventre » d'Égypte et du Liban) identifiée comme féminine et qui se distingue radicalement des sauts et de la vitalité masculine des danses rurales tunisiennes. En bougeant le bassin, les hommes prennent le risque de « danser comme une femme » ou pire, "danser mieux qu'une femme », ce qui porterait atteinte, devant témoins, à leur identité sexuelle (l'assemblée des fêtes de mariage portant une attention appuyée à ce qui se déroule sur la piste de danse).

Pour une femme, en revanche, le fait de savoir danser est reconnu comme une qualité, et constitue une part importante de leur identité de genre. D’où leur application à perfectionner ce savoir-faire en milieu intime (par des exercices chez elles, face à leur miroir pour les adolescentes) ou dans un contexte plus formel, en s'inscrivant à un cours de danse.

À Tunis, la danse est avant tout une affaire de femmes. Contrairement aux campagnes, où des danses spécifiquement masculines permettent aux hommes de s'exprimer en toute légitimité, la capitale limite la danse à une forme féminine.

Peu d'alternatives s'offrent finalement aux hommes qui désirent danser dans le contexte de la dernière fête de mariage : qu'ils se décident à danser et leurs mouvements se doivent d'être beaucoup plus minimalistes au niveau du bassin que ceux des femmes, privilégiant une position de bras spécifiquement 
masculine. Ils peuvent aussi faire les pitres et neutraliser ainsi tout soupçon qui porte atteinte à leur virilité. De l'avis des Tunisiens, seules les femmes dansent pour le plaisir de danser. Les hommes, eux, peuvent danser mais ils sont souvent invités à le faire. Cette invite peut d'ailleurs être pressante et difficile à refuser. Il est particulièrement intéressant à ce propos de voir combien les gestes pendant la danse répondent à des codes, contrairement à ce que pourrait laisser croire le discours sur la danse : «tu sais, on danse comme ça, ça vient naturellement ».

Concernant les mouvements de bassin des hommes, par exemple, le mouvement est quantifié. Ainsi « les femmes font-elles le mouvement à $100 \%$, les hommes à $20 \%$, et si c'est plus, ça devient louche». Ou encore, à propos d'un homme dansant particulièrement bien la danse orientale, on dit de lui en souriant qu' «il danse mieux qu'une femme ». Tout cela en dit long sur les catégories de genre que véhicule la danse, et les risques de stigmatisation, voire d'exclusion pour ceux qui dérogeraient aux règles.

La danse des hommes est d'autant plus délicate à gérer qu'aux représentations sociales de genre viennent s'ajouter celles de classes. Les professions reconnues comme supérieures à Tunis se sont réappropriées le rapport au corps de l'ancienne noblesse tunisoise, qui se caractérise par la réserve. Chefs d'entreprise, responsables d'administrations, patrons de banque, avocats, médecins et autres cadres supérieurs se doivent, en public, de contrôler leur enthousiasme et leurs émotions en général. La notion de public implique ici la possibilité que parmi les invités des fêtes soient présents des collègues de travail ou des subalternes. C'est pour garantir la hiérarchie que les chefs ne dansent pas. La règle s'applique seulement aux hommes, les femmes étant libres de danser dans la limite des règles déjà énoncées, et d'une manière correspondant à leur statut social, c'est-à-dire doucement et avec réserve. Du côté masculin, les membres de la famille du marié ou de la mariée sont bien évidemment autorisés à danser. C'est même socialement recommandé. Pour les autres, « cela ne se fait pas ». Parallèlement, la réserve n’est pas forcément le propre des chefs, quand certaines conceptions coraniques relatives à la manière de se comporter en public rentrent en jeu. C'est le haya, la pudeur (réserve, honte), au commencement réservée aux femmes qui, comme l'explique A. Bouhdiba, a fini par déborder le cadre des rapports entre les sexes pour désigner une manière d'envisager les rapports avec l'autre au sein des hiérarchies collectives surtout avec les « supérieurs » : parents, personnes âgées, frères aînés, professeurs, maîtres, patrons, compagnons de travail.

«Il n'est pas jusqu'aux prophètes eux-mêmes qui ne soient pas pris de haya, devant Dieu, devant ses anges et face à la majesté de toute révélation »4.

\footnotetext{
4 Abdelwahab Bouhdiba, La sexualité en Islam, Paris, PUF, 1984, p. 94.
} 
Les rapports entre hommes influencent aussi la manière dont ils abordent la danse. Dans les espaces publics ouverts, tels la rue, le café, et tout autre endroit de rencontre, l'attitude masculine a toujours le souci de faire preuve de virilité, et implique souvent de s’imposer face aux autres. Le modèle masculin fondé sur l'honneur s'accompagne, surtout chez les jeunes gens, d'une nécessité de rapports de force. Or l'espace de danse implique le risque de perdre la face, de devenir - comble du déshonneur - sujet de moquerie pour un danseur s’il est le seul à s’y avancer. Ses amis peuvent, hilares, faire des commentaires raillant sa manière de danser. Cependant, dans certaines occasions, l'espace de danse peut aussi devenir le lieu pacifié de la sociabilité masculine. E. Buisson-Fenet ${ }^{5}$ a montré en Algérie que dans les salles de concert les relations entre hommes se trouvaient brusquement pacifiées, autorisant pour une fois un répertoire d’attitudes liées à la danse et à la joie d'écouter de la musique ensemble, une certaine forme de confiance envers l'autre.

Cette forme pacifiée de sociabilité, décrite ici dans les concerts de musique populaire peut se retrouver sur les pistes de danse de mariage en milieux populaires tunisiens, comme par exemple dans les villages de l'agglomération de Tunis. Les jeunes hommes, souvent ivres, s'adonnent à la danse de manière collective (rondes, accolades incessantes) sans précautions par rapport à l'image qu'ils renvoient aux invités présents.

On peut considérer que les hommes, dans les situations dansantes « à comité de contrôle », c’est-à-dire rassemblant un large panel d’invités, se retrouvent entraînés dans une stratégie de « négociation », dont les paramètres relèvent de la place qu'ils occupent dans leur environnement social et culturel. Car plus encore que les femmes, dans cette mise en scène de la société que représente l'événement danse, ils ont à perdre en dansant. L’opinion publique est stricte en matière de dépassement des limites du « socialement correct » que peut constituer la danse.

L'étude de la danse à Tunis montre que loin d'être une activité anodine, elle s'inscrit au contraire de manière forte dans le fonctionnement de la société. On constate qu'au-delà du célèbre contrôle du corps des femmes au Maghreb, le corps des hommes est lui aussi soumis à un contrôle social sévère. Si les séances de danse constituent un espace-temps privilégié de la confirmation du statut de genre, danser n'implique pas les mêmes effets selon que l'on est homme ou femme, et requiert donc des modes de gestion différents d'une même pratique.

La danse, à Tunis, en tant que loisir, se présente donc à la fois comme l'expression de la participation à la vie publique et comme un facteur

\footnotetext{
5 Emmanuel Buisson-Fenet, « Relations pacifiques et relations agonistiques : les jeunes Algériens et la musique durant le ramadan ", in M. Anastassiadou (éd.), Sociétés et cultures musulmanes d'hier et d'aujourd'hui, Lettre d'information de l'AFEMAM, 10, Actes de la XI ${ }^{\mathrm{e}}$ réunion des chercheurs sur le monde arabe et musulman, fév. 1996, p. 295.
} 
d'intégration à la communauté. Sa fonction socialisante se vérifie à la fois dans les fêtes et dans le contexte plus formel des cours de danse.

\section{BIBLIOGRAPHIE :}

Hanna J.-L., 1987 [1979], To dance is human : a theory of non-verbal communication, Chicago, University of Chicago Press.

1988, Dance, Sexe and Gender. Signs of identity, dominance, defiance and desire, Chicago-London, The University of Chicago Press.

Kurath G. P., 1960, « Panorama of Dance Ethnology », in Current Anthropology, vol I, 3, may, 233-254.

Lacoste-Dujardin C. et Virolle M., (dir.), 1998, Femmes et hommes au Maghreb et en immigration. La frontière des genres en question. Études sociologiques et anthropologiques, Paris, Publisud.

Lane E. W., 1833, « Public Dancers », in Modern Egyptians, vol II, London, Charles Knight and Co, 98-105.

Lièvre V., 1987, Danses du Maghreb, d'une rive à l'autre, Paris, Karthala.

Mead M., 1969, « Le rôle de la danse », in Mours et sexualité en Océanie, Paris, Plon, 373-380.

Nicolas M., 2000, « Ce que “danser” veut dire. Représentations du corps et relations de genres dans les rituels de mariage à Tunis », in Terrain, 35, 41-56.

2001, « De la fête familiale au cours de danse : apprentissage de la danse à Tunis », in Correspondances, 67, Bulletin d'information scientifique de l'Institut de Recherche sur le Maghreb Contemporain, 10-17.

Pasqualino C., 1998, «Femme, danse, société chez les Gitans d'Andalousie », in L'Homme, 148, 99-118.

Turner V. W., 1990 [1969], Le phénomène rituel. Structure et contre-structure, Paris, PUF.

\section{FILMOGRAPHIE :}

Tlatli M., 2000, La saison des hommes, Film tuniso-français, $124 \mathrm{mn}$. 1994, Les silences du palais, Film tuniso-français, $127 \mathrm{mn}$.

Amari R., 2002, Satin rouge, Film franco-tunisien, 100 mn. 


\section{II - FORMES ET USAGES DU TEMPS ET DE L’ESPACE}





\title{
LES LOISIRS DU PRINCE DANS L'ITALIE DE LA RENAISSANCE : ENTRE DILETTO ET STUDIO
}

\author{
Florence ALAZARD, \\ Université François-Rabelais de Tours, CESR
}

\begin{abstract}
"Messeigneurs, vous devez savoir que je ne suis pas satisfait du Courtisan s'il n'est aussi musicien, et si, outre la capacité de lire une partition, il ne sait pas jouer de divers instruments ; car, si nous y pensons bien, on ne saurait trouver aucun repos des fatigues et aucune médecine pour les esprits malades qui soit plus louable et honnête en temps de loisir que celle-ci ; et principalement dans les cours, dans lesquelles, outre le soulagement des ennuis que la musique donne à chacun, on fait beaucoup de choses pour contenter les dames »1.
\end{abstract}

On aura reconnu un des passages les plus célèbres du Livre du Courtisan de Baldassare Castiglione. Dans l'Italie de 1528, il semble donc admis d'une part que le courtisan organise le loisir du prince et d'autre part que la musique participe du loisir du prince. L'idée que le prince a droit à un moment de répit qu'il occupe à autre chose qu'à gouverner les hommes n'est pas neuve. Reprenant des thèmes développés par Cicéron, Pline et Horace, les hommes de la première Renaissance avaient opposé la vie saine à la campagne à la vie urbaine frénétique et avaient élu la villa comme lieu de repos et d'éloignement du travail citadin. C'est d'ailleurs dans ce cadre que s'étaient développées les réflexions de l'entourage du pape Innocent III sur la recreatio corporis². Déjà

1 Baldassare Castiglione, Le livre du courtisan (1528), tr. fr. Alain Pons, Paris, Gérard Lebovici, 1987, p. 89.

2 Agostino Paravicini Bagliani, Le corps du pape, tr. fr., Paris, Seuil, 1997. 
se trouvait mis en évidence le lien indéfectible entre le loisir et le travail, en particulier le travail de celui qui gouverne : sans cette recreatio, point de travail efficace. Pour les hommes de la Renaissance, la distraction n’est pas le plus sûr moyen pour s'éloigner du travail, mais au contraire l'assurance de rassembler ses forces en vue d'un labeur plus intense.

Castiglione le réaffirme avec plus de vigueur encore dans son Courtisan lorsqu'il fait dire au seigneur Ottaviano :

« et tantôt par le moyen de la musique, tantôt par celui des armes et des chevaux, tantôt par celui des vers, tantôt par des propos d'amour et par toutes les manières dont ont parlé ces seigneurs, [le Courtisan] tiendra l'esprit [du prince] continuellement occupé à des plaisirs honnêtes, en y imprimant néanmoins toujours aussi, comme je l'ai dit, en compagnie de ces invitations alléchantes, quelque habitude vertueuse $»^{3}$.

Ce n'est donc pas seulement parce qu'il repose que le loisir musical permet au prince de se livrer avec davantage d'ardeur au gouvernement de ses sujets, mais c'est parce qu'il produit un effet positif sur le prince qu'il assure ce dernier de pouvoir accomplir son devoir de la meilleure façon possible. Sans le loisir, point de prince. Grâce au loisir, une activité politique soutenue.

Dans l'Italie du XVIe siècle, les textes des dédicaces de partitions témoignent de la fonction de la musique dans l'activité princière : instrument privilégié du diletto princier, la musique occupe une place de choix dans la vie du prince. Rares sont ceux qui, comme Luca Marenzio, prennent prétexte de la perfection du prince pour en conclure que l'activité musicale ne lui est pas nécessaire ${ }^{4}$; la plupart reprend une idée développée par Claudio Monteverdi dans la dédicace qui prélude à son troisième livre de madrigaux à cinq voix lorsqu'il précise que ses chants sont : «acerbi forse \& insipidi al suo finissimo gusto, ma pero conceputi, \& fatti per lei »5.

La musique est donc faite pour le prince ; elle est pensée pour lui. Et d'abord parce qu'elle remplit une fonction spécifique dans son activité. Ce diletto, récurrent dans les textes dédicatoires, n’est jamais pensé comme un plaisir ou une distraction détachés des autres occupations du souverain et susceptible d’être appréciés par un chacun. Au contraire, bien qu'invariablement tenu pour un loisir, il est toujours considéré comme une pratique indissolublement liée à l'activité politique du prince, au fait qu’il consacre la majeure partie de son temps à gouverner. Ruggiero Giovannelli l'écrit clairement dans la dédicace qu'il offre au cardinal Aldobrandino :

\footnotetext{
3 Id., p. 333.

4 «Quanti beni, et perfettioni, V. A., hà in se medesma ond'ella non hà bisogno di cosa alcuna fuor di se per dilettarsi, o giovarsi », Luca Marenzio, Il terzo libro de Madrigali a Sei voci, Venise, Herede di Girolamo Scotto, 1585.

5 Claudio Monteverdi, Il terzo libro de Madrigali a Cinque voci, Venise, Ricciardo Amadino, 1592.
} 
«E à chi convengono piu l'opere musicali, che à Lei, che sostenendo il gravissimo peso de gl'infiniti negotij, e del governo dello stato Ecclesiastico, e havendo tanta parte in ogni affare d'importanza della Christianità, ha bisogno alle volte di ristorar le forze e di rinfrancar gli spiriti, con la soavità della Musica, e del canto ? ${ }^{6}$.

Le prince n'a pas à pratiquer la musique comme un loisir en quelque sorte ostentatoire. Il n'a pas besoin de montrer qu'en consacrant une part non négligeable de son temps à l'art il aime le beau et qu'il doit donc être admiré pour cette capacité dont il fait preuve de pouvoir aussi être affecté par une émotion esthétique. Ce texte est plutôt l'occasion pour l'auteur de rappeler ce qu'est le travail du prince et à quel point il signifie pénibilité et fatigue. Dès lors se dessine également un envers du labeur princier: la recreatio assure l'efficacité du studio. Loin de s'opposer au travail, le loisir en est l'instrument privilégié. Dans ce contexte, la musique aide le prince à gouverner dans la mesure où c'est à sa source qu'il peut «retrouver ses forces et reprendre courage ». C'est également ce qu'entend faire savoir Paulo Gradenigo dans la dédicace qu'il adresse à Giacomo $S^{\prime}$ aranzo $^{7}$ : énumérant les trois fonctions habituelles de la musique - la capacité à faire passer le temps de façon vertueuse, les effets bénéfiques qu'elle produit sur l'auditeur lorsqu'elle le conduit à cultiver les vertus et le réconfort qu'elle apporte à celui que le travail a fatigué - le musicien ne retient que la dernière comme susceptible d'intéresser l'usage princier de la musique. Le prince en effet n'a guère le temps de se consacrer à la musique puisqu'il est trop occupé par les affaires politiques $^{8}$; il n'a pas non plus de leçon à recevoir de la musique puisqu'il est déjà fort bien doté en vertus ${ }^{9}$. En revanche, et comme une sorte de contrepoint au travail de l'homme politique, la musique aide celui qui est responsable de la bonne marche de l'État à supporter cette lourde tâche ${ }^{10}$. Point de temps, donc, à consacrer au loisir, mais un loisir qui se dilate et qui finit par phagocyter l'espace de travail du prince. La fonction thérapeutique de la musique participe pleinement de l'action qui consiste à gouverner les hommes. Ici, comme chez Ruggiero Giovanelli, l'art musical est pensé

\footnotetext{
6 Ruggiero Giovanelli, Il terzo libro de Madrigali a Cinque voci, Venise, Giacomo Vincenti, 1599.

7 Paulo Gradenigo, Il primo libro de Madrigali a Cinque voci, Venise, figliuoli di Antonio Gardano, 1574.

8 «la sappi dunque ch'io non glie la appresento per darle occasione, ch'ella passi il tempo virtuosamente, essendo proprio suo lo adoperarsi continuamente in negotij. dove pende la salute non solo della Venetiana, ma anco di tutta la Christiana Republica », id.

9 «ne anco glie la porgo à fine di prepararse, \& diporre nell'anima sua quei costumi; senza la virtù de'quali par che non si possi acquistare la vera prudenza : onde la Musica hebbe luogo tra le discipline, astrahendo l'anima ; la quale astratione altro non è, che una affettione di costumi intorno ad essa anima ; pero che ella è già adorna di tutte quelle virtù \& costumi, che ponno fra i più degni Heroi renderla chiara, \& illustre », id.

10 «Ma ben di essa le so libero dono per apportarle quel piacere nella relassatione dell'animo, che suo le essere medicina del dolore cagionato dalle troppo assidue fatiche », id.
} 
comme partie prenante et agissante : c'est parce qu'elle agit sur le prince en le délassant que ce dernier peut exercer son métier. On retrouve sous la plume de Christofano Malvezzi cette idée selon laquelle la musique vient seconder le prince en lui apportant le secours, le délassement nécessité par une activité qui le sollicite excessivement :

«Essendo io risoluto Illustre Signor mio mandare in luce alcuni miei Madrigali, \& sapendo certo quanto V. S. Illustre gradisca simili fatiche, \& quanta recreazione, \& conforto ella prenda della Musica, tenendola in quella stima, \& veneratione, nella qual si dee tenere, all'hora a che più, et diverse voci concordevolmente convenendo insieme, ne fanno soave concento, \& grata harmonia sentire, ho per cio intestimonio dell'affettione che io le porto, giudicato cosa convenevole, donarle, \& dedicarle queste mie compositioni »11.

Une fois encore, la musique est dite récréative pour le prince. Et, tout comme chez Gradenigo, la récréation du prince n’est pas un acte gratuit, uniquement tourné vers le plaisir. La raison pour laquelle le prince doit cultiver son goût pour la musique tient uniquement au fait que la musique est capable de faire cohabiter ensemble des voix différentes et de les rendre agréables à l'oreille. L'art musical n'est autre finalement qu'une forme d'organisation de sons très différents les uns des autres. Bien que la métaphore musicale souvent employée dans la plupart des textes contemporains ne soit pas ici explicitement revendiquée, il semble impensable que les musiciens et ses lecteurs n'aient pas en tête cette idée selon laquelle l'activité du prince, c’està-dire la façon dont il gouverne ses sujets, fonctionne un peu selon les mêmes principes d'organisation que ceux auxquels la musique doit se conformer. En somme, le prince, lorsqu'il se consacre à l’activité musicale - qu'il écoute ou qu'il pratique - ne se distrait pas au sens où la musique le détournerait de son activité principale ou lui permettrait de n’y plus songer. Au contraire, la musique lui permet de se livrer à la contemplation d'une image possible de son activité. On peut alors considérer le loisir musical du prince comme une continuité de l'action qui consiste à gouverner les hommes.

Une fois acceptée cette idée selon laquelle le loisir du prince est consubstantiel à son activité politique, une question demeure : le prince peutil, doit-il exceller dans ce diletto au point d'être reconnu par ses contemporains et par ses sujets non plus seulement comme un bon prince, mais aussi comme un savant musicien ? En effet, la fonction protectrice du prince, aussi complexe et importante soit-elle, n'est pas seule en cause lorsqu'il s’agit pour le musicien de placer sous tutelle son œuvre musicale. La compétence musicale du souverain est de fait très souvent présentée comme l'un des éléments essentiels dans le choix du dédicataire. Jacques de Wert insiste à deux reprises - et alors qu'il s’adresse à deux dédicataires différents -

11 Christofano Malvezzi, Il primo libro de madrigali a sei voci, Venise, Herede di Girolamo Scotto, 1584. 
sur l'importance de la connaissance musicale du prince. Ainsi lorsqu'il publie une dédicace au duc de Mantoue, Guglielmo Gonzaga :

«Non sarà ad alcuno meraviglia, se ad altri che à V. E. non ho voluto offerirli : si perche non conosco persona, che tanto lo meritasse per rispetto de la cognitione de la Musica ${ }^{12}$.

Il le répète encore quelques années plus tard alors qu’il dédicace un ouvrage à Leonora Medici :

«Hora gradisca V. A. come fautrice della virtù, \& come quella, che della Musica tiene intelligenza $» 13$.

On pourra bien sûr objecter que la plupart de ces dédicaces s’adressent à Guglielmo que l'on sait musicien et dont on est certain également qu'il a procuré un madrigal, voire plusieurs, à Jacques de Wert ${ }^{14}$ : il n’y aurait alors rien d'étonnant à ce que sa compétence soit valorisée et il nous serait interdit d'en conclure, par exemple, que le prince est en quelque sorte sommé d'acquérir une légitimité dans le domaine musical. C’est en tous cas l'impression qui peut s’imposer après la lecture de la dédicace que Francesco Soriano adresse au duc de Mantoue :

«Ho sentito molti di quegli, che dedicano opere sue à Principi grandi, molte volte dolersi, che quei signori eletti da loro per la grandezza dell'authorità, non havessero insieme tanto giuditio di quella professione, che potessero distintamente conoscere il pregio de i libri, che lor si dedicavano. Ma à me aviene apunto tutto il contrario : percioche sendo io resolutissimo di non offerire queste primitie mie ad altro Signore, che all'Altezza V. quando dall'altro canto considero, quanto essa oltre tutte le scienze piu gravi, \& oltre tutte le professioni convenienti à Prencipe, si anco instrutta maravigliosamente nelle cose della Musica »15.

Le musicien distingue ici très clairement ses collègues, avant tout soucieux de se placer sous les auspices d'un nom qui symboliserait une gloire,

$\overline{12}$ Giaches de Wert, Il quarto libro de madrigali a cinque voci, Venise, Antonio Gardano, 1567.

13 Giaches de Wert, Il primo libro delle canzonette villanelle a cinque voci, Venise, Angelo Gardano, 1589.

14 «Contemporary documents further show that Gonzaga was the author of one printed set of madrigals, one of motets, and one of magnificats. There are no publications attributed directly to Gonzaga, but Alfred Einstein suggested that the madrigal print be identified with an anonymous print brought out by Angelo Gardane in 1583 ; this has been substantiated by Claudio Gallico, who points out that the print contains a text referring to three Margheritas (mother, daughter and daughter-to-be) which could only have been written for or by Gonzaga. Further more, the first madrigal in the print "Padre del Ciel», is another version of a madrigal by the same title attributed to the duke in Giaches de Wert's fourth book of madrigals (published Venice, 1567)», Richard Sherr, "The publications of Guglielmo Gonzaga », Journal of the American Musicological Society, 33, 1978, p. 119.

15 Il primo libro de madrigali a Cinque voci, Venise, Angelo Gardano, 1581. 
de lui-même qui a su s'adresser à un prince, en l'occurrence Guglielmo, capable de comprendre son œuvre. Il serait faux cependant de considérer que ce souci ne préoccupe que les seuls musiciens susceptibles de se placer sous la protection du duc de Mantoue. D'abord, parce que de nombreuses dédicaces, adressées à d'autres princes que celui de Mantoue, font référence à une compétence musicale. Ainsi lorsque Jacques de Wert offre une œuvre à Alfonso II, c'est son intelligence musicale qu'il salue à travers les louanges qu'il adresse au concerto delle donne ${ }^{16}$. Ensuite, parce que, même lorsque le prince, quel qu'il soit, n'est pas reconnu comme un «professionnel » de la musique qui pratiquerait cet art avec assiduité, il est de toute façon presque systématiquement présenté comme un amateur éclairé qui évolue dans un univers musical qu'il est donc capable de décrire et de comprendre. On observe ainsi que la plupart des dédicaces à Alfonso rappellent qu'il entretient un ensemble de chanteuses virtuoses ${ }^{17}$; celles qui s'adressent au grand-duc de Toscane témoignent également de l'implication personnelle du prince dans la vie musicale ${ }^{18}$. Il serait outrancier également de penser évaluer la pertinence de ces allégations des musiciens qui revendiquent une tutelle éclairée : que Guglielmo ait été instruit en musique ne fait aucun doute; que d'autres princes soient reconnus par les musiciens comme avertis dans la science des sons, il n'est pas toujours possible de le vérifier. Mais ce qui importe, c'est de remarquer que la question de la compétence musicale du prince est récurrente dans les textes dédicatoires et de s'interroger sur la présence de ce thème : pourquoi cette référence constitue-t-elle un passage obligé dans la dédicace ? On peut certes répondre tout d'abord que la compétence du prince légitime

16 « Havrei commesso notabilissimo errore se dovend'io dar in luce questi miei componimenti di Musica fatti per la maggior parte in Ferrara ad altro personaggio indirizzati gli havessi che à $V$. A. Percioche à cui piu degnamente dedicare gli potev'io ? [...] Et essi in qual parte del mondo potrebbon esser meglio cantati che nella Corte di V. A. ? dove io non mi so ben risolvere qual sia maggiore o la maestria di chi canta o'l giudico di chi l'ascolta. Percioche lasciando stare di tanti altri eccellenti \& Musici, \& Cantori che sono nella sua numerosissima e perfettissima Capella : à cui non sono hoggimai note le meraviglie \& d'arte, \& di natura, la voce, la gratia, la dispositione, la memoria, \& l'altre tante \& si rare qulità delle tre nobilissime giovani Dame della Serenissima Signora Duchessa di Ferrara ? Il qual rispetto per se solo bastar dovrebbe à indurre tutti i compositori del mondo, che le loro opere indirizzassero à V. A. », Giaches de Wert, Ottavo libro de madrigali a cinque voci, Venise, Angelo Gardano, 1586.

17 Paolo Virchi loue ainsi la possibilité que lui offre le duc de Ferrare de faire chanter ses œuvres par des virtuoses : " cosi per havermi raccolto nella sua Corte nella quale sono huomini famosi, \& illustri in questa scienza e nell'altre, come per haver mi favorito in farne cantare la maggior parte di essi, \& gratiosamente udirli ; Là onde ho preso ardire di porli in luce, Ben é vero ch'io non attribuisco tanto al mio artifitio quanto alla soavità della voce di quelle Illustre Signore che li cantarno... », Il primo libro de madrigali a cinque voci, Venise, Giacomo Vincenzi \& Ricciardo Amadino, 1584.

18 Voir, par exemple, la dédicace de Giovanni Bernardino Nanino à Ferdinando III : « Non doverà parer maraviglia à Vostra Altezza, che io venga horà dedicarle, conme stesso, le primitie del mio ingegno, poi che à lei sola si rifuggon hoggi, \& come à lor proprio albergo vengono à demorarsi tutte le piu nobili scienze, \& le piu belle arti, \& massime questa della Musica... », Il primo libro de madrigali a cinque voci, Venise, Angelo Gardano, 1588. 
l'œuvre et lui confère en quelque sorte un label de qualité dont le musicien aurait tort de prétendre se passer. Mais encore ? Ce leitmotiv ne serait-il pas l'occasion de dire quelque chose des rapports qui lient le prince à la musique ? S'adressant aux comtes Girolamo Roverelli et Enea Montecucculi, Lodovico Agostini avait établi, neuf ans avant Francesco Soriano, cette distinction entre des dédicataires qui ne sont là que pour prêter leur nom et ceux dont la connaissance musicale est susceptible d'apporter une dimension supplémentaire - reste à savoir laquelle - à l’œuvre concernée :

«Per due principali, \& honorate strade caminano (per quel, ch'io ho osservato Illustri Signori miei) coloro, che dedicano altrui le sue fatiche, pero che altri solamente à principi le inviano per honorarsi del nome loro, o per riceverne guiderdone ; altri à quelli solo indirizzano i frutti dei studij suoi, i quali (o sieno Principi, o privati) si dilettano di quella professione, nella quale essi si sono con qualche loda affaticati, \& come i primi non biasimo punto, cosi approvando più il parere de i secondi, mi sono in questa mia dedicatione conformato con quelli. Onde sapendo certo quanto diletto prendino le Ill. S.S.V.V. della nobile, gioconda, \& grave professione della musica, \& quanto sia conforme alla Natura, \& genio di quelle ; ho preso per ispediente dedicarle questa mia operetta di Musica, tenendo per fermo, che debba esser da esse vista, cantata, \& ascoltata con viso allegro, con cor sincero, \& orecchie benignissime $» 19$.

Il existerait donc deux «écoles » dans le choix du dédicataire et le musicien, tout en affirmant ne pas se prononcer sur ceux pour qui importe la renommée de la personne à laquelle est consacré l’ouvrage, précise qu’il préfère s’adresser à des individus dont la compétence musicale est avérée et surtout reconnue. Deux groupes de termes semblent pouvoir expliciter la position d'Agostini : ainsi lorsqu'il parle de la «nobile, gioconda, \& grave professione della musica » et lorsqu'il précise à quel point la musique est « conforme alla Natura, \& genio di quelle ». Est développée ici l’idée selon laquelle doit exister une forme d'équivalence entre la musique et le prince : la musique n'a pas simplement des fonctions à remplir (distraction, instruction...), elle est aussi une image du prince dont les qualités - qui définissent le «genio » du souverain - peuvent lui être attribuées. En retour, la musique façonne le prince puisqu'elle suppose une écoute qui devra être adaptée : c'est "avec un visage heureux, un cœur sincère et des oreilles bienveillantes » qu'il faut goûter aux plaisirs de cette production sonore. Les qualificatifs répondent donc comme en écho à ceux qui caractérisaient la musique, à la fois "noble, joyeuse et grave ». Affirmer la compétence du prince, c'est donc à la fois reconnaître qu'il est peut-être le seul à pouvoir juger de la valeur de l'œuvre musicale ; c'est en tous cas admettre que l'œuvre ne se soustrait pas au jugement des hommes. C'est aussi l'occasion de dire que la musique fonctionne un peu comme un miroir pour le prince.

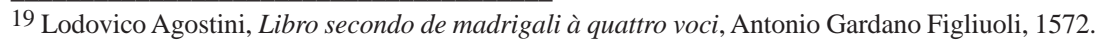


Le cas de Guglielmo, duc de Mantoue, est à la fois bien et mal connu. On sait qu'il a composé un certain nombre d'œuvres musicales ${ }^{20}$. Certaines d'entre elles ont été publiées anonymement, mais toutes ne nous sont pas parvenues. Il est frappant de constater pourtant à quel point l'activité musicale du duc de Mantoue est fort mal documentée. Dans l'article qu'il lui consacre, Richard Sherr est contraint de travailler essentiellement avec des dédicaces de partitions rédigées par d'autres musiciens : c’est parce que Agostini ou Belli font référence à la pratique musicale du prince, qu'il est possible de l'aborder. La correspondance qu'entretient Guglielmo avec Palestrina en est aussi un bon indicateur ${ }^{21}$. Mais, finalement, c'est assez mince. On ne dispose d'aucun texte du prince s'expliquant de ces œuvres et les contemporains - hormis donc certains musiciens choisis qui gravitent autour de la cour de Mantoue - semblent taire les expériences musicales de Guglielmo ${ }^{22}$. Cette absence de commentaires autour de l'activité musicale du duc, cette relative discrétion aussi sur des publications qui, anonymes, ne revendiquent pas leur caractère princier, si elle ne disent pas forcément quelque chose de cette dernière (de sa réalité, de son importance ou de sa qualité), témoignent probablement de la gêne que provoque chez les hommes de la fin du XVIe siècle la production musicale du prince.

Dans son Discorso sopra la musica publié en 1581, Francesco Bocchi recommande au prince de ne pas pratiquer la musique. Pour les contemporains, entre musique et politique, le prince doit choisir. Certes, le prince doit écouter la musique, il doit favoriser la création musicale, et permettre, en assurant sa diffusion par l'imprimerie, qu'un public le plus large possible ait connaissance des spectacles musicaux et des innovations musicales. Il n'empêche. Le prince, jamais ne doit se faire musicien. Peut-être plus que le cas de Guglielmo, c'est celui d'Alfonso, duc de Ferrare, qui retient l'attention de l'époque. On lui reproche de s'adonner trop facilement aux plaisirs artistiques et d'en oublier le travail quotidien et fastidieux que requiert l'administration d'un territoire. Giovanni Botero, grand théoricien politique de la Venise de la fin du XVIe siècle, met ainsi en exergue la préférence que le duc a accordé au plaisir et au loisir, au détriment des travaux qui s’avéraient pourtant nécessaires afin de maintenir le Pô dans son lit (« lasciando l'utile per il diletto »)23. Cette préférence a occasionné des conséquences terribles sur les campagnes avoisinant Ferrare et Botero de

\footnotetext{
20 Richard Sherr, art. cit.

21 Knud Jeppesen, « Pierluigi da Palestrina, Herzog Guglielmo Gonzaga und die neugefundenen Mantovaner-Messen Palestrinas, ein ergänzender Bericht », Acta Musicologica, XXV, 1953, p. 132-179 et Oliver Strunk, «Guglielmo Gonzaga and Palestrina's Missa Dominicalis », The Musical Quarterly, XXXIII, 1947, p. 228-239.

22 S'il est souvent fait allusion dans les dédicaces de partition à la très grande connaissance musicale du duc, les musiciens semblent éviter cependant d'évoquer trop précisément une réelle pratique de la musique et une véritable ambition créatrice chez le prince.

23 «Il duca Alfonso II di Ferrara, lasciando l'utile per il diletto, impiego alla Mesola il tempo, e le opere, che i communi erano obligati a dare per contener il Po nel suo letto, e per assicurar i campi dalle inondationi di quel fiume », Giovanni Botero, Relatione della republica venetiana, Venise, Giorgio Varisco, 1605, p. 116.
} 
suggérer que le choix d'Alfonso tenait peut-être à l'angoisse qu'il éprouvait à l'idée que son duché devait certainement échapper aux Este ${ }^{24}$ : il aurait alors volontairement sacrifié son territoire et porté ses efforts sur des œuvres plus éphémères qui, en tous cas, ne se lèguent pas aussi facilement qu'une principauté, dont aucun prétendant ne peut s’arroger la propriété. Pour l'observateur, donc, et surtout pour le théoricien du politique, la primauté accordée aux œuvres d'art ne doit pas toujours être louée, surtout lorsqu'elle se fait aux dépens de l'ouvrage habituel du prince. Tous les textes en tombent d'accord, ainsi qu'en témoigne cette chronique qui, décrivant le duché de Ferrare en 1598, remarque :

«tutta la piazza fatta in giardino piu tosto per luogo di piacere che per fortezza, come suono tutti gli luoghi fatti dall'ultimo Duca »25.

C'est l'excès qui est condamnable. Il n'est aucune raison de blâmer le prince tant qu'il parvient à se consacrer de manière équitable et aux loisirs et à son travail. Il faut en revanche le retenir de faire passer en priorité les premiers. Mais pas seulement. Car celui qui, partageant raisonnablement son temps entre la musique et l'administration, se croit cependant à l'égal du musicien, celui-là doit être dénoncé. Giovanni Antonio Palazzo, autre grand théoricien du politique entre XVIe et XVIIe siècles, réfléchissant aux sciences qu'il importe au prince de connaître pour bien gouverner, place l'Harmonie après l’Arithmétique et la Géométrie. Pour lui :

"l'Armonia conviene al Prencipe non perche lui debba quella esercitare, essendo, che molte cose, le quali hanno del leggiero o del meccanico, se ben si deono dal Prencipe sapere, tuttavia non si deono esercitare, e percio basta al Prencipe ascoltare al quanto l'armonia per rilassare l'animo da i gravissimi pensieri, e per inalzarlo alla Divina contemplatione ${ }^{26}$.

Bien évidemment, sont ici exposés les mêmes principes que ceux qu'énoncent les musiciens dans les dédicaces de leurs partitions : le prince doit écouter la musique car elle le repose du difficile et épuisant labeur qu'est le gouvernement des hommes et parce qu'elle lui permet de demeurer dans sa foi. Mais Palazzo introduit une nuance d'importance dans ce propos que tous sont susceptibles de tenir : si le prince doit écouter la musique, il ne doit pas lui-même en faire. Par cette précision, il suggère que la musique peut se prévaloir d'un statut particulier parmi l'ensemble des sciences - il les qualifie de spéculatives - que le prince doit cultiver. Ainsi qu’il l’écrit quelques lignes plus haut, ce dernier doit en effet exceller dans l'Astronomie, l'Arithmétique

\footnotetext{
24 «E forse che Alfonso, disperato, che il Ducato di Ferrara fosse per restar nella casa da Este, non sicuro di lasciarlo mal concio \& in tanti parti deteriorato », ibid.

25 Relazione di Ferrara, 1598, BAV (Biblioteca Apostolica Vaticana), Barb. Lat. 5356, fol. 1.

26 Giovanni Antonio Palazzo, Discorso del governo e della ragion vera di stato, Venise, s.e., 1606, p. 70 .
} 
et la Géométrie qui lui permettent de se distinguer dans l'art militaire27 et peuvent être vraiment exercées par le prince qui n’a rien à craindre de telles pratiques. La musique demeure donc un cas exceptionnel. Le prince pourra se faire, à l'occasion, mathématicien, jamais il ne devra s’inventer musicien. Si cette restriction n'est pas clairement justifiée, c'est sans doute parce que les raisons en sont évidentes. Parce qu'on ne maîtrise pas bien le fonctionnement de la création musicale et que l'inspiration inquiète, qu'elle n'est probablement pas digne du prince. Parce que, aussi, la musique oblige à distinguer celui qui pratique de celui qui profite : aucun bienfait, aucune vertu ne sont reconnus à la composition musicale ; la musique n’est bénéfique que lorsqu'elle est exécutée, lorsqu'elle peut finalement produire des effets sur son auditoire. Mais aucun musicien, aucun théoricien ne soutient que la création musicale est édifiante ou méritoire. Il faut donc se résoudre : le prince doit demeurer dans une attitude passive et contemplative à l'égard de la musique.

Quelques années auparavant, Francesco Bocchi se faisait plus explicite en insistant d'abord sur le fait que la connaissance précise de la musique n'était pas requise, à la différence d'autres arts. On peut profiter de la musique, on peut goûter au plaisir qu'elle procure sans nécessairement être compétent dans la science musicale. Les compétences musicales du prince doivent donc être limitées et il est certain que le prince ne sera pas plus fort, ni plus autoritaire, ni plus aimé de ses sujets, ni plus respecté s’il montre une capacité particulière en musique. Pour en convaincre son lecteur, Bocchi s’appuie sur une anecdote concernant Philippe de Macédoine :

«Perloche volendo Filippo Re di Macedonia disputare con un sonatore sopra la ragione del toccare alcune corde di uno stromento di Musica, avvisando di haverne maggior notizia, che questo artefice non havea, ridendo gli disse il Musico per dolce modo : Iddio ti guardi o Re, che in tanta miseria tu non caggia, che tu sappia meglio, che io conosco, le cose à questa mia arte pertinenti: Peroche si come à gli huomini vili, \& a'fanciulletti si danno le cose leggieri, \& di poco momento ; cosi à gli huomini di matura età, \& molto nobili sono le gravi occupazioni assegnate, ove si debbono dirittamente esercitare ${ }^{28}$.

Francesco Bocchi a certainement lu cet épisode chez Plutarque qui, en plusieurs endroits de son œuvre, le rapporte ${ }^{29}$. Pour l'historien grec,

\footnotetext{
27 «l'Astronomia conosce le stagioni, e qual tempo sia atto, o mal'atto al navigare, à fare, o tralasciare l'imprese. Con l'Aritmetica, e Geometria conosce i numeri, e gli spatij ne i quali, e con i quali ordinera gli eserciti, e le fortezze, \& provederà à tutte l'altre cose necessarie, per la sua difesa, e per l'offesa de i nemici », ibid.

28 Ibid., p. 32.

29 « Philippe, qui avait commencé tard à étudier, faisait preuve à la fois d'une médiocrité et d'une présomption rares chez lui. Un jour, dit-on, il discutait du toucher de la harpe avec un spécialiste et se flattait d'avoir raison contre lui : l'artiste, sans se troubler, sourit et lui dit: Ne plaise au ciel, roi, que vous soyez jamais réduit à en savoir plus que moi là-dessus », Plutarque, La Fortune ou la vertu d'Alexandre (II), 334 D, Françoise Frazier \& Christian Froidefond (trad.), Paris, Les Belles Lettres, 1990, p. 134.
} 
l'anecdote a vraiment une valeur édifiante car, dans la discussion technique qui oppose les deux protagonistes, les valeurs sont inversées : c'est Philippe, le roi, qui est prétentieux et ridicule alors que le musicien - et sa réponse en témoigne - s'avère intelligent, fin et plein d’à-propos. Voilà donc à quelle anomalie conduit l'exercice de la musique par le prince, nous dit Plutarque, et Bocchi à sa suite. La réponse du musicien permet d'insister à nouveau sur cette exhortation. "Plaise au ciel, roi, que jamais tu ne sois réduit à en savoir plus que moi en ces matières » : si le prince persiste à nouveau à vouloir faire la leçon au musicien, il risque fort d'y laisser sa place. Bocchi s'inscrit donc ici dans la tradition des Anciens : il sait que, dans l'Antiquité, « rien ne passait pour plus critiquable, chez un prince comme chez un futur citoyen, que de se montrer trop habile musicien »30. Le prince ne doit pas déroger. Ou alors il n’est plus le prince.

En guise de conclusion, on laissera à nouveau la parole à Castiglione :

«je ne veux pas que notre Courtisan fasse comme beaucoup, qui, à peine arrivés quelque part, et fût-ce en présence de seigneurs qu'ils ne connaissent absolument pas, sans se laisser trop prier se mettent à faire ce qu'ils savent, et souvent aussi ce qu'ils ne savent pas, de manière qu'ils semblent ne s'être montrés que pour ce seul motif, et que ce soit là leur principale profession. Que le Courtisan fasse donc de la musique comme en manière de passe-temps, et comme si on l'y forçait »31.

Contre l'ostentation, le loisir musical que le courtisan assure au prince permet que se déploie la sprezzatura de ceux qui s'y consacrent : les manières gracieuses des cours italiennes de la Renaissance doivent d'abord à leur conception d'un diletto qui vient épauler le travail du prince. Si le prince de la Renaissance italienne jouit de l'écoute musicale comme d'un loisir vertueux sans pouvoir cependant pratiquer cet art, le prince absolu de la France du XVIIe, joueur de guitare et de clavecin, chanteur et danseur ${ }^{32}$, est en mesure de transformer le diletto princier. Véritable changement de civilisation, cette mutation mériterait d’être explorée davantage pour que soit mis au jour les liens étroits qui unissent le loisir à la définition du pouvoir.

\footnotetext{
30 Annie Bélis, Les Musiciens dans l'Antiquité, op. cit., p. 222.

31 Baldassare Castaglione, Le Livre du Courtisan, op. cit., p. 121-122.

32 Philippe Beaussant, Louis XIV artiste, Paris, Corps 16, 1999.
} 



\title{
Diversion AND Pleasure in Damascus DuRING THE OTTOMAN PERIOD
}

\author{
Abdul-Karim RAFEQ \\ College of William and Mary of Williamsburg, Virginia
}

Amid political and social turmoil, oppression, profiteering, recurrent natural calamities and abuse of Islamic and Ottoman laws by rulers and laymen alike, what sort of diversions and pleasures, one might ask, did the Syrian people engage in? Local chroniclers and foreign travelers who described the misery of the people also described the types of pleasures they engaged in. The cumulative effect of oppression is that it widened the gap between the rulers and the ruled and perverted the people's sense of tolerance. When, for example, a judge faithfully administered the law in Damascus in 1743, the people rose against him and brought about his deposition ${ }^{1}$. In another case from the late 1820s, the Damascenes rose against their governor because of his excessive justice². Pious individuals who were appalled at the prevailing immorality, lawlessness, profiteering and poverty in 18th century Damascus committed suicide to protest against these practices ${ }^{3}$.

European travelers described the misery of the local population in Syria. The French traveler Volney, who visited Egypt and Syria in 1781 to 1783, for example,

\footnotetext{
1 Ahmad al-Budayri al-Hallaq, Hawadith Dimashq al-Yawmiyya, 1154-1175 A.H./1741-1762 A.D., edited by Ahmad 'Izzat 'Abd al-Karim (Cairo: al-Jam'iyya al-Misriyya li'l-Dirasat alTarikhiyya, 1959), p. 132.

2 Mikha'il al-Dimashqi, Tarikh Hawadith al-Sham wa-Lubnan, 1197-1257 A.H./1782-1842 A.D., edited by Luwis Ma'luf (Beirut: 1912), p. 49.

3 Budayri, 49-50, 56, 92.
} 
left a detailed description of the misery of the local population. He wrote:

"Il est encore dans l'extérieur des Orientaux un caractère qui fixe l'attention d'un observateur; c'est leur air grave et flegmatique dans tous ce qu'ils font et dans tout ce qu'ils disent : au lieu de ce visage ouvert et gai que chez nous l'on porte ou l'on affecte, ils ont un visage sérieux, austère ou mélancolique ; rarement ils rient; et l'enjouement de nos Français leurs paraît un accès de dèlire. S'ils parlent, c'est sans empressement, sans geste, sans passion; ils écoutent sans interrompre; ils gardent le silence des journées entières, et ils ne se piquent point d'entretenir la conversation ; s'ils marchent, c'est posément et pour affaires, et ils ne conçoivent rien à notre turbulence et à nos promenades en long et en large ; toujours assis, ils passent des journées entières, rêvant, les jambes croisées, la pipe à la bouche, presque sans changer d'attitude; on dirait que le mouvement leur est pénible, et que, semblables aux Indiens, ils regardent l'inaction comme un des élément du bonheur $»^{4}$.

Under these distressful circumstances, the people engaged in their traditional pleasures trying to make the best of their times. Most of their pleasures were of a collective nature spread across gender, age group, religious community, profession or social class.

Middle Eastern society is traditionally a male-dominated society. Women enjoyed the domestic life of their residences and engaged in a few collective gatherings outside their homes. The men had the public spaces at their disposal. In an official report about the statistics of Syria in 1840 prepared by John Bowring for Britain's Secretary of State for Foreign Affairs Palmerston and the two houses of parliament, Bowring mentions that the amusements of the laboring classes in Syria were of a simple and tranquil kind. As respects the men, their amusement was confined to smoking in the open air; whilst a visit to the bath was the usual recreation of the females, who at other times women pass their lives in domestic occupations, or assisted their husbands in their labors 5 .

\section{Home and Neighborhood Pleasures}

Almost every house in Syria had a courtyard which contained a pool and fruit-trees. Children played under the eyes of their parents. Europeans who visited Damascus were overtaken by the beauty of its houses from the inside. D’Arvieux in 1660, Maundrell in 1697, Pococke in 1743, Lamartine in 1833 and de Vogué in 1872, among others, described the beauty of the inner section of the Damascene house. Chevallier D’Arvieux, who visited Damascus in 1660, described its houses as:

\footnotetext{
4 Constantine François Chasseboeuf, Comte de Volney, Voyage en Égypte et en Syrie, edited by Jean Gaulmier (Paris-The Hague, 1959), p. 400.

5 John Bowring, Report on the Commercial Statistics of Syria (London: William Clowes and Sons, 1840), reprinted by Arno Press, New York, 1973, p. 111.
} 
«...sont que de terre la plupart. Elles paraissent peu au dehors; mais les dedans sont toute autre chose. Les appartements sont grands et bien aménagés, ils sont propres, bien meublés, lambrissés, plafonnés et peints à la mode du pays. L'or et l'azur n'y sont pas épargnés. Il y a très peu de ces maisons qui n'ait une fontaine pour son ornement et sa commodité » 6 .

Forty years later, Henry Maundrell the Anglican chaplain for the English merchants of the Levant Company established in Aleppo in 1581, visited Damascus on April 25, 1697 and described its houses as follows:

"The streets here are narrow, as is usual in hot countries, and the houses are all built, on the outside, of no better a material than either sun-burnt brick, or Flemish wall, daubed over in as course a manner as can be seen in the vilest cottages... In the inside, the houses discover a very different face from what you see without. Here you find generally a large square court, beautified with variety of fragrant trees, and marble fountains, and compassed around with splendid apartments and duans $»^{7}$.

The rest of the houses, Maundrell was told, resembled the same description.

Nothing in fact had changed over the centuries in the structure of the houses and their function as centers for family social life. Later descriptions demonstrate this reality. The French author Lamartine, for example, on a visit to Damascus in April 1833, when Syria was under the Egyptian rule of Muhammad 'Ali Pasha, noted in the Armenian quarter of Damascus that « Les maisons sont construites de boue ; elles sont percées, sur la rue, de quelques petites et rares fenêtres grilles...». Upon entering the houses of Armenian merchants, Lamartine:

«a été frappé de la richesse et de l'élégance de ces habitations à l'intérieur. Après avoir passé la porte et franchi un corridor obscur, on se trouve dans une cour ornée de superbes fontaines jaillisantes en marbre, et ombragées d'un ou de deux sycomores, ou de saules de Perse... Les femmes et les enfants y sont ordinairement accroupis ou étendus, occupés des différents travaux du ménage... le maître de la maison a toujours un de ces salons pour lui seul ; c'est là qu'il reçoit les étrangers »8.

Despite increasing European influence in Syria under Egyptian rule (18311840) and later, the house remained the core of family social life. According to the French traveler de Vogué who visited Damascus in 1872:

« Le grand attrait et la grande originalité de Damas, le seul côté de la ville qui puisse défier sans péril les caprices de l'imagination, ce sont les intérieurs des

\footnotetext{
${ }^{6}$ Laurent d'Arvieux, Mémoires du Chevalier d'Arvieux, par le R. P. Jean-Baptiste Labat, 6 tomes (Paris : Charles Jean-Baptiste Delespine le Fils, 1735), tome 2, Chapitre XXVI, p. 447.

7 Henry Maundrell, Journey from Aleppo to Jerusalem at Easter, A.D. 1697 (London: Richard Edwards, 1819), 168-169.

8 Alphonse de Lamartine, Voyage en Orient, 2 tomes (Paris : Hachette, 1855-1856), 3-4.
} 
maisons. Extérieurement, je l'ai dit, toutes les habitations se ressemblent par une pauvreté égale. On y pénètre par quelque porte basse, par quelque couloir borgne et timide ; les gens de ce pays, les Chrétiens et les Juifs surtout, sont payé pour nourrir toutes les craintes et cacher leurs richesses sous une enveloppe misérable, comme dans nos ghettos du Moyen-Age. En franchissant le seuil, on ne sait jamais si l'on tombera dans une cabane ou dans un palais. La disposition intérieure de ces habitations est à peu près la même partout : une cour rectangulaire, pavée de marbre, avec un bassin d'eau vive au milieu; des orangers, des citronniers, des grenadiers, sortent des dalles précieuses, ombragent la vasque limpide et emplissent la cour du parfum de leurs fleurs et de l'éclat de leurs fruits. Tout autour règnent des galeries ou des appartements de plain-pied, sur un des côtés, le sélamlik, salon de parade, parqueté, dallé de marbre, ou simplement tapissé de nattes, partagé en deux par un degré qui exhausse la moitié honorable de la pièce... Dans ces grands appartements, isolés par leurs cours du bruit de la rue, protégés contre l'été par leurs arbres, leurs fontaines, leurs pavés, tout est fraîcheur, silence et plaisir des yeux ${ }^{9}$.

Such lavish houses usually belonged to rich people and were inhabited by extended families, employing servants, to help in their maintenance. The houses of the poorer classes also had a courtyard with trees and a pool of water of modest structure where the children could play during the day and the family enjoyed its summer evenings in the open.

Families also went on picnics to neighboring gardens. Occasionally women went alone on picnics with women relatives or friends to enjoy privacy. Men also went with other men on their own. The English traveler Pococke who visited Damascus in 1737 spoke highly of the natural beauty of Damascus neighborhoods. He wrote:

"Damascus is famous likewise for its gardens; and whatever is beautiful in them is chiefly owing to the great command there is of water; they afford a very fine prospect from a height at a small distance, on account of the great variety of trees that are there; and it is certain they are the most beautiful of any of these parts. In these gardens the people often spend the whole day, and there are always some to be let for that purpose, in which the guests are at liberty to eat what fruit they please, and those who have houses in their gardens frequently retire to them for two or three days in the summer 10 .

One of the major pleasures for women was to go periodically to the public bath where they met with friends and neighbors. Almost every neighborhood had a public bath. The bath had a time for men and a time for women. The time for men usually began in the early hours of the morning and ended about noon. This arrangement was to allow the men to go to work early during the day The

\footnotetext{
9 Le Viscomte Eugène-Melchior de Vogué, Syrie, Palestine, Mont Athos, Voyage au pays du passé, Paris, Plon, 1922, 77-79.

10 Richard Pococke, A Description of the East and Some Other Countries, 2 vols., London: W. Bowyer, 1743-1745, vol. 2, 123-124.
} 
time for women took place in the early afternoon until the early hours of the evening. Women usually spent more time than men in the public bath. The bath for women was a social occasion where they met with women neighbors and friends. Male children up to the age of seven or eight were allowed into the public bath in the company of their mothers. Older children went to the public bath with their fathers.

Women's primary pleasure, however, was their participation in wedding ceremonies, especially when the bride was one of their family. They spent weeks, even months, preparing for this occasion, tailoring clothes, and learning songs.

Christian and Jewish women engaged in the same social activities practiced by Muslim women. However, during periods of religious tolerance, such as happened in Damascus during the rule of As'ad Pasha al-'Azm (17431757) and under Egyptian rule (1831-1840), Christian women engaged in social practices that went far beyond the acceptable social norms. Feeling liberated under the rule of As'ad Pash al-'Azm, Christian women drank wine and smoked tobacco openly on their picnics. This drew much criticism from the contemporary Damascene Greek Orthodox priest Mikha'il Breik who chronicled the events of Damascus at the time. Breik accused the Christian women most of whom were from his own church of departing from the accepted social practices by openly drinking wine and smoking tobacco. Breik was also critical of Christian women wearing green clothing because green was restricted to the Prophet Muhammad and his descendants (Ashraf)11. The Muslims who could establish their descent from the Prophet were privileged to wear green turbans and carry the title of sharif or sayyid, which means of honorable descent. Women also had these privileges.

Young children usually played in the courtyards of their homes under the eyes of their parents. Older children were allowed to play outside the house, usually on the neighboring street or in a nearby public square. Most neighborhoods had dead-end alleys which made it safer for children to play without being exposed themselves to the dangers of passing traffic or strangers.

Extended families very often lived in the same house to maintain the solidarity of the family, contribute to its expenses and help in raising their children ${ }^{12}$. One of the pleasures of grandparents was to take care of their grand children, watch them grow, and tell them stories which they always kept in their memory. In spacious homes, children did a lot of activities which increased

\footnotetext{
11 Mikhai'il Breik, Tarikh al-Sham, 1720-1782, edited by Qustantin al-Basha (Harisa (Lebanon): Matba'at al-Qiddis Bulus, 1930), 62-63.

12 See for examples Abdul-Karim Rafeq, « The Social and Economic Structure of Bab al-Musalla (al-Midan), Damascus, 1825-1875 », in Arab Civilization, Challenges and Responses: Studies in Honor of Constantine Zurayk, edited by George N. Atiyeh and Ibrahim M. Oweiss (New York: Suny, 1988), 272-311; see also Brigitte Marino, Le Faubourg du Midan à Damas à l'Époque Ottomane : Espace Urbain, Société et Habitat Damas, Institut Français, 1997.
} 
their alertness and promoted competitiveness among them. A popular game for children inside the house was for one child to hide and for the rest to look for him. Outside the house, adult children played a variety of games 13 .

Men had their own social spaces and pleasures. A well-to-do Muslim who owned a spacious house would receive visitors in the public section of the house, known as salamlik, as opposed to the private section reserved for the family known as haramlik, meaning forbidden to strangers. Men also went with friends on picnics to neighboring gardens. The Damascene biographical dictionaries during the Ottoman period abound with information about religious scholars ('ulama) meeting in salamliks and going on picnics. The 'ulama who met in those places usually spent their time reading verses from the Qur'an, quoting sayings of the Prophet (hadith) and reciting poetry. Several 'ulama smoked opium and tobacco during their pastime. A few of them enjoyed having young men in their company whom they admired for their beauty, singing or other services. The Damascus biographical dictionaries abound with information about these relationships which were met with criticism by the conservative scholars ${ }^{14}$.

\section{Weddings and Public Ceremonies}

Women's participation in weddings was a private affair. Men's participation was more public and included holding processions, dancing with swords and shields in front of the bridegroom on the night of the wedding, serving food and drinks to the guests and distributing money to the poor. If a son or a daughter of a notable were married, the festivities would be enormous to emphasize the social and political prestige of the family15. The treasurer of Damascus, for example, staged public celebrations for seven days in May 1743 on the occasion of the marriage of his daughter. The celebrations were preceded by a ceremony for the heads of the sufi orders in Damascus. The sufis were associated with the guilds and the troops and by inviting them the treasurer aimed at winning the favor of these influential groups. Each day of the seven days was assigned to a specific social group. The governor of Damascus was entertained on the first day, the religious officials on the second, Islamic scholars on the third, merchants on the fourth, Christians and Jews on the fifth, peasants on the sixth, and prostitutes on the seventh day. The guests were offered gifts of gold and silver ${ }^{16}$. The invitation of prostitutes by

13 Ahmad Hilmi al-'Allaf, Dimashq fi Matli' al-Qarn al-'Ishrin, edited by 'Ali Nu'aysa (Damascus: Dar Dimashq, 1983), 334-335, 374-381.

14 See for Examples: Muhammad al-Amin al-Muhibbi, Khulasat al-Athar fi A'yan al-Qarn alHadi 'Ashar, 4 vols., (Cairo: al-Matba'a al-Wahbiyya, 1284 A.H.), several reprints have been made with the same page numbers, see II, p. 9, III, 244,249, 321, 334.

15 See examples in Muhammad Ibn Kannan, Yawmiyyat Shamiyya, 1111-1143 A.H./1699-1740 A.D., edited by Akram 'Ulabi (Damascus: Dar al-Tabba', no date), 223, 290, 468.

16 Budayri, p. 37; Abdul-Karim Rafeq, The Province of Damascus, 1723-1783, paperback edition (Beirut: Khayats, 1970), 151-152. 
a state treasurer seems odd in a Muslim society and state, but it indicates the importance of the prostitutes and their large number at the time and also their close relationship especially with the mercenary troops who protected them. Prostitution usually thrives on poverty and political and social anarchy. When the governor of Damascus As’ad Pasha al-‘Azm was approached by the Damascenes in the 1740 s to put an end to prostitution in the city, after prostitutes walked in procession on the streets, and he declined to act. His rationale was that the prostitutes would appeal to God against him and that God would accept their appeal and act against him. A popular belief at the time considered prostitutes weak creatures who bear the sins of humanity. Their appeal to God, therefore, would be granted. The governor seems to have been afraid of alienating the troops who enjoyed the company of prostitutes. Prostitutes also paid taxes and their expulsion would have affected the treasury.

The treasurer's celebrations occurred one week after the governor had publicly celebrated the circumcision of his son. Damascus was decorated for seven days on the occasion, and the children of poor people were circumcised free and given money and clothing17. Such festivities which were not uncommon occupied the people of the city who took part as actors, viewers and beneficiaries, for days.

Public rejoicings and decorations of the city for other purposes were ordered by the state for three or seven days on a number of occasions. Rejoicings were initially ordered to celebrate Ottoman victories on the battlefield. When victories became rare, rejoicings were still frequently ordered to celebrate the accession of a new sultan to the throne or the birth of royal babies. The birthday of the Prophet Muhammad was also a major occasion for public ceremonies in Damascus.

\section{Neighborhood and Professional Celebrations}

The youths of residential quarters and craftsmen belonging to professional organizations, such as guilds, staged collective celebrations on a number of occasions. The youths of a certain quarter, for example, would assemble under the headship of a leader from among their ranks known as shaykh al-shabab (chief of the youths). They often paraded on the streets of Damascus to celebrate a social occasion, to compete with youths from other quarters, or merely to express their militancy in defiance of the government. Such parades attracted large crowds and frequently ended up with clashes among the contending parties.

Professionals had their own collective celebrations. When a craftsman in the guild was promoted from one professional rank to the next, celebrations known as shadd (binding the candidate with a silk or cotton belt) were staged to mark

17 Budayri, p. 38. 
the occasion. An honorary person known as shaykh al-mashayikh (supreme head of the guilds) presided over the ceremonies. In the guilds that were composed of members belonging to different religious communities, such as the guilds of butchers and druggists composed solely of Muslims and Jews, or the guild of tailors that included Muslim, Christian and Jewish members, the shadd ceremony was accompanied by religious rituals in accordance with the religion of the promoted member. If the member was a Muslim, the fatiha (the first sura (chapter) of the Qur'an) was read, for a Christian, the Lord's prayer was recited, and for a Jew the Ten Commandments were read18. Moreover, when the head (shaykh) of the guild was elected by the members of the guild and the election was legalized in the court the shaykh al-mashayikh would receive the elected head amid celebrations and provide him with advice.

The market served as a social space for both the merchants and the customers. Traditionally, each market was assigned to a special commodity, such as the market of silk cloth, of soap, or of ropes, etc. Each of these markets carried the name of the commodity it marketed. The rationale behind having specialized markets was for the head (shaykh) of the market to monitor the quality of the goods on display, fix their prices and collect taxes from each shopkeeper according to the size of his business.

Neighborliness in the market place promoted a special relationship among merchants and between them and the customers who would go back to the same shop not necessarily to buy but to renew social connections. Tea and coffee would be served to the customers to persuade them to buy. When no customers were in sight, the merchants would engage in conversation with each other. In the main markets, shops opened and closed at about the same time for security reasons. After work hours were over, merchants met again in coffeehouses. It was always a delight for people who were not pressed by time to frequent the old markets and spend part of the day chatting, bargaining, sipping tea or coffee and not necessarily buying.

At times of trouble and unrest, craftsmen, like the members of other compact organizations, would band together to defend their interests. On several occasions, they paraded on the streets, with other militias, carrying arms in self defense.

In addition to the streets that served as public spaces for parades and celebrations, the mosques and their surroundings attracted crowds on religious occasions. News from Istanbul announcing major decrees was relayed to the people by public criers on the streets, from the minarets of mosques, or from the headquarters (saraya) of the governor. If the news were joyful, people would fire into the air to declare their joy. Such firing was known as shanik (an Arabic corruption of the Turkish word enlik)?

18 Ilyas 'Abduh Bek al-Qoudsi, « Nubdha Ta'rikiyya fi'l-Hiraf al-Dimashqiyya », in Actes du VIème Congrès des Orientalistes, ed. Carlo Landberg (Leiden, 1885), 15-30 ; Adul-Karim Rafeq, "Craft Organization, Work Ethics and the Strains of Change in Ottoman Syria » Journal of the American Oriental Society, 111.3 (1991), 495-511. 


\section{The Pilgrimage as Diversion}

The annual departure of the pilgrim caravan from Damascus to the Hijaz was an occasion for public ceremonies. Numbering roughly between fifteen to twenty thousand pilgrims from Syria, Anatolia, the Balkans and Persia, spent time in Damascus preparing for their journey, renting camels to carry them, buying food and selling the products they brought with them. The departure of the caravan was marked with public celebrations. A magnificent procession led by the commander of the caravan took place. The governor of Damascus headed the procession after he was appointed commander of the pilgrim caravan in 1708. He appeared accompanied by the Mahmil (a richly-decorated litter representing the authority of the Ottoman Sultan in his capacity as Protector of the Two Holy Sanctuaries, Mecca and Medina), the sanjaq (standard or étendard), and a number of élite troops. To ensure a good view of the procession within Damascus, people rented window overlooking the procession road and jammed sidewalks. Foreigners also enjoyed the spectacle. The abbot Giovanni Mariti, who visited Damascus in the 1760s, gave a vivid description of the departure of the pilgrim caravan. He wrote:

«La marche, donc, de cette caravane de Damas est ouverte par quarante delis ou soldats, montés à cheval, et tenant chacun à la main une petite bannière de soie verte, rouge ou jaune. Ils sont suivis de trois compagnies de Segmens, autres gens de guerre, et d'un pareil nombre de Spahis, troupe de cavalerie. Vient en troisième lieu un bataillon de soldats Barbaresques, qu'on nomme Magrabins, piétons destinés à la garde de six pièces de canons de campagne. Une escouade de la garnison de Damas, armée en mailles de fer, marche à la suite, accompagnée de deux détachements de Janissaires, cavalerie, que commande l'Aga en personne... Trois queues de cheval suspendues à des javelines, annoncent la présence du Bacha... Parait après le mahmal, grand étendard de soie noire que porte un chameau superbe, orné de la manière la plus bizarre, avec des plumes, des sonnettes et des colliers de diverses couleurs. Ce mahmal est entouré de plusieurs franges d'or, et bordé en paillettes de même matière, en considération de l'Alcoran qu'il doit envelopper. Il est recouvert d'un riche tapis, que le Grand-Seigneur envoie au tombeau du Prophète, à la place de l'ancien qu'on rapporte chaque année: ornement précieux, et vénérable dans l'esprit d'un Turc, qui ne balanceroit pas de le préférer au premier trésor du monde. Le chameau, qui une fois a été honoré de cette charge, est dispensé à l'avenir de porter aucun fardeau »19.

After an absence of about three months in the Hijaz, the pilgrim caravan returned to Damascus amid festivities welcoming the returning pilgrims. The return was usually heralded by the arrival of a messenger dispatched by the commander of the caravan to announce that the pilgrims on their way back were safe from Bedouin attacks and any natural calamities. The pilgrims more

19 L’Abbé Giovanni Mariti, Voyages dans l’Isle de Chypre, La Syrie et la Palestine, 2 tomes, traduit de l'Italien (Paris, Belin, 1791), t.2, 101-102 ; see also Abdul-Karim Rafeq, « Le Mahmal en route pour la Mecque » in Damas: Miroir Brisé d'un Orient Arabe, dirigé par Anne-Marie Bianquis avec la collaboration d'Élizabeth Picard (Paris, Autrement, n65, Janvier, 1993), 49-57. 
anxious to be back made their entry about one week before the Mahmil and the commander. Their houses would be decorated and festivities staged for several days.

When the Turkish and Balkan pilgrims took to sea travel in the nineteenth century, especially after the opening of the Suez Canal in 1869, when the sea route be came cheaper and safer, Damascus lost the material benefits of hosting a huge number of pilgrims. It also lost many of the annual festivities and much of the glamour that accompanied the pilgrimage 20 .

\section{SufisM AS Diversion}

Overwhelmed by social ills and natural calamities, such as earthquakes and plagues, and exposed to oppression and injustice, some people found consolation in indulging in sufism which preaches withdrawal and denial of worldly pleasures. The devotional practices in which sufis engaged not only satisfied their religious duties but also constituted their major pastime.

Many Damascenes, mostly men, belonged to sufi (mystical) tariqas (paths leading to God) which were institutionalized as orders or brotherhoods, each of which had a head (shaykh), a convent (zawiya) for retreat and a set of practices. Sufi practices varied according to the type of the order, the social milieu from which its members were recruited, and the nature of their work. Most religious scholars, according to biographical dictionaries, belonged to one or more of the sufi orders. All sufis, however, engaged in dhikr (repetition of God's name) in their rituals. A sufi resident in Aleppo of the Khalwatiyya order, for example, is reported to have had more than one-hundred thousand followers (muridun). Every winter he and some of his followers would meet for three days in a sufi retreat (khulwa), where they only ate bread and drank coffee while engaging in $d h i k r$ and prayer21.

The heads of popular sufi orders, like the Taghlabiyya, practiced the dawsa, a very popular although cruel sufi practice. The dawsa was performed by the head of the order who on horseback tread over the bodies of his followers who lay prostrate on the ground with their faces down. A dawsa took place in Damascus in 1707 near the official residence of the governor who ordered it to curry favor with the people. The head of the Taghlabiyya Order performed the dawsa with fanfares amid a large crowd that gathered at the scene ${ }^{22}$. Pleasing as it was to many, the dawsa had inherent dangers which were difficult to assess. Complaints by participants who suffered from injuries during the dawsa were not reported for fear of antagonizing the shaykh and losing his patronage. Popular Sufi shaykhs

\footnotetext{
20 Abdul-Karim Rafeq, « Damascus and the Pilgrim Caravan, » in Modernity and Culture: From the Mediterranean to the Indian Ocean, edited by Leila Tarazi Fawaz and C.A. Bayly (New York: Columbia University Press, 2002), 13-143.

21 Muhibbi, I, 389-390.

22 Ibn Kannan, 117-118.
} 
also performed other extreme practices such as piercing the tongue, lips or flesh of a follower with a skewer without causing him pain, or so they believed.

When performing their practices in public, the sufi orders usually attracted large crowds. The sufis only had to display colorful flags, rattle the tambourines (mazhar) and chant the name of Allah (God) to attract the people23. Such public ceremonies were frequent and popular. When, for instance, locusts devoured crops in the Damascus region in the 1740s, the sufi orders were the first to take to the street urging people to put out water obtained from a special far-away source which would attract a certain bird, Samarmar, that devours locusts 24 . These attempts to combat locusts were a complete failure. The only practical way to do away with locusts was to collect them and bury them as the Damascenes eventually did. However, the attempt by the Sufis to do away with the locusts in their own way coupled with the simplistic beliefs of the common people helped in keeping the people busy and hopeful.

When Wahhabism emerged in the Arabian Peninsula in the eighteenth century it directed its bitter criticism at the sufi orders accusing them of deviating from true Islam. Wahhabism attacked the veneration of sufi saints and condemned visitation to their shrines. It declared that there should be no intercessor between God and the believer, not even the Prophet Muhammad himself. Muslim scholars in Syria in the second half of the nineteenth century under the influence of Wahhabism called for a return to the purity of early Islam when it was under the rule of Arab ancestors (Salaf). Sufism declined in Syria in the face of Salafism. The pleasures connected to it also declined.

\section{The Coffeehouse as a Major Center for Pastime}

The introduction of coffee from the Yemen into Syria early in the 16th century created a new social space, the coffeehouse. The coffee plant was brought from Ethiopia to Yemen in the fourteenth or the fifteenth century where it found a suitable terrain and climate to grow. Sufis were the first to consume coffee in the Yemen because it helped them stay awake to perform their religious duties. Coffee drinking soon spread into Mecca and was carried from there into Syria early in the sixteenth century with the Damascus pilgrim caravan ${ }^{25}$. The coffeehouses soon spread into Istanbul. Two Syrians are reported to have introduced coffee to Istanbul and opened the first coffeehouse there during the rule of Sultan Sulayman the Magnificent (1520-1566)26.

\footnotetext{
23 Ibn Kannan, p. 462.

24 Budayri, 73, 89-90.

25 Abdul-Karim Rafeq, « The Socioeconomic and Political Implications of the Introduction of Coffee into Syria, 16th-18th Centuries ", in Le Commerce du Café avant l'Ère des Plantations Coloniales, édité par Michel Tuchscherer (Le Caire, Institut Français d'Archéologie Orientale, 2001), 127-142.

26 Bernard Lewis, The Middle East: A Brief History of the Last 2,000 Years (New York: Simon and Schuster, 1997, 8, 162; see also Ralph Hattox, Coffee and Coffeehouses: The Origins of a Social Beverage in the Medieval Near East (Seattle: University of Washington Press, 19991), 24, 28, 81-82.
} 
Yemeni coffee was exported by sea to Egypt, the Ottoman Empire and Europe through the Yemeni seaport of Mukha. The current word Mokka used for an expensive brand of coffee is a corruption of the word Mukha.

The Ottoman authorities initially banned the drinking of coffee and coffeehouses because of their association with unruly persons and immoral behavior. The Ottoman judge of Damascus, for instance, banned the drinking of coffee in 1546. An order from the Ottoman sultan to the judge of Jerusalem in 1565 ordering him to close the five coffeehouses newly established there mentions that they had become the meeting-place of rascals and ungodly people who day and night did not cease to act wickedly and mischievously, thus keeping the Muslims from pious devotion and divine worship27. As late as 1623, the Ottoman authorities still attempted to ban the drinking of coffee and the smoking of tobacco ${ }^{28}$. However, despite continuing bans on coffeedrinking by the Ottoman State, this beverage soon spread throughout the Ottoman Empire.

Coffee drinkers usually smoked tobacco in coffeehouses. Tobacco was introduced into Syria in the seventeenth century and was initially banned by the state. In the first quarter of the eighteenth century, the Syrian Hanafi jurist and Sufi Shaykh 'Abd al-Ghani al-Nabulsi legalized the smoking of tobacco, as did the top jurists in Istanbul and Cairo at about the same time. Nabulsi issued a fatwa (legal opinion) legalizing smoking tobacco which he developed into a monograph entitled al-Sulh bayna al-ikhwan fi hukm ibahat aldukhkhan (Peace among friends regarding the legalization of smoking) ${ }^{29}$. Nabulsi was pragmatic in his approach to tobacco smoking. His rationale was that smoking is like food, if it hurts a person he should not smoke, but if it does not hurt him he can smoke.

Prior to tobacco smoking, opium had been smoked in Syria for long periods. Muslim scholars, according to the Syrian biographical dictionaries, were among the consumers of opium. A Muslim Shafi'i scholar Muhammad al-Zuhayri, for instance, who was a preacher in the Mu'allaq Mosque in Damascus and a teaching assistant in the famous Damascene Shafi'i school alShamiyya al-Barraniyya around the middle of the seventeenth century was addicted to opium, according to biographer Muhibbi30. Opium smoking was an individual practice which brought ecstasy to the smoker and induced a state of contemplative union with God, or so the religious 'ulama addicted to opium believed.

Wine, banned in Islam, was consumed illegally in some coffeehouses in Damascus. The wine about Damascus, according to English traveler Pococke in 1737, " is strong and good, generally of the colour of Burgundy; and they

\footnotetext{
27 Uriel Heyd, Ottoman Documents on Palestine, 1552-1615 (Oxford: The Clarendon Press, 1960), 160-161.

28 Muhibbi, IV, p. 339.

29 Edited by Muhammad Ahmad Dahman (Damascus, 1334/1924-1925).

30 Muhibbi, III, 332-334.
} 
have plenty of all sorts of provisions excellent in their kind, and fruits in the greatest perfection » ${ }^{31}$. The coffeehouses that served wine were referred to as coffee taverns. In 1764, for example, the governor of Aleppo ordered the closure of the coffee taverns because the rabble and the lawless gathered there drinking wine ${ }^{32}$. Under Egyptian rule in Syria, wine taverns were allowed to function in the Christian and the Jewish quarters. Their owners were nonMuslims and protégés of European consuls. In July 1845, Jewish residents in the Jewish quarter in Damascus objected to the authorities about a wine tavern (khammara) which functioned day and night in their quarter causing many problems to them. The authorities ordered its closure even though those who operated it were protégés of European consuls 33 . The coffeehouses established near the citadel to cater for troops were also closed because they served wine. Their owners appealed to the authorities in August 1845 to allow them to reopen their coffeehouses because they were about to go bankrupt. The owners acquired Greek citizenship to protect their interests. The Greek consul in Damascus intervened on their behalf and pledged himself as guarantor for their good behavior. The authorities then agreed to the reopening of their coffeehouses 34 .

When coffee drinking was officially allowed and coffeehouses were established in Damascus, several guilds emerged dealing with the roasting and selling of coffee and the ownership and running of coffeehouses. Other guilds were also established for producing and marketing tobacco. The rapid grouth of roasting places for coffee in Damascus during the eighteenth century attests to the widespread use of coffee as a popular beverage served to people in their spare time and during social events. Most of the roasting places were located near the citadel, where troops were stationed, and also next to the saraya, the seat of the governor. They also spread in key markets where large numbers of people gathered. Soldiers were the owners of most of the roasting places and of the coffeehouses which suggests that big money was involved in the widespread use of coffee 35 .

The spread of coffee drinking in the Ottoman Empire and Europe alerted the European colonial powers to the importance of the coffee trade. The British, the French and the Dutch took the coffee plant from the Yemen to their colonies. By the first quarter of the eighteenth century, colonial coffee was exported to the Middle East and elsewhere. But colonial coffee could not compete with Yemeni coffee in the excellence of its taste and its use for preparing bitter coffee which was in great demand for social occasions in the

\footnotetext{
31 Pococke, p. 125.

32 Muhibbi, IV, p. 98.

33 Damascus, Center for Historical Documentation (Archives), Majlis Shura al-Sham al-'Ali, 1260-1261 A.H., see folio 334.

34 Majlis, folio 365.

35 Rafeq, "The Socioeconomic and Political Implications of the Introduction of Coffee into Syria », 134-137.
} 
urban centers and by the Bedouin in the desert. However, because colonial coffee was cheap and available, it soon dominated the markets of the Middle East 36 .

Becoming the major social space for the leisure time of the male population, coffeehouses soon spread all over Damascus. In the 1870s, for example, Damascus had over 110 coffeehouses compared to 58 public baths and 153 mosques ${ }^{37}$. The total number of public establishments in Damascus at the time was 596. The number of coffeehouses thus constitutes 18.46 percent of all the public establishments.

The coffeehouses as places for recreation and pastime attracted the attention of the European travelers who visited Syria. Richard Pococke, who visited Damascus in the summer of 1737, for example, commented on the coffeehouses in Damascus as being:

" remarkably pleasant; many of them are large rooms, and the ceiling of them are supported with rows of pillars, round which they have their sopha's; there is generally a court behind them with a basin of water, and a fountain in the middle, and the seats round the courts are either shaded with trees, or covered over. One in particular on the Barrady which runs through the city, has an island behind it, planted with trees, and the place is accommodated in a very convenient manner, which renders it one of the most delightful places one can imagine in the midst of a great city; in these coffeehouses they have concerts of musick at certain hours every day, and in some, a person paid by the house tells at a fixed hour Arabian stories in a very graceful manner, and with much eloquence » Pococke also says that coffeehouses are « where all idle people, strangers and others, who are not of the first rank, pass their leisure hours ». He concludes by saying: «I spent my time very agreeably in Damascus, passing my leisure hours in the coffee houses and commonly taking my repast in them ».

Pococke's overall judgment on the Damascenes is that they were much addicted to pleasure and loved to pass their time in a lazy indolent manner ${ }^{38}$.

The contemporary Damascene chronicler Budayri, who wrote about the same time as Pococke, mentions three Jewish musicians who arrived in Damascus from Aleppo in 1747. The musicians showed much expertise in playing music in coffeehouses 39 . Aleppo at the time had a substantial Jewish community which made of Aleppo a major center for Jewish music. As in Damascus, Jewish musicians in Aleppo performed in coffeehouses as well as at private parties ${ }^{40}$.

\footnotetext{
36 André Raymond, Artisans et Commerçants au Caire au XVIIIe siècle, 2 tomes, Damas, Institut Français, 1973-1974, t.1, p.156.

37 Nu'man al-Qasatli, al-Rawda al-Ghanna' fi Dimashq al-Fayha' (Beirut, 1879), new edition (Beirut: Dar al-Ra’id al-'Arabi, 1982), 105, 111.

38 Pococke, vol., 2, 122-126.

39 Budayri, 34, 95.

40 Na'um Bakhkhash, Akhbar Halab, 3 vols., edited by Father Yusuf Qoshaqji (Aleppo: Matba'at al-41 Ihsan, 2000), vol.2, p. 288.
} 
Budayri also confirms Pococke's observation about storytellers operating in coffeehouses. He refers in the events of February 1743 to the death of his mentor, a story teller (hakawati), who recited the stories of the Arabian black hero 'Antar in coffeehouses, despite the fact that he did not read nor write ${ }^{41}$. Storytellers in coffeehouses nowadays are a rarity. Their craft is dying. The sons of hakawatis do not want to continue in the tradition of their fathers

Lamartine noted during his visit to Damascus in April 1833 that with the exception of the mosque the coffeehouse was the only place for the Damascenes to communicate with each other. What also attracted his attention was « une foule, aussi nombreuse que celle des galeries du Palais-Royal, circule tout le jour dans le bazar ». He also saw a few distinguished persons (agas) heading with their followers and servants «qui marchent silencieusement derrière eux, et portent leurs pipes et leur narguilé ; ils vont s'asseoir, une partie du jour, sur les divans extérieurs de cafés bâtis au bord des ruisseaux qui traversent la ville $» 42$.

The french traveler De Vogué, who visited Damascus in November 1872, gives a vivid description of the crowd filling the coffeehouses in the month of Ramadan. He says:

«le soir, nous suivons la foule dans les cafés, où elle se presse pendant les nuits de Ramadan. Ce sont de larges salles sous des voûtes écrasées... Tous aspirent silencieusement le calioun, composé de deux tiges de roseau emmanchées à angle aigu dans un œuf de métal ou de bois noir, et l'arrosent d'innombrables tasses de café. Les amateurs de spectacle suivent les faits et gestes cyniques, commentés par des plaisanteries risquées, de plusieurs karagheuz installés aux angles de la salle, les mélomanes écoutent un orchestre uniformement composé d'une darbouka, d'une espèce de rebec et d'une série de cordes tendues sur une table de bois, qui recommence éternellement l'unique mélopée arabe ; des chanteurs l'accompagnent avec ces gammes de tête dont les Orientaux ont le secret, et racontent sur le rythme mélancolique les amours, les combats, les drames du désert »43.

Karakoz (karagheuz) shows consist of puppets moved from behind by an actor and are projected on a screen lit by a lamp. The puppets move through strings, and the actor tells stories of love and adventure by moving the puppets. Karakoz shows are difficult to come across today except perhaps in the month of Ramadan when Muslims fast during the day and entertain themselves at night. Like the storytellers, Karakoz shows operate in select coffeehouses mostly for a special clientele.

The Dutch traveler Nijeholt, who visited Damascus in the summer of 1868, described what he called «Les cafés du peuple » which had more natural settings than the closed caffeehouses and seem to have been located in the suburban neighborhoods. His description of the coffeehouses clientele goes as follows:

\footnotetext{
41 Budayri, p. 24.

42 Lamartine, p. 10.

43 De Vogué, p. 83-84.
} 
" Accroupi ou couché sur son tapis, à l'ombre d'un arbre, au bord d'un bassin, le Damasquin hume son café, boit sa limonade à petites gorgées, et fume son narghilèh posément, nonchalamment, échangeant de temps à autre quelques paroles avec ses voisins. Les discussions, les disputes sont réservées pour les promenades de bazar ; au café, c'est le triomphe et la volupté du farniente " ${ }^{44}$.

Under the impact of Europe, coffeehouses in Damascus introduced European-style amusements towards the end of the nineteenth century. A tricker (muza'bir), often a European, would appear in certain coffeehouses at an advertised time, and perform tricks intended to puzzle people and win their admiration. The crowd attending the show included respectable religious scholars and writers who sat in the front row to gain a better view. All were puzzled by the unexplainable tricks 45 .

A theatre was established in Damascus in 1878. A group of men and women performed plays about love or the life of kings and princes. Within six years, the theatre had become so popular that working people spent much of their earnings on attending its plays. Families and parents complained to the Ottoman authorities in Damascus about the distraction and loss of money caused to those who attended the theatre. The authorities responded and shut down the theatre. To compensate for its closure, groups of Armenians and Greeks, consisting of men and women, came to Damascus for short periods and were employed in coffeehouses as performers, dancers and entertainers. Clowns and singers were employed by rich people in Damascus to entertain their guests on special occasions, such as weddings. Egyptian performers came to Damascus in the early twentieth century and presented Arabic plays which attracted a lot of people ${ }^{46}$.

Cinemas were introduced into Syria on a large scale under the French mandate (1920-1946). Silent films were popular in the 1920s. Talking films soon followed in the 1930s. Conservative Muslim clerics opposed women going to the movies. In the 1930s the radio was introduced into coffeehouses making them more appealing to the people ${ }^{47}$.

\section{Bedouin Diversions and Pleasures}

The pleasures and diversions of the Bedouin who live outside the urban centers were consistent with their nomadic way of life. A good description of

\footnotetext{
44 T. M. Chevallier Lucklama A. Nijeholt, Voyage en Russie, au Caucase et en Perse, dans la Mésopotamie, le Kurdistan, la Syrie, la Palestine et la Turquie, executé pendant les années 1865, 1866, 1867 et 1868, 4 tomes (Paris : Arthus Bertrand et Amsterdam : C. L. Van Langenhuysen, 1872-1875), vol. IV, p. 549.

45 Muhammad Sa'id al-Qasimi, Jamal al-Din al-Qasimi and Khalil; al- 'Azm, Qamus al-Sina'at alShamiyya, edited by Zafer al-Qasimi (Damascus: Dar Tlas, 1988), 434-435, 449-450.

46 al-Qasimi, 470-471.

47 Elizabeth Thompson, Colonial Citizens, Republicans Rights, Paternal Privileges, and Gender in French Syria and Lebanon (New York : Columbia University Press, 1999), 97-108, 181.
} 
the ways the Bedouin spent their pastime is given by French traveler De La Roque who traveled to Palestine in 1688 by order of King Louis XIV. De La Roque devoted a whole chapter to the pastime of the Bedouin to which he gave the title: Des Plaisirs et des divertissements que prennent les Arabes ${ }^{48}$. The term « Arabes » ('Arab, A'rab or 'Urban) was and still is used for the Bedouin. De la Roque wrote:

«Les Arabes ne sont pas dans un état, ni dans des lieux, à pouvoir jouir des plaisirs qu'on trouve ordinairement dans les villes. Ils s'en font un très particulier de vivre à la campagne, et d'y mener une vie libre et sans grand embarras; ils y trouvent du repos et de la douceur, exempts d'ambition et d'envie de changer jamais d'état.

Les hommes passent leur temps à monter à cheval, pour se promener d'un village à l'autre, ils prennent garde à leur bétail ; ils vont à la chasse au sanglier, qu'ils tuent à coup de lance; ils forcent les lièvres et les gazelles, avec de grands lévriers qu'ils nourrissent soigneusement pour cela ; ils ont des oiseaux de proie dressés pour la perdrix, et ceux qui sont accoûtumés à tirer, tuent aussi les autres oiseaux à coups de fusil, mais il y en a très peu qui s'en servent parmi eux.

Ils se visitent les uns les autres, et passent des journées entières à prendre du tabac et du café, et à s'entretenir des affaires du temps, et de toutes les histoires qu'ils savent : comme ils sont naturellement fort sérieux, ces sortes de conversation sont leurs divertissemens les plus ordinaires. Ils parlent de la guerre, de leurs courses, de ce qui leur est arrivé pendant leur vie, et de ce qu'ils ont entendu dire à leurs pères, lesquels leur ont laissé les traditions de leurs Ancêtres ; ils n'ont presque point de livres, et ne s'amusent point à lire. Ils ne connaissent ni cartes, ni dés, et rien de tout ce qui peut exciter quelque passion, n'est en usage parmi eux : ils ne jouent ni argent, ni meubles, ils se contentent de voir l'évènement de la perte ou du gain. Les jeux des échecs, ceux de Dames, et du Manqala sont les seuls auquels ils se divertissent.

Ce Manqala est composé d'une table de bois ; où il y a douze creux faits comme les coupes d'une petite balance, dans chacun desquels ils mettent six petites pierres, ou autant de sèves, ou de coquilles. Les deux joueurs visent successivement chacun un trou, et ils font le tour du Manqala en mettant une pierre à chacun des autres creux, et lorsque la dernière forme un nombre pair avec celles qui s'y trouvent, on prend toutes les pierres; et celui qui en a davantage à la fin du jeu, a gagné la partie.

Ils montent à cheval avec l'Emir, et s'exercent au jeu des Geriddes, ou des Roseaux dont nous avons déjà parlé. Ils s'accoûtument par cet exercice à se tenir bien à cheval, et ils dressent leurs chevaux par le même moyen, à l'usage qu'ils ont accoûtumé d'en faire.

Les divertissemens des femmes ne consistent qu'à se visiter, à causer ensemble, à chanter, et à faire le ménage de la maison. Elles n'ont point l'usage de la musique ; elles chantent naturellement d'un ton uni, assez lent et langoureux, avec de grandes pauses, et des reprises en même temps; leurs instruments sont des violons, des tambours, des tambours de basque et de cliquettes, ils en mettent aux deux mains en dansant. Ces cliquettes sont deux petites pièces de bois bien dur, comme de l'ébène ou du buis, rondes et longues comme deux petits cervelas : elles en tiennent une pièce avec le pouce, et l'autre avec le reste des doigts; elles les

\footnotetext{
48 M. de la Roque, Voyage dans la Palestine, Fait par Ordre du Roi Louis XIV, (Amsterdam, chez Steenhower et Uytwrf Libraires, 1718), 243-247.
} 
choquent en serrant la main avec tant d'adresse, qu'elles leur font faire le même effet que font nos castagnettes: c'est avec cela et avec le tambour de basque qu'elles marquent la cadence. Les tambours sont d'une pièce de bois creusée, et de la grandeur d'une cullière à pot, le manche en est fort long, et il n'y a ordinairement que deux ou trois cordes d'airain, ou de boyau, sur lesquelles elles forment toutes sortes de tons ; les violons sont carrés, et le dessus est de parchemin, ils n'ont qu'une seule corde de crin pareille à celui de l'archet; le manche en est fort long, ces poils au reste frottés avec de la résine, font un son assez lugubre et sombre. Ils ont encore des flûtes de bois et de roseaux; les premières sont à peu près comme les nôtres ; celles de roseaux sont fort longues, et leur son se forme en soufflant à l'embouchure, d'une manière que la moitié du vent entre dans la flûte, et l'autre moitié passe par dehors. Ils accordent fort bien tous ces instruments ensemble, et ils s'en servent chez le Prince, et dans toutes les occasions où les Arabes se réjouissent.

Les hommes, et les femmes en général, ne dansent point en public, ils croient cet exercice malhonnête ; il y a cependant des gens parmi eux qui en font métier, et qui vont danser partout où l'on veut pour de l'argent. Ces danseurs n'ont point de pas reglés, et dansent moins des pieds, que des mains, et de tout le reste du corps, l'oreille les conduit, et toute leur manière de danser ne consiste qu'en gestes, en contorsions, et en minauderies burlesques, toujours en jouant des cliquettes ».

With the spread of urbanization and education, the Bedouin were eventually integrated into urban societies. They soon turned to the types of diversions and pleasures that dominated urban life. 


\title{
HORS LA COUR, AU-DELÀ DE LA FOIRE : LES SPECTACLES DU PALAIS-ROYAL À PARIS À LA FIN DU XVIIIe SIÈCLE
}

\author{
Olivier DAUTRESME \\ Université François-Rabelais de Tours, CEHVI
}

En 1986, sous le joli titre de Farce and Fantasy, Robert Isherwood consacrait un livre au loisir populaire dans le Paris du XVIIIe siècle1. L'auteur y faisait une large place au théâtre, divertissement emblématique des loisirs urbains à l'époque moderne, singulièrement à Paris, « capitale du théâtre »². L'étude, bien informée mais plutôt descriptive, était fondée sur une problématique aujourd'hui datée dont l'auteur lui-même accusait les limites dans son dernier chapitre, voué au Palais-Royal de la fin de l'Ancien Régime : dans ce foyer de plaisirs, Isherwood voyait la convergence des cultures élitaire et populaire.

À peu près au même moment, cette opposition était plus radicalement remise en cause, à propos du théâtre de boulevard cette fois. Dans une thèse américaine restée inédite, Michèle Root-Bernstein montrait en 1984 que l'opposition entre troupes privilégiées et « tréteaux des boulevards » cachait en fait une transformation du théâtre populaire de la première à la seconde moitié du XVIIIe siècle qui s’opérait tant dans le répertoire, épuré sur le

\footnotetext{
1 Robert Isherwood, Farce and Fantasy. Popular Entertainment in Eighteenth-Century Paris, New-York \& Oxford, Oxford University Press, 1986.

2 Daniel Roche (en collaboration avec Pierre Goubert), «Les Français et l’Ancien Régime », t. 2, Culture et société, Paris, Armand Colin, 1991 (1984), p. 259.
} 
modèle du " grand théâtre », que sur le plan institutionnel, par l'intégration légale des «petits spectacles » dans l’ordre théâtral de Paris³.

Depuis, nombre d'études d'histoire culturelle ont renouvelé l'approche, soit en examinant la manière dont a pu, dans tel ou tel domaine, s'opérer un tel partage entre culture savante et culture commerciale, soit en explorant, selon le schéma d'Habermas d'émergence d'une sphère publique bourgeoise, les voies par lesquelles les productions culturelles ont pu participer à la formation d'un espace public émancipé de la cour, de l'Église, des académies ou du mécénat aristocratique ${ }^{4}$. Dans ce dernier champ, les recherches les plus récentes tendent cependant à nuancer ces nouveaux partages, réévaluant la prégnance des modèles aristocratique ou académique dans l'émergence d'un tel « public » 5 .

En tenant compte des acquis ou des pistes de l'historiographie culturelle récente, je propose ici de revenir sur la mystérieuse « convergence » dont parlait Isherwood, en faisant l'hypothèse qu'elle désigne en fait la promotion du Palais-Royal au rang d'espace public nouveau, espace marchand émancipé et de la cour et de la foire dans le jeu même des protections aristocratiques et des privilèges académiques. En explorant en particulier le cas emblématique du spectacle des Variétés, je voudrais montrer que cette promotion s’appuie sur trois éléments : d’abord la qualité même du lieu qui l’abrite (une demeure princière transformée en foyer de plaisirs publics) ; ensuite l'argumentaire polémique alors dirigé contre les troupes privilégiées en vue de faire émerger

\footnotetext{
3 Michèle Root-Bernstein, Boulevard Theater and Revolution in Eighteenth-Century Paris, Ann Arbor, Michigan, UMI Research Press, cop. 1984, p. 30.

4 Voir à titre d'illustration de l'une et de l'autre voie, Anne Marie Leterrier, « Musique populaire, musique savante ", Revue d'histoire du XIXe siècle, 1999, 19, et Jeffrey S. Ravel, The Contested Parterre : Public Theater and French Political Culture, 1680-1791, Ithaca, Cornwell University Press, 1999. Pour une discussion des usages du schème d'Habermas dans les sciences sociales, voir Craig Calhoun (Éd.), Habermas and the Public Sphere, Cambridge, MIT Press, 1992, et spécialement, pour ce qui est du XVIII siècle, la contribution de Keith Baker, "Defining the Public Sphere in Eighteenth-Century France : Variations on a Theme by Habermas », ibid., p. 181211, ainsi que Claire Hancock, «Ville et espace public : la théorie habermasienne et le cas de la capitale française à la fin du XVIIIe siècle », Espaces et Sociétés, 1996, n86, p. 127-143.

5 À propos de la multiplication des concerts semi-publics à la fin de l’Ancien Régime, David Hennebelle a ainsi récemment souligné le rôle central, quoique déplacé, de l'aristocratie, « Nobles, musique et musiciens à Paris à la fin de l'Ancien Régime : les transformations d'un patronage séculaire (1760-1780)", Revue de Musicologie, tome 87/2, 2001, p. 395-418. S'agissant des formes renouvelées de sociabilité de la République des lettres que furent les clubs, musées et lycées, également réputés vecteurs de l'affirmation d'un nouveau public, on a également récemment insisté sur leur caractère commercial ainsi que sur la force du modèle académique, moins rejeté qu'adapté, même si ce fut sans succès; voir Laura Auricchio, «Pahin de la Blancherie's Commercial Cabinet of Curiosity (1779-1787)», Eighteenth-Century Studies, vol. 36, n¹, 2002, p. 47-61, et Charlotte Guichard, « Hors l’Académie, les amateurs et les expositions artistiques publiques à Paris à la fin du XVIII siècle : le Musée de Pahin de la Blancherie (17771788) », in Katia Beguin et Olivier Dautresme (dir.) La ville et l'esprit de société, PUFR, Tours, 2004, actes de la journée d'étude du 27 mai 2002 organisée par le CEHVI à l’Université François Rabelais, Tours.
} 
une nouvelle scène intermédiaire; enfin le jeu des négociations institutionnelles dissimulées derrière les invocations à la liberté dramatique ou à l’intérêt du public.

Il s’agit donc d'explorer l'articulation entre la géographie ludique de la ville et la hiérarchie symbolique des spectacles et des genres théâtraux en examinant comment le Palais-Royal de la fin du XVIIIe siècle a constitué un enjeu en apparaissant comme le lieu où pouvait se faire jour ce renouvellement de l'offre culturelle.

De cette manière de lier le sort du théâtre des Variétés et le Palais-Royal témoigne une curieuse pièce anonyme prétendument publiée à Amsterdam en 1786, la Lettre de Barogo et consorts, maîtres ramoneurs au Palais-Royal, à M. Figaro et Compagnie, négociants au faubourg Saint-Germain6. Cette « lettre » fantaisiste met en scène les justes réclamations d'un dénommé Barogo, ramoneur au Palais-Royal, contre les prétentions des négociants du faubourg Saint-Germain. L'argument est simple: Barogo qui, comme il l'expose lui-même, « a gagné queuque sous grâce à son succès » - car l'auteur prête au personnage le parler populaire du théâtre forain - entend mieux s'habiller, ce que lui refusent les négociants du faubourg Saint-Germain. Les propres réclamations de Barogo sont relayées par la conversation de deux gros clients présents dans la boutique, conversation surprise par Barogo et son acolyte Jérôme Pointu. Défendant la cause de ramoneurs injustement entravés dans leur projet d'amélioration, le premier, un marquis, passe en revue toutes les raisons qui plaident en leur faveur. Le second, un comte, tente faiblement de défendre le point de vue des négociants du faubourg, avant de se laisser gagner par la démonstration implacable du marquis : il sert évidemment de faire-valoir.

D’une certaine manière, je propose ici d'élucider cette lettre en en donnant les clefs. Car, derrière la métaphore parodique, pas toujours exactement filée, se dissimulent à peine les véritables acteurs du conflit : le personnage de Barogo, tiré du répertoire du théâtre des Variétés - une pièce à succès récemment créée au Palais-Royal7 -, incarne évidemment le spectacle forain récemment installé auprès de la demeure du prince du sang, tandis que Figaro et compagnie représentent la Comédie-Française, et le marquis l'intérêt du public. Dans la bouche de Barogo ou dans celle du marquis, on trouve l’ensemble des arguments qui ont alors été employés en faveur des Variétés

\footnotetext{
6 Bibliothèque nationale de France (BNF), 8 Z Le Senne 6121 (21), 30 p. in-8.

${ }^{7}$ Le Ramoneur prince et le prince ramoneur, comédie-proverbe, en un acte, en prose, attribuée à Maurin de Pompigny, et représentée pour la première fois à Paris, sur le théâtre des VariétésAmusantes, le 11 décembre 1784, a connu un succès tel (123 représentations de 1785 à 1788), qu'il a eu deux suites : Barogo, ou la Suite du Ramoneur prince, créé dans le même théâtre le 24 juillet 1785 et réprésenté 120 fois jusqu’à la fin de l'année 1788, et Le Mariage de Barogo, créé le 24 novembre suivant et représenté 61 fois. Le texte de ces trois comédies a été édité par Cailleau, à Paris, en 1785-1786, et conservé à la Bibliothèque Historique de la Ville de Paris (BHV.), 611674 (1, 2 et 3).
} 
contre les réclamations de la troupe royale, et finalement les enjeux de la nouvelle vocation ludique du Palais-Royal. Ces arguments sont de trois ordres : les premiers touchent à la qualité du site, les deuxièmes à la dignité et à l'utilité sociale du spectacle, les derniers, enfin, aux justes droits d'une entreprise qui verse son écot.

\section{LES VARIÉTÉS ET LA « FOIRE PERPÉTUELLE »}

Dans sa lettre, Barogo expose d'abord qu'il entend se « décrasser » pour ne pas «faire fuire les pratiques », car, explique-t-il :

« les ceux que je servons t'à présent, sont des personnes qui pouvont manger leurs choux gras, et faut pas que je leur fassions honte, parce que autrement, i me diroient, Et ben,... Pourquoi que t'es déménagé pour venir gâter l'inducation de not'quartier? ». Le marquis, quant à lui, évoque le cri du public "pour avoir une boutique dans ce quartier, capable de nous servir d'une manière décente et convenable».

Ce quartier, c’est bien sûr le Palais-Royal, tout récemment transformé par Louis-Philippe-Joseph, duc d'Orléans.

\section{Le Palais-Royal, UnE « FOIRE PERPÉTUelLe »}

En 1781, le duc de Chartres, futur Philippe-Égalité, prince d'autant plus libéral et anglophile qu'il est en disgrâce à la cour, vient d’hériter du PalaisRoyal par avancement d'hoirie ; il entreprend alors sa transformation et le lotissement du pourtour du jardin selon une opération de spéculation immobilière qui donne naissance au « nouveau Palais-Royal » : de promenade à la mode, le Palais-Royal devient pour un demi-siècle la « ville dans la ville », le « centre de Paris », une véritable « foire perpétuelle ». En 1785, le rédacteur des Mémoires secrets juge ainsi que le Palais-Royal est «devenu le centre de tous les marchands à la mode, de toutes les curiosités, des petits spectacles, en un mot, des divers objets qui attiroient aux foires $»^{8}$.

La qualification foraine du Palais-Royal, si courante, tient d'abord à ce transfert. Le «nouveau Palais-Royal » tire une partie de sa substance des foires, et paraît précipiter leur déclin amorcé en 1762. En 1786, l’Almanach des Petits spectacles de Paris résume l'affaire d'une formule9 :

\footnotetext{
8 Mathieu-François Pidansat de Mairobert, Louis Petit de Bachaumont, Moufle d'Argenville, Mémoires secrets pour servir à l'histoire de la République des lettres en France, depuis 1762 jusqu'à nos jours, ou Journal d'un observateur, Londres, John Adamson, 1777-1789, t. 28, p. 309, 17 avril 1785.

${ }^{9}$ Les petits spectacles de Paris, ou Calendrier historique \& chronologique de ce qu'ils offrent d'intéressant [...] Pour l'année 1787, Paris, Cailleau, [1786].
} 
«Les Galeries du Palais-Royal, qui forment une foire perpétuelle, et réunissent la variété à la magnificence, ont donné, pour ainsi dire, le coup mortel aux très antiques foires Saint-Germain et Saint-Laurent ».

De cette nouvelle géographie des loisirs parisiens, l'Almanach tâche d'indiquer les causes. Le "goût actuel » d'une part, "l'immensité de Paris » de l'autre profiteraient aux lieux en vogue, moins excentrés que les foires, que sont les boulevards, le jardin du Palais-Royal et autres « fondations nouvelles et brillantes » comme le Wauxhall d'hiver, issu de la foire Saint-Germain, qui s’installe en 1785 sous le nom de « Panthéon » située rue de Chartres, à deux pas du Palais-Royal. L'Almanach suggère deux autres causes, complémentaires: la "sorte de consistance et de réputation » nouvellement acquise par quelques-uns des petits spectacles, et la volonté de se soustraire à « l'obligation » de suivre les foires.

L'attraction du Palais-Royal repose ainsi sur quelques éléments : l'enceinte offre tout à la fois des locaux, un public et un prestige à des spectacles qui aspirent à un nouveau rang. Dans leur volonté de se fixer à demeure et, parfois, dans leur quête de respectabilité, ils bénéficient par ailleurs du soutien du prince, qui y voit la source d'une valorisation immobilière de sa propriété, ainsi que des marchands, qui y voient un facteur d'attraction du chaland.

Au total, cette concentration de divertissements confère au Palais-Royal un nouveau statut : objet d'un chapitre propre de l'Almanach des Petits spectacles de 1786, placé en tête de l'édition de 1787, l’enceinte, qui accueille huit de la quinzaine des spectacles divers recensés, constitue en elle-même un ensemble identifié et reconnu : c'est la consécration symbolique de la place du jardin princier dans la géographie des divertissements urbains. Le Palais-Royal constitue en soi un « complexe de loisirs », à l'instar du boulevard, ou de chacune des foires.

\section{LA FIXATION DEs VARIÉTÉS Au PALAIS-ROyAl ET SES ENJEUX}

Parmi ces curiosités multipliées à l’intérieur de l'enceinte princière, le spectacle des Variétés tient le premier rang. En 1781, la salle de l’Opéra, située au Palais-Royal depuis sa création plus d'un siècle plus tôt, disparaît dans un incendie; une salle provisoire est élevée sur le boulevard, en attendant l'hypothétique et toujours repoussée édification d'un monument digne du premier spectacle de la capitale. Au même moment, le duc de Chartres a projeté l'augmentation de son palais que doit financer une opération de spéculation immobilière ${ }^{10}$. Or, pour valoriser ses nouveaux bâtiments, destinés à être loués puis vendus, le duc entreprend d'obtenir le retour du spectacle de l'Académie royale de musique dans sa demeure. Comme il n'y parvient pas, et soucieux qu'il est «d'attirer de plus en plus les curieux dans son palais par

10 Pour l'histoire du Palais-Royal, voir l'étude ancienne mais à ce jour non remplacée de Victor Champier et G.-Roger Sandoz, Le Palais-Royal, d'après des documents inédits (1629-1900), Paris, Société de propagation de livres d'art, 1900, 2 vol. 
toute sorte de jeux, de divertissements et d'actes publics », le duc de Chartres obtient de Gaillard et Dorfeuille, deux entrepreneurs de spectacles venus de province qui ont récemment acquis le privilège d'un spectacle forain fondé en 1772 par Lécluse, les Variétés-Amusantes, qu'ils s'établissent au PalaisRoyal11. C'est à partir de là que fut bâtie la salle qui, reconstruite après son incendie en 1900, est actuellement occupée par la Comédie-Française.

Cette translation présente pour les entrepreneurs un double avantage. Le premier tient au domicile unique: fixées à demeure, les Variétés sont désormais affranchies de l'obligation non seulement de suivre les foires, mais encore de s'éloigner de l'Opéra ses jours de représentation. Le second est lié au site lui-même : la double proximité d'un palais princier et d'une promenade en vogue est gage de fréquentation et de prestige pour des entrepreneurs dont l'ambition est de faire des Variétés un " second Théâtre-Français »12.

Pour le prince, soucieux de conserver une salle de spectacle qui manifeste sa puissance sociale et garantisse la fréquentation de sa propriété, elle compense le départ de l'Opéra. Quant au public, à en croire la Correspondance secrète, c'est avec une vive impatience qu'il attend l'ouverture de ce théâtre " au centre de la capitale, point unique qui réunit tous les plaisirs possibles "; nul doute que ce spectacle participera à cette "réunion et cette diversité de plaisirs qui flatte tous les goûts » et desquelles « on s'arrache avec peine pour aller chercher l'opéra à la porte Saint-Martin ou la Comédie Française à l'extrémité du faubourg Saint-Germain »13.

Les effets de cette fixation des Variétés au Palais-Royal sont toutefois ambivalents car si, pour les partisans d'un renouvellement de l'offre théâtrale, le Palais-Royal, par son rang et son prestige hérités, donne au spectacle les moyens d'une nouvelle existence et signifie l'émergence d'une nouvelle scène

11 Mémoires secrets, op. cit., 16 novembre 1784, t. 27, p. 17. À la date du 25 décembre 1783, les Mémoires secrets (t. 24, p. 110) rapportent déjà que le duc de Chartres, "trompé dans ses spéculations de bénéfice sur ses nouveaux bâtiments, cherche à y suppléer de toutes les manières, en procurant à l'avenir à ceux-ci au moins une valeur factice. En conséquence, depuis quelque temps, on parle d'une nouvelle spéculation de sa part, qui serait de laisser s'établir au PalaisRoyal une troupe de spectacle foraine à ses ordres, moyennant une redevance, ce qui, outre ce revirement, donneroit plus de prix à ses locations ». Sur le théâtre des Variétés, voir Louis-Henri Lecomte, Histoire des théâtres de Paris. Les Variétés-Amusantes, 1778-1789, 1793-1798, 18031804, 1815, Paris, H. Daragon, 1908. L'auteur cite, p. 111-112, la requête du duc auprès du roi en octobre 1784 à l'effet d'obtenir un arrêt du Conseil l'autorisant à établir les Variétés au PalaisRoyal ; il y « expose qu'il a toujours eu le désir de conserver la faculté d'avoir au Palais-Royal un spectacle public », et renonce à quelque privilège que ce soit : il consent à ce que les directeurs soient assujetis à la taxe des pauvres et à se concerter avec le Lieutenant général de police et son propre conseil pour établir un règlement capable d' 's assurer le maintien de la décence et du bon ordre dans les compositions et les représentations ».

12 Sur cette mobilité, voir L.-H. Lecomte, op. cit., p. 104-112.

13 Correspondance secrète, politique et littéraire, ou Mémoires pour servir à l'histoire des cours, des sociétés et de la littérature en France, depuis la mort de Louis XV [par Imbert, Métra et autres], 28 décembre 1784, t. 17, p. 213. 
digne de l'attente du public, pour les contempteurs du lotissement du jardin, au contraire, l'installation des Variétés-Amusantes au Palais-Royal marque l'indignité d'un prince cupide, et la perte de grandeur d'une demeure autrefois de haut rang.

Dans les deux cas, cependant, le sort du spectacle des Variétés est lié à celui de l'enceinte magique. L'intégration architecturale de la salle au «nouveau Palais-Royal » imaginé par Victor Louis, l'architecte du duc, en constitue la plus éclatante manifestation : le bâtiment fait corps avec le Palais-Royal tout entier. En effet, si le spectacle investit d'abord une salle provisoire, élevée en moins de deux mois et ouverte au public le $1^{\mathrm{er}}$ janvier 1785, elle se voit consacrée une salle définitive, ouverte pour la rentrée de 1790 , un an après la date prévue. Dans les deux cas, la salle fait corps avec le palais et les nouveaux bâtiments dont, structurellement, elle ne se distingue pas, à rebours du modèle du théâtre monument inventé et diffusé au cours du XVIIIe siècle ${ }^{14}$. En outre, l'ornementation de la façade de la salle définitive, du côté de la rue, en reprenant des motifs développés dans les nouveaux bâtiments, accorde l'édifice à la grandeur de la demeure d'un prince. Par ailleurs, l'aménagement dans son pourtour d'une galerie couverte et ininterrompue, assure l'intégration du bâtiment au dispositif de circulation du Palais-Royal tandis qu'elle constitue, par son ouverture sur la rue de Richelieu, un point d'accès au jardin et aux galeries. Enfin, la bordure de la salle est investie de commerces multipliés, qui viennent s'ajouter aux boutiques aménagées sous les arcades ou sous les baraques de bois.

Par le décor de la scène, et son lustre, imité de celui du Français, la nouvelle salle consacre l'ambition première des Variétés de rivaliser avec les grands théâtres. Dès 1785, le rédacteur des Mémoires secrets moque la "prétention [des Variétés] à singer les premiers spectacles et à gagner beaucoup d'argent »15. Car, pour garantir le nouveau rang de leur spectacle, et son succès commercial, les entrepreneurs ont encore joué sur d'autres cordes : le prix des places et la forme des annonces dans la presse.

Si l'augmentation du prix des places a bien évidemment une fonction pratique (augmenter les recettes), il forme aussi un enjeu social et symbolique: il est, avec les loges, l'un des instruments du partage entre « grands » et " petits spectacles » selon l'idée d'un rapport étroit que le prix d'entrée et la disposition de la salle entretiennent avec le profil des spectateurs: un bas prix et un parterre debout, sans loges, permettraient d'écarter la «bonne compagnie » des tréteaux, tandis qu'inversement un prix élevé, un parterre assis et des loges exclueraient la populace des salles privilégiées. Les permissions accordées aux spectacles forains stipulent le montant maximum des billets d'entrée et excluent parfois parquet assis et rang

\footnotetext{
14 Daniel Rabreau, Le Théâtre et l'embellissement des villes de France au XVIIIe siècle, thèse d'État de lettres sous la direction d'André Chastel, Université Paris IV, 1978.

15 Mémoires secrets, op. cit., 2 janvier 1785, t. 28, p. 8.
} 
de loges. À cet égard, la salle du Palais-Royal déroge aux conventions, plaçant les Variétés à égalité avec la Comédie-Française, comme s'en plaint l'auteur des Lettres édifiantes du Palais-Royal, qui appelle au rétablissement du «bon ordre » dans le monde des spectacles, c'est-à-dire à la distinction entre " grands » et "petits théâtres », qui passe par une distinction tarifaire16.

Il est un autre instrument symbolique de promotion: l'annonce des représentations dans la presse. Dans les Petites Affiches comme dans le Journal de Paris, le transfert des Variétés au Palais-Royal se traduit par une modification de la mise en page avec une nouvelle division à trois traits qui, là encore distingue le Palais-Royal, placé entre les troupes privilégiées et « petits spectacles » du boulevard 17 .

\section{LES USAGES POLÉMIQUES DE LA « LIBERTÉ DRAMATIQUE »}

Le nouveau rang des Variétés, ainsi marqué, a été justifié par l'argument de l'amélioration théâtrale appelée de ses vœux par le public. Dans la lettre supposée de Barogo, le marquis s'exclame ainsi à l'attention du comte, en parlant des ramoneurs du Palais-Royal, c’est-à-dire des Variétés : « Ne voyezvous pas qu'en les tourmentant, c'est nous, c'est le public qui en souffre». La concurrence n'est pas à craindre, ajoute-t-il, qui «ne peut qu'exciter l'émulation et hâter les progrès », et encourager les négociants du faubourg à offrir des tissus plus délicats. Faut-il en outre, demande, faussement naïf, le marquis, que " l'élite de la bourgeoisie ", qui ne veut pas payer 18 francs pour aller au faubourg Saint-Germain mais néanmoins jouir de délassements, soit condamnée à ce que "ses oreilles soient blessées, que ses principes soient attaqués, ou qu'enfin il en coûte à sa pudeur? ». Les riches négociants devraient eux-mêmes se féliciter de cette diversification de l'offre car ce sont «les petites boutiques [qui] ont donné leur vogue à la grande »; ils pourraient aussi y trouver d'habiles apprentis, encouragés dans leurs travaux par la perspective d'entrer au grand magasin.

TROUPES PRIVILÉGIÉES CONTRE « PETITS SPECTACLES »: UNE OPPOSITION POLÉMIQUE

Pour servir leurs ambitions, contre les oppositions venues principalement des Comédies Française et Italienne, les entrepreneurs Gaillard et Dorfeuille ont en effet argué de la nécessaire liberté dramatique, conforme selon eux à l'intérêt des amateurs. Ils ont habilement mis au service de leur intérêt particulier un argumentaire développé depuis le midi du siècle et dont on trouve des formulations vigoureuses sous la plume de Rochon de Chabannes,

16 L. Bonnefoy de Bouyon, Lettres édifiantes du Palais-Royal, par un missionnaire du camp des Tartares..., À Gattières et se trouve à Paris, chez tous les marchands de nouveautés, 1788.

17 Michèle Root-Bernstein, op. cit., p. 14-16. 
de Cailhava ou de Louis Sébastien Mercier. Cet argumentaire est à double face: d’un côté, il s’appuie sur la dénonciation de la médiocrité de la Comédie-Française, de l'autre sur le vœu général d’une "seconde troupe » capable soit, par l'émulation qu'elle introduirait, d'accoucher d'une " révolution dans l'art dramatique », soit de former des comédiens destinés à une Comédie-Française renouvelée ${ }^{18}$.

On sait le poids du privilège dans l'économie théâtrale parisienne de l'Ancien Régime, où les trois "grands théâtres » détiennent le monopole exclusif du répertoire classique et des grands genres dramatiques, au détriment de ce qu'on appelait les « petits spectacles ». On a longtemps vu dans les uns et les autres l’opposition entre une culture d'élite, incarnée par l’Opéra, la Comédie-Française et la Comédie-Italienne, et une culture populaire, développée sur les scènes de la foire et du boulevard, célébrant la fonction corporelle et développant une critique implicite de la grande culture, sans toujours voir qu'elle était aussi le produit d'une polémique.

De cette double polarisation, Mercier fait ainsi à la fois le témoin et le dénonciateur. Le dramaturge et théoricien de l'art dramatique évoque dans le Tableau de Paris le "goût général du public pour ces amusements » dans lequel il lit d'abord l'émergence de nouvelles valeurs, à savoir la perte du « charme des sociétés particulières » au profit des divertissements publics. Mais s'il constate, de fait, la multiplication des théâtres, il souligne aussitôt le prix qu'en fait payer la «tyrannie absurde » des privilèges des «grands comédiens », "véritables ennemis des plaisirs publics » selon lui parce qu’ils condamnent « le peuple » à des «pièces informes qui déshonorent, et ceux qui

\footnotetext{
18 La médiocrité de la Comédie-Française est l'objet d'un lieu commun à la fin des années 1770, mais reste l'objet de discussions quant au remède. Le Mercure de France (nouvelles littéraires) rend ainsi compte dans son numéro du 8 juillet 1780 des Observations sur la nécessité d'un second Théâtre-Français, une brochure de 48 pages attribuée à M. Rochon de Chabannes. Le rédacteur admet la "médiocrité » de la troupe mais soumet la création d'une seconde troupe à une condition de poids : celle de supprimer les spectacles du boulevard qui, «tant qu'ils existeront, [...] enlèveront aux théâtres royaux la plus grande partie de leurs spectateurs [et dont la] fréquentation ne peut qu'accélérer la chute du goût; nous dirons plus : celle des mœurs ». Cailhava de l'Estandoux propose en 1772 la création d'un second théâtre de la nation à Paris ( « le théâtre de la ville ») dont les acteurs seraient tirés des théâtres de province. Chevalier du Coudray réclame aussi en 1779 ce « second Théâtre-Français, dont la troupe s'établira seulement sous le titre d'École dramatique ». Louis-Sébastien Mercier s'est également fait l'apôtre de l'«émulation » : appelant à l'instauration d'une seconde troupe, il explique que «deux théâtres qui rivaliseraient, qui entretiendraient entre eux une émulation suivie en jouant les mêmes pièces, qui seraient enfin l'un pour l'autre un perpétuel objet de comparaison, restitueraient à l'art sa pompe, sa noblesse et sa dignité », Tableau de Paris, éd. Jean-Claude Bonnet, Paris, Mercure de France, 1994, 2 tomes, t. 1, p. 524 (chapitre CCVIII, «Comédiens »). En 1789, nombreux sont les auteurs et les théoriciens réclamant une liberté du théâtre contre la ComédieFrançaise, mais dans le cadre du privilège et du contrôle collectif : s'il faut créer un second Théâtre Français, il faut aussi supprimer les tréteaux forains, comme l'explique encore Cailhava de l'Estandoux, dans ses Causes de la décadence du théâtre, rééditées en hommage à la Mairie de Paris en 1789.
} 
les composent, et ceux qui les représentent » 19 , "la plupart [étant] basses, plates, ordurières». Mercier en appelle donc, avec nombre de ses contemporains, et au nom du "public", à la création d'une "seconde troupe », que la tyrannie des gentilshommes de la chambre seule empêcherait ${ }^{20}$. Lui-même intéressé au premier chef comme auteur dramatique, Mercier exprime donc avec force l'exigence d'une liberté et d'un pluralisme des spectacles, gage de leur dignité et de leur utilité, telle qu'il l'avait déjà développée en 1773 dans son Théâtre, ou nouvel essai sur l'art dramatique. Le système du privilège, jalousement gardé par les gentilshommes de la chambre, constitue la principale cible de Mercier, parce qu'il y voit le principal obstacle contre son rêve d'un théâtre moral et pédagogique, qui présiderait « tout à la fois à l'amusement et à l'instruction publique ${ }^{21}$.

Mais cette véritable charge contre le privilège au théâtre conduit Mercier à forcer le trait. Dans un autre chapitre de son Tableau, il reconnaît d'ailleurs, pour s'en réjouir, l'affaiblissement relatif du privilège quand on a enfin permis "à quelques pièces raisonnables de paraître sur les tréteaux » à condition qu'elles soient en un acte22.

\section{Barogo contre Figaro, ou le Palais-Royal contre le faubourg Saint- GERMAIN}

L’adresse des entrepreneurs des Variétés a consisté à s'emparer de ces thèmes pour les mettre au service de leur cause : ils se sont posés en rival nécessaire de la Comédie-Française. C’est en ces termes polémiques qu'ils répliquent aux réclamations des comédiens du roi pour qui la construction d'un théâtre au Palais-Royal, dans un "monument placé dans le milieu de Paris, et dans l'endroit le plus peuplé», signifie d'avance "la perte de celui de la nation »23. Face à la "décadence» d'une institution "autrefois glorieuse », "il faut », affirment au contraire les entrepreneurs des Variétés, "fonder un second Théâtre Français dans cette capitale de la France [...]. C'est là le vœu général, proclament-ils, c'est la demande non seulement des gens de lettres, mais des gens du monde »24.

Les entrepreneurs demandent en conséquence à ce que leur spectacle soit érigée "en seconde troupe, très désirée par les auteurs et par tous les amateurs qui s'intéressent au progrès de l'art dramatique, qui seule peut

19 L-S. Mercier, Tableau de Paris, op. cit., chap. CMLXXI, « Les grands comédiens contre les petits», t. 2, p. 1351. Voir encore les chapitres CCXV («foire Saint-Germain»), CCXVII (« spectacles des boulevards »), CCCVII (« Affiches »), DCXII (« Tréteaux des boulevards »).

20 Ibid., chap CXCVI, «Petites loges », t. 1, p. 486-490.

21 Ibid., chap. DCXII (« Tréteaux des boulevards »), t. 2, p. 286.

22 Ibid., p. 285.

23 Voir la supplique adressée en 1783 par les Comédiens Français au comte de Provence (Bibl. Comédie française, carton Odéon), citée par Daniel Rabreau, op. cit., p. 207.

24 Extraits du Mémoire en réponse des Variétés-Amusantes repris dans les Mémoires secrets, op. cit., 14 août 1785, t. 29, p. 201-203. 
encourager la concurrence, mère de l'émulation ». Dans leur charge contre la Comédie-Française, ils lui retournent l'argument du répertoire, et opposent à l'obscénité qu’on leur reproche « 20 pièces des Français des plus licencieuses qu'aucune des farces jouées sur les théâtres des boulevards ». Parmi elles, ils visent sans la nommer Le Mariage de Figaro, cette comédie annoncée pour la 74e représentation, "remarquable sans doute par son originalité, par la hardiesse de ses sarcasmes contre tous les états, quoiqu'elle ne présente que des exemples dangereux et qu'on n'y trouve pas un seul mot pour la vertu »où l'on voit comment ils mobilisent des thèmes des Lumières devenus communs, tels que l'émulation ou la vertu.

Dans cette charge contre le spectacle privilégié, jugé coupable de la décadence du théâtre, les entrepreneurs ont trouvé de solides relais. Guides, almanachs et chroniques ont en effet été les premiers à voir la « révolution dramatique » à l'œuvre au Palais-Royal. À vrai dire, «l'élévation » des Variétés-Amusantes fut louée avant que Gaillard et Dorfeuille ne s’en emparent. Les Petites Affiches de 1782 présentaient déjà la comédie Ésope à la foire, pièce en un acte et en vers créée sur le théâtre des Variétés-Amusantes, comme une pièce «bien supérieure à toutes ces farces qui se jouent sur nos théâtres forains, et qui corrompent également le goût et les mœurs". L'annonce, à caractère évidemment publicitaire, vantait les mérites d'une pièce « en général bien écrite, semée de traits ingénieux et délicats, [qui] aurait pu obtenir les honneurs du Théâtre-Français »25. Le Petit Tableau de Paris se félicitait pareillement dès 1783 de ce que la morale se soit réfugiée sur ce théâtre « qui pourrait devenir quelque chose un jour »26. Leurs anciens entrepreneurs, Lemercier, Malter et Hamoir, rappelèrent aussi leur propre contribution (dans la demande d'indemnités qu'ils adressèrent aux nouveaux acquéreurs) : "D’un spectacle trivial et populaire qu'il étoit, ils l'élevèrent à un rang distingué dans son genre, tant par le choix des pièces qu'ils achetèrent des meilleurs auteurs qu'ils y employèrent, que par les salles mêmes qu'ils firent construire ${ }^{27}$.

Mais la nouvelle destinée du spectacle se dessine plus nettement à partir de la fin de l'année 1784, époque à laquelle fut décidée son installation au PalaisRoyal. Les Nouvelles descriptions des curiosités de Paris livrent, dans leur édition pour 1785, une notice tout à la gloire d'un spectacle qui se distingue par « l'engouement universel » qu'il suscite et le « bon choix des pièces qu'on y joue » : outre des farces «très gaies », on y voit en effet des pièces «d'un genre beaucoup plus noble » qui font présager " une heureuse révolution dans l'art dramatique »28. Pour le rédacteur, les Variétés pourraient ainsi «devenir

\footnotetext{
25 Journal général de France, « avis divers », 4 septembre 1782.

26 C.-C. de Rulhière (d’après Barbier), Le Petit Tableau de Paris, s.l.n.d. [1783].

27 Arrêt du Conseil d'État du 28 octobre 1785, reproduit dans Émile Campardon, Les Spectacles de la foire [...] depuis 1595 jusqu'à 1791, Paris, Berger-Levrault, 1877, 2 tomes, t. II, p. 59.

28 Jean-Antoine Dulaure, Nouvelles Descriptions des curiosités de Paris, Paris, Lejay, 1785, p. 532.
} 
une école où le premier théâtre de la nation puiserait des sujets dignes de lui ». L'Almanach du Palais-Royal pour l'année 1786, surtout, regarde ce théâtre " comme destiné à devenir un des plus intéressants de la capitale». Il en attribue tout le mérite au « goût sage et éclairé » de Dorfeuille, qui en épure le répertoire, et rapporte cette "révolution » à la qualité du Palais-Royal et de son public, car s'il a laissé au boulevard beaucoup de ses farces, c'est qu'elles " auraient été déplacées dans le lieu qu'il occupe, et où elles n'auraient pas été également applaudies ${ }^{29}$.

L'idée d'un lien entre l'installation du spectacle forain au Palais-Royal et son épuration fut réaffirmée en 1787, quand fut connu le projet de lui consacrer une salle définitive. À cette date, le guide de Thiéry souligne la nécessaire concordance du contenant et du contenu : "La salle que l'on se propose d'élever l'année prochaine pour ce théâtre dans la même enceinte, entraînera sans doute une révolution qui ne lui sera pas moins favorable ${ }^{30}$. Même chose dans le guide de Dulaure, toujours pour l'année 1787: "les VariétésAmusantes, pour s'élever au point de rivaliser un jour avec le Théâtre Français, vont avoir au Palais-Royal dans l'emplacement de la galerie, une vaste et superbe salle construite sur les dessins de M. Louis »31.

Les auteurs dramatiques eux-mêmes proclamèrent cette nouvelle ambition, garante pour eux d'un nouveau moyen d'expression, et donc aussi de revenus. Pour les auteurs dramatiques, la Comédie-Française reste au XVIIIe siècle le moyen de se faire reconnaître; le bénéfice symbolique qu'ils en attendent compense la renonciation qu'ils font de l'exploitation commerciale de leur ouvrage, d'autant que le don est négocié. Il reste que la légendaire morgue des acteurs, qui jugent des pièces proposées, était peu appréciée d'auteurs qui attendaient parfois des années avant que leur pièce ne soit représentée. Les nouveaux venus dans les années 1770 s'opposèrent ainsi à la lecture, qu'ils jugèrent déloyale ${ }^{32}$.

À travers la promotion des Variétés, à l'instar d'autres « petits théâtres », se joue donc aussi la qualification de nouvelles instances de consécration du talent de dramaturge. C'est ce qu'on peut lire en creux dans la préface qu'un auteur - Antoine-Jean Bourlin, dit Dumaniant - donne de l'une de ses nouvelles productions, La guerre ouverte, ou ruse contre ruse, une comédie mise à

\footnotetext{
${ }^{29}$ Almanach du Palais-Royal, utile aux voyageurs, pour l'année 1786, Paris, Royez, [1786], p. 86-89. 30 Luc-Vincent Thiéry, Le Guide des amateurs et des étrangers à Paris, ou Description raisonnée de cette ville et de tout ce qu'elle contient de remarquable, Paris, Hardouin et Gattey, 1787, p. 272. 31 J.-A. Dulaure, op. cit., p. 353.

32 Sur le rôle de la Comédie-Française comme moyen d'accéder au rang « d'homme de lettres » pour les auteurs dramatiques, voir Gregory S. Brown, Field of Honor. Writers, Court Culture and Public Theater in French Literary Life from Racine to the Revolution, Ph.D. diss., Columbia University, 1997. Sur les aspects liés à la question du droit d'auteur et de la propriété littéraire à la fin de l'Ancien Régime, peu étudiés dans le domaine du théâtre, on pourra aussi se reporter à un article du même, «After the Fall: The Chute of a Play, Droits d'Auteur, and Literary Property in the Old Regime », French Historical Studies, 22.4 (1999), p. 671-673.
} 
l'affiche le 4 octobre 1786 au Palais-Royal33. Il y explique que la comédie, en tant que genre dramatique, incarne la promotion des Variétés, tant dans le répertoire que dans le jeu des acteurs. Avec elle, en effet, doit «tomber un préjugé défavorable à ce spectacle », préjugé qui veut qu’une comédie « $d u$ bon genre » y soit déplacée et que les acteurs ne soient propres qu’à jouer des farces. À preuve le succès de 10 pièces, qu'il cite. Or Dumaniant fait le lien avec la rupture de 1784-1785 : « les temps ont changé », explique-t-il :

«ce spectacle n'est plus ce qu'il était, à sa naissance. On était loin de prévoir qu'il viendrait s'établir, pour toujours, dans le palais du premier prince du sang, qu'il serait honoré de sa protection, et débarrassé, à jamais, par un ordre exprès de Sa Majesté, de ces entraves ridicules qui soumettaient les pièces que l'on y destinait à la censure des grands théâtres ».

Dumaniant fait des Variétés le bon élève de la Comédie-Française et le lieu où le « public », juge suprême, verra se former tant les acteurs que les auteurs avant de donner ses « suffrages » à ceux qui voudraient œuvrer pour la troupe du roi. Contre l'autorité des Comédiens du roi, et sur le ton de la soumission et de la révérence à leur endroit, Dumaniant en appelle donc au seul tribunal du « public ».

\section{Contre les « VeXATions » DES Comédies FranÇAise et ITAlienne : LA PROTECTION, LE PRIVILÈGE}

Si les Variétés ont pu incarner le combat, au nom du public, pour la liberté théâtrale, la stratégie employée par les entrepreneurs révèle aussi les moyens de la lutte. Car cette promotion d'un spectacle issu de la foire n'est pas le simple agent ou produit d'un affaiblissement du monopole des trois grands théâtres. C'est au contraire par le système même du privilège, négocié et « commercialisé », ainsi que par le jeu des protections, que les Variétés du Palais-Royal ont gagné leur statut. La lettre adressée par Barogo aux négociants du faubourg Saint-Germain évoque à de nombreuses reprises les droits ainsi acquis par les ramoneurs. Barogo lui-même rappelle qu'il a payé "pour être plus propre », et le marquis s'indigne: "Mon cher comte, il est affreux qu'on tracasse ces gens comme on le fait ; ils ont payé et paient encore tous les jours l'impossible, et ils ont les mains liées de tous les côtés, cela n'est pas juste ». Par ailleurs, n'a-t-il pas plu au souverain d'autoriser «les syndics de ces négociants à donner des privilèges à qui bon leur sembleroit », privilèges notamment acquis par les ramoneurs ? À l'adresse des négociants du faubourg qui pensaient d'un souffle jeter les planches de sa boutique à terre, Barogo conclut d'ailleurs, pragmatique et conquérant :

« Je suis pourtant bien aise de vous dire en passant qu'il y a gros à parier que ça ne sera pas, et que nous avons de bons soutiens : c'est à savoir not'emplacement

\footnotetext{
33 Le texte en fut publié l'année même à Paris, chez Cailleau ; exemplaires à la BNF, 16 YF 2490 (8), ainsi qu'à la B.H.V.P., $8^{\circ} 3691$ (6).
} 
[le Palais-Royal] et son bourgeois [le duc d'Orléans]. Des traités bien signés avec d'honnêtes gens [le bail du 18 septembre 1784 passé par l'Académie royale de musique], et pis la bonté et l'amitié de nos pratiques [le public]».

\section{UN STATUT LÉGAL}

Dans les conflits qui ont opposé les Comédies Française et Italienne mais aussi les foires aux Variétés, Louis-Auguste Le Tonnelier, baron de Breteuil, secrétaire d'État à la Maison du Roi de 1783 à 1787, joua un rôle d'arbitre.

Les protestations les moins gênantes vinrent des foires elles-mêmes. Au mois de janvier 1785, Marville, administrateur de la foire Saint-Germain, présente une requête au ministre de la Maison du Roi à l'effet qu'il soit donné des ordres aux directeurs des Variétés-Amusantes, ainsi qu'aux autres spectacles forains, "de se retirer suivant l'usage à la foire Saint-Germain pendant sa tenue ». Les propriétaires des halles, boutiques et loges de ladite foire font peu après de même, mais ni les uns ni les autres n’obtiennent gain de cause en raison du statut particulier des Variétés, « que le Roi a autorisé[es] à ne pas déplacer »34.

L’opposition la plus farouche vint de la Comédie-Française. Illustrant jusqu'à la caricature le portrait de tyrans de l'art dramatique que ses contempteurs dressèrent d'eux, les Comédiens-Français ne cessent de réclamer contre les libertés prises par les spectacles forains en contravention à leurs propres privilèges. Leur charge est spécialement dirigée contre les Variétés. Dès le mois d’octobre 1784, Mlle Contat, actrice, est députée par les comédiens de la troupe auprès du baron de Breteuil, ministre de Paris, «pour lui témoigner de leurs alarmes » et rappeler leurs antiques privilèges face, notamment, aux nouvelles prétentions des Variétés 35 : il ne s’agit rien moins qu'on permette à la Comédie du roi d'exercer une censure efficace sur le répertoire des forains et qu'on défende à ces derniers de commencer à la même heure qu'elle, de jouer des pièces en vers «si ce n'est en vers burlesques ", d'intituler sur les affiches leurs pièces « comédies », d’y mettre le nom des acteurs ou le quantième des représentations... Les réclamations vont jusqu’à l'absurde, puisque les comédiens du roi exigent encore que, « selon leur acte d'autorisation, les Variétés-Amusantes ne puissent faire jouer que des marionnettes ». La troupe privilégiée renouvelle la démarche en juin 1785 en portant une demande auprès du Parlement cette fois, mais toujours en vain 36 .

L’affaire est réglée par l'édit royal du 25 mars 1786, qui, au terme de négociations entre le duc d’Orléans, son chancelier Ducrest, le secrétaire de la

\footnotetext{
34 Archives Nationales (AN), O1 496, f. 65 (lettre du baron de Breteuil au Lieutenant général de police de Paris Lenoir, 29 janvier 1785) et f. 94 (lettre à M. de Marville, 12 février 1785).

35 Mémoires secrets, op. cit., t. 27, p. 39-40, 28 octobre 1784. Pour le détail des réclamations des comédiens du Français, voir Maurice Albert, Les Théâtres de la foire (1789-1848), Paris, Hachette, 1900, p. 302.

36 M. Albert, op. cit., p. 303-304.
} 
Maison du Roi, les gentilshommes de la chambre et le lieutenant général de police, donne raison à la requête des « forains » et, au-delà, fixe le statut à part des Variétés. Le texte rappelle quelques-uns des privilèges des théâtres français et italiens (comme l'exclusivité du répertoire, article 2) mais donne raison à Gaillard et Dorfeuille sur la question essentielle du communiqué des pièces, dont les directeurs ne voulaient pas, au motif que la Comédie-Française s'emparait des meilleures situations : il y aura bien un censeur chargé de l'examen des pièces destinées aux Variétés, mais celui-ci sera "particulier » car «les pièces faites pour les Variétés ne seront point communiquées aux deux Théâtres Français et Italien » (article 4). Surtout, sous l'apparence d'une permission limitative, l'ordonnance consacre les libertés conquises par les «forains » : loin de devoir limiter leurs représentations à un spectacle de marionnettes, la seule interdiction imposée au théâtre des Variétés se limite à ne pas jouer de pièces en 4 ou 5 actes.

Certes, la victoire était fragile : en 1788, les directeurs des Variétés se plaignent de ce que Suard "communique aux acteurs du Théâtre-Français et du Théâtre-Italien les pièces qu'ils soumettent à sa censure »37. Surtout, il n’y a pas de liberté dramatique : les spectacles sont toujours soumis à autorisation, le genre des ouvrages représentés reste contraint, l'émulation n’est pas de mise, les « petits spectacles » ne pouvant faire concurrence aux " grands » sur leur propre terrain, en exploitant leur répertoire. Les Variétés accèdent néanmoins quasiment au rang de « seconde troupe » en se voyant reconnaître, même négativement, des prérogatives sinon inédites, du moins jamais encore formellement reconnues à aucun spectacle parisien.

Pour cela, elles bénéficièrent de la notoire protection non seulement du duc de Chartres mais aussi du lieutenant général de police Lenoir et de son successeur Decrosne38. Le baron de Breteuil, quant à lui, démontre une attitude mesurée : s'il refuse d'accorder la permission sollicitée par Gaillard et Dorfeuille, avec l'appui du duc de Chartres, de faire jouer des BouffonsItaliens les jours où il n’y a pas d'opéra par le motif qu' «il n’y a déjà à Paris que trop de différents spectacles »39, il recommande au Lieutenant général de police Lenoir « de veiller particulièrement à ce que les entrepreneurs ne soient

\footnotetext{
37 Sur l'accusation de Gaillard et Dorfeuille, voir A. N., O1 499, f. 451, lettre du secrétaire d’État de la Maison du Roi au Lieutenant général de police Decrosne, 7 août 1788.

38 Voir par exemple la lettre du secrétaire d'État à la Maison du Roi adressée au Lieutenant de police Decrosne en date du 5 juillet 1786, A. N., O1 497, f. 362 : «Vous trouverez ci-joint, M., un mémoire des entrepreneurs des Variétés-Amusantes dont l'affaire a été renvoyée à une commission que vous présidez. Je ne puis que me référer à l'attention que vous donnerez à leurs droits, et à la connoissance que vous avez des motifs qui doivent déterminer à protéger et à soutenir ce spectacle » (C'est moi qui souligne). Sur la protection de Lenoir, qui remontrait à la fondation même du spectacle, voir L.-V. Thiéry, op. cit. : «Ce spectacle, établi sous l'autorité et protection de M. Lenoir, conseiller d'État, bibliothécaire du Roi, ci-devant Lieutenant général de police, était attaché au service des foires, d'où il a été transporté au Palais-Royal, en janvier 1784, pour y être fixé à demeure ».
}

39 A. N., O1 496, f. 579, Lettre du baron de Breteuil au duc de Chartres, 23 octobre 1785. 
pas vexés par les comédiens ", et évoque les «motifs qui doivent déterminer à protéger et à soutenir ce spectacle ${ }^{40}$.

Cette attitude de compromis peut s’expliquer de trois façons. Les Variétés bénéficient d'abord du souci des autorités de Paris sinon d'encourager la « nouvelle consistance » acquise par quelques-uns des spectacles forains, du moins de négocier leur statut pour prévenir toute réclamation. Elles bénéficient en outre de la volonté de compenser la privation de l’Opéra subie par le duc, une intention d'autant plus précise qu'il s’agissait aussi de prévenir un retour du spectacle lyrique au Palais-Royal, réclamé par le prince mais redouté de l'intendant des Menus-Plaisirs, Denis Papillon de la Ferté, qui voulait doter la capitale d'une nouvelle salle à la gloire du roi. Les Variétés profitent enfin de l'intérêt bien compris de l'Académie royale de musique, et au-delà de la monarchie elle-même qui la finance, les recettes des spectacles forains alimentant les caisses de l'Opéra. L'habileté de Gaillard et Dorfeuille a consisté à jouer à fond la carte du privilège en négociant la permission la plus large auprès de l'Académie royale, dotée de la tutelle des petits spectacles depuis 1784.

\section{LA LOGIQUE DE L’ACADÉMIE ROYALE DE MUSIQUE}

À vrai dire, les intérêts de l'Académie royale de musique étaient contradictoires. D'un côté, les «petits spectacles » pouvaient être une source de concurrence, et donc de manque-à-gagner. De l'autre, la concession de privilèges assurait, sous la forme de «redevances » payées soit par forfait (pour les plus importants spectacles), soit à la représentation (pour les plus petits ou les occasionnels), des rentrées d'argent d'autant plus précieuses que l'Académie connaissait un déficit chronique ${ }^{41}$. La solution consistait à attribuer des privilèges capables d'empiéter sur le monople de la ComédieFrançaise ou de la Comédie-Italienne à l'exclusion de celui de l'Opéra. C'est ainsi que l'Académie royale de musique exercait la plus grande vigilance à l'endroit des bals publics ou des spectacles pratiquant le chant, comme le montrent les plaintes portées contre «l'extension que les entrepreneurs $d u$ spectacle de M. le comte de Beaujolais donnent à la permission de chanter qu'ils ont obtenu [sic] ${ }^{42}$.

Les contributions versées par les entrepreneurs Gaillard et Dorfeuille à l'Académie royale de musique attestent cette stratégie en même temps qu'elles

\footnotetext{
40 A. N., O1 496, f. 129, Lettre du même au même en date du 5 mars 1785 par laquelle le premier assure au second qu'il recommandera «à M. Lenoir de veiller particulièrement à ce que les entrepreneurs ne soient pas vexés par les Comédiens ».

41 L'Académie royale de musique, régie par 29 entreprises différentes depuis son établissement en 1669, accusait une perte de 700000 livres en 1778-1779 ; à cette date, le comte de Maurepas, Amelot et Necker adoptent la forme de l'administration, qui permet non de supprimer mais de réduire les pertes.

42 A. N, 01 497, f. 50, Lettre de la Maison du Roi à Decrosne le 27 janvier 1786.
} 
signent la montée en puissance du Théâtre des Variétés dans le paysage des spectacles parisiens. Le prix de la ferme du privilège des Variétés, fixé dans le bail du 18 septembre 1784 à 30000 livres par an, est bien supérieur à la redevance jusque-là versée par Malter et consorts, qui monta, pour la saison 1783-1784, à 11376 livres. En portant leur tribut à 40000 livres après la rétrocession du privilège de l'Ambigu Comique à Audinot, les Variétés contribuent plus que tous les autres spectacles forains, et autant que la Comédie-Italienne ; cette égalité était d’ailleurs peut-être le moyen de peser face aux réclamations de cette dernière 43 .

Cette inflation traduit la place progressivement conquise par les Variétés dans le paysage des spectacles parisiens à l'aube de la Révolution et, apparemment, la plus grande réussite commerciale des Variétés comparée à Nicolet, Audinot ou la Comédie Italienne, car, loin de récriminer contre le poids de la charge, les entrepreneurs des Variétés versent leur tribut sans rechigner jusqu'à proposer un surcroît pour obtenir la prolongation de leur bail, porté à 20 ans en 1789 .

Si, prosaïquement, l’installation du spectacle des Variétés-Amusantes au Palais-Royal devait, selon le guide de Thiéry, « ajouter encore à l'agrément de ce lieu enchanteur, qui réunira tous les plaisirs possibles ${ }^{44}$, l'ouverture des Variétés au Palais-Royal recelait un autre enjeu : celui de la formation, via «l'élévation » des Variétés, d’un espace intermédiaire entre les «grands spectacles » privilégiés et l'univers des « tréteaux », inséparable de l’invention de nouvelles formes théâtrales. Telle furent les ambitions - et les intérêts - tant des entrepreneurs Gaillard et Dorfeuille, qui en avaient acquis le privilège et le fonds en 1784, que du duc de Chartres, en quête dès 1781 d'un spectacle digne de sa demeure et capable de valoriser ses locations, les uns et les autres soutenus dans leur entreprise par « les auteurs et les amateurs » favorables à l'émulation des spectacles et «l'amélioration des arts »: avec la liberté théâtrale, instaurée en 1791, et la réunion d’une partie des comédiens du Théâtre de la Nation au spectacle des Variétés devenu Théâtre-Français de la rue de Richelieu, la Révolution a consacré ce processus, jusqu’à la fusion de 1799, date à laquelle le Français se fixa définitivement au Palais-Royal.

Quant à l'effet produit sur le Palais-Royal, il a constitué, aux yeux des contemporains, l'emblème de la nouvelle vocation foraine de l'enceinte magique, et au-delà servi l'imaginaire du lieu comme foyer de lumières, voué à l'émulation des arts, la moralisation du théâtre et l'épanouissement des plaisirs publics. Le sort des Variétés a ainsi activement participé à la consécration du Palais-Royal comme ce nouvel espace de liberté tôt entré dans la turbulence révolutionnaire que, avec une certaine vision romantique, la mémoire collective a conservé. L’analyse montre cependant que, loin d’être

\footnotetext{
43 A. N., O1 616, Tableaux des redevances versées par les « petits spectacles » à l’Académie pour les années 1784-1785 à 1787-1788.

44 L.-V. Thiéry, Almanach du voyageur à Paris, Paris, Hardouin et Gattey, 1785, p. 360.
} 
toujours affranchi de la cour, des académies et des privilèges, cet espace de liberté a été aménagé selon une logique marchande et dans le jeu même des privilèges académiques et des protections.

De ce processus complexe par lequel le Palais-Royal finit par incarner cette enclave de liberté, bientôt foyer révolutionnaire, on aurait pu aussi suivre d'autres fils sans quitter le champ des loisirs, en voyant par exemple comment l'enceinte a abrité des formes de sociabilité d'un nouveau genre (comme les clubs, les sociétés ou les cabinets de lecture), des formes commerciales d'une nouvelle espèce (comme le magasin, dont la visite est recommandée dans les guides), ou comment la promenade, de rendez-vous des nouvellistes, s'est transformée en marché des nouvelles et rendez-vous des patriotes. Mais c'eût été poser une autre question, celle que nourrissent les interrogations angoissées contemporaines sur la perte du sens de la ville et la disparition d'un espace public jugé authentique : la question de la manière dont les lieux de loisir, de consommation et de divertissement constituent ou non des espaces dans lesquels peut s'exprimer un désir de collectivité45.

45 Renvoyons simplement ici à l'ouvrage qui sert le plus souvent de référence dans la réflexion sur l'espace public contemporain : Michael Sorkin (Éd.), Variations on a Theme Park. The New American City and the End of Public Space, New York, Hill and Wang, 1992. 


\title{
LES DIVERTISSEMENTS QUOTIDIENS D’UN CITOYEN BAVAROIS AU XIXe SIÈCLE
}

\author{
Robert BECK \\ Université François-Rabelais de Tours, CEHVI
}

\begin{abstract}
Durant 51 ans, de 1821 à 1872, Franz Caspar Krieger, citoyen de la ville bavaroise de Landshut, a tenu un journal intime¹. Né en 1795 à Vilshofen sur le Danube, près de Passau et de la frontière de l'Empire des Habsbourg, il apprend le métier de passementier. Arrivé à Landshut, il s'y marie en 1818 avec la fille d'un maître-passementier local. Grâce à ce mariage, il obtient à la fois le statut de maître-artisan et la propriété d'une belle maison au centre de la ville. Ces deux «acquisitions» lui confèrent en outre le droit de bourgeoisie, dont ne profitent que 595 habitants de la ville, sur un ensemble de plus de 7500 habitants en 18342 .

Krieger tient ce journal avec une grande précision, n’oubliant aucune journée ${ }^{3}$. Certes, il ne se perd pas dans des réflexions philosophiques sur sa vie intérieure et ne confie que rarement ses sentiments et secrets à son journal4 ${ }^{4}$ Il
\end{abstract}

${ }^{1}$ Ce journal est conservé aux archives municipales de Landshut. Nous avons utilisé pour cette recherche, qui est loin d'être achevée, les années 1821, 1825, 1830, 1835, 1840, 1848, 1850, 1855, 1860, 1866 et 1870. Nous profitons de cette occasion pour remercier MM. Tausche et Bauer pour le soutien offert à nos travaux.

2 Alois Staudenraus, Topographische-Statistische Beschreibung der Stadt Landshut in Bayern und ihrer Umgebung, Landshut, Attenkofer, 1835, p. 173.

${ }^{3}$ Ce n'est qu'à ses vieux jours que la goutte l'en empêchera périodiquement.

${ }^{4}$ Quelques remarques, faites en français, font penser cependant à des aventures extraconjugales. On peut noter en général que Krieger note en français des faits touchés par les interdits de la société : jeux de hasard, aventures extraconjugales. 
ne fournit pas non plus d'indications sur les motivations qui l'ont poussé à tenir ce journal. Mais ces notes quotidiennes permettent de suivre l'évolution des pratiques de cet homme dans la longue durée, ainsi que celle du tableau politique, social, religieux et culturel de la société urbaine dans laquelle il évolue. Krieger note minutieusement tous ses loisirs, alors qu’il n’évoque que très rarement son travail. En étudiant les pages de ce journal, le lecteur est frappé par l'importance ludique, sociale et culturelle que la vie des loisirs recèle pour son auteur, ainsi que par les liens qui existent entre les loisirs et la religion catholique, dont la pratique est unanime dans cette ville ${ }^{5}$, sise au cœur de la Bavière catholique, à 60 km au nord-est de Munich. En 1800, Landshut devient ville universitaire et un des centres du romantisme et du renouveau catholique en Allemagne avant que l'université ne soit transférée à Munich en 1826. La présence d'une élite intellectuelle et d'une vie estudiantine assez riche donne un nouvel élan à cette ville de province plutôt endormie.

Après le départ de l’Université, elle retombera dans sa langueur, dont ni le renforcement de la garnison ni le transfert du gouvernement de la BasseBavière en 1838 ne la sortiront. Il faut attendre l'arrivée du chemin de fer en 1858 pour que cette ville connaisse un nouvel essor. Peu industrialisée, Landshut possède aussi une société assez figée au sein de laquelle une couche traditionnelle composée de "vieilles familles », mais aussi de fabricants, de commerçants et de maître-artisans exerce sa domination ${ }^{6}$. Toutefois, la ville de Landshut est riche de deux infrastructures : celle des établissements religieux d'abord7, et celle des débits de boissons ensuite ${ }^{8}$. C'est dans ce cadre qu'il faut situer les divertissements de F. C. Krieger.

\section{L'IMPORTANCE DES TAVERNES DANS LA VIE DE F. C. KRIEGER}

D’ores et déjà, il faut citer l'occupation principale des loisirs de ce bourgeois, à savoir la fréquentation quasi quotidienne des tavernes et autres débits de boissons de sa ville ${ }^{9}$. Le seul fait d'en être privé provoque aussitôt ses lamentations, preuve de l'importance capitale qu'il attribue à ce loisir. «Ah, que nous sommes pauvres », confie-t-il à son journal quand un temps trop froid l'empêche de quitter la maison ${ }^{10}$.

\footnotetext{
5 Peter Reinhold Preissler, Wirtschaft und Gesellschaft Landshuts in der Zeit von 1834 - 1914, Dissertation en sciences économiques, Université de Nuremberg-Erlangen, 1973, p. 229.

6 Simon Hölz, Das Landshuter Bürgertum von 1866 bis 1871, Zulassungsarbeit zur Lehramtsprüfung für Gymnasium, Université de Ratisbonne, dir. Prof. Peter Schmid, 2001, p. 35.

${ }^{7}$ En 1835, on recense huit églises, ainsi que trois églises de couvents, et au moins une douzaine de chapelles. Alois Staudenraus, op. cit., p. 71-166.

8 Tavernes à bière ou à vin, brasseries, cafés, caves, jardins...

9 Il lui arrive même d'y aller plusieurs fois par jour, notamment (mais pas seulement) les dimanches et fêtes : il va dans une taverne après la messe, chez un cafetier l'après-midi, et de nouveau dans une taverne le soir.

$101 \mathrm{er} / 2 / 1830$.
} 
En hiver, ce sont les tavernes et les cafés de la ville qu’il fréquente. Lors de la belle saison en revanche, ce sont les « caves »11, dont l'ouverture définit une véritable saison, allant du 1er mai jusqu'au mois d'août, qui l'attirent. Dans le cas de ces « caves », il s'agit de bâtiments à côté des caves où les brasseries stockent leur bière. Ces lieux, situés dans les faubourgs de la ville, se transforment depuis la fin du XVIIIe siècle en véritables lieux de divertissement, offrant de nombreuses attractions, musique, danse, jeux, illuminations, spectacles, feux d'artifice ${ }^{12}$. Le public s'attable dans les jardins ou dans le bâtiment dont l'architecture peut offrir une certaine richesse (Ill. 1). On comprend mieux alors l'enthousiasme de F. C. Krieger qui note en 1850 : «1er mai. Très belle journée : ouverture générale des caves. Ah, quelle belle époque! ». Complétons ce tableau avec les tavernes et jardins situés dans les environs de la ville, souvent annexes d'un moulin, château, voire église, et qui constituent des buts prisés d'excursion de la population de la ville aux beaux jours.

\section{Illustration 1 : « Caves " et lieux d'excursion que fréquentait F. C. Krieger, dans les environs de Landshut. Gravure de 1843}

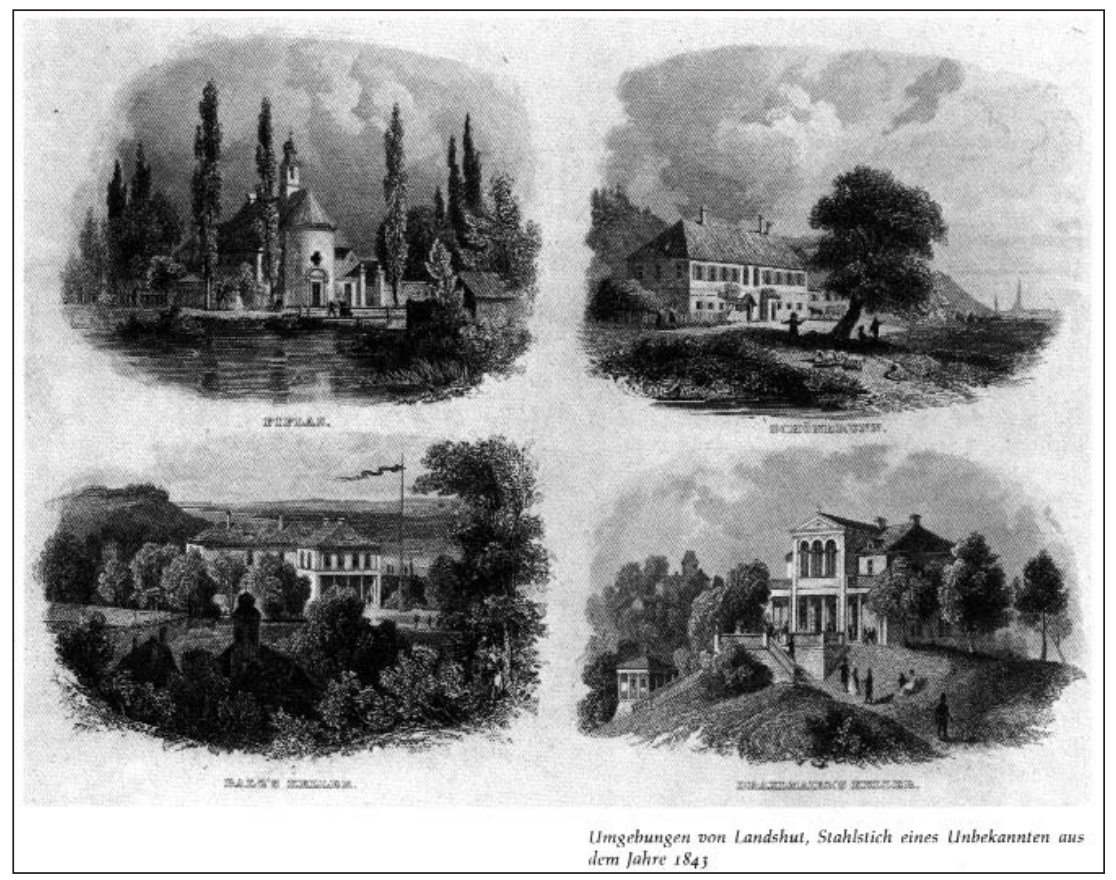

Source : Begegnung mit Landshut, Alfons Beckenbauer, Verlag Friedrich Pustet, 1979, p. 54

\footnotetext{
11 Traduction du mot allemand « Keller ».

12 Nous avons pris les informations concernant ces « caves » dans Uli Walter, « Bierpaläste », in Wirtshäuser in München um 1900, Munich, Buchendorfer Verlag 1997, p. 25.
} 


\section{LA SOCIABILITÉ TAVERNIÈRE}

Comment expliquer cette attirance qu'exercent ces lieux publics sur un homme comme Krieger? D’entrée de jeu, il faut évoquer la sociabilité qu'offrent ces lieux. Quand son médecin veut limiter sa consommation quotidienne de bière à deux demi-litres, Krieger se montre complètement désespéré : «Quelles mauvaises perspectives pour la convivialité !»13. En principe, Krieger n'y va jamais seul mais, avant 1846, toujours en compagnie de son voisin Negele14. Dans les tavernes etc., Krieger retrouve toujours le même cercle d'amis qui constitue un premier réseau restreint de sociabilité tavernière. Il ne s'agit même pas d'un seul cercle mais de plusieurs qui se superposent: le 6 octobre 1825, Krieger remarque bien un premier cercle d'amis qui, comme tous les soirs, se retrouve dans la même taverne, et il décrit ensuite un second cercle dont les membres viennent se joindre à eux périodiquement. Il est vrai que Krieger va entretenir des liens très forts avec les membres du premier cercle pendant de longues années, alors que la composition du second est soumise à de fortes fluctuations ${ }^{15}$. En général, Krieger change à partir de 1850 régulièrement les membres de son cercle : ceux de 1850 ne ressemblent pas du tout à ceux de 1860, ni à ceux de 1870 .

Lieu de convivialité, la taverne peut ainsi devenir un lieu de création de forts liens d'amitié : « fraternité avec Joseph » note Krieger dans son journal après une soirée passée ensemble dans une des « caves » 16 . Assez rares, en revanche, sont les occasions de disputes et de violences évoquées. Un soir, une dispute intervient entre des étudiants attablés dans une taverne et le groupe de Krieger, que les premiers ne veulent pas accepter dans cet endroit ${ }^{17}$. La ségrégation sociale qui règne dans les tavernes, etc. de la ville, peut expliquer cette relative tranquillité dans ces débits de boissons fréquentés par Krieger. Rares sont aussi les disputes au sein du cercle des amis de Krieger dont nous n'avons trouvé que deux évocations ${ }^{18}$. Notamment le conflit avec un ecclésiastique, qui fait partie de son entourage tavernier à ses vieux jours, est cause d'un grand chagrin car pendant plusieurs semaines, Krieger se trouve tout seul pour boire sa « bière du soir »19.

Ce réseau habituel a ses lieux habituels, notamment lors de la mauvaise saison où ce cercle peut fréquenter, jour après jour, la même taverne, située en

\footnotetext{
13 23/3/1840.

${ }^{14}$ Le 19/4/1835, ce dernier prend lui-même la direction d'une taverne, ce qui provoque les regrets de Krieger qui insiste sur le fait que celui-ci était, depuis son arrivée à Landshut en 1818, sa compagnie quotidienne pour aller boire leur bière.

15 La mort de Negele en 1846 provoque une rupture générale dans les relations de Krieger.

16 27/5/1835. Voir aussi 2/5/1855.

17 2/12/1821.

18 5/4/1835; 25/4/1870.

19 14/5/1870.
} 
principe à quelques minutes de leur domicile20. Il leur arrive aussi d'attribuer un jour spécifique à une taverne21.

Ce cercle d'amis est assez homogène sur un plan social. Il s’agit de maître-artisans, de petits fabricants, commerçants etc., qui jouissent tous du droit de bourgeoisie, sans faire partie pour autant de la notabilité22. Cette dernière semble fréquenter généralement d'autres lieux de divertissement, mais des rencontres entre elle et la bourgeoisie moyenne ne sont pas exclues. Le jeu, notamment le tarot, peut les réunir même autour de la même table, et Krieger note, avec une certaine fierté avoir pratiqué ce jeu avec des membres de la «bonne société » de la ville ${ }^{23}$, tout comme il n’oublie pas de noter des conversations avec ces mêmes personnes ${ }^{24}$. Il n'existe donc pas un cloisonnement étanche entre les diverses franges de la bourgeoisie, tandis que les classes populaires semblent exclues des tavernes fréquentées par F. C. Krieger.

Cette sociabilité tavernière est surtout masculine, même si Krieger note de temps à autre la présence de quelques femmes parmi eux. Leurs propres épouses et filles sont en principe exclues de la vie tavernière habituelle de tous les jours. La saison des caves, ainsi que la fréquentation des lieux d'excursion en dehors de la ville, changent cette donnée. Les dimanches de Pâques et de la Pentecôte, par exemple, Krieger se retrouve en compagnie de sa femme, qui l’accompagne aussi lors des soirées d'été dans les caves. Les femmes sont aussi présentes lors des sorties vers les nombreuses fêtes patronales dans les paroisses des environs de Landshut. Elles accompagnent aussi leurs maris et pères aux festivités du carnaval et de la Sainte Catherine, de même aux festivités organisées par les associations, comme la société de tir, dont Krieger fait partie.

La sociabilité informelle des tavernes se fonde aussi sur des rencontres fortuites. Krieger évoque ainsi des causeries avec des habitants de sa ville natale, ou avec d'autres passementiers de passage et rencontrés par hasard dans une des tavernes ${ }^{25}$. Même origine géographique et professionnelle se trouve donc à la base de longues discussions.

Avant 1832, les tavernes etc. constituent aussi des lieux où s'exprime un certain esprit de contestation envers les autorités locales, sous la forme de chansons satiriques ou de déclamations à l'encontre des notables de la ville26. Au moins avant la période répressive qui frappe la Bavière à partir de 1832, les tavernes représentent donc un certain espace de liberté d'expression (Ill. 2).

\footnotetext{
20 Le $1 \mathrm{er} / 12 / 1830$ : «chez [le tavernier] Hilz où nous nous rendons quasiment tous les jours depuis un mois ».

21 Le 4/12/1840 : «le soir, comme d'habitude le vendredi, au "Voglbräu” ".

22 Son ami Negele, à titre d'exemple, est maître tourneur et propriétaire d'une maison. Les autres membres de son réseau, tous propriétaires de leur maison, exercent les métiers de drapier, perruquier, imprimeur... Le fait d'être propriétaires de leurs maisons suggère qu'il s'agit de maîtres artisans.

$231^{\mathrm{er} / 7 / 1840 ; 28 / 12 / 50 .}$

24 21/11/1830.

25 22/2/1835.

26 16/5/1830 ; 25/5/1830.
} 
Illustration 2 : Interview de taverne, ici fréquentée par des étudiants.

Croquis de 1826

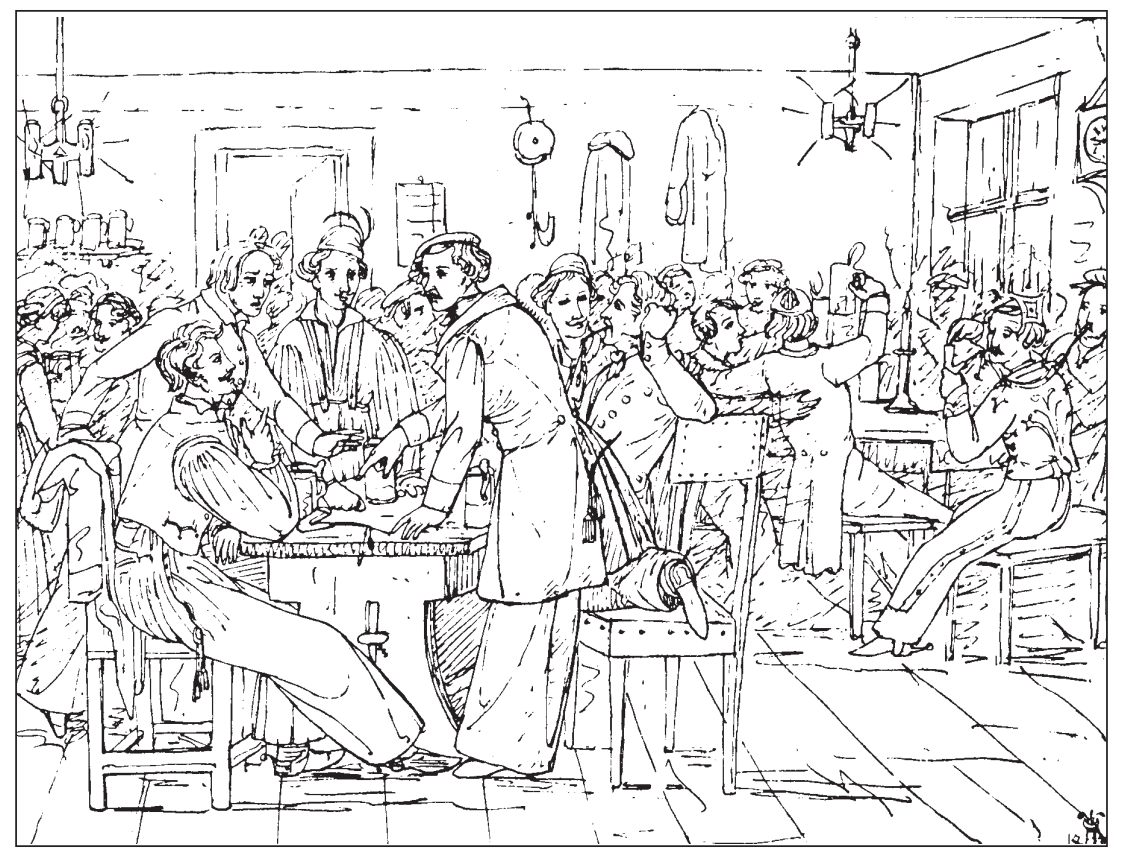

Source : Begegnung mit Landshut, Alfons Beckenbauer, Verlag Friedrich Pustet, 1979, p. 202

Au début des années 1820, les tavernes constituent aussi un lieu d'information grâce aux journaux, qu'on peut y acheter ou qu'on y apporte27. Or cette activité disparaît, si l’on suit le journal de Krieger, dès 1825 - preuve d'une certaine répression et surveillance de la vie tavernière par les autorités ? Néanmoins, la taverne reste un lieu important d'information sur les événements locaux, nationaux et internationaux - c’est attablé dans le jardin d'une taverne que Krieger apprend à la fois la nouvelle des émeutes à Munich en mars 1848, et la déclaration de guerre de la France à la Prusse28.

Pour expliquer l'attractivité de ces lieux et de la sociabilité qu'ils offrent, il est aussi impératif d'évoquer un des éléments constitutifs de la sociabilité tavernière, c'est-à-dire la conversation dont la qualité constitue pour Krieger un des critères d'une soirée réussie. L'auteur nous fournit quelques indications sur les sujets : les rumeurs, par exemple celle de l'assassinat du commandant du régiment local par un braconnier 29 , ou encore cet homme déguisé en fantôme, qui effraie les gens la nuit en sonnant à leurs portes : «Dans toutes

27 16/6/1821 ; juillet 1821.

28 4/3/1848; $16 / 7 / 1870$.

29 13/7/1821. 
les tavernes, on ne parle que de cela ${ }^{30}$. Des catastrophes survenues, comme le feu qui ravage entièrement un moulin dans les environs de Landshut, animent la conversation ${ }^{31}$. Des sujets plus culturels aussi : après une promenade vers la ruine d'un ancien château fort dans les environs de la ville, leur conversation à la taverne porte sur l'histoire de la Bavière32.

Ces conversations prennent aussi un caractère politique, comme en 1830, au sujet de la suppression du ballottage ${ }^{33}$. Arrivé à un certain âge, Krieger commence cependant à éviter ces discussions, comme en 1869 quand les débats animés entre progressistes et ultramontains le retiennent à la maison 34 ! Les événements au sein de la maison royale de Bavière préoccupent entièrement Krieger et ses amis. Le décès du roi Maximilien Joseph en 1825 « anime » toute la soirée à la taverne 35 . Un sujet de conversation est aussi le passage du couple royal à Landshut en 1840, à l'occasion duquel la ville s'est illuminée, décorée et transformée en scène de nombreux défilés. Les soirées tavernières offrent aussi au groupe de Krieger l'occasion de montrer leur patriotisme : pour célébrer la fête du roi, ils sont tous attablés dans une des tavernes de la ville, sous le portrait du monarque, et ils chantent, au son d'une petite musique, des chansons " patriotiques », et un des attablés déclame le poème La Cloche de Schiller 36 .

Des problèmes domestiques ne sont pas absents des conversations : la fugue de son fils est vivement discutée le soir dans son cercle d'amis ${ }^{37}$. Les récits de voyage d'un des habitués lors de son retour constituent un autre grand sujet de conversation.

\section{BIÈRE ET DIVERTISSEMENTS TAVERNIERS}

Cette convivialité s'organise autour de la bière qui, depuis le début du siècle, est en train de se substituer au vin dans la société bourgeoise, après avoir été considérée comme la boisson des classes inférieures. Suite à la vague nationaliste du début du XIXe siècle et à l'enthousiasme pour le Moyen Âge que celle-ci véhicule, une culture tavernière bourgeoise autour de la bière se développe, dont une forte consommation en société ne subit plus la même désapprobation qu'avant ${ }^{38}$. Certes, le vin résiste encore. Plusieurs tavernes à vin existent toujours à l'époque de Krieger à Landshut, où le vignoble couvre une partie des coteaux

\footnotetext{
30 22/12/1825.

31 16/6/1825.

$321 \mathrm{er} / 6 / 1821$.

33 21/11/1830. Krieger est en général bien informé : en 1830, il donne un récit minutieux des événements des Trois Glorieuses et de la fuite de Charles X. Journal, année 1830, « annexe ». Ces événements enrichissent à coup sûr les conversations tavernières.

34 Il s'agit de la question d'une future adhésion du royaume de la Bavière à une Allemagne sous domination prussienne.

35 13/10/1825.

36 12/10/1821.

37 10/8/1840.

38 Uli Walter, op. cit., p. 23.
} 
jusqu'au milieu du XIXe siècle ${ }^{39}$. Mais les visites de Krieger chez les taverniers à vin sont rares, tout comme sa consommation de vin reste assez limitée. Ce dernier constitue une boisson exceptionnelle, boisson de fête ${ }^{40}$, alors que la bière est la boisson quotidienne. Krieger s'inscrit donc pleinement dans cette nouvelle culture tavernière bourgeoise où règne la bière, même s'il serait vain de chercher chez ce patriote bavarois des tendances germano-nationalistes 41 .

La consommation de bière possède donc une importance capitale pour lui. La qualité de la bière joue également un rôle important dans le choix de l'établissement qu'il fréquente. Krieger note ainsi qu’ils sont allés au Dräxlmaierkeller, " où il y a une bière excellemment bonne »42, ou encore au Firmerkeller, pour sa " très bonne bière »43. De même, il lui arrive de changer d'établissement car la bière possède un trop fort goût d'eau44 ou tout simplement, parce qu'elle est mauvaise ${ }^{45}$.

Les jeux peuvent compléter cette convivialité, mais aussi constituer de nouveaux cercles de convivialité, étant donné qu'on les pratique souvent pour l'argent, comme le tarot. Le jeu de quilles, également pratiqué pour l'argent, a surtout lieu lors de la belle saison, notamment dans les caves et jardins des tavernes situées à l'extérieur de la ville et disposant d'assez d'espace pour des pistes. Plus rarement, Krieger pratique le tir46. Krieger et ses consorts pratiquent aussi un jeu traditionnel d'une grande cruauté pour nos sensibilités, «battre le coq » : il s’agit de frapper avec un fléau un coq dont les yeux sont bandés, jusqu’à sa mort. Une version « adoucie » de ce jeu, pour faire plaisir aux enfants, consiste à enfermer le coq dans une ruche pour qu'il ne soit pas touché directement ${ }^{47}$.

Krieger abandonne tous les jeux dans l'espace public à partir de la cinquantaine : à partir de 1850, il pratique le tarot uniquement dans un cadre privé.

La convivialité autour de la bière est aussi souvent liée au plaisir de la musique. Souvent, notamment lors des « jeunes années » de Krieger, ce sont des membres de son cercle eux-mêmes qui sortent la guitare pour accompagner leurs chansons48. Quant à Krieger, il lui arrive d'accompagner des chants d'enfants ou d'étudiants avec sa flûte 49 .

39 Alois Staudenraus, op. cit., p. 199-200, indique pour 1836, 5 taverniers à vin, auxquels il faut opposer 51 brasseurs et taverniers à bière.

406 janvier 1840 .

41 Dont les idées ont certainement circulé dans la ville à l'époque de l'université.

$424 / 10 / 1821$.

$438 / 5$ et $23 / 5 / 1840$.

44 26/7/1830.

45 3/7/1821 ; 21/7/1825. La qualité et la quantité de la bière dépendent beaucoup des possibilités de conservation, ce qui explique le fait d'une bière en train de "tourner ». Les brasseurs de Landshut, malgré leur nombre élevé, sont encore en 1810 incapables d'assurer l'approvisionnement de la ville en bière. Theo Herzog, Landshut im XIX. Jahrhundert, Landshut, Residenzverlag, 1994 (1ère édition 1969), p. 38.

4625 - 27/12/1821; 9/10/1825.

47 28/10/1821 ; 25/7/1835 ; 28/8/1840. Voir aussi Theo Herzog, op. cit., p. 95.

48 16/6/1821 ; 26/6/1821 ; 3/9/1821 ; 31/12/1821 ; 25/5/1830.

$494 / 1 / 1821 ; 19 / 1 / 1825$. 
Les diverses musiques des régiments ou de la garde territoriale animent à leur tour des soirées dans les tavernes, caves et jardins ${ }^{50}$, tout comme des sociétés musicales. Mais ce sont des musiciens de l’extérieur qui occasionnent un véritable plaisir auditif. Krieger confie alors à son journal la présentation d'une belle chanteuse étrangère qui s'accompagne à la harpe, et qui réunit visiblement plaisir visuel et auditif51. Ces musiciens viennent d'autres villes en Bavière 52 mais aussi de l'étranger. Le 10 octobre 1840, trois filles et leur frère handicapé du Tyrol présentent des « chansons des Alpes ». Ces musiciens sont souvent originaires de la Bohème voisine, comme ces neuf musiciens de Prague, offrant une "musique merveilleuse »53. Or c'est le passage d'un musicien de la cour royale de Bavière dans une des tavernes qui constitue l'apogée musical pour Krieger. Ce flûtiste, cédant aux pressions des consommateurs et accompagné d'un piano, présente deux morceaux de sa propre composition dont la beauté enthousiasme Krieger ${ }^{54}$.

La musique peut fournir l'occasion de danser, notamment lors du carnaval et de la Sainte Catherine, générant ainsi une sociabilité mixte. Des danses ont aussi lieu dans les « caves » lors de la belle saison, et lors des fêtes patronales. Krieger, jusqu’à un certain âge, semble assez apprécier ce plaisir55.

Les taverniers et propriétaires des caves organisent encore d'autres divertissements pour attirer la clientèle, comme des feux d'artifice ou des représentations de la Laterna magica, montrant apparitions de fantômes ou danses des sorcières 56 . Ils arrangent aussi des illuminations ${ }^{57}$ et des promenades nocturnes, après musique et danse ${ }^{58}$.

Ces débits de bière constituent aussi le cadre d'une vie associative assez riche de la ville ; Krieger lui-même fait partie de plusieurs associations : d'une société de tir, d’une "Société des Bourgeois » et, après 1848, de la "Société pour la Monarchie constitutionnelle et la liberté religieuse », et finalement aussi d'une «Chambrée de fumeurs et priseurs »59. Toutes ces associations se réunissent dans les tavernes (ou cafés), et la « Société des bourgeois » organise même une « randonnée »60 hebdomadaire vers une des tavernes de la ville, choisies alternativement.

\footnotetext{
50 Les trompettistes d'un régiment jouent ainsi tous les samedis en été dans le jardin de la même taverne.

51 16/8/1821.

52 31/7/1830.

53 26/7/1835.

54 16/8/1840.

55 3/3/1840.

56 26/7/1825.

57 13/6/1840.

58 4/8/1830.

59 De toute façon, le tabac fait partie de l'ambiance tavernière, comme le montre une remarque faite le 2 novembre 1855 : «D’horribles maux de tête. Sans bière et sans tabac ». 60 « Wandertag » en allemand.
} 
Ces associations organisent à leur tour des fêtes avec musique et danse, ainsi que des tournois de quilles61. Tout en utilisant les infrastructures des tavernes, la « Société des Bourgeois » arrange aussi des représentations théâtrales et des conférences, par exemple sur les plus nouvelles techniques de la télégraphie62. Ces associations ne constituent donc pas seulement un support de convivialité mais, en dehors d'objectifs politiques, elles contribuent à l'information et l'instruction de la population. Krieger lui-même fréquente avec plaisir ces réunions, et la vie associative constitue un élément important de ses loisirs. À partir d'un certain âge, il se retire cependant de cette vie associative, avec une seule exception : le 21 juillet 1870 où il assiste à la fête donnée par la « Société des Bourgeois » en l'honneur des troupes bavaroises qui partent pour la guerre.

La vie tavernière joue donc un rôle essentiel dans la vie de ce bourgeois, si l'on suit son journal intime. Cependant, cette vie tavernière perd de son exubérance au cours des années, ce qu'on pourrait attribuer à l'âge avancé de F. C. Krieger - seulement, Krieger note en général tous les amusements et divertissements dont il est témoin, même s’il n’y participe pas directement. La conclusion s'impose qu’à partir des années 1840, la vie des tavernes (et des caves, etc.) ne représente plus ce caractère animé, cette dimension de fête et d'exubérance, dont elle était le cadre auparavant, et qu'elle prend en revanche des formes plus régulières et « apaisées » où le client n’est plus acteur mais simple consommateur. La bière, quelques jeux et la sociabilité constituent dorénavant les seuls facteurs pour expliquer toute l'importance que la vie des tavernes garde encore pour Krieger. Le 8 février 1872, il note qu’il ne peut plus fréquenter les tavernes, et qu'il va donc arrêter son journal intime63.

\section{LES DIVERTISSEMENTS NON - TAVERNIERS DE F. C. KRIEGER}

\section{PROMENADES ET EXCURSIONS}

Les autres divertissements de F. C. Krieger sont étroitement liés à la bière et à la vie tavernière. D’entrée de jeu, il convient de citer la promenade qui, à partir d'un certain âge, se pratique pour des raisons de santé : le 16 avril 1855, Krieger fait ainsi une longue promenade avec quelques amis, "pour avoir un peu de mouvement à l'air libre ». Mais généralement, les buts des promenades sont quasiment toujours des tavernes à l'intérieur ou à l'extérieur de la ville. Certaines tavernes des environs de la ville, comme celle de Piflas (Ill. 1), proposant de beaux jardins pour s'attabler, vivent d'ailleurs surtout de ces promeneurs dont le flot ne se déverse pas seulement les dimanches et fêtes. Même les promenades « ordinaires » intra-muros et extra-muros, sont quasiment toujours agrémentées d'un séjour dans une taverne.

61 12/7/1835.

62 29/10/1850.

63 À cela s'ajoute que Krieger est victime d'une cécité croissante. Pour la vie de F. C. Krieger, voir Heinrich Egner, « Ein grosser Tagebuchschreiber tritt ab », Landshuter Zeitung, 1er/12/1992. 
Illustration 3 : Intérieur de la taverne de Klausenberg près de Landshunt, lieu d'excursion également fréquenté par F. C. Krieger.

Croquis réalisé par un prisonnier de guerre français en 1870/71

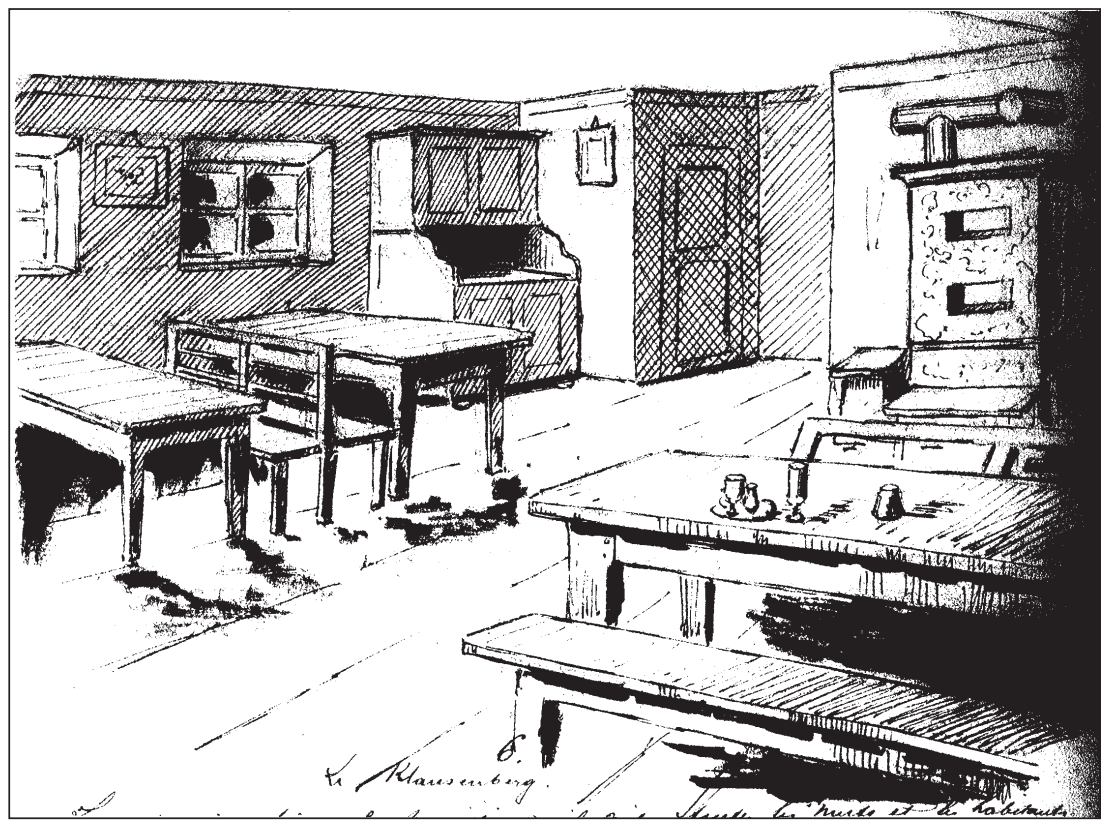

Ces promenades ont lieu intra-muros, à l'occasion par exemple de visites pour montrer les curiosités de la ville, notamment les églises, ou pour satisfaire la curiosité au sujet de nouveaux bâtiments ou de nouvelles institutions, comme la gare. Le cimetière de la ville constitue également un des promenoirs, sans que Krieger, avant la mort de son épouse en 1861, n’ait une raison spécifique de s’y rendre - signe d'une certaine familiarité avec ce lieu d'ultime repos.

Les heures de la soirée, notamment en été, voient Krieger et ses acolytes franchir les portes de la ville pour un tour à travers les faubourgs. Certaines destinations de préférence se distinguent : il s’agit du jardin de l'ancienne cour ducale de Landshut, ouvert au public en 1837, et dont la beauté attire Krieger notamment vers les années 1850, et de la paroisse d’Au, située à une heure de marche à travers prairies et forêts, avec son jardin ouvert aux promeneurs assoiffés.

De temps à autre Krieger participe à des excursions vers des contrées plus lointaines : après un bout de chemin effectué en voiture (en train après 1858), celles-ci se composent d'un mélange d'attractions culturelles (visites d’églises, de châteaux, de villages et villes en général), et de joyeusetés. Ces excursions remplissent des journées entières, avec des départs bien matinaux et des retours nocturnes, et avec des distances parcourues à pied de plus d'une vingtaine de kilomètres. Elles mettent surtout le jeune Krieger dans un état 
d'euphorie : «je peux dire qu'il s'agissait d'un des jours les plus heureux de ma vie »64, ou encore, "ce jour était un des plus joyeux de ma vie »65 s'exclame-t-il à la fin de son récit.

Le charme de ces promenades et excursions est étroitement lié à la sensibilité visuelle : à plusieurs reprises, Krieger quitte sa réserve ordinaire pour s'exclamer devant la beauté d'un panorama dont il jouit, par exemple, sur les hauteurs du château de Landshut 66 , tout comme il souligne tout le bonheur que lui procure la vue d'une nature en pleine floraison au mois de mai67. L'auteur, ainsi que ses compagnons, recherchent systématiquement de belles vues en montant sur des clochers ou grimpant sur les hauteurs des collines. Les buts d'excursions situés dans les environs de Landshut sont également pourvus de panoramas dont les contemporains vantent la beauté : au sujet d'Eugenbach, également fréquenté par Krieger, un auteur contemporain vante la vue "dont aucune imagination n'est capable de décrire la beauté » ${ }^{6}$. La beauté du paysage, liée aux rayons et à la lumière du premier soleil, explique certainement aussi les heures matinales de certaines promenades de Krieger qui le conduisent toutes vers des lieux panoramiques, comme ce 22 mai 1825 : ce jour-là, il monte à $4 \mathrm{~h}$ du matin sur une des collines qui entourent Landshut, et qui est connue pour la beauté de son panorama.

Les nombreuses fêtes patronales dans les environs de la ville, dans un rayon d'une bonne dizaine de kilomètres constituent un des buts appréciés des promenades. Ces fêtes, malgré la volonté du gouvernement bavarois de les concentrer sur un seul dimanche, ont lieu à partir d'avril jusqu'en novembre. En dépit d'un nombre considérable de faits de violence69, ces fêtes patronales sont également fréquentées par un " public cultivé »70 et constituent un lieu de rencontre entre les diverses classes de la société urbaine et rurale.

Les buts de promenade peuvent aussi prendre un caractère macabre: le 2 juillet 1830, Krieger, en compagnie de sa femme et de quelques amis, se fait conduire à la ville d'Erding, pour y assister à l'exécution publique d'un assassin qui aura lieu le lendemain. Après avoir observé minutieusement le travail du bourreau au sein d'une foule de badauds bien nombreuse, et écouté les paroles d'un des ecclésiastiques locaux après la mort du condamné, Krieger et consorts se rendent dans une taverne pour y déguster une bière « particulièrement bonne »...

\footnotetext{
64 17/7/1825.

65 12/10/1825.

66 24/4/1825.

67 12/5/1860.

68 Spaziergänge in und um Landshut, Landshut, Attenkofer, 1838, p. 91.

69 En 1825, le gouvernement de Bavière limite le droit à la musique lors des fêtes patronales aux dimanches et aux fêtes patronales des vraies paroisses, pour limiter la violence dans le district où se situe Landshut. Krieger, 10/10/1825.

70 Spaziergänge, op. cit., p. 81-82.
} 


\section{LES SPECTACLES}

F. C. Krieger est beaucoup moins concerné par la vie théâtrale, un des grands divertissements des sociétés urbaines du XIX e siècle, au moins quant à sa propre assistance aux représentations : nous n’en avons recensé que 25 pour l'ensemble de la période concernée - avec un net avantage pour ses premières années, notamment 1821 (5). Pourtant, la ville connaît régulièrement des saisons théâtrales, d'automne jusqu'au printemps, et Krieger lui-même note minutieusement dans son journal les noms et la nature des pièces, copiant très probablement ces informations dans la presse locale. On ne peut donc pas nier un certain intérêt de Krieger pour la vie théâtrale de sa ville, mais qui se heurte probablement aux tarifs élevés demandés par les entrepreneurs de théâtre ${ }^{71}$ ? Toujours est-il que Krieger, arrivé à un certain âge, se privera entièrement de ce divertissement.

Complétons ce tableau avec quelques concerts, en dehors de l'univers tavernier, et avec quelques représentations de cirque, auxquels Krieger assiste également de façon irrégulière, en principe pour faire plaisir à ses enfants.

\section{LES LOISIRS DOMESTIQUES}

La plupart des loisirs de F. C. Krieger se situent dans l'espace public, et assez exceptionnels restent dans son récit les divertissements dans un cadre privé. Dans ces rares évocations, on peut distinguer des rassemblements joyeux chez un de la «bande » durant les jeunes années de Krieger : ils boivent, chantent et jouent dans une ambiance bien animée, simple transfert de celle de la taverne vers l'espace privé. Mais à partir de 1840, ces réunions changent de caractère pour devenir des réunions paisibles de voisinage : «le soir chez M. Kusterer où nous jouons au tarot - comme lors de tous les jours de fête en hiver "72, ou "De nouveau à la maison. D’habitude nous jouons le soir aux cartes, avec Mme Groeschl, mon épouse et Walburga »73. Certes, on peut considérer cet « apaisement » comme la conséquence d’un âge avancé, mais on pourrait aussi le mettre en parallèle avec la disparition du caractère joyeux, qui caractérisait la vie des tavernes, à la même époque. Cette sociabilité domestique inclut aussi une présence féminine, qui s’organise autour des jeux de cartes et des jeux de société74. Cette sociabilité domestique disparaît cependant lors de la belle saison au profit de celle des caves.

Le jeune Krieger, vers 1825, pratique encore une autre forme domestique de loisir en invitant ses amis pour leur faire la lecture des débats de la diète bavaroise, à une époque de relative liberté de la presse dans le royaume ${ }^{75}$.

\footnotetext{
71 Voir Heinrich Egner, « Bernlochner-Konkurs und Theaterkrach », Landshuter Zeitung, 23/7/1994. $721 \mathrm{er} / 1 / 1850$.

73 3/10/55. Notons qu'il s'agit d'une des très rares occasions d'activités communes de Krieger avec son épouse.

74 22/10/1848; 11/1/1860.

75 24/7/1825. Complétons cette liste des loisirs d'un bourgeois bavarois par des baignades lors de la belle saison et en hiver par le jeu du curling sur les étangs gelés dans les environs de la ville.
} 


\section{RELIGION ET LOISIRS}

Le lecteur de ce journal est frappé par les liens qui existent entre les loisirs et la religion chez F. C. Krieger. Ceci s'explique d'abord par le fait d'une société où le catholicisme règne en maître absolu, marquant de son empreinte à la fois la vie publique et privée. Le clergé cherche en outre à donner un certain éclat aux cérémonies et manifestions religieuses. Krieger souligne en effet à plusieurs reprises la beauté d'une cérémonie qui l'a frappé, comme celle de la résurrection du samedi des Pâques ${ }^{76}$, celle d'un prône ${ }^{77}$ ou encore celle d'une cérémonie de prise de voile par une novice dans l’église d'un des couvents de la ville ${ }^{78}$. L'Église sait donc se mettre en scène à travers ses cérémonies, processions, visites de l'archevêque ou encore lors des jubilés, comme celui de 1835 qui dure une semaine : des processions affluent de toutes les paroisses des environs proches et moins proches, dont les cierges immenses, les crucifix, les drapeaux portés par des vierges, la présence du clergé et des notables marquent l'esprit des spectateurs. Des animations musicales entourent ces cérémonies du jubilé en ville, et toutes les tavernes sont pleines à craquer. Krieger y rencontre même deux moines capucins, une «joyeuse compagnie » selon ses notes ${ }^{79}$. En suivant le récit de cette semaine du jubilé dans son journal, l'impression se dégage qu'il s'agit plutôt d'une semaine de plaisirs que d'une semaine de dévotion.

Lors de la semaine sainte, les paroisses organisent des musiques sacrées le jeudi, et des représentations de la tombe du Seigneur, parfois accompagnées de mises en scène picturales de la ville de Jérusalem ${ }^{80}$. Krieger assiste aux musiques sacrées, et il fait régulièrement le tour des tombes du Seigneur dans les églises, buts de ses promenades - mais il n’oublie jamais de fréquenter ensuite une taverne.

L'église et la taverne sont en effet proches - à la fois dans l'espace et dans l'organisation du temps. Les débits de boisson entourent les bâtiments sacrés, et Krieger indique leur emplacement par rapport à l'église la plus proche81. Dans le jardin du château de Piflas, but d'excursion prisé par les habitants, l'église forme une unité spatiale avec l'espace prévu pour les consommations des promeneurs (Ill. 1). Cette proximité ne semble pas déranger le clergé de la ville qu'on peut même trouver en tant que client dans les tavernes - Krieger évoque à plusieurs reprises des conversations avec des ecclésiastiques. Ceuxci ne reculent même pas devant un jeu de tarot ${ }^{82}$. À la fin de la vie de Krieger, un ecclésiastique fait même partie de sa sociabilité tavernière quotidienne.

\footnotetext{
76 16/4/1870.

77 27/3/1825.

78 26/1/1830.

79 25/9/1835.

80 17/4/1840.

81 « chez le tavernier Vogl, proche de l'église du Saint-Esprit », 21/4/1835.

82 12/1/1825.
} 
Dans l'organisation du temps de Krieger, les cérémonies religieuses se juxtaposent à ses divertissements, tavernes et, plus rarement, promenades. Ces dernières peuvent s'effectuer pour assister à une messe dès $6 \mathrm{~h}$ du matin dans une église sur les hauteurs de la ville83. Les exemples d'un voisinage temporel entre cérémonies religieuses et visite des tavernes sont plus que nombreux : dans la matinée dominicale, dès la fin de la messe, il va dans une taverne ${ }^{84}$. De même, l'après-midi dominical, avant d'assister au prône ou à l'exposition du Saint Sacrement, il retrouve ses amis dans une taverne85. Le vieux Krieger qui, à l'âge de 75 ans, fréquente encore plus régulièrement les églises, n’oublie quand même pas sa bière quotidienne : le samedi de Pâques il va d'abord dans une église pour la cérémonie de la résurrection, ensuite dans une taverne, pour finalement assister à une seconde cérémonie de résurrection dans une autre église ${ }^{86}$. Cette complémentarité entre vie religieuse et vie tavernière dans la perception de Krieger s'exprime aussi quand il montre la ville à des visiteurs : en général, ils font le tour des églises, des tavernes et des caves87.

\section{LES LOISIRS DE F. C. KRIEGER DANS LE RYTHME DU TEMPS}

Le lien entre le facteur religieux et les loisirs se révèle aussi dans le caractère du support temporel des divertissements de F. C. Krieger : il s'agit en général du temps sacré des dimanches et fêtes religieuses, dont le nombre est bien élevé : nous en avons relevé une trentaine pour l'année 1825. Suite à sa fonction de receveur de loterie, Krieger perd le profit de nombreux dimanches durant les années 1830 et le début des années 1840, ce qui semble le mettre plutôt de mauvaise humeur : il se plaint de ce surcroît de travail, et il se sent exclu de la société ce jour-là.

Les soirées constituent le second grand temps de ses loisirs : en 1825, il ne passe pas une seule soirée de mercredi à la maison, ni même la quasi-totalité des autres soirées : 333 sur 365 !

Krieger n’hésite pas non plus à quitter son travail en cas de visite, ou en cas de beau temps. Le lundi tout particulièrement est un jour préféré pour se promener, pour s'attabler dans une cave, ou pour se rendre à une fête patronale - en 1850, il « débauche » même son compagnon. S'agit-il d'une forme de Saint-Lundi, de ce chômage du lundi certainement familier pour l'ancien compagnon qu'était Krieger avant 1818 ? Quoi qu'il en soit, les limites entre temps de travail et temps des loisirs gardent encore chez Krieger ce caractère flou, si typique d'une conception préindustrielle du travail.

Ces rythmes changent quand Krieger se retire des affaires, mais la fidélité à sa bière quotidienne reste inchangée : à l'âge de 75 ans encore, il va tous les jours, de 4 à 6 heures de l'après-midi, dans une des tavernes de son voisinage.

\footnotetext{
83 8/7/1821.

84 9/12/1821

85 19/3/1825 ; 1/1/1840.

86 16/4/1870.

87 28/5/1835.
} 
La lecture de ce journal montre donc toute la portée que possèdent les loisirs pour cet homme de l'époque du Biedermeier - au point de constituer l'essentiel d'un récit qui s'étend sur 51 ans. L'importance que F. C. Krieger attribue à ses loisirs, s'explique par le fait que ceux-ci constituent un élément essentiel de la personnalité de ce bourgeois. Certes, c'est son statut de maître-passementier et de propriétaire qui définit son rang social au sein de cette société urbaine - mais ce sont ses loisirs qui constituent l'élément décisif de son identité. Sa position sociale ne sert que de base pour la pratique des loisirs qui dominent sa vie, au détriment de la nouvelle valeur morale et sociale du travail - signe de la résistance d'un catholicisme moins ouvert aux règles et normes du capitalisme triomphant, et étroitement lié à la vie des loisirs?

Ces loisirs, au sein de cette société bourgeoise à l'époque préindustrielle représentent aussi un élément capital de la vie sociale et politique, ce qui explique également leur importance. Cependant, leur caractère joyeux et exubérant commence à disparaître à partir des années 1830/40 pour faire place à une vie des loisirs plus réglée et - même si F. C. Krieger ne le dit pas codifiée.

L'auteur de ce journal vit donc - mais en est-il vraiment conscient ? - la transition de l'exubérance festive vers des loisirs normés qui les rendent acceptables aux nouvelles élites de la société bourgeoise et capitaliste. Mais l’Église catholique semble, dans cette Bavière fervente, suivre cette évolution pour maintenir les liens étroits établis entre la vie religieuse et la pratique des loisirs - au point qu'on peut se demander si cette relation si forte ne constitue pas une des clés pour comprendre l'ancrage si profond du catholicisme dans cette région? 


\section{ARCHITECTURE DES LOISIRS EN FRANCE DANS LES STATIONS THERMALES ET BALNÉAIRES $(1840-1939)^{1}$ \\ BERNARD TOULIER \\ CNRS, UMR 8150, Centre André Chastel}

Dès la fin du XVIII siècle, les saisons passées aux eaux s'inscrivent dans le rythme de vie nomade de l'aristocratie. L'engouement pour la cure thermale, puis, à partir de la Restauration pour la saison aux bains de mer se développe au cours du XIX ${ }^{\mathrm{e}}$ siècle 2 . Au milieu du XIXe siècle, la ville d'eaux est un haut lieu de sociabilité. Que l'on s'ennuie ou que l'on se divertisse, que l'on soit malade ou bien portant, la cure thermale ou balnéaire est :

«La continuation obligée des élégances de l’hiver ; [...] le premier devoir social de tout homme qui tient à l'estime de soi; plus encore à celle d'autrui; s'en dispenser, laisser fuir toute une saison sans apparaître à Vichy, Dieppe, ni à Bade ni à Hombourg, ce serait non seulement une faute de goût, un solécisme impardonnable, mais un crime de lèse-société »33.

La ville d'eaux avec ses buvettes, ses cercles et ses casinos, ses parcs et ses digues-promenades est un vaste théâtre où baigneurs et curistes ont autant

1 Cet article s'inspire en partie de Bernard Toulier, Villes d'eaux. Architecture publique des stations thermales et balnéaire, Paris, Dexia Éditions/Imprimerie Nationale Éditions, 2002.

2 Alain Corbin, Le territoire du vide. L'Occident et le désir du rivage. 1750-1840, Paris, Flammarion, 1990, 408 p. (1ère édit. 1988).

3 Félix Mornand, La vie des eaux, Paris, V. Lecou, 1853. 
l'occasion de voir que d'être vus. Ces espaces de mises en scène sont des lieux privilégiés où s'exerce le « loisir ostentatoire » d'une « classe oisive », selon l'expression de Thorstein Veblen 4.

Le temps médical est associé à une période de plaisirs et de distractions : le temps des loisirs rentre pleinement dans l'organisation du temps du curiste. La ville d'eaux est à la fois une ville médicale (Vichy, Aix-les-Bains, Luchon, Bagnères-de-Bigorre, Châtel-Guyon,...), voire parfois une ville-hôpital (Berck-sur-Mer) et aussi une ville de divertissements et de loisirs (MonteCarlo), ville des eaux et ville au bord de l'eau où sévit la " fièvre des loisirs ».

La ville d'eaux s'organise autour des équipements collectifs dévolus à la médecine, aux loisirs, à l'hébergement et aux transports. Les grands édifices structurants spécifiques des stations balnéaires et thermales, établissements de bains, casinos, hôtels sont identiques. Seule la nature et les usages de l'eau semblent différencier les stations. Sur le littoral, la ville linéaire ouverte sur la mer, accrochée au rivage, dresse ses fronts de mer le long des plages. La ville thermale, repliée sur elle-même dans les massifs montagneux est agglomérée autour du lieu d'émergence de la source minérale, le griffon. Ces villes nouvelles établies au bord de l'eau ou autour des sources forment des « villesparcs » et des " cités-jardins ». Leur création nécessite d’importants travaux d'aménagements pour domestiquer le paysage et créer un urbanisme de loisirs et de services, aux antipodes de la ville industrielle.

Stations thermales et stations balnéaires sont des villes de villégiature. Les stations thermales aux vertus curatives existent depuis l'Antiquité. Les stations balnéaires, situées en bord de mer sont nées en Europe entre la seconde moitié du XVIIIe siècle et le premier quart du XIXe siècle. Le balnéaire possède donc un retard sur le thermalisme de plusieurs siècles. Si les pratiques balnéaires s'inspirent des pratiques thermales, leur différence dépasse la simple localisation des eaux. La fonction médicale des villes balnéaires est beaucoup moins avérée que dans les villes thermales ${ }^{5}$. Celles-ci sont des agglomérations dont l'origine ou la fonction emblématique sont le repos et la détente, le divertissement et le sport, et la visite des curiosités naturelles et culturelles.

\section{LA CRÉATION DES VILLES D’EAUX}

La création des stations thermales et balnéaires s'inscrit à la fois dans le mouvement de l'avènement des loisirs et de la médicalisation de la société française du XIXe siècle, le développement des moyens de transport et l'accroissement exponentiel du tourisme. Les villes d'eaux forment des réseaux urbains liés à la nature de leurs activités et à leur spécialisation médicale ou climatique mais aussi à leur degré d'accessibilité lié à la proximité des grands centres urbains et de Paris.

\footnotetext{
4 Thorstein Veblen, Théorie de la classe de loisir, Paris, Gallimard, 1978 (1ère édit. 1899).

5 Jérôme Penez, Histoire du thermalisme en France au XIXe siècle : eau, médecine et loisirs, Paris, Economica, 2005.
} 


\section{LES AMÉNAGEMENTS URBAINS ET LES ESPACES DE DÉAMBULATION}

À la fin du XVIIIe siècle et au début du XIXe siècle, le renouveau du thermalisme témoigne d'un changement d'attitude par rapport à la nature, jugée jusque-là étrangère et sauvage. La montagne dominatrice et écrasante autour des stations thermales, devient le lieu du sublime. La mer, incontrôlable, déchaînée et tumultueuse se transforme en un lieu de délectation. L'eau thermale, l'Océan, la douceur hivernale du Midi méditerranéen puis les Alpes à la fin du XIXe siècle, hier pratiquement méconnus ou inconnus, sont prétextes à des plaisirs mondains ${ }^{6}$.

Dans le milieu balnéaire, ce changement s'opère par un « retournement » et l'invention de nouvelles pratiques pour le touriste attiré par la mode des lieux de villégiature. Au lieu de se détourner de cette nature hostile, l’homme romantique recherche un "point de vue » dominant la nature sauvage devenue décor de théâtre. Ces nouvelles villes romantiques créent des espaces fonctionnels et hiérarchisés pour apprivoiser et recomposer la nature ${ }^{7}$. Curistes ou baigneurs sont séduits par les excursions proposées par les guides de voyage autour du lieu de séjour: ce sont des «résidents » mais aussi des « touristes ».

\section{Digues ET JETÉES}

Les digues - appelées aussi suivant les régions "seuils de garantie", « terrasses » ou « remblais » - sont édifiées pour contenir l'amplitude de la marée, résister aux grandes tempêtes qui érodent la falaise et préserver les constructions des assauts des vagues. Dès 1822, à Nice, la communauté anglaise se cotise pour ouvrir une promenade sur la mer, la Beach Road, la future Promenade des Anglais. La municipalité niçoise relaye bientôt la colonie britannique : elle élargit à plusieurs reprises $(1844,1856,1862)$ la promenade à 11 mètres de largeur avec trottoir, soutenue par une perrée côté plage. En 1903, elle est prolongée jusqu'à l'hippodrome. À l'apogée de l'âge d’or niçois, en 1931 la Promenade des Anglais est dédoublée en deux voies de 10 mètres et gagne encore une quinzaine de mètres sur la plage.

La digue-promenade, plantée ou non, ménage une vue sur la mer. Cette fonction d'agrément est complémentaire de la fonction sécuritaire d'origine. La digue est bordée d'un front de mer, véritable « vitrine architecturale de la station », ensemble de bâtiments alignés sur la ligne de côte, face à la mer (Ill. 1). La digue garantit une meilleure accessibilité aux hôtels, aux casinos et

\footnotetext{
6 André Rauch, «Les vacances et la nature revisitée », dans A. Corbin (dir.), L'avènement des loisirs. 1850-1960, Paris, Aubier, p. 83-117.

7 Marc Boyer, Histoire de l'invention du tourisme. XVIe-XIXe siècles. Origine et développement du tourisme dans le sud-est de la France, Paris, Éditions de l'Aube, 2000, p. 268-269 (cartes des stations « touristiques » en 1838 et 1869). Voir aussi, du même auteur, L'invention du tourisme, Paris, Gallimard, 1996.
} 
aux villas et abrite les cabines de bains. Avec ses terrasses et ses kiosques, elle joue également le rôle de tribune tournée vers la plage, où les promeneurs peuvent « à loisir » observer les baigneurs8. À Dinard, la promenade au Clair de Lune (1920-1935), conçue au plus près des eaux pour la déambulation balnéaire au bord des rochers est bordée par le paysage exotique d'une palmeraie achetée à l’Exposition coloniale de 1931 à Paris'.

\section{Illustration 1 : Nice, Palais de la Méditerranée et Promenade des Anglais}

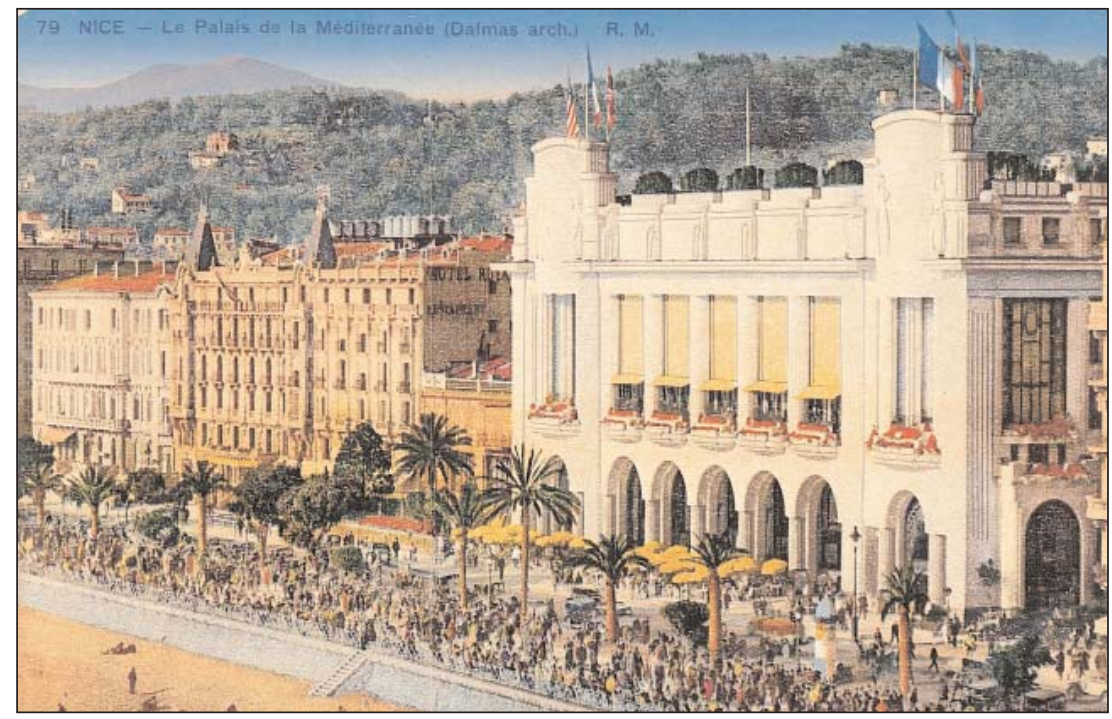

Collection particulière, Bernard Toulier

La digue est aussi le point de départ d'autres promenades. Des chemins piétonniers sont constitués de planches de bois posées sur le sable. Les célèbres " planches » de Deauville ou de Trouville, lieux de déambulation où les baigneuses rivalisent d'élégance forment durant la saison un réseau autour des établissements de bains et le long de la plage, reliant la digue à la mer par une série de diverticules perpendiculaires à la côte ${ }^{10}$.

Les estacades de Trouville ou d'Arcachon sont utilisés comme débarcadères pour l'accostage des bateaux venant du Havre ou de Bordeaux. La « Jetée-promenade » de Nice est une estacade bâtie pour le casino (Ill. 2).

\footnotetext{
8 Gaëlle Delignon, « De la défense des côtes à un espace du loisir, la digue de Saint-MaloParamé », dans F. Muel et B. Toulier (dir.), La Côte d'Émeraude. la villégiature balnéaire autour de Dinard et Saint-Malo, Paris, Éditions du patrimoine, 2001, p. 84.

${ }^{9}$ Gaëlle Delignon, « La promenade au Clair de Lune à Dinard, un aménagement tardif au plus près des eaux », dans F. Muel et B. Toulier (dir.), op.cit., p. 86.

10 Didier Hebert, Deauville. Une cité de villégiature de la Côte Fleurie, Cabourg, Cahiers du Temps, 2004, p. 28.
} 
Illustration 2 : Nice, Palais de la jetée-promenade

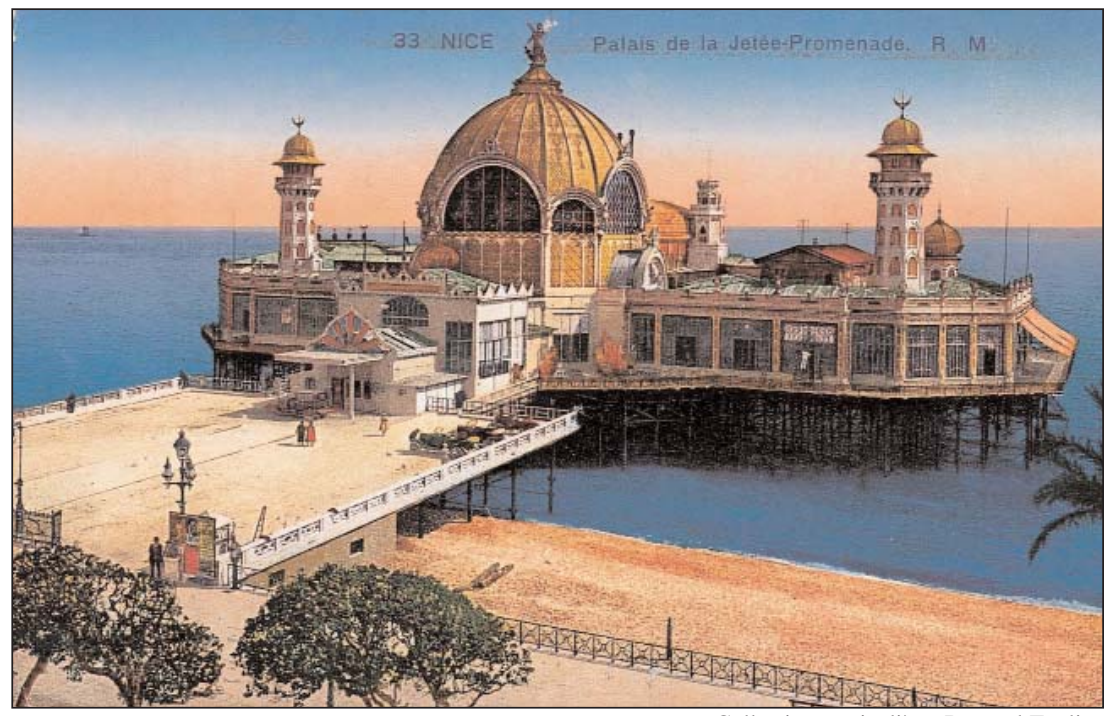

Collection particulière, Bernard Toulier

JARDINS, PARCS ET PROMENADES PUBLICS

Digues, estacades, falaises et dunes stabilisées composent le nouveau paysage marin domestiqué. Des forêts de pins comme à Arcachon ou La Baule, des plantations d'oyats sur les stations de la Côte d'Opale sont chargés de fixer les dunes en bord de mer.

Les promenades publiques, aménagées pour la déambulation et la détente, l'agrément et la rencontre sont également des espaces privilégiés de sociabilité pour la société balnéaire et thermale. Durant le second quart du XIXe siècle, Adolphe Moreau, un agent de change parisien, s’associe avec d'autres curistes pour financer la réalisation de la " promenade horizontale », entre les EauxBonnes et les Eaux-Chaudes, un des lieux les plus remarquables du thermalisme pyrénéen.

La promenade thermale est recommandée par le corps médical pour faciliter l'assimilation de l'eau de source. Le parc thermal, aménagé à l'origine aux abords des sources relie et unifie les principaux établissements de la station dans une promenade paysagère à travers la ville. Certaines villes possèdent plusieurs parcs. À Vichy, le plus ancien est localisé à proximité des griffons et le second, plus romantique et plus récent, est situé au bord de l’Allier. Dans de nombreuses stations, le parc s'ouvre au-delà de l'espace urbain, sur des «panoramas naturels ». Parcs et promenades sont agrémentés de mobiliers urbains comme les kiosques à musiques, construits à partir du troisième quart du XIX $\mathrm{X}^{\mathrm{e}}$ siècle ${ }^{11}$.

$\overline{11}$ Marie-Claire Mussat, La Belle Époque des kiosques à musique, Paris, Du May, 1992. 


\section{JEUX, SPORTS ET LOISIRS}

La ville d'eaux, d'abord ville de soins est aussi une ville de plaisir et s'organise en fonction de ses deux pôles. L’objectif exclusivement médical du thermalisme est tempéré par celui de la distraction apportée notamment par le jeu et le sport.

\section{LES CASINOS ET LES LIEUX DE SPECTACLES}

Le casino est l'édifice de représentation par excellence de la station ${ }^{12}$. Reprenant un décret de 1808, la loi de 1907 autorise les jeux de hasard «dans des locaux spéciaux, distincts et séparés » pendant la « saison des étrangers »13. Le ministère de l'Intérieur y exerce un contrôle de validation à l'ouverture et une étroite surveillance des joueurs, notamment pour détecter les escrocs qui se déplacent de casinos en casinos, entre les villes balnéaires et les villes thermales. Outre les jeux d'argent, le casino permet aussi de jouer à des jeux de « société » comme les jeux de cartes, les échecs, le tric-trac, les dominos,...

La présence du casino est un signe distinctif de l'importance de la station. Les petites plages ne possèdent pas de casinos et seules les stations thermales réputées bénéficient de leur présence. Dans les petites stations, des « salons » s’ouvrent dans les hôtels, ou sont abrités dans des « cercles » indépendants et privés, comme à Salies-de-Béarn. Les salons et les cercles, aux statuts privés particuliers offrent à la clientèle des baigneurs et des curistes des salles de conversation, de lecture, de correspondance, de réunion et de jeux (billard notamment) avec bibliothèque, fumoir,...

Durant la première moitié du XIXe siècle, salons, salles de jeux, salles de sports (escrime) et de spectacles sont le plus souvent intégrés à l'établissement de bains. Dans les stations balnéaires, la double fonction du casino associé à l'établissement de bains ou à l'hôtel persiste également, parfois jusque dans les années 1920, particulièrement dans les villages thermaux.

La majorité des stations thermales et balnéaires possède un casino. La « reine des villes d'eaux », Vichy ne possède un casino-théâtre indépendant qu'en 1865. Le cycle de constructions des casinos suit celui des termes : leurs apogées se situent dans les années 1890, 1920 et après la Seconde guerre mondiale.

Dans son Encyclopédie de l'architecture et de la construction publiée en 1898 par Paul Planat, Gustave Rives recommande que le casino soit :

« placé à l'endroit le plus agréable de la station balnéaire [...] sa situation et son orientation ont une très grande influence sur les résultats de son exploitation. Il faut que ses abords soient d'accès faciles, larges, bien entretenus, la façade principale au soleil et, si la configuration du pays le permet, le bâtiment sera bien abrité. Autour de lui des espaces seront réservés pour les jeux et les exercices du

12 Ralph Tegtmeier, Les casinos dans le monde, Arbook International, 1989 (inventaire des principaux casinos français en activité, p. 248-250).

13 Loi du 15 juin 1907 portant sur la nouvelle réglementation des cercles et des casinos dans les stations balnéaires, thermales et climatériques. 
corps ; enfin, et c'est là une des conditions essentielles de sa vitalité, il doit être à proximité du meilleur endroit de la plage où l'on se baigne, ou près de l'établissement thermal ».

Lieux de plaisirs et lieux médicaux marquent l'espace urbain. L'emplacement des ensembles et des édifices de loisirs est choisi avec soin, comme celui du casino. Sur le littoral, à Dieppe ou à Biarritz, le casino est face à la mer, au centre de la station, entouré d'espaces ouverts réservés aux distractions de plein air. À Cabourg ou à Stella-Plage, le casino est le point de convergence d'un plan radio-concentrique. À Deauville, il est situé au point focal de la symétrie urbaine. Paquebot des plaisirs, le casino est exposé à tous les regards et participe à la mise en scène de la ville d'eaux, comme à la Jetée de Nice. À Vichy, les ornements aquatiques du casino, temple des loisirs et des plaisirs dialogue depuis 1865 avec l'établissement thermal, temple de la médecine, édifié à l'autre extrémité du parc thermal.

Quand Gustave Rives, auteur du casino Marie-Christine du Havre (1910), rédige quelques années auparavant les conseils théoriques pour l'édification d'un casino, il conseille de le diviser selon les différents services : «1. la "Salle des fêtes" et ses annexes, les salons, la salle de lecture, de conversation, 2. Le "Café restaurant", le billard, le fumoir, les cabinets particuliers, 3. Le "Cercle” comprenant les salles de jeu (Ill. 3), des salles d'écarté, de baccarat, une salle de correspondance, la bibliothèque avec salle de lecture, la salle d'escrime, etc ${ }^{14}$. Ces multiples fonctions - avec salles de bals et de réceptions - nécessitent des entrées séparées, selon les types de publics, et une réglementation des accès réservés pour les salles de jeux. La lisibilité des fonctions se traduit aussi par une multiplication des volumes et des toitures. À partir des années 1920, le casino s’ouvre aux bains de soleil avec le balneumsolarium du casino de Dieppe (1932) et à la culture physique avec les piscines du casino de La Ciotat (1928), du Palm-Beach de Cannes (1929), du casinobalnéum de Dinard (1929)15 et du casino municipal de Menton (1933).

Cafés et restaurants sont intégrés au programme de ces casinos-théâtres. Les premiers « cafés-concerts » apparaissent dans les stations thermales dans les années 1860.

À partir des années 1860-1870, les casinos se dotent de salles de théâtre capables de rivaliser avec les théâtres parisiens : Deauville (1866), Les Sables d’Olonnes (1876), Monaco (1878), Nice (1879-1884). À Vichy, l'adjonction du théâtre de Charles Lecœur (1898-1902) classe Vichy au même rang que les meilleurs établissements de la capitale : sa capacité de spectateurs la place juste après l’Opéra (Ill. 4). Vichy, reflet des fastes parisiens s'enorgueillit un temps d’obtenir le titre de « capitale » d’été de la France.

14 Gustave Rives, «Casino», dans Paul Planat, Encyclopédie de l'architecture et de la construction, Paris, Dujardin, 1898.

15 Véronique Orain, « Un complexe balnéaire, le casino-balnéum de Dinard », dans F. Muel et B. Toulier (dir.), op.cit., p. 110-111. 
Illustration 3 : Biarritz, Casino Bellevue, Salle des petits chevaux

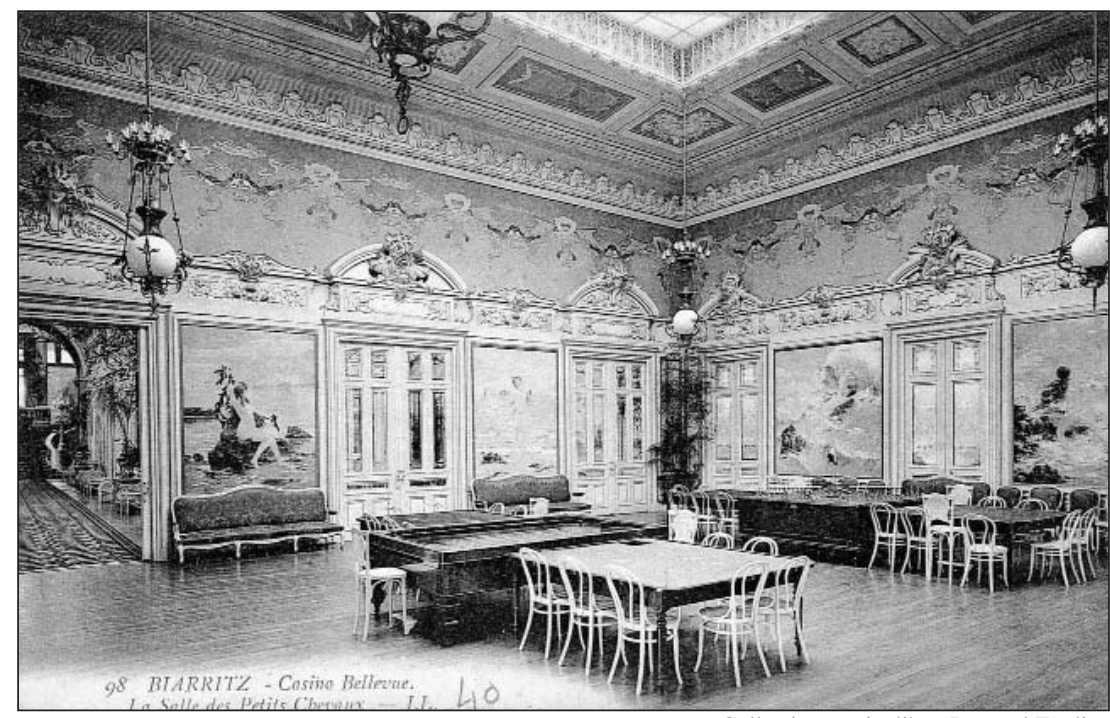

Collection particulière, Bernard Toulier

Illustration 4 : Vichy, Plan du casino-théâtre.

Extrait de " Vichy et ses environs ", Guide Diamant, 1924

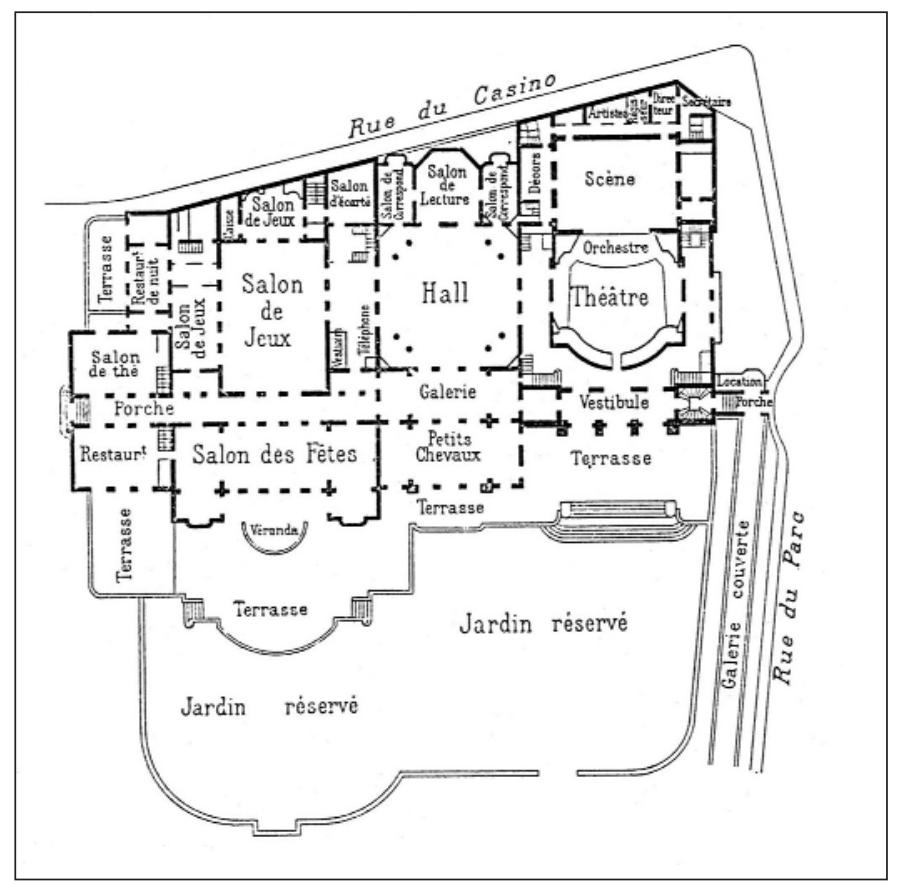

Collection particulière, Bernard Toulier 
Le parti ternaire de la façade principale du casino, avec deux ailes entourant un corps central est très fréquent, comme dans d'autres bâtiments publics (ex. les gares). On accède aux vastes halls et par les nombreux accès aménagés en façade. La façade néo-classique du casino de Monte-Carlo (1878-1879) par Charles Garnier, avec ses campaniles est un archétype dont s’inspirent de nombreux casinos comme celui de Royan édifié par Gaston Redon (1896), ou les casinos de Saint-Raphaël, Hyères ou Biarritz (casino Bellevue) ${ }^{16}$. Le casino de Monte-Carlo sert de source d'inspiration pour celui de Vittel, édifié par le même architecte trois ans plus tard : atrium ouvert sur arcades et clochetons des pavillons. Le casino de Monte-Carlo s’inscrit dans la tradition des grands casinos européens de Spa ou de Baden qui recherchent dans le classicisme français les signes de distinction et de convenance propres à la respectabilité de ces temples de jeu. Le premier casino de Vichy (1865) et celui de Contrexéville (1899) empruntent au style de la Renaissance et aux grands édifices classiques.

Le casino est fortement influencé par les modes factices et éphémères véhiculées par les Expositions universelles, depuis le «Palais de Crystal » du casino de Dieppe (1857) jusqu'au chalet suisse du Kursaal de Riva-Bella (1904). Les petits pavillons d'expositions sont parfois réutilisés, comme celui du Cercle des ouvriers de l'Exposition universelle de 1889, remonté à Calais, ou encore celui du Bouillon-Duval, reconstruit à Mers-les-Bains en 1891. Le casino se prête facilement au jeu des styles du pittoresque au mauresque, du néoclassique au néorégional, de l’Art déco au style international en évitant le néogothique trop connoté et l'Art nouveau, réservé pour la décoration intérieure.

\section{LES ÉTABLISSEMENTS SPORTIFS}

Dans ces villes d'eaux, de nombreux établissements sportifs sont issus ou hérités des goûts aristocratiques et du goût anglais. Les stations offrent un déploiement intense d'activités mondaines et sportives, comme les régates, le tir au pistolet ou aux pigeons (Ill. 5) ${ }^{17}$, la chasse ${ }^{18}$, la pêche, le croquet, le tennis ou le golf. L'architecture sportive s'intègre au programme de la ville-parc. Les petits bâtiments construits pour abriter les clubs et les vestiaires des jeux de tennis, de criquet ou de golf ornent le grand parc urbain. Ces nouvelles fabriques de jardin pour le sport en forme de kiosques ou de chalets dilatent l'espace du parc thermal ou de la station balnéaire. Sortes de petites résidences d'été, elles s’inscrivent dans la tradition des constructions vernaculaires de la « ferme ornée » de Watelet, ou du hameau de Marie-Antoinette. Certains

\footnotetext{
16 Bernard Toulier, « Les casinos de la Côte basque, 1858-1929 », dans Biarritz, le casino. 19291994, Paris, IFA/Norma, 1994, p. 20.

17 Le premier stand de tir est construit à Aix-les-Bains en 1851.

18 Chasse à courre au renard, héritée des usages à l'anglaise à Biarritz ou chasse au gibier d'eau sur la Côte picarde, par exemple.
} 
chalets en bardage d'écailles de sapin et de bois découpées sont préfabriqués en hiver et montés en quelques jours comme le pavillon de lawn-tennis (construit par André Colin) ou le chalet du golf-club construit à Vittel pour la saison 1911.

\section{Illustration 5 : Monte-Carlo, tir aux pigeons et à l'arrière plan le casino}

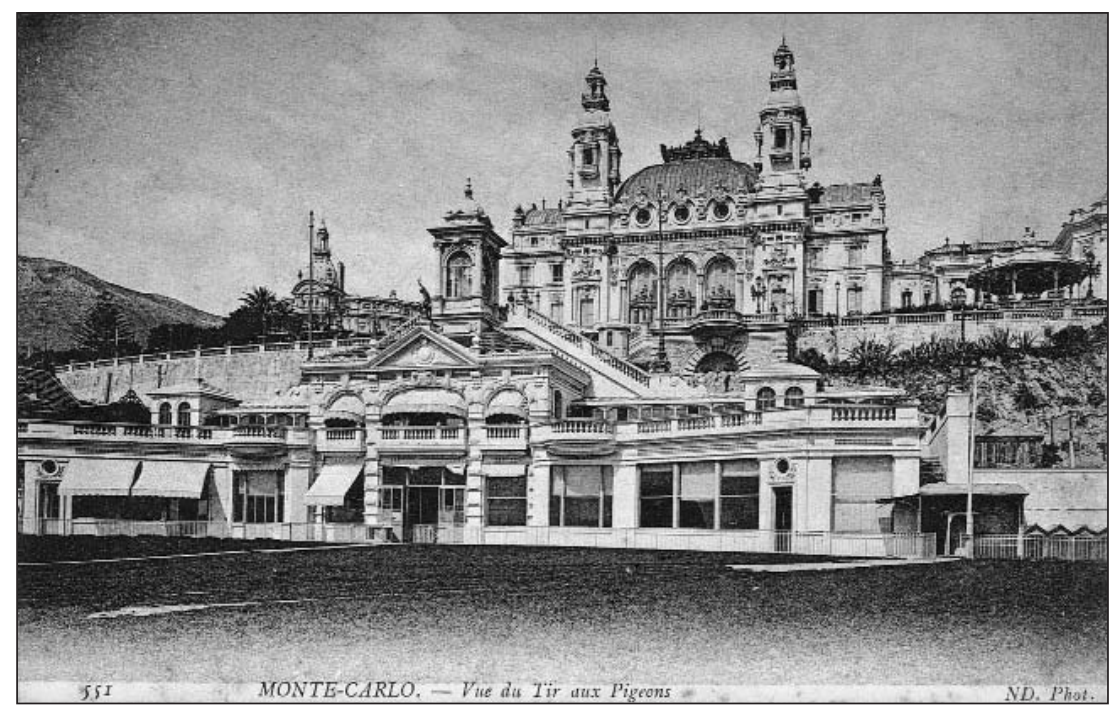

Collection particulière, Bernard Toulier

LE GOLF

Les nouveaux paysages du bord de mer sont le lieu privilégié d'implantation de terrains de golfs dessinés le plus souvent par des architectes anglais qui les implantent sur les falaises ou sur les grandes étendues des landes et des dunes. Les Anglais, déjà installés à Pau où ils ouvrent un golf dès 1856 sont à l'initiative de la création du golf de Dinard, installé sur la commune de Saint-Briac en 1890 et de celui de ParaméRotheneuf implanté trois ans plus tard à La Guimorais. Colt, le créateur du Sauningdale Golf, dessine en 1912 le golf du domaine d'Abadia à Hendaye, agrandit vers 1923-1924 le golf du Phare à Biarritz, et crée en 1926 le golf de Chantaco à Saint-Jean-de-Luz. Avant 1914, on pouvait pratiquer le golf dans les stations thermales d'Aix-les-Bains, de Vichy, de Luchon, de Vittel et d'Évian.

\section{LA PISCINE}

La période de l'entre-deux guerres verra également l'éclosion des piscines sportives. La valeur thérapeutique de l'eau s'efface au profit de l'exercice 
sportif qui entretient et régénère le corps du curiste ou du baigneur. La piscine devient autonome, qu'elle soit couverte dans une station thermale comme Vittel (Fernand César, 1936) ou découverte dans une station balnéaire comme Le Touquet-Paris-Plage (Louis Quételart, 1949)19.

\section{LES TRIBUNES DE COURSES}

Des tribunes sont édifiées pour les spectateurs des courses hippiques (Ill. 6), nautiques puis cyclistes, et les compétitions de tir. Dès 1859 à Deauville, le premier plan d'urbanisme de la ville nouvelle prévoit l'édification d'un hippodrome ${ }^{20}$. Ce sont parfois de simples constructions en bois comme les tribunes du vélodrome ou du tir aux pigeons de Vittel construits en 1905. Avant 1914, des concours hippiques sont organisés dans les villes thermales d'Aix-les-Bains, Vittel, Plombières et Vichy.

\section{Illustration 6 : Deauville, hippodrome, tribunes}

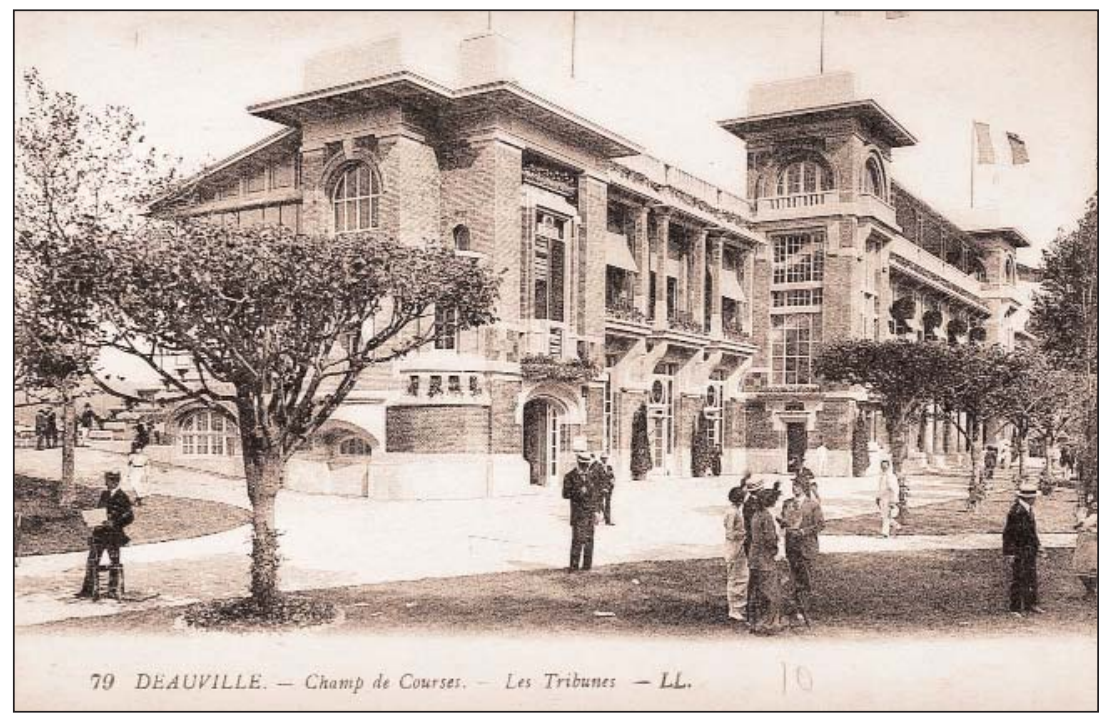

Collection particulière, Bernard Toulier

Les tribunes pour les courses de yachts utilisent plus volontiers les terrasses de bâtiments comme celles du Grand-Hôtel des Régates de SaintAdresse (Ernest Daniel, 1907) ou du Yatch-Club de Dinard (Yves Hémar, 1932). Sur le bord de mer, parapets et digues servent aussi de tribunes. De

19 Richard Klein, Le Touquet-Paris-Plage. La Côte d'Opale des années trente, Paris, IFA/Norma, 1994, p. 150.

20 Didier Hebert, op.cit., Histoire des hippodromes de Deauville, p. 47-53. 
1840 à 1897, des courses de chevaux pour le plat et les haies sont organisées sur la Grande-Grève de Saint-Malo, avant d'être transférées à partir de 1902 sur l'hippodrome installé dans la plaine marécageuse asséchée de Marville21. Les courses traditionnelles s'ouvrent également aux sports mécaniques comme à Monte-Carlo pour l'automobile et l'hydravion.

\section{LES MUSÉES ET LIEUX DE CURIOSITÉS}

Curistes et baigneurs sont avides d'explorations et de découvertes. L'installation d'un cercle scientifique est incluse dans le programme de construction du casino de Nice de L. Amat, élaboré en 1864 avec cabinets de physique et de géographie, observatoire d'amateur avec télescope, salon d'étude et de travail.

Les stations balnéaires ouvrent de nombreux cabinets de curiosités et des musées sur le milieu marin comme par exemple le musée marin des Sables d'Olonne (Amédée Odin, 1900), l'aquarium du muséum d'histoire naturelle de Dinard (Yves Hémard, 1934) le musée de la mer de Biarritz (Joseph Hiriart, François Lafaye et R. Laccoureye, 1932-1935) sur l'Océan Atlantique, l'Institut de biologie maritime de Tamaris (Paul Page, 1900) ou le Musée océanographique de Monaco (Delefortrie, 1899-1910) sur la Méditerranée.

L'emploi du temps du curiste ou du baigneur, avide d'explorations de mondes inconnus exposés dans des cabinets de curiosités ou des musées, laisse une large place aux promenades et aux excursions de découvertes des lieux romantiques et pittoresques des environs. Les guides touristiques présentent un choix d'itinéraires à destination de châteaux et d'églises ou de sites de curiosités. Ânes et chevaux de location mènent l'excursionniste à travers les dunes ou en montagne... À partir du début du XXe siècle, le curiste-baigneurexcursionniste utilise l'automobile ou l'autocar et la bicyclette22.

L'architecture des villes d'eaux est conditionnée par la présence des sources thermales et la proximité de la mer pour aboutir à une sorte de cité utopique, organisée autour de la trilogie « thermes-casino-hôtels ». Les villes d'eaux sont des espaces de féerie hors du temps et du territoire du quotidien.

Les villes de villégiature sont de véritables temples de loisirs élitaires au prétexte thérapeutique. La multiplication des spectacles et des activités de loisirs dans les théâtres, les salles de jeux et les bals concourent à la distraction, jusqu'à l'étourdissement dans une ville temporaire et éphémère.

Dès la première moitié du XIXe siècle, l'histoire de la construction de ces villes d'eaux est un éloge du temporaire et de l'éphémère : à chaque « saison »,

21 Véronique Orain, Gaëlle Delignon, Henri Fermin, «Les équipements sportifs de l'anglomanie », dans F. Muel et B. Toulier, op.cit., p. 105-106 (carte des principaux lieux de pratique sportive sur la Côte d'Émeraude, avant 1940).

22 Catherine Bertho Lavenir, La roue et le stylo. Comment nous sommes devenus touristes, Paris, Éditions Odile Jacob. 
la ville d'eaux se doit de présenter et de " produire » un visage nouveau pour attirer curiste ou baigneur sous peine de disparaître face à la concurrence et aux impératifs de l'industrie des loisirs et de l'entreprise thermale. À la veille de la Seconde Guerre mondiale, la ville d'eaux, considérée souvent comme l'anti-ville industrielle n'échappe pas aux règles du " capitalisme ». Au-delà du rythme saisonnier des prestations et des services autour du médical, certaines villes commencent à produire des animations et des divertissements pour le loisir durant toute l'année, préfigurant la ville de villégiature de la seconde moitié du $\mathrm{XX}^{\mathrm{e}}$ siècle. 



\title{
UN LOISIR URBAIN, LES CAFÉS-CONCERTS EN LORRAINE ALLEMANDE ET FRANÇAISE
}

\author{
$1870-1914$ \\ Jean-Christophe DIEDRICH \\ Université de Metz
}

Au cours du XIXe siècle s'impose "la distinction entre les pratiques de loisir jugées enrichissantes, qui relèvent de la sphère de l'amateurisme, et des distractions considérées comme peu respectables, appauvrissantes " comme celles des cafés-concerts, loisir décrié par la plupart des critiques de l'époque pour sa vulgarité et son indigence artistique. Ce loisir qu'on surnomme aussi « caf'conc » est en fait un établissement à la fois salle de concert et estaminet, réunissant dans son enceinte un public qui paie en consommations le plaisir d'entendre des romances, des chansonnettes voire des morceaux d'opéra (selon le Grand dictionnaire Larousse du XIXe siècle).

Ces spectacles connaissent un grand succès dans la capitale et bientôt en province (se diffusant sur ce modèle partout en Europe). Au moment où ce loisir tend à s'imposer sur l'ensemble du territoire français, la Lorraine va connaître une division douloureuse suite au traité de Francfort (10 mai 1871) puisqu'une grande partie du département de la Moselle est annexée ainsi que deux cantons de la Meurthe-et-Moselle. C'est dans ce contexte géopolitique inédit que se développe d'abord difficilement puis avec succès ce loisir urbain. En quoi la création de cette nouvelle frontière va-t-elle transformer le caféconcert tant en Lorraine allemande qu'en Lorraine française ?

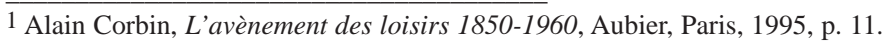




\section{LES CAFÉS-CONCERTS DANS LES LORRAINE}

\section{LA LENTE IMPLANTATION DES CAFÉS-CONCERTS}

La Lorraine comme beaucoup d'autres régions de France regarde Paris quand il s'agit de culture et de divertissement. Si à Paris, il existe plus d'une centaine de cafés-concerts au commencement du Second Empire, leurs débuts dans l'Est de la France sont timides. Les premières ouvertures d'établissements proposant ce nouveau type de loisir urbain se diffusent des grandes villes aux plus petites, Metz en 1857, Nancy l'année suivante, Bar-le-Duc l'année d'après, Épinal en 1864. Ainsi, avant 1870, les principales villes de l'espace lorrain sont concernées, les foyers secondaires demeurant pour le moment à l'écart.

La guerre de 1870 et ses conséquences vont incontestablement troubler le développement de ce loisir si on considère l'extrême rareté des annonces faites dans la presse locale des années 1870-73 - tant en Moselle qu'en Meurthe. Par la suite, la situation semble rapidement évoluer d'autant que dans le nouvel espace divisé par le traité de Francfort, les garnisons n’ont jamais été aussi nombreuses de part et d'autre de la nouvelle frontière. En Lorraine allemande, on compte ainsi 15000 soldats stationnés en 1871, 22000 en 1885 et 46000 en 1905 dont plus de 23000 dans la seule agglomération messine². L'autre capitale lorraine, Nancy connaît durant la période la même militarisation et passe d'un effectif de 8000 soldats en 1890 à 11000 en 1913. D'autres villes connaissent le même phénomène, telles Lunéville (5 000 soldats), Épinal (plus de 10000 soldats), St-Mihiel et sa région (8 000 soldats), Toul (9 000 soldats) ainsi que Bar-le-Duc et Verdun (10 000 soldats en 1910), près de 100000 soldats stationnant au final alors dans l'espace lorrain ${ }^{3}$.

Cette forte militarisation de la Lorraine concentre dans les centres urbains une population masculine friande de divertissements. Ainsi, à partir du milieu des années 1870, on constate une multiplication de l'offre partout en Lorraine. A Metz, 25 établissements donnent des concerts ou spectacles en 1878, la plupart d'entre eux étant destinés à ce public militaire : des publicités sont donc faites le week-end essentiellement dans la presse germanique (La Metzer Zeitung en particulier), et les tenanciers proposent assez régulièrement des tarifs avantageux aux soldats quand les spectacles sont payants. Au milieu des années 80, la plupart des établissements messins sont tenus par des immigrés allemands arrivés de fraîche date en Moselle ${ }^{5}$ qui se révèlent être très inventifs. Ils généralisent la publicité dans la presse en utilisant des illustrations qui accrochent le regard du lecteur et organisent de nombreux événements pour divertir cette garnison

\footnotetext{
2 Pierre Brasme, La population en Moselle au XIXe siècle, Éditions Serpenoise, Metz, 2000, p. 122.

3 François Roth, Histoire de la Lorraine, l'époque contemporaine, Metz, Éditions Serpenoise et PUN, 1992, p 257.

4 René Bour, La Lorraine, ses hommes, ses activités, Metz, Smel, 1976, p. 52.

5 Jean-Christophe Diedrich, « Café-concert et music-hall à Metz 1857-1914 » in A Quatre temps, la musique en Moselle des origines à nos jours, St-Julien-lès-Metz, Archives Départementales de la Moselle, 2002, p. 153-172.
} 
germanophone installée dans une ville encore majoritairement francophone et parfois hostile à ces nouveaux venus. Georg Huber, brasseur d'origine munichoise, multiplie ces manifestations le plus souvent teintées de patriotisme. Ainsi, en 1878, lors de la fête anniversaire de l'Empereur, un cortège aux flambeaux est organisé dans la ville suivi d'un concert dans sa brasserie. Ce patriotisme devient plus prégnant encore quand les annonces publicitaires faites par voie de presse sont illustrées de l'allégorie de l'Allemagne, Germania tenant un glaive et un bouclier aux armoiries de l'Empereur.

Si le développement du café-concert s'appuie d'abord sur une volonté d'affirmation identitaire et patriotique, il utilise également des traditions festives nationales comme les fêtes de carnaval, fêtes de la bière ou du cochon. Ces traditions éloignent donc des scènes de la Lorraine allemande le spectacle dit parisien composé habituellement de chanteuses de romance, de comiques troupiers ou de saynètes comiques. Dans le même temps, la nécessité d'occuper une troupe toujours plus nombreuse avec un contenu le plus souvent patriotique a obligé les autorités à porter un regard complaisant sur les autorisations d'ouverture de ces établissements. La surveillance comme la censure ne semblent ainsi aucunement restreindre le développement de ce loisir urbain qui laisse même la place au développement d'établissements destinés à un public francophone comme l'Hôtel du Nord ou le Café de la Bourse (dont une partie du spectacle est en français) ${ }^{6}$.

De l'autre côté de la frontière, le développement de ce loisir paraît plus hésitant, et les autorités préfectorales ou municipales sont encore très pointilleuses. À Épinal, par exemple, un arrêté préfectoral datant du 11 novembre 1873 oblige tout chanteur, qu'il se produise dans la rue ou dans les cafés-concerts, à ne chanter que le répertoire qui aura été visé par la censure. Les artistes doivent également obtenir une autorisation de la police municipale. Quant aux tenanciers, ils doivent préalablement à toute représentation soumettre leur programme aux autorités et les autorisations pour des spectacles ne sont en général accordées que pour une séance7 ${ }^{7}$. La jeune République continue encore à prendre des mesures très contraignantes à l'égard de ce divertissement considéré à la fois comme un lieu de tous les vices. Aussi la censure continue à édulcorer les textes dans les représentations des misères sociales, dans les luttes des classes ou le nationalisme8. Cette censure évolue d'ailleurs sur la période. En effet, si elle porte au départ sur le caractère immoral de certaines chansons, on constate qu'à la fin du siècle, la répression frappe avant tout les allusions critiques envers le pouvoir politique comme le constate Eva Kimminich dans l'analyse des 7000 textes refusés et placés dans le Fonds des Archives nationales.

\footnotetext{
${ }^{6}$ Le Messin, 7 janvier 1886.

7 Archives départementales (AD) des Vosges, 4 M 345, Cafés-concerts et représentations théâtrales, 1853-1923.

8 Pauline Fournet, Anastasie leur coupe le sifflet, le café-concert et la censure au début de la IIIe République : 1871-1906, mémoire dactylographié IEP de Grenoble, Olivier Ihl (dir.), 1996, 242 p. ${ }^{9}$ Eva Kimminich, «Chansons étouffées, recherche sur le café-concert au XIXe siècle ", Politix, n¹4, 1991, p. 19-26.
} 
Néanmoins, la ville de Nancy va connaître un grand dynamisme dans le domaine au milieu des années 1880, son équipement en salles de spectacles se révélant digne d'une capitale régionale. Le premier de ces établissements est le Casino des Familles inauguré en novembre 1884 rue St-Georges ; le second, l’Éden nancéien situé place St-Jean, ouvrira quant à lui ses portes moins d'un an après en offrant une capacité de plus de 1000 personnes. Ces deux salles spécialisées sont les premières véritables grandes salles de Lorraine dédiées uniquement au café-concert, et se lancent dans une concurrence néfaste qui met en difficulté à plusieurs reprises l'Éden, racheté en définitive par son concurrent et son directeur, Armand Bel10. À ce moment, l'exemple d'une spécialisation semble être suivi partout en Lorraine française, et à Bar-le-Duc en 1889, Gustave Henrion ouvre le café-concert des Variétés avec scène et jeu de décor ${ }^{11}$. À cette date, ce loisir s'impose donc dans les grandes villes lorraines alors que les cafés-concerts parisiens connaissent une amorce de déclin à la fin des années 189012 .

Ainsi, la militarisation de la Lorraine a permis le succès du café-concert avec une véritable accélération au milieu des années 1880.

\section{L’ÂGE D’OR DU CAFÉ-CONCERT EN LORRAINE 1890-1910}

C’est à partir des années 1890 que ce loisir se diffuse plus largement dans la plupart des localités urbaines tout en se généralisant pour devenir une véritable industrie. C'est d'ailleurs dans un contexte de forte industrialisation que le « caf'conc » gagne l'ensemble des villes lorraines. L'intensification de l'exode rural et l'industrialisation du nord de la Moselle et de la Meurthe-etMoselle entraînent une urbanisation rapide et parfois anarchique de ces régions. Ceci s'accompagne de l'implantation de nouveaux établissements dédiés plus spécifiquement aux loisirs des ouvriers. Dans cet espace plus ouvert aux flux, plus dynamique et plus riche, le café-concert s’affirme comme l'un des principaux loisirs urbains.

Il apparaît après un recensement qui ne peut, hélas, pas être exhaustif, (nous avons recensé d'après les archives des différents départements, des annonces dans la presse, des annuaires et des registres des Bureaux de bienfaisance) un total de 170 établissements de café-concert sur l'espace lorrain entre 1890-1910 (Ill. 1). On constate d'abord la domination des deux capitales régionales Metz et Nancy. L'agglomération messine avec 76 établissements paraît sur-représentée, ceci ne pouvant s'expliquer que par la très forte concentration militaire et le regard bienveillant des autorités. La

\footnotetext{
10 Maurice Cajelot, Petite histoire nancéienne des spectacles de divertissement, du Caf'conc au Music-Hall, Mémoire de l'Académie Stanislas, 1985, p. 489-503.

$11 \mathrm{AD}$ de la Meuse, I1 72, débits de boissons et cafés-concerts.

12 Ce décalage est également constaté pour Lyon par Jean-Luc Roux, Le Café-concert à Lyon, Éditions lyonnaises d'art et d'histoire, Lyon, 1996, p. 39.
} 
définition même du café-concert ${ }^{13}$ dans sa plus large acception peut éventuellement grossir ce chiffre. Pourtant près de $66 \%$ des établissements se trouvent en Lorraine annexée où d'autres villes montrent leur vitalité dans ce domaine, Sarreguemines, Forbach ou Thionville étant des garnisons, Moyeuvre-Grande ou Rosselange bénéficiant du dynamisme des industries sidérurgiques et minières proches (Ill. 2).

\section{Illustration 1 : Les cafés-concerts en Lorraine, 1890-1910}

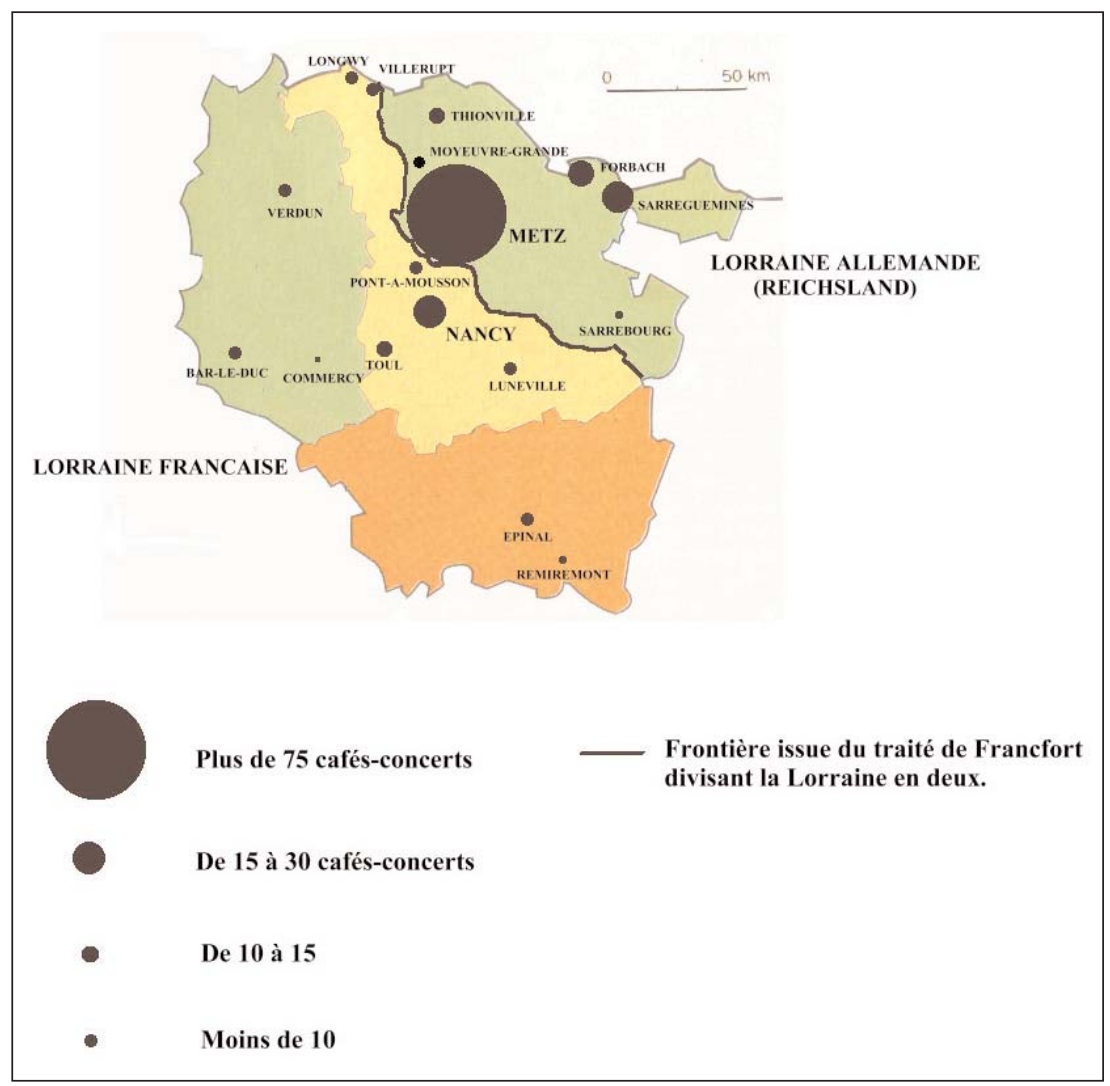

Quant à la Lorraine restée française, on constate que les deux départements à dominante rurale que sont la Meuse et les Vosges demeurent à l'écart de l'engouement engendré par ce loisir, tandis qu'en Meurthe-etMoselle, il se diffuse dans le réseau des petites villes ainsi que dans les zones industrielles telles que Longwy ou Villerupt.

13 Nous entendons ici par café-concert, tout débit qui présente plus ou moins régulièrement des concerts ou spectacles. 


\section{Illustration 2 : Café Scala de Moyeuvre-Grande (Moselle)}

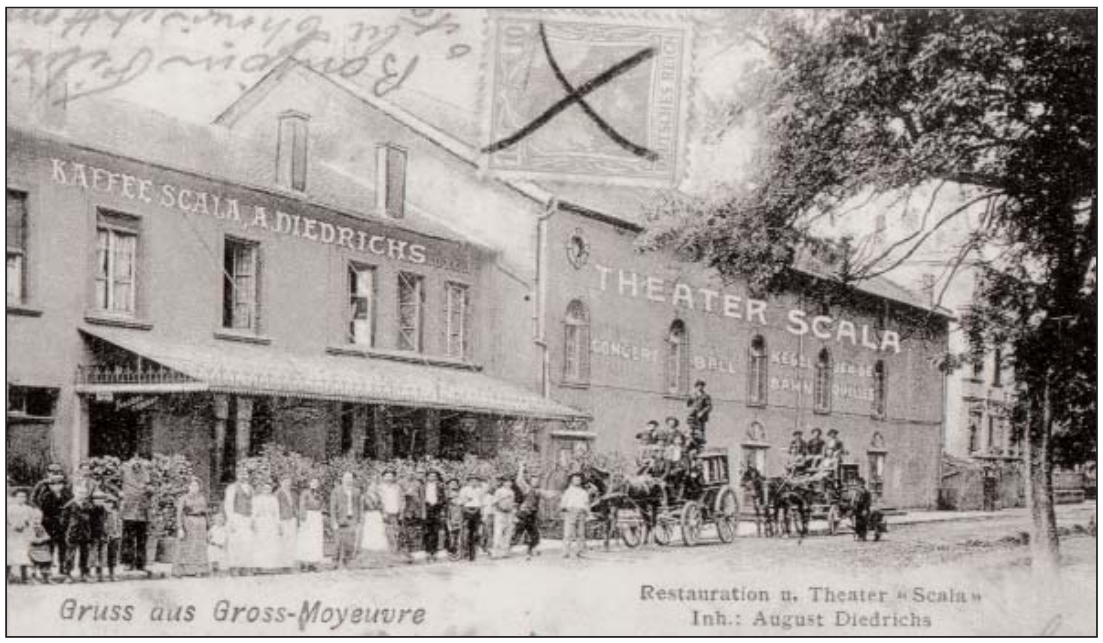

Si inégale que soit l'implantation des cafés-concerts dans les deux Lorraine, les années 1910 marquent le début d’un déclin. Certes, à cette date, le café-concert s'est mué en music-hall, c’est-à-dire qu'il propose des spectacles de variétés, un formidable mélange des genres faisant autant appel à la tradition du cirque que du théâtre mais aussi à toutes les innovations récentes y compris le cinéma.

C’est justement ce dernier qui va lentement transformer ce vaste réseau de salles de spectacle si différentes par leur aspect en salles obscures. Ainsi, de grands établissements vont connaître ce lent glissement comme par exemple L'Éden Théâtre de Metz où les séances de cinéma s’intègrent lentement au spectacle de variétés. Toujours à Metz, l'Eldorado devient cinéma en 1912, alors que l'année suivante à Verdun, c'est le Café-concert de l'Univers qui se transforme en Éden Cinéma14.

\section{DU CAFÉ AUX « TEMPLES DES LOISIRS »}

Ces évolutions quantitatives passent sous silence la diversité de ces établissements. Sous l'appellation générique de café-concert, des réalités différentes existent dans les faits. Du simple débit dans lequel le patron a l'habitude de recevoir quelques artistes payés d'une soupe ou de quêtes, à la salle de spectacle spécialisée, débordante de luxe et de stuc, ces salles déclinent toute la diversité de la notion de café-concert.

14 Archives municipales de Verdun, série I 33. 


\section{LA MULTIPLICITÉ DES ÉTABLISSEMENTS}

S’il n'est pas réellement possible d'établir une typologie du contenu des spectacles faute de sources, une classification des établissements permet de saisir une part de cette diversité. En respectant l’ordre chronologique d'apparition, il faut évoquer tout d'abord les premiers débits qui accueillent de façon irrégulière des musiciens ou des chanteurs. Après la disparition des goguettes au début du Second Empire, les cafés-concerts multiplièrent ces expériences pour en faire une activité d'appoint. Cette pratique est attestée par exemple par l'annonce du Café Schmitt dans la Saargemunder Zeitung du 24 décembre 1878 qui accueille pour l'occasion le couple praguois, Carlo Chyba et Anneta en soubrette allemande, ou encore par le Café du Commerce de Toul15. Ces cafés qui aménagent à la hâte une scène sont nombreux dans toute la Lorraine, et ne laissent, à part quelques annonces ou quelques autorisations, que peu de traces.

Certains débits, sous la pression de la réglementation municipale ou de la concurrence, envisagent alors d'aménager leur débit soit en y installant une simple estrade, soit en construisant une salle attenante à celle du débit agrémentée d'un décor plus ou moins luxueux. Là encore, les exemples, sont nombreux tant en Lorraine allemande qu'en Lorraine française. À Metz, l'un des premiers cafés-concerts, le Café du Midi, aménage une scène et devient à partir du début des années 1880 le Bavaria où le spectacle devient la principale activité. Toujours à Metz, la scène de la Germania voit le jour dans son jardin d'hiver en 1895.

Certains aussi ouvrent pour la belle saison un jardin à proximité de la salle de débit qui devient alors un jardin-concert, mais c'est surtout dans la périphérie des villes qu’on retrouve ces jardins-concerts : autour de Metz, on en dénombre cinq, le plus connu étant celui d’Oesterreich dans la périphérie messine (l'île de Chambière).

Enfin, pour répondre à une clientèle de plus en plus exigeante, des salles sont spécialement construites à cet effet. À Nancy, en 1884, on voit ainsi naître le Casino des Familles et l'Éden en 1885, à Metz la salle de la Cigogne en 1890, le Colosseum en 1895, à Bar-le-Duc la salle de spectacle Café des Oiseaux (Ill. 3) qui devient théâtre municipal, à Sarreguemines la Saalbau, etc...

Pour compléter cette offre, les puissantes brasseries des deux Lorraine vont construire de vastes débits qui donneront la possibilité d'organiser toutes sortes d'activités dont celles des concerts et spectacles. À Nancy, on trouvera par exemple la Brasserie Vagner (Ill. 4) servant la bière des Grandes brasseries réunies de Maxéville, avec une salle de 1600 places, et proposant des séances de cinéma ou des concerts. À Metz, la Cigogne est achetée par la Brasserie Lorraine en 1890 pour en faire une salle de spectacle polyvalente.

\footnotetext{
15 AD de Meurthe-et-Moselle. 4 M 128, Lettre du Sous-Préfet de Toul au Préfet de Meurthe datant de 1907.
} 


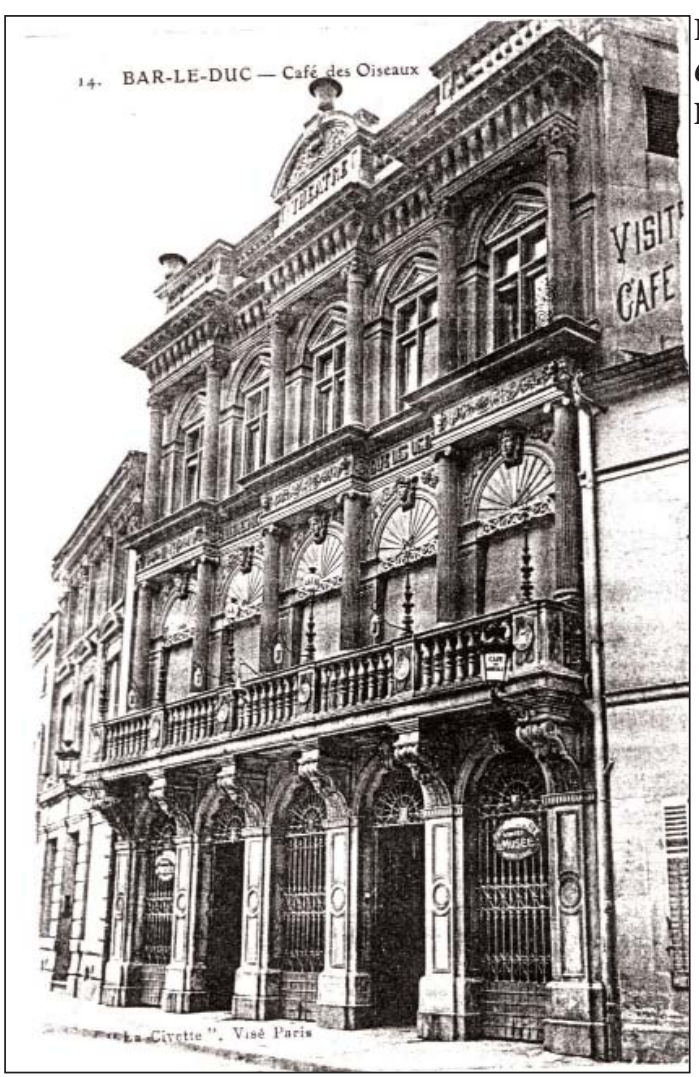

Illustration 3 :

Café des Oiseaux à Bar-leDuc (Meuse)

Illustration 4 : Brasserie Vagner à Nancy (Meurthe-et-Moselle)

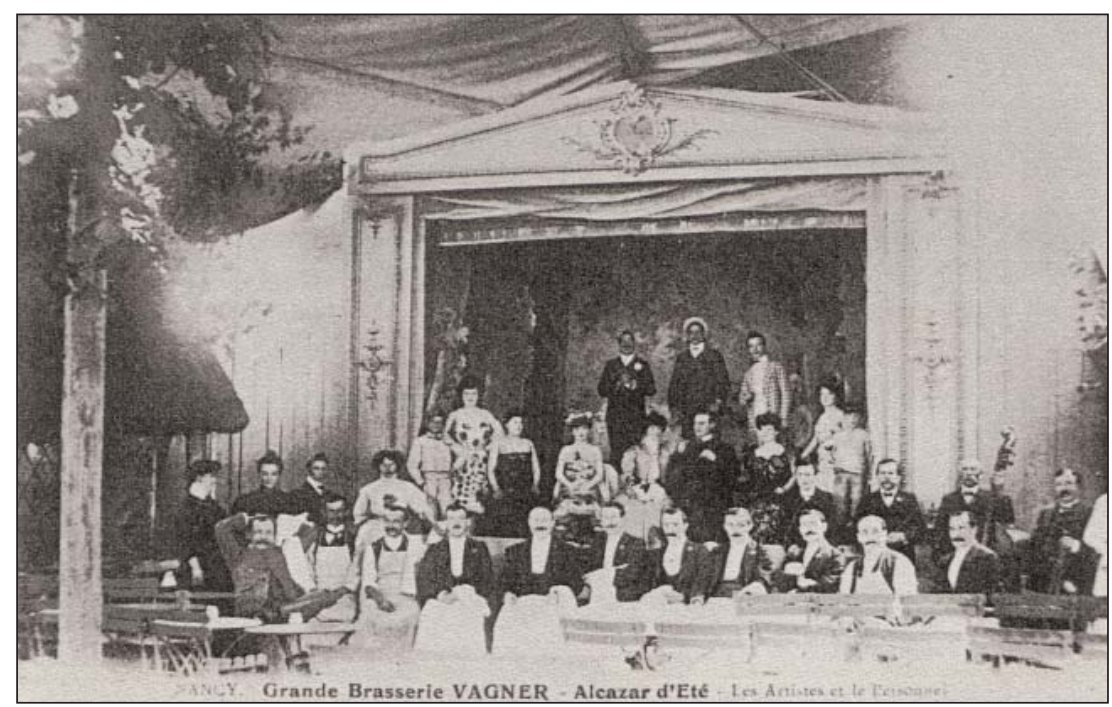


On trouve enfin, des Hôtels-palaces qui vont également proposer des salles et compléter leur activité par des concerts, comme le Terminus de Metz, ou l'Hôtel Schillerhof de Thionville.

Mais c'est sans doute le Palais de Cristal de Metz qui va proposer le concept le plus original et novateur. Construit en 1909, il est en effet conçu comme un temple du loisir qui intègre en son sein tout l'éventail des loisirs : il est donc à la fois piscine, bain privé, salle de billards, jeu de quilles, casinorestaurant, bar américain, salle de cinéma et salle de café-concert appelé Zillerthal et accueillant près de 2000 personnes. Ce complexe va connaître ainsi un véritable succès malgré une concurrence toujours plus forte.

\section{CAFETIER OU CHEF D’ENTREPRISE ?}

La diversité des établissements proposant des concerts est une réalité mais ce qui unit la plupart de ces tenanciers, c’est qu’ils sont au départ limonadiers. Profitant de cette mode, les débitants de boissons ayant des locaux suffisamment vastes et étant suffisamment entreprenants se lancent dans le métier d'entrepreneur de loisir. Mais beaucoup continuent à exercer avant tout leur métier de cafetier, accueillant plus ou moins régulièrement quelques artistes de passage, ce qui constitue un véritable complément de revenu. Parmi ces limonadiers lancés dans l'aventure du monde du spectacle, on nous décrit ainsi le père Henrion16, tenancier d'un des tout premiers cafés-concerts nancéiens situé à l'angle de la rue St-Jean et Mazagran :

" c'était un ancien petit cordonnier, aux manières dépourvues d'élégance et dont les pataquès firent à cette époque le tour des journaux, (...) le Sieur Henrion semblait extrait d'un album de Daumier ou de Gavarni, affligé d'un mufle de bouledogue sur lequel chevauchait de travers un binocle en or, il avait l'aspect le plus rébarbatif qu'on puisse imaginer ».

La soi-disant grossièreté de ce personnage ici décrite n’empêche pas ce personnage de poursuivre une carrière plutôt brillante. En effet, on le retrouve en 1885 à la tête du prestigieux Éden de Nancy pour sans doute deux saisons. En 1889, il établira à Bar-le-Duc ${ }^{17}$ un autre établissement appelé le Variété, puis il abandonne alors la direction de ce dernier pour s’établir à Amiens où il dirige le Casino.

Si les premiers entrepreneurs sont encore considérés comme des limonadiers finalement très éloignés du monde des spectacles, les grandes salles construites depuis peu ne peuvent supporter l'amateurisme en la matière. La seconde génération va ainsi rapidement se professionnaliser. Pour beaucoup, ces nouveaux entrepreneurs appartiennent déjà au milieu du café-concert.

\footnotetext{
16 Armand-Paul Vogt, La vie théâtrale à Nancy 1882-1914, propos d'entracte, souvenirs et anecdotes, Imp. Lorraine, Nancy, 1922, p 43.

$17 \mathrm{AD}$ de la Meuse. I1 72, débits de boissons et cafés-concerts.
} 
Armand Bel (de son vrai nom Armand Ferdinand Lefèvre) né à Neuilly en 1861, fils de négociant et propriétaire du Casino et de l'Éden de Nancy débuta comme chanteur (au Concert Européen puis à l'Alcazar d'été de Paris) à l'âge de 16 ans ${ }^{18}$, crée plusieurs revues locales au Havre et se produit dans les plus grandes villes de France avant d'être nommé secrétaire au Casino de Paris puis administrateur à Nancy. Ce talentueux entrepreneur devenu propriétaire fait fructifier pendant une vingtaine d'années les deux établissements nancéiens.

À Metz, la plupart des établissements sont tenus par des limonadiers mais pour les quelques salles plus spécialisées, on retrouve des directeurs artistiques provenant du monde du spectacle. C'est par exemple, Gruneberg, artiste au Colosseum, qui se lance à partir de 1895 dans la direction d'un nouvel établissement, le Gambrinushall, avec l'idée de présenter des spectacles en français pour attirer une clientèle francophone, mais dont le passage éphémère à la tête de l'établissement tend à prouver que le pari du bilinguisme n'est pas synonyme de réussite. La position de directeur artistique comme celle de tenancier, qui se confondent souvent sont finalement très précaires. Les difficultés peuvent aboutir parfois à des faillites, comme c'est le cas pour le dénommé Kurz - ce dernier avait repris la succession des Variétés de Bar-le-Duc en 1896 après avoir été garçon de café au Buffet de la Gare et quatre ans au Café des Oiseaux (l'autre grand caféconcert de Bar-le-Duc), mais il est finalement déclaré en faillite en 1905.

À travers les destins de ces quelques tenanciers, il apparaît que ces entrepreneurs qui ont réussi à se spécialiser n’ont pas pour autant limité les risques. Ce loisir qui incarne le loisir urbain populaire à la mode souffre en effet rapidement de la désaffection du public et des difficultés réglementaires.

\section{UN COMMERCE RISQUÉ ET SOUS HAUTE SURVEILLANCE}

La concurrence entre ces établissements engendre une véritable émulation tant sur le contenu des spectacles que sur la façon de les diriger, mais elle génère aussi des difficultés à la mesure des investissements mobilisés.

Des locaux luxueux (rénovés régulièrement), des publicités nombreuses et des artistes recrutés de plus en plus loin et pour de courtes périodes alourdissent la facture des plus grands établissements. Aussi la moindre baisse de fréquentation fragilise ce commerce si sa gestion n'est pas rigoureuse. Dans les deux plus importants établissements nancéiens dirigés par Armand Bel en 1891 les recettes dépassent les 128000 francs sur l'année (Ill. 5) ${ }^{19}$. Ces résultats très honorables sont le fruit d'une programmation très adaptée à la demande : les deux établissements ferment donc durant les mois d'été quand les spectateurs désertent les salles pour la campagne alors que l'Éden redémarre la saison plus tôt afin que les deux établissements n'entrent pas en concurrence au moment où les spectateurs ne sont pas encore trop nombreux.

18 Étrennes nancéiennes, 1906, p 77.

19 Archives Municipales de Nancy, Bureau de Bienfaisance, 1 Q 2 C, 1808-1923. 
Illustration 5 : Évolution des recettes des établissements d'Armand Bel de Nancy sur l'année 1891 (d'après les Archives municipales de Nancy, bureau de Bienfaisance)

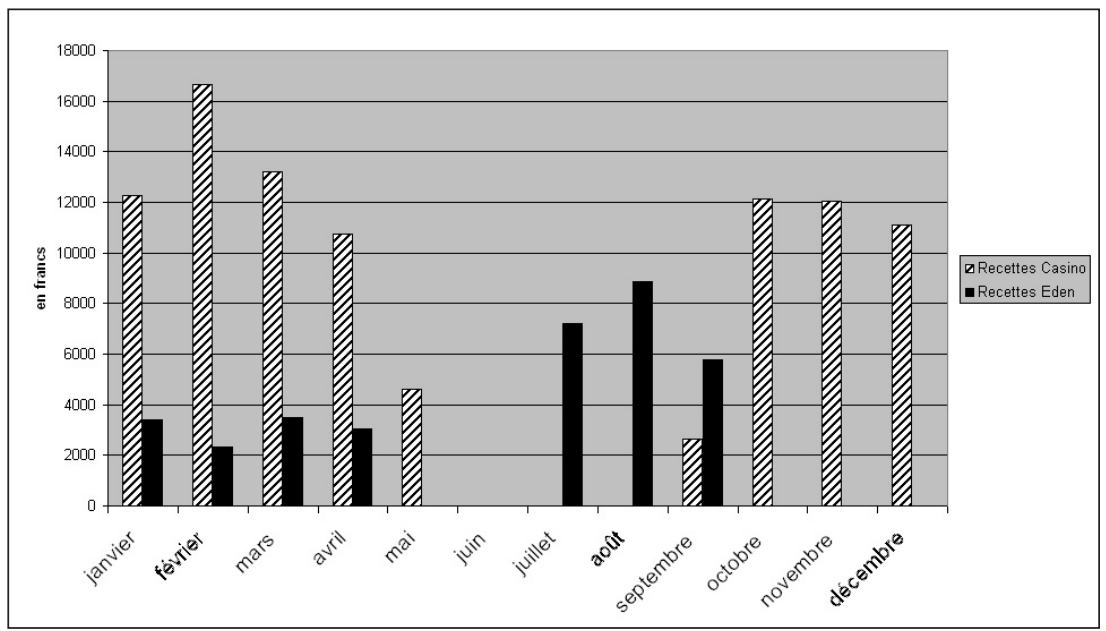

Quand à la mi-septembre le Casino ouvre ses portes (Ill. 6), l’Éden n’organise plus que des bals ou des programmes dits complémentaires comme des opérettes par exemple. Cette gestion savante de ces deux établissements joue sur la complémentarité et permet de s’inscrire dans la durée, avec des bénéfices substantiels.

Mais les moyens mis en œuvre pour attirer le spectateur sont de plus en plus lourds. La publicité dans la ville tend à augmenter elle aussi, surtout pour les établissements très spécialisés qui doivent communiquer quasi quotidiennement par affiches mais surtout dans les principaux quotidiens locaux ; le plus bel exemple est ainsi le Colosseum de Metz qui rend compte par voie d'annonces de son programme détaillé dans la Metzer Zeitung mais également dans le Courrier de Metz et Le Messin. À Nancy, le Casino d'Armand Bel préfère investir dans une publication qui est un journalprogramme de ses salles de spectacle et du théâtre municipal de Nancy. Ce journal, La Soirée Nancéienne ${ }^{20}$, décrit avec précision l'affiche du soir, et le journaliste rédige un compte-rendu de la soirée de la veille dans un style on ne peut plus laudatif. À chaque fois, le renom des artistes venant de Paris ou des pays anglo-saxons, leur talent dans leur spécialité sont autant d'arguments publicitaires. La nouveauté, la variété du spectacle proposé et parfois le sensationnalisme sont les autres arguments avancés par la presse.

\footnotetext{
${ }^{20}$ La Soirée Nancéienne (1893-1907) succède en quelque sorte au journal plus généraliste Le Petit Nancéien (1884-1891) ; ce quotidien va progressivement évoluer pour prendre la forme d'un livret-programme avec des photographies des artistes les plus en vue et quelques publicités.
} 
Illustration 6 : Le Casino (des familles) extrait de Nancy-Artiste, ${ }^{\circ}$ 15, 1886

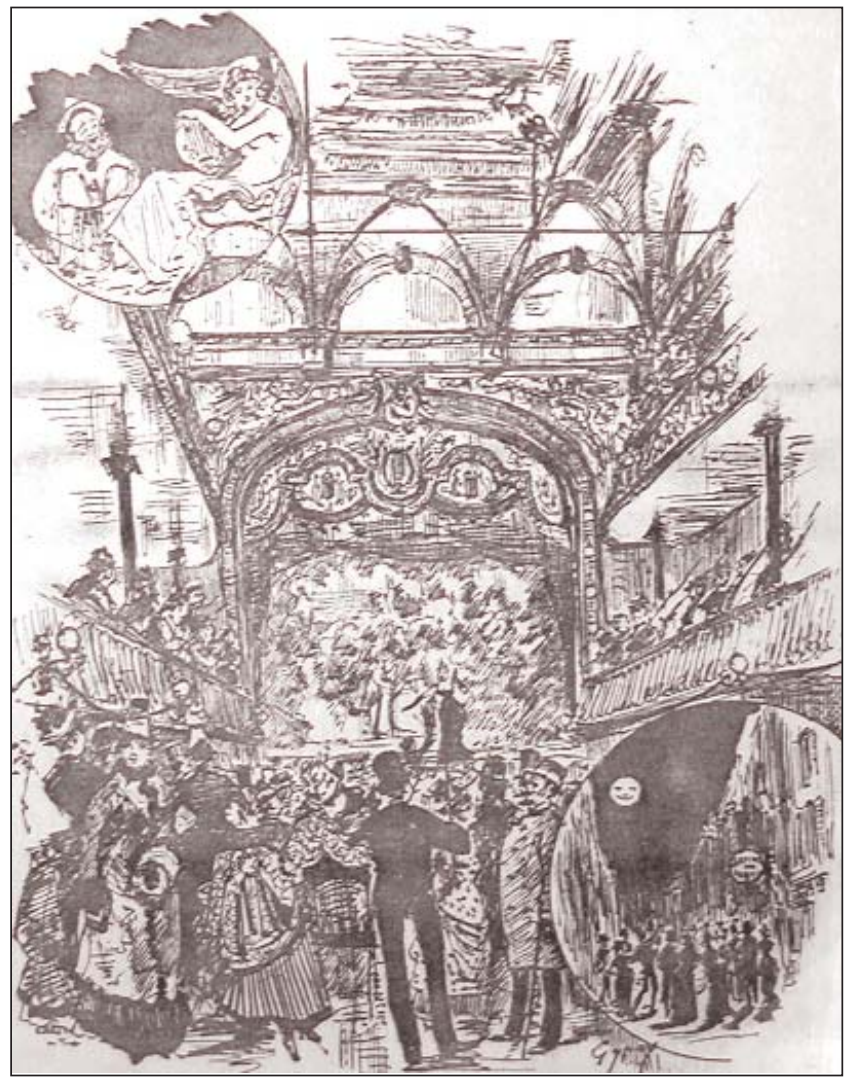

Ces charges financières sont doublées d'autres contraintes. Les règlements en Lorraine allemande comme en Lorraine française fragilisent encore l'entreprise. Outre les chicanes administratives liées à l'ouverture même de la salle (avec progressivement une réglementation qui impose des normes de sécurité strictes contre l'incendie, sortie de secours etc...), à l'autorisation des spectacles ou à la censure, l'entrepreneur de spectacle doit également assurer les frais occasionnés par la garde de police pour le maintien du bon ordre ainsi que ceux des pompiers. Ledit entrepreneur est également tenu d'acquitter, au profit des indigents, le droit dit des pauvres qui finance le Bureau de Bienfaisance de la ville. Cet impôt doit selon la loi du 8 thermidor an $\mathrm{V}$ s'élever à $10 \%$ de la recette mais, comme tous les cafés-concerts ne demandent pas un droit d'entrée, les entrepreneurs négocient généralement un abonnement mensuel qui leur est sans doute plus favorable. Ainsi, des établissements comme le Casino de Nancy paient mensuellement plus de 1000 francs en 1891 alors que le Colosseum de Metz dépense pour sa part un peu moins, autour de 200 francs. 
Enfin, si les cafés-concerts tentent d'attirer de plus en plus les familles, il n'en demeure pas moins qu'il existe des salles de spectacle où la morale est mise à mal. Les artistes qui en majorité sont des femmes sont le plus souvent exploités par des entrepreneurs à la fois peu scrupuleux et pressés par les contraintes financières décrites plus haut. Là, certains n’hésitent pas à se transformer en « négriers ». La frontière avec la prostitution s’estompe alors, entraînant des dénonciations et de nouvelles réglementations. À Bar-le-Duc en 1897, les tenanciers de maison close considèrent que les artistes féminines de café-concert, se livrent ouvertement à l' « inconduite » ce qui concurrence leurs établissements. Ils demandent alors au maire de limiter le nombre des femmes qui se produisent sur les scènes de Bar-le-Duc ${ }^{21}$. Le Commissaire de police de la ville, quant à lui, a dénombré durant la même année, 92 artistes femmes contre seulement 49 hommes, et propose ainsi de limiter le nombre de femmes par spectacle à trois comme l'a déjà fait la ville de Cambrai, précise-t-il. Ailleurs, un artiste engagé depuis un mois à Bar-le-Duc chez Kurtz n’hésite pas à dénoncer cette exploitation, constatant que les femmes sont insuffisamment payées (40 à 50 sous) et qu'elles sont contraintes de ce fait à se prostituer :

«À la cuisine qui sert de passage aux artistes pour aller sur la scène, il y a toujours cinq ou six clients bien souvent en état d'ivresse qui stationnent autorisés toujours par la Direction qui ne sont là que pour manquer de respect aux artistes femmes, en leur passant la main soit dans la poitrine, ou sous les jupes, se permettant de les tutoyer en leur offrant des consommations qu'elles sont obligées le plus souvent d'accepter sous la pression de la Direction »22.

Ces pratiques ne sont pas isolées, bien sûr, si l'on en croit la riche correspondance développée en 1907 entre le tenancier Mutelet de Villerupt, les autorités et les artistes se plaignant de la prostitution clandestine qui s’y développe. Les époux Mutelet obligent les femmes qui remontent dans leur chambre avec un client à acheter une bouteille de champagne à cinq francs ${ }^{23}$. La dénonciation de ces pratiques par l'une des artistes de l'établissement n'est pas soutenue, une autre lettre envoyée aux autorités signées par les autres employés de la maison dément toutes les allégations de la première. Dans ces conditions, il n'est pas facile de lutter contre la prostitution clandestine qui s'étend dans les garnisons lorraines et surtout les villes industrielles de cette époque. Mais profitant de vives polémiques autour de la question de la « Traite des Blanches » et sous la pression de l’Union syndicale des artistes lyriques (concerts et Music-halls) dont le siège est à Paris, et qui publie régulièrement sa propre revue ${ }^{24}$ pour dénoncer ces dérives, des mesures vont être prises.

\footnotetext{
21 Archives Municipales de Bar-le-Duc (aux AD). I1 72 : débits de boissons, cafés-concerts 18521905.

22 Idem.

23 AD de Meurthe-et-Moselle, 4 M 128.

24 Archives Municipales de Bar. I1 72. Quelques exemplaires s’y trouvent.
} 
Le 18 décembre 1906, une circulaire ministérielle concernant la moralisation des cafés-concerts français est adoptée. On prévoit dans l'article 3, l'interdiction de loger dans l'établissement les artistes. Ces derniers devront quitter l'établissement une demi-heure après la représentation, les quêtes étant également proscrites. Ainsi, le Casino de Toul tenu par Maillard est accusé par la revue de ne pas respecter le nouveau règlement puisqu'il loge encore ses artistes. Il s’en défend et il semble qu'après cette date, les dérives les plus flagrantes aient disparu en Lorraine française. De l'autre côté de la frontière, la prostitution clandestine a atteint les mêmes proportions mais sans doute davantage dans les débits de boissons que dans les cafés-concerts qui sont en général des établissements plus en vue et plus surveillés ${ }^{25}$.

La situation des cafés-concerts de part et d'autre de la frontière connaît globalement des similitudes tant dans les contraintes administratives que réglementaires mais les divergences entre les deux Lorraine s'expriment davantage dans le contenu même des spectacles.

\section{LES CAFÉS-CONCERTS LORRAINS ENTRE INFLUENCE PARISIENNE ET ALLEMANDE}

Des distinctions vont progressivement voir le jour dans la pratique de ce nouveau loisir au sein de l’espace lorrain divisé par le traité de Francfort.

\section{DES INFLUENCES DIFFÉRENTES DE PART ET D’AUTRE DE LA FRONTIÈRE}

Avec l'apparition durant les décennies 1880 et 1890 de grandes salles de spectacle dans toute la Lorraine, la professionnalisation s'est accrue. On ne se contente plus d'une pâle imitation de ce qui se fait à Paris. Ainsi, le recrutement s'internationalise et devient d'ailleurs de plus en plus varié. Les artistes viennent de plus en plus loin et restent pour la plupart, peu de temps, quelques jours ou quelques semaines ; les troupes locales recrutées à l'année servent à compléter le programme et à combler les éventuelles périodes d'absence d'artistes. Les grandes salles lorraines (à Nancy et Metz essentiellement) peuvent révéler par leur programmation le goût du public et donc de réelles influences culturelles. La mise en place d'une nouvelle frontière va-t-elle influencer le contenu de ce loisir? Metz regarde-t-elle d'abord les scènes de Berlin, de Cologne ou de Munich pour recruter ses artistes là où Nancy lorgne de son côté vers Paris ?

En étudiant, les programmes des deux principales scènes lorraines, on constate que les artistes recrutés pour le Casino de Nancy viennent à $75 \%$ de France, la plupart du temps de Paris ${ }^{26}$, $18 \%$ sont Anglo-Saxons, $6 \%$ sont Espagnols ou Turcs et seulement une troupe se désigne comme étant

25 Jean-Christophe Diedrich, « La prostitution à Metz 1815-1914 », Cahiers Lorrains, n¹99, décembre 2001, p. 355-393.

26 Chiffres obtenus à partir de l'analyse des 136 troupes programmées durant l'année 1907 et signalées dans La Soirée Nancéienne. 
allemande (la Kastori Truppe, est une troupe d'acrobates qui se produisait auparavant aux Folies Bergères de Paris). Ainsi, force est de constater que la frontière politique est devenue une frontière culturelle, et que les artistes allemands ne jouent pas sur les scènes lorraines françaises. Le regain des tensions entre les deux États est une explication qui ne tient que pour une courte période puisque la frontière n'est pas en l'occurrence complètement imperméable dans d'autres domaines. L'esprit revanchard qui a touché durement la région est une autre explication qui doit être nuancée voire complétée par des considérations plus artistiques. Les cafés-concerts sont d'abord et surtout à l'origine parisiens, avec des genres préétablis, ce qui explique que les artistes d'outre-Rhin ne sont pas la cible des recruteurs en la matière alors que les artistes anglo-saxons incarnent sans aucun doute une certaine modernité, un exotisme quand ils se présentent comme venant du Nouveau-Monde. Enfin, les artistes turcs, dont les spectacles sont très spécialisés, complètent l'offre en proposant des hommes extraordinaires venus d'Orient, d'une force incomparable.

Quant aux établissements de la Lorraine allemande, ils offrent une programmation bien différente. Sur 323 troupes et artistes passés entre 1895 et 1913 dans les établissements messins (en fait surtout le Colosseum qui devient plus tard l'Éden Théâtre, Ill. 7), 40 \% viennent du Reich (la plupart de Cologne ou de la Rhénanie). On retrouve également des Autrichiens, des Italiens et des artistes d'Europe centrale comme le petit prodige musical âgé de sept ans, Kun Arpad qui vient du conservatoire de Pest 27 , et enfin $20 \%$ d'Anglo-Saxons. Mais surtout, ce qui semble plus intéressant, c'est l'importance des artistes français et surtout parisiens puisqu'ils représentent $28 \%$ des artistes recrutés sur la scène messine. Ce chiffre tend à prouver que Metz demeure partagée entre deux influences qui répondraient aux goûts des deux communautés cohabitant dans la ville. La cohabitation linguistique se prolonge ainsi sur la scène même si les autorités sont vigilantes. Ainsi, en septembre 1912, le directeur artistique du Colosseum, le Français M. d’Albrey chargé du recrutement des comédiens, présente un spectacle presque exclusivement en français. Le concessionnaire M. Weil poussé par les autorités intervient alors pour rétablir la domination de la langue de Goethe dans la programmation.

La situation messine demeure néanmoins originale. La ville accueille de nombreux artistes parisiens et dans une bien moindre proportion des artistes nancéiens : c'est le cas de la petite scène du Café des Roches d'Henri Maire qui propose chaque week-end des artistes exclusivement francophones comme l'atteste le programme du 10 janvier 1909, où trois artistes français dont la femme, Mlle Roger, viennent de Nancy28.

Ainsi, l'influence parisienne demeure importante tant en Lorraine que dans le Reichsland (Lorraine allemande). Mais à l'inverse, l'influence de la

27 Le Courrier de Metz, 19 octobre 1900.

${ }^{28}$ Le Courrier de Metz, 10 janvier 1909. 
culture germanique ne traverse pas la frontière et reste cantonnée en Lorraine allemande. Cette frontière n'est donc poreuse que dans un sens. Le caféconcert germanophone marqué davantage par le folklore et le caractère traditionnel des fêtes comme celles de la bière, du carnaval ou des fêtes impériales ne peut sans doute pas atteindre l'esprit français si critique à l'égard de la culture des vainqueurs de Sedan.

Illustration 7 : Éden Théâtre, ancien Colosseum de Metz (Moselle)

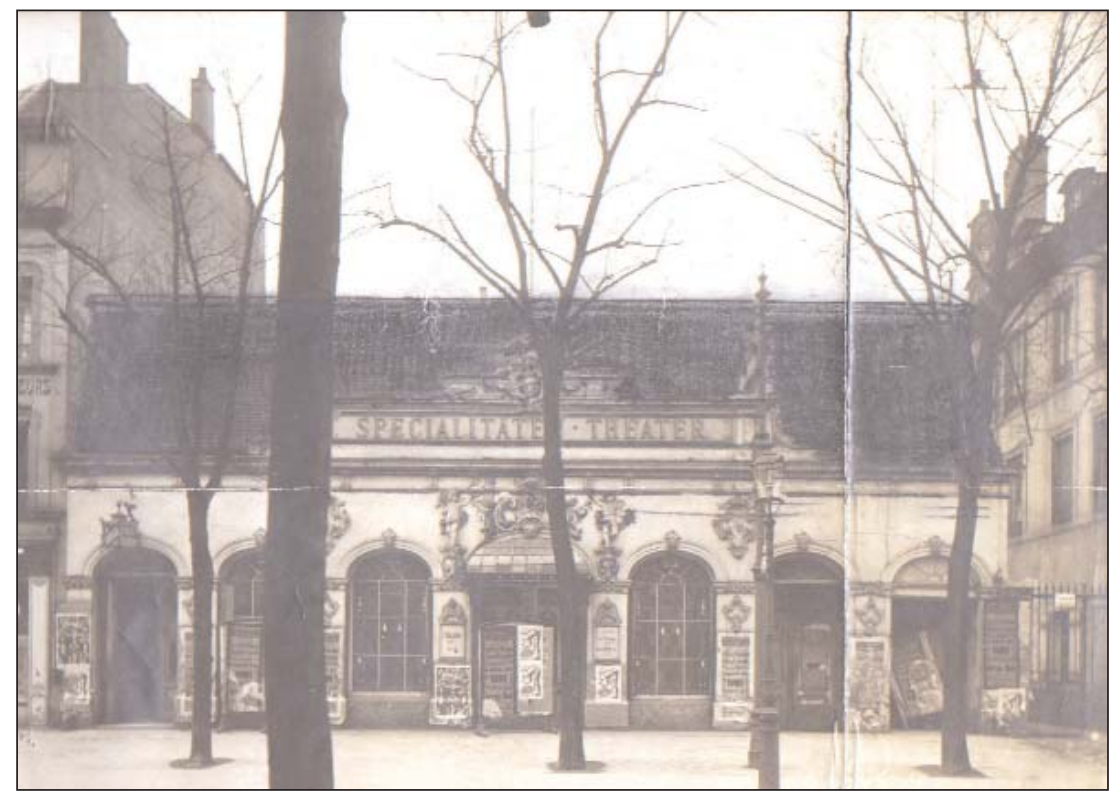

L'autre conclusion à apporter est que les liens entre les deux capitales lorraines sont à cet égard très limités. Ainsi n’y a t-il pas de troupes qui traversent régulièrement la frontière. Cette même rupture entre les deux capitales lorraines s'observe d'ailleurs dans le cinéma forain puisque les circuits des forains qui présentent des projections cinématographiques à la fin du XIXe siècle s'organisent sans jamais traverser cette frontière29. Nancy, nouvelle capitale lorraine, constitue en quelque sorte une vitrine mais aussi un rempart à la germanité. Quand elle « tolère » une troupe venant d'Alsace-Lorraine, c'est surtout pour s'en amuser ou se dépayser, comme en mars 1902 lorsque le Casino accueille le comique alsacien Bloch qui imitera l'accent de deux vieilles Alsaciennes.

En Lorraine annexée, il semble que cette culture allemande appliquée à ce loisir urbain ne se développe pas de manière identique. Certes, Metz possède quelques scènes qu'on qualifiera d'internationales, mais le reste du Reichsland

29 Blaise Aurora, Histoire du cinéma en Lorraine, du cinématographe au cinéma forain 18961914, Metz, Serpenoise, 1996, 220 p. 
est beaucoup plus germanisé que Metz (où la population indigène demeure jusqu'au début du XXe siècle encore majoritaire). Les annonces des spectacles passées dans les journaux de Thionville, de Forbach ou de Sarreguemines sont à cet égard marquées d'une germanité plus profonde.

\section{LES PRÉMICES D’UNE CULTURE URBAINE PROVINCIALE}

La frontière qui traverse la Lorraine marque donc en général une rupture culturelle assez efficace (sauf pour Metz). Le contexte international pesant entre l'Allemagne et la France influence sans doute les scènes lorraines qui tentent de renforcer une identité locale finalement plus consensuelle. Par ailleurs, les établissements qui proposent à un bas prix un mélange de tous les spectacles vivants réunissent un public populaire large. On peut estimer par exemple que le Casino de Nancy pouvait accueillir durant la saison 1891 jusqu'à 120000 spectateurs ${ }^{30}$. Une véritable culture populaire voit le jour, très souvent critiquée par les élites. En 1921, Armand-Paul Vogt, dans son histoire du théâtre à Nancy, ne traite qu'en quelques pages des cafés-concerts tout en convenant de l'importance du phénomène : "Ces deux établissements fondés par deux sociétés anonymes rivales, étaient appelés à avoir une énorme influence sur les goûts et les habitudes de nos concitoyens »31.

Comme le constate Jean-Luc Roux pour Lyon ${ }^{32}$, afin de diversifier encore l'offre, les cafés-concerts vont proposer des revues locales. À Nancy, le Casino proposera durant sa période faste ce type de spectacle s'inspirant d'abord de l'actualité locale. La première s'intitulant Nancy tout le monde descend d'Émile Roussel et Georges Gugenheim, est mise en scène pour la première fois en 1880 et reprise par le Casino plusieurs fois. Les hommes illustres, les rues de Nancy et les faits divers y sont abordés. Mais la grande histoire apparaît également, la mémoire de 1871 étant alors évoquée quand les artistes chantent sur des décors évoquant la place Thiers (figure patriotique puisqu'il est considéré comme le libérateur du territoire de l'occupation allemande) et sa statue.

Vos petits fils vers moi viendront

Chercher un triste écho de l'an soixante et onze

Mes pages alors leur diront

La guerre avait vomi ses horreurs et ses rages

Et son cortège de forfaits

Le flot envahisseur contemplait les ravages

Que ses lourds canons avaient faits

(...) Il fallait marchander la Lorraine et l'Alsace...

\footnotetext{
30Armand-Paul Vogt, Le théâtre à Nancy depuis ses origines jusqu'en 1919, imp. Grandville, Nancy, 1921, 176 p. D’après l'auteur le prix des places est de 1 franc pour le rez-de-chaussée, 1,5 franc pour les loges, de moins de 1 franc pour les galeries, on peut donc estimer qu'en moyenne, le prix d'une place vaut environ 1 franc.

31 Idem.

32 Jean-Luc Roux, op. cit..
} 
En 1893, Nancy s’amuse de Favart, pièce composée de 49 tableaux abordant divers thèmes, mais dont l'un des moments les plus forts, d'après les critiques, demeure l'interprétation de la Marseillaise par un artiste incarnant Rouget de l'Isle. Une autre grande revue à succès créée en 1902, Nancystons pas, est une fantaisie en deux actes d'Armand Lefèvre (le directeur du Casino). Dans cette pièce, toutes les actualités défilent et pour chacune l'auteur a trouvé une petite critique ironique. Tous les thèmes y passent, des élections aux scandales en passant par des arrêtés municipaux de la ville sur les charrettes.

Sans que cela soit le sujet central de ce nouveau loisir, les thèmes nationalistes semblent apparaître en filigrane dans de nombreuses productions. En 1886, lorsque Thérésa vient chanter au Casino, elle est surtout applaudie pour son interprétation des chants de Déroulède.

En Lorraine allemande, le nationalisme semble également apparaître dans les sujets abordés par les revues. Mais plus que les paroles, c'est la forme qu'adopte ce nouveau loisir qui renforce l'identité allemande. La langue allemande qui certes cohabite avec la française à Metz domine néanmoins. Ailleurs, dans le Reichsland, les chansons et les artistes ne laissent en général que très peu de place à la culture française. À Sarreguemines comme à Forbach, les troupes de passage sont allemandes même si on remarquera une exception, dans le restaurant Hilsaner à Thionville, où se produit en septembre 1908 une troupe proposant des variétés alsaciennes-lorraines33. Le spectacle est en apparence traditionnel, la langue pratiquée est l'allemand et les thèmes sans doute locaux. Mais peut-on réellement évoquer l'existence d'une culture lorraine germanophone dans ce domaine ? Les sources nous manquent encore.

Ainsi, les cafés-concerts de l'espace lorrain sont marqués par la frontière politique et le contentieux historique de la défaite de 1871. Si dans les grandes salles de Lorraine allemande, on perçoit une diversité des influences tant allemandes que parisiennes ou même américaines, la réciproque n’est pas vraie pour la Lorraine demeurée française qui s’est fermée aux influences germaniques. Quant au café-concert qui a connu ses heures de gloire durant les années 1890-1910 en Lorraine, il connaît un déclin irrémédiable face au rouleau compresseur qu'est le cinéma qui remplacera tant dans le cœur du public populaire que dans les salles de spectacle, le loisir urbain et populaire, le "caf'conc' » qui a caractérisé la fin du XIXe siècle partout en Europe occidentale.

33 Diedenhofer Zeitung, 9 septembre 1908. 


\title{
LES CRÉATIONS D’ENTREPRISES DE LOISIRS. L’EXEMPLE DE TOURS (1870-1936)
}

\author{
Cédric PERRIN \\ Université François-Rabelais de Tours, CEHVI
}

Le XXe siècle est perçu comme le siècle des loisirs. Nombre de symboles alimentent cette image : la législation sur la réduction du temps de travail, les congés payés... Cette conquête du temps libre nourrit le développement de nouvelles activités, par exemple sportives, l'historiographie, jusqu'ici a abordé les loisirs sous l'angle social et culturel. Elle possède pourtant aussi une dimension économique qu'il convient d'appréhender. Les bénéficiaires de ce temps gagné deviennent des consommateurs de loisirs. La pratique sportive, pour rester sur cet exemple, nécessite l'acquisition d'équipements particuliers. Elle va se faire dans des boutiques spécialisées. Le commerçant se fournit lui-même auprès des fabricants de ces nouveaux équipements... Les activités de loisirs sont donc créatrices d'activités économiques. L'émergence des loisirs conduit à celle d'une économie des loisirs. Peut-on déceler l'apparition d'une économie des loisirs en France à la fin du XIXe siècle ou au début du XXe siècle ?

Pour consommer des loisirs, il faut avoir du temps, un temps libre, «un temps pour soi » selon l'expression d'Alain Corbin ${ }^{1}$. C'est encore l'apanage de peu de monde à la fin du XIXe siècle. Alain Corbin parle d'une "classe de loisir $»^{2}$. Les classes populaires profitent de la diminution progressive du temps de travail et de l'introduction des congés payés mais il reste le problème des ressources financières. Dans les années 1930 et encore dans les années

1 A. Corbin (dir.), L'avènement des loisirs, 1850-1960, Flammarion, Paris, 1995, p. 16.
2 Ibid., p. 22. 
1950 bien peu partent en voyage durant leurs vacances ${ }^{3}$. Une économie des loisirs peut-elle se construire sur une assise sociale aussi restreinte ?

Les bornes chronologiques de cette étude sont celles du fonds d'archives utilisé, la série $4 \mathrm{U}$ des archives départementales où sont conservés les actes de sociétés parmi les papiers des justices de paix ${ }^{4}$. Après avoir sondé plusieurs fonds départementaux, le choix s'est porté sur le cas de Tours où ces actes sont les mieux conservés et répertoriés et les plus commodément classés 5 .

\section{LES ENTREPRISES}

\section{UNE CHRONOLOGIE}

Dans le fonds des actes de société (qui débute en 1870), il ne se trouve aucune société commerciale de loisir avant 1879. Celles-ci apparaissent donc assez tardivement. Jusqu'à la Première Guerre mondiale, les créations restent très occasionnelles. Il n'y en jamais plus d'une par an (exception faite de l'année 1879). Elles semblent correspondre à des cycles courts. En effet, ces créations se concentrent sur quelques années entrecoupées de périodes creuses. Ainsi, il n’y a aucune création entre 1880 et 1883, puis quelques-unes entre 1883 et 1889, de nouveau rien jusqu'en 1893, quelques créations jusqu'en 1897, rien jusqu'en 1901 et de nouvelles sociétés entre 1901 et 1904. Le rythme cyclique s'interrompt alors puisqu'il n'y en a plus aucune jusqu'à l'année 1920 (Ill. 1).

\section{Illustration 1 : Nombre annuel de créations de sociétés dans le secteur des loisirs à Tours entre 1879 et 1936}

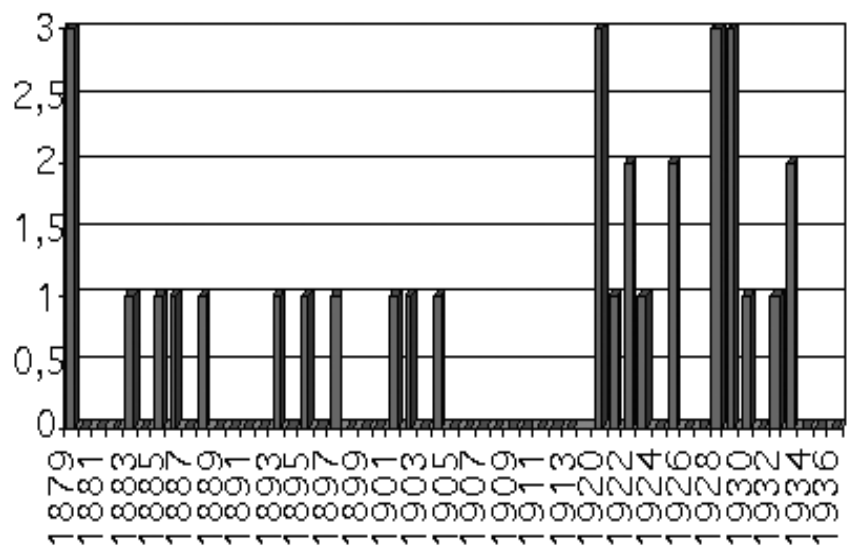

3 J.-C. Richez et L. Strauss, « Un temps nouveau pour les ouvriers » in A. Corbin, op. cit., p. 395. ${ }^{4}$ Le fonds s'arrête en 1936, césure des archives modernes et contemporaines. La suite est classée séparément, en général dans la série W qui le plus souvent n’est pas réellement ou précisément inventoriée, sans compter qu'elle n'est pas toujours libre d'accès.

5 Un relevé plus limité sur le premier canton de Rouen permet quelques comparaisons. 
On peut observer une nette césure entre l'avant et l'après-Première Guerre mondiale. Alors qu'avant la guerre, il n’y a que 3 à 4 créations par décennie, celles-ci montent brusquement à 15 dans les années 1920. On enregistre alors plus de créations en dix ans que dans les cinquante années précédentes. Peuton y voir l'émergence d'une économie des loisirs. L’hypothèse est tentante. Les années 1920 ne sont-elles pas restées à la postérité comme les « années folles » ? Cette appellation traduirait une volonté débridée de profiter de la prospérité retrouvée pour oublier les horreurs de la guerre. Dans cette optique, il serait normal que l'industrie des loisirs en profite. Les créations d'entreprise seraient une réponse à cette demande.

Mais, en réalité, cet essor des créations de société n’est pas particulier aux loisirs. Il colle au contexte local et national. C'est l'ensemble des créations de sociétés qui décolle dans les années 1920. À la veille de la guerre, entre 1910 et 1913, la moyenne annuelle des créations totale à Tours n’est encore que de 18,25; soit moins que le minimum enregistré dans les années 1920 (21 créations en 1922). Cette nette différence entre les années 1920 et l'avantguerre se retrouve au niveau national avec 7272 créations par an en moyenne entre 1910 et 1913 et 12230 dans les années 1920 .

La durée de ces sociétés n’est connue que dans dix cas, soit seulement environ un tiers du total. La moitié meurent avant deux ans, ce qui correspond à la situation générale des sociétés ${ }^{6}$. Ce qui est plus étonnant, c'est l'écart entre la médiane et la moyenne. Alors que la première est donc de 2 ans, la seconde est nettement supérieure avec 9,7 ans. Celle-ci reflète la forte proportion d'entreprises qui durent. Si $30 \%$ disparaissent au cours de leur première année, $40 \%$ durent entre 1 et 10 ans et $30 \%$ perdurent plus de 10 ans. On constate donc qu'une fois passé le seuil critique des deux ans, ces sociétés s’installent durablement dans le paysage économique local. La plus pérenne d'entres-elles dure 45 ans. Créée en janvier 1886, la société du théâtre français de Tours n’est dissoute que lors de la crise économique en novembre 1931.

\section{LES ENTREPRISES DE LOISIRS DANS LA VILLE}

Dans l'espace, le développement des entreprises de loisirs suit la croissance de la ville. Avant la guerre, 77 \% des créations sont enregistrées dans le canton de Tours-centre et $23 \%$ dans celui de Tours-sud. Après la guerre, $42 \%$ des créations se font encore dans Tours-centre mais désormais $58 \%$, soit la majorité, se font dans les nouveaux quartiers de Tours-sud. Dans Tours-centre, les implantations se font presque toutes dans la rue Nationale et les rues adjacentes qui sont les principales voies commerçantes de Tours. Au sud, les créations se font sur, ou à proximité de, l’avenue de Grammont qui

\footnotetext{
6 À Toulouse, entre 1868 et 1940, 45 \% des sociétés meurent prématurément. J.-P. Alline « Firms demography in Toulouse. A case of delayed industrialization. 1868-1940 », in P. Jobert et M. Moss (dir.) Birth and death of company. An historical perspective, Carnforth (GB)-Park Ridge (USA), Parthenon publishing, 1990.
} 
prolonge cet hyper-centre. À l'échelle de la ville, l'axe rue Nationale - avenue de Grammont se détache clairement. Tous les cinémas notamment se concentrent dans cette poche ${ }^{7}$.

Mais d'autres quartiers apparaissent : les Halles, Febvotte ou Sanitas. Les entreprises de loisirs ne s'implantent donc pas uniquement dans le centre-ville, la partie la plus animée de la cité. Un facteur ressort pour expliquer cette localisation: celui des activités. Les commerces spécialisés peuvent se détacher de l'hyper-centre, leur clientèle saura les retrouver. C'est ce que fait ce commerce d'articles de pêche installé place Gaston Pailhou, près des Halles, c'est-à-dire dans une zone commerçante mais à l'écart de la rue Nationale. Dans le canton sud, beaucoup d'entreprises sont industrielles. Elles fabriquent des articles tels que des jouets, des voitures d'enfants... Elles ne s'adressent pas directement à la clientèle des particuliers. Elles n'ont donc pas spécialement besoin de s'implanter en centre-ville. Au contraire, la partie sud de la ville est celle des activités industrielles. Les industriels des loisirs s'implantent donc à proximité des autres industriels et probablement pour les mêmes raisons : réserves d'espace, proximité de la gare et des grands axes routiers... Toutefois, tous ne sont pas des fabricants. Il se trouve aussi parmi eux de petits cabaretiers par exemple. Le développement des nouveaux quartiers s'accompagne donc de la création de leurs propres services de loisirs.

\section{LES SECTEURS D’ACTIVITÉS}

Les activités peuvent être regroupées en quatre grandes catégories : les divertissements, les jouets, les sports ou assimilables, et les autres. Le secteur des divertissements domine nettement en rassemblant 37,5 \% des créations. Il regroupe trois activités : les cinémas, les théâtres et les cabarets. Le premier cinéma est fondé en 1901 mais c’est une société fragile. Ses actes sont incomplets et il n'est pas certain qu'elle ait eu une activité réelle. Il faut ensuite attendre 1928 pour voir apparaître de nouveaux cinémas. Deux sont créés simultanément cette année-là8. L'un est l'initiative d'un cafetier du centre-ville qui s'organise pour faire des projections dans son établissement. C'est pour lui une activité nouvelle complémentaire. L'autre est une affaire plus importante, implantée également en centre-ville, et dont la projection de films est l'unique objet. Un dernier est créé en 1932. Les théâtres sont beaucoup moins porteurs de créations d'entreprises. On n'en trouve que deux dans la période et encore s'agit-il en fait du même établissement. Une première société est créée pour construire le théâtre en 1883. Puis, celui-ci bâti, une nouvelle société est fondée pour l'exploiter. La principale source de créations dans cette catégorie des divertissements est le cabaret à spectacles. Six sociétés sont créées pour

\footnotetext{
7 Voir à ce sujet la contribution d’Éric Blin dans ce même ouvrage.

${ }^{8}$ Ces deux cinémas sont créés en octobre sur des emplacements proches. Il s'agit probablement de projets rivaux.
} 
exploiter un tel cabaret ou une salle de spectacle. C'est la moitié des entreprises de divertissement et la plus importante source de créations tous loisirs confondus.

La fabrication de jouets est une activité assez importante sur la place tourangelle avec 18,75 \% des créations. En outre, ce sont d’importantes sociétés. On trouve là les sociétés aux plus gros capitaux.

Les sports et assimilables représentent la même proportion de créations de sociétés. Les activités de cette catégorie concernent l'équitation ou le tir, à travers l'exploitation d'un stand de tir, d'un hippodrome ou d'une écurie et la commercialisation d'articles pour la chasse et la pêche. En revanche, certains sports qui deviennent populaires au début du XXe siècle, comme le football, voire le tennis, ne suscitent encore aucune création. Cette catégorie semble faire apparaître une certaine spécialisation régionale des loisirs des Français. Ainsi, par exemple, à Rouen, des sociétés colombophiles sont créées dont il n'existe aucun exemple à Tours et dans les villes voisines. À Tours en revanche sont créées des sociétés d'articles de pêche, que l'on trouvent aussi ailleurs dans le Val de Loire, à Amboise par exemple ${ }^{9}$, mais pas dans la capitale normande.

Enfin, un quart des créations se font autour d'autres activités. À Tours, il s'agit d'abord de la fabrication, de la vente ou de la location d'instruments de musique (principalement de pianos). Quatre sociétés sont fondées avec cet objet, soit $12,5 \%$ de toutes les créations. Deux sociétés concernent la photographie, et enfin deux autres sont des établissements de bains.

Certaines activités sont encore insuffisamment développées pour susciter l'apparition de sociétés. Dans le domaine des voyages, une société propose bien à la vente des articles de voyage mais seulement à côté des articles pour la chasse. Les articles de voyage ne représentent pas la seule, ni même la principale activité. Aucune agence de voyage n’est créée. Dans le secteur des sports, on ne voit pas non plus apparaître de fabricants ou commerçants spécialisés.

\section{LES ENTREPRISES}

FORME

La majorité de ces entreprises sont des sociétés de personnes. SARL et SNC cumulent 62,5 \% des créations. Les SNC représentent à elles seules près de la moitié des créations (43,7\%). Jusqu’à la guerre, elles sont même largement majoritaires (61,5 \%). Jusqu'à cette date, on ne trouve d'ailleurs que deux formes sociales. Les sociétés sont soit des SNC, soit des SA, à l'exception d'une SCA, la seule de toute la période, en 1879. Le décolage des

9 AD37 4U1/122. Dans cette période, deux sociétés sont fondées avec cet objet à Amboise : un commerce d'articles de pêche en 1895 et un fabricant de ces articles en 1924. 
créations dans les années vingt introduit une diversification des formes juridiques avec non seulement l'apparition des SARL mais aussi l'utilisation des SCS, négligées jusque-là et dont l'utilisation paraît donc assez tardive.

La domination des SNC correspond à la modestie des sociétés créées. En moyenne, sur l'ensemble de la période considérée, celles-ci n'ont que 3 créateurs. Pour ces petites associations, la SNC reste la forme juridique la mieux adaptée et la plus simple jusqu'à l'apparition des SARL. La SCS, où l'un ou plusieurs des associés ne sont là que pour financer l'entreprise sans prendre part à sa gestion, est un montage financier plus compliqué qui séduit peu les entrepreneurs tourangeaux des loisirs. L'apparition des SARL fait chuter de moitié la part des SNC dans l'entre-deux-guerres. Celles-ci ne représentent plus que $31,5 \%$ des créations, soient autant que les SARL. L'introduction des SARL par la loi en 1925 apparaît donc comme un élément important dans l'essor d'une économie des loisirs. C'est cette nouvelle forme de société qui absorbe l'essentiel de l'essor de créations. Les SA ne sont pas beaucoup plus nombreuses dans l'entre-deux-guerres qu'avant la guerre ; cinq créations prennent alors cette forme contre trois avant. Elles représentent $23 \%$ des créations avant la guerre et 26,3\% dans l'entre-deux-guerres. Les SARL se substituent avantageusement aux SNC. La substitution est même nette et brutale puisque la totalité des SNC créées dans l'entre-deux-guerres le sont entre 1920 et 1925. Dès que les entrepreneurs peuvent former des SARL, il n'y a plus de SNC. La SARL a l'avantage, comme son nom l'indique, de limiter la responsabilité financière des entrepreneurs à leurs seuls apports dans l'entreprise et non plus à la totalité de leurs biens. Cette innovation était attendue par les entrepreneurs des loisirs. Un autre indice le montre: l'utilisation tardive des SCS semble également indiquer que dans les années vingt les créateurs d'entreprises sont à la recherche d'alternative à la traditionnelle SNC. L'apparition des SARL répond alors à cette attente.

À partir de 1926, les SARL représentent $60 \%$ des créations. Ce lien entre le décollage des créations et les SARL n'est pas spécifique aux loisirs. Les SARL ont dynamisé l'ensemble des créations. Mais, elles le font aussi en apportant des nouveautés. Les loisirs font partie de ces nouveautés. Ils font partie des secteurs que favorisent plus particulièrement l'introduction de la SARL.

\section{LA SURFACE FINANCIÈRE}

Les SARL et les SCS, en limitant la responsabilité aux seuls apports permettent d'attirer des investisseurs et des capitaux dans l'entreprise. Le développement des entreprises de loisirs serait-il alors une question de capitaux ?

Sur toute la période, le capital moyen en francs constants est de 120096 francs $^{10}$. Il semble que cette moyenne a beaucoup varié mais la

10 Calculé en francs de 1918. 
modestie des créations par période impose de la prudence. Le capital moyen a diminué, semble-t-il, à la fin du XIXe siècle avant de se redresser dans les premières années du XXe siècle. La différence est surtout nette entre l'avant et l'après-guerre. La multiplication des entreprises de loisirs dans les années 1920 entraîne une hausse du capital moyen. En somme, plus il y a de créations dans ce secteur, plus les capitaux investis y sont importants et plus il se trouve de grosses sociétés. La crise des années 1930 fait retomber la moyenne du capital, en même temps que le nombre de créations.

Ces capitaux sont-ils importants ? Les sociétés créées dans les loisirs sontelles de grosses créations ? Pour les années 1920, la comparaison peut être faite avec l'ensemble des sociétés créées à Tours ${ }^{11}$. Dans cette décennie, la moyenne annuelle varie entre 53475 francs et 187165 francs. Avec une moyenne de 168789 francs, les sociétés de loisirs se situent donc plutôt parmi les grosses créations. Dans les loisirs, la médiane des capitaux n’est que de 66814 francs. L'écart est important avec la moyenne ce qui s’explique par l'existence d'un groupe de grosses créations qui tire la moyenne vers le haut. D’autres indicateurs abondent dans ce sens. Le capital moyen des loisirs est de 38499 francs dans les années 1890 alors que dans la même période il est de 16340 francs pour l'ensemble des créations à Toulouse (Ill. 2)12.

\section{Illustration 2 : Capital moyen des nouvelles sociétés dans le secteur des loisirs à Tours entre 1880 et 1936}

\begin{tabular}{|c|c|}
\hline Années & Capital moyen (en francs) \\
\hline $1880-89$ & 114880 \\
\hline $1890-99$ & 38499 \\
\hline $1900-09$ & 71600 \\
\hline $1920-29$ & 168789 \\
\hline $1930-36$ & 86396 \\
\hline
\end{tabular}

Même quand le capital n’est pas très important, comparé aux autres, il est divisé en actions dont le montant nominal porte assez haut le niveau d'entrée dans le secteur. En 1879, la SA des Tirs d'Indre-et-Loire, par exemple, n’a qu'un capital de 8000 francs mais divisé en 80 actions de 100 francs, ce qui représente alors un peu plus d'un mois de salaire pour un ouvrier ${ }^{13}$.

L’importance relative des capitaux conduit à se demander qui peut réaliser ces investissements et pourquoi ?

\footnotetext{
11 Cédric Perrin, La démographie des entreprises à Tours dans les années 1920, mémoire de maîtrise, Université de Tours, 1995, p. 45.

12 D'après les données de J.-P. Alline, « Firms demography... », op. cit.

13 O. Marchand, C. Thélot, Le travail en France, Paris, Nathan, 1997, annexe 12.
} 


\section{LES CRÉATEURS ET LEURS MOTIVATIONS}

\section{ORIGINES GÉOGRAPHIQUES ET SOCIALES}

Géographiquement, 89 \% des associés viennent d'Indre-et-Loire et 79,5 \% habitent Tours même. Ils ne sont donc que 11 \% à ne pas être Tourangeaux. Ces derniers sont le plus souvent Parisiens ou d'un département proche comme le Cher ou la Sarthe. Quelques-uns viennent d'un peu plus loin (sans dépasser un rayon de 350 kilomètres), de Lorient, du Havre ou de ClermontFerrand. Le marché des loisirs dans une ville moyenne comme Tours n'est donc pas encore assez dynamique pour attirer des investisseurs étrangers à la région. Il reste essentiellement une affaire locale.

L’origine professionnelle est également assez marquée. Les ouvriers et les employés sont d'une grande rareté. De toute la période considérée, il ne s’en trouve que deux pour tenter l'aventure. Ils forment à peine $3 \%$ des créateurs. Quelle que soit leur activité et probablement parce qu'ils n'en ont pas les moyens, ces catégories sociales participent assez peu à la création de sociétés ${ }^{14}$. Néanmoins, ils sont, dans les loisirs, beaucoup moins nombreux qu'ailleurs puisqu’à Tours, dans les années 1920, ouvriers et employés constituent $6 \%$ des créateurs et leur part oscille entre $12 \%$ et $15 \%$ à Toulouse entre 1885 et 194015. La création d'une entreprise des loisirs apparaît donc comme l'affaire des classes moyennes et plus encore des classes aisées.

Les classes moyennes sont représentées essentiellement par les artisans et les commerçants. Leurs membres proviennent donc des classes moyennes indépendantes, celles des petits patrons, habituellement nombreux parmi les créateurs de sociétés. Toutefois, ils sont un peu moins nombreux dans les loisirs que dans les autres activités. Ensemble, artisans et commerçants représentent $47 \%$ des créateurs du secteur contre $51 \%$, tous secteurs confondus, à Tours (dans les seules années 1920). Les classes moyennes salariées, tout comme les classes populaires, sont peu présentes. Leur présence se résume à celle d'un technicien alors que les professions intermédiaires rassemblent $9 \%$ des créateurs tourangeaux des années 1920. Là aussi, la sous-représentation est nette.

Les salariés qui participent à la création d'une société proviennent donc principalement des classes aisées. Ils sont ingénieurs, directeurs d'établissement... Les ingénieurs se retrouvent plutôt dans des entreprises industrielles (ici, l'industrie du jouet) où leurs compétences techniques trouvent à s'employer. Ce sont des entreprises importantes : la société Nusbaumer et compagnie a un capital de 1,5 millions de francs (c’est d'ailleurs la plus grosse création de la période) et les voitures d'enfants Novelty un capital d'un million. Dans le cas de la firme Nusbaumer, l’ingénieur, Eugène Nusbaumer, est le principal fondateur ; ses 9 associés sont ses commanditaires. Alors que les ingénieurs sont fréquemment

14 Par contre, ils sont très présents dans la création d'entreprises individuelles, notamment artisanales.

15 J.-P. Alline, « Firms demography... », op. cit., C. Perrin, « La démographie... », op. cit., p. 152. 
associés à un entrepreneur (industriel ou commerçant), les cadres se passent plus facilement de cette expérience. Ils sont davantage présents dans le commerce ou les services. On voit ainsi deux cadres s’associer pour ouvrir un cinéma en 1901. Toutefois, leur association paraît aussi être la plus précaire ; leur société semblant n’avoir jamais dépassé le stade de l'enregistrement. Les autres cadres se trouvent dans des cinémas ou des cabarets, un seul dans une entreprise industrielle.

Les inactifs renforcent la prédominance des classes aisées. Ils sont souvent âgés. Ils sont industriels ou officiers à la retraite ou encore se déclarent propriétaires. L'un d'eux est au contraire encore jeune. C'est un élève-officier associé avec sa mère, industrielle selon sa déclaration, dans une entreprise d'articles de pêche. Cette association atypique, puisque l'un comme l'autre appartiennent à des catégories sociales peu présentes dans les créations d'entreprises, reprend l'activité d'une entreprise déjà existante. Vraisemblablement, le décès du père, dirigeant l'entreprise jusque-là, conduit ses héritiers à s’associer pour poursuivre l'activité familiale. Parmi les inactifs, se retrouvent d'autres femmes qui se déclarent, elles, sans profession.

Le secteur des loisirs apparaît comme un milieu extrêmement masculin, seulement $6 \%$ des entrepreneurs sont des femmes, ce qui est néanmoins un peu plus que dans les autres secteurs : 4,7 \% à Tours, 2,6 \% à Belleville ${ }^{16}$. Une seule société est fondée uniquement par des femmes : la SARL Le Cabaret créée en 1933 par deux sœurs, Julia et Maria Hérissé. L’une se déclare artiste, l'autre sans profession. Leur situation familiale est particulière puisque l'une est veuve et l'autre divorcée. Être libérées de toute tutelle masculine a certainement facilité le projet des deux sœurs. En effet, la loi oblige les femmes mariées à présenter le consentement de leur époux pour fonder une société, ainsi qu'on l'exigerait d'enfants mineurs. Le cas des autres femmes engagées dans la création d'une société confirme cette dépendance. Toutes ont des liens familiaux avec leur associé dont elles sont l'épouse, la mère ou la sœur. On devine la subordination de ces femmes dans ces entreprises. Il est même fortement vraisemblable qu'elles ne servent, à quelques entrepreneurs individuels, qu’à obtenir le statut de société et qu'elles n’ont aucun véritable pouvoir dans l'entreprise. Ainsi donc, pour être nouveau, le secteur des loisirs n'est pas particulièrement innovant dans ces pratiques sociales.

Certains notables jouent un rôle particulier sur ce marché. Par exemple, c’est à l’initiative du président de la chambre de commerce, Louis Mirault, qu'est créée la société hippique de Tours. Son siège social est domicilié dans les locaux de la chambre de commerce et, après la souscription, elle rassemble 65 actionnaires.

Professionnellement, les créateurs d'entreprises des loisirs sont majoritairement des entrepreneurs. Les trois catégories des artisans, des commerçants et des industriels rassemblent $60 \%$ de l'ensemble. Ce sont principalement de petits entrepreneurs. Les artisans et les commerçants

16 G. Jacquemet, «L'entreprise à Belleville dans l'entre-deux-guerres », Entreprises et entrepreneurs 19e-20e siècles, Paris, Presses de Paris-Sorbonne, 1980, p. 238. 
constituent presque la moitié (47\%) des créateurs. Les artisans à eux seuls en représentent un tiers. Assez souvent, ils travaillent déjà dans les loisirs. Ils sont facteurs de pianos, fabricants de jouets, photographes... La mise en société n'est qu'une étape dans la vie de leur entreprise. Entrepreneurs individuels, ils se trouvent un, voire plusieurs, associés pour poursuivre leur activité. D’ailleurs, la moitié des sociétés ont un antécédent, c'est-à-dire qu’ils poursuivent sous une nouvelle forme l'activité d'une entreprise déjà existante.

\section{RAISONS ET MOTIVATIONS DES CRÉATEURS}

Qu'est-ce qui motive ce changement de statut ? Pourquoi le créateur se cherche-t-il un associé ? L'une des raisons est la croissance de l'entreprise ou la recherche de capitaux frais. On voit alors l'entrepreneur apporter son fond de commerce à la société et son associé du numéraire. C'est la configuration la plus fréquente. Elle correspond à 68 \% des cas où l'entreprise a un antécédent. Plus rarement, l'associé n’apporte pas directement du numéraire mais une créance. Les actes ne le mentionnent pas mais peut-être s'agit-il d'une créance sur l'associé. Auquel cas, l'association est une façon d'effacer la dette de l'un envers l'autre en la faisant passer au capital de l'entreprise. Quoiqu'il en soit, les loisirs apparaissent comme un secteur neuf où des besoins de capitaux frais se font sentir.

Également dans une perspective de croissance, qui montre que le marché des loisirs est en développement, certaines sociétés sont fondées pour fusionner les entreprises individuelles des associés. Ainsi, en 1921, Bloch, Suberville et compagnie associe des patrons de PME du jouet pour créer une société importante au capital de 1,2 millions de francs.

Dans quelques cas, encore rares, la croissance est géographique. Alexandre Lecoz, par exemple, directeur de café-concert à Lorient, s’associe en 1902 à son frère Pierre, résidant au Mans, pour exploiter deux établissements du même type à Tours. Certains entrepreneurs commencent ainsi à avoir une surface nationale ou au moins régionale en possédant des établissements dans plusieurs villes.

Certains associés sont recherchés pour leur savoir. Le seul ouvrier engagé dans la création d'une société dans cette période l’est pour ses compétences. Avec un industriel, il monte une fabrique de jouets sur la base d'un brevet qu'ils détiennent en commun. De même, en 1897, un artisan photographe de Tours s'associe avec un technicien en photographie de Clermont-Ferrand qui lui apporte ses connaissances particulières. Autre exemple significatif, dans l'une des sociétés liant trois personnes, la société en commandite Trimpont et compagnie, l'un apporte le fond de commerce, l'autre ses compétences et le commanditaire du numéraire. Ainsi, dans ce secteur neuf, posséder des compétences particulières est un atout convoité. Pour mieux retenir ceux qui les détiennent, certains entrepreneurs sont prêts à associer ceux-ci à leur affaire personnelle plutôt que simplement les embaucher. L'apport de connaissances est mentionné dans un quart des actes des sociétés ayant un antécédent. 
On trouve des associations plus originales comme celle de ce patron de cabaret à spectacles qui s’associe à l'artisan à qui il a commandé des travaux. Ce dernier fait l'apport de ses travaux et de leur montant à la société. On peut supposer que ce cabaretier voulait rénover son établissement mais sans en avoir les moyens financiers et qu'il a proposé à l'artisan de l'intéresser à son affaire en guise de rémunération. En tant qu'associé, celui-ci a droit à une part des bénéfices proportionnelles à ses apports au capital de la société.

Avec cet exemple, apparaît une autre raison à la présence d’artisans dans le domaine des loisirs. Tous ces petits entrepreneurs ne fondent pas une société pour poursuivre leur activité. Leur métier d’origine peut n’avoir aucun rapport avec les loisirs. L’exemple précédent se retrouve dans le cas de ce groupe d'artisans du bâtiment qui s'associent à un architecte de la ville pour construire puis exploiter un théâtre. Eux aussi font l'apport de leur travaux à la nouvelle société. Dans toutes ces situations, les loisirs sont un marché nouveau pour ces artisans. C'est une opportunité qui les y fait entrer (dans ces deux exemples : une commande de travaux). Dans un cas comme dans l'autre, ce qui est intéressant, c'est qu'ils acceptent l'association qu'on leur propose. Ils acceptent l'opportunité qui se présente à eux. Autrement dit, ils croient suffisamment dans l'avenir du marché des loisirs pour accepter d'y investir.

D’autres encore, participent à une société parce que celle-ci concerne leur propre loisir. En 1879, par exemple, six personnes s'associent pour former la société anonyme des Tirs d'Indre-et-Loire. Leur but est l'exploitation d'un terrain de tir. Mais, son originalité est de dépasser ce seul objectif marchand. Cette société a aussi pour objet de répandre le goût et la pratique du tir notamment par l'organisation de concours. Ses membres s'interdisent toute discussion politique ou religieuse. De surcroît, la société se donne une devise : "fraternité-patrie ». Cette création cadre tout à fait avec le contexte patriotique, voire revanchard des années 1870. Ce qui surprend davantage, c’est le choix de former une société commerciale. Pourtant, l'exemple n'est pas isolé, ni propre à la Touraine. En Normandie, plusieurs sociétés sont fondées par des colombophiles. Par exemple, la SA Le progrès du sport colombophile est fondée par six Rouennais en 1906 pour fournir aux colombophiles des constatateurs automatiques en vente avec facilité de paiement ou en location. Le capital est très petit (2 000 francs) et il est divisé en actions d'un montant moderé (25 francs). On est ici plus proche de la coopérative que de la société commerciale. Le but n’est pas réellement de faire des bénéfices mais d’offrir un service particulier aux pratiquants d'un loisir. Probablement n'ont-ils pas trouvé d'entreprises capables de les satisfaire, aussi décident-ils de la fonder eux-même. Cela en dit long sur l'état du marché des loisirs à la fin du XIXe siècle et au début du XXe siècle. Dans ces exemples, ce sont des consommateurs qui fondent eux-même la société qui leur vend les produits ou les services dont ils ont besoin. Ils démontrent une certaine atonie du marché, incapable de satisfaire spontanément cette demande. 
Il est probablement encore trop tôt pour parler d'une économie des loisirs au début du XXe siècle. Les créations de sociétés restent limitées. Des consommateurs doivent fonder eux-mêmes les entreprises dont ils attendent les services. L'assise sociale paraît encore trop limitée aussi. Ces entreprises s'adressent à une clientèle bourgeoise et sont créées par des bourgeois. Les classes aisées sont clairement surreprésentées dans la population des créateurs de sociétés.

Mais, en même temps, les loisirs présentent des caractères d'une activité en gestation et en développement. Les sociétés se font plus nombreuses dans les années 1920. Des fusions font apparaître quelques grandes entreprises, ou du moins de grosses PME. Quelques patrons du secteur commencent à élargir leur implantation géographique. C'est aussi un secteur où les compétences sont encore assez rares pour être recherchées et justifier la création d'une société. Les loisirs constituent donc encore une activité économique modeste mais qui commence à se développer. 


\title{
JOUR DE FÊTE AUX MAGASINS DECRÉ1. UNIVERS LUDIQUES ET LOGIQUES COMMERCIALES DANS UN GRAND MAGASIN NANTAIS (1950-1970)
}

\author{
Éric MONIN \\ École d'architecture de Nantes, CERMA
}

Le 23 septembre 1943, un bombardement allié toucha une grande partie du centre ville de Nantes. Parmi les nombreux immeubles détruits figurait un des fleurons de l'architecture moderne française. Construits en 1931 par l'architecte Henri Sauvage, l'immeuble des Grands Magasins Decré célébrait l'avènement des palais de la consommation de la fin du XIXe siècle. Ce bâtiment remplaçait un groupe d'immeubles progressivement rachetés par Jules Decré pour agrandir sa boutique initiale fondée en 1867. Le développement des magasins Decré respectait en cela l'histoire des grands magasins parisiens. Certainement inspirés par ces modèles, les Decré s'étaient vite rendu compte de la nécessité d’intégrer dans leur magasin des espaces récréatifs capables d'attirer de nouveaux clients en offrant au public une série de divertissements exceptionnels. Ainsi, bien avant le projet de Sauvage, les magasins Decré avaient leur salle de cinéma qui proposait aux enfants, le jeudi, des films comiques tandis qu'on projetait les autres jours de la semaine

\footnotetext{
1 Je tiens à remercier chaleureusement MM. Claude et Jean-Philippe Decré qui ont mis à ma disposition leurs archives personnelles pour la réalisation de cette étude. J'adresse également toute ma reconnaissance à M. Éric Decré sans qui cette recherche n’aurait pu se faire.
} 
des comédies et comédies dramatiques². En 1931, le dernier étage du bâtiment d'Henri Sauvage était entièrement dédié aux loisirs. En plus de la nouvelle salle de cinéma, le magasin accueillait un restaurant-salon de thé, un salon de coiffure, un théâtre de guignol et une kermesse enfantine où des stands de jeu et un manège donnaient au magasin des airs de fêtes foraines.

\section{Illustration 1 : Carte postale représentant la terrasse et le restaurant des magasins Decré. À droite de la piste d'atterrissage pour hélicoptère, on peut voir le planeur qui avait été hissé sur la terrasse}

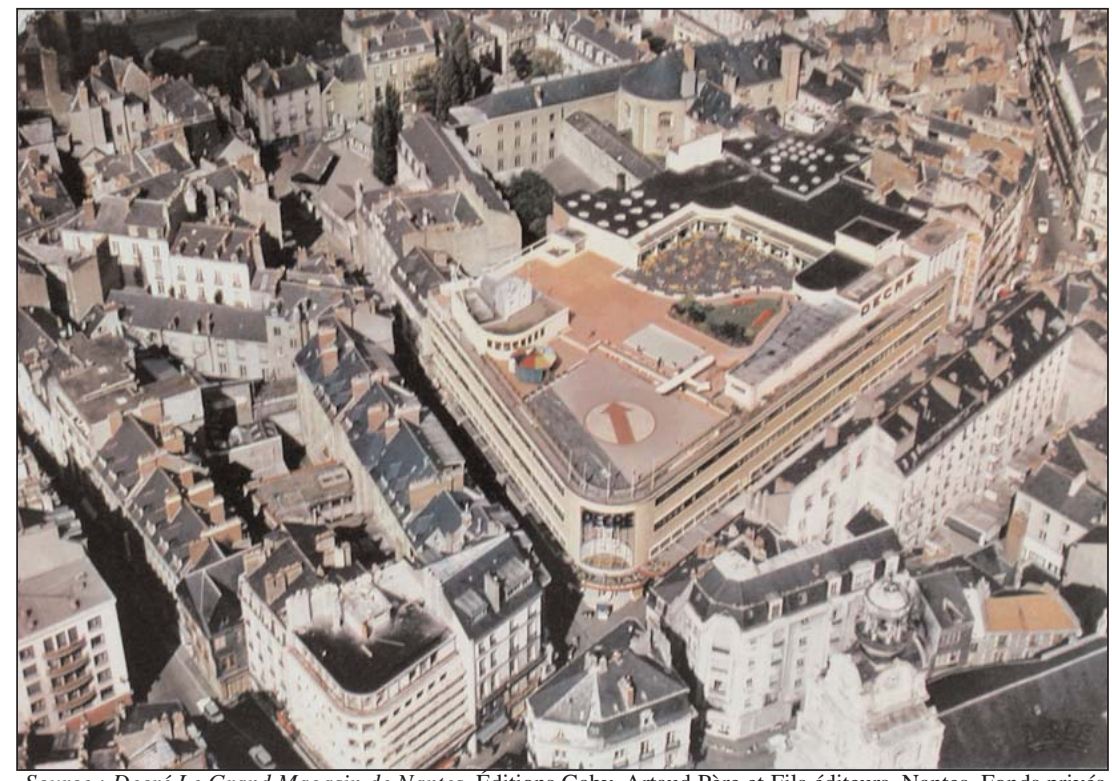

Source : Decré Le Grand Magasin de Nantes, Éditions Gaby, Artaud Père et Fils éditeurs, Nantes, Fonds privés

Des recherches consacrées au bâtiment de Sauvage ${ }^{3}$ ont déjà largement décrit l'originalité de tous ces aménagements disparus lors de l'incendie provoqué par le bombardement de 1943. Mais l'histoire ne s'arrête pas avec ce terrible événement. Les magasins Decré furent reconstruits après-guerre à partir de nouvelles idées importées de l'étranger. Charles Friésé, ancien

\footnotetext{
2 Les programmes du cinéma étaient diffusés chaque mercredi dans les publicités qui paraissaient dans la presse locale. Le programme paru le 8 janvier 1930 dans L'Ouest Éclair annonçait deux films comiques pour les enfants : La farce de Maître Patelin et Fais le beau. Ce dernier film partageait l'affiche les autres jours de la semaine avec une comédie dramatique Le voilier triomphant.

3 On peut citer le mémoire de maîtrise réalisé par Emérance Dubas en 1992 sous la direction de Gérard Monnier consacré à l'histoire et aux principes constructifs du projet d'Henri Sauvage, la publication de Jean-Philippe Decré, Nantes, Decré, Montreuil-Bellay, Editions CMD, Collection Mémoire d'une ville, 1998, l'ouvrage de Bernard Marrey, Les Grands magasins des origines à 1939, Paris, Librairie Picard, 1979, et la récente monographie de Jean-Baptiste Minnaert, Henri Sauvage ou l'exercice du renouvellement, Paris, Norma éd., 2002.
} 
disciple de Sauvage, L.-M. Charpentier et Victoire Durand-Gasselin furent chargés de mener à bien un projet qui devait concilier de nouvelles exigences programmatiques sans totalement contredire l'esprit qui avait assuré le succès de l'édifice de Sauvage. Il s’agissait de saisir les principes d'une modernité en perpétuel mouvement afin de donner à ce projet toute sa légitimité architecturale et son efficacité commerciale. Conscient de la nécessité de maintenir dans le magasin des espaces récréatifs, Friésé donnera à ces lieux une fonction centrale tout à fait comparable aux aménagements réalisés par Sauvage en 1931. Cet article propose de raconter l'histoire apparemment banale de ces espaces qui ont pourtant profondément marqué l'esprit des Nantais d'après-guerre.

\section{MODERNITÉ US. ÉVOLUTION D’UN TYPE}

Transparence, fluidité, légèreté et lumière caractérisaient le magasin édifié par Henri Sauvage. Pourtant, au sortir de la guerre, les choses avaient bien changé. La maîtrise d'ouvrage semblait vouloir reléguer ces principes derrière de nouvelles exigences moins esthétiques et architecturales, davantage commerciales et fonctionnelles. Le jour de l'inauguration de son magasin, lorsque Henri Sauvage qualifiait son projet de «machine à vendre », il ne pouvait évaluer la portée prémonitoire de ses propos. En effet, le programme établi en 1947 pour la reconstruction des magasins Decré rassemblait une série d’idées fraîchement rapportées d'un voyage d’études qu’Émile Decré avait réalisé aux États-Unis. La modernité et l'innovation venaient cette fois-ci d'Outre-Atlantique où de nouveaux prototypes commerciaux commençaient à bouleverser le monde de la vente et de la distribution. Le projet de Friésé allait répondre à la rigueur des choix de Sauvage par un rationalisme poussé à l'extrême.

Le rationalisme fonctionnel et esthétique de Sauvage devenait un rationalisme commercial commandé par des principes qui ne laissaient plus aucune place à l'imagination et à la fantaisie de l'architecte. Comme un problème mathématique, le nouveau projet n'appelait que des solutions infaillibles, les règlements de sécurité, d'hygiène et d'urbanisme faisant le reste. Tandis que des escaliers cloisonnés marquaient la périphérie, des escaliers intérieurs ouverts, «d'un meilleur rendement commercial » et en surnombre occupaient le centre du magasin. Chacun des services se trouvait cloisonné par des murs coupe-feu et des planchers résistant à l'assaut des flammes en cas d'incendie. Toutes ces précautions résultaient en grande partie des leçons tirées de l'effondrement rapide de la structure métallique de l'ancien magasin sous l'effet des bombes incendiaires. Contrairement aux plans de Sauvage qui respectaient l'organisation centrée des grands magasins de la fin du XIXe siècle, les esquisses de Friésé remettaient en cause l'espace habituellement occupé par l'escalier d’apparat. La grande verrière circulaire qui allait encore chercher la lumière naturelle à l'extérieur du magasin dans le premier projet de 1947 disparaissait définitivement dans le projet final, 
libérant ainsi la totalité de la toiture terrasse de l'édifice. Largement ouverts sur l'extérieur et sur l'atrium central dans le magasin de Sauvage, les plateaux des étages devenaient de grandes plates-formes introverties, soumises à la règle de l'éclairage artificiel, de l'air conditionné et des escaliers mécaniques qui seront introduits pour la première fois à Nantes à cette occasion.

\section{CONSTRUIRE DES AMBIANCES COMMERCIALES}

Le temps de "la cathédrale du commerce moderne, solide et légère », pour reprendre les termes de Zola est définitivement révolu. L’esprit novateur d’Émile Decré s’était rallié aux nouvelles idées appliquées aux États-Unis. Le magasin devenait un blockhaus aux ambiances artificielles chargées de mettre en valeur les produits et de conditionner le comportement des clients. En octobre 1953, l'article que la revue Bâtir consacrait à « La reconstruction des grands magasins Decré à Nantes » soulignait l'originalité du projet considéré comme «le plus moderne de ce genre en France » :

"Ici, en effet, il n'est plus nécessaire d'établir une communication avec l'extérieur. Les surfaces de vente seront donc rassemblées au centre, dans une atmosphère climatisée et une grande profusion de lumière artificielle, et les nombreux services annexes (petites réserves immédiates, salons d'essayage, bureaux, laboratoires divers pour l'alimentation) seront disposés sur toute la périphérie » ${ }^{4}$.

En affichant une maîtrise parfaite des dernières inventions réalisées dans le champ de l'éclairage artificiel, les architectes avaient réussi à concevoir des ambiances appropriées à chacun des espaces de vente. Tout n'était que bienêtre, douceur, harmonie quelle que soit la hauteur des plafonds, depuis le barrestaurant du sous-sol jusqu'au restaurant panoramique de la terrasse. La qualité des espaces dessinés par Sauvage laissait place à la qualité des ambiances nécessaires au succès de cette entreprise commerciale :

«Lorsque l'on entre dans les magasins Decré, on est, dès les premiers pas, sensible à une ambiance extrêmement agréable que l'on retrouve partout, du soussol à la terrasse. Si l'on analyse son impression, on discerne que ce sentiment de confort est dû à la température douce, à la décoration harmonieuse (qui ne fait appel qu'à des couleurs reposantes), à la musique qui ne joue qu'en sourdine, aux épais tapis qui recouvrent le sol.

Mais nous dirons que cette impression assez euphorique (et qui doit créer un climat très propice à la vente) est avant tout due à la qualité de l'installation d'éclairage. Celle-ci doit, en effet, être considérée comme un succès » ${ }^{5}$.

Dans ce projet nantais, conformément aux théories développées aux ÉtatsUnis par les promoteurs des nouveaux centres commerciaux, l'architecte

\footnotetext{
4 « La reconstruction des grands magasins Decré à Nantes », Bâtir, octobre 1953, p. 11-18, p.12.

5 Ibid, p.15.
} 
devenait un designer d'ambiances chargé d'agencer dans le magasin, un parcours sensible fait de lumière, de musique, de couleurs et de sensations tactiles. Cette atmosphère bienveillante n'avait aucun mal à flatter les sens d'une clientèle qui se laissait ainsi plus facilement séduire par des produits eux-mêmes exposés avec le plus grand soin. Le bien-être et la confiance inspirés par tous ces dispositifs artificiels constituaient l'essentiel de la stratégie mise en œuvre dans ce projet. Plutôt que l'extase et l'admiration provoqués par la finesse des structures inventées par Sauvage, le projet de Friésé n’appelait que douceur, plaisir et confort, y compris dans la mise en scène des déplacements verticaux.

\section{LES VERTUS DE L'ESCALATOR}

À la monumentalité grandiloquente des escaliers d'apparat qui bordaient habituellement l'atrium central des grands magasins6, la maîtrise d'ouvrage avait préféré faire installer un escalier mécanique, plus conforme aux aspirations modernistes de l'époque. Émile Decré faisait ce choix au moment où, à Paris, les Galeries Lafayette venaient de remplacer leur vieille batterie d'ascenseurs par un réseau d’escalators croisés depuis le sous-sol jusqu’au cinquième étage7. Certes, l'escalator permettait d'atteindre une efficacité sans égal au niveau de la gestion des flux de clients entre les différents étages du magasin. Il permettait également d'oublier les contraintes liées à l'utilisation de l'ascenseur. Le flux continu supprimait les temps d'attente et les limites de charges qui lassaient ou énervaient les clients pressés. Facile, immédiate, et sans effort, l'utilisation de l'escalator augmentait le confort du public tout en procurant un certain plaisir grâce à un mouvement continu et inhabituel. Ce dispositif permettait de redécouvrir le magasin en offrant aux clients des vues plongeantes inédites. Au moment de l'inauguration des escalators des Galeries Lafayette, et en marge des considérations techniques liées à ce dispositif, la revue Bâtir soulignait comment « le transport par cet escalator est une joie pour la clientèle car il permet de magnifiques échappées sur l'ensemble du magasin »8.

La liste des qualités de l'escalator serait incomplète si nous omettions de signaler le caractère ludique du dispositif. En devenant un des premiers escaliers mécaniques installé dans la région nantaise, il est facile d'imaginer comment l'escalator des magasins Decré s’illustra rapidement comme un formidable dispositif ludique capable d'attirer à lui seul les chalands de la ville et de la région. Plébiscité par les enfants, il faisait l'unanimité auprès de tous. Objet de modernité, l'escalator des magasins Decré devint rapidement un élément de référence, symbole d'un renouveau technique et esthétique. En 1952, la pureté de sa silhouette tendue servait de toile de fond aux modèles des collections de prêt-àporter qui illustraient la couverture du catalogue distribué par les magasins Decré.

\footnotetext{
6 Tout comme Henri Sauvage à Nantes, Benjamin Gomez avait lui aussi choisi cette solution pour la construction des Galeries Lafayette de Bayonne.

7 Jean Dauphin, «Le "nouvel escalator” des Galeries Lafayette », Bâtir, 1951, p. 15-18.

8 Ibid, p. 18.
} 
Dans un domaine plus restreint réservé à un public d'architectes et de techniciens, la société Otis se servait de cette réalisation pour valoriser localement son savoirfaire. Ainsi, l'escalator des magasins Decré était publié dans une publicité parue en 1953 dans le catalogue du 53e Congrès national de l'association provinciale des architectes français organisé cette année-là à Nantes 9 .

Participant très largement au développement de nouvelles stratégies commerciales ainsi qu'à la promotion des établissements Decré, l'installation d'un escalier mécanique au cœur de l'espace de vente signifiait également l'abandon du hall central traversant et de l'escalier d'honneur traditionnellement associés à l'espace des grands magasins. Ce choix eut une répercussion immédiate au niveau du traitement de la couverture du bâtiment. Débarrassée de la verrière initialement prévue en 1947, la toiture terrasse proposée en 1949 devenait un gigantesque espace libre prêt à accueillir l'ensemble des aménagements rejetés par les fonctions strictement commerciales du magasin. Bien avant cette version définitive, la terrasse avait déjà été désignée pour recevoir une série d'équipements ludiques et récréatifs, perpétuant ainsi d'une certaine façon la qualité de l'accueil et des services traditionnellement offerts par les magasins Decré.

\section{UNE TERRASSE SUR LA VILLE}

En 1947, lorsqu'il choisit de couvrir son grand magasin à l'aide d'une toiture terrasse, Émile Decré mesure parfaitement l'importance et la portée symbolique de cette décision. Fer de lance des théories architecturales d'avantguerre, la toiture terrasse représente encore à cette époque la solution radicale permettant de résoudre une partie des maux de la cité moderne. Bien avant la suppression du puits de lumière du projet de 1949, cette terrasse constituait manifestement l'aboutissement d’une démarche engagée par Émile Decré dès mars 1945 lorsqu'il rencontra Le Corbusier à Paris. Gabriel Chéreau, l'avocat nantais qui tenta d'imposer les principes de la Charte d'Athènes pour la reconstruction de la ville d'après-guerre, se fait le rapporteur d'une entrevue entre les deux hommes :

"Vu hier soir M. Émile Decré, retour de Paris. Enchanté de sa prise de contact avec vous. Et c'est un constructif, qui je l'espère vous aura plu. Je vous remercie de lui avoir réservé bon accueil. Il revient plein de vos idées (qu'il connaissait déjà mais il est encore affamé à ce sujet)... »10.

\footnotetext{
9 «Les ascenseurs Otis ont équipé les Grands Magasins Decré en escaliers mécaniques à grand rendement ainsi qu'en ascenseurs à contrôle automatique. La perfection mécanique et la rapidité de mise en œuvre font honneur à l'entreprise qui les a réalisés ainsi qu'au Client qui n'a pas reculé devant l'incorporation, dans son équipement, de dispositifs aussi heureusement révolutionnaires ", p. 109 du catalogue.

10 Courrier daté du 11 mars 1945 que Gabriel Chéreau adressa à Le Corbusier. Source citée par Gilles Bienvenu, Urbanisme et reconstruction : un projet d'application de la charte d'Athènes à Nantes, mémoire en vue de l'obtention du diplôme d'architecte DPLG, École d'architecture de Nantes, Nantes,1977.
} 
Bien sûr, Gabriel Chéreau cherchait en Émile Decré un allié capable de défendre à Nantes les thèses corbuséennes et de mobiliser un large public afin d'imposer un nouveau plan de ville. Cette mobilisation n'aboutira finalement qu’à la construction de l'unité d'habitation édifiée à Rezé quelques années plus tard. Ce bâtiment permettra d'ailleurs à Le Corbusier de mettre en pratique des dispositifs architecturaux largement déclinés dans ses productions théoriques antérieures. Ainsi, conformément aux textes publiés dès le début des années 1920, ce projet accordait à la toiture terrasse une fonction capitale. Aussi, la proximité contextuelle des deux projets nantais mais également les affinités théoriques et les contacts personnels entre Émile Decré et Le Corbusier laissent deviner l'influence des thèses corbuséennes sur la reconstruction des grands magasins Decré. L'étude de la toiture terrasse du projet de Friésé permet de souligner les heureux paradoxes d'un édifice qui trouva ainsi l'occasion d'entrer dans le patrimoine officieux de l'imaginaire collectif nantais.

Participant activement aux considérations hygiénistes de l’époque, les thématiques de l'ensoleillement, de la ventilation et des espaces verts ont joué un rôle essentiel dans le cadre des théories développées par Le Corbusier. Depuis le début des années 1920 jusqu’à la publication de la Charte d'Athènes, le soleil, l'air et les espaces verts se sont affirmés comme les seuls principes actifs capables d'éradiquer les derniers îlots insalubres et de pallier à une situation urbaine épouvantable. Déjà en 1923, dans Vers une architecture, Le Corbusier rendait hommage aux villes-tours imaginées par Auguste Perret, dont les toitures terrasses constituaient de véritables havres de paix libérés du brouhaha et du chaos de la ville basse: "Les cafés, les lieux de repos, etc., n'étaient plus cette moisissure qui ronge les trottoirs : ils étaient reportés sur les terrasses des toits ainsi que le commerce de luxe ». Dans Urbanisme en 1925, Le Corbusier était persuadé que « l'urbanisme pourrait étendre ses tracés au toit de la ville, en récupérant une part de cette surface accessible et y traçant un ordre nouveau de rues de repos, loin du bruit et au milieu des verdures ». Enfin, en 1935, dans La ville radieuse, il rappelle comment au Congrès de la Sarraz, les CIAM (Congrès International d'Architecture Moderne) avaient assigné un rôle essentiel au « toit-plat » ou « toit-jardin » en ces termes :

11. «...Le toit-plat, ou toit-jardin, fournit un élément nouveau, capital, de l'habitation (hygiène, soleil air pur, agrément). Étendu à la ville, le toit-jardin récupère la totalité de la surface bâtie de la ville.

12. Le toit-plat fournit de nouvelles surfaces circulables à l'urbaniste pour rues d'agrément (en l'air), cafés, magasins (hygiène et classement de la circulation) ».

Parallèlement à toutes ces qualités, la toiture terrasse était bizarrement sensée procurer un abri contre les bombardements en cas de guerre, agissant comme un bouclier capable de protéger les bâtiments de l'impact des bombes. Le Corbusier développera cet argument dès 1935 dans La Ville radieuse avant de l'exploiter avec plus d'insistance et d'opportunisme dans le Destin de Paris publié en 1941. Au lendemain de la guerre et dans le contexte d'une ville 
frappée de plein fouet par les bombardements alliés, il semble tout de même peu probable que la fantaisie de cet argument ait pu convaincre le pragmatisme raisonné d’Émile Decré. Seul le traitement constructif du dernier niveau du magasin pourrait laisser croire en cette hypothèse. Consacré aux réserves et aux ateliers de retouches et de réparations, cet étage technique était couvert d'une épaisse dalle permettant d'accueillir toute la diversité des activités programmées sur la toiture-terrasse. Il semble aujourd'hui bien difficile d'évaluer laquelle des deux fonctions, protectrice ou bien fonctionnelle, détermina le choix de cette structure. Plus sérieusement, on peut également penser que cet étage-poutre était inspiré par le prototype d'Antonin Raymond et Ladislav Rado publié en 194811 où la totalité d’un étage technique était réservée à l'infrastructure du magasin, aux stocks et aux services.

Circulation, travail, habitation et loisir, parmi les quatre points autour desquels s'organise la pensée corbuséenne, c'est bien entendu le dernier aspect consacré à la récréation que l'on retrouve dans le programme de l'avant-projet de 1947 rédigé par l'équipe d'architectes conduite sous la direction de Charles Friesé :

"Le plancher haut du second étage sera construit en terrasse: sur cette dernière se construira le Restaurant, plan libre, n'occupant qu'un tiers de la surface, enfermé dans les plans obliques du gabarit et ne dépassant pas la cote maximum admise pour la zone dense ».

«Devant la grande salle et au Sud, une première terrasse de $800 \mathrm{~m}^{2}$ pour repas et thés en plein air à la belle saison; et une seconde terrasse de $750 \mathrm{~m}^{2}$ à un niveau légèrement inférieur pouvant servir à l'atterrissage des hélicoptères ».

En intégrant à leur projet une piste d'atterrissage pour hélicoptère, les architectes donnaient à leur réalisation une dimension extraordinaire et inattendue. Grâce à cette idée géniale, les magasins Decré se trouvaient une nouvelle fois projetés au cœur d'une modernité où se mêlaient progrès et anticipation. Le temps des exploits de Jules Védrine à Paris sur le toit des Galeries Lafayette était révolu. Il s'agissait désormais de concrétiser les utopies modernistes en offrant aux citadins la possibilité de circuler dans les airs à l'écart de l'encombrement des fonds de rues. La préfecture s'opposa régulièrement à ce projet sans jamais délivrer aucune autorisation d'atterrissage. Cette issue semblait pourtant prévisible. À une époque profondément troublée par l'explosion des techniques, cette opération donna surtout aux Magasins Decré l'occasion de prouver la constance d'une entreprise d'élite capable de se maintenir à la pointe du progrès. Valorisant l'image du magasin, cette piste d'hélicoptère joua un rôle essentiel dans les stratégies de communication jusque dans les années 1970.

\footnotetext{
11 Le prototype proposé par Antonin Raymond et Ladislav Rado en 1948 efface la question des contraintes traversant l'espace du magasin grâce à l'introduction d'un étage technique chargé d'accueillir les infrastructures du magasin, les stocks et les services. Voir également le modèle de Louis Parnes proposé lui aussi en 1948 (in Morris Ketchum, Shops and stores, New-York, Reinhold, 1948.). Rem Koolhaas, Harvard design school guide to shopping, Cambridge, Taschen, 2001. p. 354-355.
} 
Derrière cet artifice, figure de proue de la terrasse des magasins Decré, on trouvait toute une série d’équipements destinés à ce lieu dédié au repos et à la détente des clients. Hygiène, soleil, air pur, agrément étaient largement dispensés grâce à un restaurant aux grandes baies vitrées exposé plein sud, un café, un jardin, un bassin où pouvaient jouer les enfants, une marchande de glaces, un carrousel et des attractions qui empiétaient épisodiquement sur la piste d'atterrissage devenue l'emblème de l'établissement. La présence de l'eau, de la végétation, les cris d'enfants qui courent, les couleurs vives des parasols, les odeurs de confiserie, la musique du manège, rien ne rappelle l'agitation du centre-ville une dizaine de mètres plus bas. Sur cette terrasse règne désormais une ambiance de « jour de fête » qui rappelle sensiblement les scènes du film que venait de réaliser Jacques Tati (Ill. 2).

Illustration 2 : Carte postale représentant le Grand Magasin Decré de Nantes. Vue générale de la terrasse, des attractions et du beffroi de l'Église Sainte-Croix

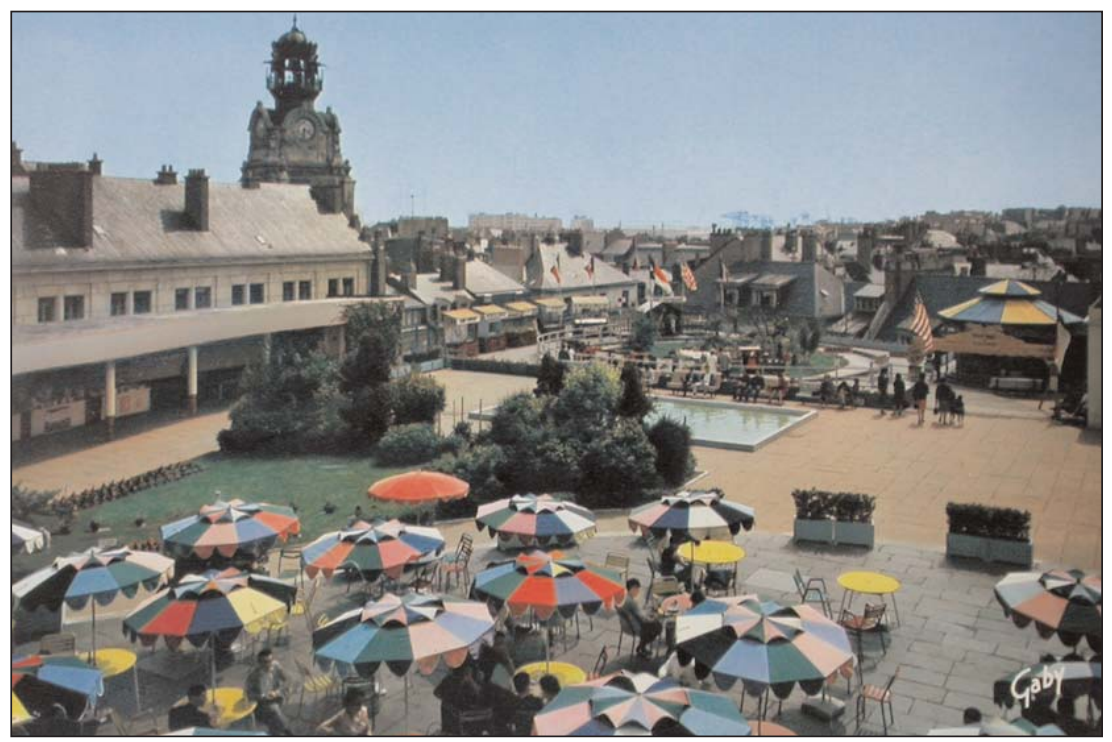

Éditions Gaby, Artaud Père et Fils éditeurs, Nantes. Fonds privés.

Entre l'intérieur du magasin et la terrasse, le contraste est saisissant. L'atmosphère introvertie et aseptisée des étages de vente laisse la place à une ambiance joyeuse, riante, largement ouverte sur le ciel et les toits de Nantes. Pourtant, c'est avec la même maîtrise que les architectes et leur client sauront contrôler les ambiances de ces espaces si différents. Il s’agit bien d’orchestrer le plaisir des visiteurs, de rassembler les artifices capables de susciter le bien-être des clients. Rien n'est laissé au hasard et le contraste qui saisit le public lorsqu'il atteint la terrasse participe pleinement à cette stratégie. Depuis longtemps déjà, les grands magasins savaient parfaitement comment leurs salons de thé devaient procurer à leur clientèle le calme et le repos nécessaires à une pause 
reconstituante lui permettant de poursuivre ensuite ses achats avec plaisirir ${ }^{12}$. Selon cette stratégie, les salons de thé étaient placés à l'écart de l’agitation des espaces de vente. En choisissant d'exploiter la toiture-terrasse de son magasin pour y loger toutes ces activités récréatives, Émile Decré accentuait la coupure entre les deux activités. Espace atypique et inattendu, source de dépaysement ${ }^{13}$, la terrasse permettait l'émergence d'une fiction dans un lieu apparemment déconnecté des logiques commerciales du grand magasin mais également des contraintes des espaces publics environnants. Voici comment Charles Friesé présentait le futur restaurant panoramique dans le programme de son avant-projet de 1947 :

"Le Restaurant du $3^{2}$ étage n'est en vue de nulle part, il a été conçu selon une Architecture plus libre, moins traditionnelle donnant un ensemble aéré et gai, face aux grands espaces des toits de la ville ».

À l'instar de Jacques Tati, les concepteurs de ce projet sauront reconstituer artificiellement une place de village idéale sur le toit du grand magasin, au cœur de la grande ville. Cette toiture-terrasse privée capable d'accueillir un large public devenait incidemment un espace public magnifié, entièrement consacré à l'agrément des visiteurs et enfin définitivement libéré des multiples contraintes qui s'appliquent ordinairement à l'espace urbain. Ainsi chaque jour de la semaine, la toiture-terrasse des magasins Decré semblait vivre en suspend, au rythme d'une fiction déconnectée des réalités de la rue ayant pour seul repère les horaires d'ouverture du magasin.

\section{LES ANIMATIONS}

La terrasse accueillait régulièrement quantité d’animations chargées d'entretenir et d'exploiter commercialement l'attractivité du lieu. Parfois, ces projets éphémères permettaient d'établir des liens étroits entre la rue et la terrasse, renforçant ainsi le caractère publique du lieu. Ainsi, on peut citer par exemple le cortège qui fut organisé à l'occasion de la fête de la Saint-Jean en 1954. Ce jourlà, les enfants étaient invités à suivre une fanfare dont le parcours avait été soigneusement planifié. Depuis l'espace très fréquenté de la place du Pilori, le cortège accédait aux magasins Decré par l'entrée principale avant de traverser les étages pour atteindre finalement la terrasse où était regroupé l'ensemble des participants. Ainsi, en prolongeant sans discontinuité le mouvement de la rue dans le magasin jusqu’à la toiture-terrasse, c'est toute l'activité du grand magasin qui se trouvait métamorphosée et valorisée par cette joyeuse animation.

\footnotetext{
12 Le n8 de la revue Parade (août 1927), consacre un article aux salons de thé dans les Grands magasins. L'auteur de l'article précise comment «Le salon de thé est fait pour retenir la cliente. Il se trouve généralement dans un coin tranquille du magasin, loin du bruit, loin de la foule ». Parade, n8, août 1927, p. 4-5.

13 «Quant à la terrasse, [...] elle est bordée par le bâtiment du restaurant, dont on a volontairement fait un ensemble architectural très différent du reste du magasin, afin de créer une agréable impression de dépaysement ", in "La reconstruction des grands magasins Decré à Nantes », op.cit., p. 13.
} 
Illustration 3 : Carte postale représentant la terrasse des Grands Magasins Decré (en arrière-plan la Cathédrale)

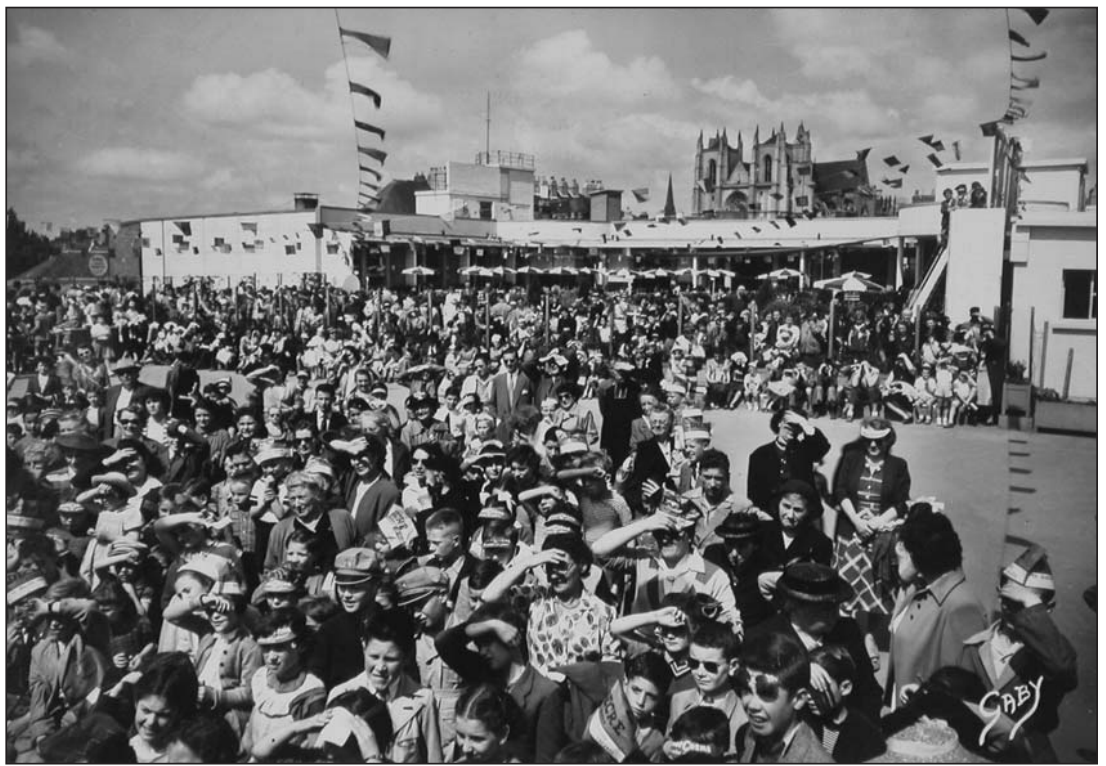

La terrasse des Grands Magasins Decré, Éditions Gaby, Artaud Père et Fils éditeurs, Nantes. Fonds privés.

Illustration 4 : Carte postale représentant la terrasse des Grands Magasins Decré

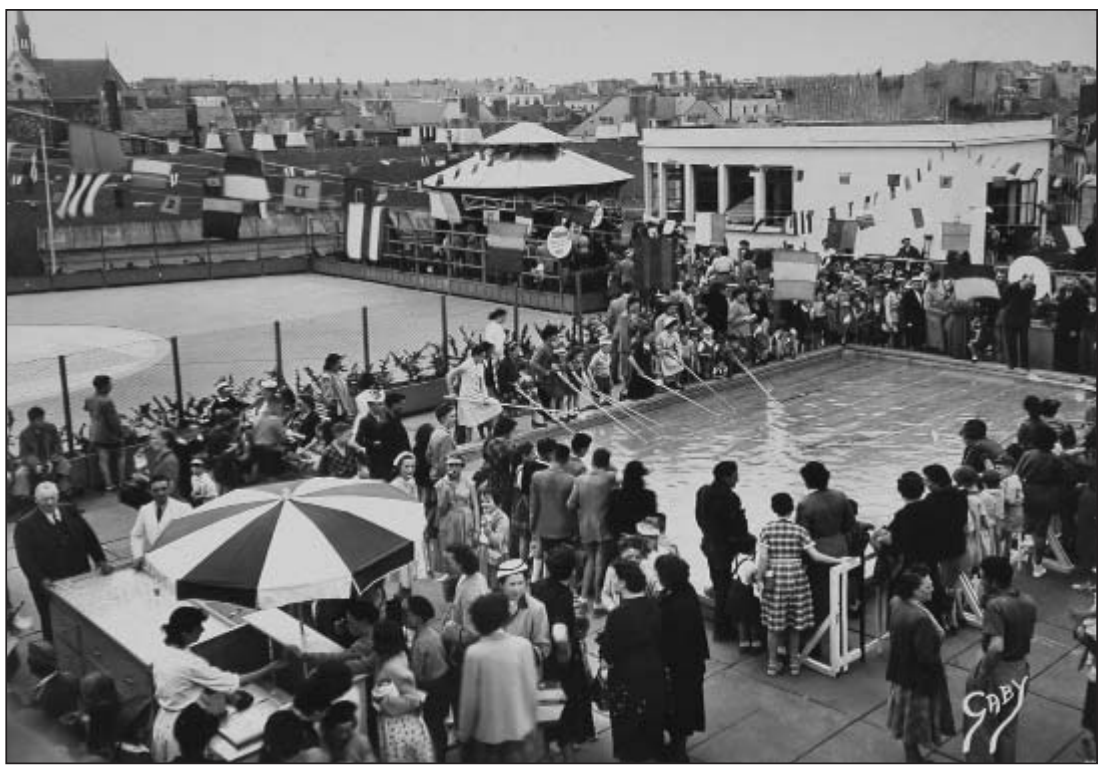

Les Attractions, Éditions Gaby, Artaud Père et Fils éditeurs, Nantes. Fonds privés. 
Calculée pour résister à l'atterrissage d'un hélicoptère, la terrasse recevait régulièrement des expositions et des manifestations originales et variées capables d'attirer des foules considérables. Tous ces projets participaient à la politique d'animation du magasin permettant d'attirer et de fidéliser un large public. La terrasse accueillait tour à tour des expositions pour lesquelles on n’hésitait pas à hisser un planeur en pièces détachées, des voitures à l'occasion du lancement de la nouvelle Simca 1300 ou bien des caravanes qui donnaient soudain à la terrasse des airs de camping improvisé (Ill. 5). Quant au restaurant panoramique, il devint rapidement un lieu à la mode, quasiment incontournable, comme en témoigne la liste des banquets de congrès qui y étaient organisés dès le début des années 1950. La terrasse était aussi l'espace des petits. Des courses de bateaux animaient fréquemment le bassin rectangulaire à proximité du café. Des exercices de prévention routière encadrés par les agents de la circulation, des courses de voitures à pédale organisées par l'Automobile Club de l'Ouest faisaient de cet espace le rendez-vous prisé des enfants de la région.

\section{Illustration 5 : Exposition de la SIMCA 1300 sur la toiture-terrasse des magasins Decré en avril-mai 1963}

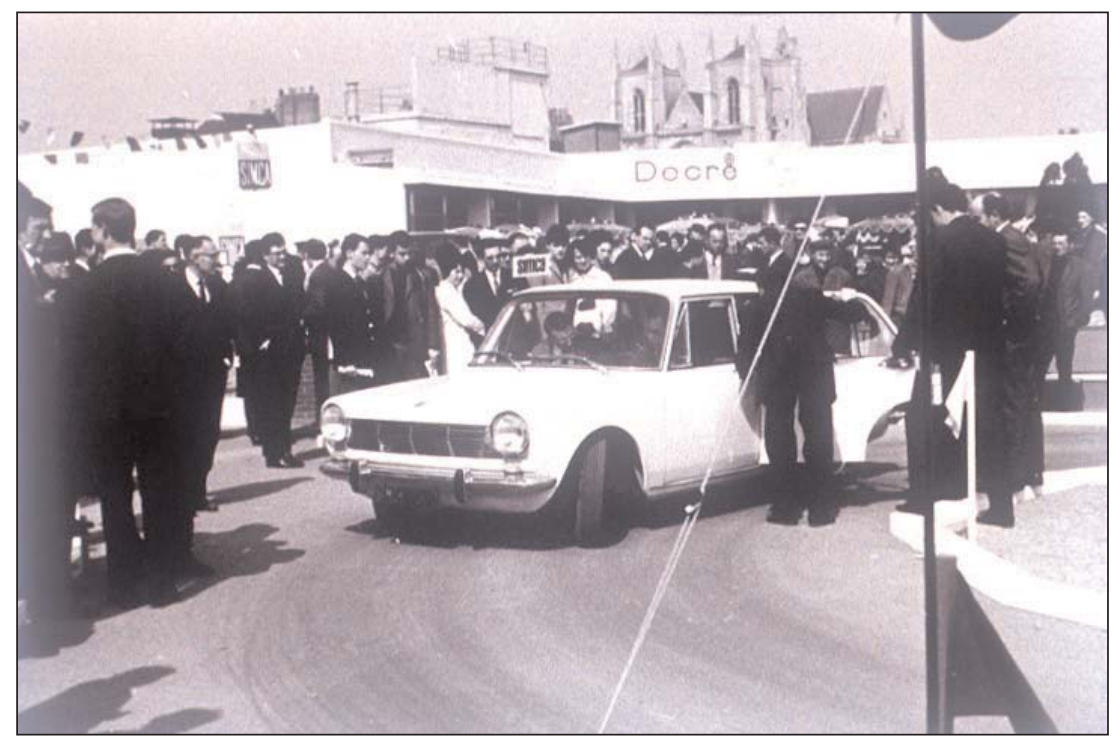

Fonds privés

Ces animations atteignaient leur apogée en période de fêtes de fin d’année. Tout le magasin était alors colonisé par les attractions imaginées pour l'occasion. Pour cela, les Decré ne lésinaient pas sur les moyens. Fidèles à leur image d'entrepreneurs férus de progrès, ils puisaient régulièrement le sujet de ces attractions dans une actualité encore marquée par le rythme soutenu des exploits techniques et des dernières grandes explorations scientifiques. En 
novembre 1960, tandis que la une des journaux était consacrée aux moyens considérables engagés par la France dans la conquête de l'espace, les Decré lançaient tous les quarts d'heure, depuis la terrasse de leur magasin leur première «fusée interplanétaire » (Ill. 6). Chaque jeudi, une foule d'enfants faisait alors la queue jusque dans la rue pour avoir le privilège d'essayer le cockpit spécialement conçu par les décorateurs du magasin. En 1962, après les records de profondeur établis par Jacques Piccard dans son bathyscaphe, le Trieste II, les Decré apprêtaient leur D62 pour conduire les enfants dans un environnement sous-marin reconstitué à l'aide d'aquariums peuplés d'espèces rares. Bien entendu, toute une logistique était mise en place pour agrémenter la visite d'une distribution de brevets et de passeports spécialement édités pour l'occasion (Ill. 7).

\section{Illustration 6 : Réclame pour l'animation organisée par les magasins Decré à l'occasion des fêtes de fin d'année 1960}

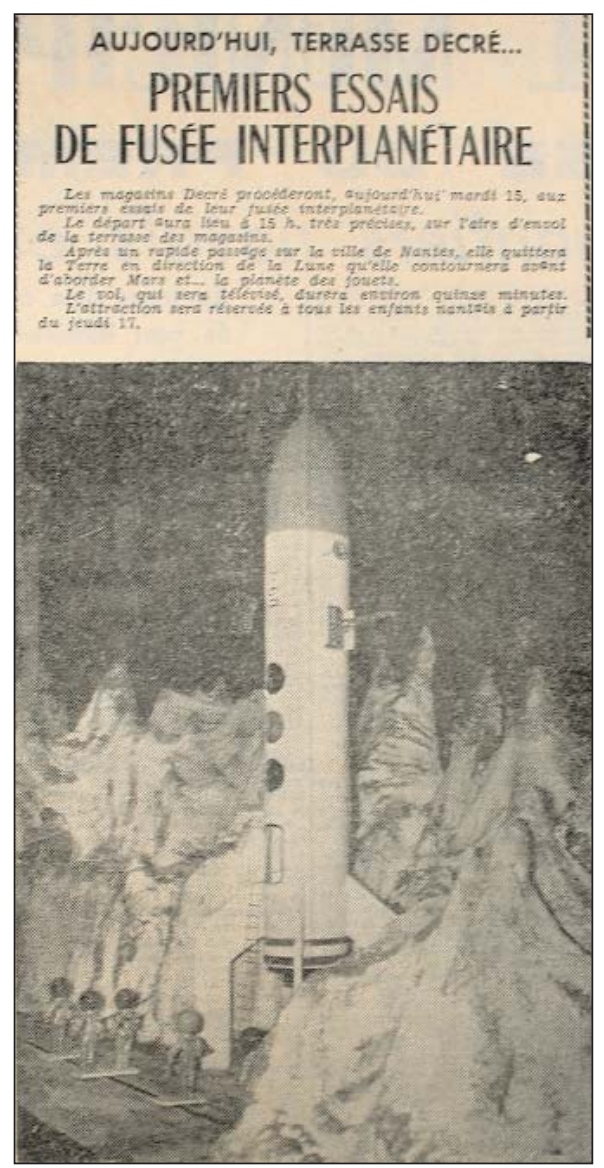

Ouest-France, mardi 15 novembre 1960 
Illustration 7 : Un extrait du passeport d'explorateur des grandes profondeurs sous-marines remis aux enfants lors de l'animation de Noël 1962

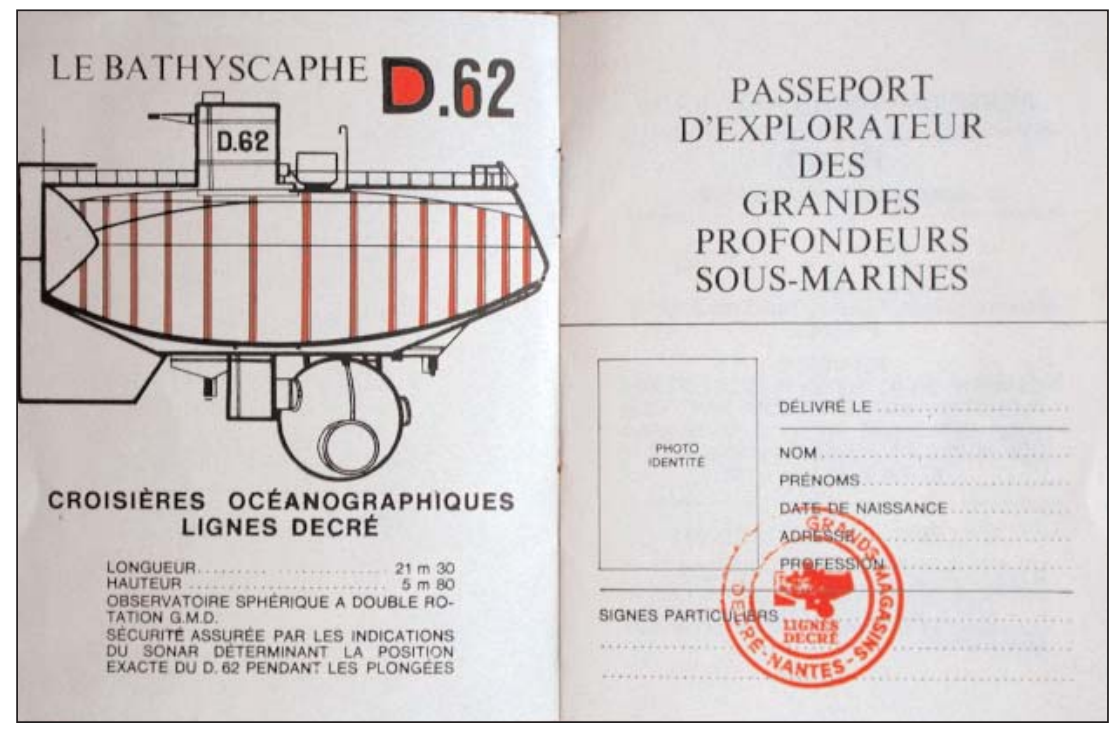

Fonds privés

\section{EXPLOITATION MÉDIATIQUE}

Ces succès à répétition témoignaient d'une grande maîtrise dans l'art de l'animation, perpétuant ainsi la tradition des grands magasins parisiens capables de transformer leur environnement en un clin d'œil pour captiver l'attention des citadins. Les Decré excellaient également dans la mise en scène de leur magasin dans les publicités qu'ils diffusaient dans toute la région. On ne sera pas surpris de retrouver des représentations de la toiture-terrasse qui devint rapidement le motif central permettant d'identifier le magasin. Au temps du magasin édifié par Henri Sauvage, les publicités reproduisaient des vues du plan coupé à l'angle des rues du Moulin et de la Marne accentuant ainsi une impressionnante monumentalité de fer et de verre. Après sa reconstruction, c’est une vue plongeante sur la terrasse qui traduisait l’homogénéité de ce grand vaisseau ${ }^{14}$ dont le pont supérieur laissait deviner un joyeux bien-être récréatif.

«Venez passer un moment agréable aux Grands magasins Decré » telle semblait être le message véhiculé par l’image. Les réclames publiées dans la presse, les catalogues du magasin, le règlement intérieur, sans oublier les cartes de visite, tous ces documents reproduisaient la même vue plongeante sur

\footnotetext{
${ }^{14}$ Charles Friésé utilisait la métaphore du navire pour mieux insister sur la taille du magasin : « $M$. Charles Friésé déclarait à l'issue des travaux que pour cet ensemble, l'ampleur des études et de la construction proprement dite fut la même que pour un cargo de 3000 tonnes", in «La reconstruction des grands magasins Decré à Nantes », op. cit., p.18.
} 
la terrasse. Déjà en 1947, les architectes du projet avaient privilégié cet angle de vue pour la perspective qui illustrait la couverture de leur avant projet. Sans nul doute, chacun était bien persuadé que cette terrasse constituait la principale qualité du nouveau magasin.

\section{Ambiances LUdiQUeS ET ARCHITECTURES COMMERCIALES}

L'étude de la reconstruction des grands magasins Decré après-guerre montre comment derrière la banalité d'un projet architectural apparemment sans grandes prétentions peut se cacher une réalisation pleine de qualités sensibles insoupçonnables. Loin de rivaliser avec la virtuosité affichée par Henri Sauvage, L.-M. Charpentier, Charles Friésé et Victoire Durand-Gasselin ont concentré leurs efforts sur la maîtrise des ambiances du nouveau magasin 15 . En concevant un lieu agréable, chaleureux, source de bien-être et de plaisir, les architectes ont parfaitement réussi à concrétiser le projet commercial du maîtred'ouvrage. À une époque où nous accordons une attention croissante au confort et à la qualité des lieux de vie, le caractère prémonitoire de cette démarche mérite d’être salué. Ce type de projet doit être réhabilité dans une histoire de l'architecture qui donnerait enfin sa place au public des usagers en relativisant les discours grandiloquents des experts et les sempiternelles commentaires des spécialistes d'une « architecture de photographie ».

\footnotetext{
15 L'auteur de l'article publié dans la revue Bâtir soulignait précisément cet aspect : « Les auteurs du projet s'astreignirent d'autre part à une discipline architecturale très méritoire qu'il est bon de souligner: fidèles une fois encore aux dispositifs de vente, ils posèrent en effet qu'un grand magasin tel que celui-ci doit pouvoir être éternellement changeant, au gré de ses décorateurs et de ses étalagistes. Il faut donc que son architecture soit discrète et qu'elle sache demeurer le simple support des fantaisies toujours nouvelles du décor " in "La reconstruction des grands magasins Decré à Nantes », op. cit., p. 13.
} 



\section{LES CINÉMAS DANS L’ESPACE URBAIN : UN SIÈCLE DE MUTATIONS}

Éric BLIN

Université François-Rabelais de Tours, CITERES-VST

S'il est un loisir étroitement associé à la ville, à l'animation de la cité, c'est bien le cinéma. Il est d'ailleurs souvent considéré comme un marqueur, un symbole du centre-ville. Et pourtant le cinéma est un loisir récent : il n’a que cent ans. Mais cent ans au cours desquels les salles de cinéma n’ont cessé d'évoluer, depuis les premières salles obscures jusqu'aux multiplexes. Aussi est-il intéressant de s'interroger, en tant que géographe, sur l'évolution des rapports entre l'équipement - la salle de cinéma - et l'espace urbain; d'apprécier les mutations, les recompositions de cet objet urbain. Comment les salles de cinéma se sont-elles adaptées à l'évolution de la ville et comment ontelles pu elles-mêmes marquer la ville ? Trois aspects seront abordés, de façon succincte: l'évolution spatiale des salles de cinéma, l'évolution de leur identité et enfin leur récente utilisation au travers des multiplexes comme instruments d'aménagement urbain.

\section{L'ÉVOLUTION SPATIALE : LE CINÉMA ENTRE CENTRE ET PÉRIPHÉRIE}

Au cours du siècle, trois périodes ont marqué l'évolution spatiale du cinéma dans la ville : une période d'expansion, une de rétraction et à nouveau une d'expansion. Cette évolution en trois temps est à replacer au cœur du débat centre-périphérie. 


\section{UNE PÉRIODE D’EXPANSION}

Le cinéma est né en centre-ville. Les premières projections eurent lieu sur les champs de foire ou dans des salles de spectacle situés dans les lieux centraux de la ville et les premières salles obscures, apparues dès 1907, s’installèrent au cœur de la ville. La diffusion vers la périphérie, d’abord timide, s’amplifia à partir des années 1930 gagnant les premières banlieues et s’accéléra après-guerre, si bien qu’à la fin des années 1950, malgré la densification des centres-villes, les périphéries comptaient plus de cinémas.

L'exemple de Tours permet d'apprécier ce mouvement de diffusion (Fig. 1, 2, 3, 4). Les premiers films sont projetés dans l'hypercentre : sur le champ de foire, au Cirque de Touraine, au Théâtre Français, dans des cafés-concerts ou d'autres salles. Les deux premières véritables salles obscures, l'American Cosmo Pathé et le Mondain Gaumont, sont créées en plein cœur de ville en 1911 et 1913. Mais déjà l'équipement des quartiers s’amorce puisque plus au sud le Ciné Grammont et le Casino ouvrent également avant la Première Guerre mondiale.

Le centre-ville s’étoffera surtout avant la Seconde Guerre mondiale. En 1939 on compte 6 salles de cinémas : l'American Cosmo Pathé, le Rex, le Caméo, le Studio, le Select et le Majestic. Quatre seront détruites pendant la guerre, mais 3 reconstruites. Les ouvertures reprendront après 1950 avec 3 nouvelles salles (l'ABC, le Rio, le Cyrano).

La diffusion des cinémas hors du centre-ville sera lente jusqu'au début de la Seconde Guerre mondiale puisque seuls ouvriront comme cinémas stricto sensu La Riche Cinéma quartier Lamartine, pour peu de temps l'Étoile boulevard Thiers, enfin l'Entracte à Saint-Pierre-des-Corps. La diffusion s’intensifiera pendant la guerre avec 3 salles supplémentaires (le Gallia quartier Giraudeau, le Vox à Saint-Symphorien et l'Éden à Joué-lès-Tours). Elle explosera après 1955 puisque 7 nouvelles salles verront le jour : à Tours, le Beaujardin, le Mexico, le Ciné-Lux et le Myriam Ciné ; à Sainte Radegonde, le Ciné-Pax; à Saint-Pierre-des-Corps, le Paris et le Rexy. Au début des années 1960, Tours compte 12 salles de quartier pour 8 salles de centre-ville.

Pendant cette première phase d'extension, les cinémas bien que répartis sur l'ensemble de la ville entretiennent la dichotomie centre-périphérie, opposant des équipements d'envergure à des équipements de proximité. Les salles du centre-ville attirent les spectateurs de la ville entière parce qu'elles sont souvent plus grandes et plus confortables, offrent plus de séances et présentent des films en exclusivité. À l'inverse, les salles de quartier, moins performantes, ne sont que des salles de faible attractivité.

\section{UNE PÉRIODE DE RÉTRACTION}

À partir des années 1960, l’essor des loisirs - de la télévision en particulier - entraîne une désaffection des salles qui se traduit par un 
Fig. 1 : Les premières projections à Tours 1896-1910

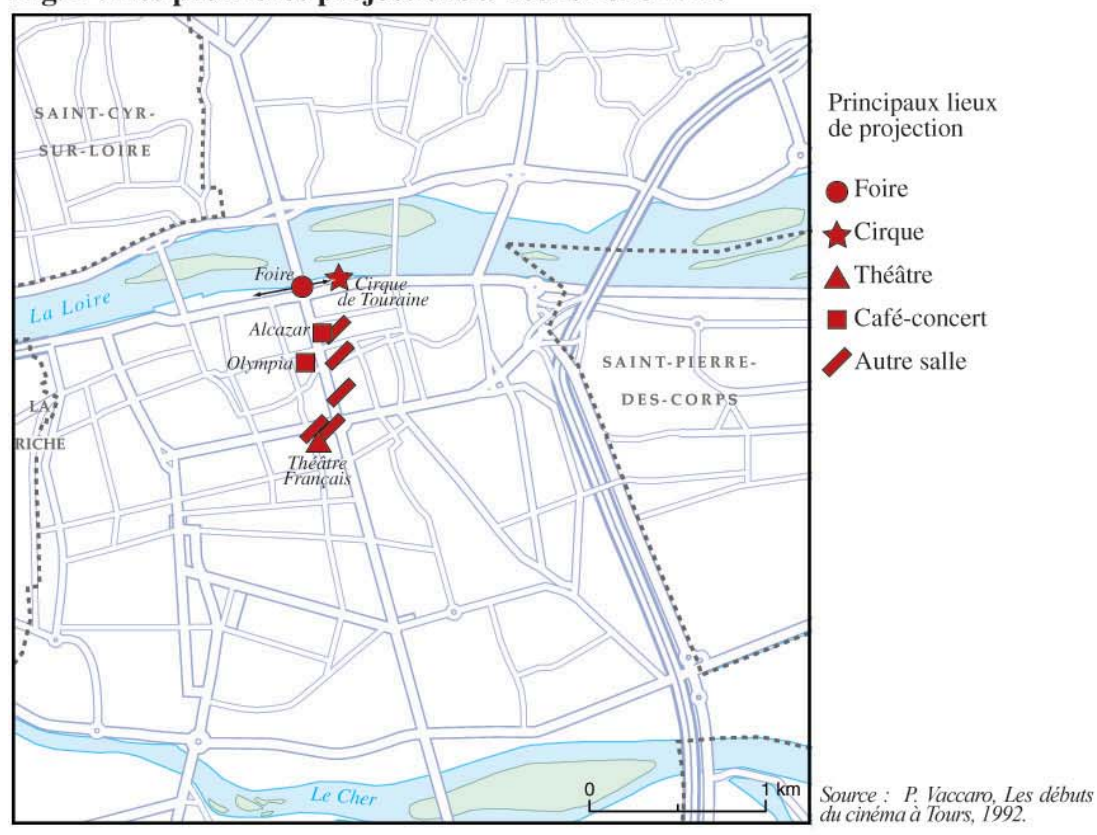

Fig. 2 : Les cinémas à Tours 1911-1914

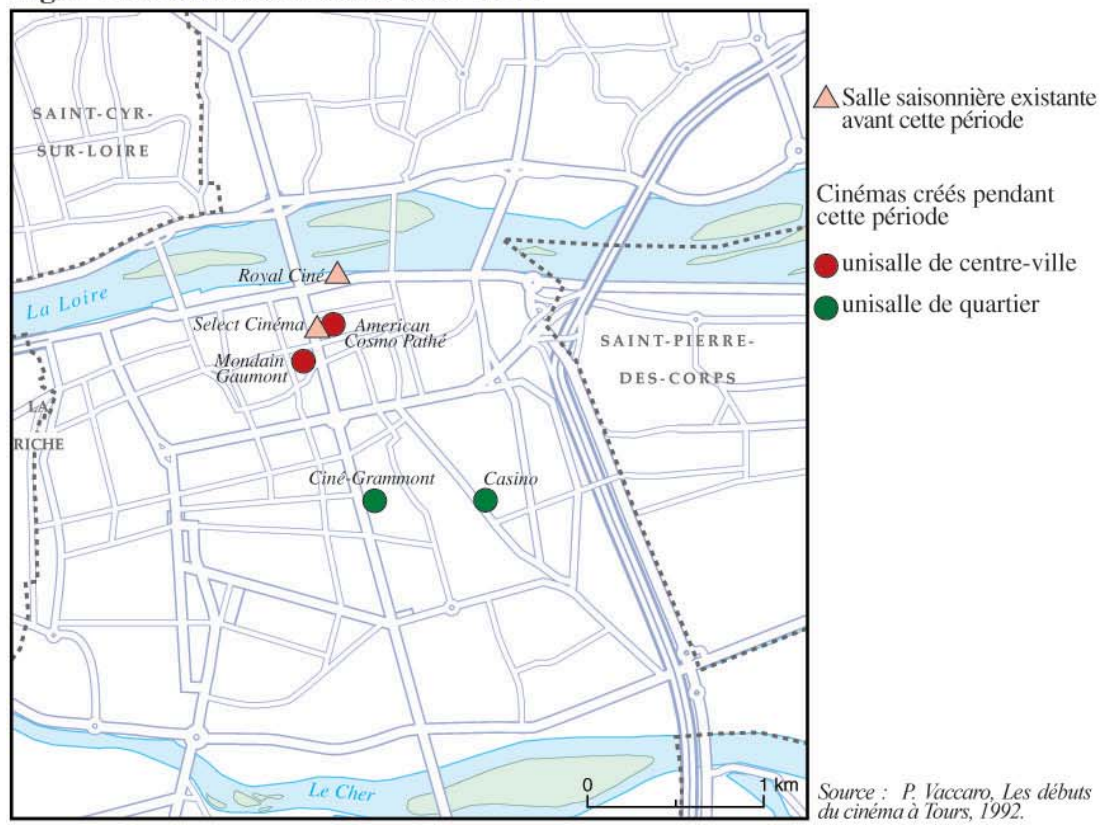


Fig. 3 : Les cinémas à Tours 1915-1939

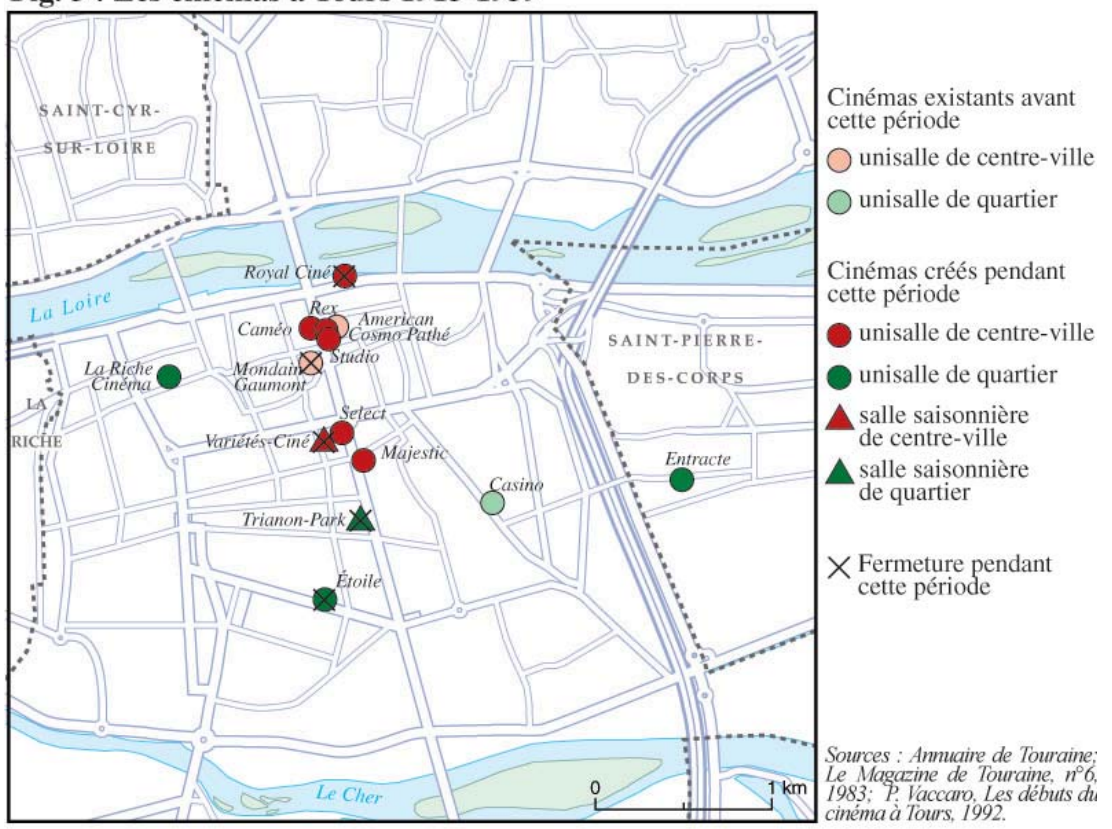

Fig. 4 : Les cinémas à Tours 1940-1962

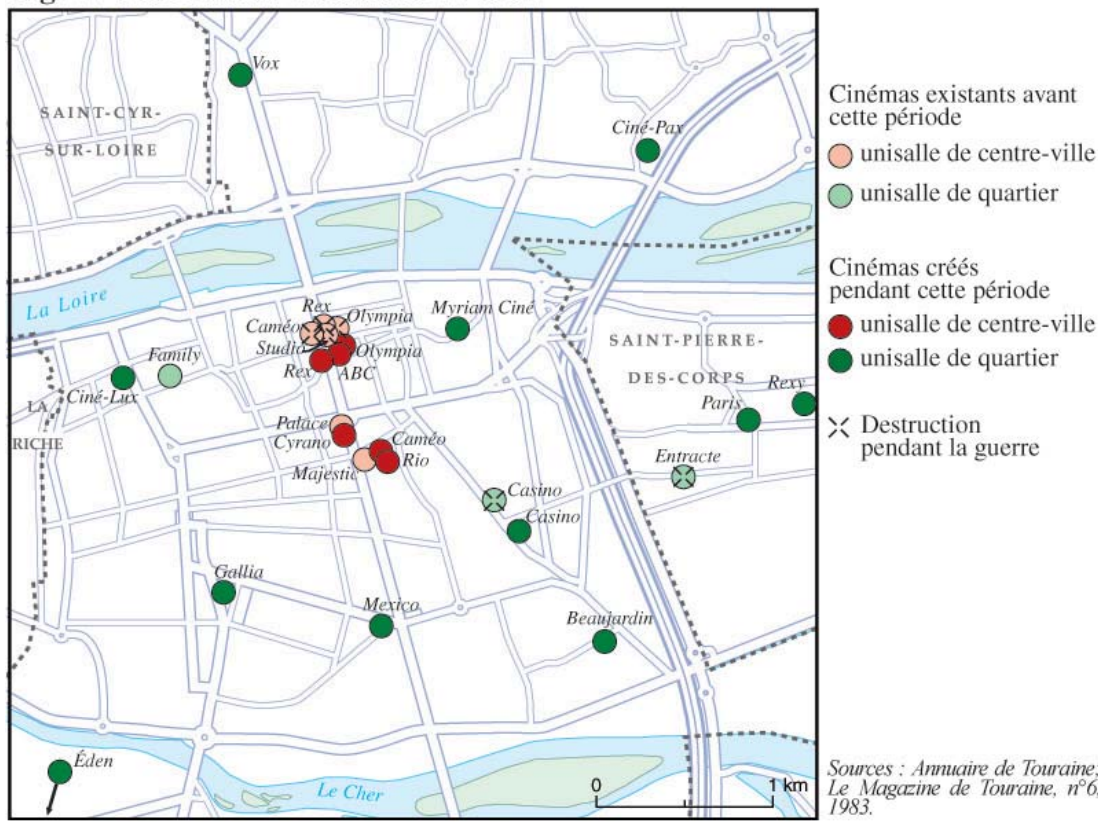


mouvement de centralisation. Les salles de quartier beaucoup moins attractives que celles du centre ferment les unes après les autres et peu à peu l’offre se réduit au centre-ville. À Tours, sur les 12 cinémas de quartier, 8 ferment en l'espace de 10 ans (Fig. 5).

Pour enrayer la chute de la fréquentation, les exploitants décident au début des années 1970 de scinder leur cinéma en plusieurs salles afin d’augmenter l’offre de films par cinéma. Cette stratégie «multisalles » stabilisera la fréquentation mais ne freinera pas le mouvement centripète. En effet, comme seuls quelques cinémas de centre-ville ont les moyens de se transformer en multisalles, les salles de quartier comme les unisalles restantes de centre-ville continuent de fermer. À Tours, les 4 derniers cinémas de quartier (l'Éden, le Rexy, le Vox et le Mexico) et les 3 dernières unisalles du centre-ville (le Palace, le Cyrano et l'ABC) disparaîtront au cours des années 1980. La rétraction ne s’arrêtera pas là puisque les multisalles les moins attractives devront s'incliner à leur tour (le Majestic en 1992). Tant et si bien qu’au début des années 1990, même les centres-villes n’offrent plus que quelques cinémas. Tours n’en comptait que 4 .

D’une certaine manière, les multisalles ont raté l'évolution de la ville. Se contentant de leur rente de situation, elles n'ont pas su innover et recouvrer une population qui ne cessait de se périphériser. Qui plus est, circonscrites au centre-ville, elles n’ont fait qu'accentuer la dichotomie centre-périphérie.

\section{UNE NOUVELLE PÉRIODE D’EXPANSION}

Depuis 1993 une nouvelle génération de cinémas est née, les multiplexes, et avec elle une nouvelle période d'expansion. En effet, pour rentabiliser ces équipements géants qui comptent parfois plus d'une vingtaine de salles, une large clientèle est nécessaire. Aussi les deux-tiers des multiplexes ont fait le choix de la périphérie qui seule peut offrir disponibilité foncière et facilité d’accès. Plus précisément, 40 \% sont installés sur une zone commerciale, plus de $10 \%$ à proximité d'axe(s) routier(s), autant au sein de quartiers périphériques dynamiques. Les multiplexes marquent donc le retour des cinémas en périphérie et par-là même contribuent à rééquilibrer l’offre cinématographique sur la ville.

Le centre-ville n’est pas abandonné pour autant. Malgré sa moindre accessibilité, il reste le lieu d'attractivité et de centralité majeures ; aussi un tiers des multiplexes y est implanté. Par ailleurs les salles classiques, bien que menacées, résistent assez bien. Seuls disparaissent certains cinémas qui ne se sont pas modernisés et d'autres dont les exploitants sont à l'origine des multiplexes comme à Tours qui, avec deux fermetures mais la création de deux multiplexes, l'un central l'autre péricentral, compte aujourd'hui 3 cinémas en centre-ville et 1 en périphérie, soit une proportion de 19 pour 12 salles (Fig. 6).

Désormais, non seulement les cinémas au travers des multiplexes sont devenus des équipements d'envergure dont l'aire d'attraction s'étend bien 


\section{Fig. 5 : Les cinémas à Tours 1963-1995}

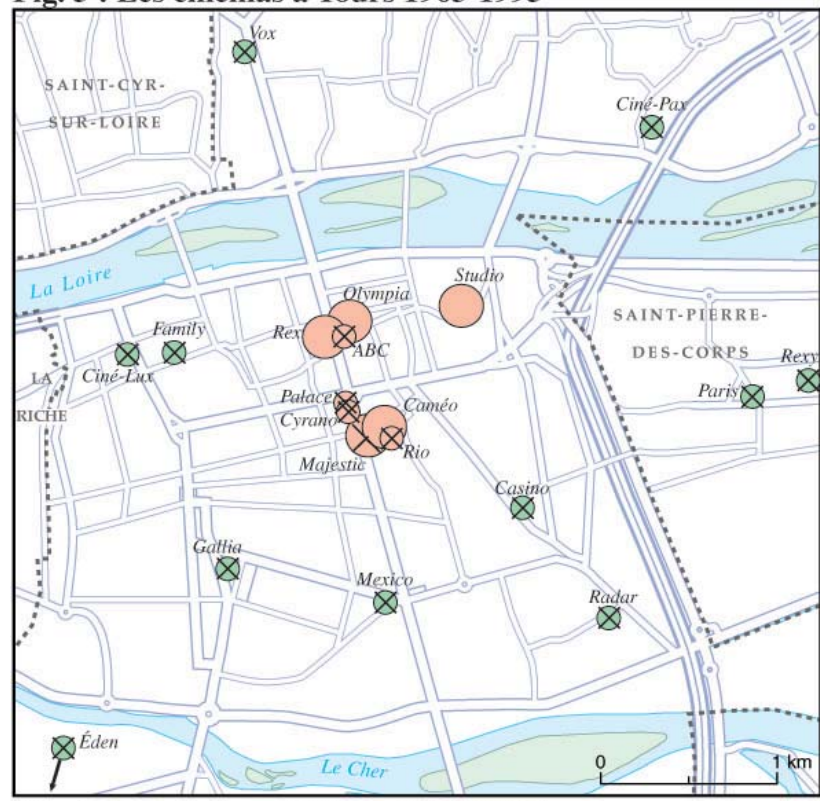

Cinémas existants avant cette période

Ounisalle de centre-villt Ounisalle de quartier

Cinémas transformés pendant cette période

multisalle

de centre-ville

$\times$ Fermeture pendant cette période

Sources : Le Magazine dt ouraine, $n^{\circ} 6$, 1983 .
Norvelle République,

\section{Fig. 6 : Les cinémas à Tours 1996-2003}

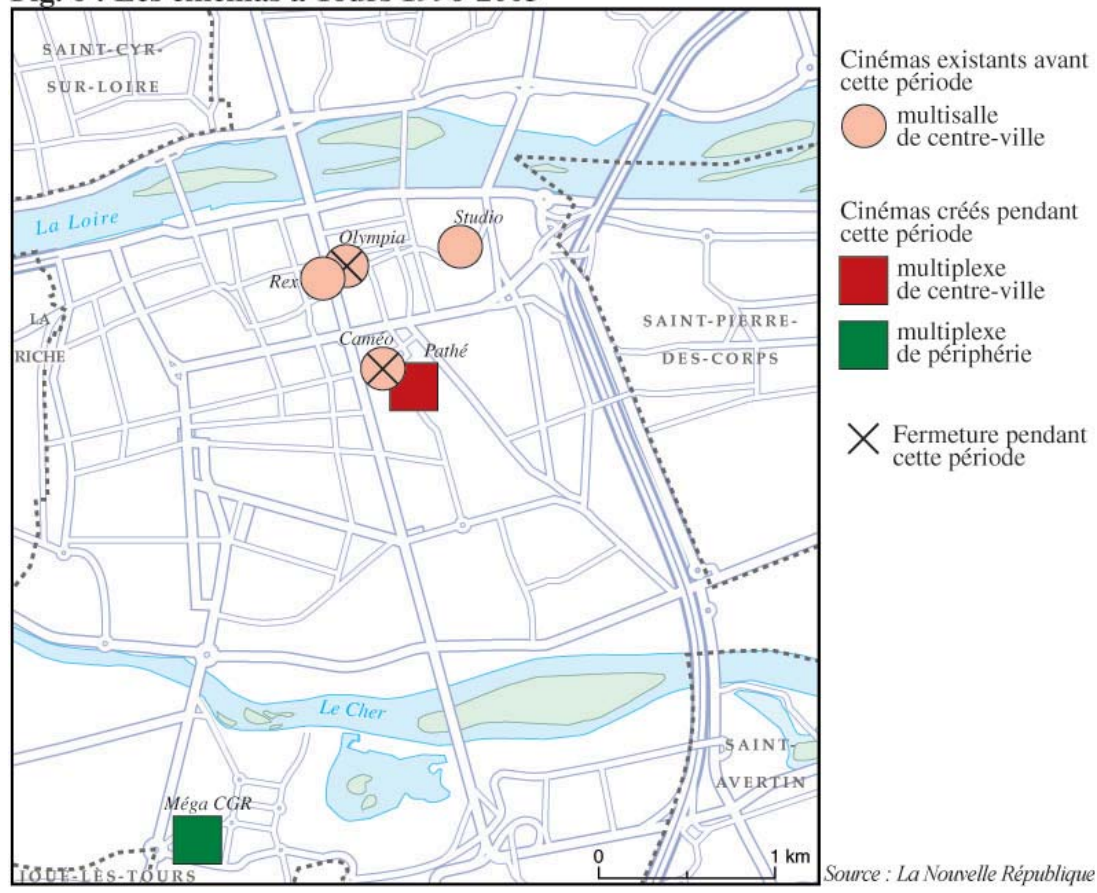


souvent au-delà de la seule agglomération, mais de plus les salles de périphérie n’ont plus rien à envier aux salles de centre-ville. De telle sorte qu’aujourd’hui, au-delà du rééquilibrage entre le centre-ville et la périphérie, ces nouveaux cinémas d'agglomération témoignent d’une autre lecture de la ville où disparaît la dichotomie centre-périphérie.

\section{UNE ÉVOLUTION IDENTITAIRE PARADOXALE}

L’évolution des cinémas n’a pas seulement été spatiale. Elle s’est doublée d'une évolution de leur identité, de leur statut dans la ville. Deux mutations quelque peu paradoxales peuvent être mises en évidence.

UN ÉQUIPEMENT BANAL MAIS DE PREMIER PLAN

Tout d'abord l'équipement s’est banalisé au cours du siècle tout en demeurant paradoxalement un équipement majeur.

Banalisation parce qu'en se généralisant rapidement à l'ensemble du territoire, il est devenu un équipement courant. Aujourd’hui, malgré les fermetures, toutes les villes de plus de 50000 habitants sont équipées, souvent multi-équipées, 80 \% des villes de 20 à 50000 habitants sont équipées et 60 \% des villes de 10 à 20000 habitants le sont.

Banalisation aussi née de la multiplication des activités et des équipements de loisirs qui le conduit à n'être plus aujourd'hui qu'un loisir parmi tant d'autres.

Banalisation encore à travers l'architecture des salles. Les premiers cinémas suivaient les canons de l'architecture théâtrale et avaient des allures de palais. Il est vrai que la plupart d'entre eux s'étaient installés dans les théâtres ou des music-halls. Les contraintes de la projection, la révolution du parlant et la crise de 1929 ont favorisé une architecture plus fonctionnelle en rupture avec celle des théâtres, avec moins d'ornements et des formes plus simples, même si de véritables monuments ont toujours été érigés avec marquises et escaliers d'honneur. Les multisalles ont intensifié la banalisation au point que l'on ait pu parler de disparition de l'architecture. Il est vrai que l'attraction reposait davantage sur la programmation que sur le lieu. Avec les multisalles, les cinémas se sont fondus dans les immeubles alentours et ont perdu toute magnificence. Quant aux multiplexes, la plupart accentuent encore cette banalisation architecturale en imitant les grandes surfaces. Qui plus est, pour la première fois un des exploitants, $C G R$, va même jusqu'à construire ses cinémas à l’identique, détruisant la personnalité des établissements.

Banalisation enfin des noms de cinémas. À partir des années 1970, les grands opérateurs (Gaumont, UGC, Pathé) ont rebaptisé leurs cinémas de l'enseigne du groupe. Ce phénomène associé à la fermeture de nombreuses salles a concouru à la disparition de noms prestigieux, magiques (l'Éden, le Palace, le Majestic) qui contribuaient pour beaucoup à la personnalité de l'équipement. Nommer un lieu c'est lui accorder une existence. 
Malgré cette banalisation, le cinéma a toujours été et reste un équipement majeur, un équipement qui compte dans la ville. D’une part, par sa taille, sa monumentalité, l'équipement se démarque et se remarque. Si l'architecture s’est peu à peu dévalorisée, quelques multiplexes de centre-ville, à Paris, Lyon, ou Bordeaux, témoignent du retour d'une architecture de qualité. Certains portent même la signature d'architectes de renom. Il est vrai que les multiplexes cherchent à remettre à l'honneur le lieu. D'autre part, l'équipement a toujours été particulièrement attractif. Au début du siècle, les foules se pressant devant les salles impressionnaient. Aujourd'hui encore le cinéma est l'un des équipements de loisir les plus pratiqués, il génère des flux importants voire impressionnants. Les multiplexes attirent 500000 à 1 million de spectateurs par an, le plus grand en accueille 3 millions, autant que le château de Versailles, une fois et demie le Parc Astérix.

Un ÉQUiPEMENT CULTUREL DE PLUS EN PLUS RÉCRÉATIF, DE PLUS EN PLUS COMMERCIAL

Une autre tendance peut être mise en évidence : les cinémas, équipements culturels, deviennent aujourd'hui à travers les multiplexes des équipements plus récréatifs, plus commerciaux.

La salle de cinéma a toujours été un équipement culturel devenu même relativement élitiste puisque le public à l'origine bien réparti dans toutes les catégories de la population - un public populaire - s'est plutôt orienté vers les milieux aisés à partir des années 1960. Il est vrai que les milieux populaires se sont aussi détournés des salles, à la fois parce qu'ils se sont retrouvés éloignés des cinémas qui se concentraient en centre-ville et parce qu'ils ont davantage réduit leur pratique cinématographique au profit de la télévision. Par ailleurs s’étaient développés dès les années 1950 des cinémas plus pointus (d'art-etessai, de recherche) qui représentent aujourd’hui $16 \%$ des établissements.

Les multiplexes qui totalisent quand même $40 \%$ de la fréquentation tendent donc à faire des cinémas un équipement beaucoup plus récréatif, beaucoup plus commercial. D'une part, des commerces et des attractions destinés à agrémenter et prolonger la séance sont présents dans le hall : bar, espace restauration, jeux, coin lecture, boutique cinéma. Cette présence prend une allure particulièrement mercantile qui dénature l'esprit culturel du cinéma. On comprend que certains les traitent d’hypermarchés du cinéma. D’autre part, des restaurants, des équipements de loisirs (bowlings, discothèques ou encore des commerces liés aux loisirs) viennent encadrer les multiplexes de façon spontanée ou planifiée au point de constituer parfois de véritables pôles de loisirs. Cet environnement récréatif ne peut que déteindre sur le caractère du cinéma. Enfin, les multiplexes favorisent cette disposition au divertissement en privilégiant les films à grand spectacle.

Cette tendance vers un cinéma plus récréatif, plus commercial ne fait que s’inscrire dans l'émergence d'une « ville des loisirs » et l'essor de la « culture- 
loisir ». Elle doit cependant être relativisée. Non seulement elle ne concerne que les multiplexes mais de plus, depuis peu, avec la reprise de la fréquentation, se multiplient des ouvertures de salles art-et-essai.

\section{UN ACTEUR DE LA CONSTRUCTION URBAINE}

Parallèlement à ces évolutions spatiale et identitaire, les rapports du cinéma avec l'espace urbain ont pris une autre dimension depuis l'avènement des multiplexes : ils sont pour la première fois utilisés comme instruments dans la fabrication de la ville qui cherche à tirer partie de leurs effets spatiaux.

\section{DES OPPORTUNITÉS À SAISIR}

Les effets sont connus, ils sont à la fois matériels et immatériels. Tout d'abord les cinémas jouent un rôle d'animation. Les quartiers de cinéma ont toujours été connus pour être parmi les lieux les plus animés ; une animation cadencée puisque les flux de spectateurs imposent à intervalles réguliers un rythme au quartier; dès l'après-midi contrairement aux autres salles de spectacle et jusque tard dans la soirée. Les multiplexes accentuent même cet effet de foule en programmant toutes leurs séances à la même heure. De plus, la concentration des cinémas dans une même rue, un même secteur, ne fait qu'accroître cette animation. Par ailleurs, les cinémas sont également vecteurs d’images: l'animation, le loisir se répercutent sur l'image du quartier lui insufflant une image d'agréabilité. De plus, devenus progressivement un symbole des centres-villes ils véhiculent aussi une image de centralité.

Depuis l'avènement des multiplexes, ces effets sont donc exploités dans l'aménagement. Jusqu’à présent les cinémas ne faisaient que suivre l'urbanisation. Pour être rentables, ils s'installaient dans les lieux les plus peuplés, les plus attractifs : le centre-ville, les quartiers et les banlieues les plus denses, mais aussi dans certains grands centres commerciaux. À la différences de ces anciens cinémas, l'irruption des multiplexes représente une opportunité pour les élus car ces cinémas, devenus des équipements d’agglomération, peuvent s’installer n’importe où dans la ville. Aussi depuis 1998, un tiers des multiplexes est associé à des projets urbains.

Deux stratégies sont adoptées : l'incitation ou la contrainte. La première consiste à convaincre l'exploitant de rejoindre un projet d'aménagement. Parfois les élus n’hésitent pas à faire quelques concessions, par exemple à baisser le prix du terrain comme à La Rochelle ou à Pau. La seconde stratégie consiste à lancer un appel d'offres à l'échelle de l'agglomération. Cette politique encore peu répandue nécessite sinon une bonne entente intercommunale au moins une réflexion collective. Par exemple, la Communauté Urbaine de Strasbourg a établi un cahier des charges qui impose notamment une installation précise près du centre-ville, au moins vingt salles et une vraie signature d'architecte. 


\section{LES MULTIPLEXES INSTRUMENTS D’AMÉNAGEMENT URBAIN}

Dans tous les cas, les multiplexes sont invités à renforcer voire amorcer un lieu de centralité ou un lieu promis à un fort dynamisme. Quatre situations peuvent être distinguées.

Le plus souvent les multiplexes sont intégrés à des projets d'extension de l'hypercentre sur des friches industrielles, ferroviaires, portuaires ou militaires. Les multiplexes, même s’ils ne sont qu'un élément de ces restructurations, permettent d'apporter l'animation et l'attraction inhérentes à un centre-ville. Par exemple à Dunkerque, un projet ambitieux prévoit de doubler la taille du centre-ville en aménageant des bassins et des friches portuaires. Le multiplexe a été intégré à un complexe de loisirs abritant également 5 restaurants et 4 moyennes surfaces de loisirs (Virgin, Connexion, La Grande Récré, Go Sport). La municipalité a volontairement opté pour un multiplexe de très grande taille (20 salles) afin qu'il joue un rôle de locomotive au sein de ce pôle de loisirs (Fig. 7).

Parallèlement, certaines communes de banlieue cherchent à se créer un centre parce qu'elles ont été dépassées par l'urbanisation, bouleversées par des centres commerciaux, ou encore fractionnées par des voies de communication. Or les multiplexes sont des équipements suffisamment imposants, suffisamment symboliques pour participer à la reconquête de ces centralités. Ainsi Talence, près de Bordeaux, marquée par le campus universitaire et ses 40000 étudiants, restructure actuellement son centre-ville un peu épars qui est d'ailleurs depuis 2004 desservi par le tramway. En convaincant Gaumont d'y implanter un multiplexe, la municipalité a considérablement dynamisé le projet. Le multiplexe qui a ouvert ses portes en juin 2002 vient renforcer le rôle de la place de l'église aux côtés d'un nouveau centre culturel et d'arts plastiques (Fig. 8).

Par ailleurs, quelques villes mettent en place des zones de loisirs périphériques, juxtaposant des équipements sportifs, ludiques et culturels, ainsi que des restaurants et des commerces liés aux loisirs. Les multiplexes sont des équipements suffisamment puissants pour constituer un élément moteur de ces nouveaux pôles. Par exemple à Montpellier, un pôle de loisirs baptisé Odysseum accueille déjà un multiplexe, une patinoire et un planétarium et prévoit également un aquarium, un bowling, des cafés, des restaurants, une discothèque et à terme un musée de l'urbanisme et un complexe commercial (Fig. 9). D'autres projets plus modestes sont en cours, comme à Lille ou Cagnes, où les multiplexes représentent l'amorce et la locomotive de ces zones.

Enfin, certaines villes cherchent à créer de nouveaux quartiers dynamiques reposant sur la mixité des fonctions comme la Bastide à Bordeaux, les Minimes à La Rochelle, l’Amphithéâtre à Metz ou les Deux Lions à Tours. Les multiplexes représentent une opportunité pour y introduire la dimension loisir. Par exemple à Tours, la municipalité a décidé de restructurer le technopôle en difficulté en envisageant des logements, des commerces et des services. Elle a saisi l'opportunité du projet d'implantation de CGR sur l'agglomération pour 
Fig. 7 : L'opération Neptune à Dunkerque

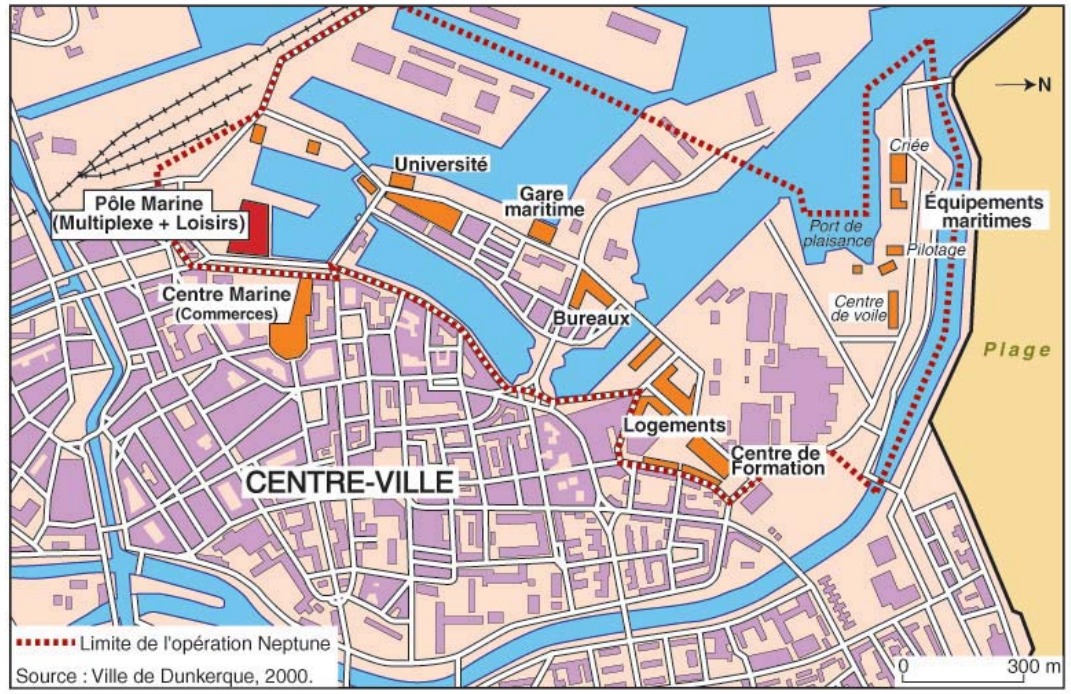

Fig. 8 : Le centre-ville de Talence

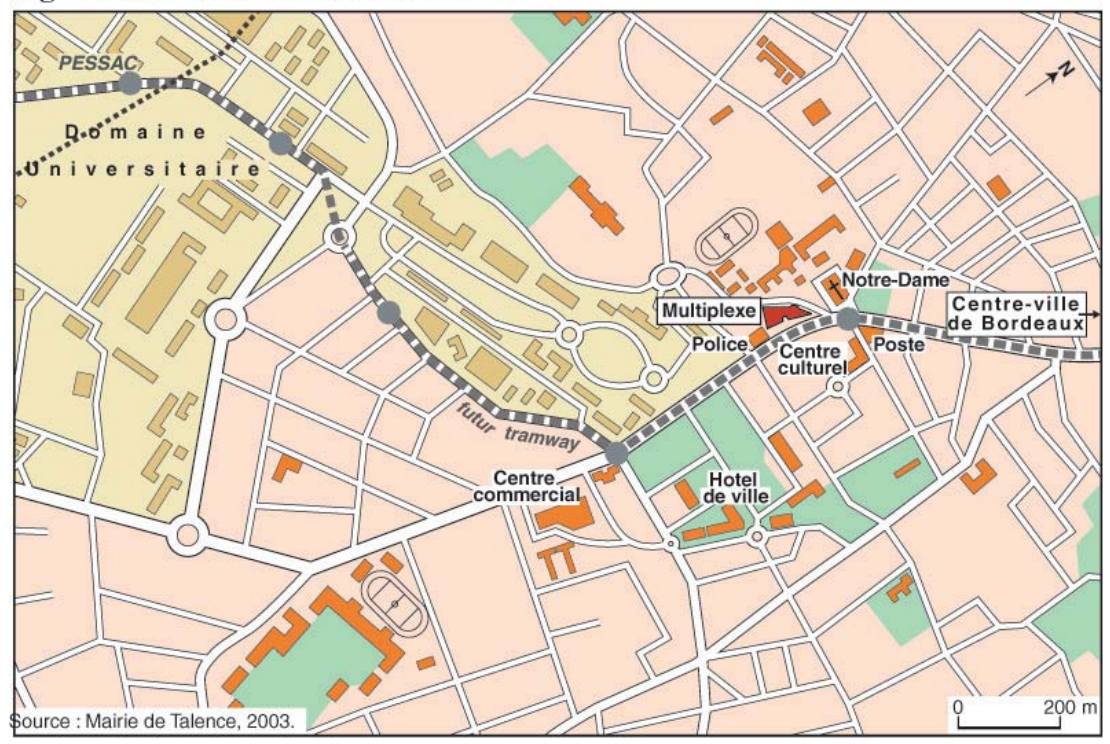


Fig. 9 : Le projet du pôle de loisirs Odysseum à Montpellier

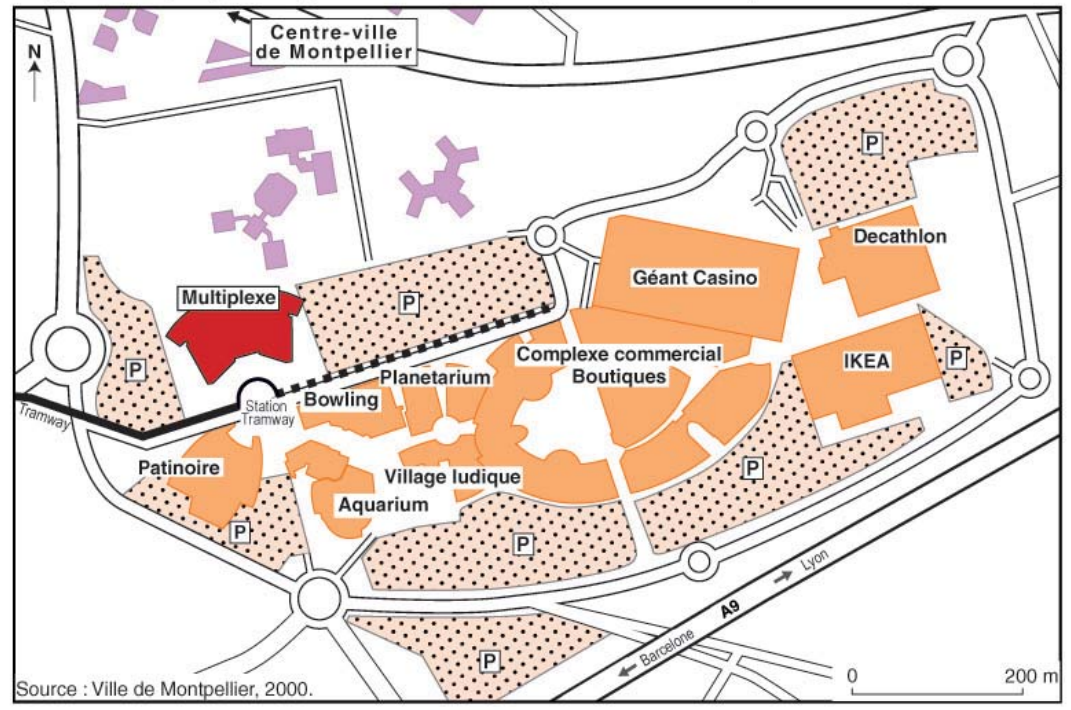

Fig. 10 : Le quartier des Deux Lions à Tours

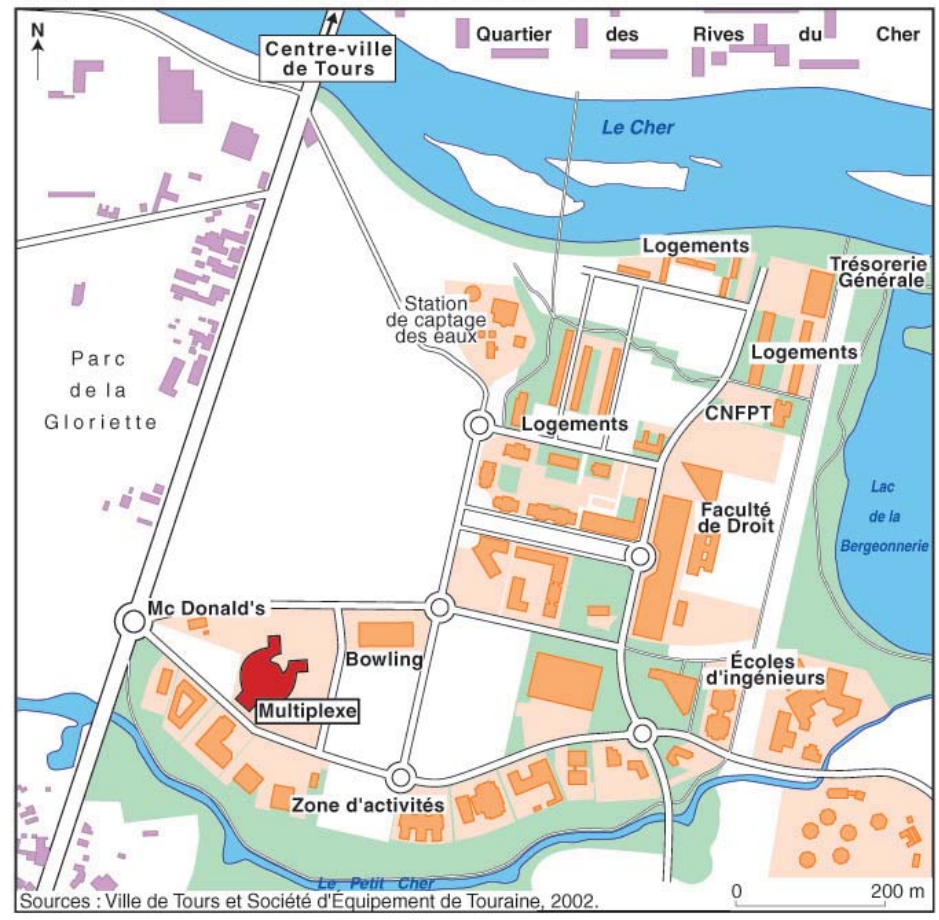


y adjoindre des loisirs en le convainquant de s’y installer. Le multiplexe est largement exploité dans les discours politiques et les publicités pour traduire l’agrément du quartier et attirer de nouveaux résidents (Fig. 10).

Les relations entre le cinéma et la ville ont donc largement évolué au cours du siècle. À l’heure actuelle, le cinéma à travers les multiplexes réaffirme sa place dans la cité après avoir failli disparaître faute d'avoir su s'adapter à l'évolution de la société mais aussi de la ville. Aujourd'hui, le déferlement des multiplexes touche à sa fin et un nouveau paysage cinématographique se dessine. Néanmoins, les loisirs urbains évoluent si rapidement que d’ici quelques années le cinéma devra sans doute encore s’adapter, se transformer. À l'image des mutations commerciales marquées par un engouement pour le commerce de proximité compatible avec celui des grandes surfaces, un nouveau cinéma de proximité - de proximité élargie - pourrait très bien se développer s’appuyant sur des miniplexes comme il en existe depuis peu dans les villes moyennes.

\section{Bibliographie :}

Annuaire de Tours et du Département d'Indre-et-Loire, Tours, Éd. Deslis Frères et Cie, Archives municipales.

Augustin J.-P., juillet-août 2001, « La ville des loisirs », Urbanisme, n³19, p. 54-57.

Blin É., juin 2002, «La ville à l'heure des multiplexes: enjeux et dynamiques territoriales », Mosella, tome XXVI, p. 305-312.

Bosseno C.-M. (dir.), 1993, « Le siècle du spectateur », Vertigo, n¹0, Paris.

Centre National de la Cinématographie, 1998, Les salles de cinéma, lieu de culture et de loisir, Paris, Ministère de la Culture.

CERTU (Centre d'études sur les réseaux, les transports, l'urbanisme et les constructions publiques), 1999, Les nouvelles frontières de la ville, Banlieues, centres, périphéries, Lyon.

Cladel G. et alii, 2001, Le cinéma dans la cité, Paris, Éd. du Félin.

Felix F., fév. 2000, « Les multiplexes leviers de la ville émergente », Le Moniteur des TPB, vol. 5022, fasc. 25, p. 62-65.

Forest C., 1995, Les dernières séances, Paris, CNRS Éditions.

Lacloche F., 1981, Architectures de cinéma, Paris, Le Moniteur.

« Le cinéma en Touraine. Des projectionnistes ambulants aux multisalles », avril 1983, Le Magazine de la Touraine, tome 1, nº6, p. 5-19.

Le Film Français, Hebdomadaire.

Lemonnier M., fév. 1995, « Du grand café aux multiplexes : le cinéma, un siècle d'aventures urbaines », Diagonal, n¹11, p. 32-37.

Vaccaro P., 1992, Les débuts du cinéma à Tours 1896-1922, Mémoire de Maîtrise d’Histoire, Université de Tours. 

DISNEYLAND,

\title{
ENTRE PARC DE LOISIR ET MODÈLE DE VILLE POUR LA SUBURBIA NORD-AMÉRICAINE
}

\author{
Sophie DIDIER \\ Université Paris 13, CRESC
}

Les parcs du groupe Disney connaissent dans l'ensemble un succès indéniable depuis l'ouverture du premier d'entre eux en Californie en 1955, et, s'ils ne participent plus aujourd'hui que pour une part mineure de la fortune de ce géant mondial des médias, ils conservent un rôle symbolique important pour l'image de l'entreprise. Au-delà de ce succès qui en fait une véritable machine de guerre touristique, il est important de souligner l'influence que ces parcs ont pu avoir en matière d'aménagement, auprès des architectes et urbanistes relevant tant du secteur privé que du secteur public (Didier, 2000). Le Disneyland originel ainsi que les différentes reproductions ultérieures de ce parc ${ }^{1}$, ont en effet été élevés au rang de modèle de ville pour l'Amérique du Nord urbaine, à la suite d'un glissement de sens dont l'identification sera ici le moteur de l'analyse.

\footnotetext{
$\overline{1}$ Les parcs du groupe sont actuellement au nombre de 11 dans le monde, et ils sont regroupés sur 5 sites : Californie (2 parcs), Floride (4 parcs), Japon (2 parcs), France (2 parcs) et Chine (1 parc, ouverture prévue en 2004).
} 
De simple parcs de loisir, ils sont en effet devenus en l'espace de quelques décennies des villes idéales. Or, l'examen des villes idéales est riche d'un double sens en études urbaines (Bonzon et al., 1993) :

- premièrement, parce qu'elles nous informent sur les transformations de la société elle-même. En un sens, il n’est pas très étonnant qu'un parc de loisir endosse aujourd'hui le rôle des cités ouvrières et autres familistères : voilà qui consacre l'avènement de la société post-industrielle dans les villes des pays développés, où le secteur tertiaire a pris la première place et où, selon la même logique, les espaces de la consommation sont désormais plus signifiants que les espaces de la production (Zukin, 1992 ; Soja, 2000).

- deuxièmement, parce que l'étude des villes idéales permet de mettre le doigt sur les dysfonctionnements de la ville elle-même. Leur élaboration s'inscrit dans les faisceaux de réflexion sur les différentes crises, historiquement situées, que traversent les espaces urbains, et qui consacrent la faillite de certains modèles d'urbanisation. Je montrerai que c'est par opposition à la suburbia des années 1950, en voie de stigmatisation à partir du milieu de la décennie 1960, que les parcs à thème du groupe Disney ont pris valeur de ville idéale et de modèle à suivre pour les aménageurs.

Une première partie replacera la création de Disneyland dans l'histoire de la compagnie qui l'a créé, en insistant sur la filiation existant entre le parc et d'autres formes de loisirs populaires inventées au tournant du vingtième siècle. Cette filiation permet de replacer Disneyland résolument du côté de la modernité, laquelle s'exprime au travers des valeurs qui sont affirmées dans l'enceinte du parc. Le second point permettra de montrer le lien profond qu'entretient Disneyland avec son environnement immédiat, la suburbia nordaméricaine ${ }^{2}$, puisque le parc est bien un pur produit de cette culture suburbaine qui a trouvé son terrain d'expression privilégié à Los Angeles. Une troisième partie aura pour but de caractériser la dissociation entre Disneyland et la suburbia, puis le glissement du statut du parc vers celui de ville idéale à partir de la décennie 1960. Ce glissement résulte en fait d'un double plébiscite venant d'une part des architectes, urbanistes et commentateurs de la ville en général qui ont reproduit plus ou moins consciemment le modèle, mais aussi et surtout de la presse nationale qui a joué le rôle de puissant relayeur du mythe Disney à partir de la fin des années 19503 .

\footnotetext{
2 J'entends ici le terme de suburbia au sens donné par Fishman $(1987,6)$ : «Suburbia can thus be defined first by what it includes - middle-class residence - and second (perhaps more importantly) by what it excludes : all industry, most commerce except for enterprises that specifically serve a residential area, and all lower-class residents (except for servants)». Bien entendu, cette définition est dépassée dès la fin des années 1950 du fait de la transformation de la suburbia (et notamment de son industrialisation).

3 D'un strict point de vue méthodologique, je rejoins ici le travail de R. A. Beauregard (1993) sur la notion de déclin des villes américaines, notion dont la popularité ne peut se comprendre qu'en raison du relais que lui donne la presse populaire américaine dès le début des années 1960.
} 
L'INVENTION DU PARC À THÈME, ENTRE EXPOSITION UNIVERSELLE ET LUNA Park Pour les Classes moyennes de l'Après-Guerre

Le groupe Disney actuel est l'héritier des studios de cinéma fondés par les frères Disney et qui connaissent dès les années 1930 une série de succès sans précédent. Outre les avancées technologiques indéniables en matière de dessin animé (Blanche Neige, premier long métrage d'animation, obtient l'oscar en 1936), les deux frères ont très tôt diversifié les productions du groupe et mis au point des techniques de promotion originales, notamment le principe de synergie qui permet de faire le lien entre les différents produits estampillés Disney (Didier, 2000). D’après les biographes officiels (Thomas, 1994) ou officieux (R. Schickel, 1968) de Walt Disney, l'idée de construction d'un parc d'attraction d'un nouveau type a mobilisé l'énergie de son créateur dès les années 1940. Malgré la renommée de son concepteur, la mise en place du parc est difficile, particulièrement en ce qui concerne son financement : les parcs de loisir sont largement en perte de vitesse depuis la Crise de 1929, et les investisseurs potentiels sont très méfiants vis-à-vis du projet. Le succès immédiat du parc dès son ouverture en 1955 vient toutefois changer la donne et suscite un grand nombre d'imitations à travers les États-Unis.

En fait, Disneyland n'est pas à proprement parler une nouveauté : il se nourrit tout d'abord de l'expérience des Expositions universelles, et tout particulièrement de l'Exposition colombienne de 1892, qui avait attiré sur son site de Chicago près de 27 millions de spectateurs. Le projet de Walt Disney emprunte aux idéaux pédagogiques de ces grands évènements, à travers des exposés «scientifiques» sur l'atome (section Tomorrow-Land) ou l'histoire de l'Amérique (section Main Street) traités sur un mode ludique à l'intérieur de l'enceinte du parc. Les manèges et les environnements artificiels du parc trouvent par ailleurs leur origine dans la section commerciale de l'Exposition de 1892, le Midway Plaisance, qui avait accueilli les tout premiers manèges illustrant la domestication de la machine à des fins ludiques: flume-rides (chutes d'eau que l'on parcourt en bateau), Ferris Wheel (grand-roue), etc.

Ce type d'attractions très populaire permettant l'expérimentation du vertige et de la vitesse avait aussi trouvé sa place au tournant du siècle dans les parcs de loisir associés aux stations balnéaires de proximité fréquentées par la classe ouvrière des grandes agglomérations de l'Est du pays, et notamment à Coney Island (Kasson, 1978) dont le parc le plus célèbre, le Luna Park, abritait manèges et monstres de foire dans un décor à l'architecture délirante. Toutefois ces parcs de la génération Coney Island représentent plus un antimodèle pour Walt Disney qu'un point direct de référence : l'hagiographie disneyienne insiste toujours sur le dégoût qu'inspirait Coney à Walt, et sur son insistance à dénoncer la saleté, la vulgarité et l'indécence de ces formes de loisir. En ce sens, Disneyland représente bien un effort de moralisation d'un loisir populaire (décrié depuis les années 1930) à travers son ajustement à la classe moyenne dont les valeurs deviennent dominantes à partir de la fin de la 
Seconde Guerre mondiale. Renouant avec la tradition des philanthropes et réformistes du XIXe siècle (Corbin, 1995), Walt Disney propose une combinaison, le divertissement familial (family entertainment) mêlant science, divertissement et histoire nationale, et qui s'inscrit à la croisée de l'industrie du loisir de masse alors en plein essor, et d'un projet moral et pédagogique pour l'occupation des temps de loisirs de la classe moyenne américaine.

La forme spatiale même du parc reflète cette distanciation vis-à-vis des Luna Parks : face à l'apparente anarchie de Coney Island, Disneyland fait figure de modèle d'environnement contrôlé, le fond (l'entreprise d'éducation des foules) coïncidant ici avec la forme (propreté méticuleuse et planification), comme dans le cadre des Expositions universelles. La forme enclose fait ainsi s'apparenter le parc à une île: l'efficacité de Disneyland repose sur un principe d'isolement physique vis-à-vis de son environnement immédiat, ce qui facilite l'illusion sensorielle d'entrée dans un monde imaginaire cohérent. En interne, le maintien de l'ordre s'illustre dans l'attention portée au cheminement des visiteurs, à l'aide de divisions internes entre les différents mondes mais aussi, héritage des techniques du studio de cinéma, à travers une manipulation des échelles architecturales facilitant la circulation en entraînant les visiteurs dans des séquences narratives (Francaviglia, 1977). Le décor est ainsi planifié au millimètre près et repeint de frais la nuit, et les employés, obéissant à des codes d'apparence très stricts, complètent le dispositif spatial mis en œuvre à l’intérieur des limites du parc.

\section{UN PUR PRODUIT DE LA SUBURBIA : LE LIEN ÉTROIT ENTRE DISNEYLAND ET LE COMTÉ D’ORANGE}

Les thématiques développées à l'intérieur de l'enceinte du parc correspondent bien à une adaptation aux classes moyennes d'une forme de loisir populaire plus ancien, mais le lien social entre Disneyland et la classe moyenne américaine est renforcé par une coïncidence spatiale entre les deux. Disneyland est en effet localisé dans la ville d'Anaheim qui appartient au comté d'Orange. Cette frange sud-est de l'agglomération de Los Angeles connaît une urbanisation brutale à la fin de la Seconde Guerre mondiale : la population totale du comté passe ainsi de 100000 habitants en 1940 à près de 500000 en 1957, et compte aujourd'hui près de 3 millions d'habitants. Ce processus d'urbanisation, bien identifié sur la plupart des franges urbaines des grandes agglomérations américaines au sortir de la guerre, résulte des effets combinés de l'équipement croissant en automobile, du lancement de programmes de liaison autoroutière entre les centres d'agglomération et leurs périphéries et de la facilité d'accession à la propriété des ménages dès l'immédiat Après-Guerre (Didier, 2000). La classe moyenne blanche qui a quitté le centre de l'agglomération angelena (phénomène là encore très classique de white flight) forme désormais la majeure partie de la population du comté d'Orange. La particularité culturelle de cette suburbia, outre sa 
relative uniformité sociale, est son orientation vers le tout-automobile, ce que consacre finalement l'articulation très étroite de Disneyland avec l'axe majeur de communication qui traverse le comté de part en part et le relie au centre de l’agglomération de Los Angeles. Les premières études lancées par la Direction de Disneyland auprès des visiteurs du parc illustrent cette suprématie de l'automobile: en 1959, $96 \%$ des visiteurs ont ainsi rejoint le parc en automobile individuelle ${ }^{4}$, et l'immense parking de 10000 places qui jouxte l'entrée du parc en témoigne tout aussi bien. En ce sens, Disneyland est un pur produit de cette suburbia, tout autant que le centre commercial régional (mall) qui a vu le jour à peu près à la même époque et qui présente le même profil insulaire combiné à une excellente connexion aux grands réseaux de communication (voir par exemple le Southdale Shopping Center mis au point par l'architecte-urbaniste Victor Gruen en 1956 dans la banlieue de Minneapolis, et qui est très similaire à Disneyland dans son rapport à son environnement).

Surtout, l'expérience Disneyland consacre finalement la montée en puissance d'une culture privée de la ville, qui s'articule autour de quelques fondamentaux : l'automobile, le logement pavillonnaire (single-family dwelling), la consommation de loisirs prenant de plus en plus place dans le cadre domestique (télévision, etc.) en sont les traits les plus distinctifs. Dans cette culture privée de la ville, particulièrement bien représentée à Los Angeles, Disneyland fait figure d'espace partagé (pour ne pas dire public) pour la communauté suburbaine, au même titre que l’église, le campus universitaire, la plage ou le centre commercial. Le parc consacre ainsi la montée en puissance des espaces semi-publics (ou semi-privés) dans la ville qui vont progressivement prendre de plus en plus d'importance (et même gagner les cœurs d'agglomération), mais qui constituent dans le cadre de la suburbia un des lieux de sociabilité d'une ville privée où la puissance publique se fait très discrète dans le paysage. Un article de Charles Moore paru en 1965 dans la revue de l'école d'architecture de Yale (dont il était alors directeur) apparaît à ce titre très révélateur : s’intéressant à l'architecture monumentale représentative de l'espace public, Moore tente de démontrer la difficulté de traiter de ce thème à Los Angeles, alors même qu'il en a été chargé par la revue. Pour Moore, le résultat de l'enquête est claire : pour accéder à l'espace public à Los Angeles, il faut payer, et ce prix est précisément celui du billet d'entrée à Disneyland pour lequel il ne tarit pas d'éloges 5 . Par comparaison, les monuments publics de Los Angeles (au premier rang desquels l'Hôtel de Ville) ne lui semblent représenter qu'un intérêt mineur et bien peu représentatif des valeurs de la société qu’ils sont censés incarner. Moore conclut enfin par une interrogation sur l'espace public en tant que lieu

\footnotetext{
4 In Disneyland Public Relations Divisions (1961), Disneyland interim report to the City of Anaheim, prepared for : City of Anaheim, Anaheim, 11 p. Document conservé aux archives de la ville d'Anaheim (cité in Didier, 2000).

5 D'où le titre de l'article : "You have to pay for the public life ».
} 
privilégié de l'expression politique : où faut-il faire une révolution à Los Angeles ? La réponse n'est pas simple, et il semblerait que seules les villes traditionnelles de l'Est soient susceptibles d'en offrir le cadre :

"It is interesting, if not useful, to consider where one would go in Los Angeles to have an effective revolution of the Latin American sort: presumably, that place would be the heart of the city. If one took over some public square, some urban open space in Los Angeles, who would know ? A march on City Hall would be equally inconclusive. The heart of the city would have to be sought elsewhere. The only hope would seem to be to take over the freeways, or to emplane for New York to organize sedition on Madison Avenue » 6 .

Et pourtant, la révolution ne s'emparera pas des autoroutes, pas plus qu'elle ne s'exportera dans ce lieu éminemment représentatif de l'espace public qu'est Madison Avenue : c'est bien à Disneyland qu'elle aura lieu, au cours d'une journée ordinaire du mois d'août 1970 qui voit un groupe de 300 Yippies $^{7}$ envahir le parc, prendre d'assaut l'île de Tom Sawyer pour y faire flotter le drapeau rouge, fumer de la marijuana et chanter des slogans contre la guerre du Vietnam. La police du comté d'Orange, appelée à la rescousse par la Direction du parc, fait rapidement le ménage et l'ordre règne à nouveau dans Disneyland (même si le lendemain, les images pour le moins surprenantes de policiers en tenue anti-émeutes défilant dans Main Street s'étaleront en une de la presse locale). Le jour suivant, après publication d'un communiqué dans la presse locale, la Direction instaure une discrimination « au faciès » à l'entrée pour prévenir la répétition de ce type d'incident... L'épisode serait anecdotique s'il ne soulignait une double leçon : en tant que cible privilégiée de la contreculture, Disneyland fait bien figure de symbole pour la suburbia blanche middle-class (Findlay, 1992). Ensuite, la question de l'accessibilité, rendue difficile par le filtrage tout autant que par le prix du billet, souligne la grande ambiguïté de la dimension publique de cet espace, et ce malgré les affirmations contraires de Charles Moore.

\section{UNE DISSOCIATION PROGRESSIVE ENTRE LE PARC ET SON MONDE D'ORIGINE : DiSNEYLAND DEVIENT UNE VILLE IDÉALE}

Les barrières qui ceinturent le parc ne suffisent donc plus à l'isoler du monde extérieur et l'épisode Yippie d'août 1970 souligne cette ouverture de Disneyland aux troubles du monde réel. Mais l'interpénétration fonctionne également dans l'autre sens, alors même que Disneyland se dissocie de plus en plus de l'environnement qui l'a vu naître.

À partir du milieu des années 1960 en effet, la crise de la ville américaine est largement soulignée par les commentateurs, cette crise se manifestant

\footnotetext{
6 Moore (1965, p. 62-63).

${ }^{7}$ Mouvement Hippie politisé issu des émeutes urbaines du milieu des années soixante, et qui s’est particulièrement illustré à Chicago.
} 
notamment par le déclin des centres dû au double glissement des logements et des emplois vers les périphéries urbaines (Beauregard, 1993). Pendant direct au déclin des centres, la croissance anarchique des périphéries est également dénoncée, à travers notamment de jugements de valeurs esthétiques stigmatisant le sprawl (étalement urbain anarchique): l'anomie de la suburbia est vigoureusement décriée par des commentateurs/urbanistes en vue comme Lewis Mumford (1956). L’architecte Victor Gruen (qui, on s'en souvient, avait construit l'emblématique Southdale Shopping Center) représente parfaitement ce courant critique. Dans son ouvrage majeur datant de 1964, il fustige ce qu'il a baptisé le subcityscape, avatar abâtardi de la ville dont le développement pathogène est comparable à la fois au viol et à la mauvaise herbe :

«Subcityscapes features gas stations, repair shops, shacks and shanties, usedcar lots, billboards, dump heaps, roadside stands, highway stores, rubbish, dirt and trash. It grows like a weed in all directions, reaching into cityscape, raping suburbia, cluttering up the spaces between cities and towns, between one metropolitan area and another ${ }^{8}$.

Le rêve suburbain est en train de se transformer en véritable cauchemar, et l'automobile qui l'avait rendu possible est désormais rendue responsable de tous les vices de formes qui affectent non seulement la suburbia mais aussi les centre-villes traditionnels. Pour les commentateurs, le chaos, imputable à l'absence de planification d'ensemble, rend le paysage totalement incompréhensible et donc fou : cette folie, à laquelle est invariablement rattachée la saleté (selon le vieux principe des hygiénistes du XIXe siècle), contraste dès lors sérieusement avec la propreté méticuleuse et l’ordre architectural régnant à l'intérieur de Disneyland. Alors même que le parc, on l'a vu, ne serait rien sans l'automobile, le voilà désormais paré de toutes les vertus. Walt Disney lui-même, qui fréquente bon nombre d'architectes et urbanistes (dont Victor Gruen) emboîte le pas aux critiques à partir de cette époque :

"I'm not against the automobile, but I just feel that the automobile has moved into communities too much. I feel that you can design so that the automobile is there, but still put people back as pedestrians again, you see. I'd love to work on a project like that $»$.

Très vite, la perfection technique en matière d'urbanisme que représente Disneyland est mobilisée dans la critique de la suburbia, tant chez les professionnels que dans la presse nationale ${ }^{10}$. Ainsi, dès le dixième anniversaire

\footnotetext{
8 Gruen (1964, p. 45).

9 Déclaration de Walt Disney lors d'un entretien avec Bob Thomas, in Thomas (1994, p. 338).

10 D'un point de vue méthodologique, il faut souligner bien entendu le rôle considérable des services de relations publiques du groupe Disney dans la transmission de cette idée, notamment auprès du grand public : une large part de l'énorme couverture médiatique consacrée à l'époque à Disneyland est plus ou moins directement recopiée des communiqués de presse du groupe.
} 
du parc en 1965, plusieurs quotidiens opèrent une comparaison entre Disneyland et la « vraie » ville, comparaison qui tourne bien sûr à l'avantage du parc :

"Ironically, the most artificial attraction in L. A. turns out to be the sanest one. This down-to-earth fantasy is Disneyland, perhaps the only true good thing about the entire smog-bound metropolis »11.

Ou encore :

« [Disneyland is] cleaner than any other city of 50,000 I've ever seen »12.

Surtout, cette idée de perfection technique est rapidement élargie à celle de perfection sociale, frisant en celà le déterminisme architectural le plus simpliste. De cette manière, Disneyland, en tant que ville idéale, n’est pas seulement un remède aux dysfonctionnements architecturaux de la ville, mais aussi à ses dysfonctionnements sociaux, si évidents à partir du milieu des années 1960 et de ses grandes émeutes urbaines (et le quartier de Watts n’est pas si éloigné géographiquement du comté d’Orange). Loin de la violence urbaine, Disneyland apparaît comme un havre de paix pour la classe moyenne, et son ordre architectural est aussi le garant de la bonne harmonie sociale. Un article de l'auteur de science-fiction, Ray Bradbury dans la revue Holiday offre un bon témoignage de ce déterminisme architectural :

«In Disneyland, [Walt Disney] has proven again that the first function of architecture is to make men over, make them wish to go on living, feed them fresh oxygen, grow them tall, delight their eyes, make them kind. Disneyland liberates men to their better selves ${ }^{13}$.

Dès lors, la seule solution possible pour régler ces problèmes urbains est, très logiquement, d'appeler Walt Disney aux fonctions de maire, et cette conclusion est explicitement formulée à partir du début des années 1970, lors de l'ouverture en fanfare de Walt Disney World en Floride. Ainsi, Peter Blake, un critique d'architecture très actif dans plusieurs grands organes de presse, préconise-t-il en 1972 ce transfert de pouvoir :

" The truth of the matter is that the only New Towns of any significance built in this country since World War II are Disneyland, in Anaheim, Calif., and Disney World, in Orlando, Fla. Both are 'New', both are 'Towns', and both are staggeringly successful. [Suit un long exposé affirmant la supériorité technique de la compagnie en matière d'urbanisme, ses résultats économiques éblouissants, et la joie ressentie par les visiteurs des parcs]. (...) In other words, the only way to have Fun-City, urban-design-wise, is to take it away from the do-gooders and lease it to Walt Disney Productions »14.

Finalement, ce glissement n'est pas très surprenant, ni même très original : la White City, surnom du site de l'Exposition Colombienne de Chicago de

11 Emporia Gazette, 15 juillet 1965, « The trip : conclusion ».

12 Newsweek, 12 juillet 1965, « Tinker Bell, Mary Poppins, cold cash ».

13 Holiday, n³8, octobre 1965, « The machine tooled Happyland », p. 100-102

14 Christian Science Monitor, 26 avril 1972, « Let Disney do it ». 
1892, avait suscité à peu près le même type de commentaires et de fait, la comparaison avec la situation de Disneyland est très riche : à l'époque de la White City, la société étatsunienne était en effet en pleine transformation et connaissait une certaine crise de confiance dans les pouvoirs publics, et cette transformation affectait particulièrement les espaces urbains. Les effets combinés de l'industrialisation et de la Dépression du début des années 1890 rendaient alors la ville de plus en plus étrangère et incompréhensible pour les citadins. Les travaux de Jacob Riis avaient révèlé par ailleurs à la même époque la montée de la pauvreté urbaine et les conditions de vie sordide de l'« autre moitié » de la société. Dans le cadre de Chicago, on pourrait de façon similaire évoquer le South Side noir en formation, lequel était géographiquement si proche de la White City que la comparaison entre l'intérieur et l'extérieur en était devenue inévitable. Au final, Walt Disney n’apparaît donc pas si différent de Daniel Burnham, l'architecte en charge des plans de la White City, lequel, après son expérience sur le site de l'exposition, partit fonder le City Beautiful Movement : Walt Disney se lancera d'une manière assez similaire dans un grand projet de ville idéale sensée accueillir les employés de son parc de Floride15, mais sa mort prématurée en 1966 signera l'abandon du projet et sa transformation en simple parc de loisirs par le groupe Disney.

Ainsi, le glissement que connaît Disneyland du statut de simple parc à thème à celui de ville idéale est très ancré dans les évolutions tant sociales que paysagères qui affectent la ville nord-américaine (et plus particulièrement la suburbia) à partir du début des années 1960. Cette élévation au rang de ville idéale inaugure à partir de cette époque la diffusion de ses recettes d’aménagement dans les espaces urbains étatsuniens : soit les pouvoirs publics des grandes villes font appel directement au groupe Disney pour « revamper » leurs espaces publics (expérience du réaménagement récent de Times Square à New York, sous l'impulsion du groupe Disney), soit ses formules sont réemployées plus ou moins consciemment par les aménageurs tant publics que privés (thématisation de districts historiques, création de villes nouvelles, etc.). C'est cette circulation perpétuelle du modèle Disney en transformation permanente qui entraîne au final un brouillage des limites entre domaines publics et privés dans la ville, accentuant la difficulté de lecture de la ville contemporaine.

\section{Bibliographie :}

Beauregard R. A., 1993, Voices of decline : the postwar fate of U.S. cities, Cambridge, Blackwell, $342 \mathrm{p}$.

Bonzon Th., Boucheron P., Marin B. \& Moret F., 1993, « Idées de villes, villes idéales et histoire urbaine », Cahiers de Fontenay, n 69/70, p. 7-18.

\footnotetext{
15 Il s'agit du projet EPCOT : Experimental Prototype Community of Tomorrow. Sur ce point, voir Didier (1997).
} 
Calweti J. G., 1968, « America on display : the World’s Fairs of 1876, 1893, 1933 », in The age of industrialism in America : essays in social structure and cultural values, F. C. Jaher (dir.), New York, The Free Press, 317-363.

Corbin A., 1995, « L'avènement des loisirs », in L'avènement des loisirs : 1850-1960, A. Corbin (dir.), Paris, Aubier, p. 9-18.

Csergo J., 1995, « Extension et mutation du loisir citadin, Paris XIXe siècle-début XXe siècle ", in A. Corbin (dir.), L'avènement des loisirs : 1850-1960, Paris, Aubier, 121-168.

Didier S., 2000, Une île dans la ville ? Invention, négociation et mise en pratique du modèle de ville Disney à Anaheim, Californie (1950-2000), Thèse de doctorat en Géographie, Université de Paris I Panthéon-Sorbonne, 423 p.

Didier S., « Disney urbaniste : la ville de Celebration, Floride », actes du colloque de l'UGI Les problèmes culturels des grandes villes (Paris, 8-11 décembre 1997), mis en ligne sur Cybergeo, http://www.cybergeo.presse.fr/revgeo.

Findlay J.-M., 1992, Magic lands: western cityscapes and American culture after 1940, Berkeley, University of California Press, 394 p.

Fishman R., 1987, Bourgeois utopias: the rise and fall of suburbia, New York, Basic Books, 241 p.

Francaviglia R. V., 1977, « Main Street U.S.A.: the creation of a popular image ", Landscape, vol. 21, $\mathrm{n}^{\circ} 3$, p. 18-22.

Gruen V., 1964, The heart of our cities : the urban crisis: diagnosis and cure, New York, Simon \& Schuster, 368 p.

Kasson J., 1978, Amusing the million: Coney Island at the turn of the century, New York, Hill \& Wang, 120 p.

King M. J., 1981, « Disneyland and Walt Disney World: traditional values in futuristic form », Journal of Popular Culture, vol.15, n¹, spécial: American amusement parks, p. 116-140.

Moore C. W., 1965, "You have to pay for the public life ", Perspecta: the Yale architectural journal, n9-10, p. 57-106.

Mumford L., 1956, Le déclin des villes, ou la recherche d'un nouvel urbanisme, Paris, France-Empire, 1970, [première édition New York, Harcourt Brace \& World].

Riis J., 1890, How the other half lives, en ligne sur le serveur de l'Université de Yale @http://www.cis.yale.edu/amstud/inforev/riis/title.html.

Schickel R., 1968, The Disney version: the life, times, art \& commerce of Walt Disney, New York, Simon \& Schuster, 382 p.

Soja E.W., 2000, Postmetropolis: critical studies of cities and regions, Oxford, Blackwell, 440 p.

Thomas B., 1994, Walt Disney : an American original, New York, Hyperion, [première édition 1976, Simon \& Schuster], 379 p.

Zukin Sh., 1991, Landscapes of power: from Detroit to DisneyWorld, Berkeley, University of California Press, 326 p. 


\title{
LES JARDINS PUBLICS DANS LE MONDE ARABE : TERRITOIRE D'UN LOISIR POPULAIRE
}

\author{
Gaëlle GILLOT \\ Université Paris 1 Panthéon-Sorbonne, IEDES
}

Contrairement à ce qu'on imagine généralement, les jardins publics dans le monde arabe sont récents. Ils ne ressemblent pas aux « jardins arabes », ou « jardins de l'islam », ou encore "hispano-mauresques », tels qu'on se les représente à la suite de descriptions célèbres comme celles de Louis Gardet ${ }^{1}$ ou de Jean Gallotti2 ${ }^{2}$ : fontaine aux mosaïques, raffinement extrême dans le choix des plantes, luxuriance de la végétation, parfums, et femmes orientales lascivement endormies sur des tapis. Ces jardins-là appartiennent au domaine du privé et n'étaient pas tellement répandus si l'on en croit les études statistiques sur l'emprise au sol des maisons, notamment au Caire ${ }^{3}$, et surtout, ils étaient jalousement réservés à leurs propriétaires et quelques invités privilégiés.

Les jardins publics du monde arabe, n'ont que peu à voir avec ce type de jardins. Ils correspondent à une volonté de modernisation des villes et/ou à la construction de nouvelles villes à côté des médinas, sur le modèle haussmannien, dans un souci d'ordre, de salubrité et d'exposition de la ville. Les jardins publics du monde arabe (et l'on s'attardera ici essentiellement sur Le Caire, Rabat et Damas), trouvent leur origine en Occident, et singulièrement en France pour ces

\footnotetext{
1 Voir par exemple la description d'un jardin d'islam dans l'Encyclopédie de l'Islam (article Djanna).

2 Le jardin et la maison arabe au Maroc, Paris, Lévy, 1926.

3 Voir notamment les travaux de Nelly Hanna sur les maisons du Caire au XIX ${ }^{\mathrm{e}}$ siècle.
} 
trois villes. Ils ont été aménagés dans les parties modernes des villes dans un souci hygiéniste, de moralité, d'aération et d'embellissement de la ville, et ils correspondent à une période de très forte influence de la France dans le monde arabe : le XIXe siècle pour l’Égypte, le début du XXe pour le Maroc et la Syrie.

Dans l'optique hygiéniste, en France comme ailleurs, la pratique normale et la plus répandue d'un jardin public, c'est la promenade. Héritée des pratiques aristocrates, la promenade est devenue au XIXe siècle essentiellement bourgeoise, procurant divertissement et détente à ses adeptes, encouragés à la marche par les médecins, mais aussi, et surtout, une occasion d'ostentation de richesse, de puissance et de culture dans la ville.

Dans le monde arabe, la promenade dans les jardins n'est pas une pratique nouvelle : on en trouve des témoignages anciens. Mais dans ce contexte, au XVIe ou XVIIe siècles, jusqu'au XIXe pour Le Caire, au début du XXe pour Rabat et Damas, les jardins fréquentés étaient privés. Il s'agissait d'aller se promener dans des vergers ou des jardins maraîchers, et d'y rester toute la journée, d'y déjeuner au milieu de la verdure et à proximité d'un canal d'irrigation, dans le but de se rafraîchir.

On peut dire que la promenade dans les jardins est une pratique aux racines anciennes, transposée dans les jardins publics et modelée en pratique urbaine, moderne, dans des jardins qui désormais ne donnent ni fruits ni légumes. Comment, dans ce contexte, la pratique des jardins a-t-elle évolué et comment les jardins publics se sont-ils transformés en lieu de loisir populaire alors qu'ils étaient conçus pour la bourgeoisie? Quels sont désormais les loisirs qui se déroulent dans les jardins publics et quelles en sont les implications?

\section{LES JARDINS PUBLICS : UN ESPACE DE LOISIRS DEVENU POPULAIRE}

La question des loisirs pose la question de l'espace public et de son accessibilité aux différentes composantes de la société. Les travaux sur les aménagements publics ${ }^{4}$ ont montré que l'espace public était un espace d'abord conçu pour la bourgeoisie et qu'il lui offrait un espace d'appropriation de la ville, d'ostentation et un moyen "d'éduquer » les couches populaires à un usage sain de l'espace urbain, en tout cas, fortement codifié : les allées plantées, les sorties de théâtre, et surtout les jardins publics étaient des lieux où l'on se rendait en grande toilette, en voiture. C'était l'occasion pour les élites de se donner en spectacle et d'affirmer leur différence sociale et de mode de vie face à des catégories socio-économiques moins favorisées.

\section{LA FIN DE L'OSTENTATION BOURGEOISE DE L'ESPACE PUBLIC ET LE REPLI SUR SOI}

Au Caire, l'avenue de Choubra notamment était ce lieu d'ostentation, avant même les grands aménagements engagés par Ismaïl (à partir de 1863). À Rabat, les

$\overline{{ }^{4} \text { Michel Foucault sur Bordeaux, Guy Di Méo... }}$ 
grandes avenues du centre ville, le boulevard Mohammed V par exemple, axe principal de Rabat, étaient également le lieu de promenade favori des classes aisées européennes, qui a été très vite adopté par les classes aisées marocaines. La littérature décrit une sorte de précipitation des couches aisées de ces villes à adopter un mode de vie et de loisirs occidentaux (comme le décrit Khaled Ziadé dans son roman Vendredi dimanche). À cette période, les jardins, également synonymes de puissance et de pouvoir public étaient somptueux et le plus grand possible.

Depuis les années soixante environ, et cela correspond aussi au développement du salariat, la promenade exerce un attrait massif pour toute la population. Loisir gratuit, rite d'appropriation au rythme lent de la marche, la promenade des couches populaires dans les espaces publics de la ville, entre autres raisons, a fait fuir les élites de l'espace public qui choisissent désormais d'autres lieux pour leurs loisirs, tant ces derniers sont le miroir de la position sociale. Désormais, les couches aisées privilégient très fortement les loisirs dans les espaces privés ou tout au moins, « réservés » et sélectifs, tels que les clubs, et délaissent l'espace public aux pauvres, et notamment les jardins publics. Ceci se vérifie particulièrement au Caire. Leur rôle alors n’est plus autant de montrer la puissance du Prince, et par conséquent, ils sont moins bien entretenus que lorsqu’ils possédaient cette signification forte d'un espace de représentation.

\section{LES SORTIES DU VENDREDI}

Les possibilités de loisirs des couches populaires sont par définition beaucoup plus restreintes que celles des couches aisées qui peuvent payer pour les pratiquer. Il est malaisé de partir à la campagne lorsque l'on n’a pas les moyens financiers, d'aller loger à l'hôtel hors de la ville, ou de profiter des offres de loisirs urbains tels que les cinémas ou les restaurants, lorsque déjà pour survivre, il faut exercer deux métiers. Au Caire notamment, les couches populaires ont largement investi les jardins publics qui sont à peu près les seuls lieux de nature accessibles aux couches populaires. Pourtant, on ne compte en 1999 que $45 \mathrm{~cm}^{2}$ de verdure par habitant, dans une ville qui compte entre 12 et 15 millions d'habitants, et où le sentiment d'étouffement peut rapidement devenir dominant. Les Égyptiens des milieux populaires se montrent très attachés à la verdure et se rendent massivement dans les jardins publics qu'ils voient comme un espace de nature poétique et romantique.

La fréquentation des jardins, habituellement assez importante, prend toute son ampleur le vendredi, jour officiel du congé hebdomadaire. Les jardins publics les plus fréquentés sont le jardin zoologique et le jardin botanique (Orman), créés au cours du XIXe siècle et situés au cœur de l’agglomération. Se pressent des centaines de milliers de visiteurs par an au jardin zoologique (Ill. 1 et 2) et 3 millions au jardin Orman. Ce qui est considérable pour ces espaces dont la surface ne dépasse pas 20 hectares pour les deux. 
Illustration 1 : Un pique-nique en famille au zoo du Caire, le jour de Cham elNessim. Le tissu noué entre les grilles de l'allée et le grillage de l'enclos des animaux protège du soleil, mais crée aussi un territoire familial

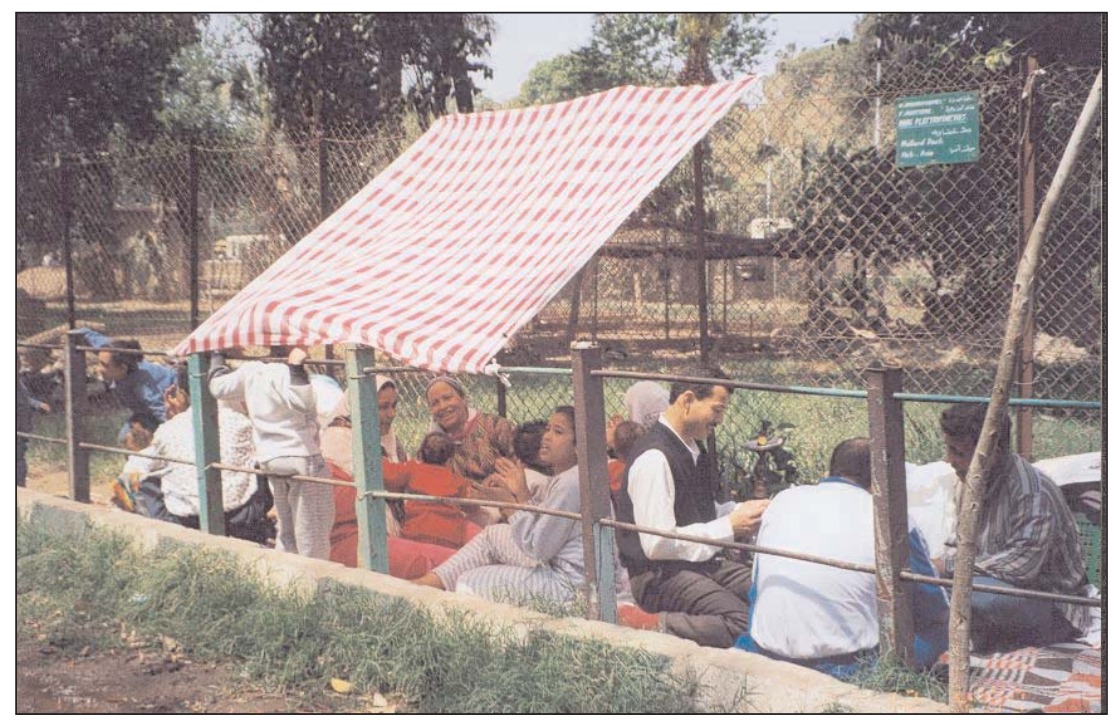

Illustration 2 : La foule dans l'allée principale du zoo du Caire le jour de Cham el-Nessim. On a peine à circuler dans les allées du jardin. La foule est compacte, joyeuse et familiale. Le zoo ne désemplira pas jusqu'à sa fermeture

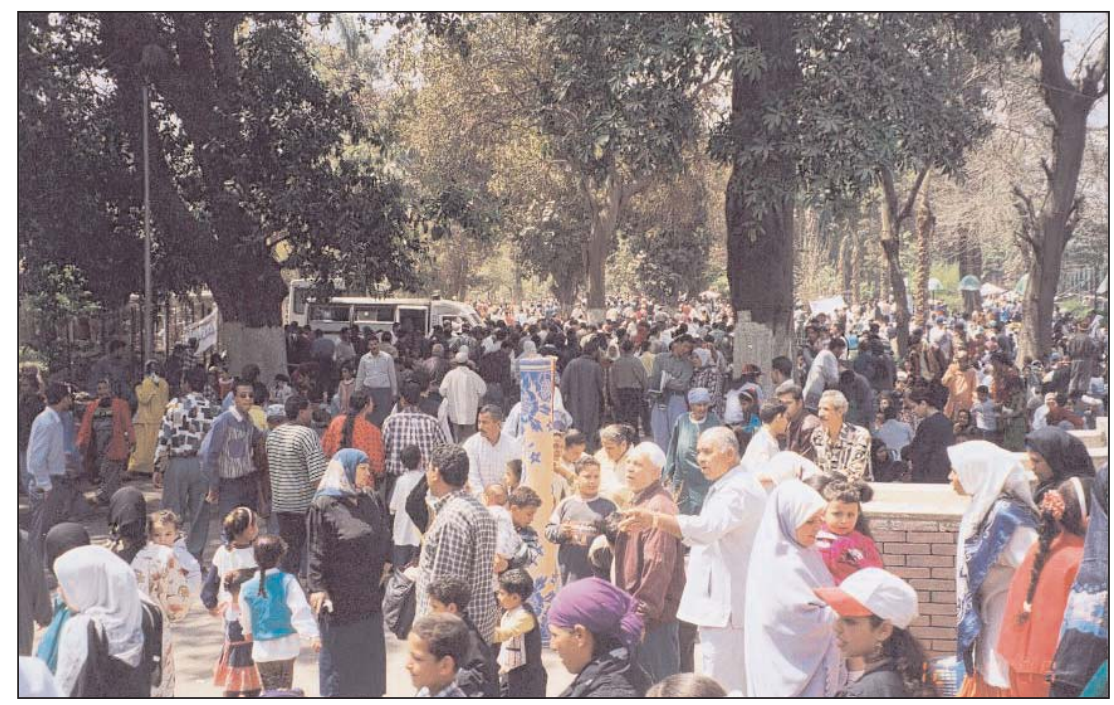


Au-delà du simple bol d'air du citadin, la pratique du jardin public est une affirmation de territorialisation pour les couches populaires, au même titre que la fréquentation du centre-ville, y compris quand les magasins sont fermés. Contrairement aux couches aisées qui ont une pratique « à la carte » de la ville, ou « en sauts de puce », les couches populaires ont une pratique linéaire de la ville et les jardins publics leur permettent de se rendre dans tous les quartiers de la ville, y compris dans les quartiers aisés, dans lesquels sont d'ailleurs concentrés la plupart des jardins publics hérités.

Les jardins publics représentent dans ce cadre des sortes d'îlots dans lesquels les couches populaires se sentent à leur place, et légitimes de se rendre. On le sait, on ne s'approprie que les lieux dans lesquels on se sent à sa place. Or, les jardins publics sont désormais des espaces qui appartiennent au territoire de la pauvreté au Caire, par défaut.

En fréquentant les jardins publics, les couches populaires affinent leur connaissance de la ville et s'approprient l'espace public. La promenade et les sorties dans les jardins recouvrent donc une signification bien plus étendue que le rôle prophylactique dont ils sont revêtus. Mais ils sont également un lieu de défoulement collectif, et de communion, l'espace de fêtes à la fois spontanées et organisées que sont les fêtes de printemps.

\section{LES FÊTES DE PRINTEMPS : LA SPONTANÉITÉ ORGANISÉE ET À DATE FIXE}

La vie des jardins publics est ponctuée de moments forts qui les mettent en valeur et abritent des manifestations parfois régulières (annuelles), ou exceptionnelles. Ils sont de fait intégrés à une sorte de calendrier rituel et n'échappent donc plus au rythme de la ville qu'en apparence. Les fêtes de printemps qui célèbrent le renouveau de la nature y prennent place alors qu'autrefois elles se pratiquaient à la campagne. Moments de liesse, ces événements du printemps représentent un moment privilégié de loisir de plein air.

UNE PRATIQUE ANCIENNE ET TRANSPOSÉE DANS LES JARDINS PUBLICS : RITES ET PRATIQUES

La fête de printemps existe dans beaucoup de civilisations antiques et consiste en général à célébrer le renouveau de la végétation, symbole de vie. À cette occasion on observe des rituels qui sont souvent d'ordre spirituel et alimentaire. En Syrie ou au Maroc, les célébrations du printemps se sont peu à peu perdues, subsistant dans certaines régions seulement, mais en Égypte, elles ont gardé une vigueur rare.

Il est communément admis en Égypte que les rites de la fête de printemps, Cham el-Nessim, possèdent une origine pharaonique et seraient précisément 
hérités de la légende d’Osiris ${ }^{5}$. La terre, comme le dieu Osiris, renaît après la sécheresse, grâce aux crues du Nil qui permet à la vie d’éclore à nouveau. Point culminant de la fréquentation des jardins publics au Caire, Cham elNessim qui signifie « respirer le zéphyr » est célébrée par tous les Égyptiens. Bien qu'elle soit liée au calendrier copte (elle a lieu le lendemain de la Pâque), elle n'est pas une fête religieuse, mais une tradition. Aujourd'hui elle est avant tout une fête familiale et de plein air.

Il était autrefois coutumier de sortir au petit matin pour respirer la brise du printemps «dont ce jour-là, on croyait qu'elle avait des effets bénéfiques merveilleux ${ }^{6}$ et d'aller se promener dans les jardins potagers et les vergers qui entouraient Le Caire. Désormais, la brise se respire tôt le matin dans les jardins publics où les familles restent jusqu'à l'heure de fermeture. Le piquenique constitue une des activités principales de cette journée à l'extérieur. Il contient les aliments rituels tels que les oignons frais, les pois chiches frais, les oeufs et le fessîkh ${ }^{7}$. Après le pique-nique les jeunes membres de la famille jouent au ballon, écoutent de la musique, dansent, ou se promènent dans le jardin. La célébration de la nature prend des allures de kermesse pendant laquelle on déguste des barbes à papa, on porte des chapeaux brillants, les enfants font voler des cerfs-volants. On se bouscule, on rit, la foule est un élément indispensable de la fête, autant que la présence de la nature.

Le jardin public se trouve au cœur d'une pratique très ancrée dans la tradition des Cairotes : au cours de cette fête, ce qui est convoqué est le jardin comme espace de loisirs, ainsi que l'idée de nature, symbolisée par les arbres et l'herbe sur laquelle on s'assoit, même s'il n'en reste plus que les racines. La ville est devenue si vaste, qu'il est difficile d'en sortir et de se rendre dans la « nature », alors cette fête a été transposée dans le contexte urbain où elle a pris ses marques, si bien que l'on peut entendre dire à cette occasion que « depuis les pharaons, on va pique-niquer dans les jardins publics »!

LA FÊTE DU PRINTEMPS FATALE AUX JARDINS: ORGANISATION SPÉCIALE ET FRÉQUENTATION

Pour ce jour de fréquentation exceptionnelle, les responsables des jardins publics se préparent à la vague populaire qui submerge le jardin. Ce jour représente pour le lieu probablement la plus grosse catastrophe de l'année, et les mois qui suivent sont presque exclusivement consacrés à réparer les dégâts d'une fréquentation massive. Dans les jardins les plus prisés les chiffres de fréquentations sont impressionnants: on recense chaque année environ 800000 entrées au jardin zoologique, 60000 au jardin botanique, 160000 au

\footnotetext{
5 Pour un récit détaillé de cette légende voir Georges Posener et alii, Dictionnaire de la civilisation égyptienne.

6 Edward Lane, The manners and Customs ef the Modern Egyptians, p.494.

7 Poisson type mulet préparé en saumure. Très salé, coloré en jaune par des épices, au goût et à l'odeur très prononcés, le fessîkh est consommé en très grande quantité ce jour-là.
} 
jardin international. La foule se presse aux abords de ces jardins et doit souvent patienter plusieurs heures avant d'y pénétrer, alors que la ville semble vide partout ailleurs.

Les gardiens des jardins sont sur le pied de guerre et une organisation particulière est mise en œuvre pour accueillir les visiteurs. Des barrières sont installées autour des jardins pour essayer de maîtriser et d'organiser la foule, et à l'intérieur pour essayer d'endiguer l'installation des familles sur les gazons. Des employés supplémentaires sont mobilisés pour assurer la vente des billets d'entrée et l'évacuation des sacs poubelle pleins. Mais cela n'est jamais suffisant et les jardins sortent de cette journée jonchés de déchets et les pelouses ravagées.

\section{LA RECHERCHE D'UNE COMMUNION IDENTITAIRE ET D’UN DÉFOULEMENT} COLLECTIF

La fête de printemps est une occasion unique8 pour beaucoup de sortir dans un lieu public en famille et d'y faire la fête, en communion avec d'autres familles qui n'appartiennent pas au cercle des relations proches. Le jardin n'est ici que le théâtre de scènes de liesse au cours desquelles des marqueurs communs permettent une identification collective. Les cris, les danses, les chants, le pique-nique, les odeurs (comme l'odeur forte du fessîkh), et les marques visuelles telles que les tenues neuves et les chapeaux, sont des rituels publics, partagés par tous ceux qui assistent à la fête et des marqueurs de l'appartenance identitaire. Le jardin public par le rassemblement qu'il rend possible devient le lieu symbolique où s'exprime la communauté des valeurs. Sans besoin d'une quelconque publicité, la fête de printemps est célébrée chaque année dans l'engouement des traditions partagées et réinventées. Sorte de point de ralliement, le parc public attire la fête, favorise l'imagination et semble protéger la tradition.

La foule immense est garante de la réussite de la célébration, et suscite les débordements des habitudes sociales. Elle permet de rapprocher les corps et de défouler les âmes. Transgression des contrôles extérieurs ou intérieurs le temps d'une journée, Cham el-Nessim permet l'expression d'attitudes habituellement refoulées et réprouvées. La mixité extrême de cette journée est une manifestation de la transgression des lois sociales qui s'appliquent en temps ordinaire. Ce jour-là, les comportements différents des autres jours sont acceptés car ils font partie du défoulement et se produisent au cœur d'un public nombreux et brassé, qui rend le regard d'autrui si présent qu'il en devient invisible, anonyme. La fête du printemps est une forme de rupture avec les normes conventionnelles, un excès socialement acceptable puisque chaque spectateur de la fête en est un acteur.

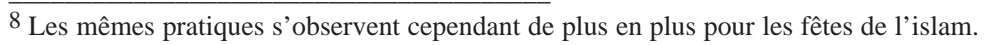


Cham el-Nessim est ainsi une fête à la fois spontanée et à date fixe puisque les habitants du Caire sortent de chez eux le jour fixé spontanément, traditionnellement, tout en étant également une fête extrêmement organisée, car attendue et encadrée par la police, les personnels des jardins, les vendeurs de poisson et de tous les accessoires afférents à la date. Mais au-delà d'une célébration annuelle, les jardins publics accueillent un loisir quotidien qui peut rendre lisibles les évolutions des sociétés.

\section{LES LOISIRS QUOTIDIENS DANS LES JARDINS PUBLICS : QUAND LE DÉSORDRE PREND PLACE}

Au Caire la fréquentation des jardins publics est très importante tout au long de l'année. À Rabat ou à Damas, cette fréquentation est moins intense, mais il faut la mettre en relation avec la taille des villes. Rabat et Damas sont deux villes millionnaires, alors que Le Caire compte entre 12 et 15 millions d'habitants. La pression sur les jardins publics n'est évidement pas la même dans ces contextes différents.

\section{LES PRATIQUES TRADITIONNELLES DES JARDINS PUBLICS}

La vie urbaine se décompose en une variété d’activités qui rythment les journées et constituent les nécessités et obligations de la vie quotidienne, auxquelles s’opposent les temps de loisir. La fréquentation des jardins publics est intimement liée au temps de loisir, à la mobilité et à l'accessibilité de ces espaces qui ont été conçus pour abriter des pratiques de loisirs précises, à tendance universelle, et de fait on peut les y observer très fréquemment.

La promenade est probablement l'activité de loisirs la plus répandue partout dans les jardins publics. Aisée, bon marché, elle est accessible à tous et apporte une satisfaction immédiate des sens (vue, odorat, toucher, ouïe). Lente, futile, pratiquée dans un espace au mode d'emploi très lisible, elle libère l'esprit pour une pratique en toute insouciance, uniquement tournée vers la recherche de la plénitude, de l'acte volontaire et donc non subi. La promenade quotidienne est souvent pratiquée dans les squares du quartier d'habitation pour plus de facilité. Au Caire comme à Damas, cette promenade quotidienne ressemble à une reprise de souffle entre deux activités, ou dans la vie familiale. Très prisée par tous, elle ne se tient pas toujours dans les jardins publics qui, trop peu nombreux, ne satisfont pas une demande toujours croissante d'espaces de délassement. D’autres endroits sont donc utilisés dans ce but. À Damas comme au Caire, les populations modestes investissent tout endroit qui ressemble de près ou de loin à un jardin, tout endroit de verdure, ou de nature : la corniche le long du Nil (au Caire) et la corniche du mont Qassiûn (à Damas), par exemple, sont fortement investies par les promeneurs.

La sortie des femmes avec les enfants dans les jardins publics, à l'instar de la promenade, n'est pas une originalité. Contrairement à ce que l'on pourrait 
penser, le jardin public n'était pas destiné à l'origine à recevoir la visite particulière des enfants. Pourtant ceux que l'on visite aujourd'hui à Rabat, à Damas et au Caire possèdent tous un espace équipé avec des jeux pour les enfants : bac à sable, toboggan, balançoires. Ces jeux sont généralement concentrés, ou retranchés, dans un espace précis du jardin ce qui pourrait suggérer que la présence des enfants n’est tolérée que d’une manière relative. Les espaces de jeux sont séparés du reste du jardin par des grilles que l'on franchit par des portillons, marquant ici encore une frontière entre le monde de l'enfance et celui des adultes. Si la sortie des femmes avec leurs enfants dans les jardins publics est très répandue, il faut noter qu'au total, peu d'équipements sont installés dans les jardins publics au Caire, à Rabat ou à Damas, sauf dans quelques-uns qui leur sont tout spécialement dédiés.

L'enfant est souvent un prétexte ou un alibi utilisé par les femmes pour sortir. En effet, accompagnée d'un enfant la sortie d'une femme dans un lieu public n'est pas suspecte, au contraire, elle est décente et respectable. Une femme seule sur un banc dispose souvent à côté d'elle un vêtement d'enfant ou un jouet. Le manque de lisibilité de la raison pour laquelle une femme est seule au jardin la rendra infailliblement suspecte d'amoralité. C'est pourquoi jamais une femme seule ne se rend au jardin sans accessoires : des paquets (une ménagère qui se repose entre deux achats), des cours (une étudiante qui révise), un sandwich (déjeuner rapide), les jouets ou vêtements d'enfants constituant l'alibi supérieur à tous les autres de sa présence dans un lieu de loisirs public. Ainsi, à travers la présence alibi de l'enfant, les femmes justifient leur présence dans les lieux de loisirs.

\section{LA FACE CACHÉE ET LES EXCLUS}

Les jardins peuvent se révéler davantage que des lieux dans lesquels se produisent des activités de loisirs attendues et prévues par les aménageurs. Ils sont aussi des espaces exutoires pour des « loisirs » marginaux, mal acceptés, ou pour des personnes mises au ban de la société.

La sieste est une activité très pratiquée à Rabat et à Damas dans les jardins publics, surtout par les hommes. Ces derniers profitent de la pause déjeuner pour se reposer sur un banc, assis, le visage dissimulé par leur veste. Si elle est relativement tolérée par les autres usagers des jardins, elle est cependant considérée comme une preuve du manque d’éducation de ceux qui la pratiquent. Au Caire, la sieste est interdite dans les jardins publics et les gardiens ont pour mission de réveiller toute personne qui s’y adonnerait. Il est en effet considéré par les responsables de l’aménagement des jardins au Caire que cette pratique est un signe de «manque de civilisation » voire de « sousdéveloppement ». Un tel état d'abandon intime est donc inadmissible dans des lieux conçus au contraire pour « éduquer le peuple ». La nature et le repos étant très compatibles, elle est cependant fort pratiquée. 
Tous les loisirs liés aux jardins publics ne se déroulent pas de jour. Certains d'entre eux, largement réprimés et condamnés prennent place la nuit, lorsque l'ombre recouvre la végétation et masque les activités. La nuit les jardins permettent la dissimulation grâce aux ombres changeantes et parfois inquiétantes. Ils se transforment en espaces où la face cachée des sociétés s'exprime, où les populations souterraines, interdites et taboues font surface. La prostitution et les rencontres homosexuelles tirent avantage de l'image nocturne inquiétante des jardins. À Rabat, à Damas et au Caire, l'homosexualité et la prostitution sont considérées comme déviantes, comme des perversions honteuses qui par conséquent ne s'expriment pas au grand jour. Elles ont donc besoin de lieux de rencontres ouverts, accessibles facilement et cependant discrets. Les jardins publics remplissent parfaitement ces conditions et permettent à la fois aux homosexuels et aux prostituées de prospecter.

La face cachée des jardins publics abrite également les exclus de la ville et ceux dont on considère que le comportement comme marginal. Ainsi, dans certains jardins, notamment au Maroc, on observe une consommation, voire un commerce, d'alcool et de drogue. Ces pratiques prennent place dans des lieux de loisirs qui n’ont pas été conçus dans ce but, entraînant pour certains lieux un conflit d'usage important qui pousse les pouvoirs publics à déployer des forces de police pour essayer de rendre les pratiques des jardins conformes à celles qui avaient été prévues. Cela passe également par le renvoi des sans domicile installés dans certains jardins.

LES LOISIRS QUI BOUSCULENT L'ORDRE APPARENT : LES NOUVELLES TENDANCES DES SOCIÉTÉS

La société se donne à voir dans les jardins publics d'une manière très différente des autres lieux de la ville. La proximité de la nature en fait des lieux perçus de façon globalement positive dans la société. On y applique des normes différentes de comportements. À travers l'étude des pratiques de loisirs dans ces lieux, on peut remarquer que c'est probablement là où s'expriment de nouvelles tendances de la société : dans les relations hommes/femmes et dans les nouvelles formes de fréquentation.

Les jardins publics sont des lieux de rencontres entre les hommes et les femmes, un espace de mixité, mais aussi un lieu de " drague verte », loisir qui occupe une grande partie du temps libre des jeunes gens. Si cette activité est plutôt positive pour la réputation des garçons, elle peut en revanche peser lourd sur celle des filles. Mais souvent ignorées des parents et de l'entourage proche des filles, car pratiquées dans des jardins éloignés du territoire familial, ces activités permettent aux deux sexes de parfaire leur connaissance mutuelle, loin du cadre codifié du mariage et du regard évaluateur des adultes. Ils permettent donc les rencontres spontanées, mais aussi procurent aux jeunes couples des lieux de rendez-vous alors que leur couple n'est pas officiel. 
Le flirt n’est pas reconnu en Syrie ou en Égypte, et mal accepté au Maroc. Bien que très largement pratiqué, il est nié car considéré comme contraire à la morale. Les jeunes filles elles-mêmes ne reconnaissent pas ouvertement qu'elles flirtent : elles rencontrent leur futur mari, c’est très différent ! Pour la réputation d'une jeune fille, être vue dans un lieu public avec un jeune homme est très mauvais pour la réputation. Or la réputation conditionne le mariage qui reste le but recherché d'une relation amoureuse. Les jeunes femmes doivent donc composer avec la contradiction entre leurs pratiques, la morale et les codes sociaux. Tant que leurs rencontres amoureuses restent secrètes, elles sont à peu près libres de leurs mouvements. Ainsi, elles se rendent dans les jardins publics loin de chez elles pour rencontrer leur petit ami. Menant une double vie à travers la liberté qu'elles prennent de mener leur vie comme elles l'entendent, ces jeunes femmes font émerger un mouvement de changement social, encore non reconnu, mais très largement répandu, qui se lit encore dans les nouvelles pratiques sportives qui marquent les espaces publics.

Depuis une dizaine d'années le rapport du sport à la ville a changé, notamment à la suite de l'apparition du jogging, à la portée de tous. À Rabat, on rencontre des coureurs surtout dans le bois de l'Agdal qui est devenu depuis dix ans le rendez-vous des sportifs de Rabat, auxquels il offre d'ailleurs un parcours de santé fléché et ponctué d’exercices avec agrès. La course à pied est largement valorisée à Rabat alors qu'elle n’est pas pratiquée par tous. Seules les hommes des classes moyennes et supérieures vont courir, signe d'une certaine modernité sociale et culturelle, synonyme de l'adoption d'un mode de vie à l'occidentale. La présence de femmes joggeuses dans le bois n'est pas une exception. Très majoritairement jeunes, vêtues à l'occidentale, elles courent le plus souvent seules. La pratique du jogging chez elles, encore davantage que chez les hommes, est d'abord provoquée par la prise de conscience des besoins du corps moderne qui, ne s'usant plus au travail doit cependant être mince pour répondre aux canons de beauté modernes. En courant ces femmes affirment une liberté physique jusque-là suspecte: offertes aux regards des hommes inconnus elles mettent en mouvement leur corps dans un lieu public. Elles affirment ce faisant leur appropriation de l'espace public et leur individualisation face à un mode de vie traditionnel dont elles rejettent les assignations territoriales liées au sexe.

De plus en plus, la pratique sportive individuelle semble se développer à Rabat, au Caire et à Damas où les directeurs ouvrent désormais les jardins à six heures du matin pour permettre aux adeptes de la marche (davantage que du jogging) de pratiquer leur sport. Car comme le jogging, la marche semble être le moyen le plus naturel de mettre son corps en mouvement, elle doit donc être pratiquée dans un lieu « naturel ». Considérée comme davantage décente, la marche est beaucoup plus développée au Caire et à Damas que le jogging, mais elle est tout autant le signe d'une nouvelle tendance tendant à montrer qu'en ce qui concerne les loisirs, on semble aller vers une individualisation des pratiques. Jogging et marche se pratiquent en effet seul ou à deux. 
Les jardins publics sont des lieux de loisirs variés qui prennent des formes nombreuses: les loisirs attendus, tels que la promenade, la sortie avec les enfants notamment, les fêtes, mais aussi les loisirs ou activités qui n’avaient pas été prévues, telles que les rencontres amoureuses non officielles et de tout type ou le sport qui se développe depuis une période récente. Dans ces conditions, on remarque que ce que les usagers attendent du jardin, c'est un cadre, un théâtre. Ils attendent davantage un espace ouvert (mais fermé par le moyen de clôtures ou de haies) qui permette aux différentes pratiques de s‘exprimer, plutôt qu'un lieu équipé dans lequel seuls certains types de loisirs trouvent leur place. Dénoncés comme des lieux «mal fréquentés » par les classes aisées, ils les mettent mal à l'aise car ils représentent des lieux de liberté et de défoulement, des lieux dans lesquels tout ne peut pas être contrôlé ; ils sont dénoncés comme des lieux de débauche dans les courriers des lecteurs des journaux locaux. Alors, pour éviter les rencontres d'amoureux le soir, des projecteurs qui éclairent les jardins sont installés. Mais les activités qui y prennent place montrent malgré les réticences et les tentatives de contrôle, des changements indéniables dans ces sociétés. La tendance est aujourd'hui à la construction de parcs de loisirs, suréquipés d'activités prêtes à consommer, et pratiquement sans verdure. On peut se demander s'ils pourront jamais assumer le même type de rôle.

\section{Bibliographie :}

Corbin Alain (dir.), 1995, L'avènement des loisirs, 1850-1960, Paris, Aubier.

David Jean-Claude, 1994, «Rencontre, côtoiement, ségrégation. Un autre type de sociabilité ? ", Monde arabe Maghreb Machrek, n¹43.

Debié Frank, 1992, Jardins de capitales. Une géographie des parcs et jardins publics de Paris, Londres, Vienne et Berlin, Paris, CNRS.

Depaule Jean-Charles, 1990, «Le Caire : emplois du temps, emplois de l'espace », Monde arabe Maghreb Machrek, n¹27.

Di Méo Guy, 1998, Géographie sociale et territoires, Paris, Nathan.

Foucault Michel, 1984, Dits et Écrits.

Hanna Nelly, 1997, « Social implications of housing types in 17th and 18th century in Cairo », dans Mohamed Naciri, André Raymond, Sciences sociales et phénomènes urbains dans le monde arabe, Casablanca, Fondation du roi Abdul Aziz Al-Saoud pour les études Islamiques et les sciences humaines.

Naciri Mohamed, 1988, «Une nouvelle fonction du centre ville moderne marocain : loisir et convivialité ", Éléments sur les centres villes dans le monde arabe, URBAMA, Tours, Fascicule de recherche ${ }^{\circ} 19$.

Posener Georges, 1959, Sauneron Serge, Yoyotte Jean, Dictionnaire de la civilisation égyptienne, Paris, Fernand Hazan.

Wassef Cérès Wissa, 1971, Pratiques rituelles et alimentaires coptes, Le Caire, IFAO. Ziade Khaled, 1996, Vendredi, dimanche, Arles, Sindbad-Actes Sud. 


\title{
BRIBES DE VIE, BRIBES DE VILLE. FÊTES DES SAINTS (MOULED-S) AU CAIRE
}

\author{
Anna MadeUf, \\ Université François-Rabelais de Tours, CITERES-EMAM
}

"Une fête ne saurait attendre sous peine de voir le soufflé s'affaisser » Pierre Sansot, Poétique de la ville, 1973, p. 144.

Les mouled-s (appellations locales de mawâlid, anniversaires) sont, en Égypte, des célébrations festives organisées en l’honneur d'un personnage saint autour du lieu de culte qui lui est consacré. Leur pratique est tout particulièrement répandue au Caire où reposent, dans ses nécropoles mais aussi dans la ville même, un grand nombre de saints, issus notamment de la lignée du Prophète Mohammed (dits ahl al-bayt "gens de la maison »), comme Husayn et sa sœur Zaynab (ses petits-enfants) dont les mosquéesmausolées sont situées au centre de la cité, et dont les mouled-s sont les plus fréquentés de la capitale ${ }^{1}$. Ces fêtes associent résidents et pèlerins venus en masse de l'ensemble du pays et mettent en scène les quartiers concernés selon des pratiques codifiées et rythmées de l’espace. Ces deux événements majeurs culminent lors de la « grande nuit », layla al-kabira, qui clôture la célébration, mais se déroulent pendant environ une semaine, durant laquelle les pèlerins provinciaux, venus essentiellement dans le cadre de confréries religieuses (soufies), campent sur place, dans de vastes tentes de cérémonie ou des abris

1 Fréquentation impossible à évaluer de manière précise mais qui concernerait selon la presse (quotidien al-Ahrâm notamment) plusieurs centaines de milliers de visiteurs. 
plus sommaires, et investissent tous les lieux disponibles dans le quartier, notamment les mosquées.

\section{DU MOULED À LA FÊTE}

Il s'agira ici d'évoquer, tout en les masquant en partie, les mouled-s du Caire, ou plus exactement, depuis ces mouled-s, utilisés en tant qu'expériences de recherches, d'essayer de présenter un certain nombre de réflexions et d'hypothèses sur les fêtes urbaines, élaborées dans un contexte qui, sans être dissimulé, ne sera pas surexposé. Ce procédé d'abstraction partielle a pour objet de soumettre la recherche à un questionnement fondé sur la notion de divertissement. De fait, les mouled-s sont simultanément, et en un même mot, pèlerinages et fêtes; c'est donc cette dernière dimension qui sera plus particulièrement évoquée, même si le motif d'essence religieuse est essentiel et donne à l'évidence un caractère et une identité propres à ces fêtes. Isoler le festif relève totalement d'un artifice puisque ces célébrations sont des combinaisons, à tonalités multiples, où la piété n'exclut pas la joie du divertissement, au contraire, et où sont associés et entrecroisés les aspects religieux et profanes de la fête. Les pratiques se mêlent, se complètent ; l'amour et la dévotion envers le Prophète et sa parentèle sont, en Égypte, synonymes de joie. En témoigne notamment ce verset du Coran, inscrit sur de nombreux mausolées : "Non certes les saints de Dieu ne sont soumis à aucune peur ni ne connaissent la tristesse ${ }^{2}$. Comment mieux honorer ces personnages qu'en reproduisant des traits de leur caractère, exemplaire s'il en est ? Même s'il s'agit d'une interprétation peut-être très égyptienne.

Les mouled-s ne peuvent pas être définis exclusivement comme étant des loisirs ou des divertissements, mais par contre les énoncer en tant que tels peut être une façon de décrypter ces manifestations. Par le biais du mouled, on peut voir, penser et créer la ville autrement, et cette perspective peut être une proposition de lecture de ces événements. Entrer ou passer dans un monde autre grâce à une échappée, la fête, même si celle-ci n'est ni aléatoire ni hasardeuse, mais résulte d'un projet et d'un projet consensuel. Il y a bien sûr une issue à cette histoire, puisque l'on ressort toujours du mouled, de son lieu, de son temps, de son ambiance. Par définition, rythmes et temporalités des fêtes sont spécifiques, le temps y est cyclique et mesuré, on le sait, mais il en va de même pour l'espace: les fêtes se produisent en des lieux qu'elles investissent et surinvestissent, les soumettant à une prise puis à une déprise. Cette inscription spatiale, constitutive de territoires dans la ville, est aussi une des pistes possibles d'une réflexion sur le sens des loisirs et des divertissements dans les sociétés urbaines. De fait, la ville elle-même peut apparaître comme fête ou illusion de fête pour ceux qui la vivent ordinairement et la voient transfigurée, et plus encore pour ceux qui ne la vivent pas au

2 Coran, sourate Yûnis, verset 63. 
quotidien (visiteurs) pour qui elle est aussi la destination du voyage, et pour qui elle peut n'exister concrètement que par le mouled et lors du mouled. L'aspect clinquant et chatoyant de la cité lui donne l'allure d'une fête perpétuelle; le nouvelliste Youssef Idris évoque cette confusion, lors de l’arrivée au Caire d'une jeune provinciale :

«Des lumières, de toutes les couleurs du spectre, qui s'allumaient et s'éteignaient en une sorte de symphonie... (...) Elle s'était figurée, en descendant du train (...) qu'il y avait en ville une grande célébration religieuse pour laquelle les gens se rassemblaient en foules nombreuses. (...) Quelle ville que celle-là où les gens vivent tous les jours comme des jours de fête !". (Youssef Idris, La sirène, 1986, p. 27-28).

Lors du mouled, chacun, visiteur ou habitant, participe à la transformation festive du quartier, ce qui attribue à chaque individu un rôle et par là un certain pouvoir sur les lieux et l'événement. De la même manière, le premier des divertissements est le(s) spectacle(s) résultant de la simple présence de l’Autre, des autres : hommes et femmes ; Cairotes et provinciaux ; pèlerins et badauds, etc. Regarder les autres, regarder la ville, regarder les autres s'amuser et regarder la même chose que soi, ou soi ou autre chose : toutes ces possibilités, toutes ces figures sont autant de sources évidentes, infinies et inlassables de connivences et/ou de moqueries. Au-delà de l'amusement d'être ensemble est le plaisir trouble d'être ensemble, de "respirer de l'humain comme d'autres s'enivrent de l'air du large » (Pierre Sansot, 1973 p. 57). Aussi, les mouled-s dans leur intentionnalité ne sont ni loisirs, ni divertissements, mais ils le deviennent. La célébration s’inscrit dans une mise en scène qui relève d'autres motivations ; la pratique religieuse n'est pas un prétexte mais impulse la fête laquelle n'est pas pour « rien », mais bien pour un tout (une foi et une identité partagées). Pourtant, la fête s'autonomise toutefois et se conforme à des logiques d'inscriptions dans des espaces, à la fois conformes et contraints, qui sont ceux de la ville laquelle, par définition, a aussi ses logiques de production d'espaces-temps festifs et d’interactions liées à ce registre.

\section{DEUX MOITIÉS DE VILLE...}

«La ville de Sophronia se compose de deux moitiés de ville. Dans l'une, il y a le grand-huit volant aux bosses brutales, le manège avec ses chaînes en rayons de soleil, la roue avec ses cages mobiles, le puits de la mort avec ses motocyclistes la tête en bas, la coupole du cirque avec la grappe de trapèzes qui pend en son milieu. L'autre moitié de la ville est en pierre, en marbre et en ciment, avec la banque, les usines, les palais, l'abattoir, l'école et tout le reste. L'une des moitiés de ville est fixe, l'autre est provisoire, et quand le terme de sa halte est arrivé, ils la déclouent, la démontent et l'emportent pour la replanter sur les terrains vagues d'une autre moitié de la ville ». (Italo Calvino, Les villes invisibles, 1972, p. 77).

Sophronia, l'une des Villes invisibles d'Italo Calvino, est une cité festive, mais elle ne peut l'être totalement ou de manière continue. Si l'une des moitiés 
de la ville est utile, pragmatique et fonctionnelle, l'autre n'est pas pour autant son contraire exact, mais plutôt tout le reste, ce qui est étrange, un autre monde, peut-être infini, surtout indéfini. Est posée ici la question combinée du stable et de l'instable fondant un équilibre, du sécable et de l'insécable fondant une totalité-globalité, du permanent et du temporaire construisant l'espace et le temps, de l'association du fixe et du flou, soit quelques éléments fondateurs d'une dialectique binaire et/mais complexe. Sophronia, espace allégorique, suggère que la fête est à la fois dissociée dans l'espace absolu de la cité et à la fois moitié de sa réalité. Elle est aussi une ville itinérante, qui se fixe de manière provisoire en un espace flottant - un terrain vague - qui est dans la ville sans en être, sans faire partie de sa composition, une forme supplémentaire.

De fait, dans le cas des mouled-s, la fête se surimpose et se rajoute, se monte et se démonte, en des quartiers dont elle contribue cependant à fonder la territorialité et l'identité. Plus largement, la pratique des mouled-s contribue à faire du Caire une capitale, un espace originel, la ville appropriée par l'ensemble des Égyptiens et la «mère du monde » (Oum al-duniya), comme elle est aussi nommée. Formulé autrement par Kevin Lynch $(1998,140)$ : "l'homme a besoin d'un environnement qui ne soit pas simplement bien organisé, mais également poétique et symbolique ». Les mouled-s sont à cette image, des événements attendus, reproduits, lesquels impliquent une adhésion et une participation collectives et mettent en scène et en valeur, pour un temps, des espaces de la ville. Les célébrations festives, moments cycliques qui rythment le cours de l'existence des êtres et marquent la symbolique des lieux, résultent de la fusion d'un moment célébré et d'un lieu distingué.

Pour poursuivre cette assertion, c'est peut-être parfois la fête qui institue la ville comme le suggère le romancier Jorge Amado en d'autres contrées. Ainsi, c'est à l'occasion de la célébration de la Saint-Jean que Tocaia, bourgade du nord-est brésilien, se " civilise »; pour l'affirmer en tant que cité, ses habitants décident d'y organiser une fête. C'est ce véritable acte fondateur qui va marquer irréversiblement sa promotion, son accession dans les représentations et dans les pratiques au rang de ville. Cette intuition romanesque est d'ailleurs corroborée par nombre de recherches montrant que les "processions et fêtes religieuses sont les activités urbaines les plus anciennes du Brésil »33.

Les fêtes contribuent ainsi à produire et à penser la ville en tant que telle, comme un lieu investi, notamment spirituellement et symboliquement, un espace animé. La fête est une des traductions de l'existence d'une société en place ; elle est à la fois forme et esprit, mais bien sûr elle est temporaire et soluble, ici forme et esprit ne sont jamais les mêmes et s'évaporent à chaque fois pour se reproduire de manière différente une autre fois.

\footnotetext{
3 Voir la contribution de Lea Freitas Perez « Lieux de fêtes au Brésil », in Lieux et non-lieux de l'imaginaire, Internationale de l'imaginaire, p. 83.
} 


\section{ÊTRE ENSEMBLE ET ÊTRES ENSEMBLE}

Si l'on considère la ville comme une expression du vouloir être ensemble, la fête en est sa consécration, un concentré, elle est aussi une manifestation de ce que Michel Maffesoli nomme la "viscosité sociale», cette "curieuse pulsion qui pousse à se coller à l'autre »4, pulsion ni verbalisée ni consciente. La foule c'est l'autre au pluriel et dans tous ses singuliers. La foule permet simultanément de s'exhiber et de se dissimuler, de rencontrer intensément sa société et de l'oublier tout aussi intensément. Le personnage de «somnambule » tel qu'il est réinterprété par Isaac Joseph (Le passant considérable), se construit en tant qu'individu et nourrit sa pratique de la société depuis un espace urbain hanté par la foule. Si l'envie sociale d'être ensemble résulte certainement de motivations universelles, les prétextes, conditions et formes de ces rencontres diffèrent, les mouled-s en sont une illustration. La fête est aussi une forme possible d'espace public lorsqu'elle est associée à l'imaginaire d'une société, à sa culture, lorsqu'elle se fait modèle et ferment. Dans le registre culturel français, la fête peut apparaître comme étant le lieu-contexte de la quête et de la rencontre de l'amour ; en témoignent de nombreuses œuvres populaires issues de divers genres, par exemple un roman $^{5}$, Le Grand Meaulnes, une chanson : La foule interprétée par Édith Piaf6, ou un film: Les enfants du paradis de Marcel Carné7. L’amour, au dénouement souvent tragique, surgit lors d'une circonstance légère, qui est celle du divertissement, prenant les protagonistes au dépourvu.

La fête est une perspective, un horizon attendu, pensé, imaginé, deviné, sans réalité unanime et objective mais qui existe néanmoins et a l'aspect et la fonction que chacun lui projette. L'horizon peut être vu comme une figure abstraite et sans contours, simultanément rien et tout, à la fois espace et temps, une figure ouverte, dégagée vers des possibles, des probables, sans limites. L'horizon est un ferment pour l'imaginaire, il est objet d'inspiration et de créations, en tant qu'il laisse envisager un élargissement du monde, une reconfiguration du réel. Cette thématique est souvent traitée dans la littérature romanesque (notamment dans le Désert des Tartares de Dino Buzzati, ou le Rivage des Syrtes de Julien Gracq) et de manière particulièrement explicite pour les mouled-s par Abdel-Hakim Qassem dans Les sept jours de l'homme, roman en partie autobiographique et écrit en empruntant le rythme saccadé

\footnotetext{
4 Voir l'interview de Michel Maffesoli dans le Monde du 14 juillet 2000, à propos du pique-nique citoyen organisé en France à l'occasion de la fête nationale.

${ }^{5}$ Le recours à la fête est un procédé ou artifice récurrent en littérature, utilisé comme une alchimie, il permet de troubler le récit, de bouleverser les caractères et de précipiter l'action. À titre d'exemple, la séduction d'Emma Bovary par Rodolphe a lieu lors de la fête du bourg où elle vit. Quant au destin du Grand Meaulnes, il est scellé après la rencontre de la fête au château.

6 À l'occasion d'une fête, une rencontre due au hasard entre deux êtres, s'ensuit un coup de foudre, mais la foule séparera les amoureux qu'elle avait unis.

7 Scénario de Jacques Prévert, film réalisé entre 1943 et 1945. On peut aussi penser à Jour de fête, de Jacques Tati.
} 
d'un mouled. L'horizon symbolise aussi l'attente et l'attente est elle-même imaginisante. Cette métaphore peut aussi être l'un des cadres d'une recherche, puisque l'on sait que c'est lorsque les horizons s'oblitèrent et se referment, que du point de vue choisi, on peut mettre fin à l'interprétation8.

Il y a des choses qui se lisent dans la ville, d'autres qui se voient, certaines dont on parle, et d'autres encore qui se savent et se vivent ; ces dernières ne sont pas toujours les plus exposées, celles que l'on décèle d'un regard. Le mouled est une voie d'accès à une réalité autre que matérielle, à un monde invisible. Lorsque la fête en l'honneur du saint est passée, son aura demeure. Le mouled est un moment d'exaltation des valeurs idéelles et symboliques de l'espace, lesquelles deviennent alors plus apparentes, car exprimées et vécues de manière visible ; le reste du temps, ces significations sont diffuses, moins lisibles, mais néanmoins présentes.

\section{MiXAgES D’ESPACES ET DE TEMPS}

L'existence pleine de la fête suppose une élaboration en trois temps, qui n'existent et ne sont définis que les uns par rapport aux autres et comme constituants d'un ensemble solidaire. Ces temps sont essentiels bien qu'inégaux : un avant - l'attente -, un pendant - le vécu -, et un après - le souvenir - avec sa recomposition au travers de la constitution de récits et de commentaires. Un exemple en est d'ailleurs fourni par John Steinbeck avec les relations magnifiées et détaillées des péripéties d'une soirée donnée à Tortilla Flat. Le souvenir, "possession en apparence irréelle et accessoire (...) par l'intermédiaire duquel le passé se blottit doucement, insensiblement contre le présent » (Stefan Zweig, 1996, p. 186), permet d'ébaucher des contours à l'avenir, de le contourner. Le souvenir d'un mouled, à un moment transitionnel, changera de nature pour devenir l'idée du prochain mouled, soit une reprise du cycle du temps. Pourtant, comment savoir exactement de quelle manière et à quel moment passe-t-on de l'évocation du passé à l'énonciation de l'avenir, comment une idée se «transvase » d'un temps à l'autre, et de surcroît de deux temps a priori contraires ? S'amuser, se divertir autant d'actions qui prennent souvent la forme d'échappées, d'esquives, de déprises à des oppressions tant individuelles que sociales, dont celle du temps. Quant au temps même de la fête, il est absolu, il a un commencement et une fin, comme une parodie résumée du temps de la vie, mais dont on connaît le moment fatidique, celui de l'issue ; on sait qu'il faut alors exister entre ces repères. Le mot divertir vient du latin divertere : détourner. Son deuxième sens est celui d'une occupation qui détourne l'homme des problèmes essentiels qui devraient le préoccuper: «le

\footnotetext{
8 « Si la signification est un jeu de relations, il n'y a rien au-delà de celles-ci, elle est comme un tissu dont on suit le motif en ses tours et détours. Il n'y a donc ni essence cachée, ni noyau intime et ultime, le sens n'a pas de profondeur, il n'a que des horizons et c'est lorsque ceux-ci se répètent et se referment, lorsque aucune relation nouvelle ne se dessine sous le regard que l'on peut décider que, selon le point de vue choisi, l'interprétation est finie » (Daniel Fabre, 1989, p. 78).
} 
divertissement nous amuse et nous fait arriver insensiblement à la mort » (Pascal) $^{9}$. Pourtant, la fête conjugue ces deux tonalités en apparence contradictoires, et c'est peut-être cette dimension de « comédie humaine » qui lui donne un caractère tragique et poignant. Elle suscite des émotions vives, contradictoires, heurtées, des bouffées de joies et d'angoisses concentrées, soit un état d'âme bien particulier, une « macédoine morale, moitié plaisante, moitié funèbre » selon Balzac ${ }^{10}$. Moments de conscience aiguë de soi, des autres, de la vie, qui se traduisent par une propension à être plus visible, plus bruyant, plus présent, à manifester et à exacerber ses «territoires du moi » (Erving Goffman, 1973).

Nous sommes toujours, par notre condition humaine, plus ou moins dans un état d'expectative, on peut supposer que la fête fournit un débouché, une issue momentanée, une pause (ou peut-être même une raison ?) à cet état. Vers la fête, chacun peut condenser, faire converger ces souhaits, aspirations, quêtes, attentes et désirs, laissés en des états vagues, confus, non formulés, qui sont projetés ou juste canalisés vers un moment et un lieu qui eux sont objectifs et deviennent alors un objectif plus précis, même s’il est probable que tout cela reste dans l'inaccompli. Quoiqu'il en soit, la fête aura toujours, à l'issue de beaucoup d'agitations, un effet apaisant sur les corps et les esprits. La fête est volatile, elle se déroule, se défait, tout y est agitation, à commencer par l'état d'esprit des participants qui suppose un soupçon d'exaltation. Le temps de la fête est compté, et même décompté, borné, il file, ce qui implique des « syndromes », dont on peut imaginer qu'ils sont ceux de la citrouille et du sablier, et qui se manifestent notamment par une angoisse du temps qui passe, tout particulièrement de la venue de l'aube, du retour du jour, qui va remettre en phase la normalité, le rythme binaire dominant diurne-nocturne, balancier régulier qui cadence la vie des hommes.

\section{DIVERSIONS ET DIVERTISSEMENTS}

S’intéresser aux fêtes implique que l'on dispose de peu de temps réel, ce temps dont on a pourtant besoin pour construire sa pensée à propos de l’objet étudié, pour que paroles, faits et images puissent décanter. Le caractère évanescent de l'événement conduit à une collecte de fragments. Par ailleurs, tout le monde semble alors vivre et agir de manière accélérée et il est aussi difficile de considérer la simultanéité de situations et de scènes. Il faut alors s'accommoder d'une saisie instantanée, spontanée, mais peut-être doit-on justement raisonner la fête ainsi, accepter l'immédiateté et en faire une condition de travail. Il faut dans ce contexte mentionner aussi l'immersion, la proximité des scènes et des personnes, la promiscuité ; la réduction des intervalles usuels entre individus, le

${ }_{9}^{9}$ Le Nouveau Petit Robert, dictionnaire de la langue française, éd. de 1993.

10 Sentiment évoqué par le narrateur, relatant le déroulement d'une fête dans la nouvelle Sarrasine, laquelle débute ainsi: "J'étais plongé dans une de ces rêveries profondes qui saisissent tout le monde, même un homme frivole, au sein des fêtes les plus tumultueuses ». 
confinement. Les rythmes et directions de circulation de chacun sont différents, les gens passent, repassent, les combinaisons sont variables à l'infini, le paysage change en permanence ; à la longue, le défilé des personnes en présence prend la forme d'une galerie de portraits animés qui suscite le vertige. Les lieux, éventuellement déjà connus, sont autres, deviennent sujets à exploration. La fête va induire un rapport au lieu spécifique en tant qu'elle est elle-même, avec ses composantes et ses limites, un espace, qu'elle se surimpose à un quartier, rendant les parcours usuels et les circuits du quotidien obsolètes. Le paysage, par les effets de foule qui l'animent, crée un décor toujours changeant, suscite des troubles de l'orientation, amène une découverte de nouvelles topographies. La fête se fonde sur un mouvement perpétuel, incessant, dont la cadence, soutenue, finit toutefois par décliner vers le milieu de la nuit, à partir d'un moment imprévisible où le rythme général bascule, se rompt. Cette cadence s'inverse, une sorte de langueur succède à l'agitation et puis la fête s'achève, dans le cas des mouled-s, non pas selon une dégradation progressive mais par une déconstruction, une "démolition générale »11 (Abdel-Hakim Qassem, 1998, p. 170).

Les mouled-s, tous différents, se ressemblent pourtant ; en s'inspirant d'un espace préexistant, en se fondant sur un lieu unique et distingué, ils semblent néanmoins l'absorber ou l'estomper en partie, le modeler. Ils présentent une gamme de caractères dominants qui font leur faculté à créer un climat à la fois unique et banal, un paysage aussi original que familier. La fête adhère à la ville et l'ingère, l'engloutit en partie. L'ordinaire se fait exceptionnel, la ville est esthétisée, sublimée, devient elle-même spectacle. Les formes des bâtiments sont redessinées, stylisées par le jeu des guirlandes lumineuses. La grande mosquée, centre et âme de la fête, est une fois l'an, illuminée ; selon la métaphore poétique, elle est parée et étincelante " comme une mariée " ('arûsa); parfois elle devient invisible sous la cascade de lumières éblouissantes. Un mouled est aussi un système esthétique. Des guirlandes d'ampoules colorées, des tissus aux vifs imprimés, des pyramides de confiseries (Ill. 1), des accessoires festifs, des étals de jouets et de colifichets, des stands de tir (Ill. 2), des spectacles ou des exhibitions, une panoplie de jeux d'adresse et de force, des grandes roues, des autotamponneuses... Attractions ou animations, les sollicitations sont multiples. Sur fond rouge soutenu, couleur récurrente et obsédante des tentures dressées le long des édifices, des arceaux ponctuent les rues, une profusion de guirlandes lumineuses, de fanions multicolores et de banderoles, tout un jeu récursif mêle ingénieusement drapés et éclairages, dissimule ou accentue des traits de la configuration des lieux. L'espace devient aussi extrêmement bruyant, dense de sons de toutes sortes, gorgé de sonorités : musiques et chants,

11 Un procédé qui rappelle la fin de la fête annuelle de la ville phœnix de Burning Man, lorsque la cité, construction temporaire, est démolie, puis incendiée. Chaque année depuis 1992, en août, dans le désert du Nevada, cette ville, fréquentée par des milliers d'Américains venus y faire la fête, naît et meurt en sept jours (cf. Le Monde du 30 sept. 2002). 
récitations, louanges, appels, cris, plaintes, pétards, crécelles et paroles profanes ou non amplifiées par les équipements de sonorisation. Le paysage visuel et sonore se trouve réordonné, recomposé, sujet à une nouvelle harmonie. La fête est aussi l'occasion de dons et d'abandons, sous des modes très divers : on s'oublie, un peu ou beaucoup, parfois on n'est plus exactement soi (sous l'effet de la transe, de la danse, de la fatigue, des stupéfiants, etc.), on se donne en spectacle, on s'abandonne même en se livrant au hasard, aux autres, parfois juste en déambulant ou en se laissant ballotter par la foule. La hiérarchie des prévalences est changée, selon une logique différente, le sucré est préféré au salé, ce qui régale plutôt que ce qui nourrit, l'esthétique l'emporte sur le pratique, etc.

Un ordre éphémère prévaut, qui modifie les parcours, place, déplace ou replace les éléments de la composition urbaine. La hiérarchie, du sacré au profane, est lisible dans la distribution graduée des éléments : la fête foraine et les tentes d'habitation sont plutôt excentrées et mises en arrière-plan tandis que les tentes de cérémonie des institutions officielles et des confréries importantes se serrent devant la grande mosquée. La fête est un territoire qui a un épicentre, la mosquée-mausolée, des lieux d'exposition, très éclairés, bruyants et nets, des bas-côtés, des coins et recoins, des culs-de-sac, des zones de lumières et de pénombres ${ }^{12}$, elle se poursuit en des lieux mitigés puis se perd vers des halos de lumières et de sons déclinants, transitions vers la ville ordinaire. En ce sens, aller à une fête peut être comme accomplir un voyage idéal, aller vers un univers tout à la fois surprenant et rassurant. La fête marque toujours une discontinuité à la fois dans l'espace et le temps, mais elle est une sorte d'intervalle autonome. Par ailleurs, le lieu de la fête - ici - est un lieu précis, mais cet ici est aussi un ailleurs, une combinaison a-territorialisée, une sorte de nulle part.

Ainsi, la fête peut être énoncée comme un phénomène socio-spatial qui permet de distinguer par l'unicité - une figure, un temps, un lieu - le monde, de lui donner forme et sens, permettant à chacun d'être (en tant qu'acteur et moteur) un participant de cette société éphémère, et par là de la société. On est heureux que la fête existe, de cette extériorisation, mais on est également satisfait qu'elle s'achève, qu'elle cesse, du retour de l'ordre dominant, auquel on aspire puisque l'on vit en société, mais ordre induit aussi par le caractère cyclique de l'existence des choses et des êtres: le décor se dégrade, les vêtements se froissent, les traits se tirent, les corps se relâchent, l'énergie s'épuise. Alors, la fête semble se dissoudre, de la décomposition de sa mise en scène émerge une autre figure. Au fur et à mesure de l'avancée de la nuit, les Cairotes rentrent chez eux ; les départs des provinciaux se feront au cours de la matinée suivante. Enfin, le quartier est rendu à la ville. Le temps n’est plus à la fête, les lieux non plus.

\footnotetext{
12 Comme on le voit dans le film Sueurs froides où Alfred Hitchcock met en scène le meurtre d'une jeune fille lors d'une fête foraine : l'alternance de la lumière et de la pénombre marque le passage de la vie à la mort, du rire à l'agonie.
} 
Illustration 1 : Stand d'un confiseur, mouled de Sayyida Zaynab

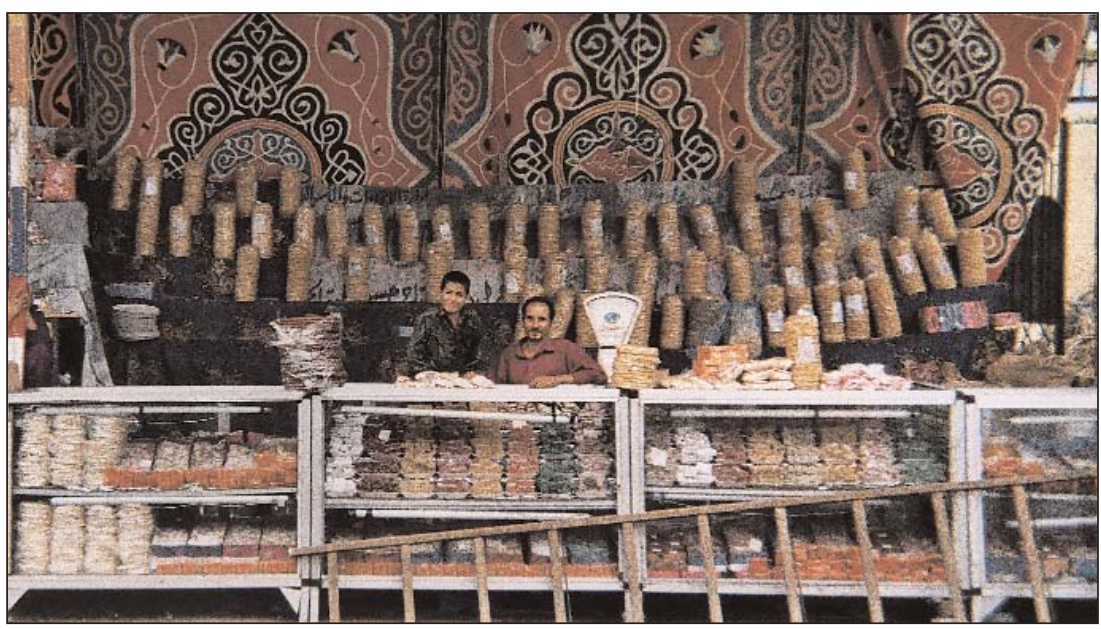

Septembre 2004, cliché A. Madœuf

Illustration 2 : Stands (fermés) de tir à la carabine, mouled de Sayyida Zaynab

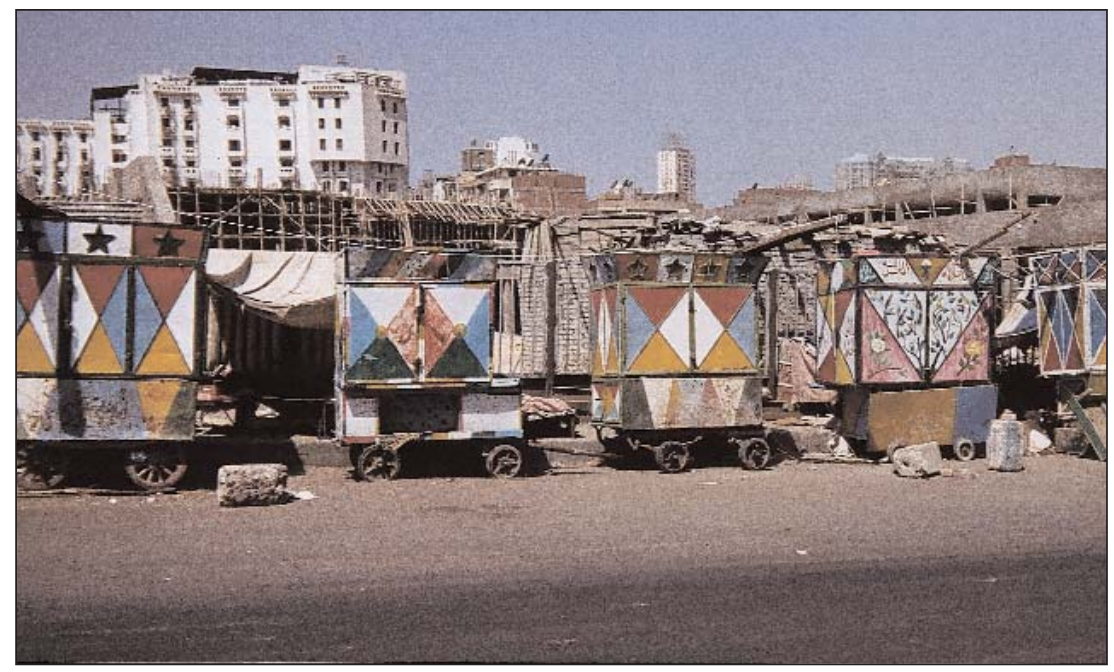

Septembre 2004, cliché A. Madœuf 


\section{Bibliographie :}

Amado J., 1985, Tocaia Grande, Stock, Le Livre de Poche, Paris.

Bachelard G., 1989, La poétique de l'espace, PUF, Quadrige, Paris.

Berque J. et Al-Shakaa M., 1974, «La Gamâliya depuis un siècle essai d'histoire sociale d'un quartier du Caire ", Revue des Études Islamiques, XLII-1, Librairie Orientaliste, Le Caire, p. 45-99.

Biegman N.-H., 1990, Egypt. Moulids Saints Sufis, Gary Schwartz-SDU, La Haye.

Calvino I., 1996, Les villes invisibles, Paris, Seuil, coll. Points.

Chih R., 2000, Le soufisme au quotidien. Confréries d'Égypte au XXe siècle, Sindbad, Actes Sud, Paris.

De Balzac H., 1996, « Sarrasine », Mille et une nuits.

Di Méo G. (dir.), 2001, La géographie en fêtes, Géophrys, Paris.

Eliade M., 1965, Le sacré et le profane, Gallimard, Folio, Paris.

Fabre D., 1989, « Le symbolisme en question », in L'autre et le semblable. Regards sur l'ethnologie des sociétés contemporaines, Paris, CNRS, p. 61-78.

Freitas-Perez L., 1994, "Lieux de fêtes au Brésil ", in Lieux et non-lieux de l'imaginaire, Internationale de l'imaginaire, nouvelle série $n^{\circ} 2$, Babel, Maison des cultures du monde, Paris.

Freud S., 1965, Totem et tabou, Petite Bibliothèque, Payot.

Frishkopf M., 1995, « La voix du poète : tarab et poésie dans le chant mystique soufi », Égypte Monde Arabe n ${ }^{\circ}$ 25, CEDEJ, Le Caire, p. 85-117.

Ghasarian C., 2002, (dir.), De l'ethnographie à l'anthropologie réflexive, Armand Colin, Paris.

Ghitany G., 1993, Épître des destinées, Seuil, Paris.

Goerg O. (dir.), 1999, Fêtes urbaines en Afrique. Espaces, identités et pouvoirs, Karthala, Paris.

Goffman E., 1973, La mise en scène de la vie quotidienne. II Les relations en public, Éd. de Minuit, Paris.

Hoffman-Ladd V., 1992, "Devotion to the Prophet and his Family in Egyptian Sufism », International Journal of Middle East Studies 24 (4), p. 615-637.

Idris Y., 1986, La sirène et autres nouvelles, Sindbad, Paris.

Illouz C. et Vidal L. (coord.), 2000, Jean Duvignaud. La scène, le monde, sans relâche. Internationale de l'imaginaire, nouvelle série $n^{\circ} 12$, Babel, Maison des cultures du monde, Paris.

Joseph I., 1984, Le passant considérable, Essai sur la dispersion de l'espace public, Librairie des Méridiens, coll. Sociologie des formes, Paris.

Lynch K., 1998, L’image de la Cité, Dunod, Paris.

Mac Pherson J.-W., 1941, The Moulids of Egypt. (Egyptian Saints-Days), Nile Mission Press, Le Caire.

Mahfouz N., 1985-1989, Trilogie. Impasse des Deux-Palais, Le Jardin du passé, Le Palais du désir, J.-C. Lattès, coll. Lettres arabes, Paris.

Mayeur-Jaouen C., 1995, « Gens de la maison et mouled-s d’Égypte », in A. Vauchez (dir.), La religion civique à l'époque médiévale et moderne (chrétienté et islam), , École française de Rome, Rome, p. 309-322.

Nora P., 1984, "Entre mémoire et histoire. La problématique des lieux », in Les lieux de mémoire, I. La République, Gallimard, Bibliothèque illustrée des histoires, p. XVII-XLII.

Qassem A.-H., 1998, Les sept jours de l'homme, Sindbad, Actes Sud. 
Sansot P., 2003, Jardins publics, Petite Bibliothèque Payot, Paris.

Sansot P., 1973, Poétique de la ville, Paris, Éd. Klincksieck.

Sennett R., 2002, La chair et la pierre. Le corps et la ville dans la civilisation occidentale, Éd. de la passion, Paris.

Steinbeck J., 1972, Tortilla Flat, Denoël, Folio.

Veillon M., sans date, Egyptian festivals, B. Ronfard Éd., The American University in Cairo Press, Le Caire.

Zweig S., 1996, Pays, villes, paysages. Écrits de voyage, Belfond, Le livre de poche. 


\section{III - CONTRÔLES ET ENCADREMENTS}





\title{
Urban Space, Public Pleasure AND CUlTURAl CONFLiCT: THE SEASIDE RESORT IN ENGLAND C. 1840-1939
}

\author{
John K. WALTON \\ University of Central Lancashire
}

This chapter must begin by emphasizing the early importance and rapid development of the seaside resort in Britain: the seaside holiday is a British more precisely, an English - invention and cultural export ${ }^{1}$. The seaside holiday, together with its urban expression, the seaside resort as a distinctive kind of urban space and entity, constitutes one of the key contributions Britain has made to the development of the modern world, along with (most obviously) the Industrial Revolution, the British Empire and association football2. It has become the most ubiquitous of this quartet, except in landlocked countries with limited capacity for generating indigenous demand for tourism; and even under these circumstances, media representations of beaches and other aspects of seaside tourism generate recognition and aspiration. Wherever it has travelled, the seaside holiday (like association

\footnotetext{
1 J. K. Walton, The English seaside resort: a social history 1750-1914 (Leicester, 1983); idem., « The seaside resorts of Western Europe, 1750-1939 », in S. Fisher (ed.), Recreation and the sea (Exeter, 1997), 36-56.

2 None of these are perfect examples of the global dissemination of a British 'innovation', but (for example) the American version of football derives from the same British roots as association football, and similar genealogies can be traced for different versions of the seaside holiday or beach resort.
} 
football, and even like the Industrial Revolution and the British Empire) has been modified and adapted to suit the preferences and expectations of the recipient cultures, sometimes at two and three removes from its origins; but the hybridisations have come from a common root, and that root has in each case been firmly grounded in the peculiarities of the English ${ }^{3}$.

Alain Corbin, whose excellent, influential and much-translated Le Territoire du Vide suffers from limited awareness of the nature and importance of the English origins and early development of the therapeutic and recreational use of the sea and its environs on a commercial scale, has exercised an undue influence on writings on this theme outside Britain. Indeed, he gets the early history of the English seaside badly wrong, especially in the detail4. But he is stimulatingly right about the importance of the transformation of perceptions of the sea, at an elite cultural level, from the mid-eighteenth century onwards in driving the development of seaside tourism. Much the same, incidentally, could be said of attitudes to mountains; and the British played a similar role in the development of mountain tourism from the eighteenth century onwards 5 . The "romantic gaze » of John Urry's influential imagining was a product of this cultural moment in Western Europe, as maritime and mountain landscapes came to conjure up the inner turbulence of the tortured self, the sublime thrill of contemplating a wildness that for most observers posed no immediate physical danger, and the spiritual encounter with Nature and Nature's God6. In the British context we should also add a patriotic dimension to the romantic, the sublime and the evangelical, emphasizing the association between maritime trade, naval might, the heroism of sailors of all sorts, and the political and economic expansion of British power and influence from the eighteenth century onwards?

But, within Britain, there is more to the story than a revolution in elite aesthetic fashions and consciousness. Its roots probably lie in popular seabathing customs associated with the pursuit of health through annual bathing rituals at or around mid-August, especially the festival of the Assumption of the Virgin Mary on August 15, which can be found right across eighteenthcentury Catholic Europe (and were even exported by Irish emigrants to the New York resort of Coney Island, where « Cure Day » was current in the midtwentieth century), but also on English coastlines, especially in Lancashire where Catholic survival was particularly strong. Such traditions may well have

\footnotetext{
${ }^{3}$ For the adaptability of association football, G. Armstrong and R. Giulianotti, Fear and loathing in world football (Oxford, 2001); and for the British Empire, David Cannadine, Ornamentalism ${ }^{4}$ Alain Corbin, Le territoire du vide (Paris, 1988); J. K. Walton, « Taking the history of tourism seriously », European History Quarterly 27 (1997), 573-81.

5 L. Tissot, Naissance d'une industrie touristique: les Anglais et la Suisse au XIXe siècle (Lausanne, 2000) ; Jim Ring, How the English made the Alps (London, 2000).

6 John Urry, Consuming places (London, 1995).

7 Christiana Payne, in Susan C. Anderson and Bruce H. Tabb (eds.), Water, leisure and culture (Oxford, 2002).
} 
provided the impetus for orthodox medical opinion to look for health-giving properties in sea-water, a trend which predated the revolution in maritime aesthetics ${ }^{8}$. The fashion for taking the waters at mineral springs, which in turn had popular antecedents, also paved the way for the adoption of sea-water cures as a variation on an established medical theme ${ }^{9}$.

So the rise of the English seaside resort as a distinctive kind of leisure space begins with the pursuit of health in the 1720s and 1730s (the earliest documented example of "polite », regulated sea-bathing under medical auspices comes from Whitby, North Yorkshire, in 1718, with nearby Scarborough close behind) ${ }^{10}$. It develops in step with the rise of a polite, hypochondriac, consuming "middling sort of people », anxious to become acceptable to the aristocracy and gentry. It becomes fashionable in the process, and the stage is set for it to gain both a distinctive aesthetic and a variety of incarnations through the second half of that century, running through the social scale from deeply provincial Allonby in Cumberland, a haunt of local farmers, through (allegedly) petit bourgeois Margate and sedate mercantile Bognor, to royal, fashionable, raffish Brighton ${ }^{11}$. From these origins the British seaside ramified and sub-divided through the nineteenth century and into the twentieth, with characteristics varying between and within coastlines and individual resorts and changing subtly over time, to produce the most complex, precisely-graded and populous seaside resort system the world has known, with a total resident population, outside the holiday season, of well over 1.5 million by 1911 and two million by 195112. It was never well-known to the world at large, because what it offered was almost entirely for home consumption, with a few token gestures towards international markets on the south coast at places like Brighton and Torquay. Little or no attempt was made to market the British seaside to overseas visitors, even when a faltering and underfunded national tourism advertising campaign began in the inter-war years ${ }^{13}$. Hence, in part at least, the limited awareness of these phenomena outside Britain, which is well illustrated by a recent historian of Coney Island, who accepts that the New York resort's claim to primacy among the popular

\footnotetext{
8 Alain Corbin is aware of these rituals, but does not develop the theme. See also J. K. Walton, "Seaside resorts of Western Europe », 40; J. Travis, " Continuity and change in English seabathing, 1730-1900 », in Fisher (ed.), Recreation and the sea, 8-11 ; M. Immerso, Coney Island: the people's playground (Piscataway, N.J., 2002), 157.

9 J. Travis, "Continuity and change », 8-9; J. A. R. Pimlott, The Englishman's holiday: a social history (London, 1947), 25-6.

10 J. Travis, «Continuity and change », 31, note 13, for the full details.

11 J. K. Walton, English seaside resort, Chapters 1-2.

12 J. K. Walton, «The seaside resorts of England and Wales, 1900-1950 », in G. Shaw and A. Williams (eds.), The rise and fall of British coastal resorts (London, 1997), 21-48, for the full dimensions of this.

$13 \mathrm{~J}$. Beckerson, «Marketing British tourism: government approaches to the stimulation of a service sector, 1880-1950 », in H. Berghoff et al. (eds.), The making of modern tourism (London, 2002), 133-57.
} 
and carnivalesque is challenged only by England's Blackpool, but places the latter on the wrong coastline (North Sea instead of Irish Sea: the opposite side of the country) and makes the erroneous assumption that many of its workingclass visitors came from Liverpool 14 .

Any attempt to depict and understand this system brings us straight into questions of space, status and culture - cultural capital, indeed - as they relate to the public consumption of leisure for profit. This applies at the level of the regional resort system, the individual resort and the sub-divisions that developed within it, and the nature of the spatial divisions and interrelationships was affected by time of day, day of the week and time of the year, in response to conventional assumptions about mealtimes and appropriate behaviour, to the evolution of the week-end and of attitudes to Sunday observance, and to patterns of holidaymaking based on school holidays, the "London season" and its impact on metropolitan manufacturing, the timing of customary holidays in industrial areas, and the varying impact of the Bank Holiday Act of $1871^{15}$. Every British coastline that was accessible to major population centres developed a variety of resorts in the nineteenth century, each oriented predominantly and enduringly to a particular market: the predominantly industrial county of Lancashire, for example, whose "cotton towns" pioneered the working-class seaside holiday, had Blackpool for the secular, pleasure-loving and (increasingly) proletarian inhabitants of Manchester and the " cotton towns », Southport for seriousminded health-seeking and sermon-tasting Nonconformist business families from the same places (with impressive ecclesiastical buildings to match), and Morecambe for supervisory and white-collar workers who wanted a relaxed, respectable and not too raucous environment, to name only the most prominent places ${ }^{16}$. Not that demand flows ever fitted perfectly into county boundaries, of course, and (for example) much of the demand for holidays generated within industrial Lancashire also fed into North Wales, and to the eastern North Sea coast as well as that of the Irish Sea, while Morecambe's railway alignment gave it more visitors from Yorkshire than Lancashire17.

From the mid-nineteenth century onwards, similar complex systems could be found across many of the coastlines of Western Europe: one thinks of Désert's Normandy, or Chadefaud's south-western France, with their gradations from the centres of international fashion like Biarritz and Deauville (where the British aristocracy were much more in evidence from the Victorian years onwards than at the British seaside) to the "petits trous pas chers ", and

\footnotetext{
14 Immerso, Coney Island, 4.

15 Pimlott, Englishman's holiday; J. K. Walton, « The demand for working-class seaside holidays in Victorian England », Economic History Review 34 (1981), 249-65.

16 H. J. Perkin, «The 'social tone' of Victorian seaside resorts in the North-West», Northern History 12 (1976), 181-94.

17 J. K. Walton, « The demand for working-class seaside holidays ».
} 
their changes of «social tone» (to borrow a common expression, and preoccupation, of Victorian England) as the season waxed and waned ${ }^{18}$. What was distinctive about England, however, was the early departure of international high society, which went abroad at an early stage in search of the excitements of roulette and the demanding security of an exclusive social ambience, together with the early, pervasive and not unrelated presence of the industrial and metropolitan working class. The rise of the popular seaside excursion, and even holiday, was a fact of life and subject for satire in England more than half a century before the great panic about paid holidays in the France of 1936, by which time the British middle classes, when on holiday, had learned either to live with the plebeians, or to avoid them by seeking out smaller places with difficult or expensive access and accommodation 19 . Everywhere on the British coastline, except in the smallest and most specialised niche-market resorts, a broad mix of visiting publics developed as soon as railways and rising real wages opened out the possibilities in the midnineteenth century, and this meant that juxtapositions between potentially conflicting classes and cultures were part of the common currency of seaside life and of its regulation and representation 20.

Under these circumstances desirable spaces, construed in terms of perceived healthiness and natural beauty as well as architecture and access to entertainment and amenity, became the objects of social competition for access and use across the whole of a changing and (in many respects) increasingly competitive society. This was especially the case at the seaside, where a limited length of stay and an expectation of competitive consumption and display intensified the pressures in an environment where the most valuable assets of all, the beach and the sea, were liminal spaces in terms of propertyownership as well as marginality. In this peripheral setting where land met sea and conventions and controls might be suspended or relaxed, uncertainty about property rights and the jurisdiction of authority posed enduring problems of regulation and control21. In contrast with the Mediterranean, the long gap between high and low tide created an extensive debatable land, and much of the foreshore was under the jurisdiction of the Crown, whether directly or through the Duchy of Lancaster or the Office of Woods and Forests, whose powers to develop, restrict access and use, regulate and charge rent were

\footnotetext{
18 M. Chadefaud, Aux origines du tourisme dans les pays de l'Adour (Pau, 1987) ; Gabriel Désert, La vie quotidienne sur les plages normandes du Second Empire aux Années Folles (Paris, 1983). See also (for example) J. K. Walton and J. Smith, « The first century of beach tourism in Spain: San Sebastián and the playas del norte, from the 1830s to the 1930s », in J. Towner et al. (eds.), Tourism in Spain: critical perspectives (Wallingford, 1996).

19 E. Furlough, 'Making mass vacations: tourism and consumer culture in France, 1930s to 1970s', Comparative Studies in Society and History 40 (1998), 247-86; J. Golby and A. Purdue, The civilisation of the crowd: popular culture in England 1750-1900 (second edn., Stroud, 1999), 157-9.

20 J. K. Walton, English seaside resort, Chapter 8.

21 R. Shields, Places on the margin (London, 1991).
} 
nevertheless open to challenge. When they were ceded or devolved, as happened increasingly as resort towns grew and their government systems became more sophisticated in the second half of the nineteenth century, they almost always passed into the hands of elected local government rather than private individuals22. Even at the height of the age of laissez-faire the British sustained a sense of common property and an expectation of access rights at the seaside, which resisted individualist assault even more strongly than the network of public footpaths across common land, which had to be defended stoutly in the courts and by direct action from time to time23. Under English law, then, reinforced by widely shared values and attachments, beaches could not be privatised, although access routes to them might sometimes be limited and local government was increasingly anxious to introduce controls over what kinds of behaviour might be proscribed or permitted, especially when dimensions of sexual morality, propriety and aesthetics were at issue 24 .

The British seaside more generally was always potentially a democratically accessible space. It was so in its origins as a desirable location and destination, for (as noted earlier) ritual, communal and customary plebeian sea-bathing practices at August high tides, mixing pleasure and prophylaxis, predated the sea's adoption by the emerging medical profession, alongside the mineral spring, as a cure for the diseases of the wealthy; and the doctors may well have picked up the hint from the popular practices. Such customs lasted strongly into the nineteenth century in the last redoubts of Catholic England and Wales, such as Lancashire (especially) and Monmouthshire, and in the former county their votaries transferred themselves to the cheap trains of the early railway age in the $1840 \mathrm{~s}^{25}$. But the railways, like the steamers of the Thames estuary before them at Margate and Southend, democratised the seaside in terms of accessibility, although for at least a generation this was a limited democracy (rather like the parliamentary one!), as the desirable shorelines were rationed by the short-term availability of cheap tickets (at an extreme, at Dawlish in Devon, demanding a breakfast-time return after an early morning bathe), their confinement into week-ends unless reputably sponsored by employers or Sunday Schools, and their limited availability on Sundays on most lines through the restrictive mid-Victorian years26. But the « respectable » middle-class families who dominated the holiday markets of the 1850s and 1860s, at the point when working-class living standards began to improve, were never entirely free from the threatening proximity of the " great unwashed » in pursuit of what was alleged to be their annual bathe, at

\footnotetext{
22 J. K. Walton, English seaside resort, Chapters 6-8.

23 Harvey Taylor, A claim on the countryside (Keele: Edinburgh University Press, 1997).

24 See above, note 20.

25 J. Travis, «Continuity and change », 9-12; J. K. Walton, "The social development of Blackpool 1788-1914 », Ph.D. thesis, Lancaster University, 1974, 234-7, 242-4.

26 J. Travis, «Continuity and change », 17; David N. Smith, The railway and its passengers: $a$ social history (Newton Abbot, 1988).
} 
a time when the earliest examples of the " playful crowd » still generated fear rather than sympathetic interest of anthropological curiosity. And it seems clear that not until the 1950s were working-class families with young children able to afford to stay at the seaside: the Victorian plebeians at the seaside were young single men and young childless couples at the first crest of the poverty cycle and a boisterous point in the life-cycle, along with older couples whose children could contribute to the family budget ${ }^{27}$. Most of the developing urban spaces of the seaside - the bathing beach, the seaside promenade, the pier, the public park, the shopping street, and those entertainments that needed to keep at least some of their prices low to maximise attendances - were necessarily democratic in ways that went beyond the more segregated world of the spa; and this is partly why, after the young Queen Victoria turned her back on Brighton in the early 1840s, British seaside resorts were conspicuous by their lack of aristocratic or even fashionable patronage. Shared spaces brought contrasting ways of experiencing pleasure into contact, and generated cultural conflict 28 .

So the internal history of many of the larger British seaside resorts resolves itself very largely into the resolution of conflicts over the allocation and use of desirable space: debates within the public sphere of the media, and above all about the public sphere of the promenade (in a broad sense: as arena for competitive display and flirtation, and for the direction of the appraising, sexualised gaze at other people; as tranquil amenity on which to relax and direct the gaze at seascape, cloudscape and romantic nature; or as liminal space in which to pursue hedonistic goals involving noise, jokes, drollery and foolery, perhaps fuelled by alcohol). Such debates were resolved, in an immediate sense, by local authorities: landowners at first, local government in negotiation with transport, entertainment and residential interests later. Where local government was powerful, and the « social tone » or place-identity/myth of the resort was clearly developed, conflicts could be resolved, or even preempted, on the side of « respectability »29. Landowners (whether aristocrats or development companies) could, and did, prohibit down-market buildings and impose regulations that forbade 'nuisances', including pubs, stalls and fairgrounds. In small resorts like Frinton (Essex) or Westgate (Kent), the

\footnotetext{
27 The best evidence on this is visual, and comes from the analysis of photographs of holiday crowds in the Blackpool Pleasure Beach Archive and from film in the Mitchell and Kenyon Collection, National Fairground Archive, University of Sheffield. For an approach to analysing such material, María Antonia PAZ, « Cine para la historia urbana: Madrid, 1896-1936 », Historia Contemporánea 22 (2001), 179-213.

28 J. K. Walton, English seaside resort, Chapter 8.

$29 \mathrm{Ibid}$; and see also Shields, Places on the margin; Tony Bennett, Colin Mercer and Janet Woollacott (eds.), Popular culture and social relations (Milton Keynes, 1986); N. Morgan and A. Pritchard, Power and politics at the seaside (Exeter, 1999); J. K. Walton, The British seaside: holidays and resorts in the twentieth century (Manchester, 2000); idem., " Popular entertainment and public order: the Blackpool Carnivals of 1923-4 », Northern History 34 (1998), 170-88. For " place-myth » see Urry, Consuming places.
} 
proximity of popular neighbours led to the sanitising of public spaces through the prohibition of (for example) picnics, games, stalls offering cheap open-air amusements (even the classic Punch and Judy show), public houses and fish and chip shops, and the imposition of expensive bathing regimes designed to deter people of limited means and presumed uncultivated habits ${ }^{30}$.

More moderate versions of such systems could be applied to the most developed or desirable parts of larger resorts, wherever there was a consensus that the « better-class » market would also pay be more reliable and best, or a moral and aesthetic preference for the decorous and modestly-dressed (flamboyant big spenders tended to go to the resorts of mainland Europe from an early stage, especially when Brighton became less raffish from the 1840s onwards). Piers charged tolls and had regulations of their own about behaviour, and in some resorts certain marine promenades also excluded the impoverished and undesirable in these ways. These even applied to Blackpool and to the popular Yorkshire resort of Bridlington for most of the nineteenth century. But the larger resorts could cultivate a mixed visitor economy by the allocation of certain areas to working-class visitors, and the zoning of attractions for them and of tolerance for boisterous behaviour into these districts. Such areas tended to be low-lying (here as elsewhere, gradient analysis was an important determinant of " social tone »), close to the old core of settlement and with unpretentious early accommodation without much in the way of planning or fashionable architectural styles and layout, and close to railway stations. These zoning systems were much easier to create and sustain in an age of mass transit systems, where the purchasing power of the better-off enabled them to escape by cab or carriage to the urban fringe and enjoy the view in select tranquillity, making voyeuristic incursions to the 'popular' districts on their own terms and when it suited them. So particular areas might be abandoned to the «lower orders » and become appropriate spaces for the toleration of fairgrounds, stalls, cheap shows and the sale of alcohol, and behaviour that would elsewhere be regarded as indecorous 31 . Such reserved spaces dedicated to, or at least permitting, the carnivalesque were not unique to the seaside, of course: Lynda Nead has documented some of them for London in Victorian Babylon, for example. But they were particularly necessary, and popular, in this setting, especially as the working-class invasion of the seaside gathered momentum in the late nineteenth century 32 .

\footnotetext{
30 D. Cannadine, Lords and landlords: the aristocracy and the towns 1774-1967 (Leicester, 1980); idem. (ed.), Patricians, power and politics in nineteenth-century towns (Leicester, 1982), chapters on Bournemouth and Southport; J. K. Walton and J. Walvin (eds.), Leisure in Britain 1780-1939 (Manchester, 1983), chapters on Blackpool, Bournemouth and Ilfracombe; Laura Chase, "The creation of place image in inter-war Clacton and Frinton », Ph.D. thesis, University of Essex, 1999; Dawn Crouch, « Westgate on Sea 1865-1940 », Ph.D. thesis, University of Kent, 1999.

31 J. K. Walton, Blackpool (Edinburgh, 1998), for a case-study. For «gradient analysis », F.M.L. Thompson, Hampstead: building a borough (London, 1974).

32 Lynda Nead, Victorian Babylon (New Haven and London, 2000). See also, for example, Simon Gunn, The public culture of the Victorian middle class (Manchester, 2001).
} 
By the turn of the century the worst problems were already receding, even in resorts that were too small for spatial sub-division and differential policing strategies to work. This was because the popular crowd was coming to be seen as better-behaved and less threatening. Norbert Elias's « civilising process », distorted in Britain by historical sociologists of soccer hooliganism, works much better at the seaside than the football stadium, at least for this period (for the late twentieth century we need to develop a concept of the « decivilising process »)33. The working-class seaside visitor was more thoroughly disciplined (by school and regular work), more attuned to saving for both a rainy day and a good time, and more clothes- and consumer-oriented. The 'respectables' came to dominate the «roughs », a process with which historians are beginning to engage; and, in Harold Perkin's phrase, the " crowd » became « structured », through its own internal dynamics (orderly movement, queuing, ebbing and flowing according to regular internalised timetables associated with mealtimes and attractions) as well as through the external pressures of policing and traffic management ${ }^{34}$. The dominant discourse saw crowds as neither violent nor threatening, but as amiable and tractable, and above all as natural, giant organisms that beat to their own rhythms ${ }^{35}$. Transgressions were isolated and viewed indulgently. Resorts boasted of their low rates of prosecuted crime, and invested in the «city beautiful » during the inter-war years, while the fairground theme-parks of the early twentieth century also pursued cleanliness and respectability in negotiation with local government. Even Blackpool's notorious «Golden Mile », with its ramshackle freak-shows, was brought within a modified and consensual spirit of carnival and saturnalia, which accepted that the normal constraints of everyday life were relaxed, but also set the revised norms beyond which it was unacceptable to go ${ }^{36}$. This applied to the beach itself, where the inter-war years saw the spread of a much more relaxed attitude to « mixed bathing " and bodily exposure and display, with the rise of the cults of sun-bathing and fresh air ${ }^{37}$. Controversy continued to erupt at the margins

\footnotetext{
33 Robert W. Lewis, «Football hooliganism in England before 1914: a critique of the Dunning thesis », International Journal of the History of Sport 13 (1996), 310-39; Jeffrey Richards, «Football and the crisis of British identity », in S. Caunce, E. Mazierska, S. Sydney-Smith and J. K. Walton (eds.), Relocating Britishness (Manchester, forthcoming 2003).

34 F. M. L. Thompson, The rise of respectable society (London, 1988); Harold Perkin, The structured crowd (Brighton, 1981).

35 Gavy Cross (ed.), Worktowners at Blackpool (London, 1990); William Holt, articles on seaside crowds in the Daily Dispatch, August 1934.

36 Helen Meller, European cities 1890-1930s: history, culture and the built environment (Chichester, 2001), Chapter 5; J. K. Walton et al., « Crime, migration and social change in north-west England and the Basque Country, c. 1870-1930 », British Journal of Criminology 39 (1999), 90-112; J. K. Walton, Blackpool; Walton, British seaside, Chapters 4-6; Morgan and Pritchard, Power and politics. 37 J. K. Walton, British seaside, 96-101; J. K. Walton, « Consuming the beach: seaside resorts and cultures of tourism in England and Spain from the 1840s to the 1930s », in S. Baranowski and E. Furlough (eds.), Being elsewhere: tourism, consumer culture and identity in modern Europe and North America (Ann Arbor, 2002), 272-98.
} 
and where frontiers were being moved, just as they did spatially where working-class areas expanded to threaten the tranquillity of nearby zones; but all of this was containable and the existing system could cope with it. The combination of the emergence and consolidation of spatial arrangements that minimised conflict, through a combination of market forces and local government policy, and the "reformation of manners" of the mature industrial working class, helped resorts to continue to grow and to maximise their markets (just as, for example, music-hall and then the cinema had done). This system ran in step with the life-cycle of the «traditional » working class as represented by E. J. Hobsbawm, with its identification with workplace, neighbourhood, pub, football and music-hall, and its conservative sartorial tastes as evidenced by the fully-clothed and formally-clad working-class throngs in Sunday suits and summer frocks to be seen on the beaches and promenades of popular resorts from the 1890s through to the 1960s, exactly following Hobsbawm's model 38 . It was not to be disrupted until the advent of mass motoring, of inter-generational cultural conflict, of a new consumer culture and, somewhat later, of competition from new Mediterranean destinations, which conspired to disrupt a settlement based on enduring invented traditions, industrial holidays, railways and class distinctions, from the 1960s onwards. But that is another story39.

38 E. J. Hobsbawm, The age of Empire (London, 1987).

39 J. Demetriadi, «English and Welsh seaside resorts, with special reference to Blackpool and Margate, 1950-1974 », Ph.D. thesis, Lancaster University, 1995; idem., « The golden years, 195074 », in Shaw and Williams, The rise and fall of British coastal resorts, 49-75; Walton, British seaside; J. K. Walton, «Blackpool and the varieties of Britishness », in Caunce et al. (eds.), Relocating Britishness. 


\title{
DE L’ « HOMME LABORIEUX » À LA SOCIABILITÉ BOURGEOISE : LOISIRS CONTRASTÉS AU PIRÉE PENDANT LE XIX ${ }^{\mathrm{e}}$ SIÈCLE
}

\author{
Yannis YANNITSIOTIS \\ Université de la Mer Égée \\ Département d'Anthropologie Sociale et d'Histoire
}

La polysémie du terme «loisir » rend vaine toute tentative de cerner sa définition, dans la mesure où l'on récuse, en tant que simpliste et scientifiquement révolue, son opposition au travail. La compréhension de ce temps exige, essentiellement pour l'historien, de le réinsérer dans son contexte social, économique, politique et culturel, sinon de rechercher «des manières dont les temps sociaux ont été perçus, représentés, symbolisés et utilisés »1, pour nous rapporter à Alain Corbin.

Dans cette étude, notre objectif sera d'examiner les moyens par lesquels le loisir a été compris par la société grecque de la fin du XIXe siècle et, notamment, par la société piréote. Notre attention va se porter sur les représentations du loisir dans la presse locale. Plus particulièrement nous allons examiner les conceptions quant aux pratiques collectives de gérance, d'organisation, de valorisation du temps dédié aux distractions et aux

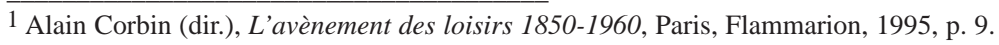


divertissements. Notre hypothèse de travail a deux volets : pour le premier, les significations de ce temps au XIXe siècle dans la société piréote s'avèrent être dues à des éléments constitutifs de plus larges représentations sociales, représentations aux attributs fortement sexués et de classe. Pour le second volet, ces significations jouent un rôle déterminant dans l'élaboration de l'image que les Piréotes ont de leur ville, en d'autres termes elles façonnent une identité culturelle de l'espace urbain.

En guise d'introduction, nous nous référerons brièvement à l'évolution socio-économique du Pirée. En premier lieu, nous étudierons les manières dont la relation entre le travail et le loisir a été conçue pendant la première période de cette ville, quand celle-ci n'était encore que l'insignifiant port de la capitale. En second lieu, nous nous efforcerons de dégager les conceptions différentes, existant au sein de la bourgeoisie locale, concernant les activités collectives de gérance, d'organisation, de valorisation du temps consacré au loisir, conceptions apparaissant au cours de la deuxième période de cette ville, quand le Pirée est devenu la ville industrielle et commerciale la plus importante du pays.

Le Pirée constitue un cas à part dans l'évolution des villes grecques au

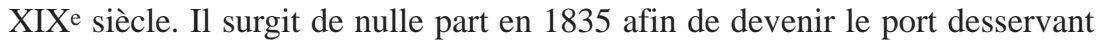
Athènes, la capitale du nouveau royaume grec, apparu après la Guerre d'Indépendance contre l'Empire ottoman. Jusqu'aux années 1850, il n'est qu'une cité insignifiante, dont la population n'excède pas les 5000 habitants. Cette dernière se consacre au commerce intérieur et aux manufactures. Il s'agit d'une société indifférenciée aussi bien au niveau des fortunes qu'au niveau de l'emploi, à l'exception d'un petit groupe de grossistes, une élite locale qui se constitue sur place, vers la fin des années 18502. Le Pirée ne peut rivaliser ni avec les deux ports grecs, déjà importants sous l’Empire ottoman, Hermoupolis et Patras, ni non plus avec Athènes, siège du pouvoir politique et au poids symbolique d'un passé glorieux aussi bien pour les Grecs que pour les étrangers 3 .

Cette ville si minime connaît, cependant, à partir des années 1860, un développement de sa population spectaculaire comparativement à celui du

2 Vassias Tsokopoulos, Le Pirée, 1835-1870. Introduction à l'histoire du Manchester grec, Athènes, 1984 (en grec) et Yannis Bafounis, La formation d'une ville nouvelle : Le Pirée au XIXe siècle (1835-1879), Thèse de doctorat non publiée, Paris, 1985.

3 Eleni Bastea, Planning the Myth. The Creation of Modern Athens, Cambridge, Cambridge University Press, 2000. Concernant la ville de Patras : Nikos Bakounakis, Patras, 1828-1860. Une capitale grecque au XIXe siècle, Athènes, 1988 (en grec). Concernant Hermoupolis, la capitale de l'île de Syros : Vassilis Kardassis, « Hermoupolis, pratiques et comportements bourgeois » dans les Actes du Colloque International d'Histoire La ville néohellénique. Héritages ottomans et État grec, Athènes, t. II, 1985, p. 585-589 (en grec), Christina Agriantoni, « Les transformations de la structure industrielle d'Hermoupolis au XIX ${ }^{\mathrm{e}}$ siècle » dans les Actes, ibid., p. 603-608, Christos Loukos «Une capitale grecque en déclin : Hermoupolis la seconde moitié du XIXe siècle » dans les Actes, ibid., p. 591-601 et du même auteur, Mourir à Syros au XIXe siècle, Hérakleion, 2000 (en grec). 
pays, grâce aux flux migratoires continus. Le Pirée atteint les 80000 habitants, à l'aube du XXe siècle et se hisse au deuxième rang du pays, après Athènes, de par sa population. Déjà au milieu des années 1880, il est devenu le premier port commercial, le point de départ des deux axes ferroviaires du pays et le centre industriel grec par excellence, dans le cadre d'une économie principalement agraire et arriérée, caractérisée par un capitalisme marchand 4 .

Quelques décennies auparavant quand les premières cheminées d'usine avaient fait leur apparition dans le ciel piréote, la presse locale soulignait, incitée en cela par le contexte politique et économique, que le Pirée était la seule ville grecque à ressembler tellement aux villes américaines. Puisque au Pirée, comme là-bas, on n'entendait point de discussions sur des questions politiques, mais uniquement autour du travail, de l'agriculture, des innovations et du commerce 5 . Très souvent la société locale était comparée à une ruche dans laquelle tous les membres, soudés, œuvraient pour l'objectif commun, le progrès. À propos de publications d'articles dans la presse athénienne relatifs à la détermination des qualifications nécessaires pour le recrutement des fonctionnaires afin de mettre un terme au clientélisme et aux brigues en tout genre pour l'acquisition de ces postes, on pouvait lire que :

«Notre ville se consacrant à ses activités industrielles, est étrangère à tout cela, ne désirant pas avoir comme qualification d'employabilité la nullité. La vapeur, le marteau, l'industrie, le commerce maritime telles sont les qualifications que possède l'employé du Pirée, ce véritable citoyen de la Grèce »6.

Le dévouement de ses habitants pour le travail la différenciait des autres sociétés locales, et surtout d'Athènes dont les habitants, toujours selon la presse locale piréote, travaillaient moins et gaspillaient leur temps à s’occuper de politique. Les Piréotes restaient indifférents aux médisances répandues, apparemment, par la société athénienne qui les traitait de rétrogrades, de véritables "garçons d'épicerie »7, refusant toute distraction. De plus, dans l’ordre des centres d’intérêt des Piréotes, « la mairie détenait la seconde place, juste après la famille »: ils lui attribuaient les rôles de meneur de leur vie collective et de garante de leur indépendance face aux députés et aux partis ${ }^{8}$.

\footnotetext{
4 Yannis Yannitsiotis, La formation de la bourgeoisie piréote 1860-1909, Thèse de doctorat non publiée, Athènes, 2001 (en grec). Concernant la première phase de l'industrialisation grecque et ses axes urbains : Christina Agriantoni, Les débuts de l'industrialisation en Grèce au XIXe siècle, Athènes, 1986 (en grec). Concernant les traits caractéristiques de l'économie grecque : Georges B. Dertilis (dir.), Banquiers, usuriers et paysans. Réseaux de crédit et stratégies du capital en Grèce (1780-1930), Paris, Éditions La Découverte et Fondation des Treilles, 1988. Enfin, pour la société grecque au XIX ${ }^{\mathrm{e}}$ siècle : Philip Carabott (dir.), Greek society in the making, 1863-1913. Realities, symbols and visions, Hampshire et Vermont, Ashgate/Variorum, 1997.

5 Journal Foni tou Peiraios (Voix du Pirée), n²10, 24 mars 1869.

6 Foni tou Peiraios (Voix du Pirée), n²61, 15 octobre 1869.

7 Jourrnal Pronoia (Prévoyance), n²38, 25 janvier 1883.

8 Foni tou Peiraios (Voix du Pirée), n¹69, 22 octobre 1868 et journal Sfaira (Globe), n40, 29 avril 1880.
} 
Sans compter que, contrairement aux gouvernements, elle gérait le budget municipal avec rationalité et sagesse, guidée par son souci du bien public ${ }^{9}$. Même en 1885, en pleine crise économique, la sagesse piréote dans la gestion des affaires économiques, notamment le choix de la mairie de ne pas entretenir de théâtre luxueux, comme ceux d'Hermoupolis ou Patras, était mentionnée comme étant une raison pour laquelle le Pirée avait été la ville la plus épargnée par l'effondrement du système bancaire ${ }^{10}$.

La spécificité piréote pourrait donc être circonscrite par un ensemble d'attitudes, telles que le détachement de ses membres des partis politiques et des engrenages étatiques, leur intérêt exclusif pour leur municipalité et leur indifférence face à une sociabilité bourgeoise athénienne ayant pour siège les bals à domicile, les premiers cafés grecs à l'européenne, les bals du Palais et les invitations, aux frais de l'État, de troupes de théâtre venant de l'étranger. À cette même époque, au début des années 1870, les marchands de Patras et d'Hermoupolis considéraient l'opéra italien comme un élément constitutif de leur vie. Les conseils municipaux de ces ports et les membres des couches supérieures dépensaient des sommes considérables afin d’inviter des troupes italiennes du mélodrame dans les théâtres luxueux qu’ils avaient érigés en un temps record11.

On pourrait se demander si la réponse de l'élite piréote ou, en tout cas, d'une partie de celle-ci, n'a pas été de fonder l' " Association austère » dont l'objectif était d'insuffler à la société locale et à ses familles, le rejet du luxe et de la richesse ostentatoire. Malheureusement on ne connaît pas bien le sort de cette association, probablement unique en Grèce12. Dans la presse locale, les diatribes contre les femmes piréotes, tentées par la mode et le luxe, étaient fréquentes. Parallèlement, on incitait les femmes des marchands à ne pas rester oisives au foyer, à aider leurs époux dans leur fonds de commerce, comme cela se pratiquait dans beaucoup de pays européens, même en France, le pays des innovations et du luxe, où l'épouse se chargeait de la correspondance, la fille tenait les livres de compte, et où l'épouse et la fille de l'employé se consacraient nuit et jour à leurs belles broderies ${ }^{13}$.

Tout cela révèle une certaine conception concernant l'organisation et la valorisation du temps personnel aussi bien que du temps collectif, conception aux dimensions fortement sexuées. Ainsi le travail, trait évident de l'identité masculine, est perçu comme un but en soi et il est symbolisé par le

\footnotetext{
${ }_{9}^{9}$ Foni tou Peiraios (Voix du Pirée), n82, 5 décembre 1867 ; n¹69, 22 octobre 1868 et n²83, 14 février 1870.

10 Sfaira (Globe), 31 mai 1885.

11 Nikos Bakounakis, Le fantôme de Norma. La réception du mélodrame en Grèce au XIXe siècle, Hermoupolis-Patras, Athènes, 1991 (en grec).

12 Journal Poséidon n484, 8 septembre 1876 et n485, 9 septembre 1876, où l’on peut lire le statut de cette association.

13 Phoni tou Peiraios (Voix du Pirée), n¹38, 2 juillet 1868 ; n²37, $1^{\text {er }}$ juillet 1869 et n²61, 15 octobre 1969.
} 
fonctionnement incessant des machines. La marginalisation du loisir était une conséquence naturelle pour ces citoyens, à partir du moment où leur unique objectif était le progrès et qu’ils considéraient que le loisir était nuisible au travail, seul moyen d'atteindre le progrès. La valeur du travail pouvait allouer un sens, même à la vie des femmes qui, par définition, semblaient s’identifier à l'oisiveté du foyer et, de ce fait, à l'effacement social. La gestion municipale rationnelle et économe peut être comparée à celle du budget familial qui devait suivre les préceptes d’austérité.

Si on tient compte du fait que, durant cette période, les femmes étaient tenues à l'écart de la vie politique ${ }^{14}$ et qu'on leur attribuait systématiquement le défaut d'être gaspilleuses par leur tendance à la consommation, on peut comprendre pourquoi les qualités de « travailleur », « mesuré », " rationnel », «bon gestionnaire des finances" étaient perçues comme des valeurs exclusivement masculines, décernées non seulement aux habitants du Pirée mais à la ville, elle-même.

À partir des années 1880 et surtout dans les années 1890, la situation change. Il s’agit d'une période où le Pirée exerce son emprise économique sur tout le territoire grec. La société locale se caractérise par une différenciation sociale et professionnelle très prononcée15. La mythologie locale découvre ses héros non plus dans la totalité de ses habitants mais dans les traits de ses industriels selfmade. Cependant, conjointement à la physionomie emblématique de l'homme d’affaires dévoué à son travail, un autre modèle de citoyen fait son apparition, celui de l'homme cultivé qui parvient à conjuguer labeur et loisir productif, éducatif et divertissant.

Les porte-parole de ces nouvelles conceptions en faveur de la légitimation du temps du loisir, dans le cadre de la culture locale, étaient principalement des membres des professions libérales, des journalistes, des fonctionnaires, des employés ainsi que quelques industriels en voie d'ascension. On soulignait que, malheureusement, le Pirée était aussi puissant économiquement qu'impuissant et pauvre quant aux modes de divertissements qu'il mettait à la disposition de ses habitants. Les discussions et débats autour de cette question étaient occasionnés par la rareté des représentations théâtrales de bonne qualité, montées en ville, phénomène qui était dû aussi à l'absence de bâtiment dédié au jeu théâtral16. L'édification d'un théâtre municipal avait été décidée dès 1884, mais la crise économique et les désaccords relatifs à l'exploitation des différents locaux du bâtiment avaient empêché l'aboutissement de ce projet.

À part la question de l'absence de théâtre, ces discussions s'étendaient sur toute une série de sujets, comme l'embellissement des places publiques, le

\footnotetext{
14 Eleni Fournaraki, «"Pour quelle raison ne pas lui accorder le droit de vote ?”. Suffrage universel masculin et exclusion féminine de la politique en Grèce au XIX ${ }^{\mathrm{e}}$ siècle », Mnimon, t. 24, 2002, p. 179-226 (en grec).

15 Yannitsiotis, op.cit., p. 76-108.

16 Pronoia (Prévoyance) n²402, 8 février 1894 et n²406, 12 février 1894.
} 
besoin de restructurer la fanfare municipale, l'organisation d'expositions culturelles et surtout le fait que la mairie devait tout mettre en œuvre afin que les Piréotes puissent se divertir dans leur ville et non plus à Athènes, comme ils en avaient l'habitude ${ }^{17}$. Les cibles, plus ou moins explicites, de ces critiques étaient les conseils municipaux, composés principalement de gros commerçants et d'industriels, ainsi que les membres de ce que l'on surnommait « aristocratie locale » qui préféraient se divertir dans la capitale et ses banlieues, délaissant le Pirée.

Tout cela se passant dans un cadre changeant, à tous les niveaux de la vie piréote et surtout au niveau de la sociabilité. Associations éducatives, artistiques et sportives, conférences, représentations théâtrales, bals au club des commerçants, fêtes à domicile, cafés-pâtisseries déterminaient le cadre dans lequel évoluait la sociabilité bourgeoise. Ce cadre se caractérisait aussi par la mixité des sexes et l'adoption de codes comportementaux et vestimentaires spécifiquement masculins et féminins fonctionnant comme critères d'admission ou d'exclusion. Cependant, à part la sociabilité privée, les autres formes n'avaient aucune viabilité. Les différentes associations dont les fondateurs étaient de jeunes scientifiques et des étudiants, avaient une vie brève en raison principalement de problèmes financiers. Certaines places publiques plus anciennes avaient été laissées à leur sort, chassant leurs habitués. Les troupes athéniennes ou étrangères de qualité prenaient difficilement la décision de visiter le Pirée, puisqu'elles n’étaient pas financées par la mairie, seules les troupes populaires venaient jouer dans les théâtres à ciel ouvert pour les ouvriers qui étaient de plus en plus nombreux.

Par rapport à la génération précédente, ces nouvelles conceptions indiquaient trois manières différentes de percevoir le temps individuel et collectif, ainsi que ses connotations.

Premièrement, s'appuyant sur l'importance de la culture théâtrale relativement au contenu du concept progrès leur approche substituait, à l'ancienne équation travail = progrès, la nouvelle (équation) travail + loisir $=$ progrès + culture, modifiant ainsi les symboles de cette relation. Aux machines des usines venaient s'ajouter les théâtres, en tant que condition sine qua non, pour qu'une société soit caractérisée progressiste et civilisée. Et ce parce que le déficit théâtral de la société était perçu comme un déficit identitaire pour la ville. Ainsi la différenciation du Pirée de la première période était sentie alors comme une altérité par rapport aux gestions régulières du temps libre effectuées dans les autres centres urbains. En plus des trois villes déjà citées (Athènes, Hermoupolis, Patras), le Pirée était comparé à d'autres petites villes, insignifiantes économiquement, mais qui avaient bâti leur salle de théâtre18. La conviction des Piréotes d'appartenir à une communauté «indépendante »,

17 Pronoia (Prévoyance) n¹939, 4 novembre 1891 ; n4028, 25 octobre 1899 ; n4342, 12 mai 1901 et $\mathrm{n}^{\circ} 4534,29$ avril 1902

18 Pronoia (Prévoyance), n²406, 12 février 1894. 
« unique » et « pionnière », si différente de celle d'Athènes, cédait la place à un effort fébrile pour corriger l'image que leurs rivaux leur avaient prêtée à eux et à leur ville. On soulignait qu'il était injuste d'accuser les Piréotes d'être bornés culturellement, et on les invitait à prouver, à l'occasion de l'arrivée dans la ville, pour une série de représentations, de la plus éminente artiste du mélodrame grec que «la noble ardeur pour l'art, celle qui anime toutes les sociétés développées, n'est pas considérée chez eux comme un luxe superflu »19.

L’achèvement du théâtre municipal en 1895, malgré tous les espoirs que l’on avait fondé sur lui, n’a pas modifié la situation. Les années qui ont suivi, selon la presse, étaient caractérisées par l'engourdissement culturel et l'absence du public piréote des théâtres, des concerts ou des conférences littéraires ${ }^{20}$.

Parallèlement, le choix des villes que le Pirée se donnait comme exemple et auxquelles il s’identifiait, se transformait : les lointaines villes américaines, symboles du travail incessant, étaient remplacées par les européennes, et même par les toutes proches cités italiennes, afin de signaler désormais le déficit culturel du premier port grec.

Rappelons qu'au XIXe siècle, la relation des Grecs avec l'Europe a joué un rôle déterminant concernant le contenu et la conception de leur identité nationale. L'Europe n'a jamais cessé de fonctionner comme un modèle de développement politique et économique malgré les fluctuations des rapports aux niveaux culturels et idéologiques. L'identification de l'Europe aux concepts de progrès et de culture était un fait incontestable. L'enjeu après la Lutte pour l'Indépendance contre l'Empire ottoman et la création de l'État grec, était l'européanisation de la société grecque et l'effacement de toute trace du passé ottoman21. Par conséquent, l'engagement ou non du cas piréote dans les canons de l'européanisation constituait un signe primordial. Les couches supérieures de la société grecque se considéraient comme des agents de ce processus en adoptant les modes de vie européens. Au-delà de cette

19 Ibid. et Pronoia (Prévoyance), n²338, 28 janvier 1894.

20 Sfaira (Globe), n5399, 22 février 1900.

21 Concernant le contenu culturel des rapports entre la Grèce et l'Europe, on trouve une bibliographie très fournie, citons à titre indicatif : Harald Heppner/Olga Katsiardi-Hering (dir.) Die Griechen und Europa. Aussen- und Innensichten im Wandel der Zeit, Vienne, Cologne, Weimar, Bohlau Verlag, 1998 et notamment pour la période traitée : Effi Gazi, «"Europe” : Writing an ambivalent concept in $19^{\text {th }}$ century Greek Historical Culture » ibid., p. 103-124 ; Philip Carabott (dir.) Greece and Europe in the Modern Period: Aspects of a Troubled Relationship, Londres, Centre for Hellenic Studies King's College London, 1991; Anthony Liakos, «The Canon of European Identity: Transmission and Decomposition », Modern Greek Studies n³, 1995, p. 129138 ; Dimitris Kyrtatas, « La conquête de l’histoire de l'antiquité grecque par le néo-hellénisme aux XVIII et XIXe siècles par l'intermédiaire de l'Occident », dans les Actes du Congrès Scientifique Les usages de l'Antiquité par le Néo-Hellénisme, Athènes, 2002, p. 251-266 (en grec) ; enfin, les deux œuvres de Michael Herzfelt, Ours Once More. Folklore, Ideology, and the Making of Modern Greece, University of Texas Press, 1982 et Anthropology through the Looking Glass. Critical Ethnography in the Margins of Europe, Cambridge University Press, 1987. 
composante permanente d'européanisation, ou plutôt dans le cadre de celle-ci, la comparaison du Pirée aux autres villes européennes se pliait à un autre fait : au cours du dernier quart du XIXe siècle, pour une petite partie de la société piréote, les formes urbaines européennes de distraction et de divertissement façonnaient une partie de leur propre expérience, en raison de leurs visites régulières à l'étranger, visites qui, semble-t-il, n'étaient pas uniquement dues à des déplacements professionnels. Le caractère "américain » de la société piréote paraissait lointain et vague, ou tout au moins se limitait au champ du travail, comparativement à l'immédiate réalité de l'expérience européenne d'une « classe de loisir » en formation.

Deuxièmement, on faisait état de nuits « prosaïques » et « lassantes » que les citoyens auraient souhaité consacrer à la " culture de leur esprit », et on soulignait que les rares ruptures à cette platitude ne pouvaient suffire. Si au cours de la première période, le temps du travail paraissait rythmer à lui tout seul la quotidienneté du Piréote, au cours de la seconde, son règne vacille à la tombée de la nuit pendant laquelle s'instaure un temps vacant du point de vue des centres d'intérêt et surtout disponible. Il s'agissait donc d'un temps potentiellement créatif et édificateur moralement, dans la mesure où le divertissement en question répondait aux aspirations culturelles et morales de la société et de ses membres, un temps répétitif et inséré pleinement dans la quotidienneté de cette société, de manière à paraître naturel et non pas luxe superflu.

Enfin, troisièmement, ces nouvelles mentalités ramenaient à l'épicentre de l'ordre du jour non seulement la collectivité mais aussi le sujet. Le loisir, à part le fait qu'il était reconnu comme un élément constitutif d'une société cultivée, était ressenti comme un temps nécessaire dans la vie quotidienne de l'individu. Le dévouement au travail non seulement ne constituait plus une preuve de virilité mais bien au contraire condamnait l'homme à l'esclavage. En 1903, un rédacteur du journal Sfaira (Globe) "au nom de soixante-dix mille ilotes » soutenait avec ferveur la proposition d'un docteur, membre du conseil municipal, qui au cours d'un débat de celui-ci, avait proposé la formation d'un comité visant au développement culturel et artistique de la ville, et il ajoutait que la seule musique au monde ne pouvait être les sirènes des bateaux22. La jouissance ou non du temps libre touchait désormais la réputation, le bien-être physique et psychique et le développement culturel de l'individu. On soulignait de plus en plus souvent que le repos et un passe-temps créatif étaient nécessaires pour la santé physique et intellectuelle de toute personne travaillant ${ }^{23}$. Toutefois la collectivité n'avait plus les mêmes traits qu'au temps de la première période. À la place d'une "ruche laborieuse » dévouée exclusivement au travail-progrès, qui ne connaissait ni division, ni discrimination intestine, on vantait les mérites de ces citoyens qui eux,

22 Sfaira (Globe), n8585, 27 décembre 1903.

23 Op.cit., et Sfaira (Globe), n7484, 22 novembre 1906. 
contrairement "aux centaines de spectateurs de la petite classe", recherchaient de nouvelles formes d'expression et de nouveaux espaces de loisir.

À part ces différentes approches, présentes au sein même de la bourgeoisie, la revendication d'un divertissement varié et de qualité dans les limites territoriales de la ville, répondait à un autre besoin, toujours de la part de cette bourgeoisie, celui de se différencier des pratiques populaires du loisir. Les spectacles de rue, les cafés avec danseuses et chanteuses, les fêtes spontanées accompagnées d'instruments de musique semblaient dominer dans cet espace urbain. La musique populaire et les chansons aux fortes influences orientales donnaient l'occasion aux bourgeois de dénoncer une ville qui « s'orientalise » alors qu'elle devrait "s'occidentaliser», assimilant à la barbarie et à la vulgarité tout trait « oriental » et par conséquent populaire24. En 1894, le fait qu’une célèbre actrice du mélodrame grec, avec sa troupe, allait devoir monter sa pièce dans un des théâtres des couches populaires, a été l'occasion de porter de virulentes attaques contre ces «bourgeois, porteurs de lunettes, de redingotes et de faces-à-main » qui se rendaient dans les salles de distraction du peuple. Ce peuple avait montré, quant à lui, qu'il était en mesure d'entretenir deux salles, alors que les amateurs de "Wagner [...], qui dormaient avec les oiseaux du ciel, étaient prêts à étrangler M. Retsina [le maire de la ville], si jamais celui-ci songeait à accorder des crédits pour soutenir des œuvres théâtrales » 25 .

$\mathrm{Au}$ cours des premières décennies après la naissance de ce port, la coexistence dans les cafés d'hommes provenant de toutes les catégories sociales était un phénomène très courant. Malgré toutes les réticences formulées à l'endroit de leur morale, l'arrivée de chanteuses étrangères dans ces lieux était saluée avec enthousiasme par la presse locale, en raison de l'ambiance européenne qu'elles apportaient à la ville. Durant les vingt dernières années du XIXe siècle, de tels spectacles et les lieux les hébergeant étaient jugés distractions populaires et condamnés comme étant dangereux pour la santé morale de la société. Les efforts coordonnés de la mairie, de la police et des « citoyens respectables » pour le contrôle de la prostitution, en les cantonnant dans des locaux bien précis, loin du centre, venaient tout juste, au milieu des années 1870, de donner ses premiers résultats. Cependant ces " citoyens respectables" sceptiques quant à ces résultats exprimaient vivement leur pessimisme jusqu'à la fin du siècle26.

Dans le cadre d'un discours normatif naissant, les dangers encourus par les bourgeois, en raison de leur coexistence avec les couches sociales inférieures, redéfinissaient les termes de l'hégémonie de la masculinité bourgeoise par l'instauration de nouveaux rapports aussi bien avec les versions de la

24 Pronoia (Prévoyance), n¹887, 5 août 1891 ; n²406, 12 février 1894 et Sfaira (Globe), n5501, 22 juin 1900.

25 Pronoia (Prévoyance), n²402, 8 février 1894.

26 Yannitsiotis, op. cit., p. 204-208. 
masculinité et de la féminité populaires qu'avec celles de la féminité bourgeoise qui, elle aussi, à son tour, traversait une phase de redéfinition. Dans ce processus, un rôle primordial était tenu par l'invocation de la famille et du nouveau contenu qui lui était attribué. Si le temps personnel de l'homme, axé durant la journée autour du travail et de la famille paraissait à l'abri de tout danger, il n'en était pas de même pour la nuit. Au cours de celle-ci, il était très facile, premièrement, que l' « industriel parvenu », le " jeune homme cultivé », l' ' honnête père de famille " soient poussés par des escrocs à l'adoption de vices populaires tels que la passion du jeu et l'alcool ; et deuxièmement, que les femmes aux mœurs faciles pouvaient les inciter à dilapider leur fortune, ruiner leur santé à cause des maladies sexuellement transmissibles et, de ce fait, à dissoudre leur famille27. Le fait que, à cette époque-là, on parle du besoin de moraliser les couches inférieures, n'est pas sans relation avec les discours que nous venons de rapporter. À ces couches était attribuée une série de comportements, d'opinions et de pratiques diamétralement opposés aux stéréotypes moraux bourgeois : rejet du travail, prédisposition à la criminalité, à l'alcoolisme, dissolution des rapports familiaux, rupture avec l’Église28.

La «famille » en tant qu'auditrice et spectatrice semblait certaines fois imposer ses règles au spectacle. Un programme culturel bien organisé risquait de connaître l'échec si les familles locales étaient mécontentes en raison du manque de pudeur de la part des artistes et surtout des femmes29.

Dans les propos, le mépris pour la qualité médiocre des spectacles théâtraux était suivi de la constatation que les couples amateurs de théâtre étaient souvent obligés de suivre ces spectacles, en souffrant les comportements brutes de la populace masculine, envers les actrices. De plus, dans certains articles, on soulignait l'absence dans la ville de cafés-pâtisseries familiaux où il n’y aurait ni les billards des cafés populaires, ni les lourds nuages de fumée, ni la clientèle exclusivement masculine. L’apparition de familles dans des cafés « purgés » des éléments évoqués, cafés qui jusqu’alors étaient des lieux de sociabilité par excellence masculine, était saluée avec enthousiasme en tant que signe d'européanisation des mœurs de la société locale ${ }^{30}$.

\footnotetext{
27 Sfaira (Globe), nº 74, 16 juin $1880 ; n^{\circ} 44,20$ septembre 1880 et 30 décembre 1883, Pronoia (Prévoyance), nº 405, 14 janvier 1884 et Sfaira (Globe), 7 mars 1890.

28 Concernant les représentations des groupes sociaux inférieurs et des pratiques moralisatrices à leur égard, principalement la charité, Maria Korassidou, Les misérables d'Athènes et leurs thérapeutes. Pauvreté et charité dans la capitale grecque au XIXe siècle, Athènes 1995 ; Vasso Theodorou, "Charité et ville. Orphelins et enfants sans abris au Pirée aux alentours de 1875 », Mnimon, t. 14, 1992, p. 71-90 ; du même auteur, "Systèmes disciplinaires et travail dans les orphelinats dans la seconde moitié du XIX e siècle », Mnimon, t. 21, 1999, p. 55-84 et Yannitsiotis, op.cit., p. 225-251.

29 Sfaira (Globe), n83, 27 juin 1880.

30 Sfaira (Globe), n5605, 23 octobre 1900.
} 
L'invocation de la famille, en tant que modèle normatif des modes de distractions de la population masculine, survient au moment où se constitue l'idéal familial et où ce dernier est promu élément fondamental d'une société saine. Le poids social croissant de la famille ainsi que celui de la présence féminine en cette dernière, à travers ses rôles de femme premièrement chargée de diriger le foyer, espace de développement de relations humaines désintéressées, refuge pour l'homme-époux-sujet de l'espace public, et deuxièmement d'élever les enfants, ont été renforcés sous l'impulsion des visées irrédentistes du nationalisme grec et par l'avènement de l'ambition de modernisation du pays. Les femmes étaient considérées les piliers moraux de la société et de la nation, et pour cette raison les voix qui considéraient fondamentale leur éducation se multipliaient, réclamant bien évidemment une éducation limitée au cadre de leurs nouveaux devoirs. En tant que mères, elles auraient la responsabilité d'élever les futurs citoyens et soldats de la nation ; et en tant qu'incarnations des idéaux supérieurs du champ privé, elles étaient jugées capables d'améliorer l'image tragique donnée par l'espace public, par leurs œuvres de charité31. Notre propos ne serait pas exagéré si nous soutenions que la féminisation de l'espace public commence au cours du dernier quart du XIXe siècle. Si les femmes n'avaient pas le droit de devenir membres des diverses associations éducatives, culturelles ou sportives ou d'y donner des conférences (à quelques très rares exceptions près), les femmes des couches sociales moyennes et supérieures suivaient toutes les manifestations de ces associations, organisaient des expositions artistiques, fréquentaient les théâtres, se déplaçaient, dans le cadre de leurs activités de charité, dans les quartiers pauvres, et se rendaient dans les magasins de "nouveautés » de la ville. Néanmoins la rue demeurait toujours un lieu dangereux, voire ennemi, puisqu'on l'appréhendait, dans l'imaginaire collectif, comme un lieu où se liaient et s'opéraient les affaires amoureuses. Ainsi, contrairement au domaine pur de la sphère privée, le passage dans cet univers dépravé rendait vulnérables les dames « comme-il-faut »32. Le fait de s’intéresser à la mode vestimentaire européenne pouvait, lui aussi, d'une part, être condamné en tant que témoignage d'une propension au luxe et au gaspillage, ou encore en tant qu'élément suspect incriminant la sexualité féminine et mettant en péril la « simplicité » et la " chasteté », deux qualités traditionnellement attribuées aux femmes grecques; mais, d'autre part, il annonçait l'apparition d'une nouvelle structure de pratiques familiales de consommation à travers lesquelles les bourgeoises redéfinissaient leur genre et acquéraient leurs

\footnotetext{
31 Eleni Varika, La révolte des dames. La naissance d'une conscience féministe en Grèce 18331907, Athènes, 1987 (en grec). Concernant le contenu de l'éducation des filles, Alexandra Bakalaki et Eleni Elegmitou, L' éducation "pour la bonne conduite de son foyer » et les tâches des femmes. De la création de l'État grec jusqu'à la réforme éducative de 1929, Athènes, 1987 (en grec).

32 Judith R. Walkowitz, City of Dreadful Delight. Narratives of Sexual Danger in Late-Victorian London, Londres, Virago Press, 1994, p. 46.
} 
attributs distinctifs 33 . Dans une société en voie d'urbanisation, où les pratiques de distraction et de divertissement culturel dans l'espace public métamorphosaient les sujets eux-mêmes en spectacle, la parade publique de la femme au côté de son époux, pouvait renforcer le prestige de ce dernier, en tant que reflet de son honneur et de sa richesse et conséquemment de sa fortune familiale.

Le divertissement en famille et la présence féminine présupposaient donc l'existence d'espaces différents de ceux réservés au peuple et caractérisés par des comportements masculins raffinés.

L'ensemble des critiques que nous venons d'énumérer, concernait le besoin de créer les conditions nécessaires pour un loisir tel que le concevait la bourgeoisie et ayant pour foyer l'espace public urbain. Cela nécessitait l'appui systématique de la municipalité qui, quant à elle, s'était fixé d'autres priorités. La majeure partie du budget municipal était allouée à l'éducation, à l'édification d'églises, d'aménagements portuaires, à des œuvres de charité et au financement régulier du club de commerce. Parcimonieuse envers les associations culturelles, artistiques et sportives de la ville, la municipalité se transforme en enthousiaste bienfaiteur de l'association la plus pérenne et active du Pirée, l'« Alliance Piréote », dont l'objectif était d'élever le niveau éducatif et culturel de la classe ouvrière ${ }^{34}$. Nous sommes en droit de nous demander si la coïncidence entre le financement systématique de cette association et l'apparition des premières mobilisations de grève, à l'aube du $\mathrm{XX}$ siècle, est un pur hasard.

La politique des conseils municipaux concernant la question du loisir ne semblait pas se différencier des pratiques sociales des quelques dizaines de familles de l'«aristocratie financière » qui pratiquaient des formes privées de sociabilité, tels que les bals et les fêtes dans leurs palaces ou dans le club de commerce local, "Hermès ». Ces manifestations se distinguaient par leur ostentation et leur splendeur. Quand ces familles décidaient de suivre une représentation théâtrale, elles se rendaient à Athènes. En été, elles recherchaient la détente et les distractions à Phaliron, un bord de mer entre la capitale et le Pirée dont l'infrastructure comprenait un théâtre, des hôtels splendides, des infrastructures pour des baignades en mer, une estrade pour des promenades, un kiosque à musique35. C'est là qu'elles rencontraient les familles athéniennes de l'aristocratie politique, de la bureaucratie d'État et des riches grecs de la diaspora.

\footnotetext{
33 Concernant le rapport mode et construction des identités féminines, cf. à titre indicatif, Cheryl Buckley et Hilary Fawcett, Fashioning the Feminine. Representation and Women's Fashion from the Fin de Siècle to the Present, London, I.B. Tauris, 2002, et plus particulièrement concernant le XIXe siècle, p. 1-49.

34 Yannitsiotis, op.cit., p. 233 - 236

35 Liza Miheli, Le Pirée, De Porto Leone à la Manchester de l'Orient, Athènes, 1993, p. 200-203 (en grec) et Sfaira (Globe) qui consacre souvent, dans sa une, une colonne couvrant la vie mondaine à Phaliron pendant les mois d'été (cf. à titre indicatif, les numéros de l'été 1900).
} 
Dans cet espace situé hors de la ville et bien protégé, puisqu’on y avait interdit même les baignades à toute personne non conviée, ces familles piréotes exhibaient leur richesse, suivaient la mode, concluait leurs affaires et réglaient les mariages de leurs enfants, le Pirée demeurant un lieu de divertissement exclusivement pour les classes laborieuses et un paysage culturellement désert, décevant les espoirs des bourgeois cultivés et des classes moyennes de cette ville.

\section{Bibliographie :}

Bafounis Yannis, 1985, La formation d'une ville nouvelle: Le Pirée au XIXe siècle (1835-1879), Thèse de doctorat non publiée, Paris.

Bakalaki Alexandra et Elegmitou Eleni, 1987, L'éducation « pour la bonne conduite de son foyer » et les tâches des femmes. De la création de l'État grec jusqu'à la réforme éducative de 1929, (en grec), Athènes.

Bakounakis Nikos, 1991, Le fantôme de Norma. La réception du mélodrame en Grèce au XIXe siècle, Hermoupolis - Patras, (en grec), Athènes.

Bastea Eleni, 2000, Planning the Myth. The Creation of Modern Athens, Cambridge, Cambridge University Press.

Buckley Cheryl et Fawcett Hilary, 2002, Fashioning the Feminine. Representation and Women's Fashion from the Fin de Siècle to the Present, London, I. B. Tauris.

Corbin Alain (dir.), L'avènement des loisirs 1850-1960, Paris, Flammarion, 1995.

Fournaraki Eleni, 2002, « Pour quelle raison ne pas lui accorder le droit de vote ? Suffrage universel masculin et exclusion féminine de la politique en Grèce au XIXe siècle ", Mnimon, t. 24, p. 179-226 (en grec).

Kardassis Vassilis, 1985, « Hermoupolis, pratiques et comportements bourgeois », dans les Actes du Colloque International d’Histoire La ville néohellénique. Héritages ottomans et état grec, Athènes, t. II, p. 585-589 (en grec).

Miheli Liza, 1993, Le Pirée, De Porto Leone à la Manchester de l'Orient, Athènes, (en grec).

Rojek Chris (dir.), 1989, Leisure for Leisure. Critical Essays, Londres, Macmillan Press.

Rojek Chris, 1995, Decentring Leisure. Rethinking Leisure Theory, Londres, Sage Publications.

Tsokopoulos Vassias, 1984, Le Pirée, 1835-1870. Introduction à l'histoire du Manchester grec, (en grec), Athènes.

Varika Eleni, 1987, La révolte des dames. La naissance d'une conscience féministe en Grèce 1833-1907, (en grec), Athènes.

Walkowitz Judith R., 1994, City of Dreadful Delight. Narratives of Sexual Danger in Late-Victorian London, London, Virago Press, p. 46.

Yannitsiotis Yannis, 2001, La formation de la bourgeoisie piréote 1860-1909, (en grec), Thèse de doctorat non publiée, Athènes. 



\title{
ESPACE DE LOISIRS, ESPACE POLITIQUE : LE CAFÉ DANS LE MONDE ARABE AU XIXe SIÈCLE, L’EXEMPLE DE TRIPOLI
}

\author{
Nora LAFI \\ Wissenschaftskolleg de Berlin
}

L’historiographie européenne a, depuis longtemps, étudié la place du café dans la naissance d'espaces dévolus à la sociabilité politique, voire la relation intime entre sphère du débat public et espaces de récréation. De la France révolutionnaire à l'Angleterre libérale, les exemples sont nombreux qui illustrent l'importance des lieux de sociabilité récréative dans la formation d'une opinion au sein des élites. Pour la fin du XVIIIe et l'ensemble du XIX siècle, de nombreuses études sont disponibles pour la France quant à l'importance des lieux de réunion au sein d'un espace de loisir dans la maturation des débats révolutionnaires, dans la naissance d'une certaine opinion, ainsi que dans l'accompagnement des soubresauts de la vie politique. Il en va de même, en quelque sorte, pour l'Italie ou l'Angleterre, avec bien sûr des chronologies et des problématiques légèrement différentes. La tendance qui se dégage de cette historiographie est la description du café ou du débit de boissons comme lieu de récréation, mais aussi comme lieu de réunion. Les cafés, dans plusieurs moments particulièrement importants de la redéfinition des sociétés politiques européennes ont même joué un rôle central dans la structuration d'une nouvelle sociabilité politique.

Pour le monde arabe en revanche, lorsqu'il s'agit d'étudier le café, il est souvent plus question de ses effets sur la santé ou de l'organisation des routes 
commerciales que des lieux de consommation. De nombreux ouvrages, s'inscrivant d'ailleurs dans une tradition littéraire remontant à l'époque médiévale, ont montré cependant l'importance du café dans la vie sociale. On trouve ainsi une abondante production d'ordre juridique, de nombreuses études relevant de considérations sur l'hygiène physique, sans omettre toute une veine poétique vantant les vertus du breuvage ${ }^{1}$. Mais il paraît important également d'analyser pour le monde arabe les modes de consommation dans des lieux collectifs. Sans vouloir poser le moindre a priori analogique, ni même tirer de la comparaison avec les exemples européens des enseignements prématurés, il s'agit ici de montrer, à partir de l'exemple de Tripoli, en Libye actuelle, combien, dans le monde arabe, le café en tant qu'espace de sociabilité a joué un rôle considérable, non seulement dans l'émergence d'un débat public citadin au XIXe siècle, mais aussi dans la transformation des institutions de gouvernement urbain. Là plus qu'ailleurs encore, le café peut en effet être vu non seulement comme lieu de débats politiques et d'expression d'une vie sociale codifiée, mais constitue même en certains points le fondement de l'organisation civique citadine.

Tripoli, à la fin du XVIIIe siècle, était une ville relativement petite, de moins de 20000 habitants. Mais elle était capitale de province ottomane, et, depuis 1711, siège d'une dynastie locale semi-autonome par rapport au pouvoir central ottoman. Elle constituait aussi ce qu'on appelle une échelle du Levant, relais côtier entre Méditerranée et désert, comptoir commercial méditerranéen de redistribution et de ré-acheminement. La ville était riche d'une importante vie commerciale, autour de son port d'entrepôt. La vie civique citadine était également très développée. La population était composée aussi bien de musulmans que de juifs. L'élite était composée des plus riches marchands de la ville, contrôlant les corporations les plus actives. Les commerçants de la ville étaient en relation avec leurs homologues de Malte, de Livourne, d’Izmir ou des grands ports de la Méditerranée. La ville jouait un rôle de port d'entrepôt qui lui conférait dans l'échiquier méditerranéen un rôle supérieur à ce que le seul chiffre du nombre d'habitants pourrait laisser entendre.

\section{LE GOUVERNEMENT URBAIN D’ANCIEN RÉGIME ET LA PLACE DU CAFÉ}

À partir d'archives locales et d'archives diplomatiques, ainsi que de certaines chroniques de marchands, on peut retracer les grandes lignes de ce qui paraît constituer un gouvernement urbain de type d'Ancien régime dans cette ville. La place prépondérante du café dans la gestion citadine est apparue comme une évidence. Ce gouvernement urbain était fondé sur le pouvoir des marchands, réunis, pour les puissants d'entre eux, en assemblée citadine : la

\footnotetext{
1 Voir à ce propos la bibliographie donnée par C. Van Arendonk, «Kahwa », Encyclopédie de l'Islam, p. 469-473.
} 
jama'a al-bilâd. Ce gouvernement urbain reposait aussi sur le système des corporations. À la tête des institutions citadines, au moins depuis la fin du XVIIIe siècle, on trouvait un chef de la ville, le cheikh al-bilâd avec des attributions allant de l'ordre public urbain au contrôle des marchés et des transactions, à la tutelle sur les métiers, au contrôle du bâti, aux échelons mineurs de la justice urbaine, et de la fiscalité urbaine. Le chef de la ville émanait de l'assemblée citadine. Celle-ci se réunissait régulièrement pour à la fois avaliser les décisions de son chef, et pour débattre de différents sujets.

Or, la lecture de différentes pièces d'archives et de documents appartenant aux personnes mêmes de cette assemblée de notables, le lieu de ces réunions était fixe : le café dit du chef de la ville. Le fait que les réunions se tiennent dans ce café ne tenait ni à la qualité éventuelle d'un chef de la ville comme cafetier, ni à des circonstances imprécises : le café, espace de réunion, mais qui était aussi lieu de consommation de café et de discussion, avait été légué à la ville, en tant que corps citadin, par une riche évergète. Il appartenait en bien commun à l'assemblée citadine et les fonctions récréatives et politiques y étaient intimement liées ${ }^{2}$. Le café du chef de la ville, à Tripoli, était bien le lieu d'exercice des pouvoirs urbains d'Ancien régime et y avaient lieu aussi bien les réunions de l'assemblée des notables, que la proclamation des décisions. Par son nom même le café du chef de la ville était identifié au pouvoir urbain. À chaque changement de titulaire de la charge de chef de la ville, le café restait le lieu de réunion. Il incarnait de plus la symbolique civique urbaine.

Le café dans les villes arabes comme espace récréatif et lieu de sociabilité a été largement étudié pour la période contemporaine3. En revanche pour les périodes modernes et médiévales, cela est moins vrai. Les études sont rares et les renseignements sont souvent épars ${ }^{4}$. Pourtant la boisson est connue depuis fort longtemps et appréciée dans les régions éthiopiennes et yéménites. Des légendes et des histoires parlent de ce breuvage, tantôt comme plante médicinale, tantôt comme boisson. Le vieux terme arabe « qahwa » qui désigne au départ « boisson » et « vin » dans la poésie ancienne, qualifie plus tard la boisson à base de graine de café (qahwa al-bûn) ${ }^{5}$. Le prophète Mohammed en aurait même bu grâce à l'ange Gabriel. Cité dans des traités médiévaux en langue arabe, conseillé pour ses vertus, la consommation de café se répand dans les villes musulmanes et au-delà. Dès le XVe siècle, les régions ottomanes popularisent le café qui se répand en grande partie par les marchands arabes, sans que l'on sache pour autant avec précision comment et

\footnotetext{
2 Nora Lafi, Une ville du Maghreb entre Ancien régime et réformes ottomanes. Genèse des institutions municipales à Tripoli de Barbarie (1795-1911), Paris, L'Harmattan, 2002, 395 p.

3 H. Desmet-Grégoire et F. Georgeon (dir.), Cafés d'Orient revisités, CNRS, Paris, 1997, 228 p. Omar Carlier, "Pouvoirs, et sociétés arabes: le café maure. Sociabilité masculine et effervescence citoyenne (Algérie XVII -XXe siècles », Annales ESC, (4), juillet-août 1990, p. 9751003.

4 Voir la contribution d'Abdul-Karim Rafeq.

5 C. Van Arendonk, op. cit., p. 469-473.
} 
où il était consommé6. La première présence attestée d'espaces dévolus à sa consommation remonte à la période 1474-1554. En effet, dès le XVIe siècle, des maisons de café sont ouvertes dans des villes comme Médine, la Mecque, Le Caire, Damas, Bagdad, et à peu près toutes les capitales ou grandes villes musulmanes. Les cafés occupent peu à peu une grande place dans la vie citadine. Le vocable utilisé pour l'espace réservé à la consommation de café semble être souvent déjà le même mot qui désigne la boisson : qahwa. Même si théoriquement maqha est le schème grammatical d'usage en arabe littéraire, qahwa s'impose. On trouve en outre pour la ville de Constantinople l'expression kahwe-khâne en 1554 pour appeler le lieu de consommation. Ce serait un homme originaire d'Alep et un autre de Damas qui auraient ouvert « les premiers cafés dans cette région où les oisifs qui cherchaient de la distraction passaient leur temps à jouer au tric-trac et aux échecs tandis que les poètes soumettaient leurs nouveaux vers aux jugements ${ }^{7}$.

La lecture de journaux intimes et des chroniques offre parfois à l'histoire un regard de l'intérieur sur le café. Le journal de Muhammad Al-Makkî en est un bel exemple ${ }^{8}$. Au détour d'abondantes descriptions de la vie quotidienne à Homs de 1688 à 1722, le chroniqueur parle souvent du café en tant qu'espace familier, si bien que ce lieu apparaît comme un repère spatial très important dans la ville. Il lui sert de point de repère pour situer un lieu donné : par exemple « le bâtiment du four qui se trouve... devant le café (al-qahwa al-mu'allaqa) »9. Le café est donc pour ce notable, non seulement un espace familier, mais aussi un point central qui donne du sens à la ville. Il est assurément connu de tous, puisque servant de point de repère. La représentation spatiale de la géographie urbaine de Homs semble s'articuler en partie autour de cet endroit. Il est un lieu de détente pour les membres de la notabilité, qui vont jouer au moment du repos. On peut lire dans la chronique d'Al-Makkî par exemple «le vendredi, au café, Ramdân Ibn Abou al-Mâdî est mort alors qu'il jouait au al-Tâb wa al-dâk... »10 (une sorte de jeu de dames). La ville de Homs, à la fin du XVIIe et début XVIIIe siècle possède donc au moins un espace de sociabilité pour la notabilité citadine. Il semble même que le café devient une composante importante de l'organisation urbaine. Lorsqu'un nouveau quartier est construit, le café semble faire partie des équipements essentiels. Toujours dans le journal d'al-Makkî on peut lire : «Ce même jour, le cheikh Abd al-Ghanî al-Maghrîbî vient de terminer le bâtiment du nouveau souk ainsi que le café »11. Remarquons que la construction du café, dans cet exemple, est placée sous la responsabilité d’un Ancien.

\footnotetext{
6 Voir par exemple l'article « coffee » dans Kenneth F. Kiple, Kriemhild Coneè Ornelas, The Cambridge World History of Food, vol. II, Cambridge University Press, 2000, p. 1760-61.

7 C. Van Arendonk, op. cit., p. 471.

8 Muhammad Al-Makkî, Târîkh Homs, édité et présenté par 'Umar Nagib al-'Umar, Institut Français de Damas, Damas, 1987, 306 p.

9 Ibid., p. 74, p.13.

10 Ibid., p. 7-8.

11 Ibid. p. 74.
} 
Le café, dans les villes arabes, constitue un espace de sociabilité où non seulement on boit du café, mais aussi où la notabilité marchande y vient faire des affaires et échanger des idées. Dès le milieu du XVIe siècle, cette fonction paraît répandue. Sous Murâd III (1574-95), le café est l'endroit où la politique du jour ainsi que les actes du gouvernement sont commentés, critiqués, et parfois lieu où se fomentent les intrigues. C'est la raison pour laquelle des interdictions et fermetures administratives ont été décrétées à diverses reprises dans l'empire ottoman, ou à un niveau local dans telle ou telle ville, sans pour autant d'ailleurs être toujours observées ${ }^{12}$. En outre, il est arrivé que le sultan, sans interdire la consommation, qui devient monopole d'État, parvienne à faire fermer certains cafés. Les prétextes sont légion : lieux de complot, mais aussi parfois lieu de débauche. Pour ce qui concerne le premier cas, cela conforte notre interprétation: si les cafés ont souvent été visés par des fermetures administratives pour raisons politiques dans l'Empire ottoman, c'est bien que des activités politiques s'y menaient. Le plus probable est qu'il s'agissait de réunions de l'élite citadine, qui souvent se trouvait en contraste avec le gouverneur, représentant de l'État central.

Le cas de Tripoli d'Occident permet d'aller plus loin dans la description du café comme lieu d'expression de la notabilité citadine, et surtout d'analyser l'évolution de sa fonction jusqu'à la période des réformes ottomanes de la seconde moitié du XIXe siècle.

\section{À TRIPOLI UN ESPACE RÉCRÉATIF ET CIVIQUE}

Le café à Tripoli est un espace de sociabilité et un lieu récréatif comme à Homs ou ailleurs dans les villes arabes en général, dans lequel se retrouvent les négociants citadins et où se tiennent des réunions organisées par le corps de la ville, au moins depuis le XVIIIe siècle ${ }^{13}$.

Lieu de détente où l'on consomme à l'envi café, sirop ou jus de fruit, en écoutant parfois des histoires ou de la poésie, il semble très fréquenté par l'élite marchande de la ville14. Outre sa fonction de lieu de rencontre, il sert également d'espace de règlement des litiges commerciaux pour les négociants 15 . Dans ce cas, la détente n'est pas au menu : dans les chroniques sont souvent consignées des disputes animant la vie du café. Leur objet est invariablement un désaccord entre commerçants, négociants ou armateurs. Le café paraît constituer un espace neutre de règlement des conflits devant témoin, mais aussi de médiation. Les exemples sont nombreux dans les chroniques de narration d'un litige dont les épisodes les plus importants se passent au café. Un autre exemple réunit les deux dimensions dans le rôle du

\footnotetext{
12 C. Van Arendonk, op. cit., p. 471-2.

13 Voir pour les villes algériennes les travaux d'Omar Carlier, op. cit.

14 H. al-Faqih Hasan, Yawmiyât op. cit, tome I, p. 297, n²21.

15 « Le samedi 9 jumâdâ, Sîdî Ahmad al-Fidâwî s'est assis au café du cheikh al-bilâd et s'est mis à raconter des histoires à la jama'a », ibid., tome I, p. 216, nº113.
} 
café : espace de réunion de l'assemblée civique citadine et espace de règlement des conflits liés au port : le jour où l'assemblée de la ville (jamâ'a al-bilâd) venant à peine de conclure un contrat de location d'un bateau pour Alexandrie, un firman impérial vient tout bouleverser. Les escales de Tripoli, Tunis et Alger sont fermées, entraînant ainsi l'arrêt immédiat de tout trafic commercial dans le port. La peur passée, l'assemblée refuse de se disperser et déclenche un conflit avec les affréteurs. Au lieu de se disputer au port, ils se rendent tous au café du cheikh al-bilâd. Comme le note H. al-F. Hasan de nombreuses disputes ont lieu dans cet espace16.

À Tripoli, il existait de nombreux cafés pour la période concernée. Les compter demeure difficile compte tenu de la disparité et de la nature des documents. Cependant on peut en évaluer le nombre à environ une cinquantaine ${ }^{17}$. Mais il y a café et café : simple débit de boisson ou lieu de réunion de l'élite de la ville. Les chroniques de $H$. al-Faqih Hasan ne mentionnent que quatre cafés : celui de 'Abdallah al-Turkî18, celui de Bâb alBahr19 (de la Porte de la Mer), près du port, et celui d’Abou Salâma. C'est là l'horizon d'un notable. Mai seul le café du cheikh al-bilâd avait semble-t-il les caractères particuliers décrits ci-dessus, et un statut civique. Il était d’ailleurs situé dans le quartier dit de Belediyye, au cœur de la ville commerciale. Notons que, plus tard, le mot «belediyye » prend le sens de municipalité. Il est en arabe dérivé de la racine «balâda », dont les déclinaisons variées ont un sens d'urbanité par excellence. À Tripoli au moins, mais sans doute aussi dans d'autres villes, on peut dire que le café du chef de la ville est au cœur du système de gouvernement urbain d'Ancien régime et à l'origine des institutions municipales.

Les réunions de l'assemblée de la ville se déroulaient autour d’un café, dans la salle principale. Elles pouvaient être précédées ou suivies de représentations musicales ou littéraires. Le café citadin était à la fois le lieu de décision et le cercle récréatif des notables urbains. À chaque changement de

16 Ibid., tome II, p. 210-211, n¹03.

17 Il y aurait de nombreux cafés d'après une circulaire du gouverneur de Tripoli qui souhaitait réglementer les horaires de fermeture des tavernes, des cafés et des boutiques en 1857. Voir Archives nationales de Tripoli (Dâr al-Mahfûzât al-Târîkhiyya bî Trablus, désormais D.M.T, C.R.H.T., n³2, 21-08-1857). Une autre pièce archivistique permet également de se faire une idée pour l'année qui suit. Il s'agit d'une plainte au sujet des cafés à Tripoli rédigée en arabe et déposée au consulat français. Voir archives de Nantes, Dossier Affaires locales, Tripoli de Barbarie, $n^{\circ} 68$, 1275h./1858. Pour la fin du XIXe siècle, un rapport italien en compte 72. Voir Francesco Coro, « Che cos'era la Libia dal punto di vista civile e economico prima dell'occupazione italiana », Viaggio de Duce in Libia per l'inaugurazione della Littoranea, 1 (15), 1937, p. 42.

18 H. al-Faqih Hasan, Yawmiyât al-libiyya, op. cit., tome I, p. 467, n`1037 (« Le Hâjj 'Abdallah al-Turkî Aghâ de la Tour al-Mandrîk a commencé à détruire le café qui se trouve en face des douanes de Bâb al-Bahr le premier du mois de zîal-qa'ada 1245h »; et p. 483, n¹101, « Le qấ'id Maftâh..., sîsî Ibrahîm bû Amîs et la jamâ'a sont partis du palais au nouveau café situé à Bâb alBahr qui appartient au Hâjj 'Abadallah al-Turkî; des invités les ont rejoints dans la nuit et sont rentrés ».

19 Ibid., tome I, 34-35, n¹8 ; tome II, p. 389, p. 672 et p. 761. 
titulaire de la charge de chef de la ville, le café a conservé ses fonctions, à la différence du cabinet privé du chef de la ville (ghurfa) qui, lui appartenant en propre et constituant le lieu de certaines réunions préparatoires ou secrètes, changeait à chaque alternance. Le café du chef de la ville à Tripoli était donc l'ancrage de l'institution du cheikh al-bilâd, la machîkha dans l'espace urbain. Il fut d'office l'espace politique appartenant à l'ensemble de la société tripolitaine, puisqu'au-delà des seules réunions des notables de la ville, il fut aussi le lieu des rencontres et de réunions plus larges lors de moments particulièrement importants de l'histoire de la région : avec les délégation de représentants de différentes régions ou avec les Juifs de la ville (qui avaient leur propre système de gouvernement urbain, sur une base communautaire). " Le dimanche 20, la jamâ’a al-bilâd, le cheikh Sîdî al-Hâjj Ahmad Mahsan, cheikh al-bilâd, les Juifs, les Arabes de Misrâta et d'autres Arabes se retrouvèrent tous dans le café du cheikh al-bilâd dans lequel a été lue la question des ulamas à la jama'a mentionnée. Ensuite ils ont lu l'ordre émanant de notre souverain... »20.

Dans son fonctionnement quotidien, le café n'accueillait cependant que les membres de l'assemblée citadine, soit entre dix et vingt notables musulmans de la ville, appartenant à l'élite des marchands ou des corporations. Cet espace prit de l'importance durant le premier quart du XIXe siècle, dans la mesure où les personnes qui le fréquentaient se consacrèrent de plus en plus à la politique, ou eurent de plus en plus de place dans le circuit de la décision. Le café s'inscrivit dès lors dans les espaces réservés au domaine politique et devint officiellement, en certains moments de faiblesse du pouvoir dynastique, le lieu du diwan (conseil)21. Si bien que le diwan s'est parfois confondu de fait avec la jamâ'a al-bilâd, à la fois signe de la force des élites urbaines auprès du gouvernement de la province, et symptôme de la réduction de la province à la ville à la fin de la période Qaramânlî. Ce glissement s'est opéré au rythme de l'évolution des rapports de force politiques. C'est au même café que l'assemblée des notables urbains décide en 1832 de la destitution du pacha, première étape du processus de renversement de la dynastie qui aboutit trois ans plus tard au retour des Ottomans.

La réflexion sur la place du café dans l'espace urbain, mais aussi sur l'existence d'une sphère du débat citadin au sein de la notabilité a donc été nourrie de la narration de ces épisodes par les chroniqueurs de Tripoli22. C'est ensuite autour du moment des réformes ottomanes, et du passage à des institutions modernisées de type municipal que de nouveaux éléments méritent d'être observés et étudiés.

\footnotetext{
20 Ibid., tome I, p. 297, n421.

21 Ibid., tome I, p. 410-11, n 844.

22 Ibid., tome II, p.34-35, n¹8. Le lundi 2 du mois de rabi’ I 1248h. Le café, lieu de réconciliation, constitue l'espace privilégié de la médiation sociale.
} 


\section{LES RÉFORMES MUNICIPALES OTTOMANES ET LE DESTIN URBAIN DU CAFÉ}

Il est en effet frappant de voir qu'avec les réformes ottomanes, le café devient tout simplement mairie, c'est-à-dire siège des institutions municipales. À partir de la fin des années 1850, jusqu'en 1877, est en effet mis en œuvre par les Ottomans, qui avaient évincé en 1835 la dynastie locale des Qaramanli et repris un contrôle direct de la ville, tout un ensemble de mesures visant à créer une véritable municipalité. Mais alors qu'on lit souvent ce processus comme l'importation d'un modèle européen, il semble bien que la nouvelle municipalité ottomane reprenne dans ses grandes lignes comme dans un certain nombre de détails, les caractères propres du gouvernement urbain de type d'Ancien régime. Les membres de l'assemblée des notables deviennent ainsi en général membres du conseil municipal. Le chef de la ville devient maire. Les attributions essentielles demeurent. On constate donc une grande continuité entre le système de gouvernement urbain que l'on peut qualifier d'Ancien régime, et le régime de type modernisé, fondé sur une institution municipale nouvellement définie. Dans ce vaste processus, qui prend à Tripoli environ deux décennies, et n'est pas exempt de phases de tensions et de crise, le lieu du pouvoir urbain ancien garde une grande importance. Le café du chef de la ville devient en effet mairie. Il perd juste au passage sa qualité de café, ce qui constitue peut-être l'indication d'une réelle inflexion dans la conception de la vie civique 23.

Pour les Ottomans, qui avaient perdu les provinces algériennes et étaient en passe de perdre la Tunisie, Tripoli constituait à ce moment la dernière province occidentale en Méditerranée. La réforme urbaine devait donc à la fois assurer la stabilité et l'efficacité de la gestion, et consolider le pouvoir des élites locales afin qu'elles ne succombent pas aux attraits du clientélisme européen. La nouvelle municipalité, Belediyye, reprenait donc sous une forme modernisée les caractéristiques de la gestion urbaine précédente, afin de ne pas heurter de front les élites locales. La tentative, largement réussie, de retour des Ottomans dans la vie locale, passe par un parcours habile dans le jeu des factions de la notabilité locale. Le bâtiment du café, repère vivant de la vie civique traditionnelle, devenu plus aride mairie, témoigne à la fois de la continuité et du changement d'esprit.

Mais plusieurs traces indiquent la persistance d'un lien entre fréquentation d'un café et débat public citadin : tout au cours des années 1870 et 1880, à chaque épisode traumatique de la vie urbaine, on retrouve telle ou telle

23 Une idée à explorer : le lien entre un espace de sociabilité marchande et le café car par exemple au XIXe siècle Nubar Pacha rapporte qu’Abbas répétait « Je ne suis pas un négociant, je n'ai rien à faire avec ces messieurs,.... Je ne veux pas... que mon palais soit une sorte de café». Cité par Robert Ilbert, Alexandrie 1830-1930. Histoire d'une communauté citadine, IFAO, 1996, vol.I, p. 29. 
faction citadine à débattre des actions possibles au sein d'un café24. Ce qui est perdu, c'est le caractère unifiant du lieu. On se réunit de manière privée dans un lieu privé, avant de voter en public dans le lieu public municipal. Mais le débat citadin continue de se faire largement dans un lieu de loisir comme le café.

L'exemple de Tripoli montre donc combien au sein des villes de l'Empire ottoman la dimension locale de la vie civique était importante, et combien l’espace urbain était marqué des signes du pouvoir de l'élite marchande. Il montre aussi le lien entre capacité à l'oisiveté du notable et implication dans le fonctionnement des rouages du gouvernement urbain. De ce fait, le café est le lieu central du fonctionnement de la société urbaine dans son pôle local. L'ancrage architectural et social des institutions du gouvernement urbain est également important, et là encore le café occupe une place de choix. L'exemple de Tripoli montre combien le lien entre sociabilité de loisirs et sociabilité politique est fort, lien aussi entre esprit récréatif et esprit citadin. Ailleurs dans le monde arabe, de nombreux indices incitent à penser à l'existence de phénomènes comparables ${ }^{25}$. Dans de nombreuses villes, les chroniques évoquent les cafés comme lieux pivots dans la vie sociale des narrateurs. Ceux-ci ne donnent pas toujours les détails que donne un $\mathrm{H}$. alFaqih pour Tripoli, mais livrent de nombreux indices de l'importance du café dans les rouages de la médiation entre notables. De Jérusalem à Damas ou à Tunis, certains cafés, à certaines époques du développement urbain et citadin ont ainsi assurément été affectés d'une valeur civique, et les études tant sur le gouvernement urbain que sur les loisirs se doivent d'explorer cette piste.

\footnotetext{
24 En effet, une circulaire de la baladiyya envoyée au consulat français concernant les nouvelles mesures pour les tavernes et les cafés montre que la nouvelle municipalité entend bien préserver la ville des mauvaises mœurs et donner des amendes aux contrevenants. MAE $145, n^{\circ} 60 \mathrm{du}$ registre d'ordre, 11 septembre 1878. Une autre circulaire pour défendre de jouer dans les cafés, les boutiques et autres endroits du 4 juillet 1878: MAE $145 n^{\circ} 48$. Dans le même esprit, la municipalité en 1879 à compté « 54 cabarets à l'intérieur et à l'extérieur de la ville, où il y en avait 43 qui par leur emplacement intérieur échappaient à la surveillance de la police et de la municipalité ; le bélédié conclut qu'il est nécessaire de fermer ces établissements. Parmi les 49 établissements dont la clôture est nécessaire, 25 appartiennent à des sujets ottomans qui disent avoir payé les droits des années 1293 et 1294 ainsi que l'exigent la police et la municipalité... ». MAE 145, n²0. Fermeture d'une taverne de Choua Lévy en 1877, d'autres en 1878 (n³) : MAE $145, n^{\circ} 125$. D’autres règlements viennent éclairer en creux la pratique des cafés à Tripoli. Par exemple la circulaire pour défendre au Hadj Mehmed Boumediana de vendre ses sucreries sur la voie publique, et au S. Kadour de placer ses chaises au dehors de son café, MAE 145, n99; et d'interdire dans les endroits spacieux de jouer aux dames, au trictrac et aux cartes et de placer des canapés et des chaises en dehors des cafés, MAE 145, n 98 . Circulaire pour enjoindre les administrés de fermer à une heure à la turque, après le coucher du soleil, en 1874, MAE 145, nº 94 et MAE $145, n^{\circ} 125$. Défense d'ouvrir des maisons de jeux conformément au code pénal en vigueur de 1877. MAE 144, n²1 pour la circulaire de mars 1876. En juin 1876, le Medjlis Beledié n'autorise pas d'établir un café billard en face de l'hôpital, MAE 145, n¹44.

25 Cette piste mérite d'être explorée comme le montrent également les travaux de Abd El-Motaal Zaki sur les cafés en Égypte, et notamment sur les liens entre la naissance de la bourse au XIXe siècle et le café.
} 



\title{
LA QUERELLE DES « DÉBUTS » À LYON
} AU MILIEU DU XIXe SIÈCLE : SIMPLE LOISIR THÉÂTRAL OU EXPRESSION DE LA TOUTE PUISSANCE DU PUBLIC ?

\author{
Malincha GERSIN \\ Université Lumière Lyon 2
}

Au milieu du XIXe siècle, la ville de Lyon se développait, s'haussmannisait. Ville de la Fabrique, mais également ville bourgeoise où l'aristocratie était peu installée, Lyon se transformait. Le préfet Vaïsse qui assurait également les fonctions de maire ${ }^{1}$, remodela le centre ville en perçant trois grandes artères de communication dans la presqu'île. L'élite urbaine locale, composée en majorité de négociants et marchands-fabricants en soie vivait sur cette petite partie de Lyon. C'est également sur la presqu'île qu'une forme de loisir urbain se développait amplement au XIXe siècle : la fréquentation des théâtres.

Le Grand Théâtre, construit en 1754 par Soufflot aux Terreaux, dos au Rhône, et le théâtre des Célestins érigé en 1793 sur la place éponyme, dos à la Saône étaient les deux principales salles de spectacles lyonnaises, toutes deux situées dans des quartiers de la presqu'île lyonnaise². La date d'inauguration

\footnotetext{
$\overline{1}$ La fonction de maire à Lyon fut supprimée par le régime du prince-président en 1852.

2 Le choix du lieu de construction, la monumentalité ainsi que l'emplacement de ces théâtres dans l'espace social ne sont pas fortuits. La question de la symbolique de ces emplacements exigerait une étude à part entière. Toutefois sur le choix de construction du Grand Théâtre au XVIII siècle, se reporter à O. Zeller, « Géographie sociale, loisirs et pratiques culturelles : abonnés et abonnements au théâtre de Lyon (1761-1789) », Revue d'Histoire moderne et contemporaine, 1997, 580-600.
} 
du Grand Théâtre montre bien que la vie théâtrale n’était pas un phénomène nouveau à Lyon. Bien au contraire, des études ${ }^{3}$ ont montré l'intensification de cette pratique sociale au cours de la seconde moitié du XVIIIe siècle et pendant la période révolutionnaire ${ }^{4}$.

Les théâtres de Lyon, au même titre que les autres scènes urbaines, durent dès 1806 appliquer les décrets visant à réglementer les spectacles. Le 25 avril 1807, le ministère de l'Intérieur émit un « règlement pour les théâtres » ${ }^{5}$ de Paris et des départements.

Le Grand Théâtre devint officiellement le théâtre principal de Lyon, et à ce titre acquit le privilège de jouer le répertoire des trois Grands Théâtres parisiens ${ }^{6}$. Le théâtre des Célestins, salle secondaire, jouissait du droit de présenter le répertoire de ses homologues de la capitale7. Les deux théâtres étaient subventionnés par la municipalité et furent réunis sous une même direction à partir de 1811. Cette situation demeura inchangée jusqu'en janvier 1864, date à laquelle Napoléon III supprima les privilèges instaurés une soixantaine d'années auparavant et décréta la liberté d'entreprise théâtrale.

Au cours du XIXe siècle, la fréquentation des salles de spectacles confirma une tendance amorcée dès la fin de l'Ancien Régime : le temps théâtral devint partie intégrante des rythmes de loisirs urbains. Si la fréquentation générale des théâtres fluctuait au fil des années sans règle particulière apparente, avec un pic les mois d'hiver, l'affluence hebdomadaire variait également selon les saisons. Comme sous l'Ancien Régime, le dimanche demeurait, en terme de nombre de billets d'entrées vendus, un jour privilégié de fréquentation des spectacles. Néanmoins, aux Célestins, le milieu de semaine faisait moins recette, tandis qu'au Grand Théâtre, l'affluence hebdomadaire variait d'une année à l'autre, et les jours de bonne recette ne coïncidaient pas toujours avec les jours de forte fréquentation.

Les répertoires présentés évoluaient également au cours de la période avec toutefois une constante : sur les deux scènes les remises étaient bien plus fréquentes que les créations. L’opéra et l’opéra comique de Scribe, Auber, Adam et Donizetti ainsi que les ballets dont beaucoup étaient des créations

\footnotetext{
3 Vallas L., Un siècle de musique et de théâtre à Lyon (1688-1789), Lyon, Masson, 1932, 559 p. ; Zeller O., « L'intensification de la vie théâtrale à Lyon (1761-1788) », Cahiers d'histoire, tome 52, n², 1997, 193-216.

${ }^{4}$ Kradraoui C., Au théâtre à Lyon de 1789 à 1799, Lyon, ELAH, 1988, 112 p.

5 Archives Départementales du Rhône (ADR), 4 T 129, Règlement pour les théâtres, 25 avril 1807. Napoléon réduit à huit le nombre de salles parisiennes sur la trentaine qui officiait jusqu’à cette date.

${ }^{6}$ Le répertoire du Théâtre Français ou Théâtre de S. M. l’Empereur (Tragédie et Comédie), du Théâtre de l'Opéra ou Académie impériale de musique (chant et danse) et du Théâtre de l’Opéra comique ou Théâtre de S. M. l'Empereur (comédies, drames mêlés de musique et d'ariettes).

${ }^{7}$ Le répertoire du théâtre du vaudeville (petites pièces mêlées d'airs connus, parodies), du théâtre des Variétés (pièces du genre "grivois, poissard ou villageois »), du théâtre de la Porte-saintMartin (mélodrame), du théâtre de la Gaieté (pantomimes, arlequinades, farces) et du théâtre des variétés étrangères (uniquement des pièces traduites).
} 
locales constituaient les principaux ouvrages du Grand Théâtre tandis que les Célestins présentaient des vaudevilles, des comédies en majorité d’Eugène Scribe et quelques drames.

Au-delà de ces considérations générales il apparaît qu’un des moments importants de la saison en terme de fréquentation était les débuts des comédiens sur scène.

\section{LE RENOUVELLEMENT DES TROUPES ET LES DÉBUTS DES COMÉDIENS}

L'ouverture de la saison et les semaines suivantes constituaient un temps fort de l'année théâtrale. En effet, cette période permettait aux spectateurs de découvrir et de juger les artistes nouvellement engagés par la direction des théâtres. Au préalable, le tableau des troupes était soumis aux autorités ministérielles et préfectorales. Pourtant, même si la nouvelle composition était visée, l'engagement des artistes n’était définitif qu’après une période d’essai d'un mois, imposée par contrat, au cours de laquelle les artistes effectuaient leurs débuts sur scène.

Cette épreuve, apparue, semble-t-il, sous le Premier Empire, obligeait les artistes nouvellement engagés à s’y soumettre : à trois reprises, dans trois rôles différents, l'artiste devait prouver ses talents aux spectateurs. Lors de ces soirées, où souvent, les théâtres étaient remplis, ce qui n’était pas toujours le cas le reste de la saison, les artistes étaient livrés aux spectateurs qui pendant le spectacle, s’armaient de sifflets afin de signifier leur mécontentement quant à la qualité du débutant ou, à l'inverse, applaudissaient. Souvent, les débuts se déroulaient, malgré le bruit, sans heurts particuliers : ainsi on peut lire des commentaires tels que

« les débuts qui ont eu lieu hier, 5 septembre $1863^{8}$, ont eu peu d'opposition. Mlle

Lagge, chanteuse légère double a eu quelques coups de sifflets, mais la grande majorité était pour elle »

ou

«Mlle Lacombe, forte chanteuse qui faisait son $2^{e}$ début dans Léonor de La Favorite a eu un succès brillant, elle a été rappelée deux fois ».

Néanmoins, la tension pouvait monter rapidement lorsque des artistes ne trouvaient pas grâce auprès du public. Ce fut le cas de Mlle Nelly Coquereau, qui le 15 septembre 1858, dans La favorite ${ }^{9}$, provoqua un véritable "scandale » aux dires du rédacteur de ce commentaire dans le registre de caisse. À tel point que le commissaire de police chargé des spectacles est venu sur scène annoncer aux spectateurs qu'elle ne reparaîtrait plus sur scène ; insatisfait le public a continué de siffler et huer jusqu’à ce que le rideau se baisse en milieu de spectacle et qu'on lui annonce que la représentation lui

\footnotetext{
8 Archives Municipales de Lyon (AML), 88 WP 33, Registre des pièces présentées quotidiennement au Grand Théâtre pour la saison 1858-1859 et commentaires sur le déroulement de la soirée.

9 Opéra en 4 actes de Donizetti, Royer et Vaez, 1840.
} 
serait remboursée. La semaine suivante, avant le début du spectacle, le commissaire a rappelé au public qu'il ne devait faire entendre aucune marque d'improbation ou d'approbation pendant la représentation afin de ne pas renouveler le bruit qui avait eu lieu le vendredi précédent... la représentation, aux dires du rédacteur, a donc été très froide.

Normalement, depuis un arrêté municipal daté du 8 octobre 1844, les spectateurs ne devaient plus se manifester avant la fin des trois débuts, mais les exemples précédents montrent bien que cette disposition prise par les autorités n'avait que peu d'effets sur leur comportement.

On pourrait multiplier les exemples, mais le point d’orgue de ces soirées de débuts se situait lorsque les artistes, ayant terminé leur troisième début, se soumettaient au vote du public, qui décidait s’ils étaient dignes d’intégrer la troupe pour la saison théâtrale. Il est important de souligner que tous les spectateurs n’avaient pas droit au vote des débuts. En effet, les admissions n’étaient pas prononcées le dimanche, jour où, ordinairement, les théâtres étaient les plus fréquentés. Le public du dimanche était probablement moins bourgeois si ce n’est populaire 10 étant donné que les places les moins chères étaient les plus vendues le dimanche. Ce public spécifique était donc écarté du choix définitif des artistes. À l'inverse, il n’est jamais stipulé que seuls les abonnés des théâtres prenaient part au vote.

Par ailleurs, en octobre 1844, une commission dramatique, composée de 9 membres et présidée par le maire Terme ou un de ses adjoints fut créée afin de décider de l'admission ou du renvoi des artistes préalablement à leurs débuts publics. Il semble donc qu'elle fut mise en place dans le but de pallier la toute puissance du public qui jusqu'alors décidait seul de l'avenir des artistes. Pourtant, après cette date, les sources ne mentionnent plus cette commission à Lyon avant 1858... mais sans savoir précisément si elle fut recréée.

Ainsi, le vote se déroulait uniquement en semaine, de la manière suivante : un commissaire de police « intelligent » s'avançait sur scène après la chute du rideau afin d'inviter le public à se prononcer et appréciait qui des sifflets ou des applaudissements étaient majoritaires dans la salle. Souvent, le vote n’était qu'une formalité, il est fréquent de lire «admis sans aucune opposition, à l'unanimité, ou malgré l'opposition de quelques sifflets ». Mais parfois, les spectateurs, que le journal de spectacles l'Entracte lyonnais qualifiait de «juges parfois capricieux, bien qu'ils se proclament impartiaux»11 se manifestaient plus vivement lorsque le moment du vote arrivait.

10 En 1861, les places les moins chères s'élevaient à $0,75 \mathrm{~F}$ au Grand Théâtre et $0,60 \mathrm{~F}$ aux Célestins, ce qui restait une somme conséquente. Au sujet de la fréquentation populaire des théâtres le dimanche, voir aussi Robert Beck, Histoire du dimanche de 1700 à nos jours, Paris, Éd. de l'Atelier, 1997, p. 218-219.

11 Bibliothèque Municipale de Lyon Part-Dieu (BML), Fonds Régional, l'Entracte lyonnais du 9 septembre 1860 . 
Ainsi, le 18 septembre 1861릴 le commissaire Claverie, en charge des votes, demanda au public de se prononcer sur le sort de M. Depotier, basse de Grand opéra qui venait d'accomplir son 3e début dans Robert le diable13. "Une très forte opposition s'est déclarée contre lui » et il fut impossible au commissaire de se faire entendre pour se prononcer sur le sort de l'artiste étant donné que le bruit des nombreux sifflets et les cris des spectateurs couvraient entièrement sa voix... en conséquence, il fit évacuer la salle. Le lendemain, ce fut au tour de M. Mamert, second danseur et Madame Laurençon d’être refusés. Le public était tellement bruyant et déchaîné que le commissaire dût se servir d'une pancarte sur laquelle les mots accepté ou refusé étaient inscrits. Mais, parfois le public était versatile. Lors de la soirée du 23 septembre 1861, M. Mamert jouait dans les Dragons de Villars ${ }^{14}$ en attendant son remplacement. Et, à la fin de la représentation M. Mamert, ayant été vivement applaudi, M. Claverie demanda au public si le rejet de cet artiste avait été le résultat d'une erreur et si l'on entendait revenir sur la décision prise. «Les applaudissements ayant répondu oui, M. le commissaire a prononcé l'admission de M. Mamert »15. Ainsi trois jours après son rejet violent, $M$. Mamert put être repêché par les spectateurs.

Les artistes étaient donc soumis aux réactions parfois imprévisibles du public. Lorsque leur chute était prononcée, ils devaient quitter la troupe théâtrale ou jouer en attendant leur remplacement. Néanmoins certains artistes préféraient résilier leur contrat avant leur troisième début si l'accueil s’était avéré froid ou hostile les soirs précédents. S’agit-il d'éviter une ultime humiliation ou de chercher rapidement un autre contrat pour vivre ? Ces questions mériteraient une étude à part entière, néanmoins, il semble que le public se souciait peu des états d’âmes des artistes déchus. En effet, la période des débuts semblait être un rituel privilégié pendant lequel il apparaît que les spectateurs avaient l'impression de pouvoir s'exprimer sans contrainte dans cet espace confiné et fermé qu'était le théâtre.

Pourtant, ces débuts ne faisaient pas l'unanimité, surtout dans les années 1850, et le débat sur leur suppression était régulièrement relancé, dans toutes les grandes villes françaises qui disposaient d'une ou deux salles de spectacles.

Les spectateurs, de leur côté, y étaient très attachés et la correspondance entre le Ministère et la Préfecture ainsi que les articles de presse le montre bien. Néanmoins, il est important de comprendre pour quelles raisons cette courte période dans la saison théâtrale revêtait une telle importance.

\section{L’ATTACHEMENT DU PUBLIC AUX DÉBUTS}

Ce n'était pas que les spectateurs fussent d'ordinaire calmes et silencieux, pourtant, la période des débuts revêtait une importance particulière pour eux.

\footnotetext{
12 AML, 88 WP 66, Commentaires insérés dans le registre de caisse du Grand Théâtre, 1861-1862.

13 Opéra en 5 actes de Meyerbeer, Scribe et Delavigne, 1831.

14 Opéra Comique en 3 actes de Lockroy et Maillard, 1856.

15 BML, Fonds Régional, Extrait du journal le Progrès du mercredi 25 septembre 1861.
} 
En premier lieu, voter pour l'acceptation ou non des artistes était considéré comme un droit « qu'à la porte on achète en entrant ». En payant sa place, le spectateur estimait acheter un droit d'expression.

De plus, la situation même des théâtres de Lyon le confortait dans cette idée. En effet le Grand Théâtre et les Célestins étaient des salles privilégiées, subventionnées par la municipalité. Le budget de la ville étant constitué en grande partie par les impôts des Lyonnais, ceux-ci estimaient donc concourir au financement de leur spectacle. En conséquence, leur droit de regard et leur vote leur apparaissaient légitimes.

D'autre part, il semble que le choix des artistes conférait aux spectateurs lyonnais une certaine indépendance. En effet, lorsqu'en 185816 le ministère de l’Intérieur écrivit aux préfets sur le mode à adopter dans le but d'éviter les débordements constatés lors des soirées de débuts, un feuilletoniste du Salut Public $^{17}$ répondit à sa place et on peut lire, le 21 novembre 1858, que :

«supprimer les débuts en province, comme c'est déjà le cas à Paris (où les salles sont libres et nombreuses) ce serait décréter l'inviolabilité des comédiens et des directeurs. Le public n'aurait qu'à venir s'asseoir en silence devant les idoles de la rampe pour les adorer, il ne lui resterait que le droit d'admiration ».

Et c’est précisément ce rôle passif que le spectateur lyonnais refusait. Sifflets et applaudissements, cris et chut ! servaient en partie d'avertissement au directeur qui présentait sa nouvelle troupe, en dernier ressort seul le public qui se considérait tout puissant choisissait les artistes qu'il voulait voir se produire sur scène pour la saison entière. Lorsqu'il estimait que des artistes lui manquaient de respect, il le faisait bruyamment comprendre, ainsi, le 5 septembre $1861^{18}$, pendant l'Opéra les Huguenots ${ }^{19}$ :

«M. Carmann n'a pas été heureux à sa phrase (je ris du dieu de l'univers) un malheureux couac s'est fait entendre c'est à dater de là que s'est déchaînée l'opposition aggravée encore par un geste que le public a trouvé inconvenant à son endroit : plusieurs personnes ont demandé des excuses à l'artiste d'autres, la résiliation immédiate ».

Et il s’est excusé : au milieu du bruit M. Carman s’est avancé sur l'avant scène et a dit au public qu'il n'avait pas eu l'intention de lui manquer en rien, ce qui mis fin à l'incident, on a continué la représentation.

Toute puissance du public, parfois jeu, compétition même entre les spectateurs. Ainsi, M. Wicart, le 11 septembre 186120 avait eu un très beau troisième début dans La Juive d'Halévy. Mais, au quatrième acte après son air (Rachel quand le seigneur) un malencontreux sifflet s'est fait entendre ce qui

\footnotetext{
16 AML, 88 WP 001, Correspondance préfecture/ministère quant au mode de fonctionnement des débuts à Lyon.

17 BML, Fonds Régional, article du Salut public du 21 novembre 1858.

18 AML, 88 WP 006, Registre de caisse du Grand Théâtre, saison 1861-1862.

19 Grand Opéra en 5 actes de Scribe et Meyerbeer, 1836.

20 AML, 88 WP 006, Registre de caisse du Grand Théâtre, saison 1861-1862.
} 
a soulevé la salle entière en faveur de M. Wicart ; à partir de ce moment le succès a été crescendo jusqu'à la fin de l'acte où " un beau et légitime rappel a couronné cette ovation ». Et ce fut ainsi durant toute la saison.

Il semble donc que les artistes étaient tributaires de l'humeur d'un public versatile ! Néanmoins ce que subissait l'artiste pouvait n'être qu'un jeu pour les spectateurs. En effet les soulèvements pour ou contre un acteur, les joutes entre sifflets et applaudissements, s’ils étaient parfois un enjeu de réelles luttes, rarement politiques, de passion même, semblaient le plus souvent relever du divertissement. De plus, les spectateurs, la presse et même les autorités aimaient gloser, débattre, parler sur les talents ou même l'aspect physique de tel artiste. Par exemple le 3 septembre 186121, le commissaire Claverie donnait un avis personnel voire un pari sur l'avenir de Mlle Laurenti, chanteuse dugazon 22, " elle n'a pas eu un grand succès, mais elle est jolie, elle a des chances de succès "; ou encore "il est malheureux pour Mlle Lagge qu'elle soit pauvre et que ses costumes laissent à désirer mais il est possible qu'elle soit acceptée ». Sans débuts, les commentaires auraient été tronqués. Pouvoir choisir c’était également pouvoir débattre même si c’était sur la couleur d'une robe ou les cris faux d'une chanteuse.

Pouvoir réel ou leurre ? L’auteur, anonyme, d'un mémoire titré Des débuts et d'un mode d'administration des théâtres ${ }^{23}$, pensait que l'épreuve des débuts était une garantie illusoire et sans effets. Pour lui, la chute d'un artiste ne garantissait rien étant donné qu'après maints remplacements, le public, lassé acceptait l'artiste proposé par la direction. De plus, la direction ne pouvait que tirer parti de cette situation étant donné que plus les débuts étaient longs, plus longtemps les salles étaient pleines, plus la recette était conséquente. Même si le public tenait à ce qu'il regardait comme son droit, maintenir les débuts revenait, pour l'auteur, à encourager des violences qu'il qualifiait d'indécentes. C'était également le constat fait par l'autorité et certains feuilletonistes locaux. Pourtant, ceux-ci étaient contre la suppression totale de ces épreuves, en vertu de la tradition et du respect des coutumes locales. Et plus que les débuts même, c'était le mode d'expression qui pouvait être mis en cause.

Pour le Salut Public 24, l'usage des débuts tenait aux coutumes, aux habitudes et au tempérament des habitants de chaque province, ainsi les Lyonnais «ne pourront jamais se passer de manifestations extérieures: sifflets et applaudissements sont leurs votes naturels ». Pour le feuilletoniste, rien de scandaleux dans le fait de siffler, et si les journalistes parisiens arguaient que le sifflet avait disparu des mœurs, puisqu’à Paris on ne sifflait plus, il répondait :

\footnotetext{
$\overline{21}$ Archives Départementales du Rhône (ADR) 4 T, 138 rapports de police concernant les débuts 1861.

22 Nom d'une chanteuse du XVIII' siècle, devenu adjectif.

23 AML, 88 WP 001.

24 BML, Fonds Régional, toujours dans l’article du 21 novembre 1858.
} 
"Si, le sifflet est dans nos mœurs et ce qui le prouve c'est que de Rouen à Marseille et de Bordeaux à Lyon, on a, cette année sifflé sur toute la ligne ».

Il ajoutait, afin de mettre fin au débat des débordements dans les salles lors des débuts :

« Je n'appelle pas scène violente le fait de siffler et d'applaudir paisiblement, à tête reposée, un acteur à la chute du rideau; ce combat bruyant, mais pacifique, durât-il toute la nuit, ce n'est-là que l'exercice d'un droit et il n'y a point-là de scandale ».

Mauvaise foi, anti-parisianisme, le feuilletoniste par cette argumentation démontrait à quel point le droit d'expression, la tradition et la volonté de participer au spectacle étaient importants à Lyon.

À cela vint s'ajouter une autre défense des débuts, en apparence plus étonnante, émanant du préfet lui-même, qui, dans une lettre au ministère écrite 9 jours après l'article, le 30 novembre $1858^{25}$, s'exprimait en ces termes :

« [...] l'usage des débuts en province, monsieur [le ministre] est traditionnel, il a traversé toutes les époques, il a été la cause ou le prétexte de manifestations bruyantes [...] ; scènes fort regrettables mais qu'il ne paraît pas bien difficiles d'empêcher et qui d'ailleurs, il faut le reconnaître, sont le plus souvent provoquées par la médiocrité et les exigences des artistes [...] ; je pense qu'il y aurait de graves inconvénients à supprimer cet usage de manière absolue, ne serait-il pas à craindre en effet que le public, dans l'impossibilité d'exprimer son opinion dans l'intérieur de la salle n'en vienne à protester activement à la porte [...] ».

Au-delà des considérations artistiques du préfet (qui par ailleurs disposait gracieusement d'une loge à l'année au Grand Théâtre) prenant la défense de ses spectateurs en cas de débordements, un autre problème lié à cette période des débuts voyait le jour : s’ils étaient interdits, les dérapages, contrôlés dans une enceinte fermée, risquaient de s’étendre au dehors. Pour la tranquillité et l'ordre public le préfet, pensait qu'il valait mieux permettre, du moins faire croire en une certaine liberté d'expression, fut-elle confinée.

Les doutes du préfet en 1858 se révélèrent fondés quelques années plus tard, lorsque Raphaël Félix, comédien, frère de la grande Rachel, ancien pensionnaire de la Comédie Française, accéda au poste de directeur en 1864 et supprima d’autorité les débuts des comédiens la saison suivante.

\section{LA DIRECTION « FÉLIX » ET LA SUPPRESSION DES DÉBUTS}

Raphaël Félix fut nommé le 1er mai 1864 pour 5 saisons et devint le premier directeur prenant ses fonctions au moment de l'application du décret de Napoléon III datant du 6 janvier et applicable au 1er juillet qui mettait fin au statut de théâtres privilégiés et proclamait la libéralisation de l'entreprise théâtrale. Néanmoins, les deux théâtres lyonnais demeuraient subventionnés

25 AML, 88 WP 001, Correspondance préfecture/ministère quant au mode de fonctionnement des débuts à Lyon. 
par la municipalité. Mais l’application de ce décret par Raphaël Félix le fit entrer en conflit direct avec les spectateurs.

Dès son arrivée, le public le bouda. On peut en effet lire dans les rapports de police du commissaire chargé des spectacles Claverie que «les spectateurs ne se press[ai]ent pas aux débuts comme les années précédentes », il écrivit même le 20 novembre 186426 :

"Qu'il a[vait] remarqué une indifférence imméritée, depuis neuf ans qu’il [était] chargé de ce service, il n'avait jamais vu aussi peu de monde pour les débuts, la salle est toujours vide et ce n'est que le dimanche qu'il y a salle comble. Cela est attribué, dit-on, à la manière dont s'est posé le directeur à son arrivée : d'un caractère entier, ne voulant pas recevoir d'observation de personne. Tout cela joint à une augmentation des places pourrait bien être la cause de désertion des habitués ».

Est-ce uniquement dû à l'arrogance de ce directeur? Le Journal de Guignol27, hebdomadaire satyrique et populaire s'attaquait régulièrement à lui depuis sa prise de fonctions, écrivant même le 21 mai :

«Quel chinois ce directeur

Attiré par le jaune, fièvre de l'or

Il faut bien faire la part du juif dit-il avec un sourire d'enfant de cœur à tous ceux qu'il plume... ».

Il était plus reproché à Raphaël Félix son appât du gain et sa volonté d'accroître ses recettes avec l'augmentation des places et des abonnements, mais il semble que les accusations portées contre lui étaient teintées d'un certain antijudaïsme, étant donné que tout au long du XIXe siècle, le dédain de l'art et la recherche de profits furent en permanence reprochés aux différents directeurs des théâtres de Lyon.

Raphaël Félix termina cependant la saison et prépara la rentrée théâtrale 1865 par un placard, visé par le préfet, que les Lyonnais purent découvrir le 28 août 1865, deux jours avant l'ouverture de la saison. Cette affiche stipulait que les débuts des comédiens étaient purement et simplement supprimés et qu'il était interdit aux spectateurs de se manifester durant le spectacle. Par le décret de 1864 qui pourtant ne comportait pas d'article concernant les débuts, M. Félix estima qu'il avait le droit de supprimer cette épreuve, de plus toutes les ordonnances de police depuis le début du siècle interdisaient déjà les manifestations bruyantes pendant le spectacle.

Le directeur imposa peut-être cette décision en raison du manque de spectateurs pendant les débuts précédents, par volonté de choisir seul ses troupes ou encore par vengeance envers ce public déserteur lors des précédentes épreuves.

\footnotetext{
26 ADR, 4 T 138.

27 BML, Fonds Régional, Le Journal de Guignol, 21 mai 1864.
} 
Toutefois, le public n'accepta pas cette décision arbitraire, qui lui ôtait son droit de regard, et il le fit savoir en sabotant la soirée d'ouverture du 1er septembre.

Dès le lendemain, et pendant plusieurs semaines toute la presse locale, Progrès, Salut Public, Journal de Lyon ainsi que les petites feuilles se firent l'écho de ces événements...

"On savait bien que le public, irrité de la suppression des débuts se livrerait à des manifestations hostiles, mais l'événement a dépassé de beaucoup les prévisions » ${ }^{28}$.

Bien avant le lever de rideau la salle du Grand Théâtre fut « envahie, à l'exception des stalles, par une foule compacte où naturellement le public féminin ne figurait qu'à l'état de minorité »29.

Dès le lever de rideau, les sifflets, " glapissements et roulements de pieds " se déchaînèrent, le rideau fut baissé, et le public se mit à crier « $a$ bas Raphaël ! la démission de Raphaël! ! et à chanter "Malbrough s'en va t-en guerre, ah zut! alors si ta soeur est malade, tu t'en vas et tu nous quittes». Le chef d'orchestre ne put faire jouer une note, le rideau fut baissé. Le commissaire de police ordonna l'évacuation successive des galeries mais les spectateurs se reportèrent sur les autres étages ou vers le parterre en lançant divers projectiles vers la scène. Enfin, la police parvint à refouler les derniers spectateurs «qui $v$ [enai]ent grossir le flot compact dont la place de la comédie et ses abords se trouv[ai]ent garnis depuis le commencement du spectacle». La foule voulut se diriger vers l'immeuble du directeur, et pendant ce temps aux Célestins, le Progrès ainsi que le commissaire principal de la police politique, rapportent que le "public dépav[ait] la chaussée et bris[ait] à grands fracas les vitres de la façade ». Les deux théâtres furent fermés, mais à $21 \mathrm{~h}$, une foule énorme continuait à stationner avec obstination sur la place de la Comédie et des Célestins...

Cependant, cette manifestation fut calmée sans heurts avec la police ou l'armée. Le commissaire principal de la police politique, dans son rapport à la préfecture en date du 2 septembre, écrivit :

« il ne fallait pas penser à mettre fin par la force à cette attaque générale; mais nous arrivâmes au même but en faisant comprendre à quelques-uns des plus ardents que la manifestation était plus que suffisante et que d'ailleurs le théâtre n'appartenait pas au directeur...et quelques secondes après l'attaque cessa ».

Seules quelques arrestations isolées furent effectuées.

Cette soirée servit d'exutoire à la population, le rejet du directeur semble évident, on se demande pourtant si les spectateurs, unis par un ennemi commun, se sont trouvés plus blessés par le fait qu'on leur supprime les débuts ainsi que leur droit d'expression dans la salle ou par le fait qu'on ne leur ait

28 BML, Fonds Régional, Salut public, 3 septembre 1865.

29 Ibid. 
pas demandé leur avis avant de le faire. Le commissaire de police écrivit même, avec raison, que la passion et le désir de punition l'emporta sur le but principal de cette émeute, c'est-à-dire de continuer à jouir du droit consacré par l'usage. Pour lui, les partis politiques n'étaient pas étrangers à cela, il estimait même qu'ils avaient, par là voulu avertir l'administration que, si elle gardait Raphaël Félix au mépris « des droits et des désirs de la population », les émeutes pouvaient aisément recommencer. Vrai ou faux, l’urgence pour l'autorité était de faire démissionner le directeur afin que la tranquillité publique soit rétablie. Étant donné que la répression avait été faible au soir du $1^{\text {er }}$ septembre, elle ne voulait pas laisser croire qu’il était si aisé de déranger l'ordre public. Afin de pacifier la situation, l'administration publia dans les journaux une lettre où elle expliquait que l'interdiction des sifflets s'appliquait

«uniquement aux manifestations tumultueuses de nature à empêcher les manifestations et non point au droit du public à manifester son mécontentement pour les artistes ».

Pendant ce temps Raphaël Félix avait fui à Paris. Il démissionna dans la semaine non sans intenter un procès à la ville de Lyon qui rejeta toutes ses demandes, notamment celles de remboursement des frais engagés et ce, en grande partie en raison de son manque de respect envers les Lyonnais. Il finit sa carrière comme directeur du théâtre de la Porte St-Martin à Paris où il n’eut pas de démêlés avec le public.

Habitué de la direction des Théâtres lyonnais, Médéric Delestang prit sa succession. Son premier acte de directeur fut, bien évidemment, de rétablir les débuts en expliquant au public, par voie de presse, le 10 septembre 186530 qu' « il ne pouvait se passer de l'approbation du public lyonnais; approbation qui [était] la condition nécessaire à la prospérité de toute entreprise théâtrale!».

Le 11 septembre les théâtres rouvrirent, et les journaux recommencèrent à parler « de ces ennuyeuses épreuves auxquelles ne succèdera jamais assez tôt le répertoire d'hiver ${ }^{31}$. Le public lyonnais obtint donc gain de cause et la peur des débordements amena les autorités à rétablir ce qu’il réclamait, bien que, légalement les débuts ne fussent plus obligatoires et les sifflets depuis longtemps prohibés. Les débuts comportaient peu d’intérêts ? les artistes restaient médiocres ? peu importe, choisir était un droit qui demeura en vigueur jusqu'en 1889.

En définitive, la toute puissance du public lyonnais, dans sa volonté de participer à la gestion théâtrale rencontra la préoccupation des autorités. Les spectateurs obtinrent gain de cause afin que les désordres liés aux débuts restent confinés dans une enceinte fermée plus facilement contrôlable. Par

\footnotetext{
30 BML, Fonds Régional, Salut public, 3 septembre 1865.
}

31 BML, Fonds Régional, le Progrès, 27 septembre 1865. 
ailleurs ces événements montrent qu'au milieu du XIXe siècle, il n'existait pas encore de sociabilité policée du silence et de la bienséance au théâtre. Toutefois ceci n’est pas spécifique à Lyon: dans les années 1850, une correspondance fournie, entre les mairies et les préfectures de Lyon, Nantes, Rouen et même Genève se demandant comment chacune réglementait ses débuts, étant donné qu'il n'existait pas de règle uniforme, montrent que les débuts et les éventuels débordements liés à cette période de la saison théâtrale concernaient toutes les autorités et administrations qui disposaient d'une ou deux scènes subventionnées. Jean-Pierre Chaline l'a souligné à Rouen ${ }^{32}$, Alain Corbin a consacré un chapitre à l'agitation dans les théâtres notamment lors des débuts dans son ouvrage Le temps, le désir et l'horreur 33 , Henri Contamine l'a montré à Metz 34 ... Néanmoins l'importance accordée aux débuts doit dépasser le simple exemple. Les débuts faisaient partie intégrante des rythmes de loisirs urbains, un moment d'expression privilégiée, à intégrer dans une étude plus générale de la vie théâtrale dans les différentes villes de France.

Se rendre au théâtre afin d'assister aux représentations était un loisir collectif qui regroupait des personnes d'origine sociale variée. En conséquence, la salle de spectacles devenait un espace politique, haut lieu de représentation sociale, d'expression et d'échanges d'idées. D'où une certaine ambiguïté : à la fois lieu de loisir et d'expression collective qui pouvait, aboutir à l'émeute, le théâtre demeurait au XIXe siècle, comme sous l'Ancien Régime, un enjeu d'ordre social difficile à maîtriser.

32 J.-P. Chaline, Les bourgeois de Rouen, une élite urbaine au XIXe siècle, fondation nationale des sciences politiques, 1982.

33 A. Corbin, Le temps, le désir et l'horreur, Essais sur le $19^{e}$ siècle, Paris, Aubier, 1991, 53-79.

34 H. Contamine, Metz et la Moselle de 1814 à 1870, Nancy, 1932, p. 84. 


\title{
LES BAINS DE MER À ISTANBUL, XIXe-XXe SIÈCLES
}

\author{
Méropi AnAstassiadou-DumONT \\ CNRS, Paris
}

À Istanbul, grande métropole située au croisement de trois mers, les bains de mer connaissent une popularité croissante à partir de la seconde moitié du $X^{X I X}{ }^{e}$ siècle. Plusieurs facteurs contribuent à cet essor : la création, en 1858, de la première municipalité de la capitale ottomane, la mise en place d'un réseau de transports intra-urbain, le développement de la médecine moderne et la large diffusion des théories hygiénistes importées d’Europe.

Même si on assiste, au dernier quart du XIXe siècle, à une multiplication des divertissements accessibles à tous les membres d'une famille, la plupart des activités de loisir ou les occasions de sociabilité (hammam, café, associations de charité, clubs sportifs) restent encore réservés aux représentants d'un seul sexe, sans possibilité de mélange. Il va de soi qu'à cette époque, hommes et femmes se baignent séparément.

Tout au long de ces dernières décennies ottomanes, la protection de la nudité du corps - masculin, mais surtout féminin - reste une condition essentielle pour le développement des bains de mer. Les gens se baignent enfermés dans des baraquements en bois qui reflètent, dans l'espace urbain, le souci de préserver la pudeur.

Les premières plages et les premiers bains mixtes sont inaugurés par les Russes blancs, vers 1920, lors de l'occupation d'Istanbul par les forces alliées - une période de profonds bouleversements sociaux, économiques et démographiques. Mais cette initiative venue d'éléments extérieurs à la société 
locale ne reste pas une parenthèse, un épisode sans suite. Le pouvoir kémaliste prend le relais et fait des bains de mer un loisir pour le peuple.

Avec la fondation de la Turquie kémaliste en 1923, une nouvelle ère s'ouvre pour cette société urbaine. Considérée désormais comme l'égale de l'homme, la femme est encouragée à participer activement à la vie économique et sociale du pays. La vision kémaliste promeut le modèle d'une société où le principe antique de l' "esprit sain dans un corps sain » est en pleine reviviscence. Il suffit de feuilleter certaines revues des années 1920 ou 1930 pour s'en convaincre : la Turquie kémaliste, mensuel de propagande, contient des nombreuses photos exhibant le corps féminin et extraites des concours sportifs de l'époque.

Reste à savoir pourquoi les autorités turques se sont intéressé à cette activité, dans quel but elles ont cherché à la développer, pour quelles raisons elles ont encouragé les initiatives privées susceptibles de contribuer à la popularisation de cette forme de loisir. Enfin, dans un autre ordre d'idées, l'histoire des bains de mer à Istanbul devrait nous permettre de voir comment une société fortement imprégnée aussi bien par l'islam que par la civilisation européenne a géré la question de la nudité du corps féminin.

Pour retracer l'évolution des bains de mer à Istanbul durant les XIXe et $\mathrm{XX}$ e siècles, cette étude s'appuie sur la presse de l'époque, des récits de voyages, des œuvres littéraires, des ouvrages médicaux ainsi que sur une récente bibliographie en langue turque. Les matériaux utilisés concernent la ville d'Istanbul. Certes, il ne s'agit pas d'en déduire que les citadins seuls avaient le privilège de se baigner ou que la baignade était un plaisir inconnu aux habitants des villages. Cependant, à la lumière de la documentation disponible, il ressort que c'est dans les villes que cette activité s'est organisée en " loisir » et que ce sont les pouvoirs urbains qui l'ont dotée de toute une série de normes de bonne conduite. Par ailleurs, aller à la mer tout simplement, sans avoir à payer un billet d'entrée, ni à passer devant un gardien est précisément un acte qui ne laisse aucune trace écrite. L'existence de documents administratifs attestant du caractère réglementé de la baignade en mer ne suffit évidemment pas pour démontrer l'absence de toute spontanéité dans ce domaine et devrait être lue et interprétée avec prudence.

\section{LES DENIZ HAMAMLARI OU HAMMAMS DE MER}

Comment traduire le terme hammam de mer ou, en turc, deniz hamami ? Faute d'équivalent exact en français, une explication de ces termes s'impose. Deniz signifie en turc la mer ; hammam est l'établissement de bains (et non pas l'acte de se baigner, de se laver). Les deux réunis désignent des constructions légères en bois et posées sur pilotis, de forme carrée, fermées des quatre côtés et situées dans la mer, à faible distance du rivage. Les quatre parois de l'édifice enferment une sorte de piscine dans laquelle on est censé nager. 
Par certains aspects, les hammams de mer sont une transposition en milieu marin des bains publics connus sous le nom de hammam. Ici aussi, la mixité des sexes est strictement prohibée. Les installations pour hommes sont distinctes de celles destinées aux femmes. Afin d'écarter tout risque de mélange, ces établissements sont séparés d’une distance suffisante pour que « la communication par voix d'homme ne soit pas possible ». Non seulement on ne peut pas se voir, mais on ne peut même pas se parler. La présence d'un policier en uniforme (çavus, sergent) qui rode en barque entre la partie féminine et la section masculine a pour but d'assurer l'étanchéité entre les sexes et de dissiper les tentations (Évren, 2000, p. 25).

À l'exemple du hammam, le hammam maritime est un haut lieu de sociabilité, surtout pour les femmes qui s'y rendent en groupes pour des séances pouvant durer plusieurs heures ${ }^{1}$. Emportée dans des paniers ou consommée dans les établissements attenant le bain, la nourriture est au cœur de ces moments de détente. La plupart de ces lieux disposent d'une construction annexe qui sert de buvette, de café ou - pour des périodes plus récentes - même de restaurant (Sehsuvaroglu, 1953).

La gestion de ces endroits est aussi calquée sur celle des bains publics. Cédée pour une durée limitée à un particulier (le plus souvent un non musulman), elle est soumise à des règles précises notamment en ce qui concerne la rémunération du personnel et les impôts et taxes dus à l'État. L'entrée est payante. Les recettes servent à salarier le gardien/policier ainsi que les maîtres-nageurs et les sauveteurs. C'est également sur ces sommes que comptent les tenanciers pour s'acquitter de leurs obligations fiscales (Évren, 2000, p. 25-26).

Dans son ouvrage consacré aux plages d’Istanbul, Burçak Évren mentionne que d'après un inventaire de 1867 il y avait, à cette date, sur les rives de la capitale, 62 constructions de ce type dont la plus grande partie était réservée aux hommes. En 1870, l’ouverture de 26 autres est annoncée (Évren, 2000, p. 25, p. 27). En 1875-76, entre en activité un nouvel établissement, situé au pied du Pont de Galata, un des secteurs les plus commerçants de la ville (Évren, 2000, p. 25). Le lieu est stratégique. Une grande partie de la population citadine active - et notamment nombre de travailleurs immigrés qui logent dans les foyers pour célibataires alignés sur le rivage - passe quotidiennement par cet endroit ${ }^{2}$. En cette année 1875, cela fait seulement trois ans que la Municipalité assure la gestion des hammams maritimes ${ }^{3}$. Avant cette date, c'était le Service de la Marine (Bahriye Nezareti) à travers l'Arsenal impérial (Tersane-i amire) qui administrait ces lieux. Le transfert d'un organisme à l'autre ne s'est pas fait sans difficultés et il a fallu que le Conseil d’État (Sura-i Devlet) tranche (Évren, 2000,

\footnotetext{
1 Sur le hammam en tant qu'espace social, voir Carlier, 2000 ; Yilmazkaya 2002, 25-31; Isin 1995, 259-264.

2 À propos de ces zones du bord de la Corne d'Or investies par les immigrés venus des provinces voir en particulier Kesisoglou-Karystinou, 1998.

3 Voir Ill. 1 : Les hammams de mer en 1875.
} 
23, 26). L’enjeu semble avoir été principalement financier, les taxes perçues sur ces installations représentant des sommes d’argent non négligeables.

Les instances municipales d'Istanbul, créées progressivement entre 1858 et 1870, ne tarderont pas à marquer le terrain en édictant, en cette même année 1875, un règlement sur les modes de construction, le contrôle et les spécificités des hammams de mer. Ce texte reprend, pour l'essentiel, les normes qui régissaient déjà la fréquentation de ces lieux : séparation entre hommes et femmes, interdiction d'entrée aux ivrognes et aux impudiques, présence obligatoire de policiers, de maîtres-nageurs et de sauveteurs (Sehsuvaroglu, 1953). À côté de ces dispositions, le document de 1875 procure aussi des informations sur la construction des hammams maritimes : faits avec des grosses poutres résistantes à l'eau, ceux-ci étaient situés à des endroits ni rocheux ni très profonds. Le même texte précise que ceux qui entreront dans la mer à l'extérieur de l'installation balnéaire seront punis. Enfin, en annexe de ce règlement, la municipalité fournit une liste de soixante établissements balnéaires repartis à travers la ville. Trente-trois d'entre eux sont réservés aux hommes, vingt-sept sont destinés aux femmes. Sur le plan juridique, le rôle de la municipalité consiste à accorder à des particuliers l'autorisation d'utiliser certains endroits du rivage pour des périodes limitées. Ces concessions sont attribuées pour deux ans renouvelables (Ergin, 1330 [1922], 2142-2145). Chaque année, vers la mi-septembre, les hammams de mer sont démolis et reconstruits à l'arrivée de l'été (Évren, 2000, 16 ; Ergin, 1330, p. 2143, 7e article). L'emplacement de ces établissements demeure inchangé d'une année à l'autre : les grosses poutres sur lesquelles reposaient ces édifices restaient tout l'hiver dans l'eau et marquaient ainsi les lieux précis d'exercice de cette activité.

À côté de ces installations accessibles à tous, Istanbul compte, dans le dernier quart du XIXe siècle, un grand nombre de hammams privés (qu’il convient de désigner ici comme «domestiques »), appartenant au palais impérial, aux ambassades des pays européens ou à des familles aisées, propriétaires de maisons en bois cossues sur les rives du Bosphore (les fameux yali) ou sur le bord de la Marmara. Minuscules, ces cabines privées ne sont pas démolies à la fin de chaque saison mais simplement rafraîchies et réparées au début de l'été (Évren, 2000, p. 38). Resat Ekrem Koçu, célèbre folkloriste turc du début de la République, décrit ces édifices privés comme des "petites chambres élégantes en bois, sur la mer fermées des quatre côtés de manière à ce qu'on ne puisse pas être vus de l'extérieur » (Koçu, p. 4438-4441). Aux dimensions d'un poulailler - l'expression est de Sermet Muhtar Alus - ces lieux d'apparence humble sont généralement décorés à l'intérieur conformément au rang social de leur propriétaire (Alus, 1934 cité par Évren, 2000, p. 38). Ceux situés à Kandilli par exemple dépendent du palais et sont revêtus entièrement de marbre. Propriétés privées, ces espaces n’échappent pas pour autant au contrôle de la municipalité, notamment en ce qui concerne les normes de construction. S’il n’y avait pas de restriction pour la qualité du 
bois utilisé, les règles portant sur la profondeur en particulier devaient être impérativement respectées. Un permis de construire émanant de la municipalité était requis, faute de quoi l'édifice était démoli et les propriétaires punis d'une forte amende (Ergin, 1330 [1922], p. 2142-2145, art. 14-16).

C'est dans un souci d'aménagement du territoire urbain que la municipalité se manifeste pour réglementer ces constructions qui sont principalement une affaire privée. La période est, en effet, particulièrement riche en directives, règlements, décisions et autres émanant des autorités municipales et ayant pour but de moderniser le paysage urbain stambouliote: tracement de nouvelles artères, élargissement des rues, constitutions de zones de sécurité contre les incendies, pavage des chaussées (Borie, Pinon, Yerasimos, 1989).

Cependant, outre les préoccupations d'urbanisme, le règlement de 1875 encadre la baignade en mer avec des normes précises visant à éviter les dérapages notamment sur le plan moral. S'il est difficile de mesurer l'impact de la municipalité ottomane d'Istanbul sur la popularisation des bains de mer, il apparaît clairement qu'en le réglementant, celle-ci indique que ce nouveau type de divertissement entre tout naturellement dans son champ de compétences. Par les mesures prises, les instances municipales cautionnent une activité dont la propagation s'inscrit dans un processus plus général de modernisation de la société ottomane ${ }^{4}$. Pour partie, c'est au développement des moyens de transport ou encore au discours hygiéniste des médecins, omniprésent à cette époque, qu'il faut attribuer la popularisation des baignades en mer.

Dans leur vie de tous les jours, les Stambouliotes sentent l'air des Réformes aussi à travers la multiplication de moyens créés pour se déplacer dans la ville. Le premier pont de Galata reliant les deux rives de la Corne d'Or est construit en 1845. Dès les années 1840 et plus intensément à partir de 1850, les liaisons maritimes se densifient et ouvrent la voie à l'urbanisation de secteurs éloignés du centre historique. Fondée en 1851 avec 16 bateaux, la société maritime Hayriye jouera un rôle capital dans ce domaine. À partir de 1870, c'est au tour du tramway et du train d'enrichir le réseau des transports intra-urbain et les liaisons avec les faubourgs. En 1873, est inaugurée la ligne ferroviaire Haydarpacha-Gebze, longue de $48 \mathrm{~km}$, qui parcourt la rive asiatique le long de la mer de Marmara. Une année plus tard, entre en service la première ligne de chemin de fer reliant Istanbul à Sofia. Celle-ci dessert aussi plusieurs localités situées le long de la côte européenne de la Marmara. En 1875, les six premiers arrêts correspondent à un trajet d'une trentaine de kilomètres et définissent les limites des secteurs en voie d'urbanisation. Il est important de noter que ces six arrêts figurent aussi dans la liste des installations balnéaires publiée par la municipalité à la même date (Çelik, 1986).

\footnotetext{
4 À partir des années 1830, une série des réformes (connues sous le nom de tanzimat) sont entreprises par l'État ottoman dans le but de moderniser l'Empire. Sur cette période et ses effets sur la société ottomane, il existe un grand nombre de travaux. Pour une synthèse rapide voir Dumont, 1989.
} 
La carte du réseau ferroviaire ou celle des liaisons maritimes se confond sans difficulté avec celle des hammams de mer. La plupart de ces édifices sont situés à proximité d'un arrêt de train ou d'un débarcadère, ce qui indique que leurs gérants comptaient pour l'essentiel sur une clientèle venue de loin. Dans ce dernier quart du XIXe siècle, la plupart des localités de banlieue sont des gros villages où les zones d'habitation restent encore assez réduites.

Autre facteur qui a contribué - sans pour autant l'avoir engendrée - à la popularité des bains de mer dans l'Istanbul de la fin de la période ottomane : le discours médical. Grâce au cautionnement scientifique, entrer dans la mer n'est plus seulement un plaisir, ne sert plus seulement à se rafraîchir lors des lourdes chaleurs estivales, cela fait de surcroît du bien à la santé. Et à cette époque, la santé du peuple est un domaine qui donne bien de soucis au corps médical constantinopolitain ainsi qu'aux autorités. Épidémies de variole et de choléra, infections et troubles respiratoires - la tuberculose fait rage dans les couches populeuses -, maladies dermatologiques, la nosologie est particulièrement riche et chargée, les taux de mortalité très élevés et l'espérance de vie dramatiquement basse. Les médecins stambouliotes entreprennent une campagne d'information de la population sur les modes de prévention des principales maladies ${ }^{5}$. C'est l'âge d'or de l'hygiénisme: propreté domestique et des lieux publics, aération régulière des habitations, conseils pour éviter les carences alimentaires sont des thèmes omniprésents dans les revues médicales de l'époque et très fréquemment débattus dans les sociétés des praticiens (Anastassiadou-Dumont, 2003). Reste à savoir évidemment quel impact peuvent avoir ces textes - souvent rédigés en français - dans une société en grande partie illettrée, n’ayant que des contacts épisodiques avec le monde de l'écrit. Pour une part, le message passe à travers les écoles qui intègrent le cours d'hygiène dans leurs programmes. Les adultes sont sensibilisés via leurs enfants lorsque ceux-ci sont scolarisés.

La littérature médicale ottomane concernant les avantages des bains de mer pour la santé n'est guère négligeable 6 . Ces travaux détaillent les bienfaits de l'iode marin et de l'eau salée sur le système respiratoire, sur les maladies de la peau, sur les rhumatismes ou les sciatiques. Leurs auteurs incitent fortement le public à prendre l'habitude des bains marins dans le cadre d'une vie saine et équilibrée. L'eau de mer n'est pas recommandée seulement dans un but préventif. Elle a également des vertus thérapeutiques incontestables. Suite à un accident, le sultan Abdülhamid II en personne entre dans la mer, sur les conseils de son médecin, au moins une fois par jour (Évren, 2000, p. 14, 16).

\footnotetext{
5 La plupart des périodiques spécialisés qui paraissent à Istanbul au cours de la seconde moitié du $\mathrm{XIX}^{\mathrm{e}}$ siècle sont en français. Voir en particulier, la Gazette médicale de Constantinople, organe officiel de l’École impériale de la Médecine; la Gazette médicale d'Orient (publication de la Société impériale de la Médecine) ; la Revue médico-pharmaceutique.

6 Voir en annexe, la liste de quelques ouvrages médicaux de la fin du XIX $\mathrm{X}^{\mathrm{e}}$ siècle et des deux premières décennies du $\mathrm{XX}^{\mathrm{e}} \mathrm{s}$., conservés, pour la plupart, à la bibliothèque de l'Institut d'Histoire de la Médecine de l’Université d'Istanbul.
} 
Y a-t-il meilleure façon de convaincre la population de l'efficacité du traitement marin ?

Cependant, tout compte fait, il est peu probable que cette production ait été suffisamment diffusée. Au demeurant, nous avons affaire à des œuvres assez tardives : les premières datent du milieu des années 1880, mais pour la plupart il s’agit des travaux publiés entre 1900 et 1914. À cette époque, l’habitude d'aller au hammam de mer est déjà bien ancrée dans la vie des Stambouliotes. C'est dire que les conseils des médecins porteront leurs fruits surtout pendant la période qui s’ouvre après la fin de la Première Guerre mondiale, celle des plages.

\section{LES PLAGES DE LA RÉPUBLIQUE}

Les années de la Grande Guerre correspondent à une période de crises successives et profondes pour la société constantinopolitaine, non seulement du point de vue économique et démographique mais aussi sur le plan des valeurs morales.

L’arrivée massive sur les rives du Bosphore de Russes fuyant la révolution d'octobre laissera des traces durables dans le paysage social. De même, l'occupation, entre 1919 et 1922, d'Istanbul par les forces de l'Entente est une phase bien singulière pour les habitants de la capitale7. Les femmes russes certaines d'entre elles sont issues de la haute société moscovite - sont réputées de nouer facilement des relations physiques avec les hommes; le « relâchement de mœurs » caractérise aussi, selon l'avis de la population locale, les officiers de l'armée d’occupation, notamment anglais et français. Pour certains, ce sont ces derniers qui ont organisé les premiers «bains mixtes ». La mémoire citadine se plaît toutefois à attribuer l'invention des plages aux Russes blancs (Évren, 2000, 92-94).

La réponse à la question de savoir à qui en revient réellement la paternité n’a pas grande importance. Il convient en revanche de retenir que les plages ne disparaissent plus après le départ des forces armées et l'intégration progressive des Russes blancs restés sur le sol turc. Elles n’auront pas été une parenthèse due à la guerre, une innovation d'étrangers ne concernant pas la population autochtone. Leur survie après «le retour à la normale » indique bien une évolution des mentalités.

En 1922-23, lorsque Français et Anglais se retirent, le pays entre dans sa période républicaine et kémaliste. Dans ce nouveau cadre, les relations entre hommes et femmes sont perçues à travers le prisme de l'égalité. Pilier de la nation, chargée de transmettre à la génération suivante l'amour de la patrie, la femme turque peut faire autant - et même plus - que l'homme. La propagande de l’époque la présente en uniforme d'aviatrice, ouvrière à l'usine, institutrice

\footnotetext{
7 Pour un aperçu sur ces années d'occupation d'Istanbul par les forces de l'Entente, voir Johnson, 1995 ; Bilge Criss, 1999. Sur les Russes blancs à Istanbul, Dumont, 1992 ; Deleon, 1990.
} 
à l'école. Promouvant une politique populiste - variante turque des idéologies socio-nationales qui fleurissent à la même époque en d'autres lieux -, le pouvoir kémaliste exalte le corps musclé, symbole d'une société en bonne santé. Désertés par les officiers blonds et les femmes russes à la chair douce, les bords de mer ne véhiculent plus un message de débauche. Désormais, elles deviennent le théâtre d'exhibition des corps sportifs et vigoureux, ne comportant la moindre trace de sensualité suspecte (Dumont, 1992).

Ce sont les autorités politiques et surtout Mustafa Kemal Atatürk en personne, le président de la toute nouvelle République turque, qui encouragent la mixité des sexes. Une anecdote concernant la plage de Beyazpark8 ${ }^{8}$, située à Büyükdere sur la rive européenne du Bosphore est instructive à cet égard. À cet endroit, il existait depuis la période ottomane, des installations balnéaires (du type hammam de mer) avec une section réservée aux hommes et une autre pour les femmes. Géré par un Arménien, le lieu était essentiellement fréquenté par des Arméniens. La grande proximité entre la partie destinée aux hommes et celle pour femmes et surtout la vente de boissons alcoolisées dans le café attenant a inquiété les habitants musulmans du quartier qui se sont mobilisés pour obtenir sa fermeture. La visite de Mustafa Kemal en 1926 aura suffi pour dissiper les craintes des propriétaires. En déclarant qu'il ne voyait pas de différence entre hommes et femmes et que rien de honteux ne se passait dans cet espace, le chef de la nation a saisi l'occasion pour souligner son engagement en faveur de l'égalité des sexes. Le calme s'est aussitôt rétabli dans le voisinage turc qui ne pouvait guère mettre en doute la parole du " père ». Peu après, deux piscines sont construites à la place des anciens édifices en bois et le lieu entre dans la catégorie des « plages » (Évren, 2000, 64-65, p. 113).

Au cours de ces premières décennies de la République, le mot " plage » en turc ne signifie ni le rivage, ni le bord de mer recouvert de sable, mais désigne les installations balnéaires à accès payant, où les barrières entre les sexes sont de moins en moins fréquentes.

Reste à savoir si le modèle sportif et les idéaux de l'antiquité grecque ont suffi à gommer, en l'espace de quelques années, les tabous liés à la nudité du corps. En réalité, l'attitude adoptée face à cette question varie selon l'origine sociale des baigneurs. Au sein des couches populaires, le contrôle de la sexualité est assuré principalement par la famille - souvent élargie. Aller à la plage est une activité familiale, ainsi que le soulignent nombre d'articles et de publicités parus dans la presse de l'époque. Pour ceux qui sont issus de milieux fortunés et instruits, la famille joue aussi son rôle, mais c'est surtout le respect des normes sociales acquis à travers l'éducation qui dicte le comportement sur la plage.

Lors de ces sorties, l'air est plus à la détente et à la convivialité qu'à la compétition sportive. Les bonnes vieilles habitudes de la sociabilité du hammam

8 La plage de Beyazpark a fonctionné jusqu’en 1980. 
ou des hammams maritimes ont des racines profondes chez les Stambouliotes. La musique, la nourriture, dans certains cas la danse confèrent même aux concours de natation un caractère de jeu et font des bains de mer un réel moment de délassement. Cette formule - une activité à mi-chemin entre l'effort sportif et le loisir - a le soutien des autorités municipales, soucieuses d'offrir des havres de détente à une population disposant de fort peu d'opportunités d'évasion.

Donner un aperçu précis de la situation sociale et économique de la Turquie des années 1920 et 1930, dépasse largement le cadre de ce travail. Qu'il suffise de rappeler ici que le pays est « en chantier », non seulement sur le plan identitaire mais aussi économique. Née sur les cendres d’un Empire ottoman en pleine désagrégation depuis plusieurs décennies, la Turquie kémaliste a tout à reconstruire - et ce sur l'ensemble du territoire national. Quelque onze millions de personnes y vivent selon le recensement de 1927. Sur ce total, 800000 se trouvent à Istanbul qui reste, malgré le transfert de la capitale à Ankara, de loin la plus grande ville de Turquie. En dehors d'une très mince frange de fortunés pour lesquels les dix années d'hostilités et d'instabilité politique (1914-1923) n'ont eu que peu d'incidence sur leur statut socio-économique, l'écrasante majorité des Stambouliotes lutte pour le gagnepain quotidien. Le congé - payé ou non - est notion inconnue et les voyages d’agrément inconcevables. Les escapades de quelques heures représentent la seule possibilité de repos et de sortie de la routine.

Dans ce contexte, les lieux proches de la ville sont les plus prisés (Ill. 1) visant à développer les infrastructures de divertissement à proximité d'Istanbul. Dans un pays qui bâtit sa philosophie politique autour du terme halk (peuple) - mot-clé omniprésent de ces débuts kémalistes -, la création d’espaces réservés aux loisirs du «peuple », loisirs toujours considérés comme éducatifs et contribuant au modelage du Turc nouveau, constitue un des axes prioritaires de la politique culturelle aussi bien du gouvernement d'Ankara que des instances locales.

La plage de Moda, située sur la rive asiatique au bord de la mer de Marmara est une des premières plages de l'ère républicaine. Elle doit, dit-on, son succès à la modicité des prix d'entrée, mais surtout à son emplacement. Pour s'y rendre depuis le centre-ville, le moyen le plus commode est le bateau : le trajet ne dure qu'une vingtaine de minutes. Pour les Stambouliotes, qui lui sont restés fidèles jusqu’à la fin des années 1980, cet endroit est intimement lié à l'identité urbaine et occupe une place particulière dans les mémoires (Önce, 1998).

La compagnie maritime « Sirket-i Hayriye » - principal transporteur intraurbain par voie de mer - fera le même constat. La proximité et l'accès facile sont des facteurs cruciaux pour le développement des loisirs. En 1929, dans le cadre d'une opération de redressement de la société, ses dirigeants annoncent l'ouverture de la plage d'Altinkum (Sable doré) au nord du Bosphore, près de la sortie vers la mer Noire (Koçu, p. 747 ; Évren, 2000, p. 115). Rien ne manque au projet pour attirer le public : café, aire de pique-nique, gramophone, musique. 
Illustration 1 : Les hammams du bord de mer (1875) et les plages de la République (1923-1990) à Istanbul

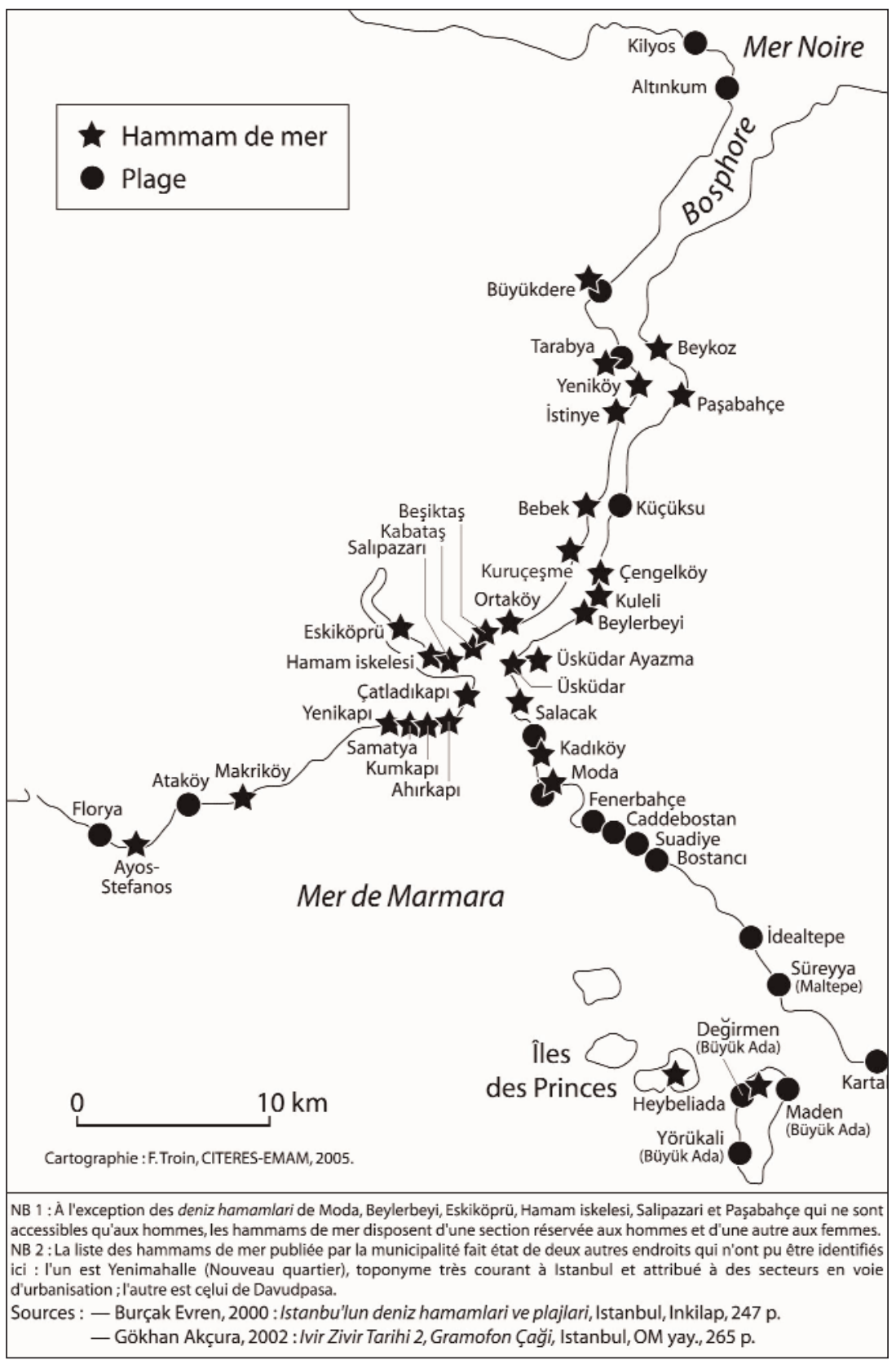


Le transport est assuré par un bateau spécialement affecté à ce parcours et pouvant accueillir près d'un millier de passagers. Cependant, le trajet allerretour dure quatre heures et, après des débuts glorieux, l’intérêt des citadins s'essouffle rapidement. Au lendemain de la Deuxième Guerre mondiale, tout ce secteur est déclaré zone militaire et devient inaccessible (Tutel, 1993)9.

Déjà perceptible à l'époque ottomane, la corrélation entre installations balnéaires et moyens de transport s’affirme avec force pendant la période républicaine et suffit à démontrer - s’il en était besoin - l’importance que les instances municipales attachent aux activités de loisirs. Florya, une des plages les plus célèbres d’Istanbul, située sur la rive européenne de la Marmara, à une vingtaine de kilomètres du centre historique, près de l'aéroport actuel, doit sa popularité au train de banlieue, mis en place durant la période ottomane. Après 1937, lorsque le réseau est nationalisé, la gare de la petite localité est desservie très fréquemment dans la journée. Signe fort de l'intérêt des autorités pour les bains du peuple : le billet d'entrée à la plage de Florya inclut, d'après les publicités de l'époque, celui de l'aller-retour par train (Évren, 2000, 100 ; Akçura, 2002, 2e vol., 259-265). Dans le cas de la plage de Suadiye ${ }^{10}$, qui se trouve sur la rive asiatique, en face de Florya, la gare ferroviaire étant un peu loin de la mer, la municipalité met à la disposition du public des autobus spéciaux. Plus au nord, dans le même secteur, la plage de Fenerbahçe est accessible uniquement par train : celui-ci fonctionne seulement pendant les mois d'été pour transporter les baigneurs (Évren, 2000, p. 135).

Pour la plupart des installations balnéaires, d’importants travaux d'infrastructure ont dû être effectués avant leur ouverture. À Suadiye, où le terrain était rocheux, il a fallu transporter seulement du sable avant de construire cabines, cafés et loges privées. Mais dans d'autres cas, il s'est agi de travaux de grande envergure qui ont transformé le paysage et ont représenté d'énormes enjeux financiers. À cet égard, les plages de Süreyya et d’Ataköy sont les exemples les plus représentatifs.

Né en 1874, fils de militaire, Süreyya pacha (qui prendra au début de l’ère républicaine le nom de famille Ilmen) s’engage lui-même dans une carrière au sein de l'armée ottomane. Mais celle-ci sera de courte durée. En 1916, en pleine guerre, il enlève l'uniforme et se lance dans les affaires en créant une fabrique de textiles de coton. C'est après 1923, dans la Turquie kémaliste, que son ascension sociale et économique devient exemplaire. Membre du Conseil municipal d’Istanbul, député de la même ville en 1927, Süreyya pacha va se signaler par la réalisation de nombreux projets urbains et sociaux sur la rive asiatique d'Istanbul. Les habitants de ce secteur lui doivent notamment la mise en place d’un tramway, l’approvisionnement en électricité, la construction

\footnotetext{
9 À propos de la réglementation concernant les rivages en Turquie, voir Keles, 1996, p. 459-61.

10 La plage de Suadiye a été gérée durant des nombreuses années par Lütfiye Güler. Lorsque celleci est décédée en 1986 les installations de Suadiye passent à ses héritiers. Fin d’une époque ? Les derniers témoignages dont nous disposons sur cet endroit datent de 1987 : Évren 2000, 148.
} 
d'un nouveau réseau de canalisation, une salle de cinéma, la création d'une société d'opérette (Ilmen, 2001 [1949] ; Akçura, 2002, 2e vol., p. 99-137).

Süreyya Ilmen n'est pas un simple entrepreneur qui a su s'enrichir en tirant profit de ses relations avec les milieux du pouvoir. À travers ses réalisations, il véhicule l'idéologie d'un développement urbain à l'intention du peuple. Ce dernier reste au cœur des décisions qu'il est amené à prendre sous sa casquette d'homme d'affaires. Lors de l'ouverture du cinéma Süreyya en 1927, il est annoncé que les séances du lundi sont réservées aux soldats des casernes des environs. Pour d'autres séances, un quota de places gratuites est attribué aux bateliers et aux portefaix. La vision qu'a Süreyya Ilmen de la société urbaine puise dans l'idéologie populiste du régime kémaliste. Le bien-être du peuple, des couches les moins aisées, qui forment la masse critique de la population turque des premières décennies de la République, constitue l’idée maîtresse de la politique d'Ankara.

C'est dans cet esprit qu'Ilmen inaugurera, en 1939, la construction d'installations balnéaires à Maltepe, sur la rive asiatique d'Istanbul. Ceux-ci seront suspendus pendant la période de la Deuxième Guerre mondiale et le lieu ne sera ouvert au public qu'en 1947. Avec ses quelques 130 cabines et des vestiaires pour 1400 personnes, la plage Süreyya est, dans les années 1950, la plus grande de la rive asiatique et une des plus fréquentées de la ville. Elle est aussi une des premières plages à proposer des locations de chambres pour la saison et non pas seulement à la journée. À l'exemple des autres installations balnéaires, la plage Süreyya dispose d'un hôtel, un casino, un restaurant. Un orchestre et une piste de danse comptent parmi les attractions de l'endroit. Autres points forts : tous les trains de banlieue s'arrêtent devant l'entrée de la plage ; des services réguliers d'autobus ainsi que de bateaux depuis la rive européenne sont mis en place par la direction (Akçura, 2002, 2e vol., p. 235237 ; Évren, 2000, p. 153-163). Construit dans la mer, à quelques mètres du rivage, le Temple des Vierges, coupole tenue par trois colonnes et entourée de frises ornées de fresques inspirées de l'antiquité grecque, deviendra la marque distinctive de la plage Süreyya et figurera désormais dans toutes ses annonces publicitaires. Cet édifice résume avec éloquence l'idéologie du maître des lieux : en l'érigeant en emblème, celui-ci souligne l'importance des arts et des valeurs classiques dans la vie sociale. Il exprime aussi son vif intérêt pour l'instruction et la culture des classes populaires.

Dix ans plus tard, en 1957, des travaux de grande envergure ont lieu à Florya, où les édifices en bois de la célèbre plage Haylayf (High Life) des années 1930 cèdent la place à des constructions modernes en béton armé. L'intervention est d'une ampleur beaucoup plus impressionnante à Ataköy, sur la rive européenne de la Marmara, qui devient le premier village de vacances d'Istanbul. Ici, la Emlak bankasi (Banque foncière) construit, face à des lotissements comptant plusieurs milliers de logements destinés aux couches moyennes, des installations balnéaires capables d'accueillir 4000 personnes (Güvenç et Isik, 1999). 
Ceci dit, à cette époque, les plages d’Istanbul sont des lieux ouverts à tous les milieux. Les signes de la stratification sociale y restent en nombre très limité. Les bâtisseurs de ces espaces semblent n’avoir prévu que deux cas de clients : les « pauvres » et les «moins pauvres ». Les premiers ont accès à la mer en payant un simple droit d'entrée à la plage : c'est la formule la plus économique. La location d'une cabine pour la journée peut intéresser ceux qui ont les moyens mais aussi l'envie de dépenser pour leur loisir. Pour se changer et déposer leurs affaires, les habitués d’Ataköy ont le choix entre les placards en fer ou les cabines revêtues de marbre. La Süreyya plaji dispose des espaces destinés à une clientèle issue de couches moyennes. Malgré la tendance générale de l’époque à concevoir la société turque comme un seul corps uniforme, les plages de la République demeurent des endroits privilégiés pour la mise en relief de la diversité sociale. L’apparence, les modes vestimentaires, les sommes dépensées pour une sortie à la plage, le genre de consommation faites sur place, le comportement général, l'encadrement familial varient en fonction de l'origine socio-économique des baigneurs.

La prolifération des plages, la construction d'installations balnéaires et la popularisation des bains de mer sont certes dues à l'initiative privée qui a su en tirer un grand profit financier : avant d'être député ou membre du conseil municipal d'Istanbul, Süreyya Ilmen était un homme d'affaires qui cherchait à s'enrichir. Cependant, ces activités lucratives s'enchâssaient dans un projet plus général de ceux qui gouvernaient la ville et le pays. La municipalité d’Istanbul a beaucoup fait, on l'a vu, notamment dans le domaine des transports en commun, pour encourager le développement des «bains du peuple ». De même, l'apparition répétée sur les plages de Mustafa Kemal Atatürk a probablement contribué à auréoler ce loisir du prestige dont jouissait, dans les deux premières décennies de la République, le «père de la nation ». Particulièrement attiré par Florya, ce dernier s’y rendait souvent, surtout vers la fin de sa vie, en donnant ainsi l'exemple et en cautionnant, aux yeux du peuple, la fréquentation de ce lieu. L’attachement d'Atatürk au site de Florya s'est traduit par la construction, en 1935, d'un pavillon de la présidence de la République au bord de la mer. En été 1936, la Turquie est gouvernée depuis cet endroit où séjournent Mustafa Kemal et plusieurs membres du gouvernement (Akçura, 2002, 2e vol., p. 259-265 ; Évren, 2000, p. 104-109). Le président dont la santé est déjà fragile - s’adonne aux sports de mer, les ministres jouent au ballon et les séances de travail n’occupent tout ce monde que dans la soirée.

Après la mort d’Atatürk, en novembre 1938, son successeur, Ismet Inönü, utilisera aussi pendant plusieurs années le pavillon de Florya. Le premier bain de mer annuel d’Inönü - président de la République de Turquie jusqu'en 1950 et premier ministre par intermittences après 1960 - sera un vrai rituel, répété tous les ans et très largement médiatisé par la presse. En ce milieu du XXe siècle, l'époque où le sultan Abdülhamid prenait, à Tarabya, son bain quotidien et thérapeutique en toute confidentialité, est bien révolue. L'immersion d’Inönü dans la mer de Florya est aussi vivement recommandée par ses médecins, 
surtout au fur et à mesure que celui-ci prend de l'âge et que les rhumatismes deviennent plus persistants. Mais, à la différence du souverain ottoman, le président Inönü est accompagné dans son effort par une foule de journalistes et de photographes qui ne manquent pas de le suivre tous les ans dans le frisson de son premier bain... et de fixer son image, plongeant dans l'eau « à la manière d'un clou », les pieds les premiers (Évren, 2000, p. 180-181).

La popularité que connaissent les plages d’Istanbul durant la période de la République ne suffira pas à faire disparaître les vieilles habitudes installées à l'époque ottomane. Les hammams de mer tiennent tête à l'air de la modernité qui balaye les mentalités pudiques ou non et continuent à marquer le paysage urbain jusqu’à une date très récente. Dans les années 1930, alors que les plages de Florya, Moda, Suadiye vivent leur âge d'or, des installations balnéaires à l'ancienne attirent encore les foules de travailleurs au pied de la Tour de Galata, en plein centre des affaires. De même, durant la belle saison, le hammam maritime de Moda grouille de monde jusqu’à la fin des années 1980.

Aussi bien à l'époque ottomane que durant la période républicaine, Istanbul - qui n'a rien d'une station balnéaire... - est une très grande ville au sein de laquelle les couches populeuses occupent une place importante. L’augmentation constante de la population urbaine s’y est accompagnée par une extension du réseau des transports vers la périphérie : la popularité des bains de mer va de pair avec celui de la banlieue de plus en plus facilement accessible. Beaucoup plus qu'ailleurs, le développement de cette activité est directement lié à celui des moyens de transport en commun. En construisant les gares ferroviaires à proximité immédiate des plages, le pouvoir local exprime éloquemment sa volonté de « populariser » ce loisir.

Localités riantes, ne ressemblant guère à la périphérie " dangereuse » des grandes métropoles européennes de l'époque, les faubourgs stambouliotes se signalent par le caractère très mêlé de leur population. Ces espaces où résidences cossues de gens fortunés voisinent avec des petites maisons modestes sont aussi bien vouées à la villégiature estivale qu’à l'habitat permanent, selon l’origine socio-économique de leurs habitants. Passer par ces endroits en train ou en bateau pour aller se baigner est souvent un moment de plaisir et compte même parmi les attraits de la sortie organisée en famille ou entre amis.

Autre facteur qui a contribué à l'essor des plages : l'absence, jusqu'à une date encore récente, de congés payés fait également des bains de mer un des rares modes de divertissement qui s'offre aux citadins. Et c'est bien pour répondre à ce besoin social que la municipalité a soutenu toute initiative privée dans ce sens.

Si pour la période ottomane, le rôle des instances locales dans ce domaine apparaît assez limité, au cours de la période républicaine, les bains de mer retiennent, dans le cadre d'une philosophie politique populiste, toute l'attention des pouvoirs publics. Il ne s'agit pas seulement d'offrir au peuple 
des loisirs capables de le distraire de ses peines. L'objectif poursuivi est aussi celui d’éduquer les masses : en encourageant la nudité balnéaire, les autorités contribuent à la diffusion d'une morale nouvelle, notamment en ce qui concerne les rapports entre hommes et femmes. Aux yeux des dirigeants de la Turquie nouvelle, mettre à mal les tabous relatifs à l'exhibition du corps humain - masculin mais surtout féminin - revient à marquer un point décisif dans le combat pour la libération des esprits.

\section{Bibliographie :}

Akçura Gökhan, 2002, Ivir Zivir Tarihi (Histoire des choses insignifiantes), Istanbul, Om, 3 vols..

Alus Sermet Muhtar, 1934, «Eski Deniz Hamamlari », Yedigün, nº 80, Istanbul [cité par B. Évren, 2000].

Anastassiadou Méropi, 1997a, "Les cafés à Salonique sous les derniers Ottomans », Desmet-Grégoire H. et Georgeon F. (ed.), 1997, Cafés d'Orient revisités, Paris, CNRS Éditions, p. 79-90.

Anastassiadou Méropi, 1997b, "Sports d'élite et élites sportives à Salonique au tournant du siècle », Georgeon F. et Dumont P. (ed.), 1997, Vivre dans l'Empire ottoman. Sociabilités et relations intercommunautaires (XVIII $-X X^{e}$ siècles), Paris, L'Harmattan, p. 145-160.

Anastassiadou Méropi, 1997c, Salonique 1830-1912. Une ville ottomane à l'âge des réformes, Leiden, E. J. Brill.

Anastassiadou-Dumont Méropi, 2003, « Médecine hygiéniste et pédagogie sociale à Istanbul à la fin du XIXe siècle. Le cas du docteur Spyridon Zavitziano », Médecins et ingénieurs ottomans à l'âge des nationalismes, Paris-Istanbul, Maisonneuve \& Larose et IFEA, p. 63-99.

Bilge Criss Nur, 1999, Istanbul Under Allied Occupation, 1918-1923, Leiden, Brill.

Borie Alain, Pinon Pierre, 1989, Yerasimos Stéphane, L'occidentalisation d'Istanbul au $X I X^{e}$ siècle, rapport de recherche, Paris, ministère de l'Équipement, bureau de la Recherche architecturale.

Carlier Omar, «Les enjeux sociaux du corps : le hammam au Maghreb (XIXe-XXe), espace menacé, espacé recréé », Annales Histoire Sciences sociales, n6, 2000.

Çelik Zeynep, 1986, The Remaking of Istanbul. Portrait of an Ottoman City in the Nineteenth Century, Seattle \& Londres, University of Washington Press.

Corbin Alain (dir.), 1995, L'avènement des loisirs, Paris, Flammarion.

Deleon Jak, 1990, Beyoglu’nda Beyaz Ruslar (Les Russes blancs à Beyoglu), Istanbul, Istanbul kütüphanesi.

Desmet-Grégoire Hélène et Georgeon François (ed.), 1997, Cafés d'Orient revisités, Paris, CNRS Éditions.

Dumont Paul, 1983, Mustafa Kemal invente la Turquie moderne, Bruxelles, Éditions Complexe.

Dumont Paul, 1989, « La période des Tanzimat (1839-1878) », Robert Mantran (dir.), Histoire de l'Empire ottoman, Paris, Fayard, p. 459-522.

Dumont Paul, 1992, "Les années blanches », Stéphane Yerasimos (ed.), Istanbul, 1914-1923, Capitale d'un monde illusoire ou l'agonie des vieux empires, Paris, Autrement, p. 184-203. 
Ergin Osman Nuri, 1330 [1922], Mecelle-i Umur-u Belediye (Traité des affaires municipales), Istanbul, 1776 p. [réédition en 9 vols, Istanbul, 1995].

Évren Burçak, 2000, Istanbul'un Deniz Hamamlari ve Plajlari (Les plages et les hammams maritimes d'Istanbul), Istanbul, Inkilap.

Georgeon François et Dumont Paul (ed.), 1997, Vivre dans l'Empire ottoman. Sociabilités et relations intercommunautaires (XVIII $-X X^{e}$ siècles), Paris, L'Harmattan.

Güvenç Murat et Isik Oguz, 1999, Emlak Bankasi 1926-1998 (Le Crédit foncier 19261998), Istanbul, Emlak Bankasi

Ilmen Süreyya [1949], Süreyya Pasa’nin Anilari. « Tesebbüslerim, Reisliklerim » (Les mémoires de Süreyya pacha. «Mes entreprises, mes présidences »), Istanbul, Kasdav, 2001.

Isin Ekrem, 1995, Istanbul'da gündelik hayat (La vie quotidienne à Istanbul), Istanbul, Iletisim.

Johnson Clarence Richard, 1995, Istanbul 1920, Istanbul, Tarih Vakfi Yurt yayinlari [cet ouvrage est la traduction turque de Constantinople Today, A Study in Oriental Social Life, New York 1922].

Kartal Kemal S. (ed.), 1980, Kiyi Kentlerimizin Temel Sorunlari (Questions fondamentales de nos villes maritimes), Ankara, Sevinç.

Keles Rusen, 1996, Kentlesme Politikasi (Politique d'urbanisation), Ankara, Imge, ze édition.

Kesisoglou-Karystinou Melpo, 1998, Enoria tis Agias Konstantinoupoleos. Tzibali (Paroisse de Agia de Constantinople. Djibali), Athènes, Idryma Meizonos Ellinismou.

Koçu Resat Ekrem, « Deniz hamamlari », Istanbul Ansiklopedisi, VIII, p. 4438-4442.

Önce Gökhan, 1998, Kendine Özgü bir Semt : Moda (Un quartier bien singulier : Moda), Istanbul.

Sehsuvaroglu Haluk, 1953, Istanbul Köprüleri (Les ponts d’Istanbul), Istanbul.

Tutel Eser, 1993, « Altinkum Plaji », Dünden bugüne Istanbul Ansiklopedisi, Istanbul, Türkiye Ekonomik ve Toplumsal Tarih Vakfi, vol. 1, p. 226.

Yilmazkaya Orhan, 2002, Aydinlik Kubbenin Altindaki Sicaklik. Türk Hamami. Istanbul Hamamlari Rehberi (La chaleur sous la voûte de lumière. Le hammam turc. Guide des bains d’Istanbul), Istanbul, Çitlembik.

Annexe : Quelques ouvrages médicaux sur les bains de mer conservés à la bibliothèque de l'Institut d'histoire de la Médecine de l'Université d'Istanbul.

N.B. : La date de l'édition suit le calendrier de l'Hégire. Entre parenthèses, figure la date selon le calendrier chrétien.

Ibrahim Cemal, 1307, Deniz Hamami Risalesi (Traité sur le hammam de mer), Istanbul, Kasbar Matbaasi, 48 p.

Hüseyin Hulki, 1310, Deniz hamamlari ve Kimler Girmelidir (Les hammams de mer et qui doit y entrer), Istanbul, Mahmud Bey Matbaasi, 36 p.

Azmi-Besim [Ömer], 1300, Kardesler, Su (Eau), Istanbul, Ceride-i askeriye Matbaasi, (voir surtout p. 311-321).

Besim Ömer, 1317 (1901), Yalova Kaplicasi (Les thermes de Yalova), Istanbul, Âlem matbaasi,47 p. Illustré.

Celâm Ismail, 1317 (1901), Deniz Havasi ve Hamamlari (L'air marin et les hammams de mer), Hatta Serviçen Matbaasi, 51 p. 
Dr. J. Suyuti, 1322, Yalovadaki Dag Hamamlari (Des bains de montagne à Yalova), Istanbul, Matbaa-i ahmed Ihsan, 8+112+1 p.

Yusuf Ragip, Isti'âde Sihhat (Reviviscence Santé). Istanbul, Hanimlara Mahsus Gazete Matbaasi, 1322, « Banyolar ve tedavi-i bi’l-ma(su ile tedavi)» (p. 19-27).

Deniz banyolari, 1324, [Les bains de mer] (Dr Dvvil'den çeviren : Yanbolulu Mustafa Sevki), Izmir Kesisyan Matbaasi, 96+5 p.

Yalova Kaplicalari, 1332 (1914), (Les thermes de Yalova), Istanbul, Matbaa-i Ahmed Ihsan, $16+16 \mathrm{p}$.

Salahaddin Ali, Hamamlar, 1334, Deniz Hamamlari ve Denizde Banyo (Bains publics, hammams de mer et le bain de mer), Istanbul, Ayyildiz Matbaasi, 63 p.

Besim Ömer, 1928, [Akalin], Kaplicalar (Thermes), Istanbul, Ahmed Ihsan Matbaasi, 21 p., illustré.

Besim Ömer, 1305 (1888), [Akalin], Su ile Tedavi ve Denizde Banyo (Aquathérapie et bain de mer), Istanbul, Mahmud Bey Matbaasi, 76 p. 



\title{
DÉFINIR LES LOISIRS PUBLICS EN MILIEU URBAIN ; UN ENJEU MORAL ET IDENTITAIRE (MONTRÉAL ET TORONTO 1900-1940)1
}

\author{
Michèle DAGENAIS \\ Université de Montréal, Département d'histoire
}

Si très tôt dans leur histoire, les loisirs sont célébrés pour leur vertu régénératrice et récréative, leur définition, les moments pour s’y adonner, leur contenu et les manières de jouer donnent lieu à d'intenses débats. À partir du moment où l'accès aux loisirs s'élargit et se démocratise, se récréer devient un enjeu social et culturel central, ce qui donne lieu au développement d'un ensemble de discours et à l'élaboration de normes destinées à encadrer cette nouvelle réalité, en particulier en milieu urbain. Dans les villes canadiennes, une des stratégies élaborées par les élites consiste en la valorisation de l'idée de loisirs publics, c’est-à-dire de loisirs pris en charge par les pouvoirs publics et destinés à faire contrepoids aux loisirs commerciaux, un secteur où il semble plus difficile d'orienter la définition et le contenu des activités et des pratiques. Regroupées au sein des mouvements réformistes, les élites qui militent en faveur du développement des activités récréatives y voient aussi le moyen de résoudre les tensions sociales, d'assainir les mœurs et les milieux de vie, dans

\footnotetext{
${ }^{1}$ Les recherches à l'origine de cet article ont été réalisées grâce à des subventions provenant du Conseil de recherches en sciences humaines du Canada et du Fonds québécois de recherche sur la société et la culture (ancien fonds FCAR) - programmes nouveaux chercheurs. Je remercie Michel Ducharme et Sheila MacManus pour leur excellent travail de dépouillement, accompli dans les archives des villes de Montréal et Toronto.
} 
un contexte d'intense urbanisation. C'est au cours de ces débats que prend forme la notion de loisirs publics ${ }^{2}$ : des loisirs dénués de références religieuses, laïcs, gratuits et donc accessibles à tous.

Même si depuis la seconde moitié du XIXe siècle, les actions menées par divers groupes, associations et entrepreneurs favorisent l'élargissement des cadres de la vie culturelle et récréative, celle-ci demeure encore largement " privée ", au tournant du XXe siècle. C'est le cas des nombreuses bibliothèques et des installations sportives mises sur pied à l'époque, par des groupes d'hommes d'affaires, des syndicats de métier, des associations culturelles francophones et anglophones ou des membres du clergé. Il s’agit là d'institutions privées, puisque financées par des groupes restreints et offrant des services à leurs seuls membres ${ }^{3}$. Le projet, à cette époque, de développer des institutions culturelles ou de loisirs qui seraient publiques s'en démarque donc radicalement. Ce faisant, il soulève la question de la signification même d'une institution publique : un problème majeur dans des sociétés telles que les sociétés montréalaise et torontoise en pleine redéfinition, notamment sous l'effet d'une vague d'immigration internationale sans précédent ${ }^{4}$. Dans ce contexte de recomposition et de brassage des populations, le projet de laïcisation contenu dans l'idée de loisirs publics se heurte à d'importantes résistances, en particulier de la part des Églises, catholique et protestante qui craignent une remise en question de leur rôle, prépondérant à l'époque, dans le domaine socioculturel. Or au-delà des considérations religieuses et morales mise de l'avant, se dessinent également des enjeux identitaires. C'est ce qui explique l'acharnement des Églises à demeurer actives dans la définition de ce domaine, et ce pratiquement jusqu'au milieu du XXe siècle. Dans chaque ville, cependant, la question se pose différemment en partie parce que ce ne sont pas les mêmes églises qui dominent, l’Église catholique étant particulièrement importante à Montréal tandis qu’à Toronto, les Églises protestantes, en particulier méthodiste et presbytérienne, sont très présentes.

\section{LOISIRS ET IDENTITÉS RELIGIEUSES}

À Montréal, les projets de développement des loisirs publics viennent remettre en question l'équilibre, toujours précaire, entre les deux grands groupes franco-catholiques et anglo-protestants, les plus importants au sein de

\footnotetext{
2 Yvan Lamonde, «Une problématique de culture urbaine : Montréal 1820-1920 », Questions de culture, 5 (1983), p. 131-148; Thomas Bender, « Metropolitan Life and the Making of Public Culture », in J.H. Mollenkopf (dir.) Power, Culture and Place: Essays on New York City, Russell Sage Foundation, 1988, p. 261-271; G. Barth, City People. The Rise of Modern City Culture in 19th-Century America, New York and Oxford, Oxford University Press, 1980.

3 Y. Lamonde, Gens de paroles. Conférences publiques, essais et débats à l'Institut Canadien de Montréal (1845-1871), Montréal, Boréal, 1990, p. 24-28 ; idem, Les bibliothèques de collectivités à Montréal (17e-19e siècles), Montréal, Bibliothèque nationale du Québec, 1979.

4 Sur Montréal à cette époque, voir Paul-André Linteau, Histoire de Montréal depuis la Confédération, Montréal, Boréal, 1992 ; sur Toronto, J. M. S. Careless, Toronto to 1918. An Illustrated History, Toronto, James Lorimer \& Company, 1984.
} 
la population. Cette cohabitation, dans une même ville, des Canadiens d’origine française et britannique, engendre de multiples tensions. Les questions se rapportant à la gestion locale et à la répartition des ressources, en particulier, sont régulièrement l'objet de débats ${ }^{5}$. Chaque nouveau projet impliquant l'installation d'équipements pose nécessairement la question de sa localisation dans l'espace et, de part et d'autre, les groupes demeurent vigilants afin que les deux grandes parties de la ville, constituée de l'est francophone et de l'ouest, à majorité anglophone, ne soient défavorisées. Pour tenter d'amoindrir les tensions, les élites ont mis en place une stratégie de cloisonnement institutionnel. Élaborée depuis le début du XIXe siècle, cette stratégie a conduit au développement d'un réseau d’institutions sur une base confessionnelle, aussi bien dans le secteur de la santé que celui de la charité notamment. L'avènement d'un nouveau domaine d'intervention que sont les loisirs publics repose donc la question du choix des instances pour les gérer6.

L'enjeu pour l'Église catholique et les groupes qui gravitent autour d'elle, c'est de maintenir la place importante qu'ils occupent dans le champ social depuis le XIXe siècle et ce, pratiquement jusqu’à la fin des années 1950. L’épiscopat montréalais craint le vent de laïcisation qui souffle sur la société montréalaise, tout comme dans le monde occidental de l'époque, dans cette période d’industrialisation, de valorisation du progrès matériel et de déploiement des valeurs marchandes. La laïcité est menaçante non seulement en ce qu'elle propose de nouveaux modèles d'organisation sociale où sont mises au second plan les références aux croyances religieuses, mais aussi parce qu'elle s’exprime souvent contre l’Église catholique elle-même. La laïcité est également menaçante car elle présuppose un engagement plus grand des pouvoirs publics dans la gestion des questions sociales, au détriment de l’Église bien entendu.

L'Église catholique craint aussi que ce projet de développement des loisirs publics ne représente une ouverture susceptible de favoriser l'avancée du protestantisme. Comme l'explique alors l’archevêque de Montréal, Paul Bruchési :

«Nous avons à Montréal deux sociétés distinctes, la société catholique et la société non catholique. (...) Nous avons nos écoles, nos asiles de charité, nos orphelinats ; les protestants ont les leurs... et c'est-là que se trouve le secret de la paix qui règne parmi nous, en même temps que du respect de la liberté de conscience qui règne à Montréal. Il y a certains terrains sur lesquels la fusion n'est pas possible »7.

\footnotetext{
5 Pour une bonne analyse de cette situation voir Christopher G. Boone, « Language Politics and Flood Control in Nineteenth-Century Montreal », Environmental History, 1, 3 (1996), p. 70-85. Voir aussi Alan Gordon, Making Public Pasts. The Contested Terrain of Montreal's Public Memories, 1891-1930, Montréal, McGill-Queen’s University Press, 2001.

6 Pour une illustration des termes de ce débat et de sa résolution dans le cas de la Bibliothèque municipale de Montréal, voir Michèle Dagenais, « Vie culturelle et pouvoirs publics locaux. La fondation de la Bibliothèque municipale de Montréal », Revue d'histoire urbaine/Urban History Review, 23, 2 (mars 1996), p. 40-56.

7 Archives de l’Archevêché de Montréal, Registre des lettres de Mgr Bruchési, Tome 2 (18 janvier 1901 - 2 mai 1904), lettre au maire de Montréal et aux échevins, 6 mars 1901.
} 
Au-delà de la défense de la religion catholique se pose celle de l'identité nationale où langue et foi, intimement liées, constituent le référentiel de base. La peur toujours vive de l'assimilation de la société canadienne-française, démographiquement minoritaire sur le continent nord-américain mais aussi sur le plan politique, le Canada étant dirigé principalement par la majorité canadienne-anglaise, alimente une définition de la nation, essentiellement culturelle, fondée sur le vieil héritage français et catholique. Ce contexte a donné lieu au paradigme de la « survivance » qui repose sur l'affirmation de la continuité entre le Canada français et la France et, par conséquent, nécessite de maintenir une fidélité aux racines pour perdurer ${ }^{8}$. Toutes ces raisons expliquent pourquoi l'Église catholique se montre défavorable aux initiatives qui risquent d'accroître le rôle des institutions politiques, en l'occurrence municipales, dans le domaine des loisirs. Ne pouvant toutes les contrer cependant, elle va chercher à demeurer présente dans la définition et, plus encore, l'organisation des activités de loisirs publics.

Du côté des anglo-protestants montréalais, l'enjeu est quelque peu différent. Il s'agit d'un groupe dont le poids démographique est en baisse depuis le début des années 1870, par suite de l'exode rural des francophones qui affluent en nombre important vers Montréal, mais aussi de l'annexion des territoires ceinturant la métropole, généralement à majorité francophone, là aussi. Afin de demeurer majoritaires mais aussi de se maintenir à l'écart d'une population urbaine qui se prolétarise, de nombreuses élites anglophones choisissent de se retrancher dans les banlieues bourgeoises à proximité de Montréal9. Elles y établissent des enclaves où elles s'aménagent des conditions de vie et des environnements privilégiés. Il n’empêche qu'elles demeurent préoccupées par le sort des populations urbaines et vont chercher, à travers la croisade entreprise en faveur des loisirs publics, à diffuser des principes moraux aptes à assurer une certaine harmonie et une cohésion sociale. Dans le cas de Montréal, les élites protestantes actives dans les débats en faveur des loisirs publics sont donc essentiellement mues par des considérations d'ordre moral, contrairement aux élites franco-catholiques.

Dans la ville de Toronto, la situation se présente autrement. La population, plus homogène, y est majoritairement anglo-protestante. Ce qui est en jeu dans ce contexte, c'est de maintenir cette majorité, alors même que la population se diversifie sous l'effet de l'immigration internationale. Les élites vont donc chercher à assimiler les nouveaux venus afin de les «britanniser ", de leur inculquer une morale et des valeurs protestantes fondées notamment sur le travail, la sobriété et le respect du dimanche comme jour chômé. Au-delà du

\footnotetext{
8 Sur cette question, voir Gérard Bouchard, « Le Québec comme collectivité neuve. Le refus de l'américanité dans le discours de la survivance», dans G. Bouchard et Y. Lamonde (dir.) Québécois et Américains. La culture québécoise aux XIXe et XXe siècles, Montréal, Fides, 1995, p. 15-60.

9 Andrew Sancton, Governing the Island of Montreal ; Language Differences and Metropolitan Politics, Berkeley, University of California Press, 1985.
} 
caractère britannique de la ville se pose aussi le problème du maintien de cette identité à l'échelle du pays tout entier, dans un contexte d'américanisation et de laïcisation de la société urbaine et industrielle.

À Toronto, cependant, les interventions de l'Église se font de manière moins directe qu’à Montréal. C’est qu’en vertu des préceptes de la religion protestante, la croyance et les pratiques religieuses sont considérées comme une question d'ordre personnel qui relève de la conscience individuelle ${ }^{10}$. Dans ce contexte, le rôle actif ou l'intervention directe de l'Église doit en principe se limiter à la sphère privée. Cette conception du rôle de l'Église résulte aussi de la coexistence d'une multiplicité de confessions protestantes. L'organisation de services dans les domaines de l'éducation, de la charité ou de la santé pour chacune des confessions s'avérant difficile et lourde, on a plutôt opté, historiquement, pour une séparation des affaires temporelles et spirituelles, considérant de ce fait que l'éducation, la santé et les loisirs devaient relever des pouvoirs publics.

Cela n'est pas sans engendrer un certain paradoxe car en dépit même de ces préceptes, plusieurs Églises participent activement aux grands débats entourant la définition des loisirs, commerciaux et publics11. Au-delà du travail pour maintenir la moralité protestante et préserver les principes religieux, l'identité nationale du pays constitue ici aussi un enjeu de taille. C'est ce qui explique la vigueur des prises de position des églises protestantes alors que se pose le maintien voir le renforcement du caractère britannique de la société canadienne. L'appartenance confessionnelle constitue donc une composante importante de l'identité collective des Anglo-Canadiens, utilisée dans la promotion de son caractère britannique, et un rempart contre la double menace de la perte de référents religieux et l'envahissement culturel en provenance des États-Unis. On comprend dès lors pourquoi le développement d'un nouveau secteur tels les loisirs publics ne peut se faire sans une bonne dose de référence à la moralité religieuse et pourquoi celle-ci va se maintenir assez tardivement au XXe siècle.

\section{MONTRÉAL : LA VILLE AUX CENT CLOCHERS}

Les débats entourant le développement des terrains de jeux, au début du $\mathrm{XX}$ e siècle, révèlent bien les dimensions morales soulevées mais aussi religieuses. Sans entrer dans les détails, disons simplement que le mouvement en faveur de l'aménagement de parcs et d'espaces verts dans la ville, amorcé dans la seconde moitié du XIXe siècle et qui a permis de doter la ville d'un

\footnotetext{
10 John Webster Grant, A Profusion of Spires : Religion in Ninetennth-Century Ontario Toronto, University of Toronto Press, 1989 ; Marguerite Van Die, « Introduction », dans M. Van Die (dir.) Religion and Public Life in Canada. Historical and Comparative Perspectives, Toronto, Univeristy of Toronto Press, 2001, p. 3-19.

11 Brian Clarke, « Religion and Public Space in Protestant Toronto, 1880-1900 », dans Marguerite Van Die (dir.) op.cit., p.69-86.
} 
certain nombre d'entre eux, s'oriente plus spécifiquement en direction de l'idée des terrains de jeux ${ }^{12}$. C'est que la réflexion sur les bienfaits attribués aux espaces verts pour embellir mais aussi assainir les milieux urbains atteint certaines limites. On admet que la seule beauté ou la verdure n’assurent pas en elles-mêmes le développement harmonieux recherché et qu'il faut doter ces espaces d'équipements qui permettent aux populations d'occuper leur temps libre. C'est en référence à des usages, en effet, que les réformateurs actifs dans les débats sur les loisirs réclament de nouveaux espaces, davantage conçus à des fins de récréation active. Cette réflexion est surtout menée en regard des jeunes et des enfants dont la formation préoccupe de plus en plus.

Ce sont ces motivations qui animent les réformatrices réunies dans la Montreal's Parks and Playgrounds Association (MPPA), une association qui, à l'instar d'autres mises sur pied dans tout le continent américain, milite en faveur du développement de terrains de jeux surveillés, au début des années 191013. Elle souhaite transformer les pratiques des enfants qui utilisent la rue pour s'amuser. Par conséquent, l'association réclame que soient aménagés des espaces spécifiques pour les jeux, placés sous la surveillance de gardiens voir même de moniteurs spécialisés car, argue-t-elle : "On the undirected playground, the play is uncontrolled, and the vicious habits of the streets are simply transferred »14. La MPPA suggère, au besoin, de ralentir le mouvement de développement de terrains de jeux s'il n'est pas possible d'en assurer la supervision adéquate. Comme elle l'explique :

"Such supervision is the only guarantee to equal participation by all who are entitled to it, and the only safeguard... toward... the immoral influence which make a playground an offence instead of a benefit influence in the community »15.

Durant plusieurs années, des demandes sont adressées à la municipalité pour qu'elle aménage des terrains de jeux, c'est-à-dire des espaces spécialement dédiés aux sports et aux activités récréatives ${ }^{16}$. Celles-ci ne permettent cependant pas de faire évoluer la situation très rapidement. Pour ajouter du poids à ces demandes, l'association décide de mener une enquête approfondie sur la situation des loisirs dans la ville. Le rapport qui en est issu, dépeint une situation assez paradoxale17.

\footnotetext{
12 Michèle Dagenais, « Inscrire le pouvoir municipal dans l'espace urbain : les réseaux des parcs à Montréal et Toronto, 1870-1940 », The Canadian Geographer/Le Géographe canadien, 46, 4 (2002), p. 509-526.

13 Jeanne M. Wolfe et Grace Strachan, «Practical Idealism : Women in Urban Reform, Julia Drummond and the Montreal Parks and Playgrounds Association », dans Caroline Andrew et Beth Moore Milroy (dir.) Life Spaces. Gender, Household, Employment, Vancouver, University of British Columbia Press, 1988, p. 65-80.

14 Ville de Montréal, Division de la gestion des documents et des archives, Rapports et dossiers de résolution du Conseil municipal et du Comité exécutif, $2^{\mathrm{e}}$ série, $\mathrm{n}^{\circ} 3739$, Montreal Parks and Playgrounds Association, Report on Parks and Open Spaces for Play, octobre 1912, p.5.

15 Ibid., p. 37-38.

16 Alan Metcalfe, «The Evolution of Organized Physical Recreation in Montreal, 1840-1895 », Histoire sociale/ Social History, XI, 2 (mai 1978), p. 155-161.

17 Montreal Parks and Playgrounds Association, « Report on Parks and Open Spaces for Play », op. cit.
} 
On prétend que les enfants n’ont généralement pas le droit de jouer dans les parcs situés dans les quartiers municipaux. L’Association s’émeut de la situation, elle qui cherche par tous les moyens possibles à retirer les enfants des rues, estimant que celles-ci sont devenues dangereuses. Les autorités municipales accueillent favorablement la requête et en 1913, accordent à l'Association une somme relativement importante qui permet l'embauche de dix moniteurs de jeux durant l'été, dans deux des plus importants parcs de la ville: dans le parc Lafontaine d'abord, situé dans la partie francophone et dans le parc Mont Royal, situé dans la portion anglophone. À la fin de l'été 1913, le rapport de l'Association des terrains de jeux souligne leur grande popularité et la fréquentation élevée dans les deux parcs, qui totalise quelques dizaines de milliers d'enfants.

Il n'en faut pas plus pour que l'année suivante, une association francophone, l’Association du Bien-être de la Jeunesse Incorporée, voyant d'un mauvais œil la présence d'une association anglophone dans le secteur francophone de la ville, s’adresse à son tour à la municipalité en offrant d’organiser des activités récréatives dans certains parcs. Plus précisément, l'Association :

"hautement approuvée et recommandée par sa Grandeur l'Archevêque de Montréal qui en est le président honoraire, les membres de notre clergé et tous les citoyens qui s'intéressent à la jeunesse, a pour but de travailler à son éducation physique, intellectuelle et morale...(l')Association, fondée dans un but éminemment patriotique, désire atteindre son but par tous les moyens qu'elle pourra avoir à sa disposition pour suivre notre jeunesse en tous (sic) temps... »18.

Au ton moraliste des requêtes adressées à la municipalité par l'association anglophone, s’ajoute ici un discours à forte connotation nationaliste. De fait, comme elle le précise, l’Association pour le Bien-Être de la Jeunesse « espère obtenir la charge de la surveillance des amusements...» dans le parc Lafontaine. Elle demande donc la «moitié des subsides alloués pour la surveillance et les amusements dans les parcs... ", plutôt que la totalité de la somme soit remise à l'Association anglophone. Sa proposition est retenue et il semble bien que, durant quelques années, elle assure une partie de l'organisation des loisirs dans le parc Lafontaine.

Cet exemple, parmi d'autres, illustre bien en quels termes se pose la question de l'allocation des ressources matérielles provenant des fonds publics, en même temps que la manière dont parvient à se reproduire la stratégie de cloisonnement institutionnel dans le domaine en émergence de la récréation. Il ne faudrait cependant pas conclure de cet épisode que toute la vie montréalaise et en particulier la sphère de loisirs sont définies en fonction des préceptes religieux. De fait, c'est bien parce que l'Église catholique et les associations qui gravitent dans son orbite sont inquiètes et contrariées par la

\footnotetext{
18 Ville de Montréal, Division de la gestion des documents et des archives, Rapports et dossiers de résolution du Conseil municipal et du Comité exécutif, 3e série, n²432, lettre de l’Association du Bien-Être de la Jeunesse au maire de Montréal, le 17 avril 1914.
} 
manière dont se vivent et se définissent les loisirs de la population canadiennefrançaise à l'époque qu'elles cherchent, par les moyens dont elles disposent, à exercer un contrôle sur les conduites et les consciences. Leur entreprise, pour réussie qu'elle puisse être parfois, n'en est pas pour autant toujours victorieuse. Ne pouvant dominer sur tous les plans, l'Église est bien davantage forcée de vivre avec certaines réalités qui vont à l'encontre de ses principes. C'est pourquoi, plutôt que de se battre sur tous les fronts, elle concentre ses énergies en certains domaines dont celui des loisirs publics, encore en définition et encore relativement peu occupé par les pouvoirs municipaux qui, à cette époque, se bornent à offrir des équipements pour favoriser les loisirs plutôt que de travailler aussi à encadrer les pratiques.

Une autre expérience de jeux organisés, également dans le parc Lafontaine, est menée à partir de la fin des années 1920, cette fois par les Jésuites qui dirigent la paroisse où ce dernier se trouve. Dans la foulée d'un mouvement plus large d'organisation des loisirs pour les jeunes entrepris par d'autres pères jésuites ailleurs au Québec, les membres montréalais de la communauté religieuse fondent l'Euvre des vacances de l'Immaculée-Conception en 1927, afin d'occuper les enfants durant l'été. Sous son hospice, des jeux sont donc organisés dans le parc Lafontaine, tous les étés au cours des années 193019. Disposant de revenus minimes, les pères jésuites doivent faire appel à la municipalité qui, frappée par la crise économique, ne contribue que très parcimonieusement à cette œuvre. Cette dernière ne s'enorgueillit pas moins du service offert par les religieux et ne manque jamais la cérémonie de clôture, organisée à l'issue de chaque saison. Ici encore, loisirs et nationalisme canadien-français se croisent. Comme le rapporte un journaliste à l'époque, en relatant le déroulement de la saison de jeux :

«Discipline et santé, tels sont les résultats les plus apparents de cette organisation... (que) nous considérons comme une sorte d'école normale, une pépinière, une ruche-mère... Quelle admirable école d'assimilation par la camaraderie que ces terrains de jeux! Cette assimilation ne nous est-elle pas indispensable si nous voulons rester toujours la majorité à Montréal ? »20.

On le constate aisément, ici encore, l'objectif récréatif se double d'un objectif religieux et identitaire. L'exemple, rapidement évoqué, atteste bien de l'emprise importante de l'Église catholique dans le domaine des loisirs publics, au moins jusqu'à la fin des années 1930, et surtout de l'association étroite entre loisirs et identité nationale.

\footnotetext{
19 Voir le mémoire de Jean-Christian Aubry, Pratiques religieuses et vie paroissiale en milieu urbain au XXe siècle. La paroisse Immaculée-Conception de Montréal, 1910-1940, Université de Montréal, mémoire de maîtrise en histoire, 1998, chapitre trois.

20 Ville de Montréal, Division de la gestion des documents et des archives, Dossiers historiques, D1901, 38-A, « Les jeux au parc La fontaine », Le Devoir, 29 août 1933.
} 


\section{TORONTO THE GOOD}

À Toronto, les débats entourant la définition des loisirs publics se polarisent essentiellement sur la lutte, souvent acharnée, menée pour préserver le dimanche comme jour de repos. Dirigé par certaines Églises protestantes, en tête desquelles se trouve l'Église presbytérienne, le combat se prolonge durant une bonne partie du XXe siècle. Si des dispositions légales, importées notamment d'Angleterre, ont été adoptées au Canada depuis les années 1840, elles ne sont alors pas appliquées de manière systématique ni fréquente ${ }^{21}$. Or dans la foulée de l'urbanisation croissante de la population canadienne, de la forte vague d'immigration internationale et de la modernisation générale des modes de vie, certaines élites s'inquiètent de ce que ces développements provoquent une remise en question des valeurs et de la moralité chrétiennes mais aussi de l'autorité spirituelle dont jouissent alors les églises protestantes. À l'instigation de l'Église presbytérienne, une large coalition se forme et conduit à la mise sur pied, en 1888, de la Lord's Day Act Alliance qui, dès lors, exercera des pressions soutenues sur les pouvoirs publics afin de mettre un frein au processus de sécularisation du dimanche.

La Lord's Day Act Alliance va s'employer à fustiger toute velléité d'activités le moindrement organisées le dimanche. En 1906, elle parvient à faire adopter une loi au niveau national qui interdit toute activité le dimanche, estimée nonessentielle ou qui n'est pas de nature charitable. Si, de son côté, l’Église catholique partage cet objectif du respect du septième jour, elle ne cherchera pas à l'imposer, avec la même vigueur. Il faut dire que cette croisade, c'est d'abord celle des Églises protestantes et que par surcroît, elle se double d'un objectif de nature identitaire, celui de renforcer l'héritage et le caractère britanniques de la population canadienne. On retrouve en quelque sorte ici une version à la canadienne-anglaise du paradigme de la survivance, auquel nous avons fait référence s'agissant du monde francophone. C'est la raison principale pour laquelle l'épiscopat catholique ne s'identifiera pas à la lutte pour le respect du dimanche avec la même ardeur que du côté protestant même si, bien évidemment, il appuie aussi ce principe22. Par conséquent, l’Église catholique, en contexte canadien du moins, ne va pas se formaliser du fait que ses fidèles s'amusent le dimanche, en autant qu'ils assistent assidûment à la messe dominicale. Et lorsqu'elle intervient dans le débat, c'est davantage en espérant influencer les choix de leurs activités que pour les empêcher de se divertir.

Toronto se présente donc comme le chef de file du mouvement dominical, ce qui ne peut manquer d'étonner étant donné qu'elle est la deuxième plus grande ville du pays, reconnue pour son important développement industriel et jouissant d'une économie florissante. La ville se distingue par la présence d'un

21 Paul Laverdure, Canada on Sunday: The Decline of the Sabbath, 1900-1950, Universite de Toronto, thèse de doctorat, 1990 ; Cheryl MacDonald, « Never on a Sunday : The Lord's Day Act », The Beaver, octobre-novembre 2003, p. 41-43.

22 Lucia Ferretti, Brève histoire de l'Église catholique au Québec, Montréal, Boréal, p.131. 
lobby puissant et suffisamment opiniâtre pour parvenir à faire respecter un principe de plus en plus considéré comme désuet, surtout après la Première Guerre mondiale. Jusqu'au milieu du XXe siècle, en effet, Toronto représente le haut lieu de la lutte pour le dimanche tandis que dans le reste du monde anglo-protestant au pays, la question a perdu de son importance.

Le mouvement torontois en faveur de ce qu'on appelle en anglais le "sabbath » se cristallise autour de trois grandes luttes, entre la fin du XIXe et le milieu du siècle suivant. Il perd sa première manche dans les années 1890 puisqu'à l'issue d'une longue période de débats et d'agitation visant à interdire la circulation des tramways le dimanche, celle-ci est finalement perdue ${ }^{23}$. Au début des années 1910, la ville est de nouveau le théâtre de vifs débats concernant cette fois les activités récréatives, permises le dimanche. Les églises protestantes s'émeuvent alors de l'engouement de la population pour les descentes en traîneaux ou le «tobogganing " qui bat son plein dans plusieurs parcs 24 . Elles entreprennent donc une vigoureuse campagne pour interdire cette pratique le dimanche, qu'elles vont d'ailleurs gagner en dépit même des fortes pressions exercées à la fois par les syndicats et les milieux d'affaires pour libéraliser les activités dominicales.

Durant les années suivantes, le problème ne semble pas se poser, même s'il n'est pas réglé pour autant. Il est cependant soulevé avec vigueur une troisième fois, aussi tard qu'en 1937, à propos de l'usage des parcs municipaux durant le septième jour de la semaine25. C'est alors qu'une demande à l'effet d'accorder la permission de jouer au base-ball le dimanche qui provoque la première levée de boucliers. L'idée de pratiquer des jeux d'équipe dans les parcs publics ce jourlà choque la Lord's Day Act Alliance qui soutient toujours que les activités permises doivent être soit de nature personnelle soit reliées au culte. La frontière entre les types de jeux permis et prohibés, parce que considérés comme relevant des sports organisés ou bruyants, apparaît plutôt ténue. Les différences évoquées ne sont effectivement pas tant liées aux caractéristiques propres à chaque activité qu'à la représentation que s'en font les élites. Ainsi, depuis ses origines, le baseball a été étroitement associé à la classe ouvrière, tandis que des sports tels le cricket et le tennis ont été perçus comme des activités élitaires ${ }^{26}$. En outre, dès avant la fin du XIXe siècle, le base-ball s'est commercialisé et professionnalisé dans les principales villes canadiennes, ce qui n’a pas été le cas du tennis ${ }^{27}$. Au

23 Christopher Armstrong et H. V. Nelles, The Revenge of the Methodist Bicyle Company : Sunday Streetcars and Municipal Reform in Toronto 1888-1897, Toronto, Peter Martin Associates, 1977. 24 Gene H. Homel, «Sliders and Backsliders : Toronto's Sunday Tobogganing Controversy of 1912 », Revue d'histoire urbaine/Urban History Review, 10, 2 (1981), p. 25-34.

25 Michèle Dagenais, «Entre tradition et modernité : espaces et temps de loisirs à Montréal et Toronto au XXe siècle », The Canadian Historical Review, 82, 2 (juin 2001), p. 321-329.

26 Don Morrow, « Baseball », in Don Morrow, Mary Keyes et al. A Concise History of Sport in Canada, Toronto, Oxford University Press, 1989, p.110.

27 Ibid, 125-128. Pour une analyse globale de l'impact de l'urbanisation sur le développement des sports, voir Steven A. Reiss. City Games. The Evolution of American Urban Society and the Rise of Sports, Urbana et Chicago, University of Illinois, 1989. 
cœur du litige, se retrouvent donc les conceptions divergentes des élites et des couches populaires, et le pouvoir exercé par les premières dans la définition des activités considérées comme étant socialement acceptables.

C'est tout de même en fonction de ces critères que des pressions sont régulièrement exercées sur les autorités municipales à la fin des années 1930. La Riverdale Presbyterian Church n'hésite pas, au besoin, à soulever le spectre de la désintégration sociale pour appuyer ses dires et fait valoir :

« a vigourous protest against... opening the city parks for games and amusements in the Lord's Day. As our congregation is located in the vicinity of one of the parks... we have first-hand evidence of... (the) devastating effects on the life of the community, in the disturbance of citizens who desire Christian quietness and in breaking down of respect for the Christian Sabbath »28.

Pour étonnante qu'elle soit compte tenu de la période en cause, cette demande et les autres pressions exercées sur les autorités municipales parviendront tout de même à empêcher que ne soient assouplis les règlements concernant les activités permises dans les parcs le dimanche. De fait, il faut attendre la Deuxième Guerre mondiale pour que la situation change progressivement. Il faut dire que dans ce contexte, il va s’avérer beaucoup plus difficile d'exercer des contraintes sur une population à laquelle on demande, au même moment, de contribuer à l'effort de guerre.

Au-delà de l'attachement de certaines Églises à des préceptes apparaissant plutôt désuets dans le contexte nord-américain, ce qui explique le maintien de telles normes, c'est aussi la volonté des élites de vouloir conserver à la ville sa réputation de vertueuse, considérée enviable par beaucoup et immortalisée dans l'expression bien connue : «Toronto the Good ». Comme la ville est dominée par une majorité anglo-protestante, il lui est relativement facile d’imposer ses vues. En effet, les élites locales s'accommodent bien de cette idéologie protestante qui valorise en même temps l'effort, le travail et la sobriété. Plus étonnante peut sembler l'absence d'une opposition vigoureuse à des principes aussi rigides. Il y a fort à parier que la crise économique, qui continue de secouer durement l'économie canadienne, relègue au second rang toute revendication liée à la libéralisation des loisirs. Le silence des Torontois peut aussi être interprété comme un signe de désintérêt pour une question qui les touche sans doute beaucoup moins qu'au début des années 1910. De fait, durant les années écoulées, l’accès aux loisirs s’est élargi considérablement grâce, notamment, à un raccourcissement de la journée de travail. En outre, la population en général et les jeunes en particulier n'attendent vraisemblablement pas le dimanche pour fréquenter les salles de cinéma ou les parcs. Il n’empêche que si le principe est relativement toléré par tous c’est

28 City of Toronto Archives, Department of Parks and Recreation RG12, lettre du président de l'Association au Parks Commissioner, 26 mai 1939. 
parce qu'en définitive, il se conjugue tout à fait bien avec le souci de nourrir l'identité canadienne-anglaise de référents britanniques, quand bien même ils s'appuient sur des valeurs traditionnelles.

Ainsi, tant à Montréal qu’à Toronto, la définition des loisirs, en particulier des loisirs publics, demeure longtemps liée à des questions d'ordre moral et religieux. Les initiatives menées par les autorités religieuses francocatholiques, dans le premier cas, et anglo-protestantes, dans le deuxième, sont menées dans l'espoir de ralentir le processus irréversible de laïcisation qui survient dans les deux villes, en particulier dans le domaine culturel et récréatif. Elles permettent aussi de peser de manière non négligeable sur la définition et le contenu des loisirs jugés acceptables. Certes, les populations urbaines ne se plient pas aussi complètement aux diktats des Églises que ces dernières le souhaiteraient. Les efforts déployés pour tenter de contrôler la définition des loisirs et la manière de les pratiquer, aussi tardivement que durant les années 1930, indiquent assez bien que les Montréalais et les Torontois s'amusent de plus en plus comme il leur sied.

Il ne faut toutefois pas négliger pour autant l'influence qu'exercent les discours religieux sur les consciences et les pratiques. Parce qu'ils visent aussi à sauvegarder voire renforcer les identités nationales des deux principaux groupes du pays, ces discours bénéficient d'un écho important. De fait, c'est parce qu'elles se reconnaissent au moins partiellement dans ces discours que les populations urbaines ne les remettent pas radicalement en question, les premières brèches sur ce plan se manifestant bien davantage après la Seconde Guerre mondiale. Les pouvoirs politiques de niveau supérieur qui composent le pays l'ont bien compris. Ce n'est pas par hasard que les gouvernements provinciaux et centraux s'intéressent de plus en plus aux loisirs, à partir de ce moment-là, à un point tel qu'ils vont tous, tour à tour, mettre sur pied leur propre ministère des loisirs. Ils vont ainsi faire de la participation et de l'accès aux loisirs publics, un des fers de lance des nouveaux critères d'appartenance à la nation canadienne et d'identification au nouvel État providence en voie de se mettre en place ${ }^{29}$. C'est alors que se produit véritablement la modernisation des loisirs publics où les connotations d'ordre moral cèdent la place aux considérations plus laïques, liées à la notion moderne d'épanouissement personnel et à celle, politique, de citoyenneté.

29 Shirley Tillotson, The Public at Play. Gender and the Politics of recreation in Post-War Ontario, Toronto, University of Toronto Press, 2000. 


\title{
LOISIRS DANGEREUX : MODERNITÉ, MORALITÉ ET CRIMINALITÉ JUVÉNILE EN GRÈCE DANS LES ANNÉES 1950-1960
}

\author{
Efi AVDELA \\ Université de Crète
}

Que les discours sur la jeunesse, et plus particulièrement sur la criminalité juvénile, témoignent souvent d'un malaise social plus profond est un fait solidement établi dans maintes études historiques ${ }^{1}$. Dans ce qui suit, nous allons voir comment, après la Guerre civile grecque, les discours sur la jeunesse mettent en cause les nouvelles formes de loisirs des jeunes en les considérant comme des porteurs de dépravation morale, laquelle serait à la base de la prétendue augmentation de la criminalité juvénile et enfantine. Agissant comme métaphores de changement social - pour reprendre la formule de Luisa Passerini -, les discours sur les loisirs des jeunes et la criminalité juvénile parlent de l'ambiguïté avec laquelle la perspective de modernité est perçue par la société grecque au cours de cette période politiquement et socialement difficile.

\footnotetext{
1 Voir, à titre indicatif, Michelle Perrot, « Délinquance et système pénitentiaire en France au XIXe siècle », Annales ESC, t. 30, 1975, p. 67-91 ; Luisa Passerini, « La jeunesse comme métaphore du changement social. Deux débats sur les jeunes : L'Italie fasciste, l’Amérique des années 1950 », dans Giovanni Levi et Jean-Claude Schmitt (dir.), Histoire des jeunes en Occident, t. 2: L'époque contemporaine, Paris, Seuil, 1996, p. 339-408 ; et Martin J. Wiener, « The Victorian Criminalisation of Men ", dans P. Spierenburg (dir.), Men and Violence : Masculinity, Honor Codes and Violent Rituals in Europe and America, 17th-20th Centuries, Calombur, Ohio, The Ohio State University Press, 1998, p. 197-212.
} 
La période allant de la fin de la Guerre civile en 1949 jusqu'à la junte des colonels en 1967 a été caractérisée en Grèce, dans un contexte d'apparente normalité parlementaire et de guerre froide, par un développement galopant et une oppression toute politique. Les vainqueurs semblent soucieux des changements sociaux qu'entraînent l'urbanisation, l'immigration et la crise des valeurs sociales traditionnelles. La perspective de la modernité, sollicitée dans cette conjoncture comme étant le seul moyen de braver les fractures sociales et politiques récentes, engendre tout de même des craintes : elle risque d'être porteuse de graves dangers moraux, et notamment de favoriser la montée de nouveaux types de criminalité principalement parmi les jeunes.

De quelle sorte de "criminalité » s'agit-t-il, en fait ? Il faut d'emblée préciser que le terme est ici entendu comme une notion fluide et conjoncturelle, qui trahit dans des contextes historico-culturels divers les insécurités et les craintes des groupes dirigeants d'une société face à des groupes sociaux difficilement contrôlables 2 . Or, dans le contexte auquel il est fait référence ici, il s’agit surtout du terme systématiquement employé - aussi bien dans la presse que dans les textes juridiques - pour désigner des actes qui ailleurs ou à un autre moment seraient qualifiés de "délinquance ». Mon argument principal ici est que c'est précisément l'identification souvent démesurée de tout comportement « irrégulier » de la part des jeunes avec la " criminalité » (le terme grec employé étant englimatikotita) qui témoigne de la gravité avec laquelle la question des jeunes est abordée pendant la période en question, dans le cadre plus large des préoccupations concernant les changements rapides de la société grecque.

Dans les discours sur la criminalité juvénile, celle-ci est systématiquement associée à la dépravation morale et au vice. Sa prétendue extension est considérée comme une nouvelle menace envers l'ordre établi - si chèrement payé lors du conflit civil. Dans ce cadre, où l'accent, dans les interventions successives, est mis sur la prévention de la criminalité juvénile et même enfantine, laquelle serait devenue un véritable fléau social, tous les comportements des jeunes considérés comme incongrus sont jugés par référence à la "moralité » et sont pénalisés. L’identification de la "dérive » juvénile à une crise des valeurs morales de la société grecque est systématique tout au long de la période en question, même si le contenu attribué à cette prétendue dérive se transforme dans le temps. Ce qui persiste, ce sont les références à la «moralité » et à tous ses dérivatifs. Comme nom propre, comme adjectif ou encore comme composante, la « moralité » semble relever d'une manière emblématique de la crise de cette période.

Dès le début des années cinquante, la «vague de criminalité et de dissolution des mœurs ", surtout parmi la jeunesse, est considérée comme le produit aussi bien de la familiarité qu'ont acquise les Grecs avec la violence

\footnotetext{
2 Voir, Michelle Perrot, Les ombres de l'histoire. Crime et châtiment au XIXe siècle, Paris, Flammarion, 2001. Il faut donc entendre le terme constamment entre guillemets.
} 
pendant les années quarante que des nouvelles conditions de vie urbaine. Elle est symbolisée d'une part par les actes de «teddyboyisme » (appellation du moment de ce qu'on appellerait aujourd'hui hooliganisme), auxquels est supposé s’adonner un nombre croissant de jeunes gens et, d'autre part, par les nouveaux modes de loisirs et de communication adoptés principalement par les jeunes, tels le cinéma, la musique ou les publications périodiques, et dont la surveillance défaillante engendrerait de graves dangers. Selon une enquête journalistique de 1951, l' " opinion publique » se montre très inquiète de cet état de choses qu'elle attribue "à l'éducation déficiente, à l'administration perverse, à l'Occupation, au cinéma, aux imprimés, à la déchéance morale, à la clémence des tribunaux, etc. »3.

Les thèmes se dessinent clairement dès le début : la crise des valeurs sociales « saines » chez les jeunes est illustrée par "la liberté sexuelle », par « la tenue à moitié nue et bizarre des femmes », par "l'égarement antisocial des jeunes ${ }^{4}$. Dans ce contexte, les mineurs (soit les jeunes au-dessous de vingt et un ans, selon la loi grecque d'alors) sont considérés comme étant en situation de «péril moral » permanent. La responsabilité en est attribuée à la dissolution de la famille, à la richesse nouvellement acquise, à la permissivité des parents, mais surtout aux nouveaux modes de loisirs destinés aux jeunes et notamment au cinéma, aux discothèques, aux publications.

Le cinéma, loisir urbain par excellence, constitue la cible des critiques. Des experts du ministère de la Justice affirment qu' « indépendamment du spectacle produit, "la mise en condition par la technique de la salle obscure provoque aux enfants peur, angoisse et agitation", ce qui peut avoir des effets dommageables sur leur développement psychologique $»^{5}$. D’où la proposition de leur en interdire complètement l'accès jusqu'à l'âge de dix-sept ans. L’Église qualifie le cinéma d' "école du crime et de facteur de corruption de

\footnotetext{
3 Voir E., « Anatrofi » [Education], Kathimerini [Quotidien], 7.10.51, p. 1 « Megali syskepsis dia ta metra pros antimetopisin tis entathisis anithikotitos kai engklimatikotitos» [Grande réunion sur les mesures à prendre face à l'intensification de l'immoralité et de la criminalité], Kathimerini, 28.11.51, p. 4. Voir également N. Archimandritis, Commissaire de police A, « Prostasia ton ithon » [Protection des mœurs], Astinomika Chronika [Chroniques Policiers], n¹3, 1953, p. 599-604, n¹4, 1953, p. 641-647, n¹5, 1954, p. 712-714. De même: Constantinos G. Gardikas, « I epidrasis tou polemou epi tin engklimatikotita » [L'effet de la guerre sur la criminalité], Pinika Chronika [Chroniques Pénales], nº 6, 1956, p. 417-428, 479-490 et D. Kouretas, « Psychanalitikai apospeis epi tis engklimatikotitos en Elladi » [Perspectives psychanalytiques sur la criminalité], Pinika Chronika [Chroniques Pénales], nº6, 1956, p. 330-332.

4 Spyros Melas, "I sexoualiki agogi kai ta sygchrona niata. I neotis kai ta provlimata tis " [L'éducation sexuelle et la jeunesse contemporaine. La jeunesse et ses problèmes], Apogevmatini [Journal du Soir], 8.6.50, p. 1, 5 « I Iera Synodos di'engkikliou tis katadikazei ton 'gymnikon' tropon amfieseos ton gynekon » [Le saint-synode par son encyclique condamne la tenue vestimentaire «dénudée » des femmes], Kathimerini, 8.1.53, p. 6. Théophilaktos Papakonstantinou, « Тa parastratimena paidia » [Les enfants égarés], Eikones [Images], n¹16, 1958, p. 8.

5 Théophilaktos Papakonstantinou, «Theamata kai anilikoi » [Spectacles et mineurs], Eikones, $\mathrm{n}^{\circ} 132,1958$, p. 8 , considère que la défense excessive des spectacles ne constitue pas un remède aux comportements anti-sociaux.
} 
la société et notamment des jeunes» ou encore de "mauvais éducateur des masses »6. Le saint-synode a publié à plusieurs reprises des encycliques «à l'intention du peuple », dénonçant l'influence néfaste du cinéma et exprimant sa préoccupation devant «le développement de la criminalité, notamment chez les jeunes, due au relâchement de la croyance dans les valeurs morales »7. Quant à la Société pour la protection des mineurs, elle affirme que selon ses propres données statistiques "l'influence du cinéma est responsable d'au moins $65 \%$ des criminels mineurs $»^{8}$.

Les interventions dans « le domaine de la protection de l'enfance grecque en danger moral », destinées à remédier à cette situation, se multiplient, leur but commun étant « la réformation morale de la jeunesse et la contribution de la société à la lutte pour l'élimination du relâchement des mœurs »9. L'Église orthodoxe et les diverses Sociétés de protection des mineurs - souvent en rapport étroit avec le Palais et notamment avec la reine Frédérique entreprennent des «croisades pour la limitation de la criminalité juvénile en augmentation alarmante »10. Le ministère de la Justice, quant à lui, prend l'initiative de réunir toutes les institutions et les services compétents en un Conseil coordinateur afin de prendre « des mesures efficaces de prévention du crime et notamment d'éradication des dangers moraux menaçant la jeunesse »11. Plusieurs mesures législatives sont adoptées, qu'elles soient préventives, correctives ou bien répressives : les limites d’âge par catégorie de films sont fixées, l'instauration d'un corps de juges des mineurs est annoncée ainsi que la création d'un corps de surveillants et de moniteurs spécialisés,

\footnotetext{
6 «Evdomas "Neotis kai theama” dia tin prostasian tis ithikis kai pnevmatikis akeraiotitos ton neon » [Semaine « Jeunesse et spectacle » pour la protection de l'integrité morale et spirituelle des jeunes], Kathimerini, 24.11.62, p. 10.

7 «I Iera Synodos di'egikliou tis kalei ton laon na lavei thesin enantion tis engklimatikotitos. Pigi to kakon entipon kai o kinimanografos » [Le Saint-synode dans son encyclique appelle le peuple à prendre position contre la criminalité], Kathimerini, 2.4.61, p. 14.

8 « Metra kata tis engklimatikotitos ton anilikon. Afstiros elegchos ton kinimatografikon tainion» [Mesures contre la criminalité des mineurs. Contrôle sévère des films cinématographiques], Kathimerini, 18.10.52, p. 4 «I Iera Synodos... », op. cit. Pour l'association entre l'augmentation de la délinquance juvénile et les loisirs préférés des jeunes aux États-Unis dans les années cinquante, voir L. Passerini, « La jeunesse comme métaphore... », op. cit., p. 388.

9 K. Konstantinidis, «I exathliosis ton neon » [La corruption des jeunes], Astinomika Chronika, $\mathrm{n}^{\circ} 14,1953$, p. 648-650, $\mathrm{n}^{\circ} 15,1954$, p. 715-721, n¹6, 1954, p. 758-759 et G. Sakellariou, «Ithikokoinoniki agogi » [Éducation socio-morale], Astinomika Chronika, n²8, 1954, p. 13411342 Konstantinos N. Vouilloukas, «I epidrasis tou kinimatografou epi ton antikononikon ekdiloseon ton anilikon » [L'influence du cinéma sur les manifestations antisociales des mineurs], Pinika Chronika, n², 1962, p. 577-587. Th. Papakonstantinou, «I antarsia ton anilikon » [La révoltes des mineurs], Eikones, n¹07, 1957, p. 8 idem, « Ta parastratimena paidia », op.cit.

10 « Agrotiki fylaki dia tous anilikous katadikous. Tha entathei o agon enantion tis egklimatikotitos » [Prison agraire pour les condamnés mineurs. La lutte contre la criminalité sera intensifiée], Kathimerini, 16.11.51, p. 4.

11 «Enekrithi to nomoschedion dia tin systimatikoteran organosin tou agonos kata tis egklimatikotitos » [Le projet de loi pour l'organisation plus systématique de la lutte contre la criminalité a été ratifié], Kathimerini, 14.1.53, p. 4.
} 
l'admission des mineurs dans les lieux de divertissement nocturnes est réglementée et les associations de protection des mineurs sont subventionnées. Enfin, l'organisation d'activités extra-scolaires est prévue «dans le but de détourner les mineurs d'activités incontrôlables qui leur portent préjudice »12. Même s'il n'est jamais fait mention d'une manière explicite, on ne peut s'empêcher d'associer toute cette activité à la répression anticommuniste: juste après la Guerre civile, l' «égarement moral » est souvent la métaphore utilisée pour signaler l'influence qu'exerceraient chez les jeunes les idées progressistes.

Cela dit, l’identification systématique de la «criminalité » avec l' « immoralité » dans les discours en question témoigne du sens donné aux valeurs morales pendant cette période: elles ont un contenu tout particulièrement sexuel. "La corruption des mœurs » ou «la décadence morale » renvoit toujours au renversement de l'ordre traditionnel dans la famille et des rapports de force entre les sexes, ce renversement étant attribué au mode de vie urbain et considéré comme le danger principal qu'entraîne le « progrès ». Dans ce cadre, morale signifie morale sexuelle, comme le montrent les critiques récurrentes contre les rapports sexuels prénuptiaux, contre l'amour libre, contre le mépris de la chasteté que les jeunes manifesteraient ${ }^{13}$. Ainsi, les rapports entre les sexes deviennent la représentation centrale de la crise sociale et politique.

Or, si les comportements des jeunes sont jugés par le biais d'une identification de la criminalité et de l’immoralisme, « l'égarement antisocial des jeunes » est perçu comme étant genré. Si les jeunes femmes sont accusées de renoncer aux avantages de la chasteté, avec des conséquences néfastes pour

12 «Simantikai apofaseis tou Syntonistikou Symvouliou dia tin prolipsin tis engklimatikotitos anilikon» [Résolutions importantes du Conseil coordinateur pour la prévention de la criminalité des mineurs], Kathimerini, 13.3.54, p. 6. Voir aussi, «I exormisis kata tis paidikis engklimatikotitos » [L’assaut contre la criminalité enfantine], Kathimerini, 22.4.52, p. 6. Et à titre indicatif : « Megali siskepsis dia ta metra pros antimetopisin tin entathisis anithikotitos kai engklimatikotitos » [Grande conférence sur les mesures nécessaires à la lutte contre l'immoralisme et la criminalité qui s'intensifient], Kathimerini, 28.11.51, p. 4 « I katapolemisis tis engklimatikotitos » [La lutte contre la criminalité], Kathimerini, 2.12.51, p. 6 « Ai apofaseis tis Epitropis Ethnikis Stavroforias dia tin pnevmatitin kai somatikin ygeian tou laou » [Les décisions du Comité de croisade nationale pour la santé spirituelle et corporelle du peuple], Kathimerini, 4.6.52, p. 6. « Metra ithikis anamorfoseos engklimatounton neon » [Mesures de rééducation des jeunes délinquants], Kathimerini, 12.12.52, p. 6. «To nomoschedion dia tin paidikin engklimatikotita katetethi is tin Voulin. - Symvoulion Syntonismou » [Le projet de loi pour la criminalité enfantine a été déposé au Parlement. - Conseil de coordination], Kathimerini, 5.2.53, p.6.

13 G. Gratsas, «Ithiki kai ygeia » [Moralité et santé], Astinomika Chronika, n51, 1955, p. 24542459. Th. Papakonstantinou, « O chydeos erotas. En onomati tis “fysiologikis zoïs”... » [L'amour vulgaire. Au nom de la « vie physiologique »], Eikones, n] 225, 1960, p. 12-13· idem, « I agnotis eine i den eine areti ? 3 Aggli giatroi skandalizoun palin tin arketa skandalismenin koinin gnonin » [La chasteté est-elle une vertu ou non ? Trois médecins anglais scandalisent de nouveau l'opinion publique déjà assez scandalisée], Eikones, n412, 1963, p. 11, idem, «I proïmi erotiki plirotis fernei dystichia stous neous » [La plénitude sexuelle précoce apporte malheur aux jeunes], Eikones, n506, 196), p. 12-13. 
leur santé physique, psychique et morale, les jeunes gens sont surtout associés aux pratiques « antisociales » connues sous le nom de «teddyboyisme ». La criminalité juvénile et enfantine dont il est régulièrement question, sans que ne soient jamais fournies des données précises, est en fait une délinquance presque exclusivement masculine.

Le « teddyboyisme » est considéré comme étant la preuve par excellence de l'égarement de la jeunesse. Le terme se réfère à une série de comportements juvéniles agressifs allant de pair avec une certaine tenue vestimentaire, notamment le port du blue-jean et les cheveux longs ${ }^{14}$. L'apparition de ce phénomène dans les rues d'Athènes déclenche la fureur de la presse. Et le fait qu'il fasse partie des formes nouvelles de violence observées dans plusieurs pays et associées aux effets sociaux et moraux de la guerre accentue l'inquiétude du public $^{15}$. La presse, les intellectuels, les commentateurs dénoncent les actes de violence des jeunes gens, tels le harcèlement des femmes dans la rue, les attaques au yoghourt, le vol d'usage des voitures. Selon un commentateur, le terme de «teddy boy» désigne «le jeune agitateur gâté, sans fondements moraux, prêt à prouver son antisociabilité par son accoutrement conformiste à l'américaine, dont le caractère principal (pour la Grèce) est le pantalon bleu étroit aux revers retroussés, connu sous le nom de "jean" »16. L'origine anglaise du terme « teddy boy » reste inconnue des commentateurs grecs ${ }^{17}$.

La réaction de la société « bien-pensante » est immédiate et sévère. Des mesures législatives sont décrétées et notamment le décret 4000 de 1959 « sur la répression de certains actes délictueux et le complément de l'article 6 du Code de procédure pénal »18 visant à punir plus sévèrement les actes « antisociaux ». Le décret prévoit le durcissement des peines infligées pour des actes considérés par le Code pénal comme des délits, tels les contusions ou autres dommages corporels, les insultes, les dommages causés à la propriété ou les vols de voitures. Plus précisément, un emprisonnement d'au moins trois mois est prévu pour des actes qui « de par le lieu, le temps et les

\footnotetext{
14 Pour le phénomène italien analogue, le « teppismo », voir Simonetta Piccone Stella, « "Rebels without a Cause” : Male Youth in Italy around 1960 », History Workshop Journal, t. 38, 1994, p. 157-178.

15 Nic. G. Stathatos, « To mega provlima tou teddyboïsmou tha syzitithi is synedrion eidikon. Tha symmetaschoun kai Ellines. Eis to Fraibourg tis Dytikis Germanias » [Le grave problème du teddyboyisme sera discuté à une conférence d'experts à laquelle participent des Grecs, à Fribourg en Allemagne, Ethnos [Nation], 19.8.61, p. 3.

16 « Stin Athina oi teddyboys diapompevontai stous dromous » [À Athènes, les Teddy Boys sont hués dans les rues], Eikones, n¹52, 1958, p. 30-32.

17 Les « Teddy Boys » étaient des bandes de jeunes Anglais dont le nom se réfère à leur tenue vestimentaire préférée de style "edwardien». Une des premières «cultures juvéniles", directement associées à la musique Rock and Roll, les « Teddy Boys » avaient scandalisé la société britannique des années cinquante, accusés souvent de comportements violents. Voir http://www.rockabilly.nl/cavan/teddyboys.htm et http://www.geocities.com/Nashville/7957/ historique.htm.

1830 octobre 1959, voir Konstantinos Kalias, I englimatikotis kai idios ton anilikon [La criminalité notamment chez les jeunes], Athènes, 1961, p. 13-14.
} 
circonstances générales témoignent de l'insolence particulière de l'auteur et de son attitude provocatrice envers la société »19.

Le décret fait partie des mesures prises afin de limiter la prétendue montée de la criminalité, surtout parmi les jeunes. Il est complété un an plus tard par le décret 4090 qui prévoit l'augmentation des peines prévues pour les crimes contre les mœurs 20 . La presse s'en réjouit, reconnaissant que les mesures sont « suffisamment » sévères²1.

Cependant, pour certains, cette sévérité ne suffit pas. C’est pour cela qu’il n'est pas rare que des jeunes gens arrêtés pour « teddyboyisme » soient soumis de surcroît et d'une manière peu régulière à un « traitement » supplémentaire particulier : cheveux tondus, revers des blue-jeans coupés au rasoir, pancarte accrochée au cou sur laquelle est inscrit le "crime », exhibition dans les rues du voisinage. Ce que cette imitation des rituels archaïques a de singulier, c'est que le déshonneur public est infligé aux jeunes gens et non pas aux femmes ${ }^{22}$. C'est la masculinité « insuffisante » des jeunes gens en question qui, par ces pratiques punitives, est tournée en dérision par la société elle-même, en marge des mécanismes institutionnels: sur les photos tirées au cours de telles opérations, un agent de police accompagne les «coupables» pendant la " punition ». Ces photos sont largement diffusées dans la presse à des fins "didactiques", pour prévenir du sort qui lui sera réservé quiconque serait enclin à se livrer à des actes de « teddyboyisme ». Ne sont cependant pas rares ceux qui, après coup, expriment un certain scepticisme à l'égard de cette pratique qui sort du cadre légal et qu'ils considèrent comme exagérée par rapport au caractère marginal du phénomène qu'elle est censée juguler23.

Le fait qu'en réalité le «teddyboyisme » ne représente pas un véritable danger pour la société grecque, puisqu'il reste un phénomène limité, est reconnu par le ministre de la Justice lui-même, peu après l'instauration des nouvelles mesures punitives. Il déclare en effet que si ces mesures étaient nécessaires pour "en finir une fois pour toutes avec l'insolence», elles

\footnotetext{
19 Ibidem.

20 K. Kalias, op. cit.

21 À titre indicatif : « Poiai ai proteinomenai tropopoiiseis tou Poinikou Kodikos ypo tis systatheisis Eidikis Epitropis » [Quelles sont les modifications au Code pénal proposées par la Commission spéciale], Kathimerini, 3.1.60, p. 10. Th. Papakonstantinou, « I alitheia gia tin engklimatikotita stin Ellada » [La vérité sur la criminalité en Grèce], Eikones, n²98, 1961, p. 17. "To Ypougeion Dikaiosynis antimetopizei tin lipsin metron dia tin peristolin tis engklimatikotitos » [Le Ministère de la justice envisage des mesures pour la restriction de la criminalité], Kathimerini, 29.3.61, p. 3. « Dia tin engklimatikotita syskepsis ton eisaggeleon" [Assemblée des procureurs sur la criminalité], Kathimerini, 18.6.61, p. 12. "To Eidikon Symvoulion meleta metra prolipseon kai katastolis tis engklimatikotitos anilikon » [Le Conseil spécial étudie des mesures de prévention et de répression de la délinquance des mineurs], Kathimerini, 23.6.61, p. 6

22 Pour la pratique de la tonte en France, voir Fabrice Virgili, La France « virile ». Des femmes tondues à la libération, Paris, Payot, 2000.

23 Eikones, n²152, 1958, p. 30-33, « Stin Athina oi teddy boys diapombovontai stous dromous... ». Aussi, Th. Papakonstantinou, « Ti einai poini kai ti epidiokei » [Qu'est-ce que la peine et quel est son but ?]. Idem, « I dystychia tis aneseos... », Eikones, n²186, 1959, p. 10.
} 
seraient également suffisantes. Pour le ministre Konstantinos Kallias, «la Grèce constitue une exception à la règle suivant laquelle, après les guerres, il y a augmentation de la criminalité ». La raison en est avant tout le «fond traditionnellement moral du Grec » et le "caractère moral de la jeunesse grecque », ainsi que, secondairement, le niveau de développement encore peu élevé. Les cas isolés «d'attitude antisociale » ne font que confirmer le fait que la jeunesse grecque est « une des jeunesses les plus nobles, les plus morales et les plus braves du monde ». Et le chef de la Sûreté générale d’Athènes de signaler que «la question de "teddyboyisme”, tel qu'il apparaît dans d'autres pays, n'existe pas pour la Grèce". Il s’agit "simplement de jeunes inconscients qui, étant adolescents, se laissent facilement entraîner ». Selon le chef de la Sûreté, "le 'teddyboyisme' en Grèce, a plutôt la forme d'un divertissement débridé que d'une disposition criminelle »24.

Nous sommes par conséquent devant un changement d'attitude venant du plus haut niveau. Dès le début des années soixante, en effet, le danger de la " criminalité » galopante et de la dépravation morale de la société grecque est considéré comme étant déjà maîtrisé. Les statistiques montrent que la « criminalité » est en réalité en baisse et que la jeunesse maintient son intégrité morale.

"Qu'ils soient apaisés ceux qui sont angoissés ; ceux qui voient notre jeunesse se laisser glisser sur la pente menant à la catastrophe irréparable du "teddyboyisme"! Ceux qui voient [...] les criminels de tout type agir avec impudence, qu'ils recouvrent leur sang froid. La situation est plus calme qu'elle n'est parfois présentée et le Grec - indépendamment de son âge-est plus débonnaire que ses congénères latins ou d'outre-atlantique »

explique non sans fierté un journaliste avant de conclure :

« La Méditerranée [...] ne "tolère” pas bien le brouillard, les “complexes", la "cruauté". Au fond, nous sommes plus débonnaires, moins dangereux que nous voulons l'imaginer $»^{25}$.

Le développement défectueux devient ainsi un signe de civilisation. Le climat, la géographie forment les caractères et les sentiments : plus de lumière et plus de bonhomie, moins de violence. La référence à la Méditerranée ne doit pas être fortuite : il s’agit du nouveau sujet collectif qui émerge du Congrès international des anthropologues sociaux réunissant avec succès les chercheurs de la région méditerranéenne à ce moment-là, l'été 1961, à Athènes 26.

Or, si les commentateurs s’avisent avec soulagement que « notre jeunesse » est moins corrompue qu'ils ne le craignaient, les inquiétudes face aux dangers inhérents à leurs loisirs et à l'abondance que connaît cette période ne cessent de

\footnotetext{
24 Voir pour les citations : Th. Daskalopoulow, Eikones, n²98, 1961, p. 17.

25 Ibidem.

26 Il s’agit du colloque organisé par le premier président du nouveau Centre de la Recherche Sociale, Ioannis Peristianis, publié quelques années plus tard sous le titre J. G. Peristiany (dir.), Honour and Shame. The Values of Mediterranean Society, Londres, Weidenfeld and Nicolson, 1965.
} 
s'exprimer. Ils sont plusieurs à estimer que cette jeunesse, peut-être pas " criminelle », porte tout de même les marques de "la génération débauchée de l'après-guerre » : elle affiche souvent «de l'agressivité, s'adonne aux liaisons passagères, à l'enivrement, au négationnisme universel ». Le « teddyboyisme » n’étant qu'une forme de "rébellion des blancs-becs », et de rébellion «apolitique » de surcroît, la responsabilité en est attribuée aux effets pervers du « développement » et, notamment, à la permissivité, à l'abondance et surtout à l'incapacité des parents de faire face à leurs devoirs ${ }^{27}$.

Même le cinéma, ce vecteur de la corruption, se joint au cours des années soixante à la lutte contre la "décadence bourgeoise » et la dépravation des jeunes. Selon des recherches récentes, la production cinématographique des années soixante, en plein développement et ayant acquis une audience sans précédent, se distingue par sa préoccupation à l'égard de la famille citadine et par la « crise générale des valeurs » qui la traverse, attribuée à l'extension des rapports sociaux en milieu urbain28. Mélodrames aussi bien que comédies dénoncent à maintes reprises les effets néfastes qu'a sur la famille l'abondance permissive, tant au niveau de sa cohésion qu'au niveau du comportement de ses membres. Les messages sont cependant souvent ambigus : si la mentalité patriarcale conservatrice est présentée dans les films comme un frein au progrès social, l'écroulement de l'autorité patriarcale est en même temps considéré comme ayant des conséquences négatives. C'est à travers le comportement des femmes, jeunes ou moins jeunes, et les malheurs qu'elles provoquent, que celles-ci sont représentées d'une manière paradigmatique: les femmes apparaissent souvent dans les films comme frivoles, menteuses et hypocrites, sans contrôle de soi-même ${ }^{29}$. Ces changements affectent également la représentation des modèles masculins. La masculinité des années soixante ne se caractérise plus par la recherche de la domination et de la position du plus fort aussi bien dans la sphère privée que dans la sphère publique, mais, au contraire, par son manque de « position » fixe, par la diminution de son autorité30.

Le renversement des valeurs évidentes au sein de la famille grecque est présenté dans plusieurs films comme étant responsable du comportement « antisocial » des jeunes, de leurs loisirs « dangereux », des manifestations de « teddyboyisme ». Dans le film Loi 4000 de 1962, portant le titre du décret contre le «teddyboyisme » auquel il a été fait allusion plus haut, c’est la famille qui est responsable du comportement inconsidéré et superficiel du

27 Th. Papakonstantinou, «I asynennoïsia metaxi neon - enilikon : “teddy-boys”, “beatniks” kai “anilikoi engklimatiai” " [Le manque de compréhension entre les jeunes et les adultes : “teddyboys”, “beatniks” et “criminels juvéniles”], Eikones, n³99, 1963, p. 27.

28 Maria Paradeisi, «I parousiasi tis neolaias sta koinonika dramata tis dekaetias tou exinta » [La présentation de la jeunesse dans les drames sociaux des années soixante], Ta Istorica, no 22, 1995, p. 218.

29 Élise-Anne Delveroudi, «Les joyaux du défunt (la comédie 1950-1970) », dans Michel Démopoulos (dir.), Le cinéma grec, Paris, Centre Georges Pompidou, 1995, p. 98-99.

30 Dimitris Eleftheriotis, «Questioning totalities: constructions of masculinity in the popular Greek cinema of the 1960s », Screen, t. 36, 1995, n³, p. 233-242. 
jeune homme inofficiellement tourné en dérision et sévèrement puni pour avoir lancé un yaourt au visage du père de sa bien-aimée lequel est également, par malheur, le principal de l'école 31.

Malgré les ambiguïtés, cependant, ou mieux, à cause même de ces ambiguïtés, il est évident que l'accent explicite mis par les films de la période sur l'urbanisation, l'image de la ville étant dynamique et en plein développement, s'aligne sur la marginalisation du «provincial » au sein de cette ville et, qui plus est, sur la dévalorisation du monde rural. Reconnue également par les chercheurs sociaux de cette période, cette dévalorisation de la campagne est considérée comme étant inscrite dans l'adoption des modèles bourgeois de consommation et de loisirs, marquée par une compétition croissante pour l'ostentation matérielle et le dégagement de plus en plus grand des comportements de la valorisation de l'intégrité et la valeur sociale des individus ${ }^{32}$. Nous sommes loin des positions - encore répandues - qui considéraient les valeurs traditionnelles, le mode de vie traditionnel fondé sur le village et la famille comme garants d'humanité et de santé morale. En pleine vague d'émigration, le discours dévalorisant le monde rural qui abonde dans la presse dépeint ce flux comme une fuite vers la civilisation. Et ils ne cessent de se multiplier ceux qui désormais perçoivent la ville non pas comme un lieu de perdition, avec ses loisirs dangereux et sa jeunesse débauchée, mais comme porteuse de civilisation et de discipline collective, comme un vecteur de modernisation, ne serait-ce qu'avec toutes ses contradictions 33 .

En fait, les discours sur les « loisirs dangereux », sur la criminalité et la moralité sont tout au long de cette période des discours sur le développement, en tant qu'espoir aussi bien qu'en tant que crainte. Développement non seulement économique et matériel, mais aussi - et même surtout - spirituel et moral. La question qui se pose d'une manière récurrente est de savoir dans quelle mesure la Grèce, qui, par sa victoire sur le danger communiste, s'est intégrée d'office dans l'« Europe civilisée », est prête à assumer son rôle avec succès. En associant la criminalité à la dépravation morale et tous deux aux conséquences du développement sur la nouvelle génération, les discours de la période témoignent du malaise régnant au côté des vainqueurs de la Guerre civile devant ce qu'ils perçoivent comme les effets pervers de leur victoire, ainsi qu'une attente contradictoire et inquiétante du progrès.

31 Film de Giannis Dalianidis, Loi 4000, 1962, «aventure sociale », Stathis Valoukos, Filmographia tou ellinikou kinimatographou [Filmographie du Cinéma grec], Athènes, Aigokeros, 1998, p. 211.

32 Ernestine Friedl, Lagging Emulation in Post-Peasant Society, American Anthropologist, n66, 1964, p. 569-586 et idem, Vasilika. A village in Modern Greece, New York, Holt, Rinehart \& Winston, 1962· J. Campbell, Traditional Values and Continuities in Greek Society, dans R. Clogg (dir.), Greece in the 1980s, Londres, Macmillan et Centre of Contemporary Greek Studies, King's College, University of London, 1983, 184-207. Voir également Vasilis Karapostolis, I katanalotiki symperifora stin elliniki koinonia, 1960-1975 [Le comportement des consommateurs dans la société grecque, 1960-1975], Athènes, Centre National des Recherches Sociales, 1984, p. 252 et suiv.

33 E., « To engklima » [Le crime], Kathimerini, 4.11.62, p. 1. 


\title{
Conclusions
}

\author{
Philippe CHASSAIGNE \\ Université François-Rabelais de Tours, CEHVI
}

L'ensemble des contributions rassemblées dans ce volume atteste, s'il en était encore besoin, que l'historicité des divertissements et des loisirs n'est plus à démontrer. Mieux encore : on redécouvre leur place dans les sociétés, place qu’il faut réévaluer, même dans la vie de ceux qui en paraissaient, par définition pourraiton dire, privés. Trop longtemps, une historiographie centrée exclusivement sur le travail - et les travailleurs - imposa l'image de sociétés binaires, opposant une leisured class avant la lettre, minoritaire, au reste de la population. Il apparaît qu'il n'en est rien : ainsi Jean-Marie Moine revalorise-t-il la place du loisir dans la vie des compagnons. Un monde sans loisir(s) est-il d'ailleurs vraiment concevable ?

« Divertissements »/« loisirs» : pour être le plus souvent associées, ces deux notions sont-elles interchangeables ? La question est abordée ailleurs dans l'ouvrage ; mais, et le dictionnaire nous le rappelle, l'époque moderne tient un rôle clef dans le processus d'émergence du concept actuel. Dès le milieu du XVIe siècle, le terme de " loisirs » désigne le temps dont on dispose en dehors des occupations habituelles, celui pendant lequel il est "permis » (de la racine latine licere) de faire ce que l'on désire ; et c'est au cours du siècle suivant que l'on passe, rapidement, de la conception pascalienne du divertissement (singulier), qui " nous amuse » et nous détourne des questions essentielles, aux divertissements (pluriel), activités diverses qui peuvent très bien peupler nos loisirs. La contribution de Maud Nicolas donne une autre acception intéressante du terme : décrivant une danse à base de déhanchement pratiquée par les femmes de Tunis, elle pose l'équation divertissement égale défoulement : elle rappelle la dimension physique que ces activités revêtent parfois, voire jusqu'à la violence, comme nous le verrons plus loin. 
Quatre axes de réflexion principaux se dégagent des différentes contributions. Tout d'abord, de quand dater « l'avènement des loisirs » ? Alain Corbin, dans son ouvrage éponyme, en fixait la date au milieu du XIXe siècle, mais plusieurs articles (Olivier Dautresme, ou encore John K. Walton) montrent qu'il faudrait l'antidater d'au moins un siècle ; la mi-XIXe siècle ${ }^{1}$ serait en fait l'époque où s'affirmerait l'économie des loisirs, c'est-à-dire une économie dans laquelle ceux-ci jouent un rôle significatif en termes d'emplois et de contribution à la richesse créée. On ne sera guère surpris de voir la chronologie de ce phénomène épouser la diffusion du processus d'industrialisation, la société industrielle incitant aux loisirs par la distinction des «temps sociaux $»^{2}$ plus grande qu'auparavant. Quant à l'émergence de la commercialisation des loisirs (voir John K. Walton, pour une Grande-Bretagne pionnière en ce domaine comme en bien d'autres), elle annonce la tertiarisation inéluctable des économies industrielles. Ce serait aussi le moment où s'affirme la professionnalisation des loisirs : elle est le ressort de l'itinéraire d'un Joseph Oller, entre autres (Joanne Vajda ; mais voir aussi le texte de Jean-Christophe Diedrich pour la Lorraine de la fin du XIXe siècle). Qu'en est-il dans les pays musulmans, puisque la comparaison monde occidental et monde islamisé était l'un des axes structurants du colloque ? Les évolutions y paraissent beaucoup plus lentes, comme le montre l'exemple de Damas à l'époque ottomane (Abdul-Karim Rafeq) ou celui des villes du Maghreb étudiées par Nora Lafi, et l'économie des loisirs tourne essentiellement autour des cafés et des bains publics.

Créateurs d'économie urbaine, les loisirs sont-ils aussi créateurs de tissu urbain ? La question de l'interaction ville/loisirs est récurrente33. Sophie Didier montre que le Disneyland inventé dans les années 1950 en est rapidement venu à projeter une image de ville parfaite, copiée pour cela par les acteurs tant privés que publics de la ville. Éric Blin souligne l'impact d'un loisir de masse (le cinéma), ou plus exactement des lieux qui l'accueillent (les salles de cinéma), dans l'équilibre (ou les déséquilibres) entre centre et périphérie urbaine. Dans un registre un peu différent, les grands magasins Decré de Nantes (Éric Monin), édifiés dans un contexte de reconstruction ex nihilo au lendemain de la Seconde Guerre mondiale, parvinrent à imposer, au-delà du temple de la consommation sur modèle américain, un «forum de convivialité » en plein centre-ville, une sorte de "place publique idéale, dominant l'espace nantais ». Les loisirs sont aussi créateurs d'espace(s) urbain(s), et non plus seulement de bâti : plusieurs autres contributions (Robert Beck, Gaëlle Gillot, Sandra Pascalis...) ont abordé le thème du jardin ou de la promenade, en en soulignant le rôle structurant dans la ville.

\footnotetext{
$1^{1}$ Alain Corbin (dir.), L'avènement des loisirs, 1850-1960, Paris, Aubier, 1995.

2 Ibid., p. 13.

3 Voir Florence Bourillon et Annie Fourcaut, «Temps des loisirs, espaces de la ville », entretien avec Alain Corbin, dossier « Les loisirs et la ville », Histoire urbaine, 1, 1, 2000.
} 
Une mise en perspective chronologique plus large fait en outre apparaître - et c'est le troisième point - un mouvement de va-et-vient du collectif à l'individuel, puis de l'individuel vers le collectif. En effet, on observe à partir du XVIIIe siècle un passage des loisirs collectifs aux loisirs individuels qui accompagne l'évolution économique évoquée plus haut, avec la distinction induite par l'industrialisation entre le temps privé, et la sphère privée, d'un côté, le temps de travail, et la sphère publique, de l'autre. Dans la GrandeBretagne des XVIIIe-XIXe siècles, les campagnes de " réforme des mœurs » (reformation of manners), menées notamment par les milieux évangéliques, dénoncent les loisirs collectifs, brutaux sinon sanguinaires, pour promouvoir les « divertissements raisonnables » (rational recreation), centrés sur le foyer (lecture, jardinage, etc...) $)^{4}$. Le phénomène n’est pas spécifiquement britannique : n'est-ce pas aussi ce qui apparaît à travers l'étude de Christian Joschke sur ce bourgeois de Brême, passionné de photographie ? La privatisation des loisirs explique l'essor de leur importance économique, en raison de la multiplication de marchés spécifiques (Jean-Christophe Diedrich, Joanne Vajda...). Cependant, rapidement, les loisirs s’affirment comme un domaine d'intervention des autorités, en termes de définition, de contenu(s), de contrôle : nouveau retour au collectif. L’évolution observée par Michèle Dagenais à Toronto et Montréal n’est pas spécifique à ces deux villes. On se souvient aussi du «ministère du Temps libre », dans le gouvernement socialiste de Pierre Mauroy, en France, en 1981 ! Mais c’est surtout pour des raisons de police que les loisirs urbains deviennent une affaire publique : si la chanson est, pour les compagnons étudiés par Jean-Marie Moine, un moyen de communion fraternelle et de pacification, bien d'autres formes de loisirs sont génératrices de désordre : ainsi, les émeutes qui scandent les débuts des comédiens dans les théâtres lyonnais (Malincha Gersin); Gaëlle Gillot montre la face cachée des jardins du monde arabe (exclus, drogue, homosexualité...) et, pour la jeunesse grecque des années 1950-1960 (Efi Avdela), la frontière semble mince entre un « teddyboyisme » de loisir et une petite délinquance assez classique et plutôt (semble-t-il) bon enfant (des agressions au yaourt !).

Au-delà de l'apparente immédiateté de la notion, les loisirs sont donc bien une construction sociale, modelés ad infinitum selon les milieux sociaux, l'appartenance religieuse, l'identité sexuelle ou l'âge. D’un groupe social à l'autre, en effet, la pratique des loisirs diffère, comme le montre, au Pirée (Yannis Yannitsiotis), la revendication des loisirs « utiles » par les artisans (en un retour savoureux de l'idéal classique de l'otium), par opposition à une bourgeoisie privilégiant la sociabilité privée des bals et des galas ostentatoires. Le loisir est aussi marqueur social : en ce qui concerne les loges maçonniques étudiées par Pierre-Yves Beaurepaire, on pourrait dire, en paraphrasant Cyril

4 G. J. Barker-Grenfield, The Culture of Sensibility. Sex and Society in $18^{\text {th }}$-Century Britain, Londres, 1987. 
Grange pour le Bottin mondain 5 , qu' " y être, c'est en être ». Marqueur social, encore, que la présence dans les cercles de la société cosmopolite qui s'étourdit à Paris, à la fin du XIXe siècle (Joanne Vajda). L'appartenance religieuse joue aussi son rôle, avec, notamment, la question du dégagement progressif des loisirs du domaine religieux : les deux sont encore intimement mêlés dans le monde de F. C. Krieger, que retrace Robert Beck, ou dans les mouled-s du Caire, analysés par Anna Madœuf ; à Istanbul et dans le reste de la Turquie (Meropi Anastassiadou-Dumont), le régime kémaliste veut supprimer les tabous religieux qui poussent les bains de mer à être sexuellement ségrégués. On hésitera cependant à parler trop rapidement de sécularisation des loisirs : plus exactement, nous nous trouvons face à deux phénomènes qui relèvent de plus en plus de la sphère privée et qui, donc, peuvent toujours se chevaucher. Les questions de genre, également, ont leur importance, l'identité masculine ou féminine modulant les loisirs, fixant ce qu'il convient de faire et ce qui est malséant, comme, par exemple (le Tunis étudié par Maud Nicolas), trop bien danser pour un homme. Pour les femmes, la distraction (dérobée, grappillée) ne l'a-t-elle pas, plus longtemps que pour les hommes, emporté sur le loisir (quant à lui, revendiqué) ? L'âge, enfin, est un puissant facteur de différenciation des loisirs, avec, par exemple, la crainte toujours présente des possibles débordements des adolescents ; par ailleurs, il a été question, tout au long de ce volume, des loisirs des adultes, voire de ceux du grand âge. Qu'il soit permis de conclure sur un (léger) regret : qu'en est-il des premières tranches d'âge de la vie ? Si la question est moins perceptible, parce que, source, bien entendu, de moins d'inquiétudes, elle a pourtant fait l'objet de maintes réflexions de la part des institutions, publiques, philanthropiques ou confessionnelles. Y a-t-il les mêmes attentes ? Les mêmes réactions ? Les clivages sont-ils les mêmes en Occident et dans le monde musulman? Les «grandes personnes » seraient-elles les seules à être considérées comme dignes du regard de l'historien ? On peut ne pas en être certain.

${ }^{5}$ Cyril Grange, Les Gens du Bottin mondain. Y être, c'est en être, Paris, Fayard, 1996. 
Mis en page par Muriel HourLIER

CITERES, UMR 6173 CNRS-Université François-Rabelais de Tours

Imprimé en France par

Dépôt légal.

ISBN :

ISSN : 